\title{
NAMURI:STUMY ANDOIIIFIE
}

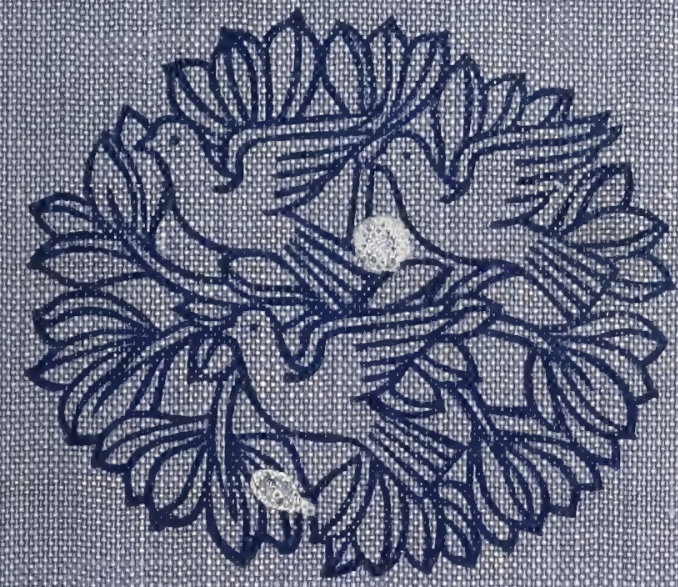

HODGE 


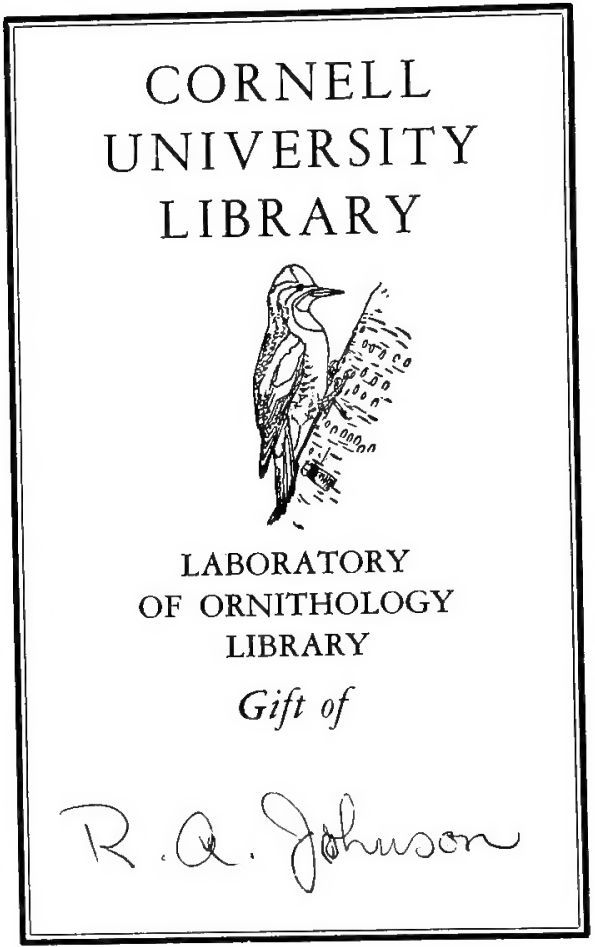


Laboratory of Ornithology

159 Sapsucker Woods Roac

Cornell University

Ithaca, New York $14850^{\circ}$

\section{QH 51.H68}

Cornell University Library

Nature study and life,

C. 3

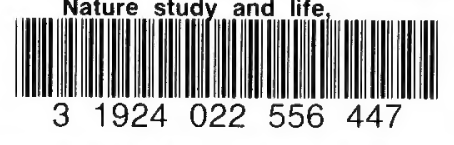

$\begin{array}{lllllll}3 & 1924 & 022 & 556 & 447\end{array}$

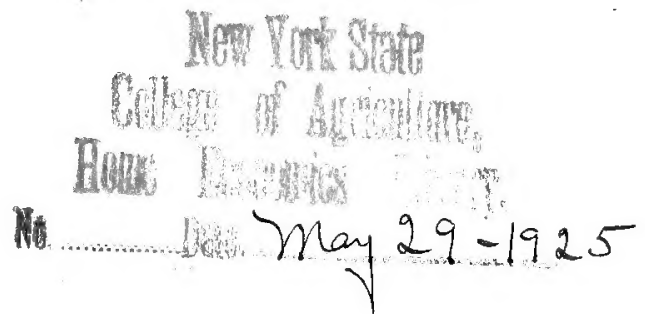

Laboratory of Ornithology

159 Sapsucker Woods Rozó

Cornell University

thate, Now York 14850 


\section{Cornell University Library}

The original of this book is in the Cornell University Library.

There are no known copyright restrictions in the United States on the use of the text.

http://www.archive.org/details/cu31924022556447 



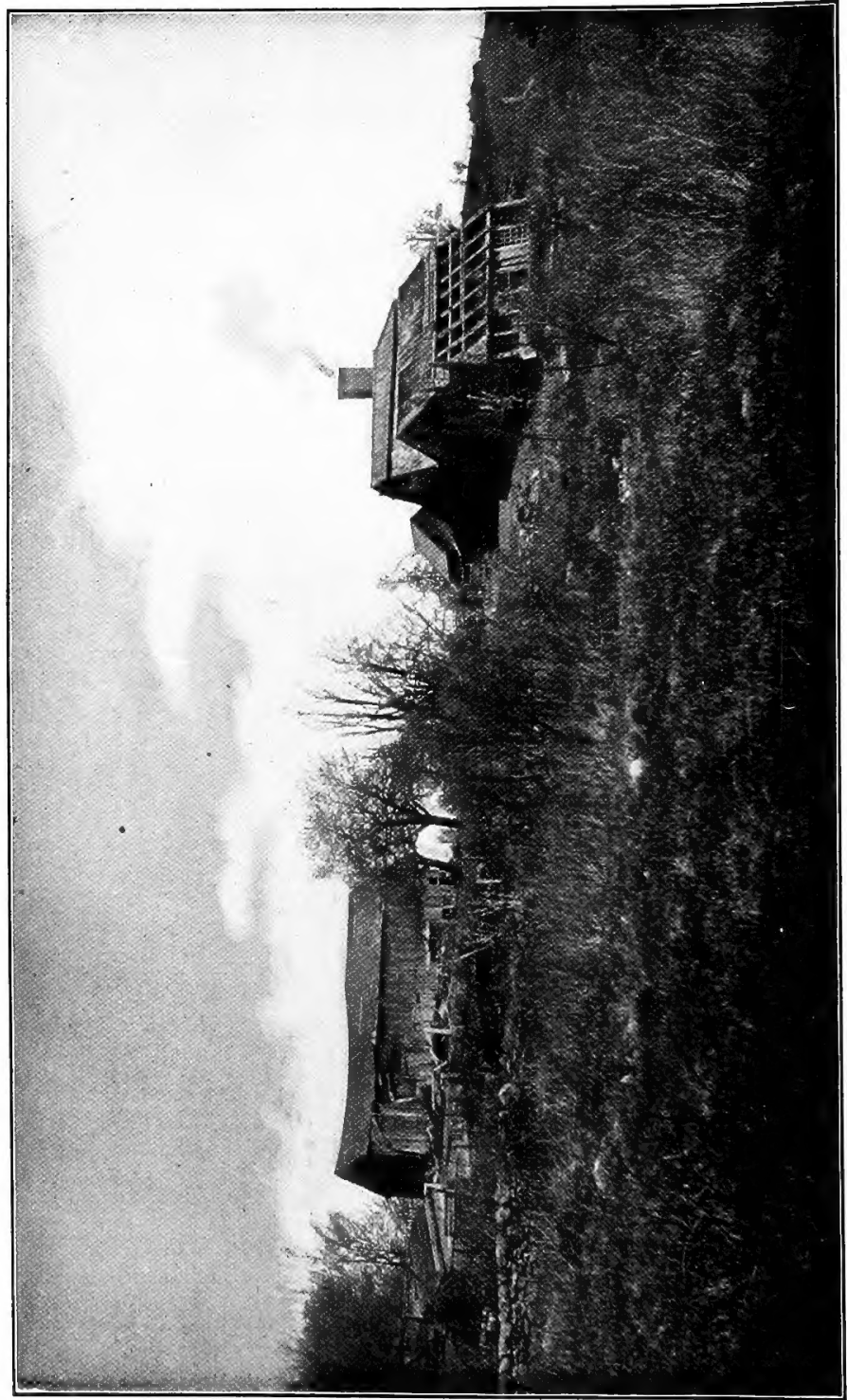

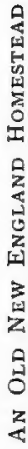




\title{
NATURE
}

\section{IF E}

BY

\section{CLIFTON F. HODGE, Ph.D.}

Assistant Professor in Clark Unizersity. Member of: The A merican Physiologica Society, Society of A merican Naturalists, Massachusetts Forestry Association, American Forestry Association, Board of Directors of the Massa. chusetts Audubon Society, American Ornithologists' Union

Zife is tesponse to the order of Dature

W. K. Brooks

\author{
GINN AND COMPANY \\ BOSTON - NEW YORK - CHICAGO - LONDON \\ atlanta - dallas - COLUmbus - SAN FRANCISCO
}




$$
\begin{aligned}
& \text { ornion } \\
& \text { O) } \\
& 51 \\
& +168
\end{aligned}
$$

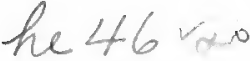

ENTEREd at StationzRs' Hale

Copyright, 1902

By CLIFTON F. HODGE

ALI RIGHTS RESERVED

322.12

Ube atbenzum Press

GINN AND COMPANY - PRO.

PRIETORS - BOSTON - U.S.A, 


\title{
NELSON WELLINGTON HODGE
}

\author{
MY FATHER, \\ WHO GAVE ME MY FIRST \\ ANIMALS AND PETS, MY FIRST GARDEN \\ PLOT AND LITTLE FARM, WHO LEFT THE \\ BIG OAK UNCUT \\ FOR ITS BEAUTY \\ AND THE WILD PRAIRIE UNPLOWED \\ FOR ITS WILD FLOWERS, WHO SET \\ THE ELM TREE BY THE \\ PORCH AND THE \\ RED MOSS \\ ROSE \\ IN THE OLD HOME \\ GARDEN
}





\section{PREFACE}

THE field which this book essays to enter has ever spread out before me like an enchanted country. The possibilities and resources of life, dissolving in changes forever fresh and new, the infinite variety of mechanism, device, and story, the display of beauty on every side that baffles expression by pen or brush, have always seemed to me the natural matrix for the highest development of the child's mind and soul. We are beginning to use fruitfully in our education the legends and myths of the past, but the fundamental conceptions of these lie in the life and nature about us. All this is the work of the Infinite Enchanter of the Universe, and forms a realm of real magic, of which human myth and fairy tale are after all but the passing shadow. This was the world of keenest interests, delights, and sufferings of my boyhood, the common ground out of which my interests in special problems of science have grown, the world to which I instinctively turn from the fatigue and technicality of special work for rejuvenation and refreshment and find that its delights do not grow old.

The more I study the problem, the more it seems to me that this side of nature is the sheet anchor of elementary education, all the more necessary as modern life tends to drift away from nature into artificialities of every sort. Recent developments of the sciences have completely dazzled our modern education with their bewildering array vii 
of newly discovered facts, and the temptation has proved irresistible to introduce their technicalities into the elementary curriculum. But the childhood of the race was very long, and we should not wish to force its period, brief at best, in the life of the individual. The weathering of rock and the formation of soil afford interesting lessons in modern geology; but men dug and planted, and established fruitful relations with Mother Earth thousands of years before geology was even dreamed of. So with combustion and the various forms of water: why not let children wonder about them for a few years, and then come with interest keen and fresh to their study in the chemistry and physics of the high school or the college? By leaving out everything else, however, I do not wish to insinuate that the study of living things is all of nature study. But other sides of nature are so fully represented in plans for nature-study courses now before the public, - I am tempted to say so much too fully representedthat my conscience is perfectly clear in leaving them to shift for themselves.

Many recent books presenting courses of nature study have divided the lessons according to the seasons and terms of the school year. This form is doubtless of service to some teachers. I have not been able to adopt it, however, for two reasons: Nature's changes were not arranged according to our school courses, and the predominant importance of subject-matter precludes such cramped and formal treatment; my purpose is to bring nature into relation to child life rather than to school life, to make it a continuous source of delight, profit, and highest education rather than a formal school task. I 
have sought to obviate this difficulty in arrangement by a somewhat detailed grade plan in which topics are suggested for the grade best adapted for their pursuit. A full cross-reference index will also assist in a similar way.

The illustrations have been selected to express the relation of man, especially the relation of the child, to nature; and since spontaneous activity is fundamental to my plan of nature study, the majority of them are intended to suggest ways and means of cloing something. To those who have contributed pictures, notably Charles Irving Rice, J. Chauncey Lyford, Myron W. Stickney, Charles L. Goodrich, The National Cash Register Company, Henry Lincoln Clapp, M. V. Slingerland, Miss Katherine E. Dolbear, and Miss Jessie G. Whiting, I wish to express my sincere thanks. Acknowledgment usually accompanies the illustration, but the picture of a deer in the velvet (p. I 5) should be accredited to Mr. Rice. The photograph of the mosquitoes (p. 89) and the portrait of a young wood thrush (p. 345) are by Mr. Stickney. Figs. I II, I 23, I25, I 3 , and I 35, together with most of the data from which the bird-food chart (p. 323) was constructed, are contributed by Miss Helen A. Ball. The other line drawings, with exception of $20 d, 22,25$, $35 b, 7 \mathrm{I}, 160,16 \mathrm{I}, 178,193,194,195$, were made under my direction by Mrs. Helen Davis Burgess. The photographs not otherwise accredited are by the author.

This book could never have been written, in anything like its present form at least, until its various suggestions had been given the test of actual school work. Miss Mary C. Henry, principal of the Upsala Street School of Worcester, Mass., has not only done this, but in addition 
has contributed many and valuable suggestions, notably with reference to the grade plan, to the school garden, and to the problem of cleanliness of the schoolroom. Thus to Miss Henry and the teachers in the Upsala Street School the book owes much of its definite character. To Professor Brooks, of the Johns Hopkins University, I am also under obligations for counsel as to the general plan of the work. For help in final revision of the text and proofs and preparation of the illustrations I am under great obligations to Mr. Lyford, and for assistance with the proof I wish to express my indebtedness to Miss Henry, Miss Dolbear, and Mr. Stickney.

Finally, I acknowledge my debt to Clark University for opportunity, and to Dr. G. Stanley Hall for suggestions which called my attention to nature study. The further I went, the more it seemed to me that the sources from which must flow the future development of science in this country all lie in the quality of the work done in the public schools. In freshness, in lively interest, in originality, nothing equals a child; and it has long been conceded that at no time is progress in learning so rapid as during the first three or four years of life. The secret of this, it has seemed to me, lies in the fact that touch with nature at first hand, original research, if you please, is the very breath of mental life. How may this splendid growth process of infancy be prolonged through life? The best answer to the question that $\mathrm{I}$ am at present able to offer is the book itself.

C. F. HODGE.

Clark University, Worchster, Mass.,

January 21, 1902 


\section{CONTENTS}

Introduction by Dr. G. Stanley Hall $\cdot$. $\quad \begin{array}{r}\text { Page } \\ \text { xiii }\end{array}$

Chapter

I. The Point of View . . . . . . I

II. Values of Nature Study • • • • 17

III. Children's Animals and Pets . . . 33

IV. Plan For Insect StUdy . • • • . 45

V. INSECTS OF THE HOUSEHOLd . . . . 62

VI. Lessons with Plants . . . • . 9I

VII. Elementary Botany . . . . . 102

VIII. Garden Studies, - Home and School Gardens I2I

IX. Nature-Study Property of Children . 139

X. Nature-Study Property (Continued), - Gar-

DEN FRUITS . . . . . . . 147

XI. Propagation of Plants . . . . 155

XII. Insects of the Garden . . . . . I8I

XIII. GaRden Insects (Continued) . . , 202

XIV. Beneficial Insects, - The HoneybeE . . 228

XV. Insects Beneficial and Beautiful . . 246

XVI. Insectivorous Animals, — THE Common ToAd . 274

XVII. Common Frogs and Salamanders . . 295

XVIII. OUR Common Birds . . . . . . 305

XIX. The Bird Census and Food Chart • . 3 Ig

XX. Practical Domestication of our Wild

BIRDS . . . . . , , . 327 
XXI. Taming and FEeding Bird • . • • 347

XXII. Elementary Forestry . . . . 365

XXIII. ELEMENTARY Forestry (Continued) • • 379

XXIV. Aquaria, - Their Construction and Man-

AGEMENT • . . . . . . . 393

XXV. Miscellaneous Animals . . . . 405

XXVI. Flowerless Plants . • . . . . 435

XXVII. Flowerless Plants (Continued), - Moulds, Mildews, Yeast, Bacteria . . . 457

XXViII. The Grade Plan . . . . . . 478

INDEX $\quad$ - . . . . . . . . 497 


\section{INTRODUCTION}

For this book I have no hesitation in predicting a most wholesome, widespread, and immediate influence upon primary and grammar school grades of education in this country. No one has gone so far toward solving the burning question of nature teaching, and to every instructor in these subjects this volume will be not only instructive but inspiring.

Unlike the authors of most of the many nature-study manuals now current, Professor Hodge has been for some years the head of a University Department, is a specialist in two or more of the fields of biology, and has made original contributions of value to the sum of human knowledge. His mind thus moves with independence, authority, and unusual command of the resources in the field here treated.

New as his method essentially is, it is now made public only after years of careful trial in the public school grades in Worcester, until its success and effective working in detail is well assured. Thus it has passed the stage of experiment and is so matured and approved that, with slight local adjustments, it can be applied almost anywhere for children of from six or seven to thirteen or fourteen years of age.

I have also observed the growing appreciation with which this matter and method have been received by the representative teachers from nearly every state it the xiii 
Union in the successive sessions of our Summer School, in which approval has grown to deep interest and hearty enthusiasm.

Although the author has striven to secure the best results sought by other nature books, this differs not only in all respects from some, but in some respects from all, and chiefly as follows:

It contains a richer and more varied subject-matter. Instead of elaborate methods applied to a few species, it presents the essential and salient points about many and thus avoids the current fault of over-elaborate and overmethodic treatment, prolonged till interest turns to ennui.

Another principle soliclly established and here utilized, is that interest in life forms precedes that in inanimate nature for children of the age here in view. Rock forms, crystals, stars, weather, and seasons are all interesting, but have their nascent period later, and at this stage pale before the deep, instinctive love of pets and the fauna and flora of the immediate environment.

Again, the principle of utility is here often invoked in a new field, and in a way calculated to advance one of the chief objects of modern pedagogic endeavor - an increasing unity and solidarity between the school and the home. The new use of this motive is distinctly national and sure to appeal to the practical spirit of this country.

The author is a born naturalist, and his love of nature and children, which is infectious, is not less but more because he does not forget nature's uses to man. Believing profoundly, as I do, in the poetic, sentimental, and religious appeal which nature makes to the soul, it is plain that for some years preceding adolescence the 
normal child can be appealed to on the practical, unsentimental, and utilitarian side of his nature.

Once more, this work is opportune because it stimulates spontaneous, out-of-door interests. It is with abundant reason that we find now on every hand a growing fear of the effects of excessive confinement, sedentary attitudes, and institutionalizing influences in the school. Such work as is here described must tend to salutary progress in the direction of health.

Lastly, many modern nature books suffer from what might be called effeminization. This is a book written by a man and appeals to boys and girls equally.

The time has now happily passed when it is necessary to urge the importance of the love and study of nature, or to show how from it have sprung love of art, science, and religion, or how in the ideal school it will have a central place, slowly subordinating most other branches of study as formal and accessory, while it remains substantial. To know nature and man is the sum of earthly knowledge.

G. STANLEY HALL.

Worcester, Mass., Dec. 3, Igor. 
I shall try to show that life is response to the order of nature. ... Our interest in all branches of science is vital interest. It is only as living things that we care to know. Life is that which, when joined to mind, is knowledge, - knowledge in use; and we may be sure that all living things with minds like ours are conscious of some part of the order of nature, for the response in which life consists is response to this order. -W. K. Brooks.

To learn what is true in order to do what is right is the summing up of the whole duty of man, for all who are not able to satisfy their mental hunger with the east wind of authority.-T. H. HuXLEY.

Nature study is learning those things in nature that are best worth knowing, to the end of doing those things that make life most worth the living. 


\section{NATURE STUDY AND LIFE}

\section{CHAPTER I}

\section{THE POINT OF VIEW}

And God blessed them, and said unto them, be fruitful, and multiply, and replenish the earth, and subdue it : and have dominion over the fish of the sea, and over the fowl of the air, and over every living thing that moveth upon the earth.

And God said, Behold, I have given you every herb bearing seed, which is upon the face of all the earth, and every tree, in the which is the fruit of a tree yielding seed; to you it shall be for meat.

And the Lord God took the man, and put him in the garden of Eden to dress it and to keep it.

Aims and Purposes of a Nature-Study Course. - The heart of education, as of life itself, is purpose. Through the maze of infinite variety in form and structure and action that nature presents to the student on every side, the only thing that can hold him to definite lines with patience, persistence, and continuity enough to make his work amount to something is purpose. Hence, in order to select intelligently the materials for a successful course, we need at every step to have the purpose of nature study clearly before us.

This may be expressed in a brief formula, as : Learning those things in nature that are best worth knowing, to the end of doing those things that make life most worth living. 
What things are best worth knowing is indicated in a fundamental way by the relations toward nature that the human race has found necessary and valuable to develop; and nowhere in literature are these relations expressed with such force, beauty, and high authority as in the words at the heading of this chapter. The fundamental relations to nature of the race, the individual, and the child have been more fully discussed elsewhere, ${ }^{1}$ and it is necessary only to summarize them here briefly as follows :

Of first importance is the fact that man's primitive relations to nature are mainly biological - relations to animal and plant life.

Subjugation of Animals. - Development of these relations followed the order of logical necessity. Subjection must come first if man is to live in safety. on the earth. This great process of subjugation, this handto-hand fight against nature, must have constituted the main lines of human nature study for thousands, probably for tens of thousands of years before language took form and written history began, and it has formed a large part of the work ever since. And how far have vermin, weeds, insects, and microbes been brought under subjection even now? To what extent this phase of struggle and warfare should enter into a course of nature study must remain largely a matter for individual parents and teachers to decide, but that it has played an important and fundamental rôle in development of civilization and formation of human character there can be no doubt. And it remains as true as ever that character

1 "Foundations of Nature Study," The Pedagagical Seminary, vol. vi, No. 4, pp. 536-553; and vol. vii, No. I, pp. 95-1 10, No, 2, pp. 208-228. 
can only be developed by struggle, by active, intelligent, patient overcoming of difficulties, the elements that achieved success throughout the ancient travail of the race. It is still "To him that overcometh"; and nothing can take the place of the hard task in education. But there need be no reversion to barbarism. In fact, the

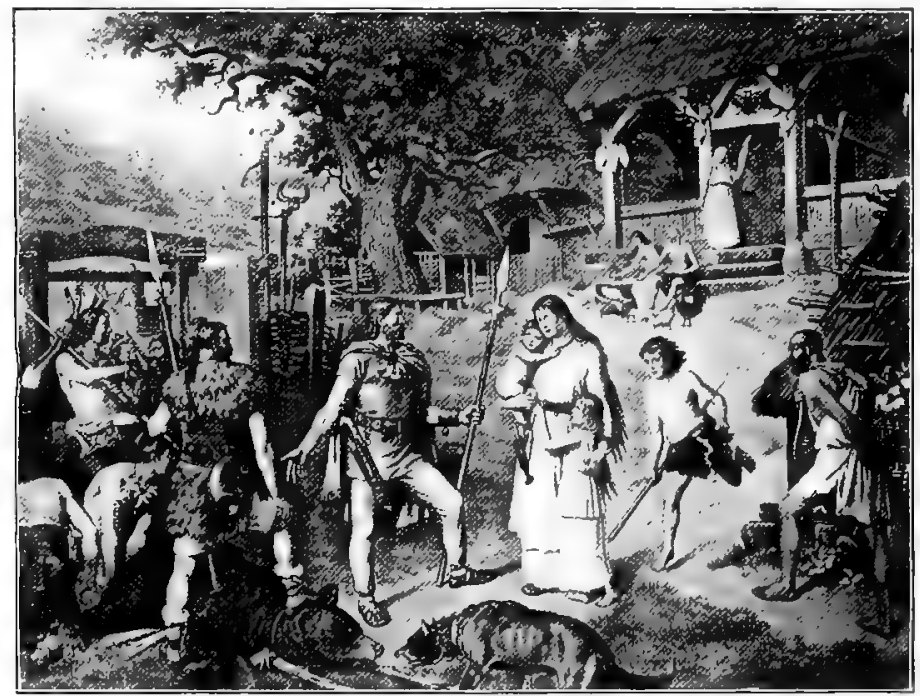

Fig. I. Primitive German Home and its uccupations

(From a painting by Joh. Gehrts)

work should all be planned to exert the strongest possible uplift toward civilization instead.

Dominion over Animals. - The step from abject savagery, by which a new relation between mankind and nature was opened up, was domestication of animals. Hitherto life had been a struggle against all nature, against friends and foes alike. At this point man first developed intelligence 
enough to distinguish between friends and enemies and to discover companions and helpers among the animals about him. The first animal tamed was the dog, which is still the idol of the child's heart. Although taming of the dog antedates all historic records, it is quite probable that this great advance was made by the plastic fancy of a child, - that the first animal domesticated was the playfellow of some savage boy or girl.

Then follows, also before the dawn of authentic history, domestication of the horse, sheep, goat, horned cattle, and most of our clomesticated birds, and it is self-evident that the family or tribe first to develop the patience and intelligence to tame and thus utilize animal helpers must have rapidly outstripped all rivals in the race for life.

Human races, in fact, may be divided into those that have and those that have not tamed the horse. In long struggles small margins of strength are often decisive, but one "horse power" equals that of five men, from which we see what an enormous advantage accrued from domestication of this one animal. Who first tamed and rode a colt no one will ever know, but it must have been some boy, lithe, strong, and daring. Certainly the twelve-yearold Alexander succeeded better with Bucephalus than the royal grooms of his father Philip.

The important interest for nature study is the process of domestication, the gaining" of "dominion" expressed in the command, the establishment of helpful relations, rather than anything connected with the animal itself. Thus we miss the substance for the shadow when we attempt to give this kind of education by pictures of animals; and we also lose the humanizing and educational 
essence of the process when we substitute the demonstrational method of the "school animal " or the zoölogical garden for the primitive, normal, natural relation of companionship between the living animal and the child. The pet animal is thus for the child, as it was for the race. the key to the door into knowledge and dominion over all animal life. Domestication of animals in its widest

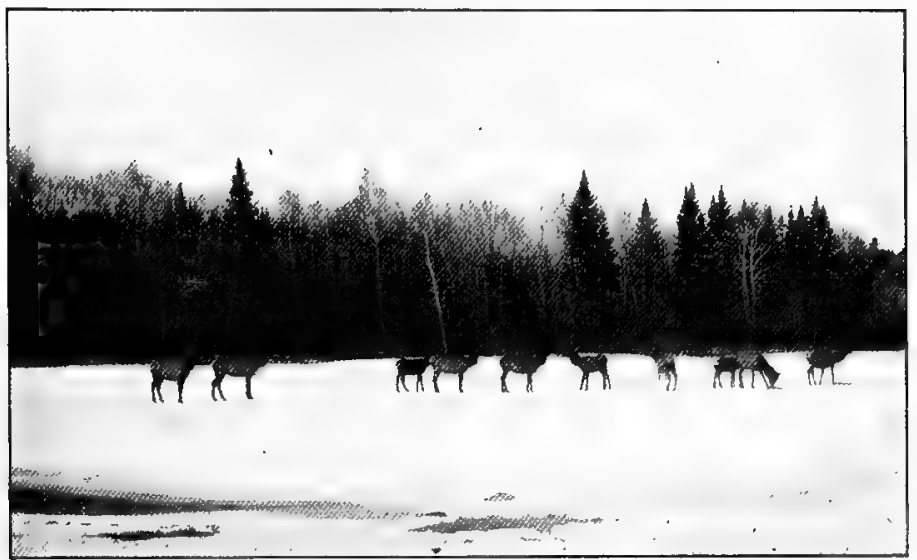

Fig. 2. Herd of Elk, Blue Mountain Forest (Photograph by Charles Irving Rice)

sense (and possibly we should add certain phases of hunting and fishing) is elementary zoölogy. Its fundamental character and value for education are evinced in the passion of children for pets; and as in the race, so in the life of the child, it should be made the most of as a step toward civilization. This subject will be more completely developed in a chapter by itself, and will also form the key to the animal nature study advocated 
throughout the book. But two general considerations belong in this connection.

At this point introduce an easy coördination with language and writing by asking the children to make a list of all the animals, wild and tame, that they know. Let them write "tame" and "wild" in separate columns and number each as they go along, thus :

Name of Child ....................... Age .............. Date

\section{Animals zhose Names $I$ know}

Tame Animals
I. Dog.
6. Rabbit.
10. Duck.
2. Cat.
Birds.
I . Canary.
3. Horse.
7. Hen.
4. Cow.
8. Turkey.
5. Sheep.
9. Goose. Insects.
I2. Honeybee, etc.
13. Silkworm

\section{Wild Animals}
I. Bison.
I2. Wren.
Insects.
2. Moose.
13. Chickadee.
2I. Milkweed Butterfly.
3. Deer.
14. Eagle, etc.
22. Potato Beetle.
4. Red Squirrel.
Snakes.
5. Gray Squirrel.
I 5. Garter Snake.
23. Meal Worm, etc.
6. Rat.
7. Mouse, etc.
I6. Green Snake, etc. Worms. Amphibia. Birds.
17. Bullfrog.
8. Quail.
I8. Wood Frog.
24. Earthworm.
9. Partridge.
19. Common Toad, etc. Fishes.
25. Leech, etc. Mollusks.
10. Robin.
I I. Bluebird.
2o. Trout, etc.
26. Oyster.
27. Clam.
28. Snail, etc. ${ }^{1}$

${ }^{1}$ Ask the children to underline the names of animals about which they know any facts or a good story. These may be used for oral language lessons, and the teacher can find out the extent of the children's knowledge and will thus be able to correct what is false and add to what is insufficient. 
A little wholesome rivalry may be permitted as to who can give the longest list. Copying names is waste of time, so that this exercise should be given to the class in a way that shall not allow recourse to books. I have indicated elementary lines of classification that may be utilized or wholly disregarded, according to advancement of the class or preferences of the teacher. They are of some interest as showing in general that it was found worth while to clomesticate certain kinds of animals, as mammals and birds, and but few others.

After the class have reached their limit ascertain how many animals, wild and tame, the longest lists contain, and then have one of the children copy on the blackboard the following list.

\section{Numbers of Different Kinds of Animals known}

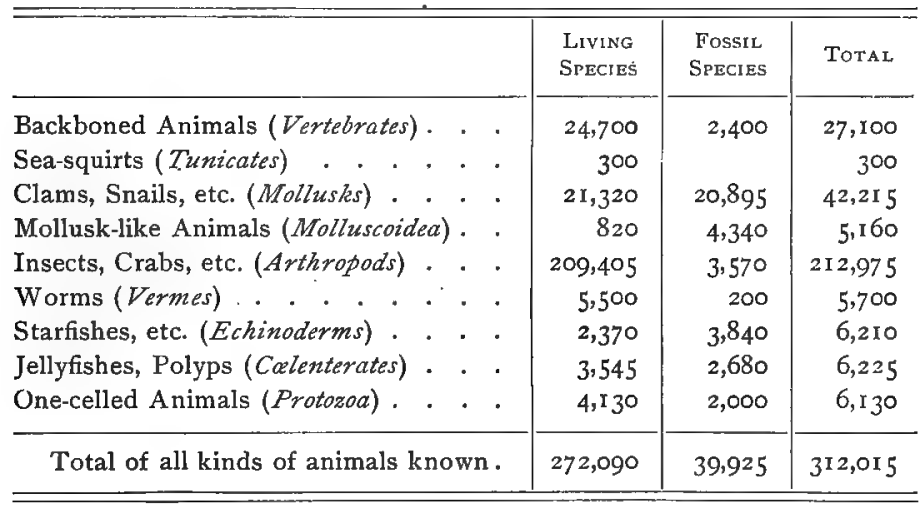

Professor Riley's estimate of insect species on the earth is $10,000,000 .^{1}$

1 Any teacher is expected to use only so much of this table as is reasonably intelligible to the class. Still the object of using it is distinctly to tench how much we do not knowe. The scientific names are inserted to aid the teacher. It is not intended that they be taught to the class. 
These figures may serve to suggest what a little way human dominion as yet extends over the animal life of the world and how much remains to be done. ${ }^{1}$

Somewhat of sadness attaches to the column "fossil species." We shall never see any of these alive upon the earth again. Among their number were the largest and most powerful animals that the world has ever produced or will ever see again, the animal kings of creation for their epochs : the mammoth, a third taller and more than twice the weight of our elephant; the mastodon, larger still ; the Irish elk, the gigantic, Cervus giganteus, and its American cousin, C. Americanus; the largest members of the deer family, animals that used to square accounts with antlers that measured eleven feet from tip to tip; an American lion, Felis atrox, as large as the Asiatic species; at least two bisons of enormous size, one with horns that measured fully ten feet across, - all are past and gone. Probably man has been responsible for the extermination of most of the larger species within recent geologic time, and in the process of subjugation it would seem that he has been needlessly severe. Men had little use for menageries then, but now what would we not give to see some of those wonders of the world in life again!

What is more to the point, extermination of animal species is now going on, and at a rate never before equaled. With modern rifles, shotguns, and dynamite bombs, coupled with modern steamships and railroads, by which the remotest corners of the earth become readily

1 Shaler speaks of "near a hundred animals" that man has domesticated. Domesticated Animals. Their Relation to Man and to his Advancement in Civilization, p. 219. New York, Charles Scribner's Sons, 1895. 
accessible, any species of any size or value, either in the oceans or on the land, stands small chance against extermination, unless directly preserved by man. Within the past forty years the largest mammal native to our continent, the bison, has been practically, and doubtless would have been absolutely, exterminated had it not been for

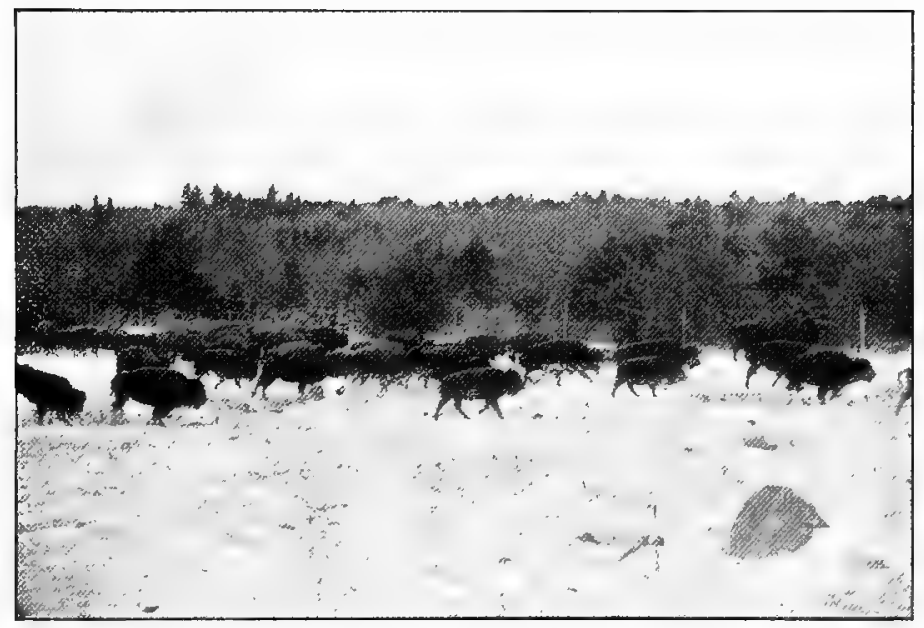

Fig. 3. Buffalo Herd on a Stampede, Blue Mountain Forest (Photograph by Charles Irving Rice)

the wise action of the government and of a few publicspirited men. Prominent among these was the late Austin Corbin of New York, who established the Blue Mountain Park as a preserve for large game. In this area of 26,000 acres, containing a mountain range, we are permitted to see wild life, not in menagerie cages and pens, but in its magnificence, in the setting Nature designed for it. Surely the Corbin Preserve is an institution of national interest. 
Cultivation of Plants. - Important as domestication of animals is, the greatest advance of the race in its relations toward nature is found in the cultivation of plants. This has constituted the largest factor in the transition of human tribes from wandering nomads to stable, populous, civilized communities. In the stability of landhold we have the beginning of home, as distinguished from the casual camping ground; and in the footsteps of Ceres and Pomona has followed Flora, to make home beautiful. With home is founded commerce, and arts, literatures, philosophies, and sciences as well.

Cultivation of plants indicated and developed elements of character fundamental to civilized life. Willingness to work for daily bread, intelligent provision for the future, courage to fight for home, love of country, are a few among the virtues attained. When we consider its universal and fundamental character in relation to civilization and human advancement, the omission of soil lore from a system of education of the young is suggestive of relapse to barbarism. To allow a child to grow up without planting a seed or rearing a plant is a crime against civilized society, and our armies of tramps and hordes of hoodlums are among the first fruits of an educational system that slights this important matter.

Elementary botany is chiefly cultivation of plants. We shall see in its proper place, as we have already noted with animals, that there are certain plants that man has found worth while to domesticate. Certain other plants are of great human value, though not domesticated, and others, weeds and poisonous species, have been recognized as enemies of the race. The nature study of plants in 


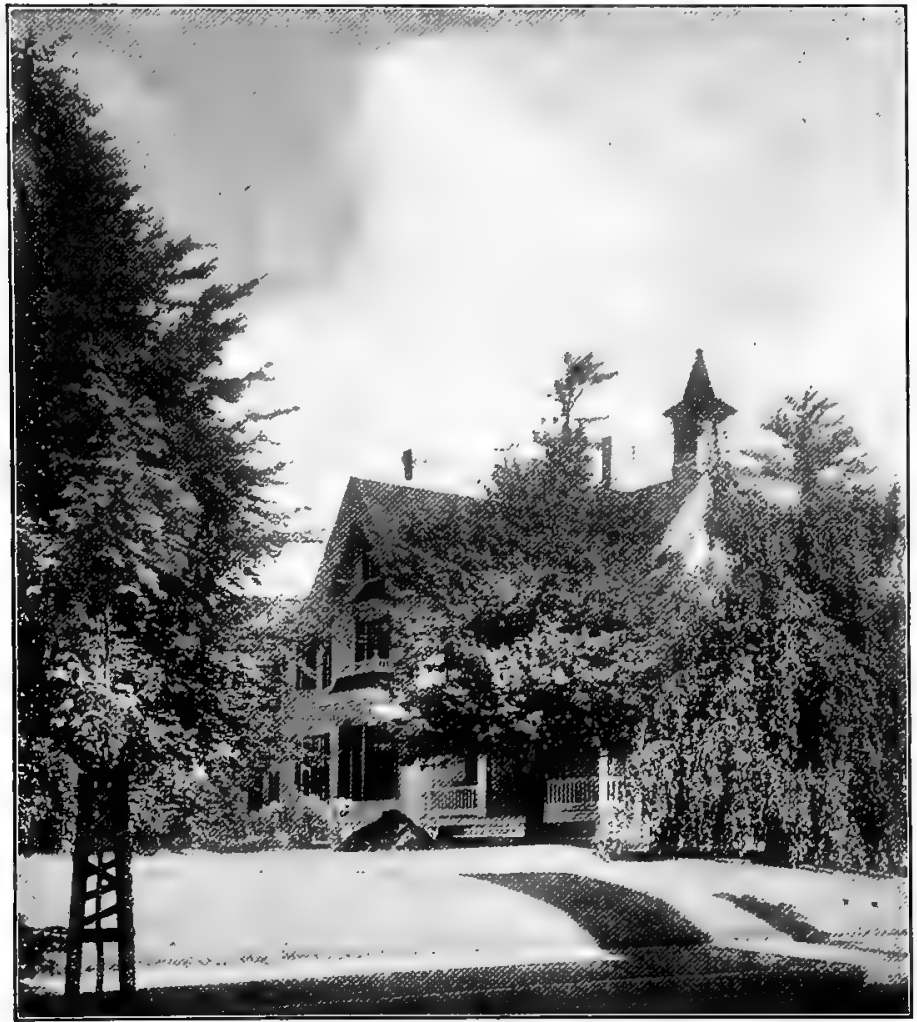

FIG. 4. A Ном E

elementary public schools should consist in just this fundamental knowledge that has grouped itself most closely about human life. Modern botany is a special interest of adult minds. Compared with this ancient body of plant lore it is recent, technical, superficial, and special, and as such it is a profound mistake to attempt to introduce it into a general plan of elementary education. 
Humanity, like the giant Antæus, renews its strength when it touches Mother Earth. Sociological studies suggest that city life wears itself out or goes to decay after three or four generations, unless rejuvenated by fresh blood from the country. Thus these deeper relations to nature are not only ancient and fundamental but are also immanent and persistent. While I should not advocate teaching trades in the public school, although we are wont to say that every boy should learn one, this study is so much deeper down in the warp and woof of life, so immediately supports the whole structure of civilized social organization, and is so closely associated in the creation and maintenance of the home, as distinguished from the camp on the one side and the tenement-house barrack on the other, that it stands on quite a different footing. I should like to see the nature-study course give to all boys and girls the knowledge and the power to surround their homes with the most useful and beautiful plants available, and actually to produce their living by rearing plants or animals, or both, if occasion ever require. Many will say that this instruction belongs to the home. This is true in a measure; much of it should and must be done by the home, and one of the chief aims of this book is to unite home and school in the work. Often a home from which this fundamental "nature study" has lapsed can be reached and rejuvenated by the children through the school. This is not only the easiest and most natural way, but in many cases the only hope.

But, the teacher says, the parents make all sorts of objections to nature study, call it a "fad," "nonsense," complain of "waste of time on new-fangled notions," say 
that "they never had to learn such stuff." These objections of the home are for the most part right as to what

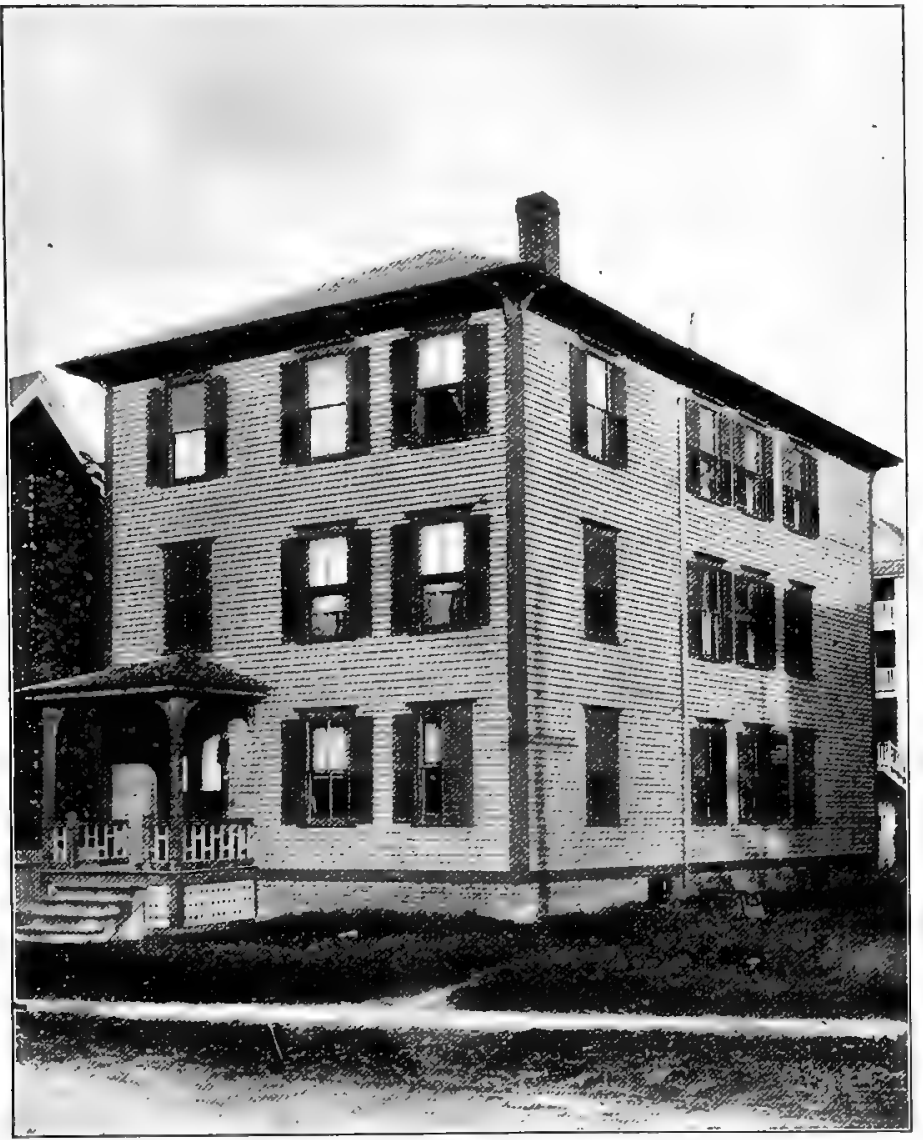

Fig. 5. A TENEMENT House

often goes by the name of nature study, and nothing could be more helpful for development of ideal courses 
adapted to local conditions than to invite their freest possible expression. If we cannot find a nature study worth while, a nature study so full of human good that it will meet and overcome all such objections, then we should devote the time to other subjects. But from several years' experience the writer is confident that all reasonable objections can be met, and that we can find a nature study so good that this attitude of parents can be completely reversed and their interest and enthusiasm so thoroughly. aroused that they will say: "We had no chance to learn these things, but we wish our children might be given the opportunity and teach us."

When this is accomplished, we shall have a nature study that shall bind home and school together as nothing in the curriculum does at present. Instead of giving over our entire school system to passive book learning, we shall have at least one subject that shall keep alive in the child the spirit of research, under the impetus of which he makes such astounding progress in learning the great unknown of nature around him during the first three or four years of life. This matter of original research in hand-tohand contact with nature ought to be made the breath of life in an educational system. It will form perhaps the most essential feature in every lesson in this book, and will be treated more fully under a special heading. By its means we may reinstate childhood in the function for which it was designed and created. John Fiske has pointed out that infancy was developed as a prolonged period of plasticity, by which "the door for progressiveness was set ajar." 1

1 John Fiske. The Meaning of Infancy. Excursions of an Evolutionist, p. 3 I4. 
If life is response to the order of nature, the higher and more complete the response, the higher and richer must be the life. Since response presupposes knowledge, nature study must take its place in public education as one of the chief means by which the race may push forward toward the more perfect response to the order of nature, which shall be its more perfect life. "I am come that they might have life, and that they might have it more abundantly."

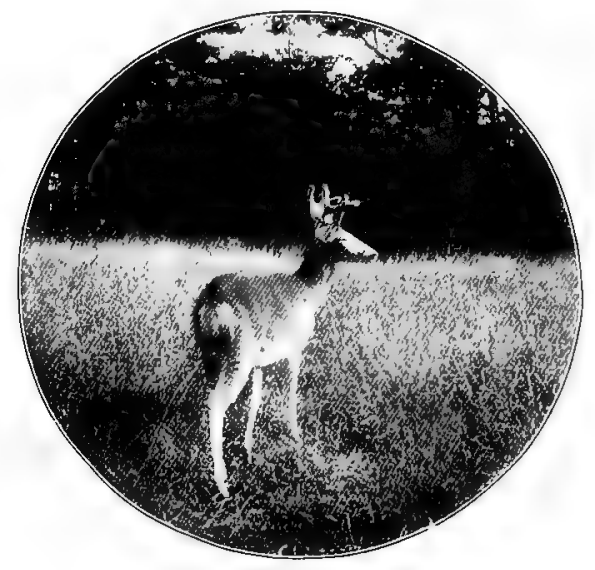




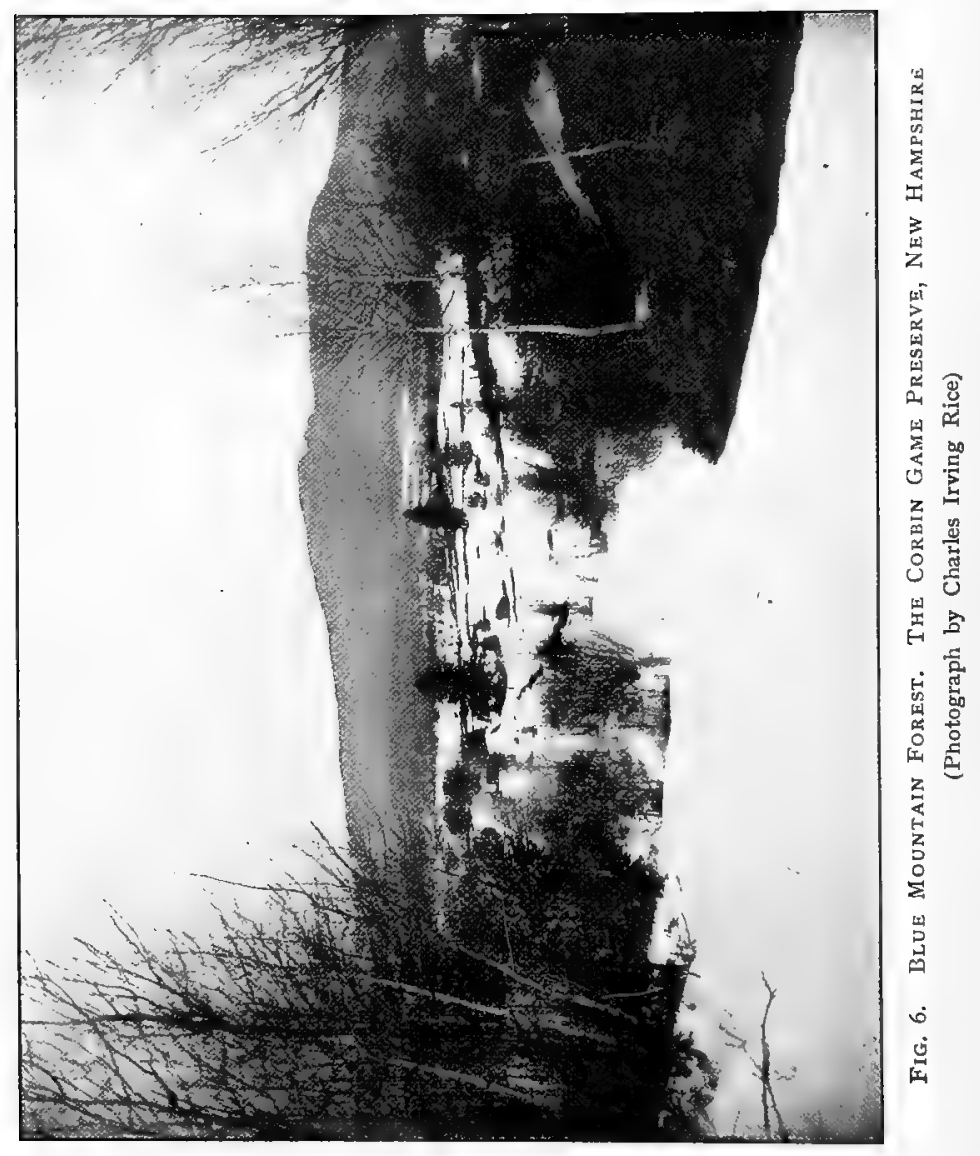




\section{CHAPTER II}

\section{VALUES OF NATURE STUDY}

\section{Economic, Æstheic, Educational, Ethical, ReLigious}

Consummation of happiness is the natural outcome of the perfecting of character, but that perfecting can be achieved only through struggle, through discipline, through resistance. It is for him that overcometh that a crown of life is reserved. The consummate product of a world of evolution is the character that creates happiness, that is replete with dynamic possibilities of fresh life and activity in directions forever new. Such a character is the reflected image of God, and in it are contained the promise and the potency of life everlasting. FISKE, Through Nature to God, p. II 4 .

And sure good is first in feeding people, then in dressing people, then in lodging people, and lastly in rightly pleasing people, with arts, or sciences, or any other subject of thought. Ruskin, Sesame and Lilies, p. 236.

Economic. - In basing a plan of nature study upon its human values it may be necessary to explain what is meant by the worth of a study in the curriculum. Throughout all the details of the various kinds of values we shall discuss, the paramount value to be aimed at is character, will to do good, power to create happiness. No lesson that does not contribute toward this end can claim the right to a place in the course.

Different plans of nature study are more or less strong in presenting a certain class of values, generally the æsthetic or scientific. My own plan has often been 
criticised on the ground that it emphasizes unduly the economic side, some even going so far as to insinuate that economic values are the only ones recognized. Nothing can be farther from my thought, as I hope this chapter will conclusively prove; but I would include all human values in about the relations that they bear to life, especially to child life in its different phases and interests. I have made economic values prominent because all other plans of nature study ignore them almost completely. I have used them because money is the common, universal expression of value that every one understands and respects; and while we may realize that there are many things that money cannot buy, no other measure of value is so fundamental to the ordinary affairs of life. Money value is, moreover, the trunk that supports many of the higher values. Some measure of assured material wealth must be attained before art, literature, and science can develop, and what holds true in the race, among different peoples, holds, in the main, with individuals. Further, the entire organization of society, social ethics, laws, and customs group themselves about this as the common measure of value for the life and work of man.

More and more, as society becomes organized, the common goods of nature come to form a great public property, - pure air, pure water, forests and roadside trees and flowers, game and fishes, birds, and other beneficent animals; and the laws founded on these nature values are yearly widening their circles of influence as knowledge of nature advances. On the other hand, the evils in nature, - insect pests, noxious weeds, fungous or bacterial diseases, injurious animals, - constitute a continual menace 
to the public good. No man has the right (and ignorance cannot be pleaded as adequate excuse) to allow things to breed upon his premises that may cause damage to his neighbor. This fight for the good and against the bad in nature is primordial and fundamental; it has existed as long as the human race; it cannot and should not be set aside by any considerations of a sentimental character, but it should be made in our plan of public education what it is and always has been in the education of the race, the dominant idea in nature study. We cannot expect intelligent observance of laws until the facts of nature upon which they are based become common property of the community. To lay this foundation for right living is certainly one of the functions of a publicschool system. As it is now, few people know even the names of the things that are doing the greatest harm or the most good in their own gardens. Insect pests, weed seeds, and the spores of destructive fungi are no respecters of fences, and we must look to a rational nature study to render universal the needed information.

Finally, with many the financial motive is the strongest one we can bring to bear to induce them to study or allow their children to study nature. After a beginning has been made, other, and so-called higher, motives may develop. There is the greater need of enlarging upon the economic motive because it has never been adequately brought before the public. Our biological science has been too largely a dead museum affair with little relation to the life of the community. When we study nature alive and at work, we begin to realize the incalculable worth of knowledge, the human value of science. A single 
insect species, inconspicuous and uninteresting in itself, like the San José scale or the codling moth, has the power to destroy or cripple the fruit industry of the entire country. Another, like the gipsy moth, can possibly strip the continent, periodically at least, of its forests, and others, for example the Hessian fly or chinch bug, hold in their power the wheat crops of large sections of the country. Practical knowledge in this field stimulates interest in birds and other insectivorous animals, and we have a foundation from which to study their work in the economy of nature. Fungous and microbic diseases of plants, animals, and man are other important topics of recent development which must be handled with discretion, but about which the public should have intelligent information. It is needless to multiply illustrations. My point is that nature study, or elementary science, for the public school ought to be all for sure human good. We must winnow our science of chaff and by careful selection fill the limited time with the best knowledge the experience of the race and modern science has to offer.

\#sthetic. - After the necessities of life are secured, man has instinctively turned toward the beautiful to complete his satisfaction in nature. Flower culture is an ancient line of human interest. Possibly nothing in modern times equals the hanging gardens of Babylon. Here we must turn for real education on the æsthetic side to the creation of the beautiful in nature and not content ourselves with talking about it or with passive enjoyment. Nature study should thus fill and surround our homes and schoolhouses with the most beautiful things attainable and instill the spirit of creating and preserving the natural beauties of 
roadside and field and forest rather than that of ruthless destruction. This side is provided for in chapters on cultivation of flowers, school and home gardens, and elementary forestry.

Unless the active and creative side is emphasized, a constant danger is that the study will fall to the level of fancywork, which may interest the teacher but fail to appeal to a large part of the class, especially the boys. While beauty should be given its due share of attention, a still greater danger is that it usurp the whole field. We then have a condition so well described by Huxley:

In these times the educational tree seems to me to have its roots in the air, its leaves and flowers in the ground; and, I confess, I should very much like to turn it upside down, so that its roots might be solidly embedded among the facts of nature, and draw thence a sound nutriment for the foliage and fruit of literature and of art. No educational system can have any claim to permanence, unless it recognizes the truth that education has two great ends to which everything else must be subordinated. The one of these is to increase knowledge; the other is to develop the love of right and the hatred of wrong.

With wisdom and uprigntness a nation can make its way worthily, and beauty will follow in the footsteps of the two, even if she be not specially invited; while there is perhaps no sight in the whole world more saddening and revolting than is offered by men sunk in ignorance of everything but what other men have written; seemingly devoid of moral belief or guidance; but with the sense of beauty so keen, and the power of expression so cultivated, that their sensual caterwauling may be almost mistaken for the music of the spheres. Science and Education Essays, p. I30.

Finaily, beauty should be permitted to bring its own message, to speak for itself. Explaining it and talking 
about it more often detracts from its best appreciation and enjoyment.

You send for me to talk to you of art; and I have obeyed you in coming. But the main thing I have to tell you is, - that art must not be talked about. ... Does a bird need to theorize about building its nest, or boast of it when built? RUskin, Sesame and Lilies, p. 216.

Educational. - On the side of educational values in building up sound brain tissue and mental power, the school should yield to Nature, "the Old Nurse," so far as possible, the position she has held in the education of thr race. Clearly, this relation is that of active response in direct, first-hand contact with nature. Doing something with nature has ever formed a large factor in education, of which nothing can take the place. This alone, as Froebel says, can prevent education from becoming hollow and empty, artificial, and a wholly secondhand affair.

We do not feel the meaning of what we say, for our speech is made up of memorized ideas, based neither on perception nor on productive effort. Therefore, it does not lead to perception, production, life; it has not proceeded, it does not proceed from life. FroEBEL, Education of Man, p. 88.

With a distrust in "book larnin" that has become proverbial, it is strange that it has been allowed to dominate the school curriculum so completely. This danger is now so widely recognized that it is unnecessary to dwell upon it, and, while some of our best plans of elementary science teaching aim to bring nature and the child into direct contact, much remains to be done by way of deciding what to bring to the child and what sort of 
contact, relation, or association it is best to form. Upon these two things depend largely the quality of knowledge and texture of mind that education yields to the child. Space does not permit a full statement of the argument, which I have given at length elsewhere, ${ }^{1}$ but its two important conclusions must be clearly borne in mind. These are, first, that quality of knowledge depends upon the ideas with which it is associated in the mind; and, second, that the strongest associations are related to the spontaneous activities of the individual. That is, for elementary study we must select those things that stand in fundamental associations with life and about which the children can find something worth while to do. In line with Herbart's doctrine of apperception and Froebel's of self-activity, it is the active as distinguished from the passive method of instruction, of which Professor Burnham says :

The great maxim of modern reform in education is the activity of the pupil instead of the didactics of the teacher. There are but two methods of instruction: as regards the pupil, the active and the passive; as regards the teacher, the method of demonstration and the method of suggestion. The active method of the kindergarten and the university should be adopted in all the grades. [Italics mine.]

In connection with it we must lay special stress upon the fact that the highest type of spontaneous, whole-souled activity cannot be developed about trifling or worthless things. "Give children large interests and give them young." This motto of Alice Freeman Palmer may well be used in deciding whether a topic should be

1 Pedagogical Seminary, vol. vii, No. 2, p. 208. 
admitted to the nature-study course. Will it form or help to form an important, lifelong interest, - an interest not technical or superficial, touching life only on the surface, here and there and at long intervals, but one that lies close to the heart, to the home, and to all that makes life worth living? The value of such an interest is inestimable. It may add a sparkle to the eye, elasticity to the step, and a glow to every heart beat, and be the most efficient safeguard against idleness and waste of time, evil, and temptation of every sort. The love of something worthy and ennobling is a passport the world over, for "All the world loves a lover." To find such an interest in some worthy nature-love is to discover the fountain of youth.

Nature is the great mother of such interests, and in proportion as education becomes thus alive and active, nature study must form a prominent factor in the curriculum. What is there for the whole child - hands, feet, eyes, ears and brain, mind and soul - to work with actively, except phenomena of nature, responses to which have constituted the chief education of living forms through all time? Language has grown up out of and around the things of nature to such an extent that even our common-school reading and writing is little more than a hollow mockery without the fundamental nature study to give it life and content; and much of our best literature must fail to be appreciated if its allusions to nature are not properly sensed.

When we consider that the Engis skull is a "well-shaped average human skull," indicating an average European brain of the present, and when we think that Nature 
has thus built up the human brain to the level at which civilization was possible, we begin to see the true importance of her tuition and to realize that a plan of education that leaves "the Old Nurse" in the background is quite likely to fail in laying the solid foundations of intelligent human character. It is in danger of posing as a system of elementary education with really elementary education left out.

Before discussing its value from the point of view of the child's development, I may say a single word for the teacher and for the tone and spirit of the school in general, as it appears largely in the relation of teacher to child. The impossible idea that a teacher must know everything is at present the shackles of our school system. Here is a subject that shatters these fetters by its very presence. In this field any child may ask a question that all the wise men cannot answer. The field is so boundless that to expect an elementary teacher to know all or much about a small part of it is preposterous. The most advanced specialists really know only a little about a very few animals or plants, and this little relates chiefly to technical details that have no place in a nature-study course. On the active side of growth and movement children, teachers, and specialists are all learners together.

Thus, father and son, teacher and pupil, parent and child, walk together in one great living universe. Let not teacher or parent object that he himself is as yet ignorant of this. Not the communication of knowledge already in their possession is the task, but the calling forth of new knowledge. Let them observe, lead their pupils to observe, and render themselves and their pupils conscious of their observations. . . . 
Even the knowledge of a previously given name is unimportant; only the clear and distinct apprehension and the correct naming of the general and particular attributes are important. . .

Let not the teacher of a country school object that he knows nothing about natural objects, not even their names. Even if he has had the scantiest education, by a diligent observation of nature he may gain a deeper and more thorough, more living, intrinsic, and extrinsic knowledge of natural objects in their diversity and individuality, than he can acquire from ordinary available books.

Besides, that so-called higher knowledge rests, ordinarily, on phenomena and observations within the reach of the plainest man, observations which frequently - if he know how to use his eyes come to him with little or no expense, in greater beauty than the costliest experiment could yield them. But to this he must bring himself by continued observation; to this he must let himself be brought by the boys and youths around him.

Parents should not be timid, should not object that they know nothing themselves and do not know how to teach their children. If they desire to know something, their ignorance is not the greatest evil. Let them imitate the child's example; let them become children with the child, learners with the learner; let them go to father and mother, and with the child be taught by Mother Nature and by the fatherly spirit of God in nature. The spirit of God and nature will guide them. FroebeL, Education of Man, pp. $200 \mathrm{ff}$.

From how much impossible cram, mental pretense, obliquity, and distress such a natural relation would relieve the teacher. It would bring us up to natural, ideal relations of teacher to pupil, relations of mutual helpfulness, that would sweeten and leaven the whole lump of our educational system and make it instinct with interest and life. "If I could only tell teachers how easy it makes the whole school go I would be satisfied," remarked a teacher who had given this kind of nature study a trial. Instead of being afraid or ashamed to say "I don't know," the 
teacher who sincerely desires to learn will be glad to say it, glad to have something brought in that affords him an opportunity to learn, and not only that, but at the same time the best possible opportunity to teach. Such teaching and learning will transform education from a deadly mechanical grind to a. living process.

But after all, childhood, - active, fresh, spontaneous childhood, - and its need of the normal environment for growth and vigor, supplies the imperative demand for a natural and active nature study. Truly "trailing clouds of glory do we come"; and when we discover the right way, there shall be no "shades of the prison-house" to "close upon the growing boy." In rare cases now we find the charm of childlikeness, the open interest and rapid growth, extending on through boyhood and to the end of old age. When we learn how to educate normally, this may become the rule rather than the exception.

The term is being much abused at present, but I hope I may be rightly understood when I say that the key to the solution of this problem is original research. The mind seeks for truth as the body for food. Search is a primordial element in all life, in all education. Cut this out and you have parasitism and degeneration of the higher functions. Everything that lives, from the amoba seeking for food to the artist or the scientist in search of beauty and truth, spends the best effort of life in just this thing, - search. Witness the way the infant learns during the first years of life, the incessant activity and infinite delight and wonderful rapidity with which it reaches out into the unknown of nature around it. Let us study how we may continue this splendid process of growth through 
all the years of school life. To do this we shall need nature at every turn, and the result will be a living, active, creating mind instead of a helpless parasite.

Again: I am incessantly told that we, who advocate the introduction of science in schools, make no allowance for the stupidity of the average boy or girl ; but, in my belief, that stupidity, in nine cases out of ten, fit, non nascitur, and is developed by a long process of parental and pedagogic repression of the natural intellectual appetites, accompanied by a persistent attempt to create artificial ones for food which is not only tasteless, but essentially indigestible. HUXLEY, Science and Education Essays, p. 128.

Ethical and Social. - As to the ethical values of nature study, an active, vigorous mind will find something to do, some way of expressing itself. Whether such a person does good or evil must depend largely on " the love of right and the hatred of wrong." Much evil is done through pure ignorance. A boy has little idea how much harm he may be doing when he kills birds or destroys their nests, because he has never been taught how much good they are capable of doing; and further, he has no basis of knowledge to tell him how much pain and distress he may be causing; and finally, he has no realization of the greater pleasure that he himself would clerive from an intelligent study of the same birds. No one can estimate the damage that the introduction of certain insects to new continents has wrought and may cause, but we must know these things in order to take proper precautions in the future. To do our duty by our neighbors we need a large body of knowledge of the common things that surround the home. No one, if he knew what he were doing, would breed about his premises noxious insects 
or weeds or the fungi of plant or human diseases that might cause his neighbors annoyance or loss. These things must be made matters of common knowledge in order to form the basis of right living, and how can this be done so universally and well as in our nature-study courses? In order to safeguard public interests and prevent a person from causing damage to his neighbors in these respects, laws are being rapidly passed in the different states. We cannot hope for a general observance of them until the facts upon which they are based become the common property of the community. Under the several subjects collect the nature laws of your state or city and town ordinances and make them a part of the nature-study course, - the laws and board of health regulations touching birds, insects, weeds, street trees, forest fires, destructive fungi, and bacterial diseases. These laws express the highest level of intelligent public knowledge and opinion, and their influence and scope should be largely increased for the public good. How can this be done so well as by studying the laws in connection with the facts of nature upon which they are based?

Everywhere in our theories of education the negative is giving place to the positive. We must have positive effort for good at every point and then there will be little need of the dull machinery of repression. Just in the period of early childhood, with its passion for activity and its capacity for interests, we need this ethical training more than at any other time. To turn the stream into beneficent channels is far better than to let it run to waste or to dam it up. If the boys of a neighborhood make the raising of peaches and grapes impossible, a better remedy 
than the jail would be to start them raising peaches and grapes of their own. Effort for the production of property is ethical, and the moment the child engages in it he places himself upon the side of law and order in the community. To rear a flower is an ideally ethical thing and may elevate the moral and asthetic tone of a household. We need this ethical training, not in the way of moralizing, but in unconscious positive doing, as the warp of our education, and nature study offers boundless opportunities for its daily inculcation and practice.

Religious. - Finally, no one can love nature and not love its Author, and if we can find a nature study that shall insure a sincere love, we shall be laying the surest possible foundation for religious character.

A good deal has been written of late about the child repeating the history of the race, and it seems to have been taken for granted that the nature worships of primitive peoples form the normal stepping-stones for the child to higher conceptions of religious truth. The reasons that seem to render such suppositions unnecessary or possibly untenable are stated more fully in the paper just referred to. ${ }^{1}$ It is sufficient to say here that all the nature worships of which we now have any knowledge are relatively modern phenomena, terminal twigs on the evolutionary tree, rather than fundamental elements in the main trunk of human progress. They would thus have no relation to the normal development of the child.

Creative effort for good: this is the fundamental conception of religious progress, aside from all matters of race, creed, or sect, - "The character that creates

1 Pedagogical Seminary, vol. vii, p. 208. 
happiness, that is replete with dynamic possibilities of fresh life and activity in directions forever new." Nature is given as the great matrix with which we are to create, and to go through life with no attempt to gain a knowledge of it, with no effort to learn its possibilities, is dull, dead atheism. The child that puts forth creative effort to make the world better, the child that plants a seed or cares for the life of an animal, is working hand in hand with nature and the Creator, and what higher religious development can we desire than that he become the "reflected image of God"?

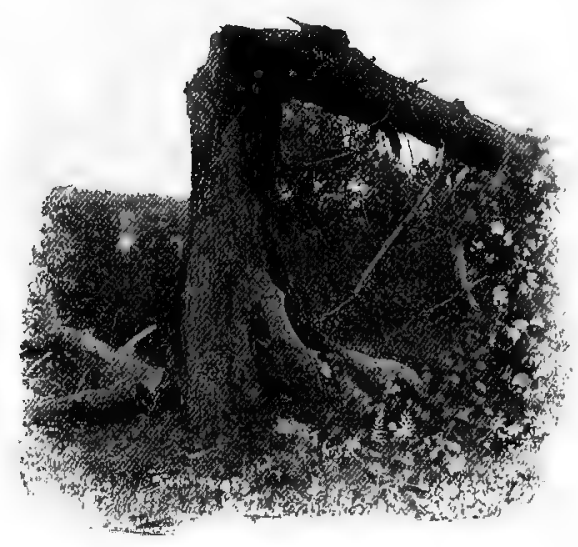




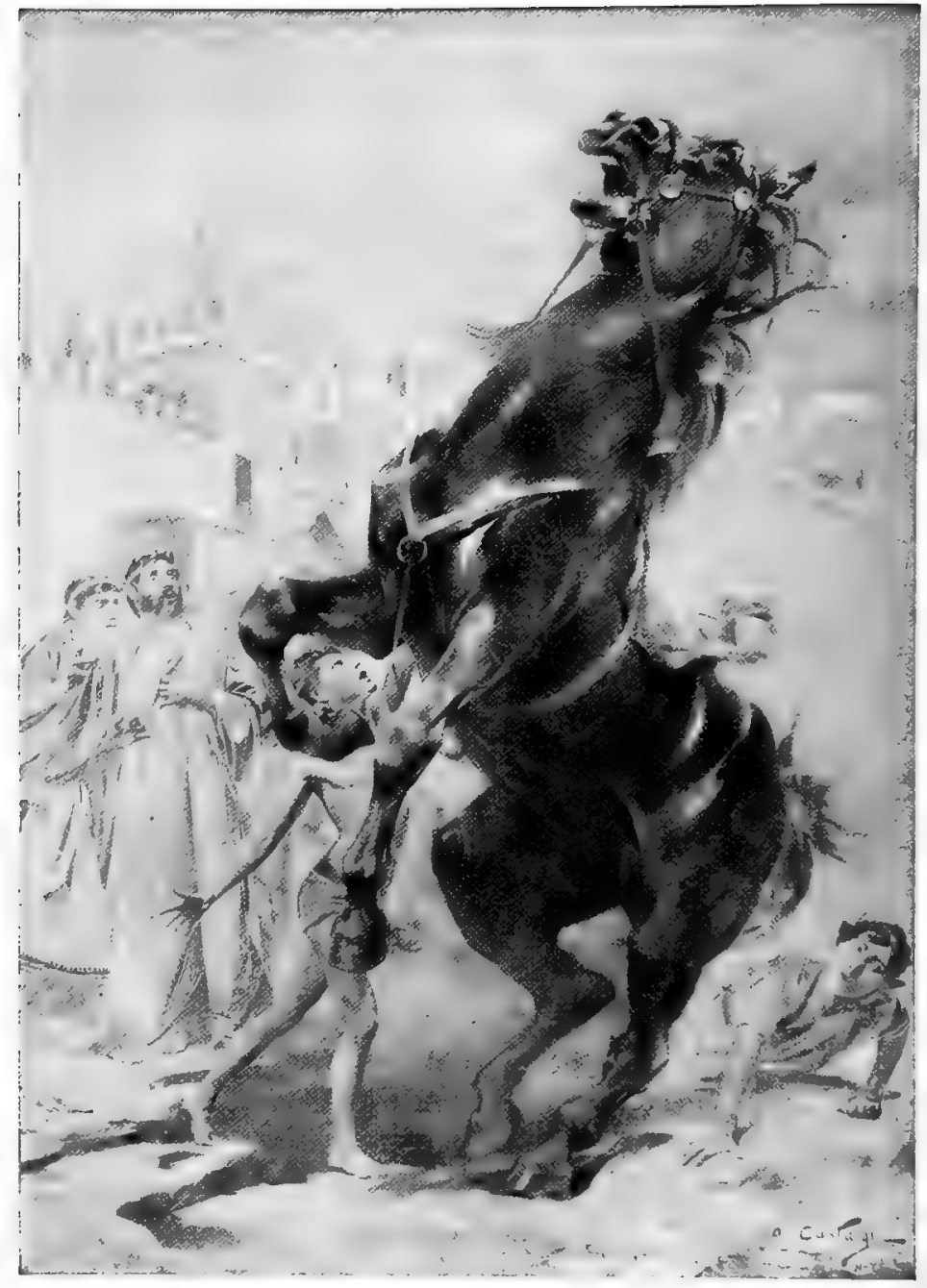

Fig. 7. Alexander taming Bucephalus

(A. Castaigne) 


\section{CHAPTER III}

\section{CHILDREN'S ANIMALS AND PETS}

The wolf also shall dwell with the lamb, and the leopard shall lie down with the kid; and the calf and the young lion and the fatling together; and a little child shall lead them.

They shall not hurt nor destroy in all my holy mountain : for the earth shall be full of the knowledge of the Lord, as the waters cover the sea. Isaiah, xi.

$\mathrm{He}$ comes to the teacher with his eyes filled with a thousand pictures, but these are ignored, and he is robbed of them one by one, until the beauty of this world fades from his sight, and it is changed to a vale of tears. JACKMAN.

Thanking the true Pan

Who by low creatures leads to heights of love.

Mrs. Browning, Flush or Faunus.

PETs are the child's natural introduction to animal life. By their means the knowledge gained of the animal as a whole, its habits, life, individual character, intelligence, disposition, affection for its master, its health and wellbeing, is infinitely more living and real than that imparted by any other method of instruction. By its associations with the child's spontaneous activities in caring for his pet this knowledge becomes a part of his life and will thus enter into the formation of his character to exert its civilizing influence as long as he lives. Of how little value, compared with this, is learning of names, schemes of classification, or anatomical structures. 
In the development of the child's emotional and moral life this relation to his living pet is of even greater importance. Nothing is better fitted to develop patience and conscientious carefulness than the daily attention to its needs. Unselfishness is fostered by this care and by the generous sharing of his good things with his humble friend.

Play is coming to be recognized more and more as an important factor in life and education. Nothing as fully brings into healthful activity every function and power, so that Froebel truly says: "A man is a whole man only when he plays." Plays of the young are generally preparatory to activities of adult life, and pet-plays prepare, as nothing else can, for the most important of all functions, the care of the young. The care of the pet involves the same reasoning, the same thinking and feeling and willing and doing, as the care of the child. Finally, love. of nature is a thing of slow growth. It begins when the love of a child flows out toward some one specific thing; it gathers force when something else is loved, and so on until he loves so many things and has come to look so deeply into nature's heart that he feels the love of all nature. This is a result worth years of patient education.

With these educational values in view, parents would naturally provide for their children pet animals suited to their ages and inclinations so far as possible, and they can steady and assist the child in faithful care and proper treatment.

For the school, the main point of interest being the relation between the child and pet, we must begin by finding 
out what animals the children have. This may be done by simply asking them to write a language lesson about their pets, in which each tells what animals he has, how he cares for them, and what he does with them or how he plays with them. The teacher may then preserve these for future reference, and during the nature-study hour have the children recite about them in order, describing their interests in the pet, its character, intelligence, and disposition, the care it receives, its health, and cleanliness. One after the other the children might be invited to bring certain kinds of pets to show and to use as models for drawing lessons.

Another way of securing a statement of the resources at command of the class is to have blanks printed with names of a number of different animals and ask the children to fill them out as indicated. A form is here given that may, of course, be modified in any way to adapt it to local conditions.

\section{Animals and Pets owned by:}

Name

School

Grade

Age

Date 190 .

The pupil will please draw a line under the names of animals that he owns and indicate the number of each.

$\begin{array}{llcll}\text { Dog } & \text { Rabbit } & \text { Other animals } & \text { Chicken } & \text { Frog } \\ \text { Horse } & \text { Squirrel } & \text { Pigeon } & \text { Other birds } & \text { Fish } \\ \text { Cat } & \text { Rat } & \text { Canary } & \text { Toad } & \text { Turtle } \\ & \text { Lizard } & \text { Butterfly } & \text { Anything else } & \end{array}$

NoTE. - Please write a short description of your animal, giving breed or species, if known, age, size, etc., and state who takes care of it and what care it receives daily. Add anything that you wish to tell about it, using the back of this sheet, if necessary. 
With the papers in hand the teacher sees exactly what the resources of the class are for this series of lessons in the zoölogy work. A plan may then be made that shall bring out the best knowledge the children have about their animals, their habits, likes and dislikes, foods, care, uses, etc. If the class is well supplied with pets, the children may study and observe them, thus learning their lessons from the living realities rather than from books; and, as just intimated, such pets as are not likely to cause annoyance and disturb the school may be brought in during some of the lessons. But, in general, schoolrooms are not adapted for keeping animals, and even a pigeon or a rabbit may be a nuisance when thus out of place.

It is not intended to give the natural history of each animal pet in the series, and great care must be taken not to allow the lessons to grow dull with commonplaces that everybody knows, or run off into details of technical and superficial interest that it makes no difference whether any one knows or not. People may live long and die happy without ever having lumbered their minds up with such ideas as "a chicken has three eyelids," "a dog is covered with hair," "a cat has five toes on the front feet and four toes on the hind feet," and so on ad nauseam. There are plenty of common-sense, valuable, and interesting things to be learned about animals to occupy the time, and we may leave all details of comparative anatomy to special courses in colleges or medical schools. The following is intended as merely suggestive upon the more important of these matters, to illustrate the point of view rather than to give a complete list. The resources of the 
children and the common sense of the parent or teacher must supply the rest.

The Dog. ${ }^{1}$ - This was the first animal domesticated by man and the only animal that the North American Indians had tamed before settlement of the country by Europeans. The reasons for this are to be sought in the character of the dog and in his value to man. Let the children illustrate from their own pet dogs so far as possible, and from observations that they have been able to make for themselves, each of the following points: fidelity and love for master, unselfish devotion, courage, strength and endurance, intelligence and docility, ability and willingness to learn. Study the dog's work in the hunt, his keen scent and ability to track game, his speed and endurance, his passionate love of hunting and retrieving game; the shepherd dog, his work with flocks and herds; the watch dog. The following topics will appeal to the children more strongly: the dog as a companion and playfellow; the games and tricks of dogs, - fetching sticks or balls when thrown, retrieving from water, drawing sleds and carts, sitting up, begging, speaking, etc.

Among the many who keep dogs but few know how to take proper care of them. Most people overfeed, thus allowing the dog to grow fat, lazy, and stupid. For an adult dog one meal a day, given in the evening, is generally better than two or three. It should consist of dog

1 Read to the class the best story you know about a dog, e.g., Castle Blair, Shaw; Helvellyn, Scott; Rab and his Friends, Dr. John Brown; Doz, J. T. Fields; To Flush, my Dog, Mrs. Browning; "How William of Orange was saved by his Dog," Motley's Rise of the Dutch Republic. 
biscuit or the coarser table scraps, bread crusts, brown bread, oatmeal, bones with not too much meat, and vegetables. In severe weather or with much exercise in the open air a dog needs to be fed oftener and to have more food. The best indication as to whether the feeding is proper is the condition of the animal. He should be neither lean nor fat, but sleek. One should be able to take up a handful of soft, loose skin anywhere on the dog's body. A gnawing-bone is the dog's toothbrush, and he should be kept well supplied at all times, both for business and amusement. Too much meat and lack of cleanliness is apt to give rise to offensive odors, the "dloggy" smell of animals not properly cared for. Fleas are the great burden of a dog's life (see page $8 \mathrm{I}$, under insects). To kill every flea on a dog it is necessary only to lather him completely with some mild, clean soap, castile or ivory, let it stay on for two or three minutes, then rinse in clean water or let the dog take a swim. A dog is thus the best possible flea trap. He will pick up every flea in the house or neighborhood, and they may then be easily killed. If every one did this, which is no less than he should wish to do for the health, cleanliness, and comfort of his pets, a neighborhood might soon be rid of these pests. For other matters as to the dog's health and care, their owners should be referred to standard authorities.

The Horse. - Domesticated before the dawn of history, probably by a branch of the Aryan race in the north of Asia, no animal has exerted a more powerful influence in human progress, either in war, in sports, or in the arts of peace. To learn to control and ride a spirited horse is 
an education in itself for a boy, closely associated with one of the greatest lessons in the nature study of the race.

Many of the children are likely to have more or less to do with horses in connection with either their pleasure or their work, and the aim of these lessons may well be to establish a fellow-feeling with them and high ideals as to their care and humane treatment. We may see daily instances of misuse, if not of actual abuse, which a few reasonable lessons might have prevented; and the object at which such education should aim is the development of general public sentiment. To this end lead the

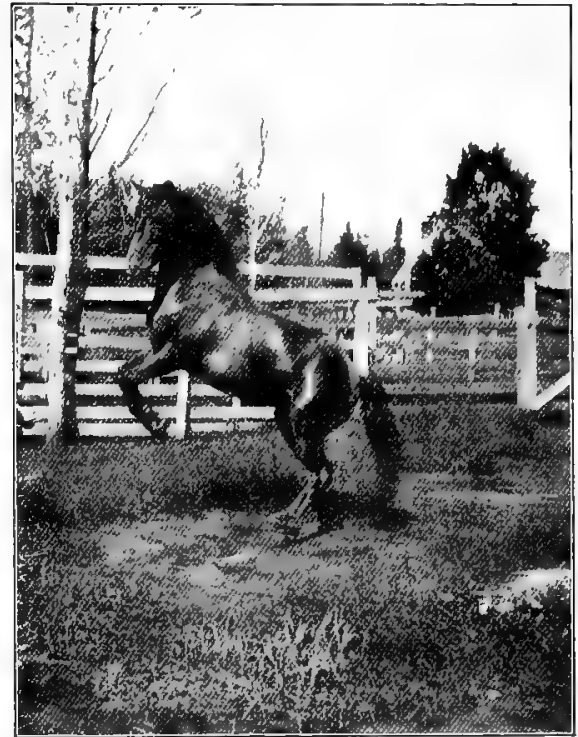

Fig. 8. A Noble Animal (Photograph by Charles Irving Rice) children to observe the treatment of horses in the neighborhood and then group language lessons about such topics as naturally suggest themselves. Among these will be : care and feeding, blanketing in bad weather, overdriving and overworking. Teach the law of your state with reference to cruelty to animals. Have the children 
read Black Beauty. How much time is devoted to these topics must depend largely on local conditions and on the interests and resources of the class.

The intelligent and humane taming of so powerful an animal is perhaps the point of chief interest. We often hear of "breaking" a horse instead of "taming" it, and a poor spiritless thing is apt to result. The best story in this connection is the following, a very old one; but it may still serve as an inspiration to every child as long as horses exist.

Philonicus of Thessaly had offered to sell Philip his horse Bucephalus for thirteen talents. So they all went down into the plain to try the animal. He proved, however, to be balky and utterly useless. He would let no one mount him, and none of the attendants of Philip could make him hear to him, but he violently resisted them all. Philip, in his disgust, ordered the horse led away as being utterly wild and untrained. Whereat, Alexander, who was present, said: "That is too good a horse for those men to spoil that way, simply because they have n't the skill or the grit to handle him right." At first Philip paid no attention to him, but as he kept insisting on being heard and seemed greatly disturbed about the matter, his father said to him: "What do you mean by criticizing your elders, as if you were wiser than they, or knew so much more about handling a horse than they do?" "Well, this horse, anyway, I would handle better than any one else, if they would give me a chance." "In case you don't succeed," rejoined his father, "what penalty are you willing to pay for your freshness?" "I 'll pay, by Jove, the price of the horse!" Laughter greeted this answer, but after some bantering with his father about the money arrangements, he went straight to the horse, took him by the bridle, and turned him around toward the sun. This he did on the theory that the horse's fright was due to seeing his own shadow dance up and down on the ground before him. He then ran along by his side awhile, patting and coaxing him, until, after a while, seeing he was full of 
fire and spirit and impatient to go, he quietly threw off his coat, and swinging himself up, sat securely astride the horse. Then he guided him about for a while with the reins, without striking him or jerking at the bit. When now he saw that the horse was getting over his nervousness and was eager to gallop ahead, he let him go, driving him on with a sterner voice and with kicks of his foot. In the group of onlookers about Philip there prevailed, from the first, the silence of intensely anxious concern. But when the boy turned the horse and came galloping up to them with pride and joy in his face, they all burst out into a cheer. His father, they say, shed tears for very joy, and, as he dismounted, kissed him on the head, and said: " $\mathrm{My}$ son, seek thee a kingdom suited to thy powers; Macedonia is too strait for thee."

Bucephalus became from this time the property and the inseparable companion of Alexander. He accompanied him on his campaigns, "sharing many toils and dangers with him," and was generally the horse ridden by him in battle. No one else was ever allowed to mount him, as Arrian says, "because he deemed all other riders unworthy." He is reported to have been a magnificent black charger of extraordinary size, and to have been marked with a white spot on the forehead. Benjamin Ide Wheeler, Life of Alexander the Great.

The Cat. - This, according to Shaler, "is the only animal that has been tolerated, esteemed, and, at times, worshipped, without having a single distinctly valuable quality." "It is," he goes on to say, "in a small way, serviceable in keeping down the excessive development of small rodents, which from the beginning have been the self-invited guests of man. As it is in a certain indifferent way sympathetic, and by its caresses appears to indicate affection, it has awakened a measure of sympathy which it hardly deserves. I have been unable to find any authentic instances which go to show the existence in cats of any real love for their masters." 
Unlike dogs, cats readily return to a wild, or semi-wild, life, and thus become a menace to much of the valuable and interesting nature life of the country, game birds and animals, and even to poultry. They breed in great numbers in cities, where their lives are, for the most part, a prolonged misery both to themselves and the community. Their cries at night are the mosi disagreeable sounds we have in nature. The various smells that mark the places they infest are utterly nauseating and intolerable.

Cats are the worst enemies of our common birds. Mr. Forbush estimates that on the average a cat kills fifty song birds a year, and he has known of a single cat destroying six bird's-nests in a day. In most states the legislature has deemed it wise to pass laws imposing fines ${ }^{1}$ upon those who kill birds. It is obviously absurd to fine a man for killing one bird and at the same time allow him to keep a cat that kills fifty. In some cities in Europe, where every effort is being made to protect the birds, cats are considered public nuisances if allowed to run at large. People who wish to have cats must confine them within their own premises, both by day and night, because numerous cat traps are continually set for strays. While not inaugurating a crusade against cats as pets, the lessons in nature study may exert some influence toward inducing children to observe what cats do and possibly to keep other pets so far as possible. Special attention should be directed toward preventing cats from killing birds ; abundant feeding, keeping in at night during nesting time, and possibly training, may prove effective in

1 Maine, $\$$ I to $\$ 10 ;$ Massachusetts, $\$ 10$; Indiana, $\$ 10$ to $\$ 50$; California, $\$ 20$ to $\$ 500$. 
some cases. Bells worn about the neck, as sometimes advocated, may save now and then an old bird, but not the newly hatched nestlings or young birds that are not yet wary or strong enough to fly.

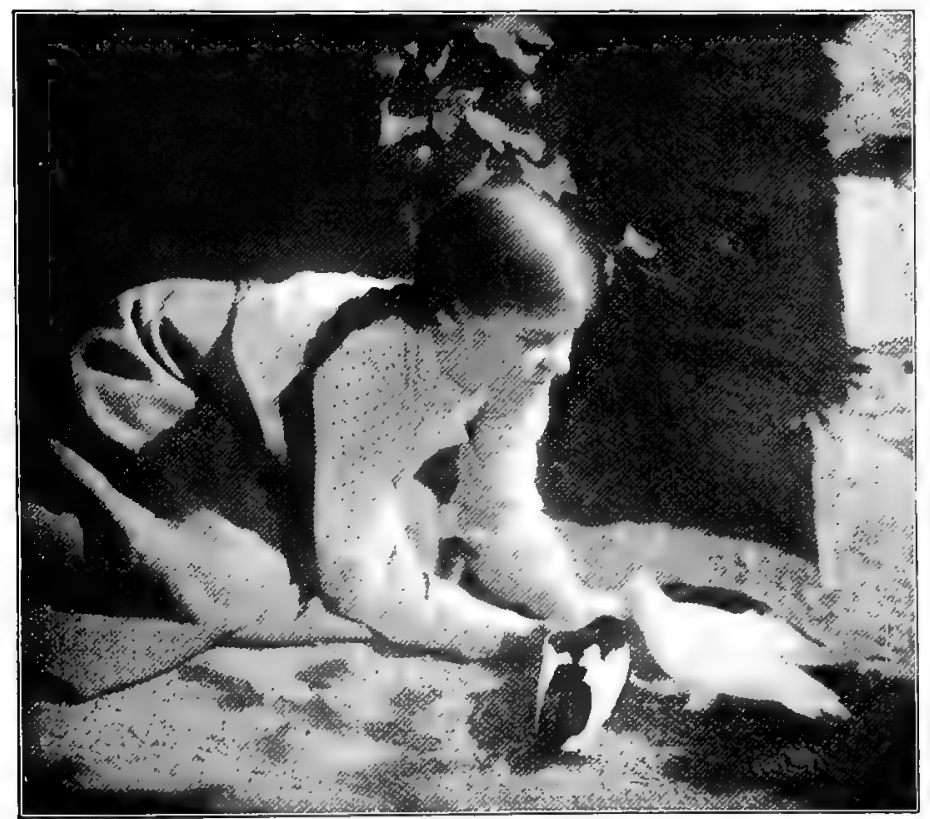

Fig. 9. Taming the Pigeons

(Photograph by J. Chauncey Lyford)

Care of the other common pets, - rabbits, guinea pigs, white mice, canaries, pigeons, chickens, and the like, may be taken up in series, according to the resources of the class. Different breeds of the various animals, - rabbits, pigeons, chickens, - with such knowledge as the children 
may possess of their comparative merits, will furnish material for valuable lessons. Homing pigeons are especially interesting.

Pets out of the common run will prove instructive. A wild bird tamed by some member of the class, a tame toad, frog, newt, turtle, snake, fish, or even butterfly, is not only interesting because of its rarity, but widens human relations toward nature. In the great process of animal domestication, in which we have made so little advance in the last four thousand years, such work may be made to constitute the crest of the wave of human effort, in itself the most interesting thing in the world.

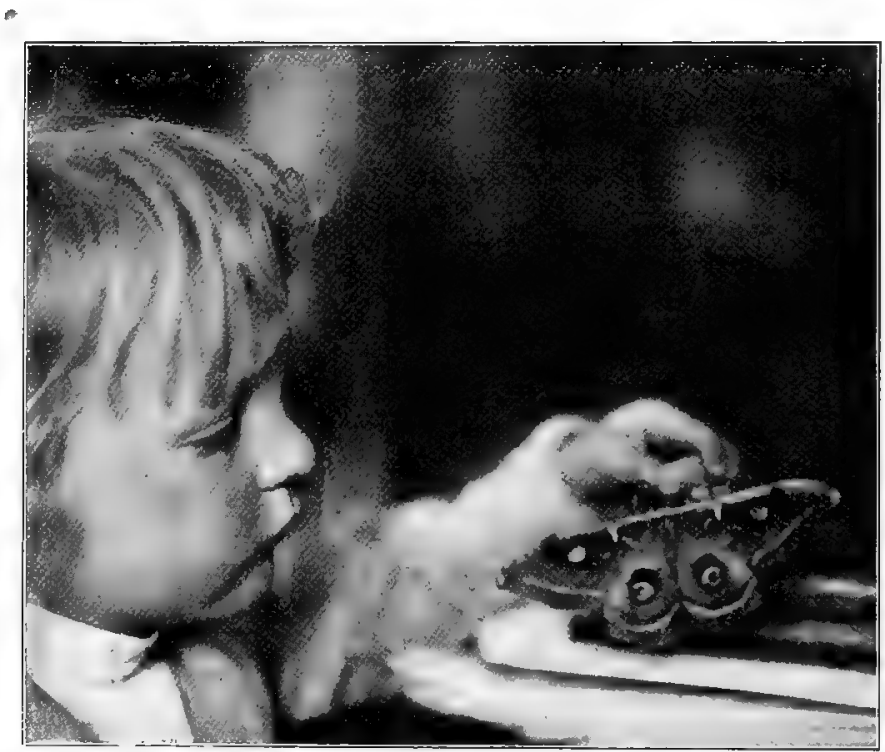




\section{CHAPTER IV}

\section{PLAN FOR INSECT STUDY}

\section{Methods; Materials; Insect Collections}

Teachers ordinarily feel quite at a loss where to begin or what to do with insects, but in no other subject should they feel more at their ease. The trouble has been that the field is so boundless and the books so technical that it has seemed impossible to bring it into any fruitful relation to elementary teaching. But leaving all the anatomy, the minutiæ of structure and classification for the specialists, and taking the common forms alive and at their work, no study furnishes more fascinating or valuable lessons. We shall have daily to say "I don't know," but so do the professors of entomology who have done nothing but study insects all their lives; or, since some teachers have not yet learned the value of saying "I don't know," let them play ball with the questions.

In an elementary course the aim should be to learn what every one ought to know about a few of the most important insects, and, for this purpose, we may study them in the following groups:

I. Insects of the household.

3. Insects of field and forest.

2. Insects of the garden.

4. Beneficial insects.

5. Insects beautiful and interesting. 
On the side of injury and damage to man, it has been calculated that insects about equally divide the produce of the soil with the farmer. Professor Riley estimated that insects destroy annually from $\$ 300,000,000$ to $\$ 400$, 000,000 worth of produce in this country alone. These

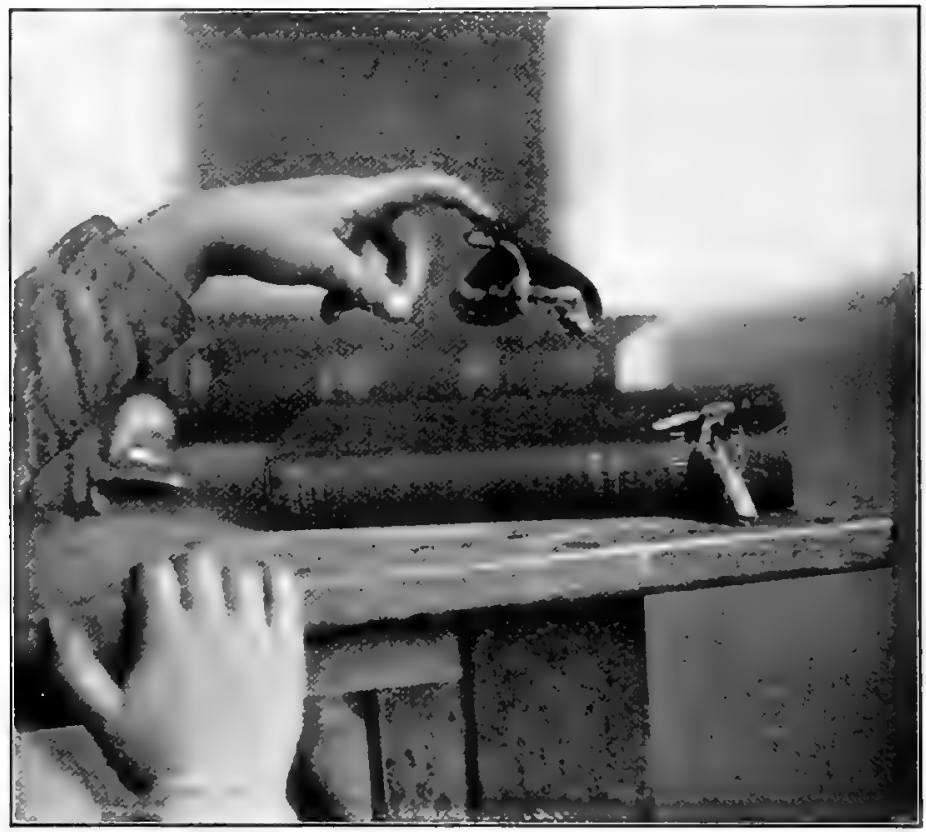

Fig. Io. Promethea just emerged

figures were given twenty years ago and are low, as we shall see, when we study the ravages of single insect species.

The beneficent work of insects consists in practically creating by cross-pollination our bcautiful and fragrant 
flowers and most valuable varieties of fruits. So important is this great work that the question continually arises: Might we not be doing harm if we reduce the numbers of insects too much? Its practical answer must be sought in a study of each species of insect, but it is safe to say that as most of the injurious kinds do little or no good, destruction of them is

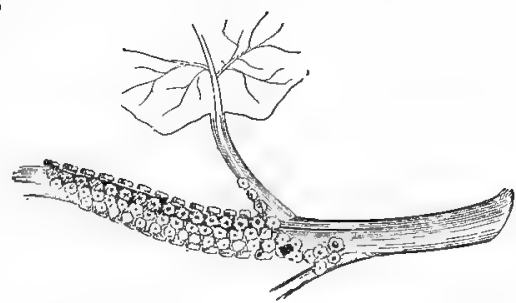
the only problem. It is

Fig. it. Eggs of Antiopa butterfily also a wonderful coincidence that the most useful and benign of all insects, the honeybee, is practically sufficient

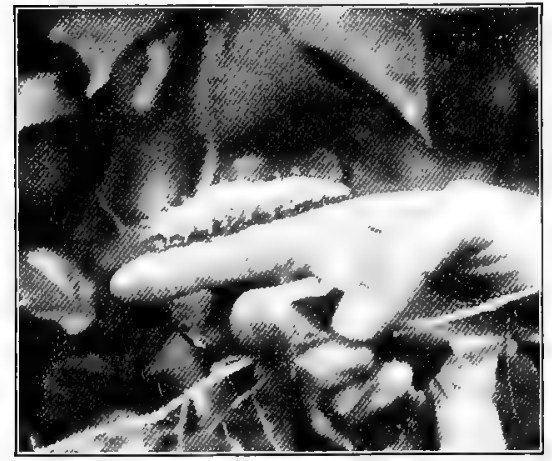

Fig. 12. Larva of CeCropia REAREd from THE EGG

(Length, $3 \frac{x}{2}$ inches) for the work of crosspollination of fruits and flowers.

Methods of insect destruction have run of late years toward the use of poisons and spray pumps. These are expensive and laborious, and a ride through the country in any direction will convince the unprejudiced observer that these methods are inadequate to the task. One man may rid his garden of insect pests only to have it restocked from his neighbors' 
across the way, and soon he gives up the fight. We need rather to study how to make the most of the far more powerful and universal agencies of living nature, the natural enemies of various insect species; and with an intelligent public educated about these problems and all working together, many of the worst insect ravages may

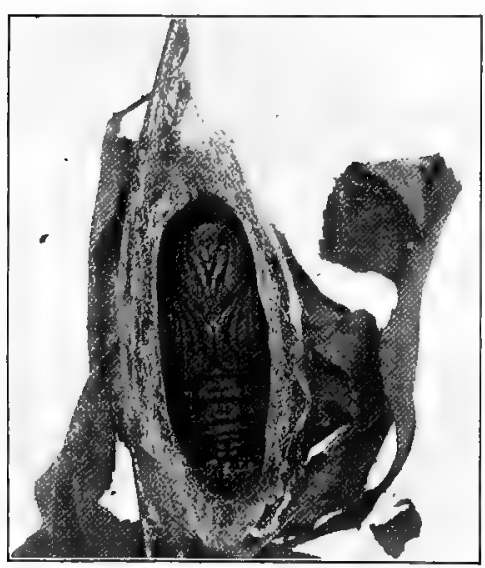

Fig. 13. Chrysalis of Cecropia in Cocoon

( $\frac{1}{2}$ natural size) be easily and speedily abated.

First, as to a few simple terms: By the life history, or the life story, of an animal, we mean all the changes it goes through and all that it does from the time it hatches from the egg, or is born, until it dies of old age. Most insect eggs hatch out into something quite unlike the parent. This is called a "larva." The larvæ of flies are often called "maggots," those of beetles, "grubs," and those of moths and butterflies, "caterpillars." After feeding actively and shedding its skin from five to twenty times as it grows, the larva passes into its third stage, the "pupa." To outward appearances this is a quiescent stage, the insect being incased in a hard shell, but inwardly active changes of form are going on. The pupa of a butterfly is often called a "chrysalis." After the internal rearrangements have been made and the proper time has arrived, the 
pupa case is split open on the back, and the adult insect emerges; the fourth and last stage begins. The adult female lays the eggs, and the life story from egg around to egg again is completed. This change of form in insects is called "metamorphosis."

A few insects hatch out from the egg more nearly like their parents in form. Children will notice this in the case of their grasshopper or water-bug eggs. Insects that do not thus completely change their form are said to present an incomplete metamorphosis, and the young

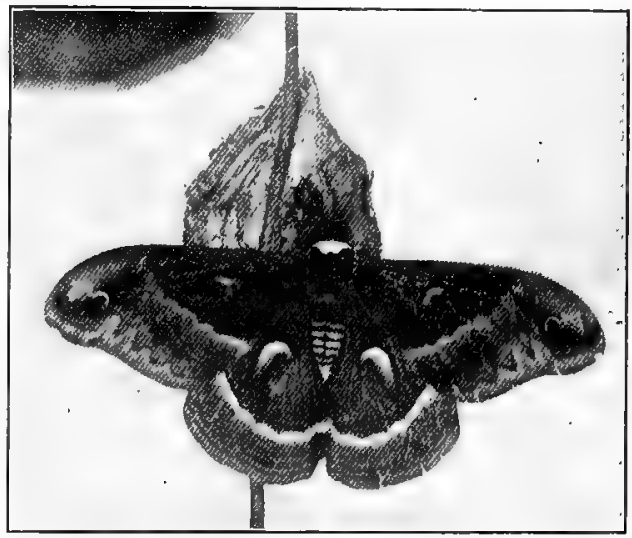

Fig. 14. Adult Cecropia on CoCoon ( $\frac{1}{2}$ natural size) in all stages are called "nymphs" instead of larvæ.

With our insect enemies it is important to learn the whole life story in order to find the weakest point, at which we may most easily attack and destroy them. We shall endeavor always to point this out for the insects described, but it will be possible to give only a few which happen to be of greatest importance at present in order to illustrate a method for insect nature study. The best rule to follow is to study the insects that happen to be of most importance or of greatest interest for any locality or season. 
Until we have the country much fuller of birds and other insectivorous animals than it is, we may expect to have storms of different kinds of insects. It may be grasshoppers or crickets or army worms or plant lice or June beetles or caterpillars of a hundred kinds. We never can tell what will come next, so, while the following are described as probably of greatest importance at present and for some time to come, we must not be too much influenced by a formal list, but keep our minds open to study nature as it flows by and be ever ready to do the thing that is most worth our while.

Apparatus and Methods. - The first thing to provide is something to catch insects with, the insect net. This may be easily made by taking a piece of No. 12 spring brass wire four or five feet long. Bend it into a round loop about a foot in diameter, crossing the wire six inches from the ends and giving it one firm twist. Next, clamping it tightly against a small iron rod or round stick in a vise, wind the ends closely around the rod into a spiral. You now have a convenient frame into which any stick can be screwed for a handle. The net may be made from three-quarters of a yard of cotton tulle or light cheese cloth sewed into a bag rounded at the bottom and just as large as the frame at the top. It lasts longer if a narrow border of sheeting to cover the wire is stitched around the top. The bag should be a little more than twice as deep as the frame is wide, so as to lap over and close well when an insect is caught. It is lively work catching insects, and no one piece of nature-study apparatus will give a child more exercise in the fresh air and better training of eye and hand than an insect net. Nothing will 
secure for him such an inexhaustible supply of material for study, and every boy and girl should have one of his own.

To preserve your insect, you must first kill it without injury, and this is best done with a cyanide bottle. Get a wide-mouthed bottle and a good cork to fit it tightly. In the bottom put an ounce of potassium cyanide broken into

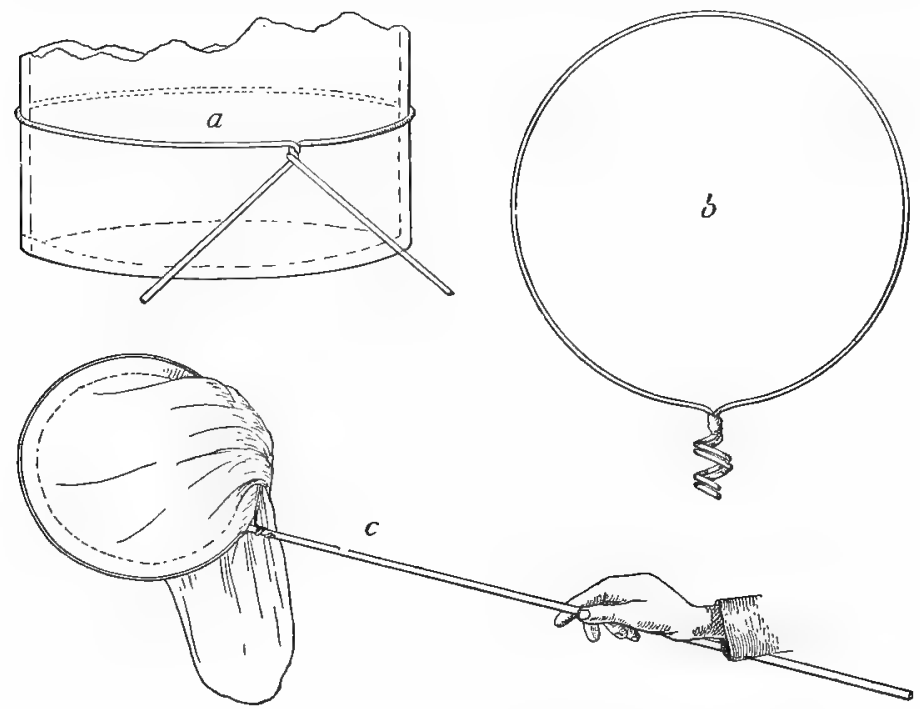

Fig. I5. MAKing The INSECT NeT

lumps not larger than a filbert; add sawdust a little more than enough to cover the largest lumps and pour in plaster of Paris, mixed to the consistency of thick cream, to form a layer a quarter of an inch thick. The plaster will harden in a few minutes, and an insect dropped in and corked up will die almost instantly and without injury or apparent suffering. What kills the insect is the fumes 
of the cyanide coming through the plaster and saturating the air within the bottle; hence avoid breathing any of these fumes yourself and keep the bottle tightly corked at all times. The cyanide is a deadly poison, and the fact that it is a harmless-looking white substance, not unlike lump sugar or rock salt and many other things, renders it one of the most dangerous poisons to keep about the

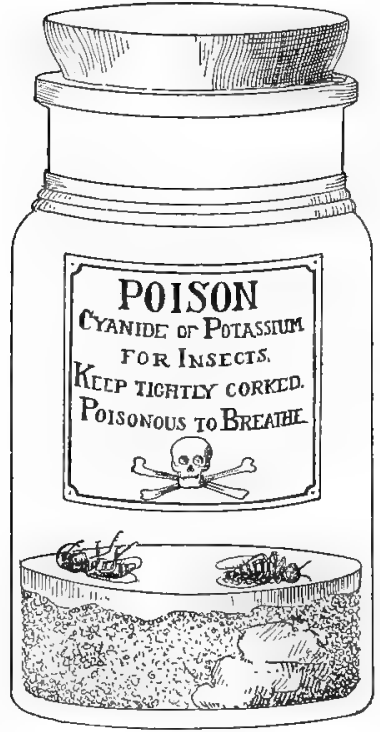

Fig. 16. Cyanide Bottle house. Label the bottle as in Fig. I6. Such a bottle will remain good for a season. If moisture collects in it, wipe dry with blotting paper or a soft cloth.

Insects may also be killed with chloroform. If this is preferred, get an ounce of it in a flat vial; stick the handle of a small camel'shair brush into the bottom of the cork, and, holding the insect in a fold of the net, apply a drop to each side (for insects breathe through a row of minute holes along the sides), and it dies instantly.

On a collecting trip you will also need strips of newspaper, in which the insects may be neatly folded without breaking the wings or legs.

Insects are mounted in a number of ways. The common method is to pin them in a large tray provided with a sheet-cork bottom and glass top; but these trays or cases are expensive and cannot be recommended for 
school collections. Another way, after the insect has been properly "stretched," or "spread," is to mount permanently in the depression of a block of plaster of Paris, a plate of glass just fitting the plaster block being fastened with gummed paper, as a cover. Most moths and butterflies in our large museums are now mounted in

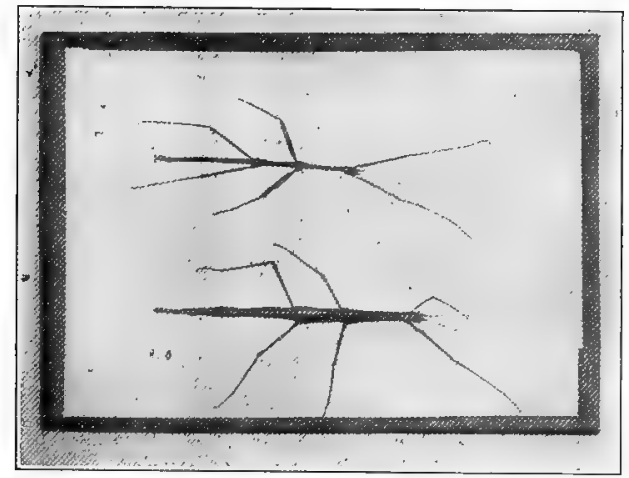

Fig. I7. WaLking Sticks

Male, female, and eggs. (To show method of mounting)

this way for exhibition. This method has the disadvantage of allowing only one side to be seen.

The method here advocated, which, I think, will supersede all others when its advantages come to be properly understood, consists in simply inclosing the insect between two plates of glass. ${ }^{1}$ Since our method of spreading insects depends upon properly exhibiting them in this way, I will describe it in this connection.

1 I am indebted for this method of mounting insects for school collections to Miss Martha F. Goddard, who found it in use in the Swiss schools and kindly described it to me. 
Take two rectangular plates of glass of the same size, large enough for your specimen, or specimens, for this method is admirably adapted for life-story collections. Cut a strip of thin wood as wide as the thickness of your largest specimen, - berry-box or cigar-box wood is good, - brush over one side with ink to blacken it, and, with glue or shellac, stick the wood around the edges of one of the glass plates. You now have a box with glass bottom and wooden sicles as deep as your thickest specimen. ${ }^{1}$ Arrange your specimens in order: egg cluster; single egg; larvæ of increasing sizes; moulted skins, if you have them; pupæ, male and female; cocoons ; pupæ cases, from which the insects have emerged; leaves eaten by the larvæ; male and female adult insect. Fasten in place with minute drops of glue where the specimen touches the glass, ${ }^{2}$ and, if desired, glue a neat label under each specimen, giving perhaps the date of the different processes represented. Put the other glass on for a cover and glue a strip of black paper or passe-partout around the edge of the whole just wide enough to hide the wooden frame. You now have a series of. specimens that tell the story of an insect's life from beginning to end in its reality. You can see both sides of your insects, - head, mouth parts, legs, feet, wings, - all equally well. ${ }^{3}$

1 "Insect mounting strips," made in one piece, to fold together, like a honey section, for cases $2 \times 5,4 \times 5$, and $5 \times 7$ inches, and of different widths, are now obtainable from the A. I. Root Co., Medina, Ohio, at about \$1.25 per thousand.

${ }^{2}$ Glue sometimes dries so hard that it scales off the glass. To prevent this I add to an ounce bottle about twenty drops of glycerine.

${ }^{8}$ Insects are often marked and colored differently above and below, so that this is no small matter in deciding on a method of preparation for imparting clear and complete conceptions to children. 
As scrap glass, broken glass of all sizes, and old photographic negatives ${ }^{1}$ can be utilized in this way, the cost, either to the children or the school, for mounting a good working collection of insects need be practically nothing, not even the price of insect pins.

Spreading. - As we have now a clear idea of what we wish to do with our insects, the matter of spreading - arranging wings and legs so that they will show what we wish

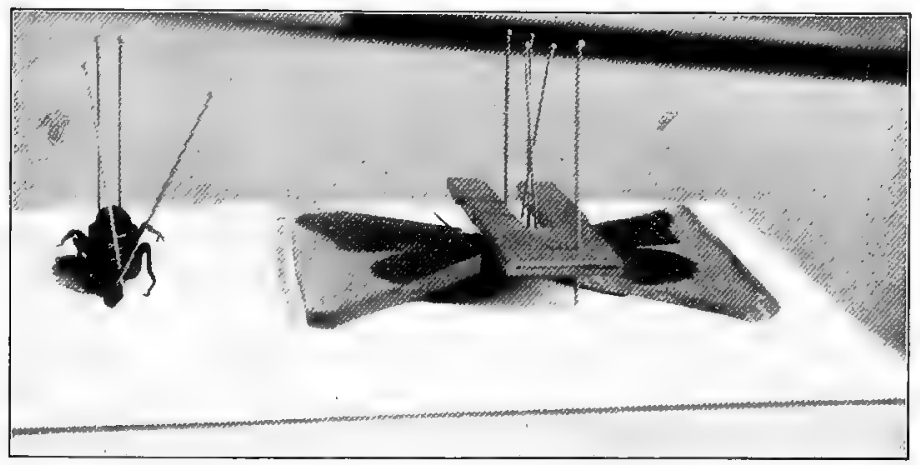

Fig. 18. New Method of Spreading Insects

to see - becomes one of ordinary common sense. While the specimen is flexible, simply arrange the parts and have them held as you wish until they dry. We will study natural positions of the various insects and set the parts accordingly.

Since we do not mount insects in the old way, we do not need the minute and technical apparatus and materials usually described for this work. All that is required is

1 Waste negatives are the best glass obtainable, thin, clear, and free from bubbles. The films may be easily removed by hot water in which a little sal soda or other alkali has been dissolved. 
some thin boards or cards, cigar-box wood or grape-basket covers, and a few pins, or better, fine needles mounted in match sticks. ${ }^{1}$

To spread a butterfly or moth lay it on its back on the board and stick a pair of pins, one each side of the body, between the thorax and abdomen. If necessary, insert a second pair at the neck or in front of the wings. Bring the wings down flat on the board, move the fore wings to their natural position, and lay on bits of glass, one on each side to hold them, and to press them smooth and flat while they dry. To arrange the legs have a little piece of berry box, cut as in the figure, or two narrow strips, mounted on a pin; bring it down over the insect, just the right height to suit the length of its legs, and with a mounted needle arrange the feet upon it in their natural positions. See that the feelers are in good position, setting a pin against them to hold them until they dry. Possibly you will wish to uncoil the tongue and pin that out. Dragon flies, hellgrammites, bumblebees, and other large winged insects may be spread on their backs in the same way. To mount butterflies with wings closed over the back you will, of course, place them feet down, but it will be well to let them rest with the body on the board, as the legs will be too fragile to support the weight when they become dry.

Beetles, bugs, grasshoppers and crickets, ants, flies, spiders, etc., are easily spread, feet down, in natural positions (Fig. I4). Some of the smaller and stouter ones

1 While we do not use pins to stick through the insects, insect pins are good to use for holding the parts in place while they dry. A package of one hundred, assorted sizes, costs but fifteen cents. 
may be able to stand on their dried legs, but it will generally be safer to mount them, with the aid of a drop of glue, so that the thorax will touch the glass. If it be desired to have them stand higher, glue a little post of the right length, - a bit of broom, splint, or cork, - to the thorax, or thrust a point of a toothpick (dipped in ink) into the thorax from below and cut it off as high as you wish the insect to stand, and glue this to the glass of the permanent case. With beetles and grasshoppers it is well to raise one wing cover so that the wing below may be seen.

Caterpillars and grubs and larvæ of various sorts may be mounted in several ways. First, to prepare dried skins lay the dead caterpillar on a blotter, and using a lead pencil for a roller, begin at the head and gently roll the viscera out. The flattened skin may then either be pressed as we would a flower, until it is dry, or inflated with a blowpipe and dried over a lamp. ${ }^{1}$ If the larva is green, it will turn yellow in drying, and the color may be imitated by shaking into it a little green chalk or Paris green. Mosquito wrigglers and similar larvæ may be allowed simply to dry on the glass of the mounting case in

1 The blowpipe for this purpose is made from a small glass tube drawn to a moderately fine point, three or four inches long. Slip over the open end a piece of small rubber tubing about a foot long, for a mouthpiece. By cutting off the intestine about a quarter of an inch behind the body and blowing sharply at the cut, it will open up, and the whole caterpillar will be inflated; keep blowing and slip the intestine over the end of the blowpipe; it will soon stick fast to the glass, and by holding it over a lamp, high enough not to scorch, and keeping it inflated, the skin will dry in a few minutes. If the blowing is too tiresome, the blowpipe may be attached to a "dying pig" or a toy rubber balloon, the inflation of which will keep up a constant pressure until the skin is dry. 
the place where it is desired to have them. White, soft larva, grubs, apple worms, or maggots may be preserved whole in 75 per cent alcohol (alcohol to which onefourth water has been added), or better, if obtainable, 5 per cent formalin, in small vials with the corks sealed with wax. ${ }^{1}$

If the specimens become stiff or too dry, they require relaxing before they can be spread. This is done by leaving them in a tight box - I use a small aquarium, but a tin pail or box will do as well — with about two inches of moist sand in the bottom. Lay a paper over the sand to prevent injury to delicate specimens, and if mould appears, light two or three sulphur matches and let them burn in the closed box, or pour in a few drops of strong formalin or carbolic acid. It will take from an hour to a day, or even more, to relax an insect, according to its size and dryness. The softening may be hastened by moderate warming and is retarded by cold. If a leg or antenna is broken, it may be mended with a touch of white shellac.

Very small insects, - gnats, fleas, lice, newly hatched larvæ, etc., - can be mounted by simply gluing them to the glass, with no attempt to spread. ${ }^{2}$

The dried specimens should be placed in their permanent positions in the glass mounting cases and sealed up as speedily as practicable to insure them against attacks

1 Instead, these specimens may be easily sealed in glass tubes, making neat and permanent mounts.

${ }^{2}$ Many of these minute insects may be mounted beautifully on an ordinary microscopic slide, and the whole life story be brought under a single cover slip. 
of museum pests. The one especially to be feared is a minute beetle, Anthrenus, that feeds, both in the larval and adult state, upon such dry animal substances as museum specimens. This is the insect pest that reduces practically every uncared-for specimen to a heap of brown dust. Heretofore it has made the gathering of biological school collections almost impossible. A class leaves a fine collection in the cabinet at the end of the spring term, only to find it dust in the fall, and the teacher and school are naturally discouraged. Specimens promptly sealed up in the way just described have already stood the test of several years, but we cannot tell when Anthrenus may have laid its eggs on a specimen, and we must watch for the first indications of its presence, - fine brown dust on and underneath the insect. If this be seen, drill a small hole through the wooden frame of the mounting case, and with a pipette, with the point drawn out to a fine tube, insert a drop of carbon bisulphide. Plug the hole immediately, and its contents will be safe forever after. ${ }^{1}$

With the above suggestions any class in nature study may easily begin a permanent collection of insect life stories that will be an invaluable aid in instruction and grow in excellence and completeness for the important insects of the neighbor ${ }_{\perp}$ ood from year to year. The collection should be kep in the dark, except when in use, to prevent fading of specimens, and it may be packed in small space in a drawer or box. The mounting cases should be labeled on one end with the name of the insect

II have never been obliged to do this, but give it as a suggestion to those who may be troubled by museum pests. 
contained in it, and also with that of the child or class that contributes it to the school collection.

It is not intended, however, to allow the use of these collections to degenerate to the museum method of studying insects. Each life-story collection should be made merely the starting point, - a means of imparting clear ideas as to just what insect to look for in beginning

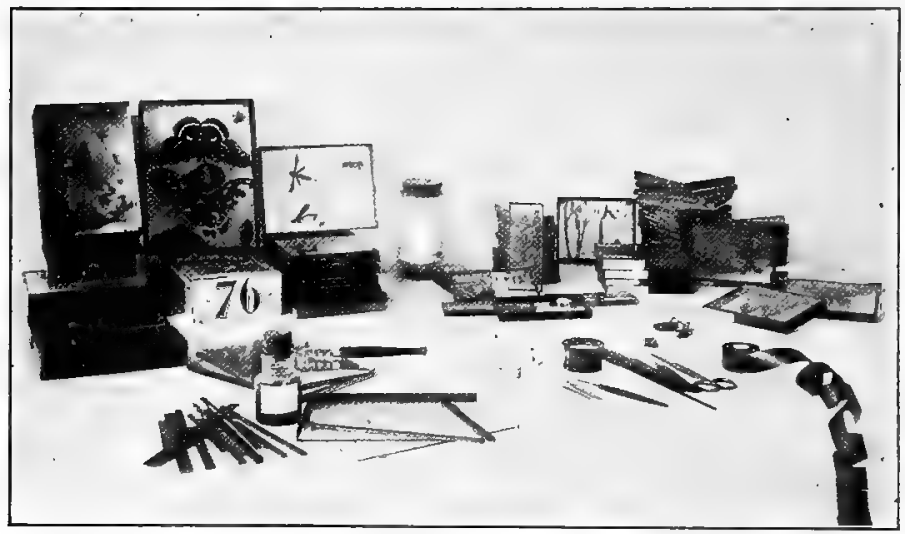

Fig. 19. Beginning of a Nature-Study Insect Collection

the study of the active life and work of the species in the infinite museum of nature always present about our homes.

In case it is undesirable to make insect collections, drawings, preferably colored, may be made illustrating each step.

For the study of insects alive in the schoolroom, vivaria or aquaria described in Chapter XXIV may be used. If these are not at hand, a good substitute for this purpose may be made by replacing the cover of a cigar box (a chalk box or even one of pasteboard will do) with a pane of glass. These latter have proved most serviceable. Each child should have one on his desk, where he can feed his 
insects and watch them grow and pass through their various moults and transformations.

In the fall the different cabbage worms will prove instructive material for study, as they pass rapidly through their various transformations. Many of the specimens collected at this time will have been parasitized, and the emergence of the parasites from their host will afford a valuable lesson on the work of beneficial insects.

Many cocoons are likely to be brought in during the fall and winter. A good disposition of these is to have each pupil fasten his collection on a card and arrange the cards as a frieze over the blackboards around the room. When a moth is seen emerging, the card may be taken down and the whole process watched.

\section{General Books of Reference}

Comstock, A Manual for the Study of Insects, 701 pp.; 797 illustrations. I895. - The best general book of reference; rather advanced for grade school work.

BeLle S. Cragin, Our Insect Friends and Foes, 377 pp.; 255 figures.

WEED, Life Histories of American Insects, 272 pp. ; 94 figures. 


\section{CHAPTER V}

\section{INSECTS OF THE HOUSEHOLD}

Flies. - These are the commonest and often the most annoying insects we have. We are obliged to screen our windows and doors to keep them out. They flyspeck everything they can get at, crawl over our food, fall into our milk and cream, lay their eggs, flyblow our meats and fruits and other foods. There are hundreds of different kinds of flies. Little flies and gnats, so small we can hardly see them, never grow to be big flies. They are all different kinds.

The question is, How can we get rid of the three or four troublesome kinds that infest our houses? In order to answer this question, we must learn their life histories. The picture below gives the four stages in the life of every fly: the egg, larva or maggot, the pupa, and fly.

The common house fly, Musca domestica, lays its eggs in horse manure and dooryard filth. How many eggs one fly may lay is not known, nor how long a fly may live. A fly has been known to deposit as many as forty-five eggs in a single night, and she probably lays hundreds or possibly a thousand during her lifetime. The eggs, as we know from Dr. Packard's studies, hatch in about one day, the larva grow for five to seven days, and the pupal stage is also from five to seven days. Thus in ten to fourteen days a generation of flies may be produced, and 
we see why it is that from a very few individuals in early spring we may have swarms of flies by midsummer.

The stable fly, Stomoxys calcitrans, is commonly mistaken for the house fly, which it closely resembles, but differs from it in having its mouth parts formed for piercing the skin. Its bite is painful, and while it is not poisonous, it may carry disease from animal to animal or even to man. We often see horses, cattle, and dogs surrounded by swarms of these flies, and, aside from the actual suffering and annoyance they cause, they must occasion the loss of pounds
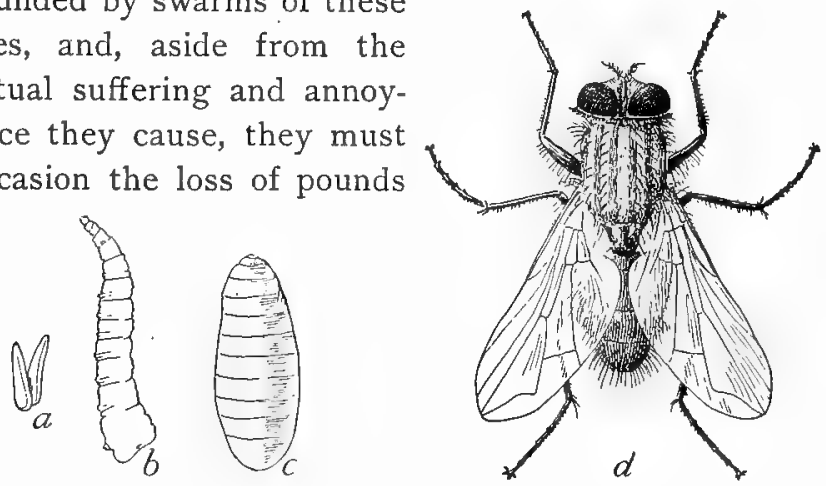

Fig. 20. House Fly

$a$, egg ; $b$, larva or maggot; $c$, pupa case, or puparium; $d$, adult male. (All enlarged)

of flesh and gallons of blood and milk during a season. These flies probably lay their eggs on manure, and with this covering our fields and pastures, we shall not be able to prevent them from breeding in the country. In cities stable pits may often be made fly proof with but little additional expense.

The bluebottle fly, Calliphora crythrocephala, is a third species that children can readily learn. It breeds in decaying animal matter. If a fish head or a piece of 
fresh meat be exposed for an hour in warm weather, it will generally be found to have masses of whitish-yellow eggs on it of the bluebottle, or blow, fly.

It is not intended that children shall make breeding experiments with flies. Such disagreeable work may be left, in general, for specialists, but the two lessons that every child should learn are that filth of various sorts breeds files and that in spite of the best we can do in keeping our premises clean, we need the help of insectivorous animals. Ask children to study what the swallows are doing when circling about a herd of cattle, what the phobe and kingbird do when they dart from their perch and you hear their bills snap. What other birds eat flies? Let some child who has a tame bat see how many flies it will eat. The writer had one that ate 243 at a meal, but it died soon after. Let the children watch the toads about the back doorstep to see how many flies one of them may eat in a day. One little girl the writer knows counted while a toad snapped up 128 flies within a half hour. A tree frog is a most interesting pet and a wonderful flytrap.

Mosquitoes. - These insects furnish a great field for outdoor study, careful observation, and experiment. There are thirty different species described for North America (for the more complete study of which refer to Bulletin No. 25, United States Department of Agriculture). It is, however, only necessary to know the life story of any one kind to do efficient and valuable work. The eggs may be found at any time in warm weather on the surface of stagnant water; they hatch generally in the afternoon of the same day they are laid and pass their larval and pupal 
stages, known as "wrigglers," in the water, and in from seven to fourteen days, according to weather, emerge as adult mosquitoes. A female may lay from 200 to 400 eggs. A good example in arithmetic is the following:

Suppose a mosquito lays 200 eggs, one-half of which hatch females, and these each lay 200 eggs, and so on, calling the time for a generation ten days; how many mosquitoes would there be after $\mathrm{I} 80$ days, i.e., in the eighteenth gen eration? The answer is 2,000,000,$000,000,000,000,000,000,-$ $000,000,000,000,000$, onehalf of which may be males. This is, according to Dr. Howard, about the minimal period in which a generation can mature. What would the result be if the period were

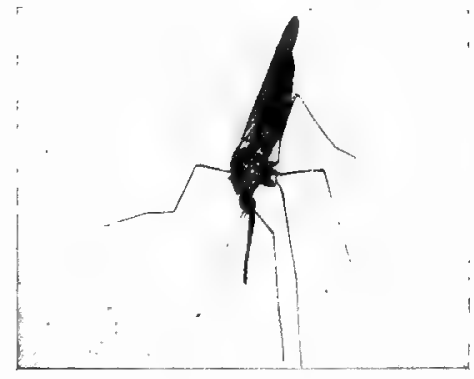

Fig. 21. Female Anupheles Miosquito (From Photograph by the Author)

twenty days? thirty days? Eggs might be collected and reared and the actual time ascertained by the class.

In one month a single female mosquito may thus give rise to from I,OIO, I00 to 2,020,000 female mosquitoes, - quite enough to stock a good-sized city.

Lessons on mosquitoes may be undertaken at any season of the year, but are especially valuable after warm weather begins in spring, - April or May for most parts of this country. A lesson or two in winter will prove instructive in discovering how mosquitoes pass this season. The children should then be asked to seek for specimens in stable and house cellars. 
After the snow and ice disappear in spring, let each child keep careful watch for eggs and wrigglers, in any stagnant pools, water pails, tubs, or barrels standing outdoors about his own home, and note the date and

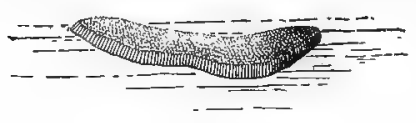

Fig. 22. EgG RafT LAID BY A Single Mosquito bring in specimens in a bottle filled with the water in which they are found.

As soon as the wrigglers appear in numbers, arrange an aquarium with a single little fish, preferably a native in the locality, - sunfish, perch, pickerel, pout, bass, shiner, dace, - but a goldfish will do. You will not have fed the fish the day before this lesson. Gather the class about the aquarium, and as you pour in a tumblerful of wrigglers ask each to count how many the fish takes for a meal.

In another aquarium keep a large quantity of wrigglers. Have the top securely covered with gauze, so that none may escape into the room, and observe from time to time to see them moult their skins, until a number have passed through the larval stages and emerged as adult mosquitoes. Then, at the beginning of the nature-study lesson, put a few drops of kerosene oil on the water and let the children observe the

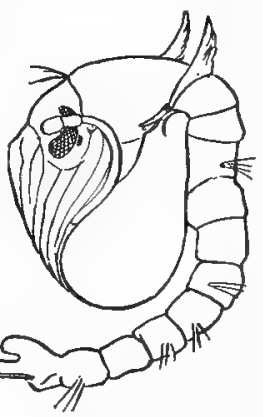

Fig. 23. Mosquito PuPA (After Howard) result. Within a few minutes all the wrigglers will have been killed, and as the mosquitoes touch the oily surface they sink down and drown. A mosquito can walk on water, as the children should already have observed in 
the aquarium, but it cannot stand on oil. Since all the mosquitoes of a neighborhood must come to the water to lay their eggs, and since all the eggs and wrigglers are killed, this is one of the easiest ways to rid the place of mosquitoes. It has been tried on a large scale and under all sorts of conditions with remarkable success, so that any inland community, not surrounded by interminable marshes which cannot be drained, may easily rid itself of the mosquito pest. The amount of oil required is an ounce for fifteen square feet of water surface, and it will not require renewing for from one to two months, unless washed off by heavy rains. As soon as live wrigglers can be found, the oil should be applied again.

The children have now learned two ways of exterminating mosquitoes. Discuss and compare them, drawing out what the class thinks is the easiest, cheapest, and most effective method. Bring out the fact that one is man's, the other is nature's, method.

As the hunt for mosquitoes and wrigglers progresses in the spring, have each child make a map of some part of the district, preferably his own lot, block, or farm, marking plainly all the pools and streams in which mosquitoes are and are not found. Have the children then go over the ground very carefully again, to see if they can discover why mosquitoes are abundant in some places and not in others; they may take their maps with them and do this on an excursion. Do the fishes make the difference? Do frog and toad tadpoles ${ }^{1}$ keep the water

1 The writer has seen toad tadpoles eat mosquito larvæ in an aquarium and has observed that in two water-lily tubs standing side by side the one without tadpoles swarmed with wrigglers, while the cne stocked with tadpoles contained none or very few. 
clear of wrigglers? Can they discover anything else that eats mosquito wrigglers in the water?

Step by step, as a point is learned, encourage each child to make what practical applications he can. If this has been done, the children will have collected minnows from ponds and streams where they are abundant in order to stock such pools as are suitable but do not contain fish. Mud puddles and all pools too filthy or temporary for fish to live in should be drained, and where this is not

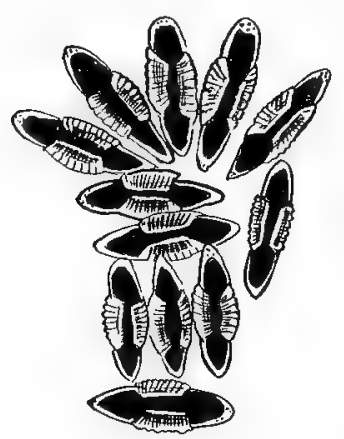
immediately possible, they may be covered with kerosene at the rate of an ounce to fifteen square feet of surface.

Mosquitoes and Malaria. - Annoyance and suffering caused by mosquitoes should be sufficient to supply motives for this work. Still another series of lessons for pupils of sufficient advancement will serve

Fig. 24. Eggs of Malarial to increase interest in the subject, Mosquito

As they appear resting naturally on the surface of the water. (Enlarged. After Howard) especially in districts afflicted with malaria.

Begin by asking the pupils how many have had malaria within a year. How did they enjoy it? Next they may be asked to tell how many cases they have known in the neighborhood. Let them describe how the different cases are distributed with reference to swamps and stagnant water. It might be well to ask them to tell how they suppose people get malaria and leave them to think over this question until the next lesson. 
At the beginning of the lesson restate the question and allow only a few minutes for them to advance their own theories. Follow up the answers that take the right direction and see if the cases of malaria cannot be accounted for readily by means of transmission of the disease by mosquito bites. Then read the following:

"The latest announced results of

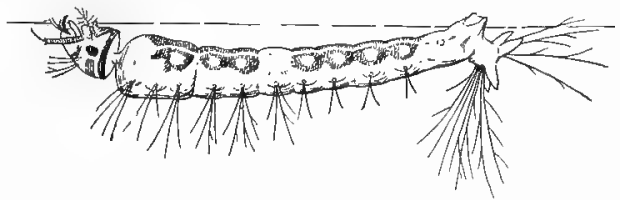

FIG. $25 a$. HALF-Grown LARVA OF ANOPhEles In feeding position, just beneath surface film.

(Enlarged. After Howard)

the most advanced investigators seem to show that mosquitoes form the principal if not the sole means of transmission of malaria, and workers in all parts of the world, including many parts of the United States, are investigating the subject, more especially in relation to local conditions." Circular No. 4o, Second Series, United States Department of Agriculture, Division of Entomology, entitled " How to distinguish the Different Mosquitoes

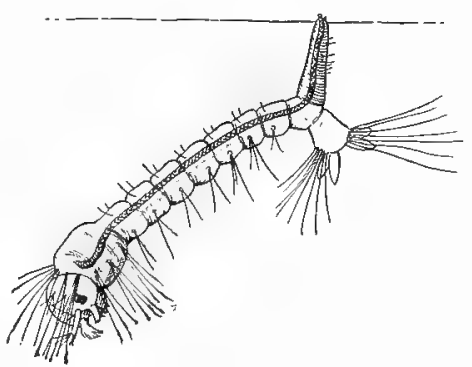

Fig. 25 b. HALF-GROWN LARVA OF Culex

In breathing position. (Enlarged. After Howard) of North America." [It is now held that yellow fever is also transmitted by mosquitoes.]

The children will see that they are doing something worth while and of present interest. It now becomes necessary to distinguish among the different species of mosquitoes the ones that carry malaria. These have all been found to belong to the genus Anopheles. The 
distinguishing characteristic of the genus is that the palpi are at least almost as long as the proboscis in both sexes. An easicr way to distinguish Anopheles from all other mosquitoes is from the position of the wrigglers in the water and of the adults when resting on a surface (Fig. 3 of above Circular and others in Bulletin No. 25).

If Anopheles is found and malaria abounds in the district, the investigation of the class should be carefully prepared for publication in the local papers and every effort
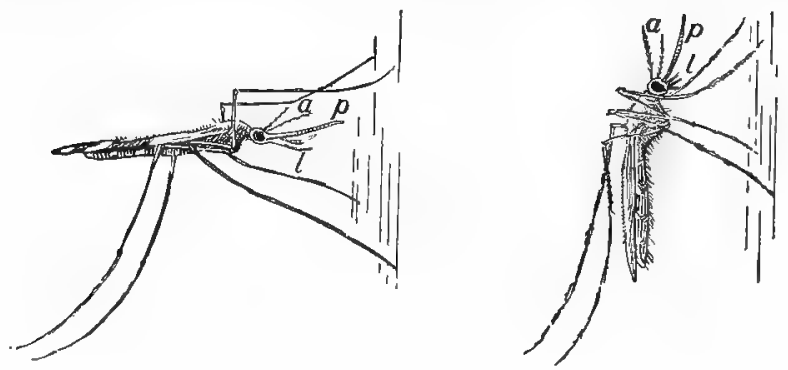

Fjg. 26. Resting Positions of Anopheles (At Left) and Culex (AT Right)

$a$, antennæ; $\not$, proboscis; $b$, palpi. (Enlarged. After Howard)

be made to effect complete extermination of the pests. Even if this be impossible, if the study succeed in influencing the children against wantonly exterminating the fishes and frogs and newts of our surface waters, it will not have been in vain.

Throughout these lessons special attention should also be directed toward observing and studying the enemies of mosquitoes in the air. Young toads and tree frogs may be experimented with to see how many they will eat at a meal. Swallows are known to destroy enormous numbers, 
and nothing is more fascinating than to watch the dragon flies, appropriately called "mosquito hawks," catching mosquitoes on the wing.

We shall not be able to devote so much time to many other insects, equally important, but this study of the mosquito should be used as the type, showing the point of view and the methods to be employed with other species.

Clothes Moths. - Comstock calls them "the dread of every housekeeper." A coat is no better than its smallest hole. Since earliest historic times these little insects have been the devourers of man's woolens and furs, and they are still as active as ever. No estimate can be made of the amount of trouble, annoyance, work, and damage they cause year by year. It must go

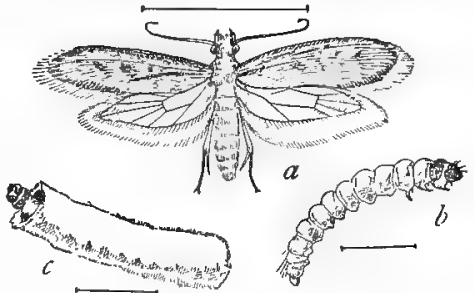

Fig. 27. Common Clothes Moth $a$, adult; $b$, larva ; $c$, larva in case. (Enlarged. After Riley)

a long way into the millions in spite of the best efforts of careful housekeepers. How many intelligent housekeepers know the life story of this troublesome insect? How much easier might it make the battle if they did!

Lessons may begin by asking the children to collect statistics of amount of damage caused by clothes moths in their own homes during the previous year. Include with the actual loss, if any, the value of time, labor, and materials used in prevention. There are sixteen million homes in this country and, if desirable, simple calculation will yield an interesting estimate of the tax that one small family of insects imposes and collects each year. 
Next let the members of the class provide themselves with wide-mouthed bottles and hunt over every closet, attic or storeroom, stable, poultry house, or woodshed where scraps of hair, feathers, fur, or woolen cloth may have gathered. Let them collect all the specimens both of larvæ and moths they can find and bring them to class in their bottles. The lesson may then be devoted to distribution

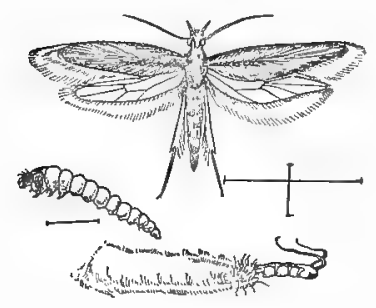

Fig. 28. Southern Clothes MOTH

Moth, larva, cocoon, and empty pupa skin. (Enlarged. After Riley) of clothes moths about the home. Put a scrap of black woolen cloth in each of the bottles containing moths, cover the tops securely with fine cotton gauze, and ask the children to study their specimens to see if they are all alike.

There are three clothes moths, distinguished as follows:

Tinea pellionella, common clothes moth, brown, with a few dark spots on fore wings; larva constructs a case to live in. Tineola biselliella, southern clothes moth, pale straw color without spots; larva spins silken webs, eats hair, feathers, furs, museum specimens, and cobwebs.

Trichophaga tapetzella, tapestry moth, basal half of fore wings black, the rest white; larva constructs burrows or galleries in which it spins a silken lining. It generally feeds on coarser fabrics, tapestries, carpets, skins, felt, carriage upholsteries, etc.

Continue study of specimens; examine black cloths with - the aid of a hand lens for eggs, tiny white specks scarcely visible to the naked eye; select as many different stages as possible and mount them permanently, as described in 
Chapter IV; make drawings and group language lessons for the time being about the life story and work of the clothes moths.

The construction of its case is an interesting process with the common clothes moth. It is made very small at first to fit the tiny larva. As it becomes too short for its growing occupant, new material is added at both ends, and when it gets too tight the larva slits it down the side, first at one end and then at the other, and inserts triangular gores. If, after they have begun to grow, the black cloth is removed and a piece of red woolen, or any other color, substituted, then later some white, ancl so on, a coat of many colors will result which will show how each addition has been made. The

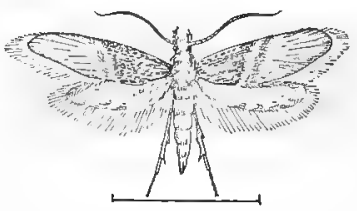
moth has but a single brood in the Adult moth. (Enlarged. After northern United States, the adult Riley)

moths appearing and laying their eggs from June to August, so that this latter experiment must be chiefly vacation work for the pupils ; but it will take only a few moments' attention from time to time, and the specimens may be preserved and brought in at the opening of school in the fall. The pupa is formed within the case, and the pupal stage lasts ordinarily three weeks. The moth eats nothing, its mouth parts being rudimentary, and causes no damage, except as it lays its eggs upon exposed materials that may furnish food for its destructive larvæ.

The final lesson should be focused upon developing clear ideas about methods of dealing with clothes moths. Draw out and arrange in an orderly fashion, so far as 
possible, every method the children can think out for themselves and all they may have learned from their homes. The first and most effective of these will be scrupulous care against allowing to be neglected anywhere about the premises any materials that may furnish food for the larvæ. Second, all woolens and furs must be packed away so that moths cannot lay their eggs on them, and it should be remembered that they may lay their eggs about cracks in trunks or chests and that the larva may find their way in when they are almost too small to be seen. We can prevent this by tying the materials in tight cotton-cloth bags or by packing them away in pasteboard boxes with a strip of paper pasted over the crack around the cover. If there have been any moths about, there is danger that eggs may have been lodged about the garments, which airing and brushing may not have removed. To insure against possible damage from this source we may pack the garments in a very tight box, wash boiler, or trunk, placing on top a saucer containing from a tablespoonful to half a teacup (according to size of receptacle) of carbon bisulphide. Close quickly and as tightly as possible and leave closed for a day. This should be done by daylight and out of doors. The fumes of the carbon bisulphide are heavy and will have descended and penetrated through every stitch, seam, and pore, killing eggs and larvæ in all stages. The garments may then be aired and packed away.

Great care should be taken not to breathe any of the carbon bisulphide, for it is poisonous; hence if kept about the house or premises at all, it must be in securely stoppered cans or bottles. No flame or fire should be allowed 
anywhere near carbon bisulphide, because it is volatile and its fumes are highly inflammable and explosive.

In leaving the subject, as with all similar topics, make perfectly clear its social and ethical bearings. In the preliminary search for specimens the children will doubtless have discovered that some cast-off garment, piece of carpet, fragment of horse blanket, or other rubbish in some corner of attic or outhouse is breeding moths enough to supply the neighborhood. It is quite as important that boys should undertake this study as girls, because often most of the moth supply is bred in stables and outhouses. Is it right that some one should be ignorant and careless and thereby cause his neighbors labor, annoyance, and loss?

The Carpet Beetle, or Buffalo Moth, Anthrenus scrophularice.Since its food is similar, this insect may be hunted for at the same time with the clothes moths and should be treated in somewhat the same way. It was imported into Boston and New York from Europe about 1874, and it is interesting, as showing how fast such pests may travel, to note that it has become a household pest throughout all the New England states, New York, Pennsylvania, Ohio, Indiana, Michigan, Illinois, Iowa, and Kansas. It is not commonly known as a carpet pest in Europe, because tacked-down carpets are little used.

The larvæ, which, as in the case of the clothes moths, do all the damage, are lively little fellows, about a quarter of an inch in length, bristling all over with stiff brown hairs. They frequent cracks in the floor about borders and unused portions of rooms and, feeding from below, cut long slits in the carpets. Besides poking them out 
of cracks a good way to trap them is to spread woolen cloths on closet floors, taking them up daily and shaking them over papers. The larvx, if kept in bottles and fed on woolen cloth, may be observed to change into pupæ within their last larval skins. The pupa case finally is split open on the back, and a little black beetle emerges. It is about one-seventh of an inch in length and is covered with black, white, and brick-red scales, giving it a mottled appearance. An amusing thing about the larvæ is that, if kept in a dry place without any. food, they will
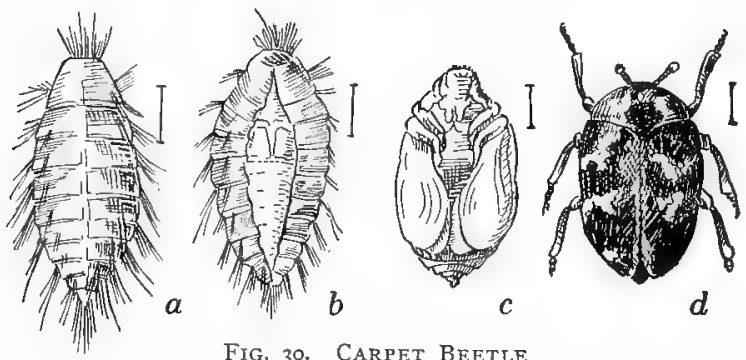

Fig. 30. CARPET BeEtle

$a$, larva, dorsal view ; $b$, pupa within larval skin; $c$, pupa, ventral view; $d$, adult.

(All enlarged. After Riley)

live for an almost indefinite time, feeding on their castoff skins, i.e., when one gets hungry he sheds his skin and eats it. Great care should be taken to teach the distinction between carpet beetles and our little lady-bird beetles. These latter often come into our houses to pass the winter and are killed by mistake. They are among our best insect friends and may be worth a quarter apiece for destroying plant lice, as we shall see when we come to study insects of the garden. 
The times and seasons in the story of the carpet beetle's life are not definitely stated in the books, which means that there is all the more for pupils to find out. There are probably two broods a year. Adults of the second brood begin to emerge in the fall and continue coming out through the winter, so that by spring, in an infested house, the rooms will be full of them. They are day fliers, are attracted to the light, and hence, on sunny days in early spring, they gather in numbers on the windows. They feed on the pollen of flowers - especially of the Scrophulariaceæ (mullein and snapdragon) and certain of the Compositæ (milfoil). They are also fond of the spiræas, and may be found on willow, currant, and cherry blossoms. It is stated in the books that "they have probably" deposited their eggs about the carpets before they seek the flowers in the spring, but it would be safe to brush them from the window panes into a saucer of kerosene oil.

Remedies. - From what we have already learned of their life story, we see that when a house is once infested it is a desperate undertaking to get rid of the pests, living as they do in all sorts of cracks and crevices. Carpets must be taken out and thoroughly sprayed with naphtha or benzine, floors must be scalded, the cracks cleaned out and kerosene or benzine poured into them. Even then the best way to deal with the carpet beetle is to revolutionize ideas of housekeeping and substitute hard-wood or stained or painted floors with rugs for tacked-down carpets. Further, since dust and stuffiness are the most unhealthful features of American homes, this change is likely to prove highly conducive to health; and if the carpet beetle 
can aid in bringing this about, it should be looked upon as a missionary rather than a pest, a blessing in disguise.

Fleas, Lice, Bedbugs. - These insects subsist upon the blood of man and all kinds of animals, generally a different variety for the different species of animals. No estimate of the time, labor, expense, and distress caused by this class of insect pests can be made. They flourish in the homes of the untidy and careless and spread throughout the community by means of appropriate channels of intercourse, - public schools, churches, libraries, public conveyances, and the shifting of servants.

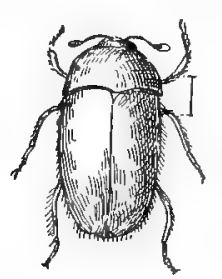

A superhuman amount of tact and good nature on the part of the teacher would be needed to carry

\section{Fig. 3r. Black Carpet BeEtle}

Larva and adult. (All enlarged. After Howard and Marlatt)

on the study of these insects along the lines indicated for mosquitoes and the other household pests, but it is not intended to attempt it. A quite distinct method of procedure should be adopted, and this must be varied according to all sorts of circumstances. But since the school is perhaps the most frequent means of their dissemination, it is no more than right that they should form a serious part of the nature-study course whenever this becomes necessary. Respectable people who are made the frequent victims of these mortifying scourges, and especially teachers, should be the first to insist upon this. 
It is not proposed to import any specimens for study or even to ask pupils to search their homes for them, since those who are successful in their search cannot be expected to own up to the fact. If sometime during the year specimens cannot be found in the school, the study may be confined to prepared specimens collected from former years, by way of prevention, or it may be omitted altogether.

Whenever specimens are found, the opportunity should be utilized to give a series of lessons that can never be forgotten. The child upon whose person or belongings any of the above-mentioned insects, with possible exception of fleas, are found should be sent home and not allowed to return to school until assurance is given that the pest has been thoroughly dealt with. Due care should be exercised, of course, not to be too severe in case of an accidental specimen for which neither the home nor child is responsible. The ethical side is very clear in all such cases, and it should be made plain to each child that his carelessness may cause a whole school and neighborhood useless labor and distress.

For purposes of reference (and information is needed by a large portion of the public) a brief outline of the life story is added for each species, together with one or two of the most approved remedies.

Fleas. - The most common flea in this country is the dog and cat flea, Pulex serraticeps, which attacks man as well and often infests houses where these pets are kept. When numerous it may cause as much annoyance as the human flea, $P$. irritans. In fact, the two species are so nearly alike both in appearance and in life story that 
no attempt need be made to distinguish them. Rabbits, squirrels, rats and mice, moles, hens, and many other animals have each their peculiar flea, but for elementary study they may all be treated alike.

From a lady's dress, on which a kitten had been fondled for a short time, fully a teaspoonful of fleas' eggs was collected. Few people ever think of this part of the life story, but here it naturally begins. The eggs are white, oval, and may be distinguished readily from particles of dust by the unaided eye that knows them. They are laid

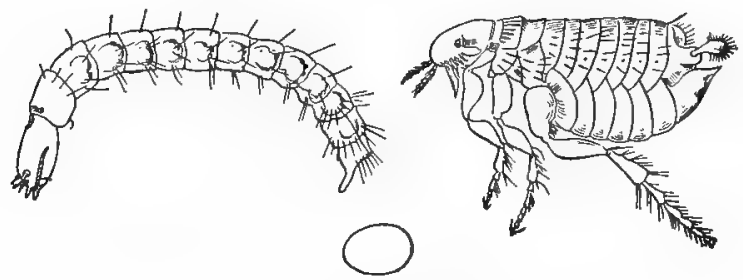

Fig. 32. Dog and Cat Flea

Egg, larva, and adult. (All enlarged. After Howard)

generally in the hair of the infested animal, or wherever else the fleas happen to be, and are easily shaken off to the ground or floor, where the eggs hatch and the larvæ develop. The larvæ are slender, white, footless, active, wormlike little creatures. They feed upon the particles of dust in carpets or cracks of floors or out of doors upon decaying vegetation in the soil. The pupal stage is also passed in the dust, where the larvæ feed. The egg hatches in about fifty hours; the larva completes its growth in seven days; and, after eight days spent in the cocoon, the adult emerges. Thus about seventeen days 
are required for the three stages, - egg, larva, and pupa, - and how long the adult lives or how many eggs one may lay nobody knows. The adult readily leaps upon a passing animal, - dog or cat, - and the life circle is repeated, generation after generation, the year round, in artificially heated houses or wherever there is sufficient warmth for development to go on.

Remedial measures must depend somewhat upon degree of infestation. If a house is badly infested, the thorough dusting of everything - floors, carpets, rugs, sofas, and all upholstered furniture-with fresh pyrethrum powder, left from two days to a week before sweeping up, may afford relief. When this is not effective, the pyrethrum is probably not fresh, but it is sometimes said to be necessary to spray the furniture and carpets heavily with benzine or naphtha and scrub and soak the floors with hot soapsuds.

By far the easiest and best way is prevention, and the humane care of household pets demands nothing short of this. As previously stated for dogs, it is necessary only to keep a sharp lookout, and as soon as any fleas are found thoroughly lather the animal before his bath. A dog thus becomes the best automatic flea trap imaginable. Cats may be held on a newspaper and pyrethrum powcler thoroughly dusted into the fur. Rabbits, white rats, and squirrels may be treated similarly. Nest boxes, kennels, sleeping rugs, and baskets should also be thoroughly treated with pyrethrum from time to time.

Lice. - The head louse, Pediculus capitis, lives in the hair of the head. The eggs are known as "nits" and are securely glued to the hairs a little distance from the scalp, 
generally back of the ears. They are laid in great numbers. Remedies are, first of all, cleanliness and constant vigilance where infection is possible. One thorough application of oil of cajeput to the hair should prove fatal to both lice and nits. Some care should be used not to flood the scalp with the oil, as on tender skins it causes slight inflam-

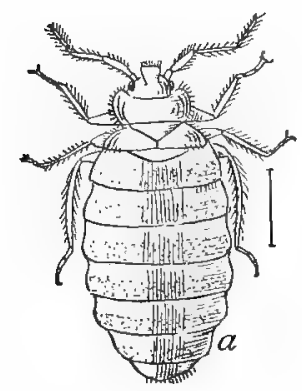

Fig. 33. Cimex Lectularius $a$, adult female gorged with blood; $b$, egg. (After Marlatt) mation and for delicate skins of young children the oil, mixed with an equal amount of vaseline, will prove as effective, with less danger of causing irritation. Larkspur and strong alcohol are other remedies.

The body louse, Pediculus vestimenti, lives and deposits its eggs in the folds and seams of human clothing. A female may lay as many as 2500 eggs a month, and in warm weather many more than this, which accounts for the suddenness with which an outbreak may appear. The remedy is thorough boiling of all infested clothing, preferably in sait water. Treatment with carbon bisulphide, as described for clothes moths, is also effective.

Bedbugs, Cimex lectularius. - These are insects the long association of which with man, extending as far back as his.toric records, has resulted in development of a considerable degree of cunning. They bite during the sleep of their victim and under cover of darkness, hiding during daylight in cracks of old-fashioned wooden bedsteads, 
under loose places in the wall paper, in crevices behind picture mouldings, in picture frames, or about door or window casings or mopboards. They are inclined to be gregarious, which aids in their destruction in case their hiding places can be discovered, and their characteristic "spotting" is of assistance in this. Bedbugs are known to migrate from one house to another, especially when a house is vacated, and they can live for a year or more without food. That they are cunning enough to steal rides from place to place is indicated to some extent by the frequency with which they get into trunks and satchels of travelers and are found on the clothing of school children from infested homes; but this may be clue to accident or overcrowding.

A common remedy consists in flooding with benzine all crevices that may harbor the pest. Filling these cracks with pyrethrum powder is not so effective

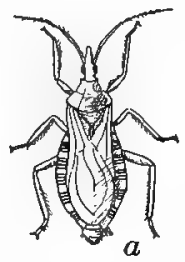

F1G. 34. Blood-Sucking Cone Nose

as with most other insects, but $a$, adult bug; $b$, first pupal stage. for immediate relief a thorough dusting of the powder between the sheets will protect the weary traveler from the most voracious of the species, and all tourists, especially in Eurcpe, should include a supply in their kits.

The "big bedbug," or blood-sucking cone nose, Conorhinus sanguisuga, is distributed throughout the Southern States. During its larval stages it probably subsists upon other insects, but the adults are provided with wings and live on the blood of mammals. They not infrequently 
fly into houses and attack men. Their bite is extremely painful and quite venomous. Closely related to these is the "kissing bug," Reduvius personatus. Its natural food, so far as known, is the bedbug, hence it is common in filthy cities ; but it sometimes bites man with somewhat serious results. In its larval stages its body is covered with a sticky substance. This collects dust and lint

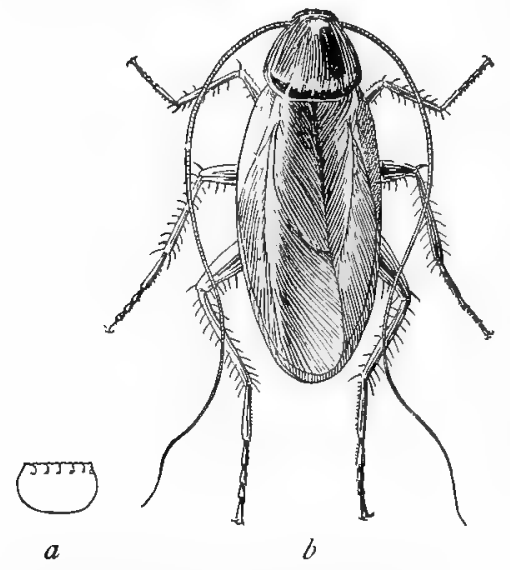

FIG. 35. THE AMERICAN ROACH

$a$, egg capsule; $b$, adult. (Natural size. After Marlatt) which effectually conceal the insect and give it one of its common names, "the masked bedbug hunter." The insect may not uncommonly be found about dusty corners of attics or barn lofts, and the adults are sometimes found in beds, where they are probably seeking their natural food.

Cockroaches. - Roaches eat practically everything they can gain access to, often doing serious damage even to book bindings in libraries. They are nocturnal and live in damp, dark places, generally about sinks, water pipes, and set tubs. They have a nauseating odor and, as they are wont to congregate about garbage, the thought of eating the food they have touched is intolerable. They may also be carriers of disease germs. 
There are four kinds of roaches common in this country: the small brown German roach, the Croton or water bug, Ectobia Gernanica, generally troublesome about hotels and dwelling houses; the large black roach, Periplaneta Americana, more common about mills, bakeries, wharves, and ships; the Australian roach, P. Australasia, common in Florida and the South; and the oriental roach, $P$. orientalis, which is quite cosmopolitan.

To be rid of these pests is easier to talk about than to accomplish. Their long association with man has made them so cunning that traps and poisons are of only partial and temporary avail. Clean, open plumbing, with no cracks for them to
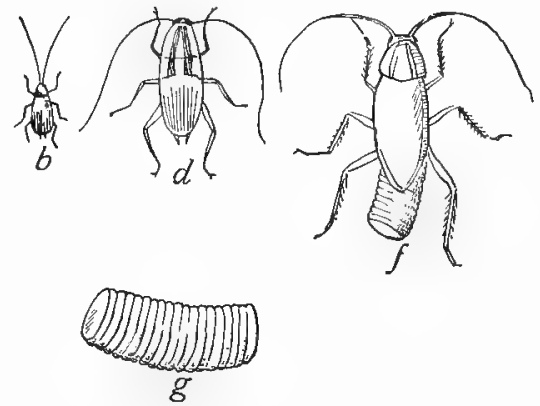

Fig. 36. The German Roach

$b$, second stage; $d$, fourth stage; $f$, adult female with egg case; $g$, egg case. (Enlarged. All natural size, except $\xi$. After Riley)

hide in, is the first consideration. If this be impossible, scalding soapsuds or benzine syringed or poured into their hiding places will aid in keeping their numbers in check. The writer has discovered that bats are very fond of roaches, and it is said that a common toad or a tree frog left in an infested room will soon exterminate them. Experiments, as opportunity may offer, with any of these natural methods may prove instructive and interesting.

The eggs of cockroaches are inclosed in large beanshaped packets within the abdomen of the female and are 
carried about until the young emerge. They are thus easy to find and may be hatched and the different stages studied if this seem desirable. For insects they are of slow growth, requiring five or six months (German roach) or a year (American roach) to attain adult size.

Ants. - This is a fascinating group of insects to study. Their social life and work, care of queens, eggs and young,
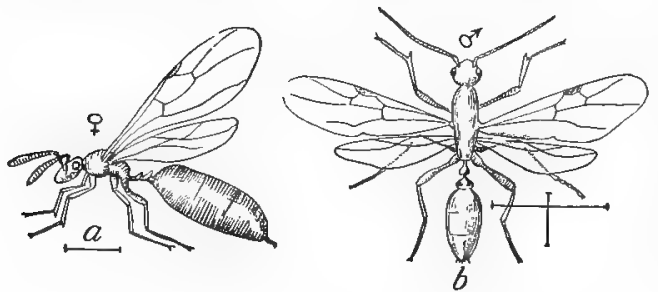

Fig. 37. The Litile Black ANT $a$, female; $b$, male; $c$, worker: egg, larva, and pupa.

(All enlarged. After Marlatt)

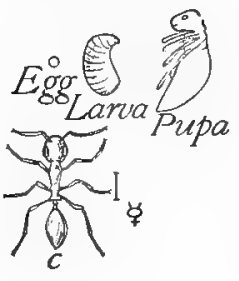

their soldiers, their armies and battles, their cows, the plant lice, and the slaves that some species capture and bring home to do the menial work of their nests place them above all other insects. We shall study some of these in the proper place, but among household insects we must consider those kinds that are often troublesome about our homes.

The little red ant, Monomorium pharaonis, is one of the smallest and often most annoying of household pests. It lives upon all sorts of human provisions, especially sweets and fatty foods, and seldom is a cover tight enough to exclude its seemingly innumerable hordes. A small black ant, $M$. minutum, and a somewhat larger species, Tetramorium cospitum, are troublesome much in the same 
way, but their nests being in the ground outside the house they are generally easier to find and destroy.

In order to deal successfully with ants we must know that their communities consist of : (I) workers, or neuters, which are wingless and very numerous, so that these are the ones we commonly see about; these are females not fully developed; (2) queens, or females, which are single or but few in a nest and which we never see outside the nest, except in mating time. The queen is much larger than the workers, her abdomen especially being much distended with eggs, of which she may lay thousands a day. The queens have wings at first, but after they have flown out and been fertilized, they either tear their own wings off or the workers do this for them, and they settle down in the nest to lay eggs for the rest of their lives. Males, generally much smaller than the queens, have wings but are short-lived and are not commonly seen about the nest, except in mating time. This occurs for most of our species in the late summer or early fall, when,

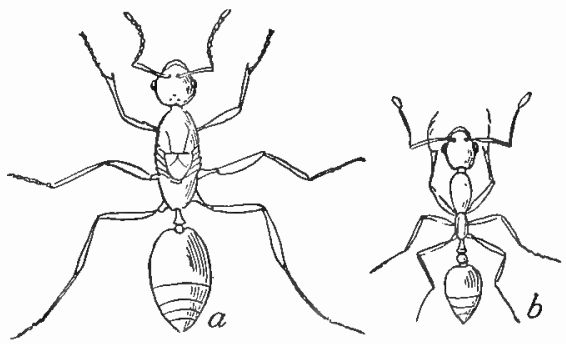

Fig. 38. The Red ANT $a$, female; $b$, worker. (Enlarged. After Riley) for a few sunny days, the air may be swarming with flying ants. These are the males and queens on their wedding journeys. A number of species have in addition to these three kinds "soldiers," which may be recognized by their large size and huge jaws. 
To rid a house of ants effectually it is only necessary to find the nest - often easier said than done - and treat it with boiling soapsuds, kerosene or benzine, carbon bisulphide or gunpowder, according to individual preference and the location of the nest.

It is a fine piece of investigation to set a boy at, this finding of a troublesome ants' nest. It can always be done, with sufficient patience and persistence, by following the streams of workers going to and from it. The little red ant generally nests in crevices about the sills or timbers, sometimes between the flooring, and often holes will have to be bored or baseboards or portions of the floors be torn up to get at them. Naturally in such places scalding suds or benzine will be used to deluge the nest. The other two species commonly nest outside, in the ground under stones or pavements, and may be thoroughly dealt with by running a stick or crowbar into the nest and pouring down any of the liquids mentioned. An interesting way, which will appeal to boys, is to load the hole with about an ounce of gunpowder, connect with a fuse, close well with earth, and touch it off, and ants will disappear as by magic. A pack of firecrackers may be used for the purpose.

Among the many insects that invade the house the above have been chosen as typical of different modes of life and as most important. Any others may be studied in similar ways, and they may also be dealt with by methods like those above described. On any topic relating to insects the most reliable information may now be obtained from either the United States Department of Agriculture or the Experiment Stations of the different states. To obtain the bulletins issued in Washington apply for the 
monthly list of publications, the facsimile heading of which is as follows :

This circular will be sent regularly to all who apply for it

UNITED STATES DEPARTMENT OF AGRICULTURE

Division of Publications

Washington, D.C., Nov. 30, IgoI

MONTHLY LIST OF PUBLICATIONS

[November, xgor.]

Noтr. - To obtain those publications to which a Price is affixed, application must be made to the Superintendent of Documents, Union Building, Washington, D.C., to whom all remittances must be directed.

The Department of Agriculture does not distribute or control the distribution of publications of the State A gricultural Experiment Stations. Application for them should be made to the several stations in the different States.

These monthly lists will serve to keep us posted on what is being done and open the way to securing the latest and most reliable information about domestic animals, birds, trees, insects, fungi, and many other nature subjects. The following may be referred to in connection with this chapter.

L. O. Howard and C. L. Marlatt. "The Principal Household Insects of the United States," Bulletin No. 4, Division of Entomology, Washington, I 896 , I 30 pp. ; 64 illustrations. Price, ten cents.

Herbert Osborn. "Insects affecting Domestic Animals," Bulletin No. 5, Division of Entomology, Washington, 1896, 302 pp.; 170 illustra. tions. Price, twenty cents.

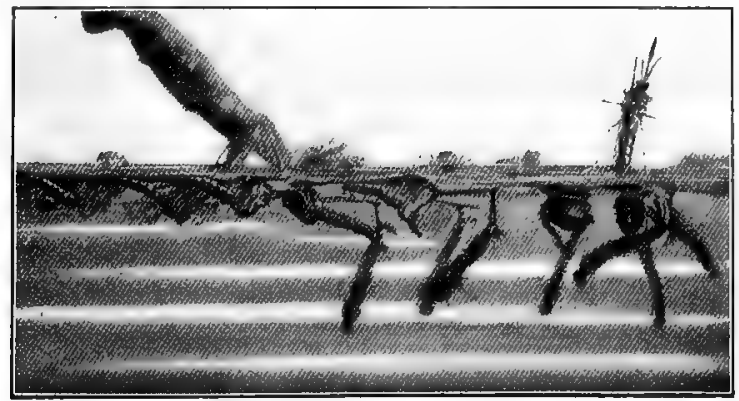




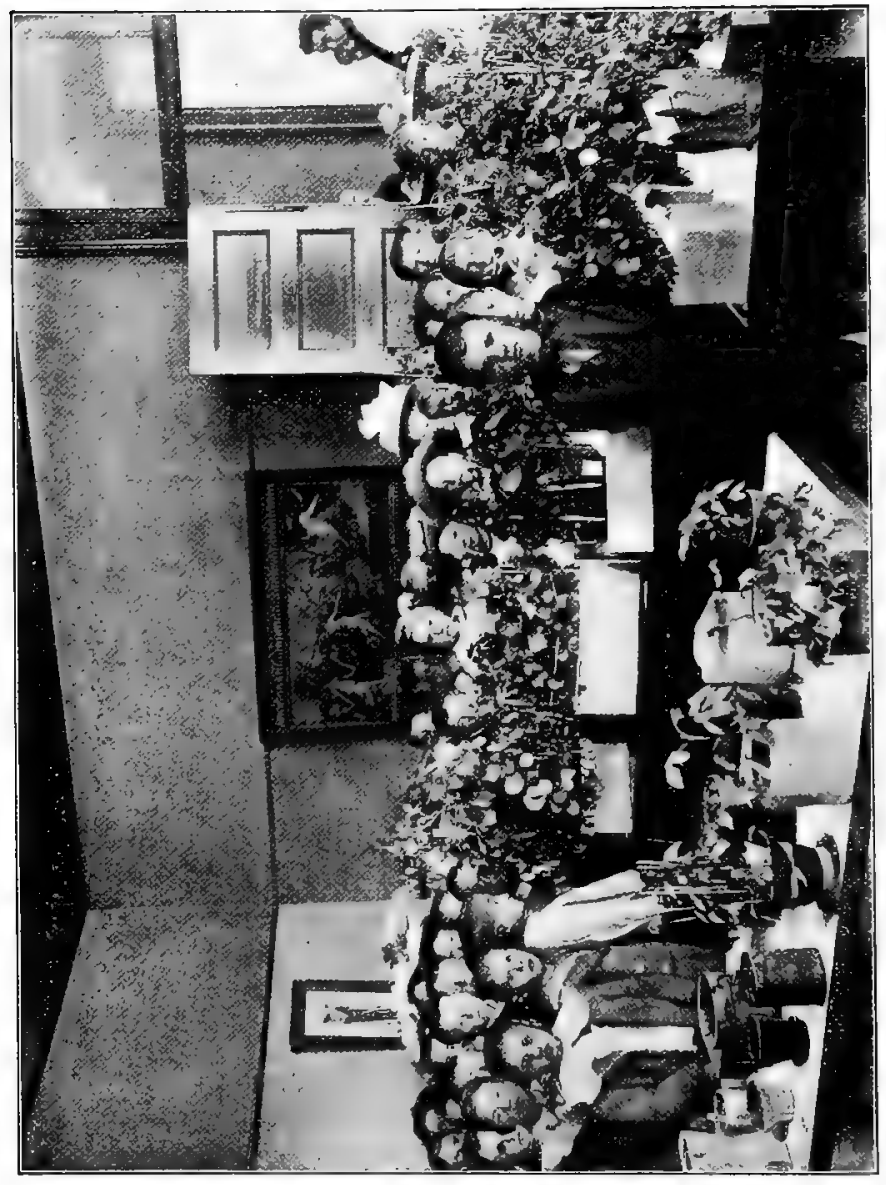

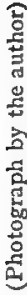

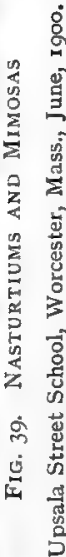

产 


\section{CHAPTER VI}

\section{LESSONS WITH PLANTS}

Consider the lilies of the field, how they grow; they toil not, neither do they spin : and yet I say unto you that even Solomon in all his glory was not arrayed like one of these.

No blooming of roses endureth forever,

The glories of sunset not alway remain;

Yet liveth their grace in the spirit, tho' never,

The senses perceive the same beauty again.

S. M. NeWMAN.

THE love of a flower in the heart of a child is the highest thing that nature study can hope to develop. No amount of knowledge about flowers can take its place nor compare with it in lif $\epsilon$ value. This, with some knowledge of horticulture, acquaintance with poisonous plants, wild flowers, trees, and some of the lower forms, is the botany that should be required below the high school.

Too often, especially in our efforts at education, when we strive hardest to develop love of a subject we succeed in awakening quite the reverse emotion. This is a delicate matter, and it must be no half-hearted love that attempts to teach. ${ }^{1}$ Books on psychology and child study

1 Since we love, what need to think?

Happiness stands on a brink

Whence too easy ' $t$ is to fall

Whither's no return at all;

Have a care, half hearted lover,

Thought would only push her over ! 
help us all too little in these fundamental matters. The best we can do is each to ask himself: What flowers do I like best? How did I come to like them? How old was

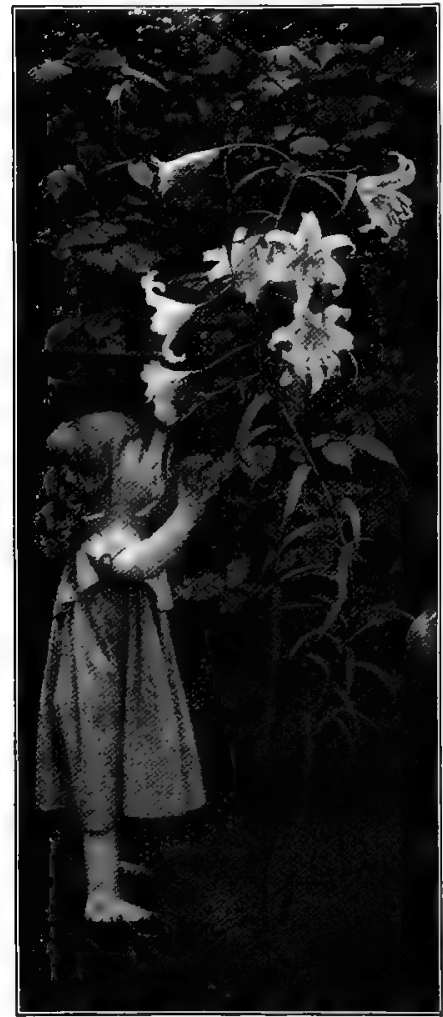

FIG. 40

I when the feeling began, and what associations have I formed with them? How and when were these formed?

When we analyze these emotions in ourselves and observe their expressions in others, we find different kinds of love: the love of the fresh-cut flowers of the shop windows, a commercial affaire de cour, as fleeting, superficial, and rootless as they ; the botanist's passion to analyze and know the names of more flowers than any one else, a refined love of himself; the so-called love of the rare, the new, the strange, and curious; and finally, the love of the gardener for the flowers he has planted and reared, like the love of parent for child. Through all these different kinds we note that the particular feeling is mainly a matter of association. If flowers are good only to enhance the pleasure of a ball, when the 
party is over they are valueless. Flowers greet us with a burst of color and fragrance on a perfect morning in June, awakening feelings of delight, and we associate the pleasing emotions with them. On the other hand, the same flowers, sensed in some striking way at a funeral, become unendurable because of the associations they arouse.

When Queen Louise was fleeing from Napoleon with her family, the carriage broke down; and while they were waiting, to soothe little William's crying, the queen made him a crown of the blue corn flowers by the roadside. Ever afterward they reminded him of his mother's eyes and became his best-loved flower, Centaurea Emperor William.

The problem of developing love of flowers thus becomes one of forming pleasing associations with them, and it should be remembered that the strongest and most persistent association is that related to the will of the individual. Under normal conditions a person will love those things about which his work centers, to which the effort and energy of his life is clevoted. This is the only real "treasure" of life, and "where your treasure is, there will your heart be also." Parents, even, do not love their children, nor children their parents, unless they work and sacrifice themselves in each other's behalf. In fact, love is often defined as the desire to do good to the object loved, so fundamental is this aspect of its development. In a word, we may say that the affections form and grow about our habitual doing, if this be pleasurable.

With these preliminaries clear, we may begin by asking the children: What flowers do you like best? Why do you like these better than any others? 
Let this be a writing lesson, giving it to the class without warning and encouraging each one to write honestly just as he may feel. If any do not like flowers, encourage them to state the fact and give the reasons, as far as they can, for their feelings.

Next make a composition lesson on what the children know about cultivating flowers. Ask them to write about their own doings in this line. What flowers have they raised? How did they succeed? Let them describe the seeds, and tell how they planted and cared for them. Those who have done nothing of the kind may have to be provided with a routine writing lesson for this period. But from these lessons you may gather the lines of interest that the children have already begun to develop.

Have a package of seeds, if possible of the flower that most of the children like best, and ask how many would like to take some seeds and see who can raise the best plant. Distribute an equal number of seeds to as many as wish to undertake the work, and give a simple lesson and demonstration on the preparation of soil and best way to plant. This should be done some time in March, so that the plants may be well grown and in fine bloom for the flower show at the end of the spring term. The seeds should be planted and reared at home, each child promising to do all the work himself, to take the sole care of his plant, and to bring in his result, whatever that may be, at the end of the term.

It will be better for many reasons, for the independence and ingenuity of the children and to preserve the impartiality of the teacher, if the children be given to understand that each must find out for himself, from books or 
parents or anybody who knows, the best way to rear his plant. A number of seeds, five to a hundred, according to the variety, must of course be given to each, and it may be clearly pointed out that, if a child be careful, he may have a number of plants. The question being, Who can raise the best single plant? a child may try different methods with different plants, and so learn for himself which way is best. Thus we cultivate thoughtfulness and power to reason, and initiate unconsciously into scientific experiment, directed toward tangible and practical ends.

We may begin in the first grade with some plant of easy culture and continue with more difficult plants, making this a regular feature of the spring botany work throughout the grammar grades. In neighborhoods where none of the children have ever planted a seed or tried to rear a plant of any sort, it may be necessary to begin with easy plants for all grades.

For the best success of these lessons we neea to select plants as beautiful, attractive, and interesting as possible, that will bloom well between time of planting and end of spring term. They should also be adapted to pot culture. The table on the following page may be suggestive as to varieties best adapted on account of short period between planting and bloom.

This work has been tried as an experiment for the past four years with increasing evidence of its value. ${ }^{1}$ The

1 The first year the children were purposely not told what seeds they were given, and in consequence they had little else but beautifully grown weeds to show at the end of the term. Petunias were planted sometimes three inches deep. 


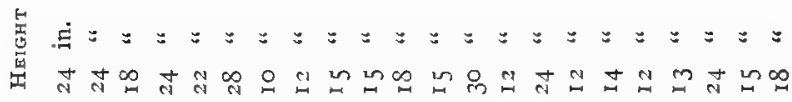

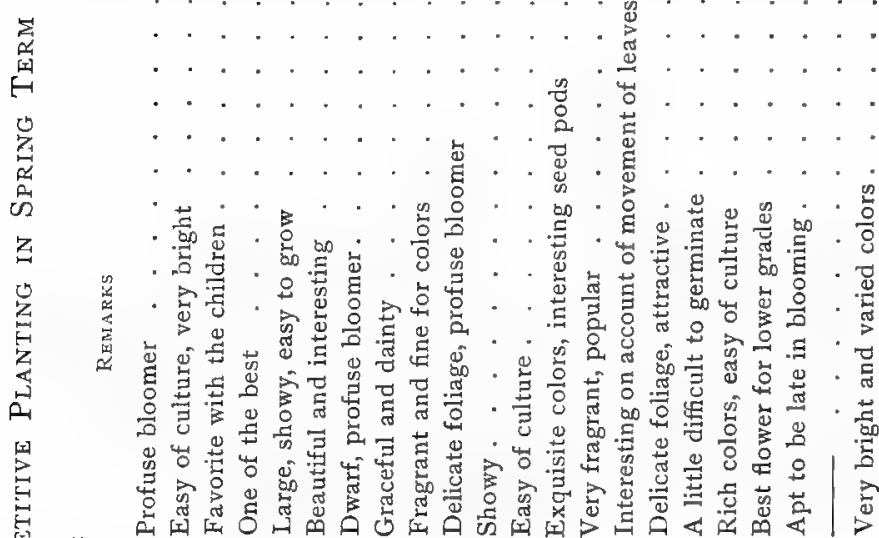

突

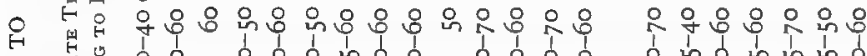

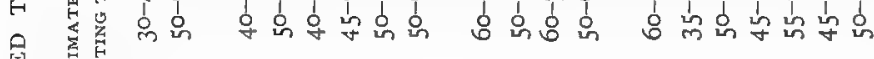

且

告

范

(-
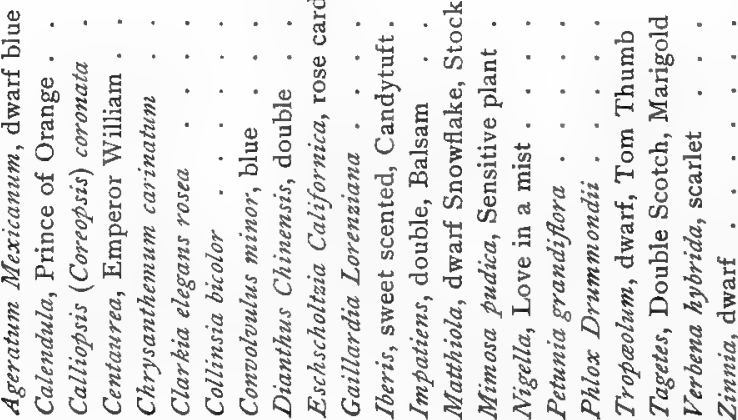
distribution of plants to the different grades last year was as follows :

Grades I and II. Dwarf nasturtium, Tom Thumb, Tropoeolum minor. This has never failed to bloom profusely and greatly delight the children.

Grade II. Calliopsis coronata, very successful.

Grade III. Sensitive plant, Mimosa pudica. The best plant to teach that plants are alive.

Grade IV. Bachelor's button, Centaurea. Always succeeds and is a great favorite in the school.

Grade V. Balsam, Impatiens. This has done only fairly well, and the number of failures indicate that it needs good care.

Grade VI. Petunia. ${ }^{1}$ Interesting on account of dustlike seeds.

Grades VII and VIII. Ten-weeks stock. Has done fairly well.

To rear a plant best is the lesson. A man is a whole man only when he plays. This competitive element thus enlists the whole child, brings into action every scrap of power to think, reason, investigate, experiment, to will and to do, of which a child is capable. And do we think how large a lesson we have given? No man yet knows how to rear any single plant best or has ever been able to do it. It is the lesson, in epitome, of the human race in learning the best cultural conditions for different

1 Petunias had been tried by grades VII and VIII and failed two years in succession. They were accordingly given up for a year. The next year grade VI begged to be allowed to try petunias, just because the others had failed, and scored a brilliant success. This was due to simple instruction upon preparation of soil and planting the seeds given as a class lesson. 
plants, the making of two blades of grass grow where one grew before, the lesson of improvement by culture, applicable not only to plants but to everything else that has life and grows. It represents the momentous step of the race from barbarism to civilization. In this simple, easy, and natural way we permit the child to throw himself into the great current of human effort, that has done

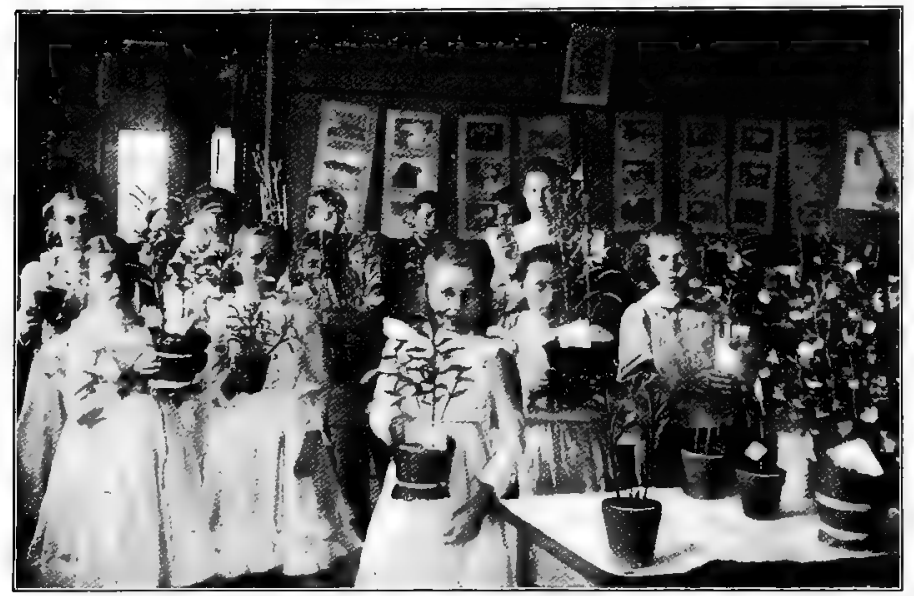

Fig. 41. Prize Plants

Grades IV-VII, Upsala Street School. June, 1900. (Photograph by the author)

more than anything else to uplift human life, and let him play and learn to swim in it; and we may be sure that no child who has once thrown his whole heart and soul into this effort can ever develop into quite the ruffian or savage he might otherwise have become. Unless we do introduce this element, the work may fall tô the level of meaningless drudgery. With it the lesson epitomizes 
in a tangible, practical way the universal struggle for existence, the effort to do things well, which is the first condition of all success in life. It has seemed from the sustained interest and enthusiasm of the children that they feel this truth instinctively. Here is no mere book and word lesson the relation of which to success in life few children can adequately appreciate. It is a mastery of the real forces of nature. They must use the sun's heat and light, the air, water, and earth, and it is a natural step from such a lesson to think, "If I can do this well, I can succeed in life itself."

Of all the wonderful things in the wonderful universe of God, nothing seems to me more surprising than the planting of a seed in the black earth and the result thereof. Take a poppy seed, for instance: it lies in your palm, the merest atom of matter, hardly visible, a speck, a pin's point in bulk, but within it is imprisoned a spirit of beauty ineffable, which will break its bonds and emerge from the dark ground and blossom in a splendor so dazzling as to baffle all powers of description. The Genie in the Arabian tale is not half so astonishing. Cella Thaxter, An Island Garden, p. 3.

On the mental side, in training the powers of observation, the child sees the wonderful life story of his plant - from seed through root, stem, leaf, and flower to seed again - unfold under the closest daily scrutiny of which he is capable. Not all the books nor all the plants in the world could teach him so much as just this one plant so closely associated with his own thinking, feeling, willing, and doing. Ability to think for himself, reason, and experiment will be cultivated with every step. All the power gained stands naturally related to everything he may do in life. To throw about his plant those conditions that 
will make it grow best, as we have already seen with the care of the pet animal, calls into play the same logic as is required in taking the best care of himself or of any human life that may be intrusted to him.

For ages before writing was invented literatures were passed from one generation to another by living word of mouth. In like manner no skilled gardener can even tell, much less write down, a hundredth part of what he knows about raising plants. While we cannot neglect means of expression in language and drawing, nature is too infinitely complicated and life too deep for our shallow formulas, and the more fully we take these facts into account the better. It was thought at first that the children might be induced to keep diaries or records of their plants, giving just what they did and just how fast the plants grew ; but it was found that their writings were of little value, and were even thought to act as a chill to the spontaneous interests of some of the children. This method must be used with great reserve. Some children have a passion to write, while in others the very thought of writing secms to benumb every impulse. Oral lessons, on the other hand, were eminently successful, the only difficulty being, as one teacher expressed it, to "get the children to stop talking about their plants."

After throwing his plant "over the banister" because it did not grow fast enough to suit him, one little boy wrote: "The best thing one learns from this lesson is patience. I should like to try it again next year, to see if I can have more patience than I had this year." The ethical value of such a lesson is too patent to require comment. Patience, carefulness, faithfulness in little 
things, continuity of purpose are all instilled unconsciously without preaching, and, best of all, the pupils come to love their flowers as parents love their children.

Only a little shrivelled seed, It might be flower, or grass, or weed;

Only a box of earth on the edge

Of a narrow, dusty window-ledge;

Only a few scant summer showers;

Only a few clear shining hours;

That was all. Yet God could make Out of these, for a sick child's sake, A blossom-wonder, as fair and sweet As ever broke at an angel's feet.

VAN DykE, The Builders, p 4r.

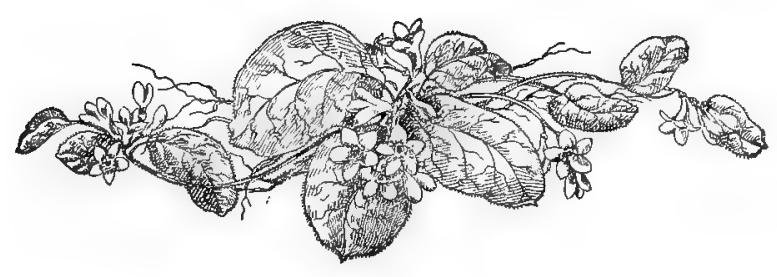




\section{CHAPTER VII}

ELEMENTARY BOTANY, FLOWER CALENDARS, WAYSIDE FLOWERS, POISONOUS PLANTS, WEEDS

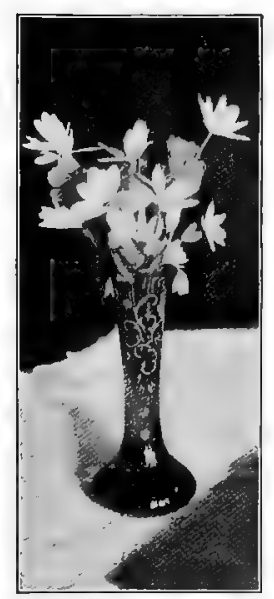

Fig. 42. BLoOdRoot

Die Blume, die dein Auge heute sieht, Hat vor Aeonen schon in Gottes Geist gebliiht.

(The flower thine eye beholdest to-day, Hath in God's spirit bloomed eternally.) Angelus Silesius, I650.

Flowers are thoughts of the Spirit of God, Their love is love of his grace, Their fragrance is breath of divinity, Their beauty, the light of his face.

LET us begin by giving a few simple language lessons to find out what the children know and think about the common plants. We may ask them first to describe and name the chief forms of plants that they know. They will probably group them somewhat as indicated for the higher plants, in the table on the following page. To some of the lower groups their attention will have to be called by common specimens and descriptions. Next we may ask them to write the names of all the plants they know. After the lists are handed in, one of the pupils may be asked to write the following table on the blackboard and all the children to copy it into their notebooks. 
List of AlL KNown Plants ${ }^{1}$

\begin{tabular}{|c|c|c|c|c|c|c|c|}
\hline & & & & & & $\begin{array}{l}\text { NuMBer } \\
\text { OF KINDS }\end{array}$ & Characteristics \\
\hline \multirow{2}{*}{\multicolumn{6}{|c|}{$\begin{array}{l}\text { FLowERING PIANTS } \\
\text { Trees in United States }\end{array}$}} & I 2 I, 96 I & Reproduce by Seed. \\
\hline & & & & & & $(495)$ & $\begin{array}{l}\text { Woody, single stem, trunk at least } \\
20 \text { feet tall. }\end{array}$ \\
\hline Shrubs & . & . & - & . & & & Woody, diffuse stems, bushes. \\
\hline Vines . & . & . & . & . & & - & Woody, slender climbing stems. \\
\hline Herbs . & $\cdot$ & $\cdot$ & - & - & - & & $\begin{array}{l}\text { Non-woody stems, dying to the } \\
\text { ground yearly. }\end{array}$ \\
\hline \multirow{3}{*}{\multicolumn{6}{|c|}{$\begin{array}{l}\text { Flowerless Plants } \\
\text { Ferns . } \cdot . \cdot \cdot \cdot \\
\text { Mosses and Liverworts }\end{array}$}} & 74,586 & REPRODUCE BY SPORES. \\
\hline & & & & & & $3,45^{2}$ & \\
\hline & & & & & & 6,750 & \\
\hline \multirow{2}{*}{$\begin{array}{l}\text { Lichens } \\
\text { Algæ . }\end{array}$} & . & . & . & - & & 5,600 & \\
\hline & $\cdot$ & - & - & • & - & I 5,554 & $\begin{array}{l}\text { Mostly aquatic, seaweeds, green } \\
\text { pond slimes. }\end{array}$ \\
\hline Fungi . & . & $\cdot$ & - & . & \{ & $\begin{array}{l}(48,574)^{2} \\
42,860\end{array}$ & $\begin{array}{l}\text { Mushrooms, lichens, mildews, smuts, } \\
\text { moulds, yeasts. }\end{array}$ \\
\hline Bacteria & $\cdot$ & $\cdot$ & . & - & - & 970 & $\begin{array}{l}\text { Plants smaller than the finest dust } \\
\text { that we can see. }\end{array}$ \\
\hline \multicolumn{3}{|c|}{ Other kinds . } & - & $\cdot$ & . & 5,000 & \\
\hline \multicolumn{3}{|c|}{ Total } & . & - & - & $\overline{196,547}$ & \\
\hline
\end{tabular}

How many plants were there in the longest list?

As we found with animals, so with plants we can hope to learn even the names of only a small number, and we must select these, as we do our friends, with great care. There are some that we meet every day, so common that we ought to know them. Others are so beautiful or fragrant that we would go far to visit them.

I I am indebted for these estimates to Prof. George E. Stone, Amherst, Mass.

${ }^{2}$ Saccardo's estimate. 
I know of no better device for introducing children of all grades to the wild flowers than one quite commonly used by local teachers but not described in manuals of nature study. I refer to the Flower Calendar. Clear a space on the blackboard and write at the top:

Flower Calendar. igoi

Date Name of Flower Pupil who first pinds it in Bloom

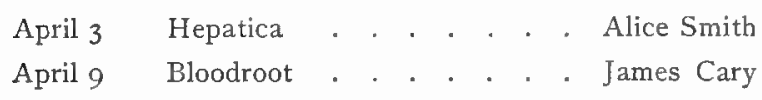

and so on, and at the end of the week, or when the board is full, have the school copy the list into their nature notebooks. It will form an interesting record, may be referred to often, may bring back pleasant school memories, and be a treasure for life. Here again we have the spice of rivalry, the spirit of play, and while some may insist that " work must be work," we never can hire or whip a child to work half as hard as he works when he plays. It will send the children out of doors to learn their lessons from the fields and woods, keep their eyes bright and wide open on their way to school, and give them lifelong interests, acquaintances, friends.

Hast thou named all the birds without a gun?

Loved the wood-rose and left it on its stalk?

$\mathrm{O}$, be my friend, and teach me to be thine.

EMERSON, Forbearance.

Except with the most common plants, encourage the children to bring in descriptions, or only so much as will make the identification possible. It is a distinct loss to 
have our rarest and most beautiful flowers so completely exterminated near our towns and cities that few ever see them blooming. A strong feature of this work may well be the beautifying of roadsides with as great a variety of wild flowers as possible, and a good rule will be, not to pluck any roadside flowers. Leave them for passers-by to enjoy, and gather only from private fields where permission is granted and only such flowers as are superabundant. This will leave no reason for complaints, often raised, that interesting thoughtless children in the study of flowers results in their wanton extermination.

Wayside songs and meadow blossoins; nothing perfect, nothing rare; Every poet's ordered garden yields a hundred flowers more fair ; Master-singers know a music richer far beyond compare.

Yet the reaper in the harvest, 'mid the burden and the heat, Hums a half remembered ballad, finds the easy cadence sweet, Sees the very blue of heaven in the corn-bloom at his feet.

VAN Dyke, The Builders, p. 42.

While the flower calendar may be repeated from year to year, and even increase in interest by repetition, it will not consume the time nor supply all the work desirable with our flora. Some flowers must be studied more thoroughly than others, and to avoicl confusion and repetition from year to year in this work, we need to have a concerted plan understood and agreed upon by the teachers of a town or city, with plants assigned to each grade. Such an assignment is made in the year and grade plan at the end of this book and need not be repeated here. It is designed especially to include the flowers that every child in New England ought to 
know, and for other sections the teachers, at some of their local meetings, should appoint a committee to arrange a

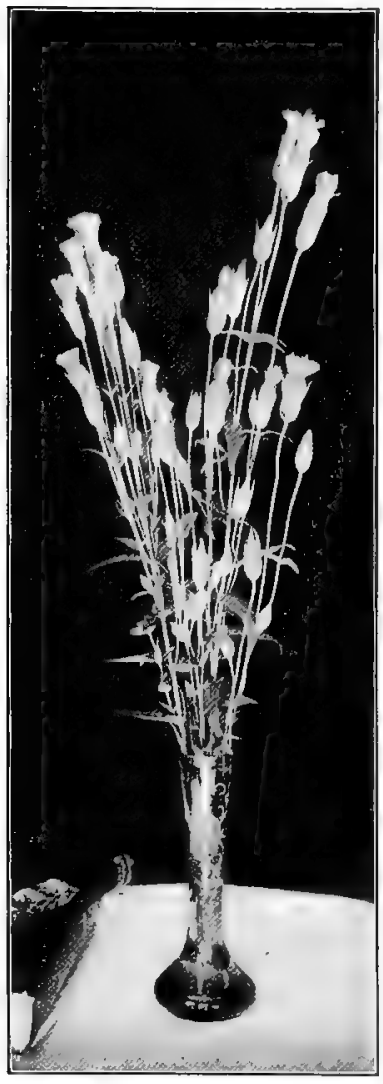

Fig. 43. Fringed Gentians

(Photographed, but not plucked, by the author) suitable list.

It has been thought by teachers of long experience that, beside the casual acquaintance of a good many more, it will not be too much to learn a little more fully twelve plants a year, grouping, drawing, and writing lessons about them. The children should be directed to follow their growth, learn their habitats, make collections of their seeds, and be able to tell the plant by a leaf, flower, or seed. If this be done during the eight grades, the children should have formed a practical acquaintance with about one hundred of our common plants.

A number of poisonous plants occur, either widely distributed or locally, in the United States. ${ }^{1}$ Fourteen of these are included in the above lists, and they may be briefly described below. The

${ }^{1}$ V. K. Chesnut. "Thirty Poisonous Plants of the United States," Farmer's Bulletin, No. 86, United States Department of Agriculture. 32 pp., 24 figures. This can be obtained gratis on application to the Department of Agriculture, Washington, D.C. 
others should be carefully studied by teachers where they' abound and introduced into their nature courses. Every parent and child ought to know the dangers connected with these plants, and the general study of them, as indicated, would result in the saving of considerable suffering, sickness, and death year by year.

Poison Ivy, Rhus radicans. - [Poison oak, three-leaved ivy, mercury, black mercury, markweed, pikry (Me.).] This is a common climbing, sometimes bushy, shrub about roadsides and orchards. The stem has aërial roots by which it clings. The leaves are compound with three leaflets irregularly toothed and notched. They are bright red when they appear in the spring, turn red again in the fall, and are frequently gathered in children's bouquets. The greenish flowers appear in May and June, and the white waxy fruit remains through the winter. Through ignorance it is sometimes even planted about houses. The Bulletin says : "It is highly desirable that legal measures be adopted compelling the destruction of these plants where they abound in cities and in places of popular resort."

The poison is a heavy, gummy oil contained in all parts of the plant and exuded from leaves, bark, and fruit. This is very non-volatile and retains its virulence unimpaired in old dry stems and leaves, which, therefore, should always be promptly burned in destroying the plants, and care taken not to inhale the smoke. Imperceptible amounts, coming in contact with the skin, cause the characteristic painful blisters. Such minute quantities are effective that specially susceptible persons are sometimes affected by merely walking near the plants, when 
it would seem that either pollen or particles of dust that had absorbed the oil from the leaves must be carriers for the poison. Ordinary washing, even with soap, merely

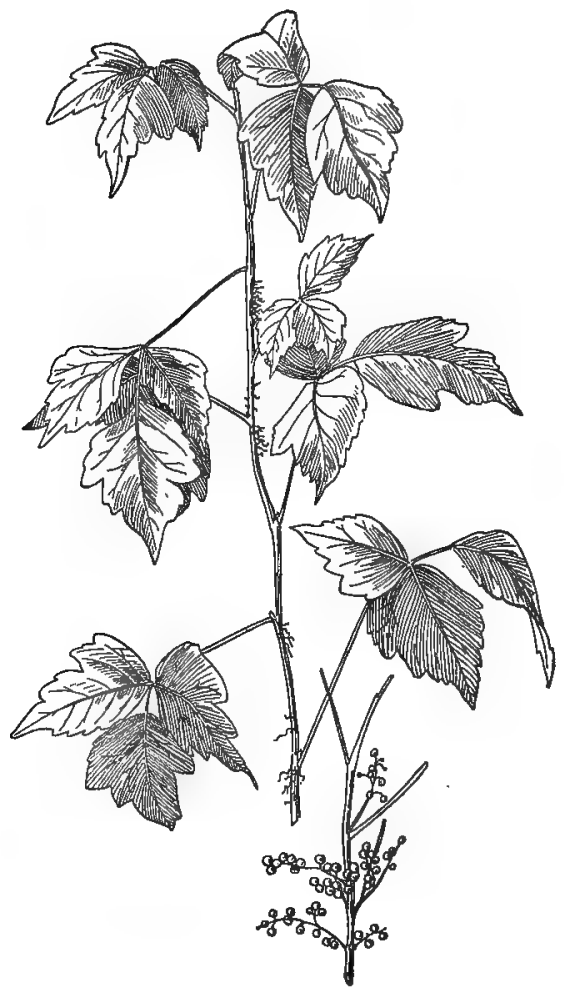

Fig. 44. PoIson Ivy

spreads the oil and serves to rub it in. If poisoning has occurred, or if there has been serious exposure in handling or destroying the plants, affected or exposed parts should be bathed in a strong solution of lead acetate in 
dilute alcohol (alcohol one-fourth to one-half water, with as much sugar of lead as will dissolve cold). This will quickly neutralize the poison and prevent further injury. Clothes, towels, even the handles of tools that have been used by those engaged in destroying poison ivy, must be thoroughly washed in strong hot soapsuds, or in the lead acetate solution, before being allowed to come in contact with any one else. The sugar of lead solution is itself poisonous, if taken internally.

We cannot, of course, ask children to bring in specimens of such a plant, and none of it should be allowed exposed about the schoolroom. It may generally be pointed out in the first excursion with the children, or the teacher may take proper precautions and press specimens of leaves, stems,

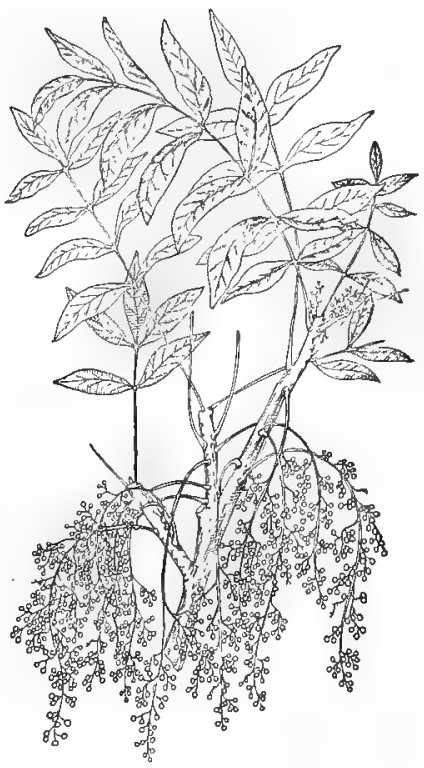

Fig. 45. Poison Sumac with Fruit flowers, and fruit and mount them between two plates of glass, as described for insects. This also applies to the other plants that are poisonous to the touch.

Poison Sumac, Rhus vernix. - [Swamp sumac, dogwood (Mass.), poison elder (Ala.), poison ash (Vt.), thunderwood (Ga., Va.).] This is a treelike shrub six to thirty feet tall, with slender pinnate leaves of seven to thirteen leaflets, 
without marginal teeth. Its very prominent leaf scars are sufficient to distinguish it from other shrubs in winter. It grows in swamps and damp woods from Florida to Canada and westward to Louisiana.

It is poisonous to the skin in the same way as poison ivy and requires the same precautions in handling and the same treatment.

Poison Oak, Rhus diversiloba. - (Poison ivy, yeara, California poison sumac.) This is a western plant of the same class with the two preceding and should be treated in the same way. 1

Poison Hemlock, Conium maculatum. - (Hemlock, wild hemlock, spotted parsley, stinkweed, poison root, poison

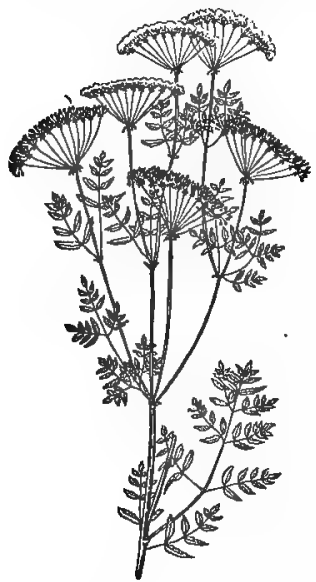

Fig. 46. Poison Hemlock snakeweed, cashes, wode-whistle.) Poison hemlock is a hollow-stemmed biennial, two to seven feet tall, stems smooth and purple spotted, widely distributed about roadsides and waste lands. The flowers are white, appearing in July and August. The leaves have an extremely nauseating taste and when bruised emit a characteristic "mousy" odor. Poisoning occurs by eating the seeds or roots or even by blowing whistles made from the hollow stems. It probably furnished the poison administered to Socrates.

1 The nomenclature for all these poisonous plants is here given according to Bulletin No. 86, and so much confusion exists that it would be a great desideratum if the names could be fixed and made reasonably uniform for the whole country by means of nature-study lessons in the public schools. 
Many domestic animals are killed by eating the plant in hay. It should be exterminated by hand pulling before the seeds mature.

Water Hemlock, Cicuta maculata. - (Spotted parsley, snakeweed, beaver poison, musquash root, muskrat weed, cowbane, spotted cowbane, children's bane, death of man.) This is a smooth, erect perennial, three to six feet tall, stiff hollow stem, streaked with purple, twice to thrice decompound leaves with leaflets finely serrated, the veins running mostly to the notches instead of, as usual, to the points of the teeth. The plant is easily recognized by the root, which consists of a clump of thick fleshy tubers, each from one to three inches long. It is quite common in swamps and wet pastures throughout the United States and Canada, but less common in the arid regions west of the Mississippi. The flowers are white, in umbels two to three inches across, and appear in August.

The root is especially dangerous, because of its wholesome appearance and aromatic taste, which often tempts children to eat it. No estimate of the annual damage to stock can be made. Cattle are sometimes poisoned by eating the roots and even by drinking the water of pools into which these have been trampled.

For nature study, children in every school, city and country, should be given a clear idea of this plant, - root, stem, leaf, flower, and seed, - and in rural districts they should make careful surveys to discover its abundance and distribution and adopt practicable measures for its extermination.

Pokeweed, Phytolacca decandra. - This is not very poisonous, and its succulent shoots are widely esteemed for 


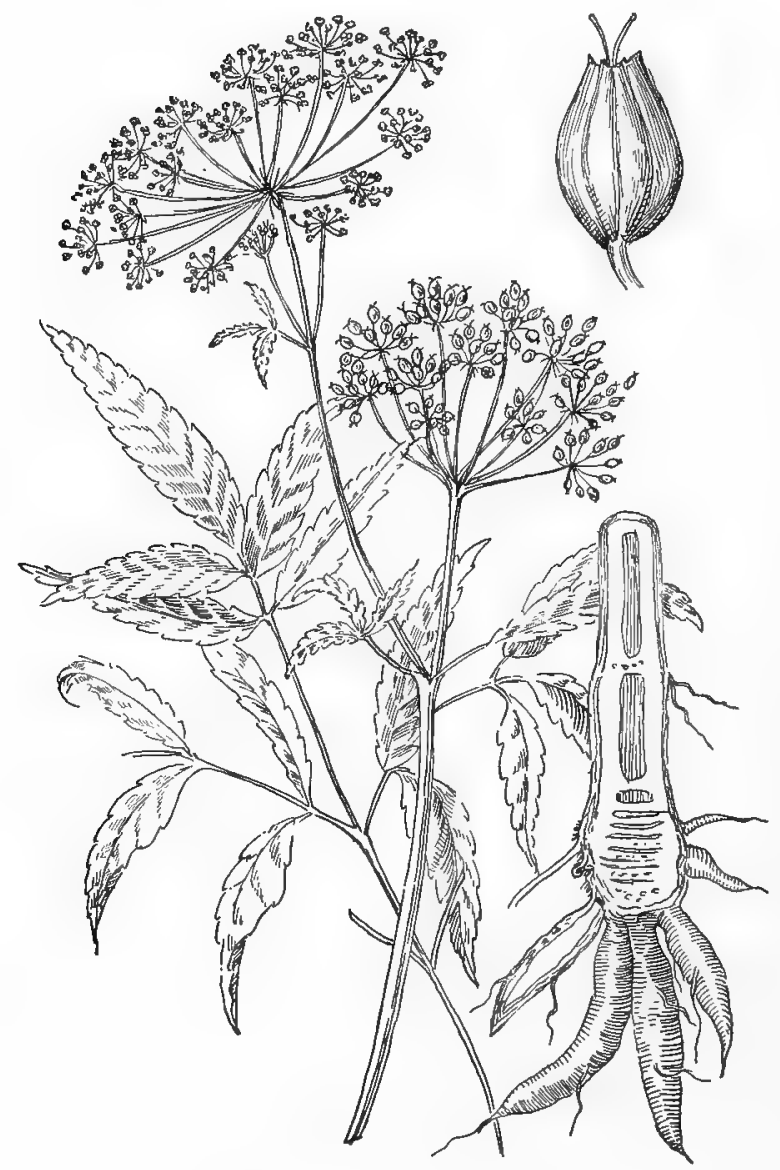

Fig. 47. WAter HeMLOCK

greens in the spring, and may be so used if care be taken not to include any of the root, which is bitter and poisonous. Cases of poisoning sometimes occur from eating the berries, 
probably on account of poison contained in the seeds. It is a valuable bird-food plant and is highly ornamental in its clean, robust growth and masses of purple-black berries, and may be grown with impunity and even advantage if the above simple precautions are understood.

Corn Cockle, Agrostcmma githago. - This is a well-known, pretty, purple-red flower of the grain fields. Poisoning occurs among poultry and all sorts of domestic animals from eating the seeds in screenings or ground feed. People are sometimes poisoned by low-grade flour made from wheat containing the seeds. This can generally be distinguished by black particles from the seed coats and by a peculiar odor when the flour is moistened. This plant should be more generally understood, and great care should be taken not to sow grain containing its seeds.

Black Cherry, Prumes serotina. (Wild cherry, rum cherry.) This is a valuable forest and cabinet-wood

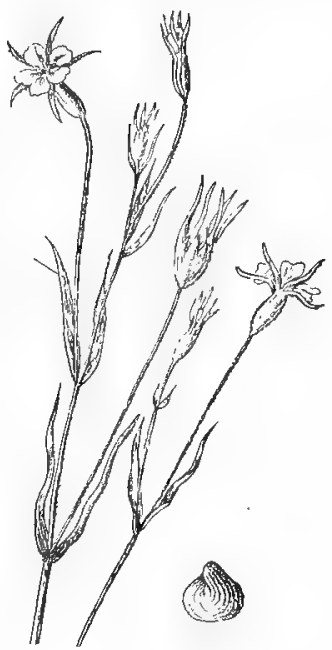

FIG. 48. CORN COCKLE tree, and its loads of black cherries make it one of our most important bird-food trees. The fruit may be eaten with impunity if the seeds be discarded. but it should be commonly understood that the kernels and leaves may contain prussic acid in amounts sufficient to cause serious poisoning. Children should be cautioned against eating the kernels, and freshly cut branches should not be thrown where stock may eat them. 
Red Buckeye and Common Horse-Chestnut, Asculus pavia and hippocastanum. - Both contain active poisons in their seeds and fresh leaves and twigs. Fish may be stupefied by stirring the crushed nuts and twigs into small pools. Poisoning may occur from eating these parts, but the bitter taste serves, in general, as a sufficient safeguard.

Broad-Leaf Laurel, Kalmia latifolia. - (Laurel, north of Maryland, ivy, south of Maryland, mountain laurel, sheep laurel, poison laurel, wood laurel, small laurel, high laurel,

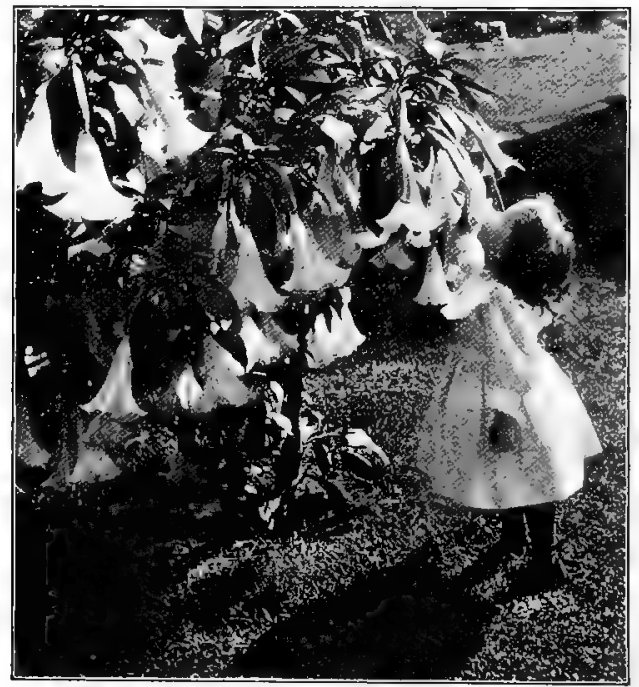

Fig. 49. DATURA

Beautiful but dangerous. (Photograph by Charles Irving Rice)

American laurel, poison ivy, ivy bush, ivy wood, big ivy, calico bush, spoonwood, kalmia, wicky.) Laurel is too well known to need description. It is our most beautiful native 
shrub by reason of its polished evergreen leaves and profusion of exquisite flowers. In very rare cases sensitive people are said to experience discomfort if too large quantities of the flowers are kept in their rooms, but it can safely

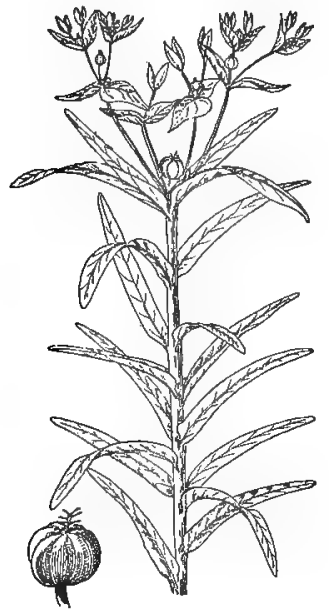

Fig. 50. CAPer SPURge

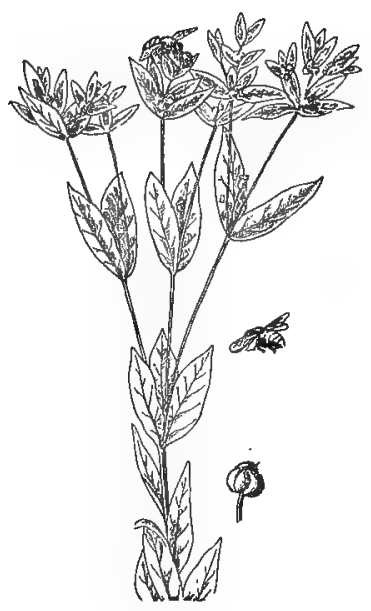

Fig. 51. SNow on the Mountain

be handled and enjoyed all the usual ways with perfect impunity. The only precautions necessary are to prevent animals not accustomed to it from eating the leaves. Even goats have been known to clie from this cause.

Narrow-Leaf Laurel, Kalmia angistifolia. - (Sheep laurel, lambkill, sheep poison, lamb laurel, small laurel, low laurel, dwarf laurel, wicky.) This shrub is dangerous in the same way as its larger cousin.

Jimson Weed, Datura stramonium and D. tatula (the taller and purple-flowered species). - [Jamestown weed, common stramonium, thorn apple, apple of Peru, devil's apple, 
stinkwort, stinkweed, Jamestown lily, white man's plant (by the Indians).] This is a rank ill-smelling weed, common in vacant lots, rubbish heaps, roadsides, and waste places. It is a stout, bushy annual with coarse, smooth stems, two to five feet high, and large flaccid leaves. The flowers are white (or purplish), shaped somewhat like a morning-glory, "heavy scented," from two to four inches long, and appear from May to September (the fruit ripening from August to November), according to

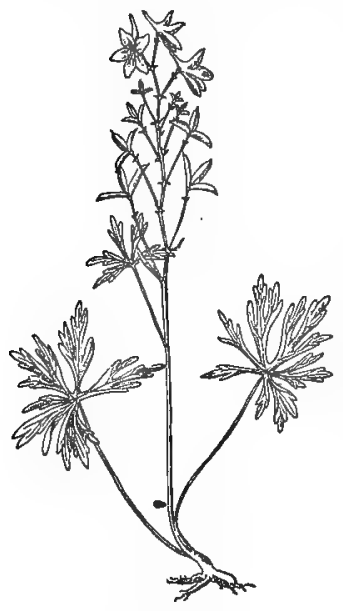

Fig. 52. DWarf Larkspur latitude. The fruit is a large, conspicuous, prickly, four-valved pod containing great numbers of dark roughened seeds.

Cases of poisoning arise from the use of the plant as a stimulant or medicine, from children eating the seeds or playing with the flowers (holding them in their mouths), and with cattle from eating the plants in hay. The jimson weed should be much better known, and no child should permit one to ripen its innumerable seeds.

Caper Spurge, Euphorbia lathyris. - (Garden spurge, mole plant, gopher plant, wolf's milk, springwort.) This spurge is a garden, roadside, and pasture perennial, common over most of the United States and Canada. The milky juice is extremely acrid, and the fruit is poisonous. Women and children are often poisoned by handling the plant or by getting the juice on the hands or face. 
Snow on the Mountain, Euphorbia marginata. - This is an erect annual, two to four feet high, conspicuous for the white margins of its leaves. It is often listed in seed catalogues and planted for ornament. Poisoning commonly occurs through honey gathered from its flowers, large quantities of autumn honey being yearly rendered unsalable by the presence of this plant. Like the preceding spurge its acrid juice on delicate skins not infrequently causes blisters and inflammation similar to that produced by poison ivy.

Other poisonous plants are:

Death-Cup Mushrooms, of the genus Amanita, described under fungi.

American False Hellebore, Veratrum viride (white hellebore, swamp hellebore, Indian poke, poke root, Indian uncus, crow poison, devil's bite, duckretter, itch weed, bugbane, wolfsbane, bear corn).

Dwarf Larkspur, Delphinizum tricorne, Stagger Weed (O.), and Purple Larkspur, D. menziesii.

Woolly Loco Weed, Astragalus mollissimus and Stemless Loco Weed, A. Lambertii.

Rattlebox, Crotalaria sagittalis.

Oregon Water Hemlock, Cicuta vagans.

Great Laurel, Rhododendron maximum.

Staggerbush, Pieris mariana.

Branch Ivy, Leucothoë catesbcei.

Black Nightshade, Solanum nigrum.

Bittersweet, Solanum dulcamara.

Sneezeweed, Helenium autumnate.

It is certainly no more than common sense should dictate to provide adequate instruction about these plants wherever they abound. The school, by coöperation of teachers, intelligent parents, and pupils, should provide a neatly labeled collection. The specimens should be 
mounted so that they may be handled and studied without danger, and kept in a drawer or suitable box by itself and labeled :

\section{POISONOUS PLANTS \\ OF THIS LOCALITY. ${ }^{1}$}

Weeds. - A weed is a plant that persists in growing where it is not wanted. This insistent impudence, the vigor and tenacious hold on life, the great number of seeds produced, and the numerous devices weeds employ to secure their distribution, the brigandish crowding aside and killing down of all other plants within reach, all tend to constitute the weeds a most interesting group of plants to study.

We may first ask the class to write the names of all the weeds they know. For another lesson let the pupils write descriptions of the more important and interesting plants on their lists, giving their life stories, telling when they blossom, and especially when they begin to ripen their seeds. After these lessons we may make an excursion around the school yard and count the different kinds of weeds found growing in the area.

A lesson that never fails to interest the children may be arranged by having them fill a number of flowerpots with earth from different sources, - from their gardens, from different levels in some freshly dug cellar, from the bottom of the pond, etc. Keep them in a warm place and watch the different plants as they come up. Many interesting questions will arise as to how the weed seeds got into the soil and how long they may remain dormant.

${ }^{1}$ In making this collection such plants as are poisonous to the touch may be handled by means of pieces of newspaper. 
Study the seeds of ten of the most troublesome weeds in the neighborhood. Select large vigorous plants, and estimate the number of seeds produced. A Russian thistle has been found to produce about 20,000 seeds, and a single plant of purslane about 1,250,000 seeds. We may next investigate the methods of seed dissemination and arrange an instructive school collection that will show the various devices adopted by different weeds. As a concluding lesson we may take samples of different grains, - wheat, oats, barley, rye, clover, and the different grass seeds, - and each pupil may examine a small quantity and report the number of weed seeds discovered.

Weeds have been called by some the "farmer's friends." How can this be so? They necessitate good cultivation of the soil, and this is of great benefit to the growing crops. They compel the farmer or gardener to keep the ground well occupied with vigorous useful plants. Certainly not all weeds are friends, and after proper methods of cultivation have been attained, they only make the work more difficult. Weeds like the thistle, dandelion, or milkweed, the seeds of which may be carried long distances by the winds, or which are likely to be carried by other means, may be a cause of serious damage to neighboring fields. This brings us to the final topic for study, viz., the weed laws of the state. Obtain a copy of these laws and discuss them with the class. ${ }^{1}$

${ }^{1}$ Lyster H. Dewey. "Two Hundred Weeds: How to know them and how to kill them," 1895 , and "Legislation against Weeds." Bulletin No. 17, United States Department of Agriculture, Washington, D.C., I896. This gives all the laws of the different states regarding weeds. 


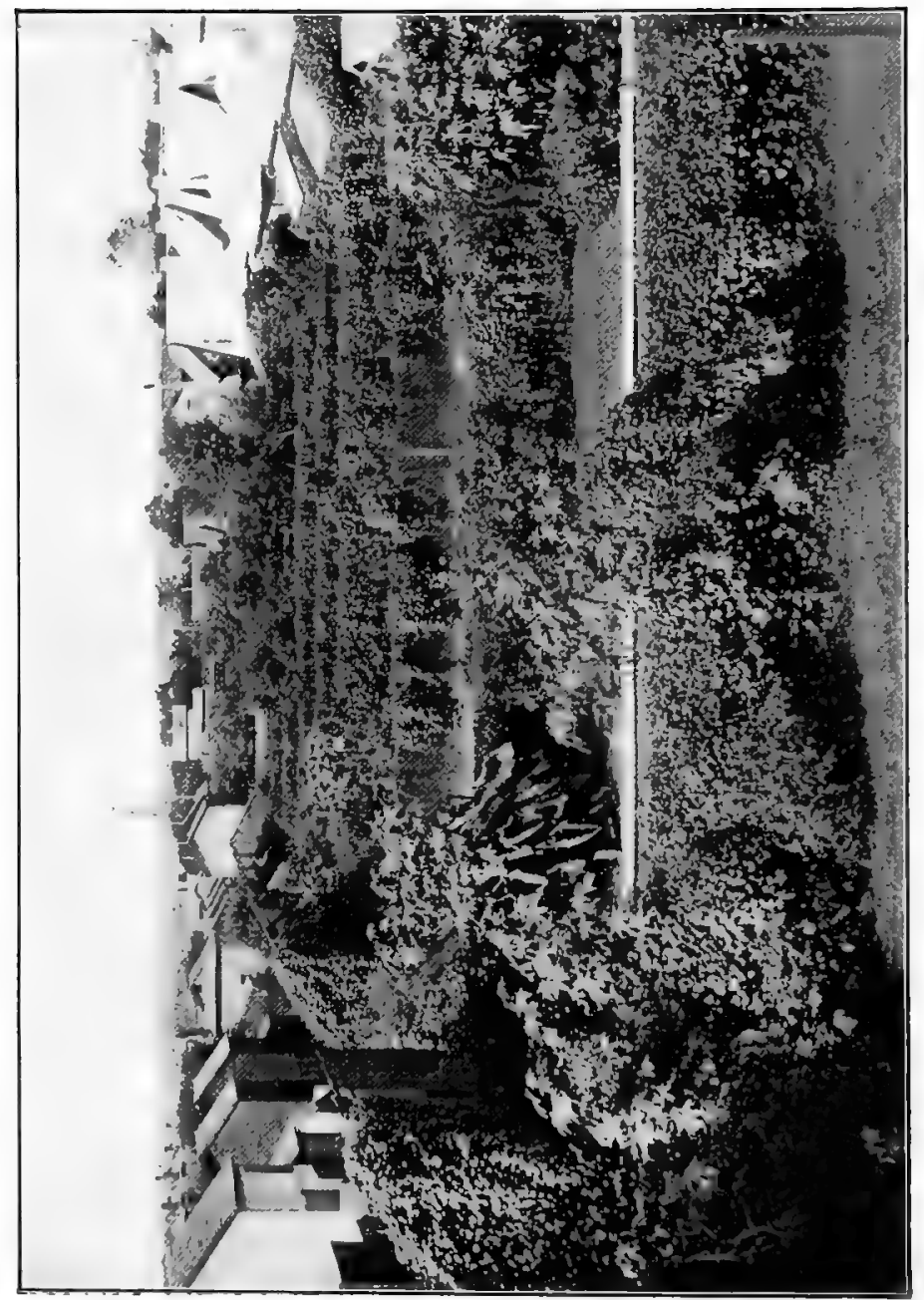

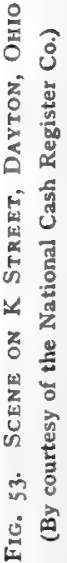




\section{CHAPTER VIII}

\section{GARDEN STUDIES}

\section{Home and School Gardens}

Spacious and fair is the world; yet oh! how I thank the kind heavens That I a garden possess, small though it be, yet mine own. One which enticeth me homewards; why should a gardener wander? Honor and pleasure he finds, when to his garden he looks.

GOETHE.

EAcH of the children of the German emperor has a garden of his own in which he works and sees plants grow from his own sowing, and learns innumerable things that books and the best of instructors could never teach.

When we consider the fundamental relations of the race to the soil and its culture and products, and when we remember that the establishment of these relations constituted the greatest uplift of the race toward civilization, we realize that to leave soil lore out of a plan of public education is likely to prove reversion toward barbarism. The vandalism, juvenile and even adult, that renders pursuit of horticulture in a New England city or town well-nigh impossible must be accounted a first fruit of this unwise neglect. ${ }^{1}$ It would also seem that failure

1 Recent studies (Flynt) have shown that our tramps are the natural product of our school system, not foreign born, as we are commonly tempted to suppose. Their manner of life demonstrates with remarkable force a reversion to nomadic ways. 
of usual methods of control - repression, preaching, policing, and punishment — had amply demonstrated their futility, and naturally, because in a child that has never reared anything of his own there is little or no foundation upon which to build regard for the rights of others in these respects.

Since Froebel wrote, this subject has been long in gaining due recognition, but it is now making rapid headway under the influence of educational leaders both abroad and in this country. But, while a few things are sprouted in sawdust, chiefly for technical lessons in "botany," the practical absence of the subject from text-books on nature study now issuing from the press is reason for profound regret.

A garden is a part, and we might with truth say a necessary part, of the home. It is thus to the home garden, the relation of children to it, its possibilities and its educational values that I shall direct chief attention; and upon the presence or absence of home gardens must depend largely what we attempt to do in school gardens.

The relation of the child to the home garden is a proverbially painful one. This is mainly due to his lack of ownership, responsibility and, consequently, spontaneous and creative interest in it. $\mathrm{He}$ is used in the garden as a mere slave or tool to do the drudgery and disagreeable work and naturally comes to loathe it accordingly. Even this drudgery may be better for the child than no garden training at all, but it is apt to leave so many disagreeable associations in his mind that he will hate gardens for the rest of his life and permit this important part of his children's education to lapse. 
Another reason for the decline of the home garden is found in the increase of weeds, noxious insects, caused by wanton destruction or neglect of our insectivorous animals, and fungous diseases, mildews, rusts, blights, and moulds. All these things conspire to render gardening unnaturally and unnecessarily difficult. For one individual to fight against these things in a small city lot is a hopeless task. It is the old story of the broom against the ocean. These great forces of living nature enforce the brotherhood of man. Each must do his part, and all must coöperate for the common good, and if properly understood and utilized, the good forces in nature can largely be balanced against the evil and thus gardening be relieved of many of its most discouraging features. But at present people do not even know the names of the insects and fungi that are doing the most harm in their own back yards, and scarcely one in a hundred has any conception of the things that are doing the most good. How can we lay the necessary foundation of common knowledge of these forces in nature except through our system of universal education? And, further, these important common processes going on about us form the most normal basis for lifelong interest and intimacy with nature. When a beginning is made, some of our greatest difficulties become most fascinating studies. For example, as soon as we realize that codling moths have ruined all the apples on our trees, and during the winter are hiding under the scales of bark on their trunks, it is with a thrill of delight that we see a downy woodpecker industriously pecking into one scale after the other and extracting the larva. Or when our cherry trees have been black masses of aphids, 
if we see a chickadee in winter going through his trapeze performances as he picks out the little black eggs from behind the buds, we feel like encouraging his presence in every way we can. He becomes thenceforth an interesting friend of ours for life. And so it is with a thousand other things. Knowledge lives and grows, if we have this common ground, these fundamental interests, about which to group our otherwise unrelated observations. Lacking this, everything falls apart, and the whole becomes a chaotic, unorganized affair. Adults may be able to form more abstract, idealized relations with nature, but even this is rare, and we cannot hope to establish them wholesale with children.

The garden thus becomes not only a vital part of a child's education in itself, but the great center, the heart of vitalizing influences and interests that radiate into nature in every direction.

The status of children demands a thorough revival of this work. In the first place, children of native New England parentage are becoming very few. Our vital statistics are complicated by foreign immigration; but it is probably safe to say that in our strictly native New England population there are more deaths than births. We often hear France alluded to in this connection, but official statistics for New Hampshire (I 892) show that to every Iooo inhabitants there are I9. I births and 20. I deaths. In France the ratio is 22.1 births to 22.6 deaths. As a whole, New England stands third lowest, 24.9 birth rate per rooo population; France, 22.1 ; Ireland, 22.4 ; Germany, 35.7; Hungary, 40.3; and, despite her lower death rate, she stands also third lowest in increase of 
population from this vital source. From strong families of six to ten children we have dropped in a single generation to families of one, two, or none, so that writers abroad are pointing to New England as the most glaring example of sudden racial degeneration on record. And with our few children, why is it that we see so many advertisements "House to let to family of adults"? Simply because children are not properly trained, are idle and consequently mischievous and destructive. Give them interests and work to do in upbuilding the home, and they will not tear it down. Formerly children were helpful members of the household, and while sometimes they were forced to work too hard, even that was better for them than idleness.

In cities one of the hardest of family problems is how to keep the children interested and healthfully employed at home. Where even a little land is available this problem may be solved in such wise that these advertisements will be changed to read: "House to rent to family with two or more children ; no family without children need apply."

How this may be accomplished with only wholesome exercise, without drudgery, is a problem which must be worked out largely for each inclividual child, and upon which the best thought and effort of both teachers and parents should be focused. Only a few more general elements of its solution can be here suggested.

The element of prime importance is incividual ownership by the child.

Probably the best way to teach selfishness is to try to teach unselfishness too early. The passion for ownership is coextensive with life. It is an expression of "The Will to Live." It is as universal as bunger. It begins in the 


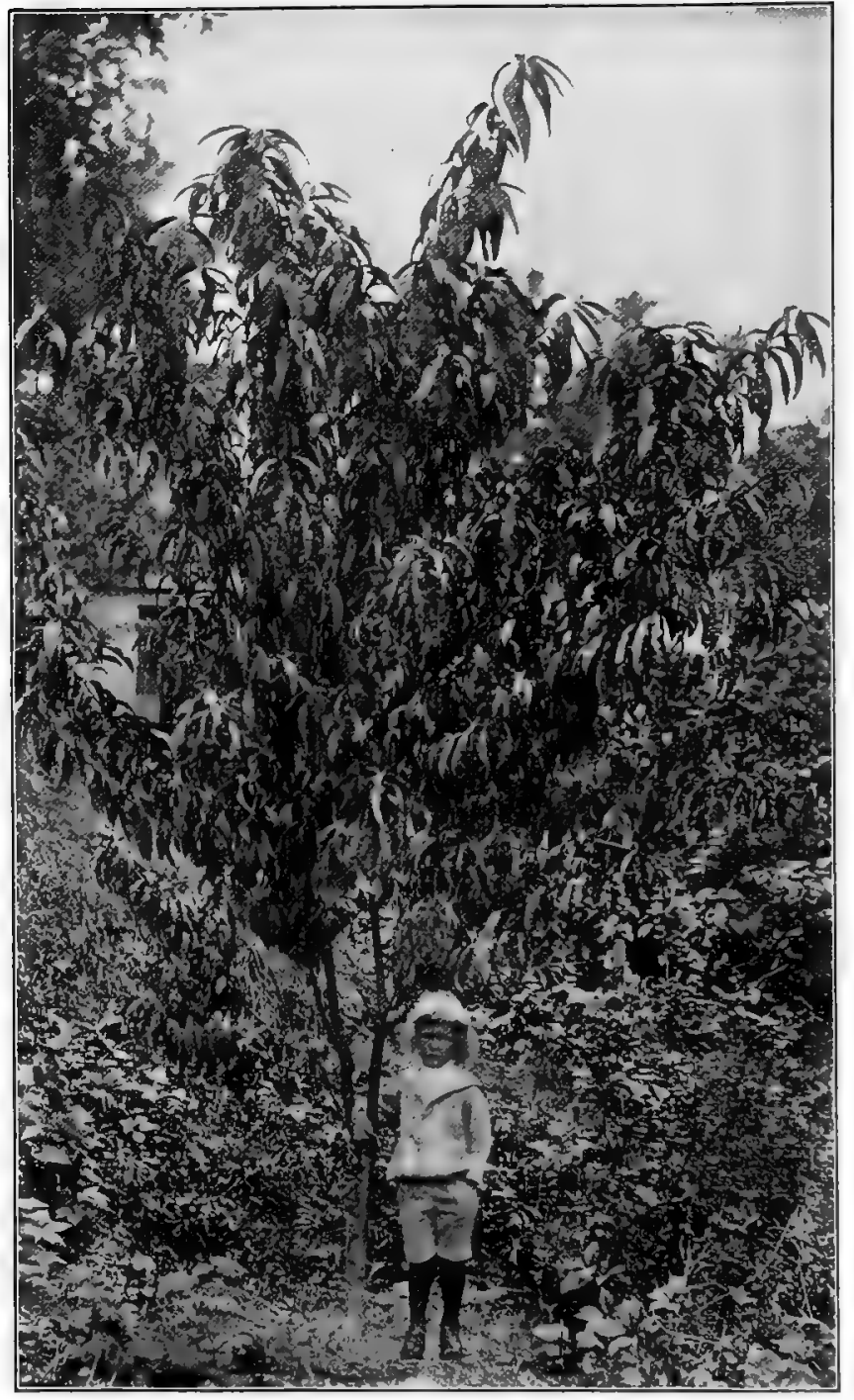

Fig. 54. Planter and OWner of Peach Trees

Old Mixon, fifth year from seed 
living series when an amoba swallows a particle of food. By the effort put forth in the act of swallowing, the particle becomes the amoeba's property for the sustenance of its life. With man it is the foundation of government and social organization, as well as the chief incentive to labor, invention, and discovery. "From the old stone age upward so far as we can trace the history of man," says Dr. Brinton, "the one efficient motive to his progress has been the acquisition and the preservation of his property. This has been the immediate aim of all his arts and institutions, and the chief incentive to individual exertion." L. H. Morgan says that " monogamy resulted from increase and variety of property through the establishment of inheritance in the children of its owner; the influence of property in the civilization of mankind it is impossible to overestimate. It was the real power that brought the Aryan and Semitic nations out of barbarism into civilization." 1

Far from being antagonistic to unselfishness and altruism, the desire for ownership is their necessary forerunner, their normai preparatory and embryonic phase, for no man can give until he possesses something worth giving. The more he possesses, the greater his power for good. Mental power and acquisition of knowledge and skill in this regard are like material property. Abuses of this power naturally occur, and we find exceptional cases of arrest in this normal process of development. But the miser has stood scarecrow too long.

1 Linus W. Kline and C. J. France. "The Psychology of Ownership," Pedagogical Seminary, vol. ví, pp. 421-470. 
Kline and France in their study of the Psychology of Ownership have shown that extreme selfishness, the desire to own and to keep, is normal to childhood. Through its natural exercise and development the child learns in the only real way possible to appreciate the property rights of others. With adolescence he blossoms into altruism, which, unless blighted, ripens into valuable life work.

Another point, attested by common experience, is that unless effort is put forth toward attainment of an object, its value is not appreciated. The most worthless things for which a child has hunted or into which he has thrown his work become the treasures of his life. The most costly things, no matter how beautiful or interesting, lavished upon him without this inner relation to his will, remain but so much rubbish, "pearls before swine." What can be better calculated to call forth a child's best activities and, after due patience, to crown his efforts with possessions of solid value than cultivation of fruits or flowers? And what other occupations stand in such fundamental relation to life and civilization? Other " historic occupations" are special and technical, besides being dead and antiquated, in comparison with this; while this must remain perennially in vital relations to life.

The way in which parents approach this problem will naturally vary with differences of opinion. But those who appreciate the point of view suggested will begin by apportioning to each child, at three, four, or five years of age, some little plot of ground that he can call his own. They will furnish him, or allow him to earn, tools of his own, - a trowel, rake, seed box, - give him a place to keep them and instruct him in the proper care of them. They 
will hunt over garden catalogues with him and encourage him to form his own plans, select the things he wishes to raise, and give him necessary information. Then if the child chooses to raise something of real value to the household, they may pay him the market price for it and encourage him to start a savings-bank account of his own. Year by year, as the children grow in ability, the parents will gradually increase the size of their gardens, give to this one an apple tree, to another a grapevine, to another the crimson rambler by the porch, and so on, thus apportioning the nature property of the home where it will yield the greatest amount of education to their children. They will thus gradually and naturally increase responsibilities and opportunities for creative and productive work.

This work will, of course, take every possible direction according to the circumstances and needs of the home. A well-kept garden can easily supply half the living of a family, and the fresh vegetables and fruits, which are beyond all comparison superior to the stale products of the markets, may have a wonderful influence upon the health of the household. But, if these things are not considered desirable, the land at disposal may be devoted to ornamental plants and the home be made a paradise of flowers and trees.

If the boy cannot have the care of a little garden of his own, he should have at least a few plants in boxes or flower pots, filled not with rare and delicate or double plants, but with such as are common, rich in leaves and blossoms, and thrive easily. The child, or boy, who has nursed and cared for another living thing, although it be of a much lower order, will be led more easily to guard and foster 
his own life. At the same time the care of plants will satisfy his longing to observe other living things, such as beetles, butterflies, and birds, for these seek the vicinity of plants. Translated from Froebel's Menschen-Erziehung, p. 69.

Finally, we must begin young. "Give a child large interests, and give them young." 1 Early impressions are proverbially deep. By eight or nine the child's brain has practically attained its adult size. While refinement of structure may go on even into mature age, the fundamental lines are laid down, and the basal habits and philosophy of life are pretty solidly established. If habits of indolence, carelessness, or possibly vice have been formed, and vitiated tastes and appetites have been allowed to develop, the reformation will be so much harder and the results fragmentary and unsatisfactory. And this work is so fundamental, simple, and primitive that young children, excepting only the abnormal and spoiled, will enter into it with delight and by this act enter into civilization.

To lead children early to think, this I hold as the first and most important object of child-training.

To train the children early to work and industry seemed to him, the ideal father, so natural, and matter of course as to need no statement. Besides the child that has been led to think is it not led, at the same time, to industry and diligence - to all virtues of home and country?

Those words are a seed from which develops a shady evergreen tree of life, full of fragrant blossoms and sound, ripe fruit. Let us hear and heed this who allow our children to grow up thoughtless and idle, and therefore dead.

But - it is hard, yet true, as will appear if, in our intercourse and daily life with our children, we cast a searching glance upon the condition of our minds and hearts - we are dead, our surroundings are 
dead to us. With all our knowledge, we are empty for our children. Almost all we say is hollow and empty, without content and without life. Only in the few rare cases, when our speech rests on intercourse with life and nature, do we rejoice in her life.

Let us hasten, then! Let us impart life to ourselves, to our children; let us through them give meaning to our speech and life to the things about us! Let us live with them, and let them live with us; thus shall we obtain through them what we all need.

Our surroundings, the objects we see are lifeless; they are dead matter. They crush, instead of uplift us, for they lack the quickening word that gives them significance and meaning.

Our speech is like the book out of which we have learned it, at third or fourth hand.

Fathers, parents, let us be up and doing! what we lack let us provide for our children. What we no longer possess - the all-quickening, creative power of child-life - let it be again transfused from their life into ours. Translated from FroEBEL's Menschen-Erziehung, p. 55 .

In adult science we have been studying dead things so long, dissecting and analyzing type-forms, that we have well-nigh gone blind to the living, active side of nature; but this has furnished the primitive and fundamental, and must furnish the larger future, interests of mankind in nature. So completely does this side monopolize our college and even university courses in biology that our teachers know nothing else to teach. However much value this may have for adult thought, when we attempt to teach little children we must moult it all, heed every suggestion of the great teacher, and become as little children ourselves. 
In the general movement toward active education manual training, cooking, and sewing have made rapid progress toward assured positions in the curriculum, while the most wholesome and educative work of all, work in the fresh air and sunshine, with the soil and growing things, practical gardening, has lagged behind. In Europe, according to $\mathrm{Mr}$. Clapp, there are eighty-one thousand school gardens from Sweden to Switzerland. As long ago as I 887 a decree was passed in France by which no plan of a school building could be accepted unless a school garden was attached. "The absence of the school garden is the most radical defect in our êlementary education." 1

The form a school garden should take, the things planted in it, and the sphere of its influence in the education of a neighborhood must, of course, vary with local needs and conditions. Where home gardens are lacking or neglected, nothing can so awaken the children to the resources and possibilities of life and nature. In one case over 80 per cent of the children started gardens of their own at home, and many of the parents, mostly foreigners, sought information through the teachers as to where seeds and garden supplies could be obtained.

Even where home gardens are all that could be wished or desired, the school garden can furnish opportunities for such class lessons in soils, soil preparation, and fertilization, methods of planting seeds, methods of propagating fruit and forest trees by seeds, cuttings, buds, grafts, and layers, as will be described under those topics, _ pruning, thinning fruit, insects, and fungous diseases. A wild-flower garden

${ }^{1}$ Henry Lincoln Clapp, in Education, May, Igor. 
along one fence with a fernery in a shady corner will afford instruction as to the whole life story of these plants and supply nature study and drawing material, always fresh and near at hand, without the necessity of trespassing on private grounds or robbing waysides.

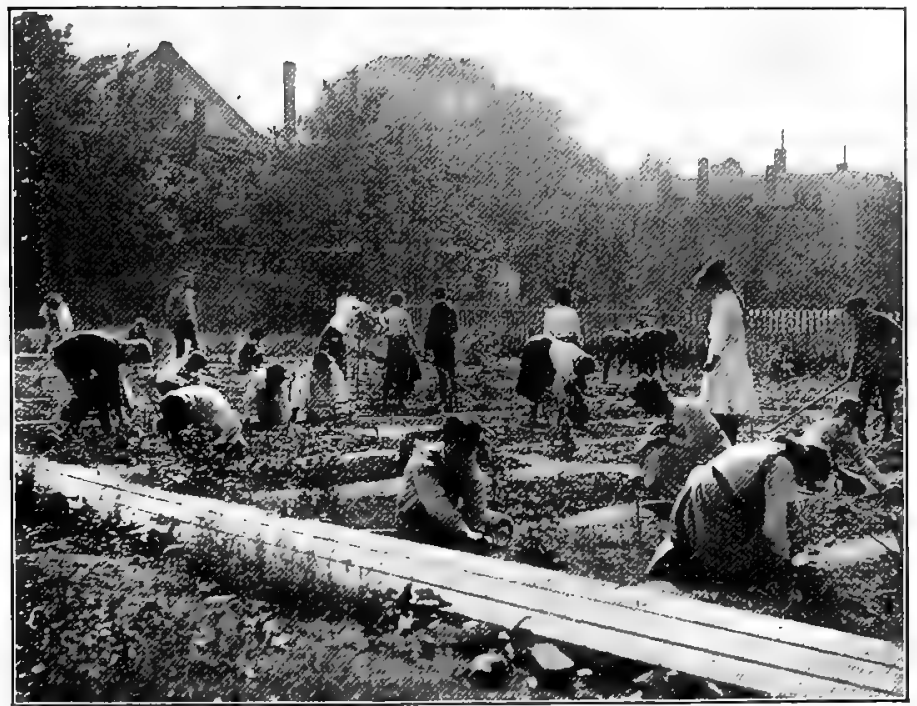

Fig. 55. SChOOL Garden

George Putnam School, Roxbury, Mass. (Photograph by Henry Lincoln Clapp)

I do not wish to be understood as advocating any serious encroachment by the school garden on the playgrounds. Trees are not only ornaments but additions to playgrounds and might well be selected with some regard to instructive and pleasing variety and especially to attracting birds. A list that might meet these requirements will differ greatly with soil, locality, and available space. 
The list that I would select, conditions being favorable, might be the following, in order; that is, if room was sufficient for but one, take the first, if sufficient for three, the first three, and so on.

I. Mulberry.

2. Asiatic Wild Apple, Pyrus baccata, with the European Wild Apple, $P$. malus, planted beside it or grafted to one of the main branches.

3. Hackberry.

4. Red Cedar.

5. Black Cherry.

6. One of the improved chestnuts, Paragon, Numbo, or Parry's Giant.

7. Hickory Nut.

8. Black Walnut.
9. Butternut.

Io. An Oak.

I I. White Pine.

I2. Native Wild Crab Apple.

I3. Sassafras.

I4. Tulip Tree.

I 5. Sycamore.

I6. Soft Maple.

I 7. Hemlock.

r8. Larch.

19. A Spruce.

20. A group of White Birches.

21. Purple Beech.

22. A Locust.

23. Linden.

24. An Ash.

There is apt to be so much monotony in street and public park planting that the school garden may well contain trees that are less commonly seen.

For the fruit garden we should have one, or several, if there is room, of each of the standard fruits - peach, pear, plum, apple, quince, grape, cherry-the best for the locality ; or several varieties may be grafted into one tree, for experiments in cross-pollination. A number of the bush fruits - raspberries, blackberries, currants, gooseberries, and strawberries - might furnish instructive materials, but it should be remembered that they ripen during the summer vacation and hence belong more properly in the home gardens. 
The school grounds often afford opportunitics for lanclscape gardening. Flowers may be arranged in harmonious and pleasing combinations of color and against suitable backgrounds of shrubbery. The trees may be grouped naturally to form artistic pictures. The building, if practicable, can be covered with woodbine and

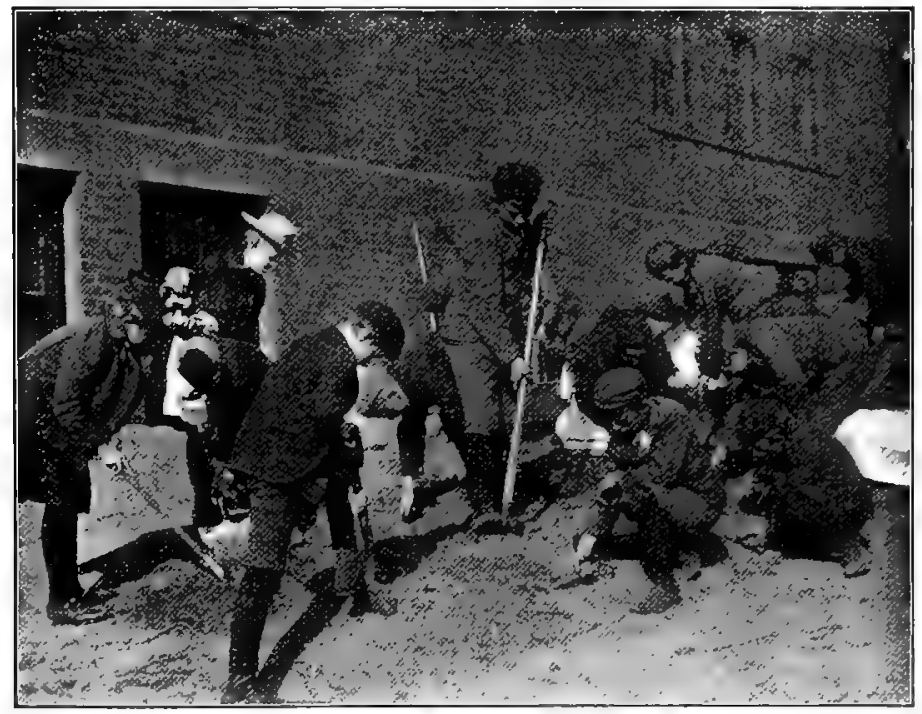

Fig. 56. Portion of Seventh Grade Garden Upsala Street School, Worcester, Mass.

ampelopsis, with wistarias and bignonias, actinidias and honeysuckles interspersed, and with climbing roses trained about the lower windows. Thus the school may be made an attractive place, supply material for practical instruction, and at the same time elevate the taste of a community. 
The A, B, C of Landscape Gardening. - When we study the way Nature plants her trees and vines, the principles of good arrangement become simple matters. $A$. Leave open glades for sunshine and air. $B$. Plant in masses, in natural groups, so as to form pleasing pictures for different seasons; and, combining this principle with $A$, leave open vistas toward beautiful views and cover unsightly features of the landscape. Flower beds are much more effective when framed in a suitable background of foliage than when planted in open spaces. $C$. Avoid straight rows wherever possible; Nature never plants that way; it is stiff, monotonous, and tiresome.

Study and discuss with the class specimens of good planting in the neighborhood. Little trees may look lonesome at fifty feet apart; but measure the spread of large trees of different kinds. We need to acquire the power to look ahead twenty, fifty, a hundred years when we plant trees. Failing to do this, people of ten plant too close to the house, and the trees grow up and bury it in shade so dense as to invite dampness and decay. In consequence they are obliged to cut them down in their prime. Leave open vistas toward the sunrise and sunset; plant a heavy mass of deciduous trees to shield the house from the noonday and afternoon sun; arrange the evergreens on the north, where they may break the force of storms but not cut off the winter sunshine. In groups the trees should stand good hammock-distances apart.

The school garden can also supply ethical culture where it is most needed. A small fraction of the community, with uncultivated tastes and with little regard for the rights of others, may practically render impossible its best 
horticultural development. It may seem to some like flying in the face of Providence to plant fruits in the school garden, but this is just the thing to do. It is the only rational way of "taking the bull by the horns." One school, within my knowledge, in which this theory was given a trial raised peaches, and the children sold them to buy books for the school library. Not a peach was stolen. In another school in which a similar experiment is being tried the juvenile vandalism that made pursuit of horticulture almost impossible disappeared completely after the first year.

Wherever possible, besides the general features described, each child should be given a plot, where he can plant whatever he pleases. This will serve to develop individuality, and the condition of the plot will be the natural index of what a child knows and is able to do by himself.

By being content to begin in a moderate, sensible way, by planting those things adapted to local conditions and needs, and varieties that will flower or fruit either before the middle of June or after the first of September, a school garden is reasonably sure to grow in favor. And "the most radical defect in our elementary education" may be soon supplied. 


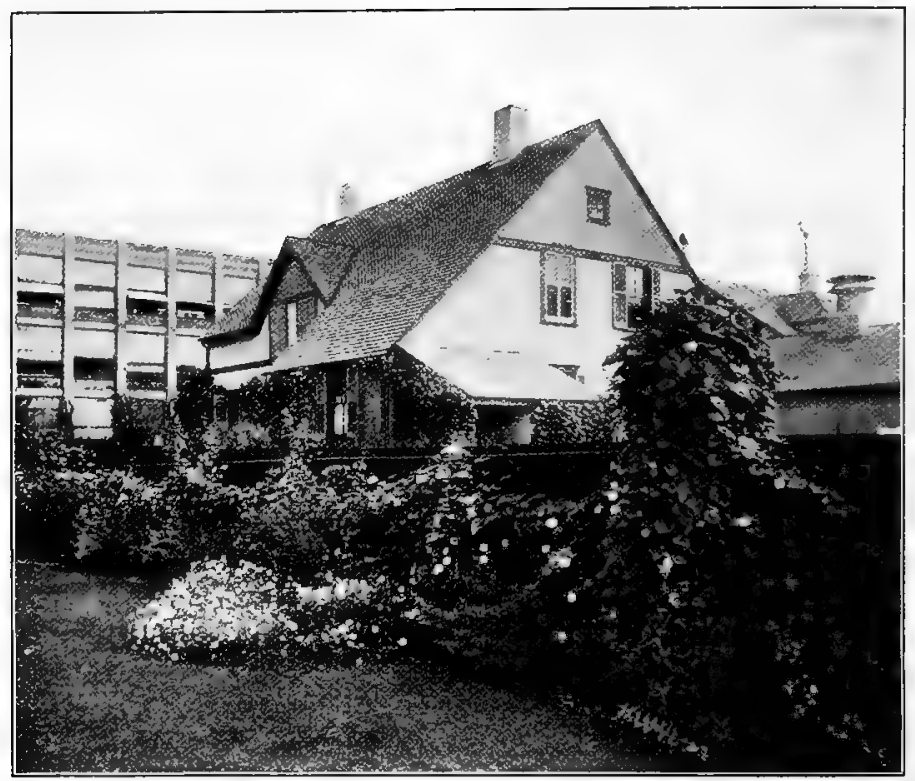

Fig. 57. Example of Tasteful Plantine

(By courtesy of the National Cash Register Co., Davton, Ohin) 


\title{
CHAPTER IX
}

\section{NATURE-STUDY PROPERTY OF CHILDREN}

\author{
Flowers and Vegetables
}

At Noey's house when they arrived with him How snug seemed everything, and neat and trim:

With little paint-keg, vases and teapots Of wee moss-blossoms and forgetmenots : And in the windows, either side the door, Were ranged as many little boxes more Of like old-fashioned larkspur, pinks and moss And fern and phlox; while up and down across Them rioted the morning-glory-vines On taut-set cotton-strings.

James Whitcomb Riley, $A$ Child World.

IN order to develop the educational values connected with the plants children are trying to rear at home we must first know what they are. For a simple language lesson, ask each pupil to write a list of what plants he owns. This will, of course, result in a mass of unclassified data that the teacher must arrange and tabulate before it becomes usable. This entails an unnecessary amount of labor, and a better method is to have blanks with the names of the commoner sorts printed in order on sheets of school writing paper. The data will thus be uniformly arranged by the children themselves, and the teacher can keep them on file as a basis for assignment of lessons on 
any plants that it may be desirable to study. Each group of teachers, of course, will have to decide on the exact list of plants best suited to the locality. Three of these blanks will probably be found useful, one for flowers and ornamental plants, one for the vegetable garden; and one for fruits; but by including fewer varieties these may be all printed on a single blank. However, in the present low condition of our horticultural life, the printing of as many names of plants as possible may serve as a most valuable means of calling the attention of the children to desirable varieties to plant.

In graded schools these blanks might be passed along to the teacher in the next higher grade as the children are promoted. (See next page.)

The object of the lessons should be simply the culture of flowers with reference to the highest enjoyment of them. With blanks properly filled out the teacher has in hand the resources of the class for future lessons. Plan with reference to seasons of blooming and planting, begin with such as the greatest number of children have, invite them to bring in of each kind enough, if practicable, to supply the class and teacher with specimens, including buds, open blossoms, and seeds. Some of these may be kept in the school collection. Then let the children recite on methods of culture, compare notes as to best methods, appealing to quality of the specimens in hand, discuss form and colors, enjoy together the fragrance, and call out anything that the children have noted as to the insects or humming birds that visit the flower. Finally, question the class about the insect enemies that make culture of the plant difficult, and the fungi, blights, and mildews that attack it. 


\section{Nature-Study Property — Flowers}

School.

Grade.....

Date.

Name

Age.

Home rented or owned.

Note. - Without rewriting the names, each pupil will indicate the number and variety of each, if known, and if unknown indicate this by a (?).

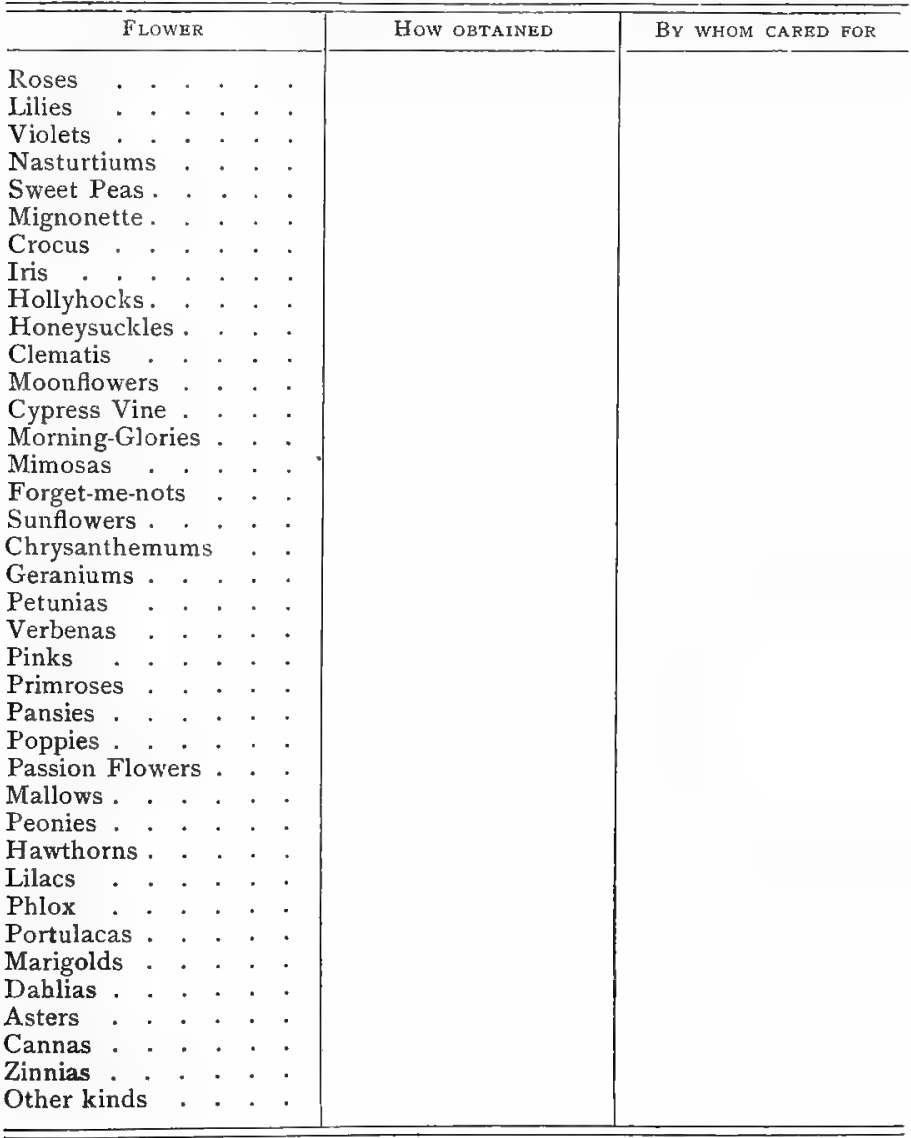


The best text-book for this work is any first-rate floral catalogue, and the best book for reference, which should be supplied as a desk book to the teacher, is the book on horticulture and landscape gardening that best applies to the region as to climate and local conditions.

Must the teachers, then, learn all this and tell it to the children? Far from it. They need only the sincere love of flowers and the first rudiments of their culture; and then to have judgment enough not to try to tell the children even half they know. The very breath of life for a healthy, vigorous child is original investigation; and to stuff the memory faster than the power to think and the will to do are developed, is the quickest road to mental indolence. "Yes, but they will ask all sorts of questions," says the timid teacher who is afraid to say "I don't know." Well, then, questions are the best things in the world to play ball with. They are too good to break by answering. Toss them back to the class.

"Alice asks how deep to plant her tulip bulbs. How many know?" A dozen hands go up. "John, will you tell us how deep to plant tulips?" John: "About a foot deep." More hands go up. "No! no! no!" the children are saying to themselves, and John gets red in the face. "How do you know tulips should be planted a foot deep, John? Did you ever plant any?" "No, ma'am." "Well, then, you don't know but only guessed about it, John; is that true?" "Yes, ma'am." "Well, perhaps we had better not waste any more time guessing. How many raised tulips last year?" Hands again go up. "Mary, will you please tell us how deep you planted yours?" "I planted my tulips six inches deep." "Did they grow well?" "Yes, they all came up the next spring, and every one blossomed." "How many agree that six inches deep is about right to plant tulips? Well, every one seems to think you are right. Mary, how did you find out?" "I saw Mrs. Johnson planting some one day and watched 
her do it, and she said that they must be planted six inches deep. Her tulips always grew so well I thought she must know. Then I read it again in a flower catalogue, and I have tried it myself."

So every question is a prize, a living, bursting bud; be careful of it. Make the most and best of it. If the children are really doing something, there will be no end of questions with real purpose in them, and the naturestudy period will be the liveliest, most quick-witted and mutually helpful, and the happiest lesson of the day. If they are not actively doing something with nature at first hand, as Froebel says, all will be dull, empty, lazy, dead, and no teacher can lift the load.

Do not harshly repel him; show no impatience about his everrecurring questions. Every harshly repelling word crushes a bud or shoot of his tree of life. Do not, however, tell him in words much more than he could find out himself without your words. For it is, of course, easier to hear the answer from another, perhaps to only half hear and understand it, than it is to seek and discover it himself. To have found out one fourth of the answer by his own effort is of more value and importance to the child than it is to half hear and half understand it in the words of another; for this causes mental indolence. Do not, therefore, always answer your children's questions at once and directly; but as soon as they have gathered sufficient strength and experience, furnish them with the means to find the answers in the sphere of their own knowledge. Froebel, Education of $\operatorname{Man}, \mathrm{p} .86$.

But suppose, as often will occur, the question is one that no one knows anything about. If reasonably within their "sphere of knowledge," call for volunteers. Who will try to find this out and tell us about it? The thing we need to develop most in our public education is individual initiative, power to think and do-resource. If 
the question is too hard to answer in a day or a week or a year, so much the better. If it be one worth while to work at for a lifetime, so much the better. You may have given a life work, the highest prize a teacher can ever give a pupil. It may make the difference between a life worth living and not worth living. ${ }^{1}$

A blank for the vegetable garden similar to that for flowers may be prepared about as on the opposite page.

${ }^{1}$ Blessed is he who has found his work ; let him ask no other blessedness. He has a work, a life-purpose; he has found it, and will follow it ! How, as a free-flowing channel, dug and torn by noble force through the sour mud-swamp of one's existence, like an ever deepening river there, it runs and flows; - draining off the sour festering water, gradually from the remotest root of the remotest grass-blade; making, instead of a pestilential swamp, a green fruitful meadow with its clear-flowing stream. How blessed for the meadow itself, let the stream and its value be great or small! Labour is Life. From the inmost heart of the Worker rises his God-given Force, the sacred celestial Life-essence breathed into him by Almighty God; from his inmost heart awakens him to all nobleness - to all knowledge, "self-knowledge" and much else, so soon as Work fitly begins. Knowledge? The knowledge that will hold good in working, cleave thou to that.' Properly thou hast no other knowledge but what thou has got by working : the rest is yet all a hypothesis of knowledge : a thing to be argued in schools, a thing floating in the clouds, in endless logic-vortices, till we try it and fix it. "Doubt, of whatever kind, can be ended by actions alone."

Work is of a religious nature:- work is of a brave ... nature; which is the aim of all religion to be. All work of man is as the swimmer's; a waste of ocean threatens to devour him; if he front it not bravely it will keep its word. By incessant wise defiance of it, lusty rebuke and buffet of it, behold how it loyally supports him, bears him as a conqueror along. "It is so," says Goethe, "with all things that man undertakes in this world." Carlyle, Past and Present, p. Igo. 


\section{Nature-Study Property - Vegetable Garden}

School ............................ Grade ............ Date.

Name Age

\section{Home rented or owned.}

NOTE. - Without rewriting the names, the pupil will please indicate the quantity, amount and variety, if known, of each.1

\begin{tabular}{|c|c|c|c|c|c|c|}
\hline Name o & $\mathrm{oF}$ & Plant & & & $\begin{array}{l}\text { How is SEed or } \\
\text { Stock OBtaINED? }\end{array}$ & BY WHOM CARED FOR? \\
\hline Artichokes . & & $\cdot$. & - & . & & \\
\hline Asparagus . & . & .. & - & . & & \\
\hline Chives . & - & . . & . & . & & \\
\hline Cabbage. . & - &. & - & . & & \\
\hline Caulifiower. & & .. & - & - & & \\
\hline Celery . . & & $\cdot$. & . & . & & \\
\hline Cress. . & & $\cdot \cdot$ & $\cdot$ & $\cdot$ & & \\
\hline Cucumbers . & & $\cdot \quad \cdot$ & . & . & & \\
\hline Eggplant . & & $\cdot \cdot$ & . & . & & \\
\hline Lettuce . . & & $\cdot \cdot$ & $\cdot$ & . & & \\
\hline Mushrooms & & . $\cdot$ & . & . & & \\
\hline Melons . . & & $\cdot \cdot$ & - & . & & \\
\hline Onions . & & $\cdot$. & $\cdot$ & - & & \\
\hline Parsley . & & . . & . & . & & \\
\hline Radishes & & $\cdot$. & . & . & & \\
\hline Squashes & • & $\cdot \cdot$ & . & . & & \\
\hline Tomatoes & & $\cdot \cdot$ & . & . & & \\
\hline Sage. . . & & $\cdot \cdot$ & - & . & & \\
\hline Anise. . & & $\cdot \cdot$ & . & . & & \\
\hline Rhubarb . & & $\cdot \cdot$ & - & . & & \\
\hline Other Plant & & .. & . & . & & \\
\hline
\end{tabular}

1 It may be objected that I have left a number of the commoner sorts out, notably beans. Of course, in preparation of these blanks for use, each group of teachers must again decide for themselves, according to local interests and conditions. The greatest danger in the lessons will be the cut-and-dried, "systematic" inclusion of things too commonly known to be anything but dull and unprofitable. And where garden work is all that it should be in a neighborhood, where the children are carrying it along with success and enthusiasm, most of it may safely be left in charge of the children and the home.

New and choice varieties of common vegetables may be brought to attention of the school, and knowledge about them thus be disseminated through the neighborhood. Insect enemies and fungous diseases of even the commonest things will also furnish many valuable lessons. 


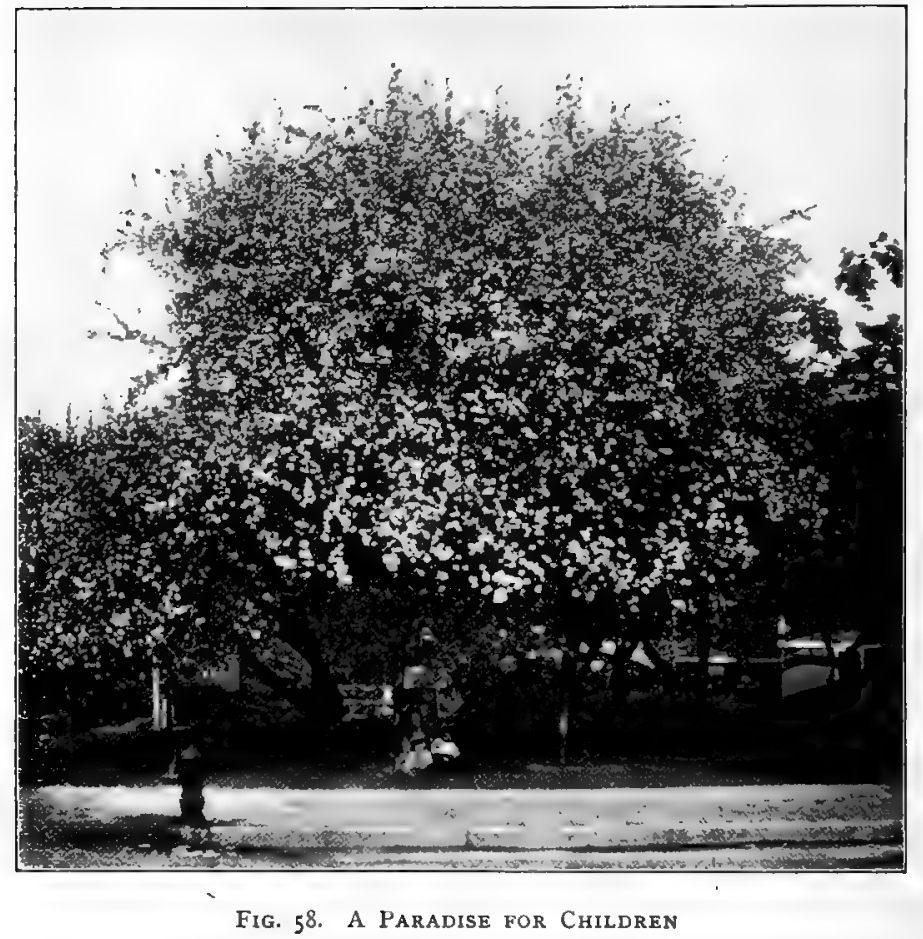




\section{CHAPTER $\mathrm{X}$ \\ NATURE-STUDY PROPERTY (Continued)}

\section{GARDEN FruITS}

WE must have recourse to our blanks again in order to find out what the children have for this most fascinating field of study and work. The fruit-blank may be arranged somewhat as indicated on the following page.

With either the rich or the poor, every fact learned about fruits, their qualities and culture, may be of lifelong value. To know how to grow any fruit to highest perfection opens up a noble and useful life work. Improvement of varieties by judicious cross-pollination is a bounclless field for intelligent experiment and patient work; and a gain of even a small margin in quality, color, flavor, and size of any standard fruit is a service to mankind that cannot be calculated in money. This work represents one of the most ancient and noble struggles of man to regain paradise, and it will go on as long as human life exists upon the earth. No sooner has a "best" variety been produced than by judicious breeding a better may be obtained. Until recently this progress has depended mainly upon accidental seeds. A seed gains a foothold and some wise, thoughtiul man notices that it produces fruit better than its kind. He cares for it, and within a few years every garden in the land or zone may be reaping the benefit of his work. 


\section{Nature-Study Property - Fruits}

School

Grade

Date

Nane

Age

Home rented or owned ${ }^{1}$

Note. - State after each the number you own and variety, if known.

\begin{tabular}{|c|c|c|c|c|}
\hline FRUITS & & BY WHOM PLANTED & CARB GIVEN YEARLY & CROP PRODUCED \\
\hline $\begin{array}{l}\text { Apples } \\
\text { Apricots : } \\
\text { Blackberries } \\
\text { Cherries . } \\
\text { Currants . } \\
\text { Gooseberries } \\
\text { Grapes . } \\
\text { Mulberries } \\
\text { Nectarines } \\
\text { Peaches . } \\
\text { Pears . . } \\
\text { Plums . . } \\
\text { Quinces . } \\
\text { Raspberries } \\
\text { Strawberries }\end{array}$ & 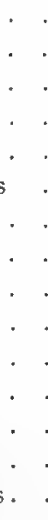 & & & \\
\hline
\end{tabular}

Fruit culture, furthermore, forms the natural center for interests in many other things. Innumerable insect friends and foes await acquaintance, whose common names refer to the trees about which they may be found: the

${ }^{1}$ In these different blanks I have placed the question "Home rented or owned" for several reasons. To some this, at first sight, seems needlessly prying into home matters. But no general publicity need be given to the answers, and the data secured will be of great sociological value and will assist the teacher in advising the child with reference to what to plant. It may, of course, be omitted if desired. 
apple worm, apple maggot, apple and plum curculios, apple-, peach-, and cherry-tree borers, grape sphinx moth, grape berry moth, and so on through a long list. If the children have trees and vines, there will be no lack of interest and materials for insect studies. From this they will also gain a practical insight into the work of birds and other insectivorous animals, and appreciate the need of protecting them and attracting them to their homes; and they will be glad to study the work of bees in carrying pollen from flower to flower. Finally, they will at least be awakened to see the value of knowledge about the blights and mildews and other fungi that now make fruit culture so difficult.

Wherever I go I find common knowledge of the best varieties of fruits falling out of the public mincl. It is certainly little enough to ask of nature study that it keep alive this ancient and beneficent tree of knowledge, root, trunk, and branch.

To begin with, set a series of composition lessons upon each of the more important of the fruits commonly raised in the vicinity, asking the pupils to name all the varieties they know. Let them describe each as to vigor of growth, color, size, shape, flavor, fragrance, quality, origin, uses. This will open the eyes of both teachers and pupils to how little is commonly known of such matters.

In proper season the liveliest lessons may be arranged by asking the class to bring in specimens of all the varieties of a certain fruit they have. Let the children smell, taste, and handle them, and discuss which is the best kind for different purposes. Make a practical fruit show of it, a game of "bests," to learn not only the best 
variety, but also who can raise the best specimens of a variety. How did he succeed in doing it ?

In connection with these exhibitions and lessons the teacher should have on his desk the latest revised Catalogue of Fruits. ${ }^{1}$ He should not allow the pupils to see it until they have guessed which is the best fruit of the kind they have before them - apple, pear, peach, plum, grape, etc. - known in the world.

This Catalogue of Fruits represents the combined efforts and the best judgment of the members of the American Pomological Society, the men, living in every part of the country, who are best skilled and most deeply interested in advancement of American fruit culture. It is arranged so that he who runs may read. It contains a map with all the various fruit belts or districts clearly indicated and numbered, and then follow tables that give more modern information on American fruits than could be found in all the horticultural libraries.

From these tables we are able to read at a glance a description of each fruit, under its accepted name, giving its size, form, color, flavor, quality (marked on a scale of Io for best), season, use, origin, and the region where it grows to greatest perfection. It is an interesting exercise simply to read the names of these fruits over to a class in order to realize how few we know practically and how little people in general know about them. It is not to be expected that every one will agree with all the estimates given by the American Pomological Society, but

1 Revised Catalogue of Fruits recommended for Cultivation in the Various Sections of the United States and the British Provinces, United States Department of Agriculture, Washington, D.C., I899. Every teacher should be furnished this or should get it by ordering it, with five cents inclosed, from Superintendent of Documents, Union Building, Washington, D.C. 
differences of opinion are valuable to set people to investigating and exercising their judicial powers.

I will give for some of the standard fruits only those that are scaled Io for quality, i.e., the very best known and of such preëminent excellence as to deserve the mark, with a few others for comparison. (See next page.)

While it may not seem worth while to a child to try to rear a peach tree, grapevine, or other fruit, knowing as little as he does about them, give him the idea that this is the best thing of its kind in the world, and await the result.

In case the children have no fruit trees of their own, which, I regret to say, will generally be the case, it may take two or three years to get this work well under way. ${ }^{1}$ But the school may be a great means of inducing children to get things of their own, of helping them to secure the varieties they wish, and it may furnish the natural channels through which scions, cuttings, buds, seeds, and plants may be distributed and exchanged throughout the neighborhood. Horticultural exhibits and fairs may be utilized for studying varieties to excellent advantage.

Next to study of varieties of fruits comes naturally the knowledge of best soil, treatment, care, food supply,

1 Every home garden is, of course, a garden of "bests" in accordance with its owner's knowledge and tastes. Too often, however, it is filled with such comparatively worthless things as to awaken no interest on the part of children and to give the impression that they are not worth taking care of. But in every neighborhood some one may be found who knows something about these things and has the best garden and orchard of the vicinity in at least certain features. Get his permission to take the class, giving all assurance that nothing shall be stepped on or injured, to his garden when various fruits are in their prime, or when instructive work is going on,-pruning, fertilizing, grafting, budding, etc. I can see you smile at this, but try it. 


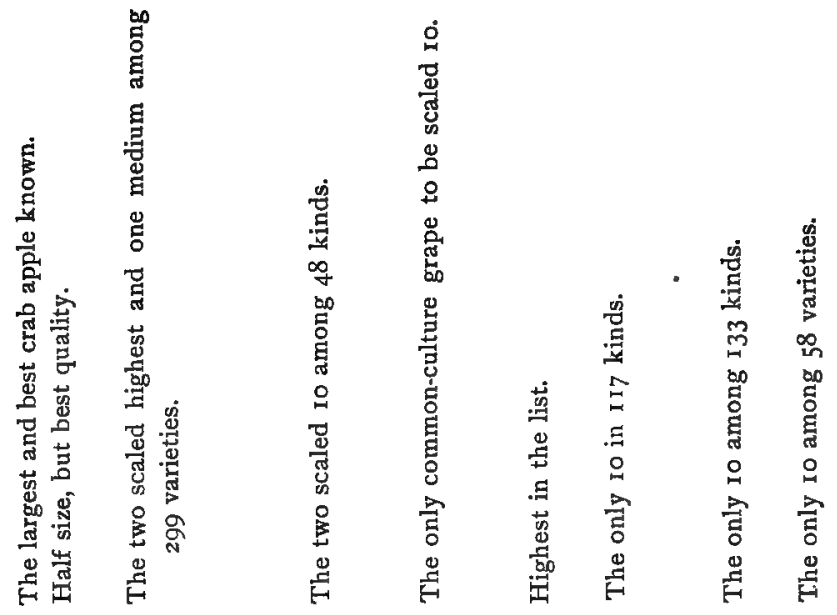

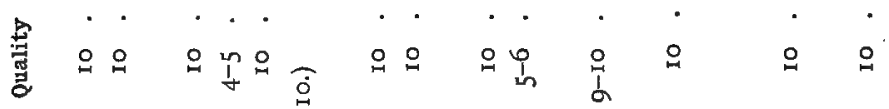

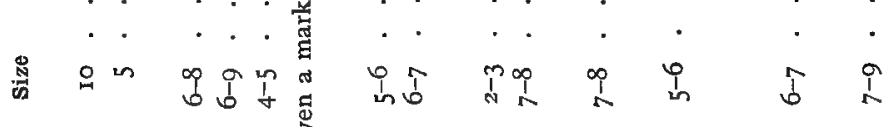

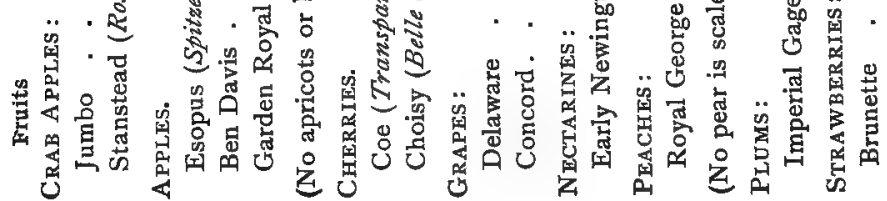


and methods of culture for each. Many points of interest in all these connections will come up during the fruit shows, and while the specimens are being compared it is just the time to ask: How did you do it? Did you thin the fruit? How did you prune the tree? How did you keep the insects off? What do you feed your trees? and so on. Of course most of these topics are matters for lifelong study, and though it may not be possible to do as much with them as you wish, are they not better on this account? 


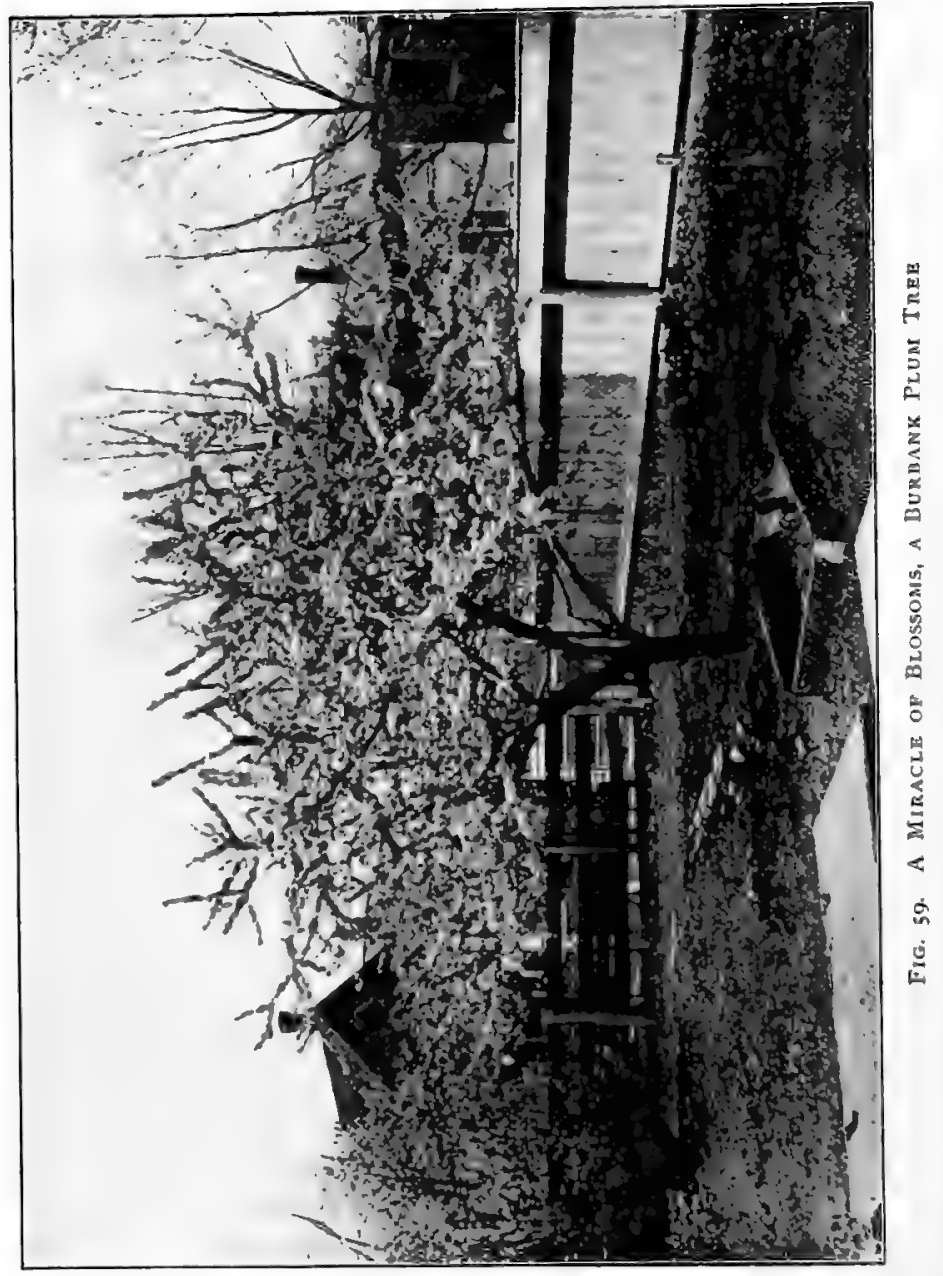




\section{CHAPTER XI}

\section{PROPAGATION OF PLANTS}

Seeds, Layers, Cuttings, Grafting, and Budding; Transplanting

The Seeds. - First have each member of the class make a neat collection of the seeds of all the fruits - crab apple, apple, pear, peach, plum, strawberry, etc. -- given in the preceding list, or of as many as possible. A lesson or two may be devoted to mounting these neatly in vials or on cards. Label them in such wise that they may be used for tests to see whether the children can distinguish the different seeds at sight.

We may next ask each of the children to bring in a number of fruit seeds for observations and experiments in germination. Certain seeds are naturally better adapted to these studies than others. Still, any which have local importance may be used; and so few children have ever seen the germination of some of the smaller seeds - strawberry, raspberry, grape, etc. - that these may prove the most instructive of all, especially in sections where their culture is a prominent industry. If time allows the use of not more than one seed for these studies, the peach will probably be the best in all sections where its culture is possible; but with just this seed the greatest care must be taken to be sure that it is from vigorous stock and not 
contaminated by the disease "peach yellows," that has desolated the orchards in so many sections of this country. So serious is this danger said to be, since peaches are shipped from diseased orchards to all parts of the country, and "yellows" peaches are not infrequently seen even in horticultural fairs, that it will be much safer to purchase the peach seeds from reliable nurserymen or from the State Experiment Station. The peach is placed first on account of its large seed, its beautiful and rapid growth, the short time before it comes into bearing, and the need of stimulating and popularizing culture of this valuable fruit.

The object of this work in germination is to raise plants that may be used for lessons in budding and grafting and for distribution throughout the neighborhood, and its needs and possibilities must naturally determine the number of seeds planted. A secondary purpose is to give each child a chance to see one of these plants start out in life, and, even if the district be fully stocked, to have a single pot of fruit-tree seedlings in a schoolroom will serve to keep this lore alive in the hearts of the children and prove a most suggestive bit of nature-study equipment.

The first general topic is naturally methods of saving and germinating the different seeds. This may be most conveniently stated in the form of a table. (See next page.)

The chief lesson to be learned from seed propagation is that new varieties of fruits are secured in this way. The seed of a Baldwin apple, for example, will not produce a Baldwin. It may be a better apple, but the chances are thousands to one that it will not be as good. The original apple, Pyrus malus, from which our cultivated varieties are 
derived, is a little fruit less than an inch in diameter, now growing wild over southern and central Europe, mixed with cultivated apples. Its earliest home was probably the region south of the Caucasus along the Black and Caspian seas. Small forests of these trees still occur in that country. These apples were known and used and probably cultivated long before authentic history began. They were dried for winter by the Swiss lake-dwellers,

\begin{tabular}{|c|c|c|}
\hline VARIETY & Method of Saving Seed & $\begin{array}{c}\text { Method and SEASON OF } \\
\text { PLANTING }\end{array}$ \\
\hline $\begin{array}{l}\text { A pple, Apricot, } \\
\text { Cherry, Nectarine, } \\
\text { Peach, Pear, Plum, } \\
\text { Quince. }\end{array}$ & $\begin{array}{l}\text { Remove from fruit } \\
\text { and, if necessary to keep } \\
\text { over winter, mix with dry } \\
\text { sand and store in a cool } \\
\text { cellar. Or put under a } \\
\text { flat stone out of doors } \\
\text { and leave over winter. }\end{array}$ & $\begin{array}{l}\text { Without allowing to } \\
\text { dry, plant from one to } \\
\text { two inches deep in } \\
\text { deeply spaded seed bed, } \\
\text { well drained so that water } \\
\text { will not stand over it } \\
\text { during the fall or winter. }\end{array}$ \\
\hline $\begin{array}{l}\text { Blackberries,Grapes, } \\
\text { Currants, Gooseber- } \\
\text { ries, Mulberries, } \\
\text { Raspberries, Straw- } \\
\text { berries. }\end{array}$ & $\begin{array}{l}\text { Wash clean from pulp, } \\
\text { partially dry, and, if de- } \\
\text { sired, store in a cool } \\
\text { place until the following } \\
\text { spring. }\end{array}$ & $\begin{array}{l}\text { Plant when ripe, or } \\
\text { the following spring, in } \\
\text { fine loam from one- } \\
\text { fourth to one-half inch } \\
\text { deep. }\end{array}$ \\
\hline
\end{tabular}

and it has been shown that they knew two varieties of apple back in the stone age, before they had discovered any metals. Fig. 60 shows in outline one of the latest achievements, the Bismarck apple, originated in New Zealand, and the little wild apples of thousands of years ago.

This gain has all been made by planting apple seeds and taking good care of the trees. And of those who have the patience and perseverance to plant the necessary thousands of seeds, - for they tend so strongly to fall back to the little wild apple from which they sprang, — and to care for 
them until they bear fruit, the one who finally discovers an apple better in some respect than all the rest, has become a benefactor of mankind; for from the billions on billions of apple seeds that have been ripening for thousands of years we have only 299 kinds, some poor, some fair, some good - a few very good - only two best. We cannot see

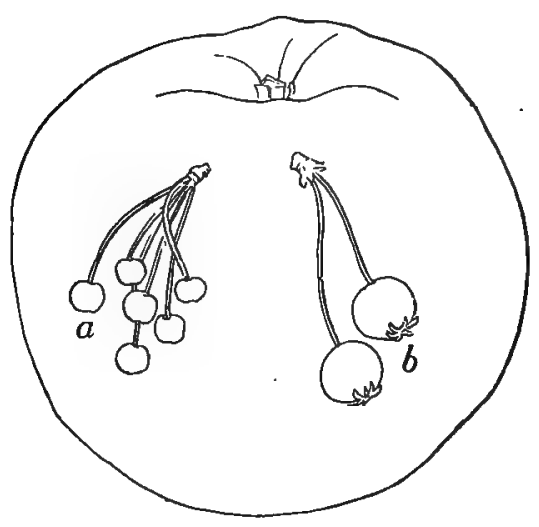

Fig. 6o, Bismarck Apple $a$, the wild Asiatic crab apple, Pyrus baccata; $b, P$. malus, the wild apple of Europe.

(All $\frac{1}{2}$ natural size) deep enough into the heart of nature to know just what benign influences joined hands to produce these "bests." But two apple blossoms on two different trees must have set out to make the best seeds in all the world; the rains and the dews and the winds were just right that year, the soil was good, a bee carried pollen from one blossom to the other, and a bird guarded the fruit from devouring insects, and finally some child, who knows? - ate the apple and planted the seed in good soil.

Taking the hint from nature's ways, men have at last begun to make careful experiments in "plant breeding." Read or tell to the children the stories of John Chapman, better known as "Johnny Appleseed," who supplied the early settlers in Indiana and Ohio with apple seeds and 
apple trees; of Ephraim Bull, of Concord, who originated the Concord grape; and of Luther Burbank, "the wizard of plants," who has given to every garden in the land some of its choicest varieties of fruit, ${ }^{1}$

The theory and method of procedure are comparatively simple. Select the two plants, trees or flowers, that you wish to breed. Be sure they are healthy, vigorous, and grown to the highest perfection possible. In general, it is best to have the female of a kind preëminent for robust growth, while the male possesses the color, fragrance, or flavor that you wish to perfect. Next choose a well-placed bud, or cluster of buds, about equally advanced on both plants. Before they open, carefully tie a paper bag over the buds from which you inter,d to take the pollen. From the female flowers, also before they open, remove all the stamens, and in like manner cover them with a paper bag. When the anthers of the male flower open, indicating that their pollen is ripe, remove the pollen with a clean soft brush and clust it thoroughly over the stigma of the other flower. Replace the paper bag over the female flower. Let it remain covered until the seeds begin to grow, when the bag should be taken off. Then make a careful note of exactly what you have done, giving the varieties used, which one was taken for pollen and which for stigma, and the date and methods of culture given

"For "Johnny Appleseed," see Ohio Archroological and Historical Quarterly, January, I901, p. 303 .

For references to Mr. Bull, see Massachusetts Agricultural Reports, $1850-1860$; =lso article on "Progress of Plant Breeding in the United States," Yearbook, Department of Agriculture, 1899.

For a recent note on Luther Burbank and his work, see American Gardening, vol. xxi, p. 35, 1900. 
to the plants. The best of memories are apt to play all sorts of pranks, and this is only a safe and easy precaution. Label the flower, so that there can be no possibility of mistake. When the seeds are ripe, plant them carefully in soil that has been thoroughly baked, or that you are sure does not contain a single seed of the kind you are to plant in it. With such seeds the chances are

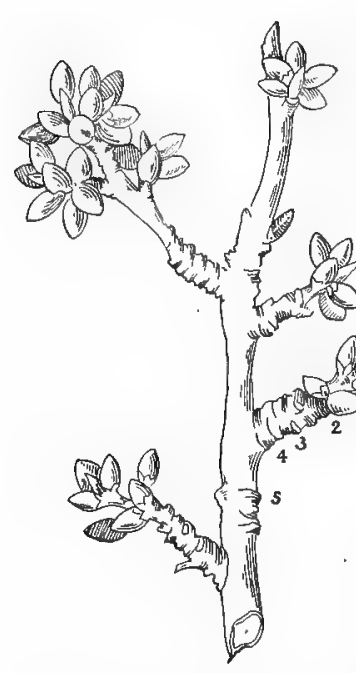
greater that you may rear a flower or fruit that combines the qualities of both parents and is possibly the finest of its kind in the world.

Fig. 6r. Cherry 'Twigs of Burbank plum there were I 73, on A growth shoot and fruit spurs. a Royal George peach, 240, on a $1,2,3,4,5$, yearly growth rings; $t$, terminal buds; $l, l$, lateral or leaf buds. A pointed leaf bud may be seen in the center of each cluster of fruit buds

Niagara grape, 9I. A bud, except a fruit bud, is in possibility a tree of its kind. The buds on a tree produce shoots or trees that vary little if at all from one another; so, in order to multiply a desirable variety, we have only to place its buds where they may grow. 
If a bud produce fifty buds a year, and each of these produce fifty buds, and so on, how many buds will there be at the end of the fifth year? Ans. 312,500,000.

Last spring I was glad to pay a dollar for a young Campbell's Early grapevine. Now the vine has thirty-eight buds on it and has produced a second vine from a layer that I bent down and covered with earth early in the summer. The grape is said to be as much better than the Concord as the Concord is better than the wild grape. If this be true, its originator is welcome to the dollar, and I hope he may be a multi-millionaire by this time, as he deserves to be.

Let the children each bring in branches of some kind of tree, preferably a fruit tree, and help them to study the annual growths that it may show. Study with them the two kinds of twigs (growth twigs and fruit spurs) and the different kinds of buds (leaf buds and fruit buds). We shall need to have clear ideas of these when we study how to bud and graft, make cuttings and layers, and prune and feed our trees.

Yearly growths are distinguished by roughened lines around the branch at the position of each successive terminal bud. Beginning with the present year's growth, these may be counted back for four, five, and sometimes many more years. In seasons where a wet, warm autumn follows a drought in summer there are sometimes two distinct periods of growth with all the appearance of the annual markings between them.

With the buds distinguish the large terminal bud, which is to continue the growth of the shoot; the side, or lateral, buds, that are destined to make leafy side branches; and the fruit buds, that are to produce the fruit of the ensuing year. The chief purpose of this study is to enable the pupils to tell a fruit bud from a leaf bud, and a fruit spur 
from a growth shoot; for if they set a fruit bud or graft a fruit spur instead of a tree they will at best get but a single fruit.

Any time after the leaves fall this study of buds may be begun, but it should preferably be put off until late winter, - February or March. If branches bearing both kinds of buds - of apple, cherry, pear, peach, and plum

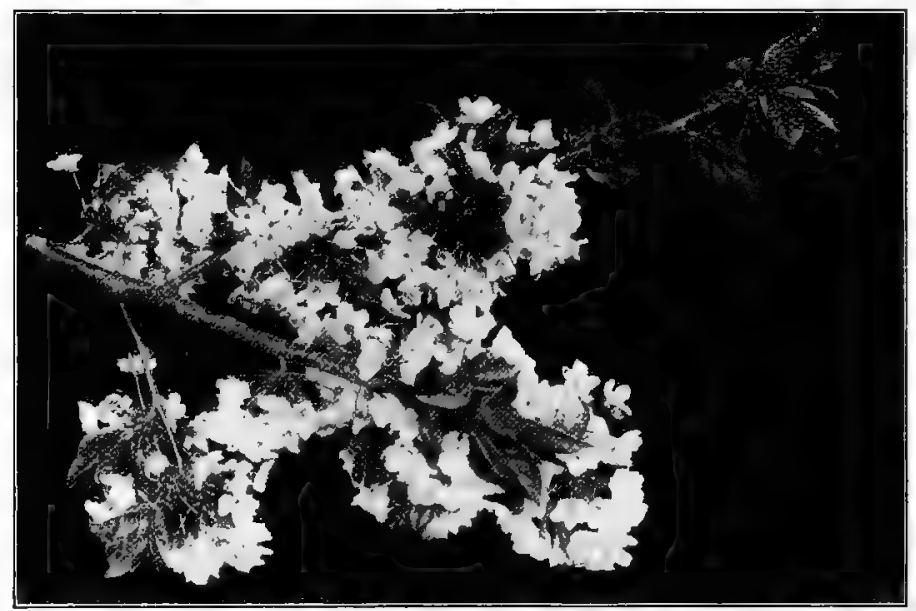

Fig. 62, CherRy TWIGS

The story as told by the buds themselves

- be then set in a vase in a window in the schoolroom, they will soon begin to swell. Fruit buds are plump and short, while leaf buds are slender and pointed. For the lower grades select a twig of the five kinds named above and have the children guess which buds will produce leaves and which blossoms. Tie a red string at the flower and a white string at the leaf buds, and two or three weeks will tell who is right. 
For the higher grades it will be possible to work out two or three trees more carefully. Suppose we have apple or pear, branches, and each child is provided with one about two feet long (Fig. 63); let them, after reviewing the yearly growths, make out the general arrangement of buds, the leaf scars underneath each bud, and the large fruit scars, which show where the branch has borne apples. The position of these will serve to illustrate the characteristic appearance of the fruit spurs, and from the condition of their buds we can tell whether the tree is to blossom the coming spring. With the point of

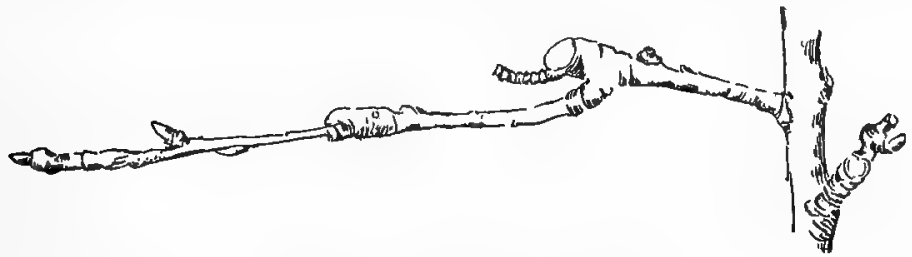

Fig. 63. FRUIT SPURS OF PEAR

Showing rings of yearly growth and enlargements where fruits have been borne

a sharp knife - a needle or pin will do - lift off one by one the scales that cover the bud. If in the center a little clump of knobs is found, we may know that a cluster of blossoms would have come forth in the spring. If, instead, we find a group of slencler points, folded leaf embryos, we know that the bud would have produced such a cluster of leaves as we see on the fruit spurs of an apple tree in the off years. The function of these leaves is to gather food and strength to form a fruit bud for the year to follow.

After thus dissecting a few buds of each fruit, the pupils should be able to tell a fruit bud at a glance; and 
at the end of their work in this subject they should have learned that the apple, pear, plum, and cherry bear fruit upon short scarred spurs or branches of several years'
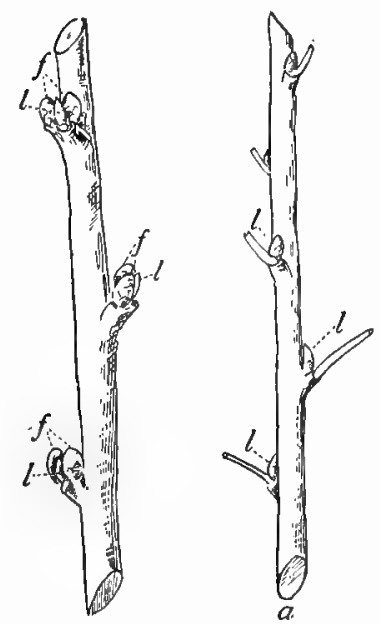

Fig. 64. Peach Twig

Showing fruit buds, $f$, and leaf

buds, $l$. $a$, trimmed to use for budding growth, i.e., on the "old wood," while peaches, apricots, and nectarines produce all their fruits upon wood of the previous season's growth, i.e., upon "new wood." It will be noted further that peach buds often occur in threes, - two large plump buds (fruit buds), with a slender leaf bud between. Higher up the branch we shall generally find large single buds, slender and pointed, and these we shall select for budding.

With the above points clear, and by the aid of the table at the end of this chapter, we shall be able to propagate any fruit in the way best adapted to its culture. It will thus accomplish two objects at once if $\mathbf{I}$ illustrate the various methods by describing the practical rearing of three typical fruits, - the grape, apple, and peach.

How to raise a Grapevine; Cuttings. - Ascertain who in the neighborhood has a vine of the desired variety. As soon as the leaves fall in October, if he knows how to take care of it, he will prune off almost all the new season's growth. Ask him to contribute some of the largest and ripest of these waste canes, cut them into lengths with 
two buds each (Fig. 65), tie in a bunch, and bury six inches deep, butt ends up, in a well-drained spot in the school garden.

As soon as the ground can be worked in the spring; set your cuttings slantingly, about six inches apart, in a row in the propagating bed (see Chapter XXII). They should be pushed down into the soft, fine earth, so that the top bud is flush with the surface, and then covered with an inch of sifted loam, leaf mould, peat, or street sweepings. The buds will readily push through this, and it will retain moisture. If given good care, they will be strong enough to transplant to the place where you wish to have them grow permanently the next spring.

Layers.-You may save from one to two years in the growth of your grapevine by obtaining permission to make a layer of one of the canes still attached to the vine. A layer is formed by bending down a vigorous young shoot, pinning it securely in a little furrow in the ground, and covering it with three or four inches of soil. Roots will start along the covered part of the stem and leaves and branches from the tip, and with the help of the parent Fig.65. GRAPE Cuttings vine for the first season you may have
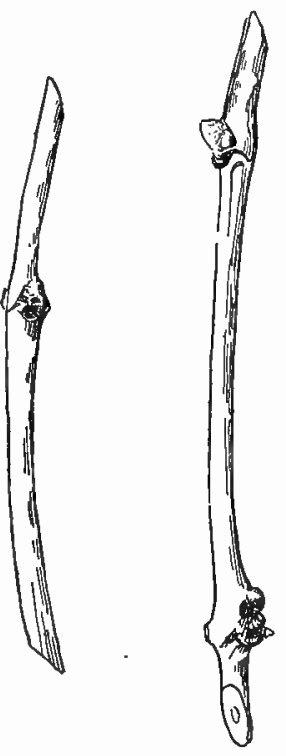
a strong young vine equal to a two- or even three-year-old cutting. If it be impossible to bend the branch down to the ground, you may put the tip through the hole of a 
good-sized flower pot, fasten the pot securely, and fill it with fine, rich soil. This will have to be watered carefully every day in dry weather. By either of these methods you can have a strong vine, which you should sever from the parent and plant where you wish it to grow as soon as the

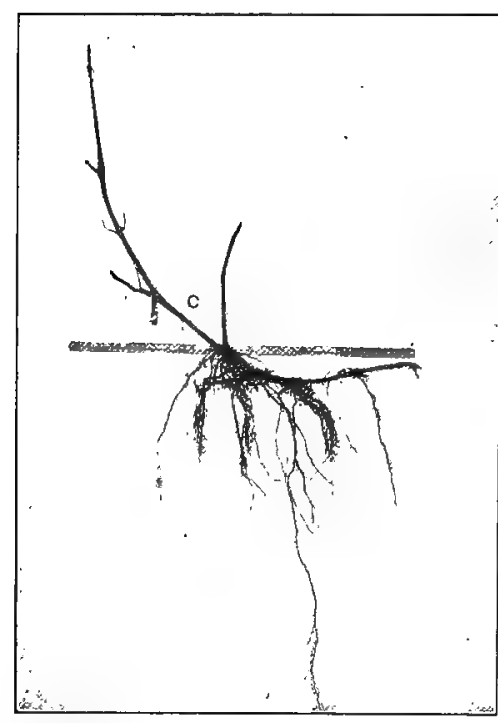

Fig. 66. LAYer of Winchell Grape Showing one year's growth of roots. A yardstick is included for comparison. In transplanting, cut back as indicated at $c$ leaves fall off in autumn.

Transplanting. - Prepare a large hole, make it three or four feet wide, so that the slender roots can be spread out naturally in it, mellow the soil deep (if the ground is poor, dig it out and put in a wheelbarrow load of rich loam), and scatter into the bottom of the hole a peck of bones that you have saved. Now dig up your plant carefully, to save the fine roots, and without exposing them to the air any more minutes than necessary (if it has to be carried far, wrap the roots in wet paper or burlap), spread them naturally in the hole, filling in with fine earth as you arrange the roots of different levels, and tramp the earth firmly about the plant. Finally, put two or three stakes around it for protection. If the ground be dry, soak it thoroughly, and after it has dried so that it works mellow without puddling, rake the 
surface fine and smooth. Before digging your vine you must cut it off to within two buds of the ground. Yes, you must. Boys and girls always demur at this, but the reason for it is plain. We want one large, strong cane to grow. There are from thirty to forty buds on your vine. If all are retained they will all try to grow, and those that succeed will make only weak branches. By doing as I say you will have one strong stem instead of ten weak ones, and your vine will be ten times as good. When the two buds you have left begin to grow and have made two or three leaves, pinch off the tip of the weaker one and give the other a support to climb. If you wish to have it grow tall as fast as possible, so that it may cover an arbor or reach a second- or third-story porch or window, pinch the tips of all its side shoots in the same way. By this means a growth of from ten to thirty feet may be secured in a season.

Pruning. - Practically every bud or young vine or tree must be looked upon as a little blind creature, wild with ambition to overgrow the world. Your grapevine now has forty or fifty buds. Only two of them can be allowed to grow. If you wish to train to a trellis, cut your vine back again to within four or five buds of the ground, and the following spring allow only the two strongest branches to grow, pinching the others as soon as they have made a leaf or two. If you wish your vine to grow taller, you may cut it off as high up as the wood is fully ripe, and before it begins to grow smaller toward the tip pinch all the side buds below the two topmost ones and allow only one or two of the highest buds to continue the growth. Care and patience should be exercised not to allow the 
young vine to overbear; for if it does, it may not regain vigor for four or five years. The first year, if from a strong layer, or the third, if from a cutting, it will probably show a cluster or two of blossoms. Nip them off and wait, and the next year do not allow it to bear more than three to six clusters, according to its strength.

If you study your vine, you will learn that the fruit is always borne on shoots of the season's growth, which spring from buds on the wood of the preceding year; and your rule for all subsequent pruning should be to leave not more than twenty to thirty buds on the vine. Cut off all weak canes close to the stem and, supposing there are five or six vigorous young canes, cut them all back to within four or five buds. Mr. Saunders, late Superintendent of Gardens and Grounds, United States Department of Agriculture, advocates doing this soon after the leaves fall in autumn; and he gives as his reason the fact that the roots continue somewhat active and distribute food materials to all the buds through the fall and early spring. If this material be concentrated on the few buds left after pruning, the fruit will be larger and ripen earlier than if most of it were wasted in the portions of the vine afterwards cut away. Since this is true, wood intended for cuttings should be more vigorous if taken in February or March. It should always be cut before the least signs of growth appear in the spring; and all pruning must be done by March in most northern states ; otherwise great loss of sap will occur from bleeding in the spring. 


\section{How to Raise an Apple Tree}

By the time a child is one year old he may plant an apple seed in the earth. He may not know what he has done for several years afterwards, but this is apt to be the case with all great works of man, no matter how old he may be.

Ask each one of the class to save a few apple seeds, and without allowing them to become dry, have the children plant them in a drill across the propagation bed. Drive a stick labeled "Seeds of __._Apples" at one end of the row. When the seedlings come up in the spring, thin to two or three inches apart and keep the ground mellow and free from weeds. See how tall you can make them grow. Before the ground freezes in the fall dig them up, saving all the roots, tie them in a labeled bundle, and keep in moist, not wet, sand in a cool cellar. We must now learn how to graft before we can go on. ${ }^{1}$

Grafting. - You have learned that a bud is in embryo a plant of its kind. When set in the ground, certain kinds that are strong enough will form roots of their own. Other buds that do not form roots so readily we plant in some closely related tree, and they may grow up to form its trunk, or, if inserted in a limb, one of its branches.

1 I regret to differ with a number of recent writers on nature study who advise children to get nursery-grown trees to start with. We should do this, of course, if fruit and quick returns are the objects; but where cultivation of patience, resource, and education are the ends in view, this is just the thing that ought not to be done. This work will require only a few minutes' attention each year, and to have started at the seed, the natural beginning, may develop in the child a relation to his tree deeper than the purely commercial. 
Apples of all kinds are nearly enough related to inter. graft, so that we might have as many different kinds of apples on one tree as the tree has branches; and this makes not only an interesting tree, but a most serviceable
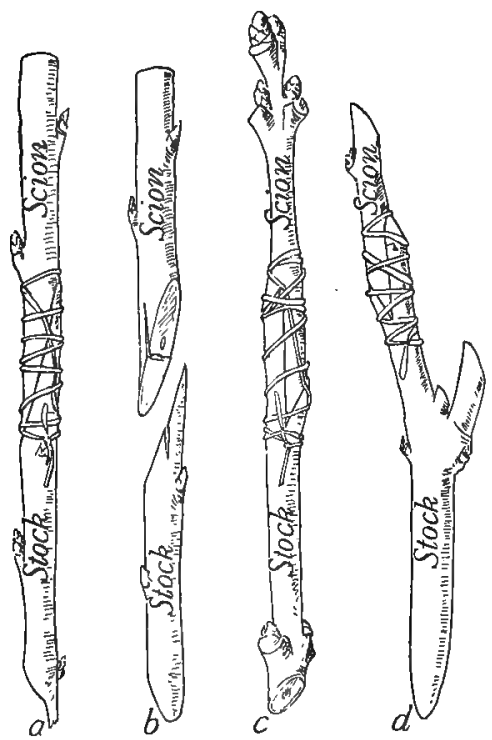

- Fig. 67. Various Methous of WhiP GRAFIING

$a$, plain whip graft; $b$, whip-tongue graft; $c$ and $d$, modifications which give large contact surfaces, stiggested to the author by Jackson Dawson one where a child has no room for more.

For grafting we need a very sharp knife, cloth bands or raffia to tie with, and grafting wax. ${ }^{1}$ The stock is the stem, into which we set the graft. This we already have in the little yearling apple tree. The scion is the shoot, from which we wish to prepare our graft. The graft is a scion or part of a scion, a little stem carrying a bud or two, that we wish to propagate. Fig. 67 shows all these in their proper relations. Scions are prepared, somewhat like grape cuttings, by removing vigorous shoots of the previous season's growth at any time before they begin to start in the spring and storing in a

1 Grafting wax may be prepared by melting together four parts resin, two parts beeswax, and one part tallow. It should be used to cover every part of the cut surface around a graft to keep out the air and prevent drying. 
cold cellar in moist sand or moss. Cut your scions from the ends of strong bearing limbs fully exposed to sunlight and air, since these have been found to do much better than the large tempting "water shoots" that often spring up in the center of the tree.

There are about fifty methods of grafting described in the books, but they are all different ways of doing one

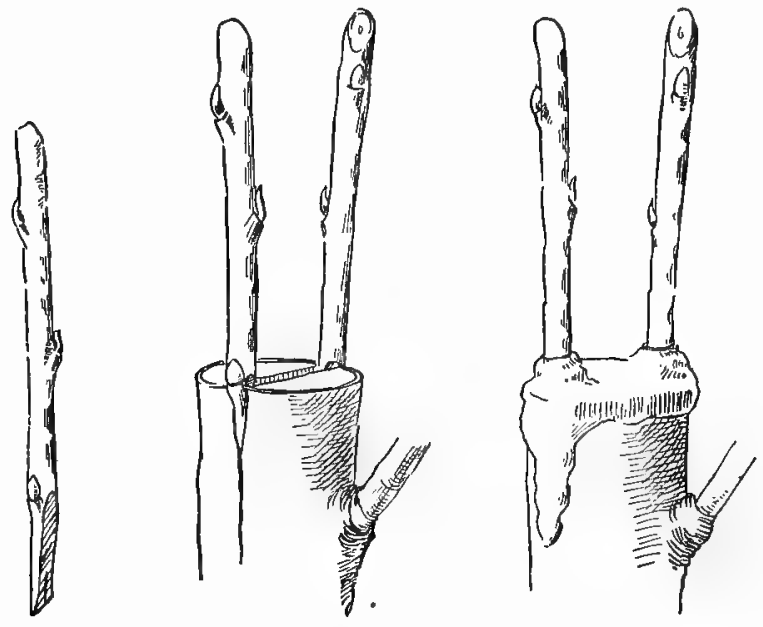

Fig. 68. Cleft Grafting

thing, viz., matching the line between the bark and wood of the scion to that of the stock and fastening them together until growth unites them into one. You will see the need of matching these lines together when you think that this soft substance between the bark and wood is the only living and growing part of a tree. You must, therefore, make close contact between the living part of scion and stock if any growth is to occur, and growth of 
the scion will be good or bad according as this contact is more or less perfect.

Of the many methods of grafting I will figure two, one of which we shall use with our apple tree, the whiptongue graft; the other, common cleft grafting, we may need to know if we wish to add new varieties to an old tree. Let us suppose that we have secured the scions of

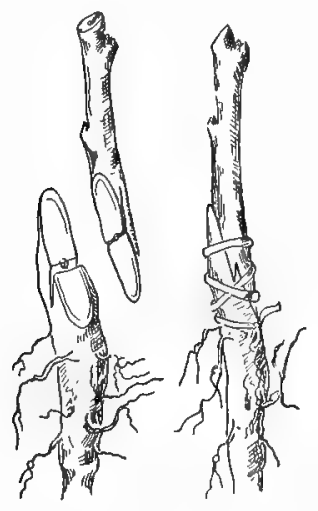

F1G. 69. GRAFting A Seleding Apple Tree

the kinds we wish and buried them in the sand with the little trees in the cellar.

Along in March or April we will take them both up and, selecting the largest stock cut it off at the junction of root and stem with one smooth, slanting cut about an inch in length. Selecting a scion that is the same size, we will cut off its lower end in the same way, and, splitting the stock and scion a little, near the middle, as shown in Fig. 69, slide them carefully together. Wrap them tightly around with fine cotton thread that has been dipped in melted grafting wax and cover the whole wound with grafting wax and replace it in the moist sand until spring. It will be best to plant it back in the propagation bed and let it grow there for two years. As the buds of your graft start, allow only the strongest of them to grow to form the trunk of the future apple tree; and after two years you should have an apple tree from four to six feet tall, ready to transplant, as described for the grapevine. At the time of transplanting we shall cut the 
tree back pretty well and begin to shape its permanent head. In doing this we must again call to mind the fact that the little tree is blind and ambitious. Numbers of buds will start that, if permitted to grow, will only be in its way later on. It will greatly conserve the strength of the tree if we keep watch for a time and rub these buds off as soon as they start and allow only the four or five to grow that we wish to form the main branches of our tree. Another way is to let all the buds grow as they please and then prune off all but the four or five that we wish to keep the next spring. But this is wasteful, and by the easier method first given, as Mr. Saunders ${ }^{1}$ says, we can have a tree as large three years from transplanting as could be had in five years by the more wasteful and laborious procedure.

In forming the head of a young tree we must be careful about two things: allowing two branches to start from the same place to make a crotch that will split the tree when it bears its load, and allowing branches to grow across the top, interfering with other limbs and making the crown too dense for air and sunlight to penetrate. This latter we can do by often looking over the tree through the growing season and rubbing off a shoot here and there that we see is taking a wrong direction, and thus keep the top open to sunlight and air without having to saw off large branches. ${ }^{2}$

1 William Saunders. "Pruning of Trees and Other Plants," Yearbook, 1898, United States Department of Agriculture.

${ }^{2}$ G. B. Brackett. "The Apple and how to grow it," Farmer's Bulletzn, No. $I_{3}$, United States Department of Agriculture. Figs. 7 and 9 show type forms of trees that have objectionable crotches. 
The condition of a tree is indicated by its annual growth. If this is too vigorous and the tree is going to bud and wood, the soil is too rich in nitrogenous materials. We may leave it unfertilized a year and possibly prune off a number of its roots. If the annual shoots over the out-

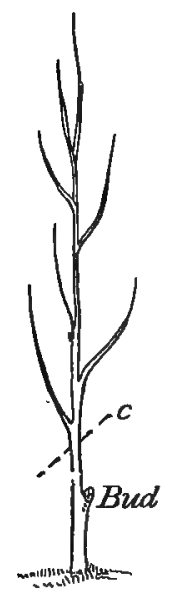

FIG. 70. PEACH TREE

First year, bud set in September. Cut off at $c$ the following spring side of the tree are less than a foot long, the tree probably needs feeding. For a tree, after it has begun to bear, to make a vigorous growth of about a foot on the tips of its exposed branches is considered an index of good condition.

\section{How to raise a Peach Tree}

First, as before stated, we must be sure that we are starting with seed of unimpaired health and vigor. This we shall get from our State Experiment Station or from some reliable nurseryman in the neighborhood or save it from fruit of a tree that we know is not tainted with yellows. ${ }^{1}$ As early as the ground can be worked in the spring we will plant our seeds, about six inches apart and two inches deep, in a row across our propagation bed. Cutworms are fond of young peach trees, and if there are any of these pests around, we shall do well to melt the

1 The cause of peach yellows has not been discovered; but it is certain that it is communicated by seeds and by buds or grafts of diseased trees. Write to the Agricultural Experiment Station of your state for latest information on the subject. 
top and bottom out of a tin can and, forcing it halfway into the ground, plant the seed in it. Otherwise we may not have a single tree to show for a dozen seeds.

Nothing in the whole garden is more graceful than a seedling peach, and it grows faster than almost any other tree. By the end of the season, with good treatment, it should be about four feet tall and nearly an inch in diameter at the ground.

Budding. - Along in September, or earlier farther south, we shall need to bud our tree, i.e., plant a bud of the desired variety; let us say this is the Royal George. Budding is done by slipping a bud, with a little shield of its own bark, under the bark of the stock. To do this we cut a
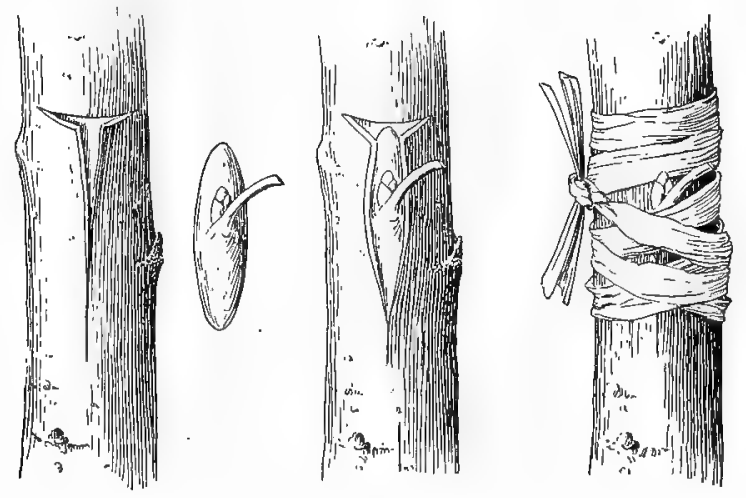

Fig. 7I. Budding a Peach Tree

" $\mathrm{T}$ " in the bark, very carefully lift up the angles with the thumb nail, a wooden blade, or the ivory blade of a "budding knife," cut off our bud as shown in Fig. 7I, being careful not to include any wood in the slice except 
a mere point under the bud itself, slip it into place, and tie snugly with a bit of raffia or a strip of cloth. The time to bud is as early as possible in either fall or spring, when the bark "slips" easily. For the peach it is usually done in the fall, because the bud will have become a part of the tree and be ready to begin growth early in the spring. The bud should be set close to the ground on the north side of the tree, and we can test whether it is in proper condition by opening the bark higher up to see whether it slips easily. After a week or so we must loosen the band 'to prevent girdling our tree, and we shall be surprised to see how much the little trunk has grown in diameter during this short time.

The tree, of course, is not dug up to bud,

Fig. 72. REARING a Peach Tree

Second year. $h$, heel; $c . h$, cut-off heel in July and it stands in the propagation bed where it was planted until the following spring. Examine it at this time to make sure that the bud is alive. If it is, as soon as it begins to shoot cut the tree off a few inches above and rub off all other buds that attempt to dispute the field. Before any growth occurs you may transplant the tree to its permanent place or allow it to 
remain where it is for another season. You now have something to show what a single bud can do in a year, i.e., make a tree with a trunk and branches, with hundreds of buds, six or seven feet tall. Put a stick beside it and mark from noon to noon for a few days and you can never think of a tree as an inanimate thing again. We cut off the old trunk three or four inches above the bud and tie the tender shoot to it so that it may not be broken off by the wind. This "heel," as it is called, should be cut off smoothly, close to the bud, in July or August, so that it may heal over nicely before winter.

We now need to know how to form the head of a peach tree and something about its pruning and care. It is com-

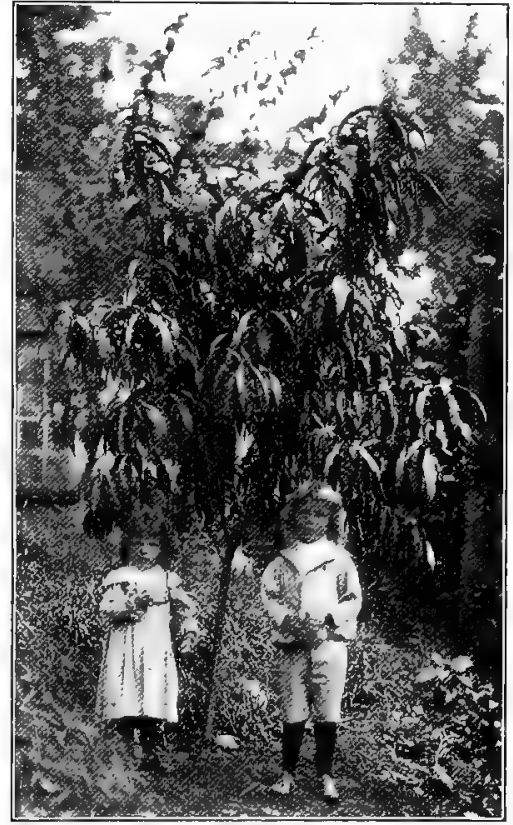

Fig. 74. Rearing a Peach Tree Autumn of third yearfrom seed. The branches have grown from buds since spring. Planted by the boy when one year old. (Photograph by the author) monly recommended to prune the peach in February or March, as late as possible, but certainly before any signs of growth appear in the buds. ${ }^{1}$ The following February,

1 In regions where severe ice storms prevail it is advised to prune back late in the fall. 
then, we must prune our ambitious little tree back to a "whip," removing all the side branches and cutting off the top to within two or three feet of the ground

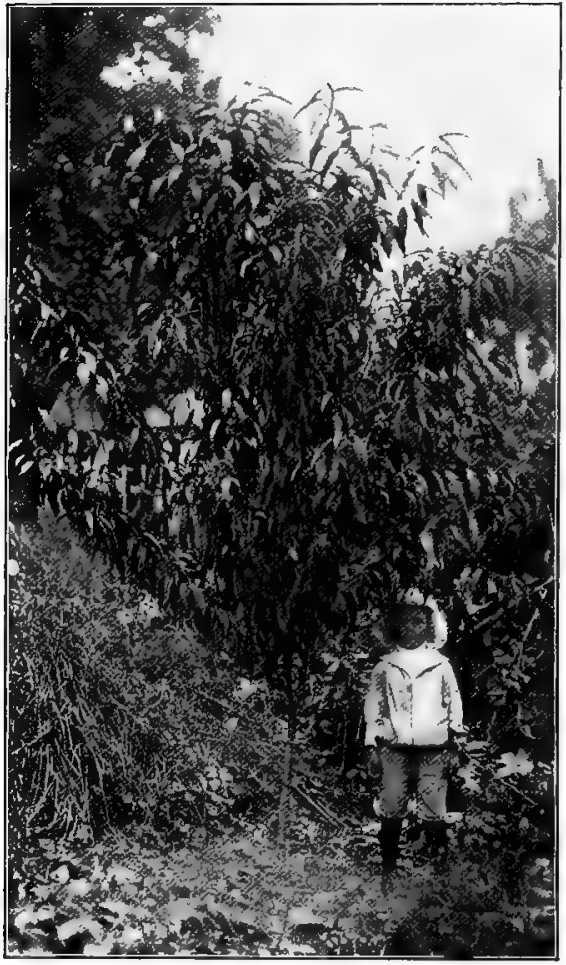

Fig. 75. Rearing a Peach Tree

Autumn of fourth year from seed. (Photograph by the author)
(Fig. 73). ${ }^{1}$ As the buds start again we will allow only three or four to grow, being careful that they do not form crotches which may split the tree later on. There will be demurrings, but you have learned what a bud can do, and one strong branch is better than ten weak ones in this stage of the trce's growth. By allowing

1 This matter of pruning back, especially at time of transplanting, is one of great practical importance. Numbers of young trees die yearly, or make little or no growth the first year after transplanting, solely because this has been neglected. Nurserymen are obliged to deliver unpruned stock because their customers do not know the value of proper pruning. Later on, for lack of it, trees and vines overbear and break down or become worthiess by overgrowth of weak branches. 
only three or four to grow, each will be again five or six feet long by fall. The next February we must again cut back fully one-half of this new growth and permit two buds to grow from each of the three or four main branches. The tree will probably blossom this spring, but should not be allowed to bear more than three peaches. We have now a beautiful little tree with six or eight main branches. The following February we must cut these back half their new growth and remove all weak shoots that may have started. The next spring we shall again let each of the six form two branches, and we shall have a tree with about twelve limbs, stocky and able to support the burdens of coming autumns. This year, the fifth from seed, our tree may be allowed to bear a peck of peaches, and the next a bushel, and after that, from five to ten bushels. The future pruning will consist in removing entirely all weak and slender shoots and cutting off about half the new growth of the stronger branches.

The universal complaint is that peach trees are no longer capable of living and bearing more than four or five years. This is thought to be due to retaining too much of the new bearing wood and thus allowing the tree to overbear too young. Nurserymen of long experience have assured me that by the above method, and good yearly feeding and care, there is no reason why peach trees should not be kept in good bearing from twenty to thirty years. 


\title{
Methods by Which Different Fruits are propagated
}

\begin{abstract}
ApPles . . . .
Crab APPLES. . $\left\{\begin{array}{l}\text { From seeds of common apple, crab apple, or wild } \\ \text { crab, seedlings grafted or budded after one } \\ \text { season's growth. }\end{array}\right.$
BLACKBERRIES . . ( From underground runners and root cuttings, i.e., RED RASPBERRIES . $\{$ pieces of roots three or four inches long will form new plants. BLACK RASPBERRIES $\{$ In most varieties the layers form spontaneously; WINEBERRY . . . a few need to have the tips of the canes covered with earth.

DEWBERRIES . . . f From root cuttings or by layering tips of canes.

From seeds of mazard cherry for large trees, and from seeds of mahaleb cherry for dwarf; grafted or budded after first year's growth. In severe climates morello, or the wild pin-cherry, seeds are used to furnish a hardy root system.

CURRANTS . * .
GoOSEB ERRIES .
GRAPES . . $\left\{\begin{array}{c}\text { By cuttings of previous season's growth, by layers, } \\ \text { especially with the grape. }\end{array}\right.$ Mulberries . . . $\left\{\begin{array}{c}\text { From seeds, more often by cuttings of mature } \\ \text { wood. (Downing.) }\end{array}\right.$ ORANGES . . . $\{$ From orange or lemon seeds, seedlings grafted or LEMONS . . . $\{$ budded.

Peacies . . . . $\{$ From seeds, seedlings budded in early fall of first APRICOTS . . . $\{$ season; from plum seeds in cold climates.

PEARS . . . $\left\{\begin{array}{c}\text { From seeds of pear, grafted; or from quince or } \\ \text { thom-apple seeds for dwarf trees. }\end{array}\right.$ Plums . . . . From seeds of plum or peach, budded.

QUiNCES . . . $\left\{\begin{array}{c}\text { From cuttings; varieties difficult to root, grafted } \\ \text { on cuttings of vigorous kinds. }\end{array}\right.$
\end{abstract}




\section{CHAPTER XII}

\section{INSECTS OF THE GARDEN}

Success in gardening is quite as likely to depend on knowing something about insects as about the plants themselves; and further, the child's interest in the animal discussed in the chapters to follow will depend largely on his knowledge of what the insects are doing in his garden.

I shall endeavor to choose a list of garden insects that will include some of the most important, simply as illustrating methods of study; but the only rule for a teacher to follow is to take up those insects that possess the greatest interest and importance for the locality and season. And here, as with the programme for flower study, some special committee of teachers may well prepare the local lists.

The Codling Moth, or Apple Worm, Carpocapsa pomonella. This is possibly the most important and to children, when they begin its study, one of the most interesting of garden insects. The larva of this moth lives in apples, crab apples, pears, and quinces and sometimes attacks peaches, plums, apricots, and cherries. The damage it causes annually has been estimated for three states as follows: Illinois, \$2,375,000; Nebraska, \$2,000,000; and New York, $\$ 3,000,000$. It was early imported from Europe and is now at home wherever fruit is cultivated in this country and Canada, causing a loss of from 25 to 75 per cent of the apple crop, as well as that of many other fruits. In 
the heavy bearing years the wormy apples fall off and are discarded, but the great number of apples serves to rear enormous numbers of the worms, and, according to my

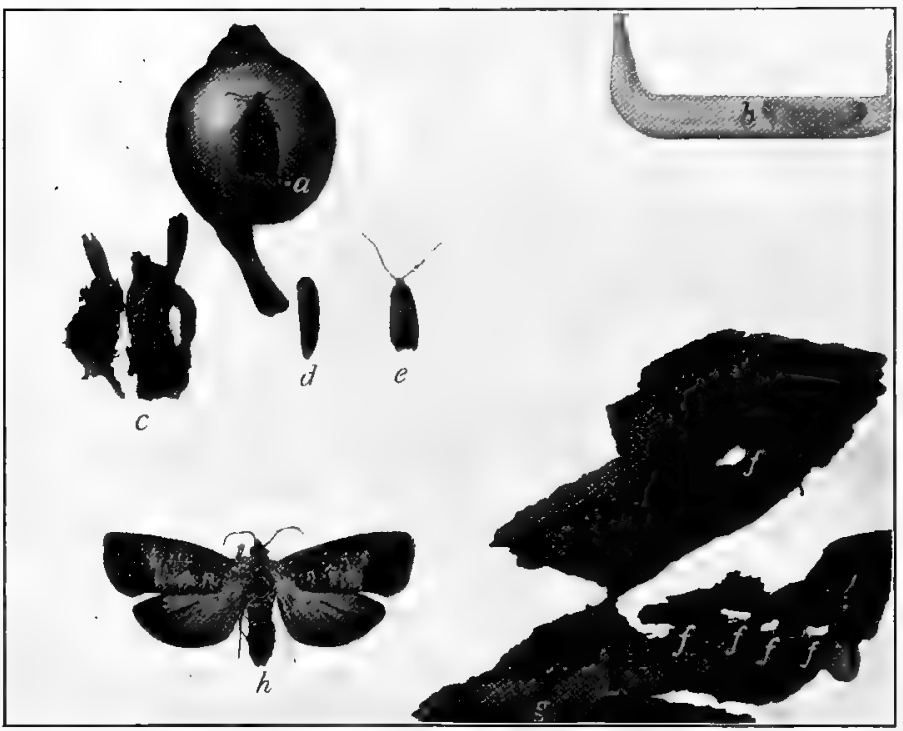

Fig. 76. The Coding Moth (A Life-Story Collection)

$a$, egg; $b$, larva; $c$, cocoons; $d$, pupa $; e, h$, adults; $f$, work of downy woodpecker on apple bark; $g$, moth on apple bark, to show protective coloration. ( $a$ and $h$ after Slingerland)

observations and experience, in the off years, when apples would be valuable, the worms take the whole crop.

Let us first endeavor to gain a practical knowledge of just what the insect is doing in the neighborhood. The study should be undertaken early in the fall. Ask the pupils to examine roo apples, from their home supply or 
as they are picked from the trees, and bring in the percentage injured by the codling moth. Next they may take a more general survey of the pears and other fruits, and let each estimate from his own observations the proportion of fruit injured and the damage caused according to market price. Of course in starting the pupils the teacher will appoint one of the class to prepare beforehand a demonstration of wormy fruit, so that all will know exactly what to look for.

The next step is to work out the life story as it is being lived about their fruit trees. Any time from October to May, by scraping the bark scales from the trunks of apple or pear trees, the pupils will be able to find the larvæ, the "worms," so familiar in apples, snugly ensconced for the winter in their silken cocoons. They may also find them often by thousands in fruit barrels or in the cracks about places where fruit has been stored. Let them bring in as many as they can find in two hours' diligent search and put them away in a vivarium in a cool place for further study the coming spring. No child who has gone thus far can ever again molest a downy woodpecker that he sees working over the trunk of his apple tree.

Early in the following May, review these lessons briefly and bring the vivarium with the larvæ into the schoolroom. At this time a few of the moths may have emerged, but probably most of the cocoons will be found to contain pupæ. A number of the larvæ may have been prepared for the school collection, and now a supply of pupæ should be saved for the same purpose.

Renew the hunt about apple cellars and barrels and either kill or collect every larva or pupa found. If they 
are numerous about the cellar, keep the windows closed or screened, so that the moths cannot escape to the apples outside. Make an excursion to a neighboring orchard and search the trees over. Look especially for bark scales that have been pecked into by woodpeckers. You will find numbers of these if there are any of the birds about, and by lifting the scale you will find the empty cocoon. If all the cocoons are not thus empty, you do not have woodpeckers enough to take care of the trees. Have any of the children observed woodpeckers at work on the trees during the winter? Did they save the bark scales from which they saw them pecking the larvæ? These bark scales tell a story as interesting as apples, birds, and insects all combined, and one or two should find a place in every school collection of the codling moth.

Later in May and early in June the dark-gray motbs will be emerging in numbers in the vivarium. Fig. 76 shows them, natural size, and it will be noticed that they have a little horseshoe of bright copper-colored scales on the front wing. This will serve easily to distinguish the codling moth from the other innumerable little gray millers of about the same size. Shortly after the moths begin to emerge in numbers in the locality look for the eggs, flat oval scales about one millimeter in diameter, laid commonly (in the spring) on the young apples a week to ten days after the petals have fallen. Most observers speak of beginning to find them about the time when the apples have grown to be an inch in diameter. ${ }^{1}$ This is

1 The eggs are commonly stated to be laid in the calyx of the apple, but all recent observations prove that those who started this story had not seen the egg, but reasoned from the fact that the larva eats its way into the 
an extremely important point, because the apple trees are sometimes sprayed with poison solutions in the hope of killing the newly hatched larva before it eats its way into the apple, and if this be done when the blossoms are on, practically all the honeybees in the neighborhood will be killed. Besides, the poisons will probably be washed off by rains at this season before the eggs are even laid, and it will be a week or more before they hatch. ${ }^{1}$

As many as eighty-five eggs have been found in a vial, laid by a single codling moth. As the insect lays its eggs singly and flits actively about in the process, the eggs come to be pretty well distributed, generally one to an apple, though sometimes several are found on the same fruit. In the northernmost sections of the United States the codling moth has generally about one and one-half broods a year, i.e., those that emerge early give rise to a second brood, while the late ones produce but one. In all the great middle fruit belt there are regularly two broods, and farther south there are three.

An example in arithmetic might be made as follows: Suppose there are fifty apples in a peck; how many might a codling moth spoil if she lays fifty eggs on as many apples, and half of these eggs hatch female moths, and in the second brood, again, each lays fifty eggs on fifty apples? Ans. 26 pecks.

If a downy woodpecker eats one codling-moth larva a day from November to April inclusive, I 80 days, what might be the value of its work to an orchard if apples are fifty cents a bushel?

Ans. \$585.

apple at this point. The eggs are laid anywhere on the surface of the apple and sometimes even on the leaves near it.

1 If spraying is resorted to, it should be done after the petals fall and before the calyx lobes close together. 
Beginning with the caterpillars under the bark of the apple trees, the life story of the codling moth may be briefly told as follows: The larvæ change to pupæ in May, emerge as moths in late May or June, and lay their eggs for

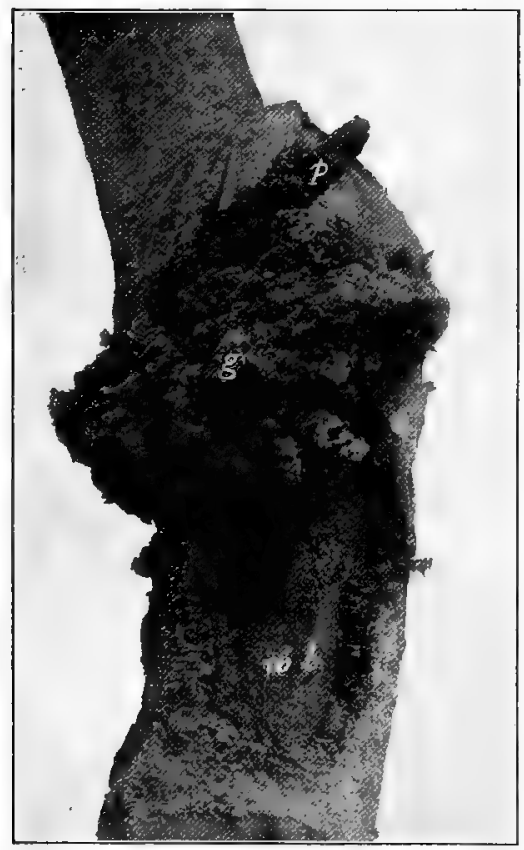

FIG. 77. WORK OF A SINGLE BORER ON A Young PEACH TREE

$p$, pupa; $g$, gummy exudation.

(Photograph by Slingerland) the first brood in June. The larvæ generally crawl into the calyx cup of the young apples and eat their way to the core, complete their growth in about three weeks, commonly eat their way out through the side of the apple, and either spin to the ground and crawl to the trunk of the tree or crawl down the branches and make their cocoons under the bark again. This occurs with the greater number early in July. ${ }^{1}$ In the warm weather of midsummer the larvæ complete their transformations

1 This habit affords one of the most vulnerable points of attack. To trap practically all the codling moths in an orchard it is only necessary to scrape all loose bark off from the trees and fasten around the trunks a band of burlap or heavy paper. Remove the bands and collect all larvæ once a week during July. 
quickly and emerge in two or three weeks, about the middle of July, and, greatly increased in numbers, lay the second brood of eggs, generally on the late apples. Many of this brood are barreled with the apples, and the rest escape from windfalls and discarded fruit and return to the tree trunks for the winter.

The final topics for study are the habits of the moth in relation to its natural enemies. It will be found to be nocturnal. Its color, as it hides on the apple bark, renders it almost invisible even to the sharp eye of a bird. Taking refuge thus in the darkness, it escapes the day birds, and we have no evidence that any of our insectivorous night birds feed upon it. But we have one misunderstood and wrongly despised little nocturnal animal, the bat, which Koebele, in California, has actually observed in the rôle of "a most efficient destroyer of this insect." 1 Should children make similar observations, they would not kill every bat they find. Finally, what birds prey upon the codling moth? We shall discuss in a subsequent chapter what we may do to increase the numbers of such bircls about our homes. ${ }^{2}$

The Peach-Tree Borer, Sanninoidea exitiosa. - "We suppose that few of the peach trees which have been planted

1 Koebele writes: "Every night during June as many as six of these bats were to be seen flying around an isolated apple tree upon which there were a large number of the moths, not only taking the codling moth on the wing, but very often darting at a leaf to get the resting moth."

2 Refer to Bulletin 142 , Cornell University Agricultural Experiment Station, Ithaca, N.Y., "The Codling Moth," by M. V. Slingerland, r $898,-$ the best source of information on the subject. The birds mentioned as eating the codling moth are downy woodpecker, nuthatch, bluebird, crow blackbird, kingbird, swallows, sparrows, wrens, chickadees, and jays. 
east of the Mississippi River during the last quarter of a century, have lived to produce a crop of fruit without suffering more or less from this dreaded borer." 1

I chanced recently to visit a young peach orchard set out by a man with the view of raising peaches for market. The trees were

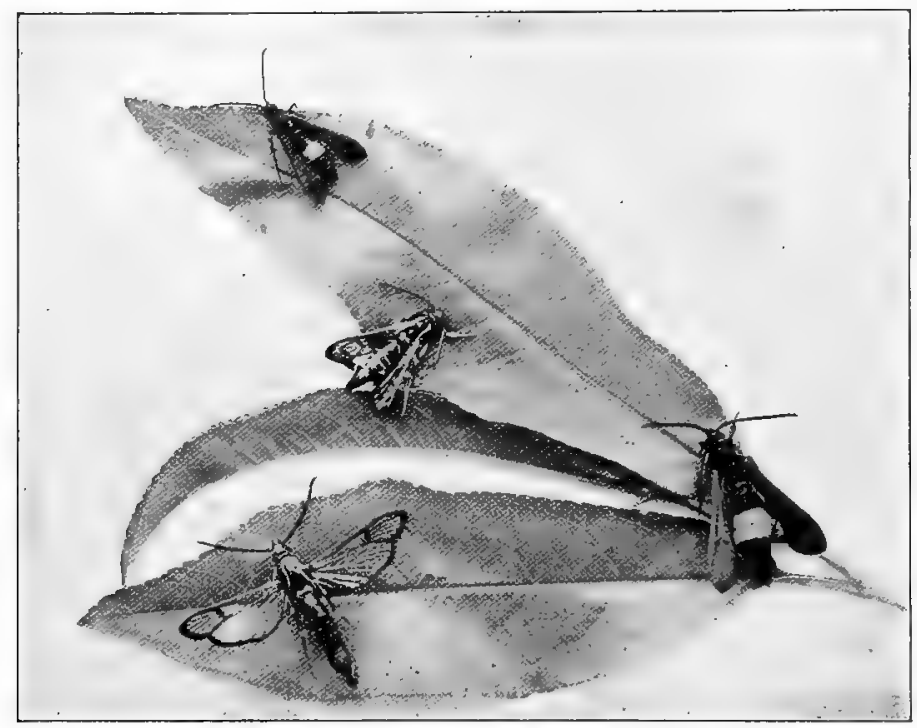

Fig. 78. Peach-Tree Borers, Male and Frmalr

Female with broad yellow band across abdomen.

(Photograph by Slingerland)

only three or four years old and had begun to bear finely. As he was showing me about, I pointed to a mass of borer chips and gummy exudation at the base of one of his trees and asked him if he knew what that meant. He replied that he did not. I then dug out the

1 M. V. Slingerland. "The Peach-Tree Borer," Bulletin 776 , Cornell University Agricultural Experiment Station, Ithaca, N. X., I899. 
borer and showed it to him, explaining how one such larva might kill a tree, and how, if it had lived to lay eggs, it might have cost him many more.

Thanks to Slingerland's pictures we have this arch-enemy of all good peach trees before us, egg, larva, pupa, moth, and evil doings, the latter written so plainly that no child can fail to read them. The children should be asked to keep a sharp lookout about their peach trees, and all the trees in the neighborhood in fact, because one old stub may grow borers enough to stock a large area, and gather specimens of the different stages for the school collection.

To facilitate this work the life story may be told in a word, as follows: The moths, somewhat resembling steel-blue wasps, emerge from their cocoons on the peach trees from late June to early September (for latitude of New York; earlier in the south and later farther north) and during this time lay their eggs on the trunks of peach and plum
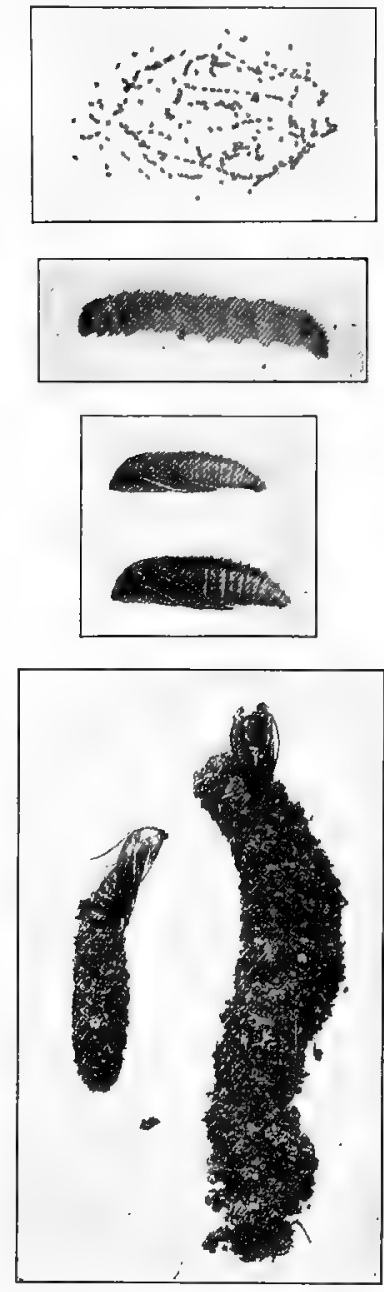

Fig. 79. EgGs, Larva, Pupa, AND COCOONS OF PEACHTrEe Borer 
trees, generally within eighteen inches of the ground. The eggs are brown, and almost seven hundred have been counted in a single female. They are glued to the bark and hatch in about a week, and the little borer immediately crawls into a crack, bores down to the juicy inner bark and

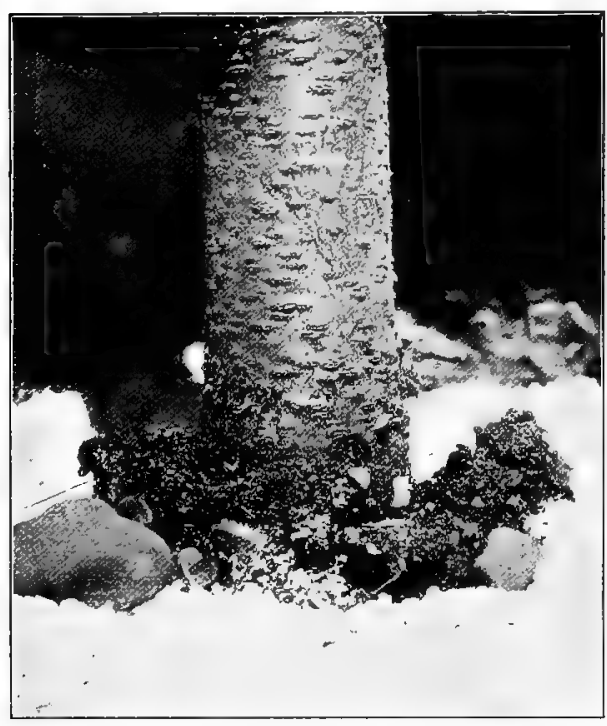

Fig. 8o. Borer Signs around Base of Peach TREE

(Photograph by Slingerland) there remains for about ten months, feeding during all but freezing weather. It then makes its brown cocoon, generally on the tree trunk close to the ground, and after three weeks cmerges to repeat the story. The moths are day fliers, are not attracted to lights, but visit flowers for nectar or pollen.

The best way to deal with the peach-tree borer is to watch the trees and as soon as the gummy exudation appears dig out the larva with a knife. Peach trees heal up wounds readily, and there need be no fear of injuring the tree as much with the knife as the borer would without it. All peach trees should be gone over very carefully in September, 
again in May, and, finally, late in June. This latter is to make sure that none of the larvæ escape and thus prevent any adults from emerging to lay their hundreds of eggs. Excepting a few parasitic insects, no natural enemies of this pest are mentioned by Professor Slingerland, but quite possibly some child may be able to discover a flycatcher or redstart or some other bird catching the moths as they flit among the trees, laying their eggs. It is needless to add that such an observation would be of great value.

A number of other borers belong to the same family and resemble the peach-tree borer in appearance and life story.

The Pear-Tree Borer, Afgeria pyri. - This is often quite destructive to pear trees. Its presence is revealed by chips, resembling fine sawdust on the bark of the tree. It should be dug out with knife and wire wherever found.

The Grapevine Root Borer, Egeria polistiformis. - In the larval stage this insect bores into the roots of grapes. The adult, a large, brownish-black, wasplike moth, measuring from an inch to an inch and a half across the wings, appears in August.

The Imported Currant Borer, Egeria tipuliformis. - This is widely distributed and renders the culture of this valuable fruit difficult or, if neglected, impossible. All hollow canes should be cut out and burned in the fall or early spring.

Other destructive borers are the larvæ, or grubs, of beetles. Several of these which should be more commonly known are the following.

The Roundheaded Apple-Tree Borer, Saperda candida. - This beetle is a very serious enemy of apple and quince trees. 
The larva is supposed to require three years to complete its growth, during which time it feeds in the bark and trunk of the tree. The children should be directed to search over the trunks of their apple trees, especially after a rain, for the sawdust-like chips that mark its presence. The large borings often penetrate deep into the heart of the tree, but the grub can be reached and destroyed by means of a wire. The beetles are to be found in June and July, remaining concealed by day and becoming active about dusk. They are about three-fourths of an inch long, pale brown, with two broad creamy-white stripes running the whole length of the body, so plainly marked as to be easily recognized.

The Flat-Headed Apple-Tree Borer, Chrysobothris femorata. This is an even more formidable enemy to the apple trees than the last species and attacks also the pear, plum, and peach. Whether the larva requires one or two years to complete its growth is not determined. The beetle may be found from the latter part of May on through the summer. It is very active in the daytime, running about the trunks and branches of the trees in the hot sunshine and depositing its minute yellow eggs under the scales and in the cracks of the bark. It is generally about one-half inch in length, but varies a good deal. The color is shining greenish black, with two transverse, depressed brassy spots above, under parts and legs appearing like burnished copper, with the feet shining green. This borer does not confine its attacks to the trunk, but may be found in the larger branches as well.

The Broad-Necked Prionus, Prionus laticollis, is of interest on account of its huge size, the larva often reaching a length 
of three inches. It attacks the roots of grapevines, and when a vine dies of no apparent cause its roots should be searched for this destructive pest. The adult is a brownish black beetle, with short, heavy jaws, commonly about an inch and a half in length. It begins to appear about the middle of July. A near relative of this beetle is the tile-horned Prionus, $P$. imbricomis, which has a similar life story and attacks the grape in the same way.

The Divaricated Buprestis, Buprestis divaricata. - The adult is a bronze or copper-colored beetle, a little less than an inch in length, the larva of which attacks the cherry and not infrequently the peach. The wing covers are elongated into blunt, divaricated tips, from which the name is derived.

Two important borers attack the strawberry: the strawberry root borer, Anarsia lineatella (which often destroys also the tender twigs of the peach), is a minute moth; and the strawberry crown borer is a beetle, Tylodema fragaria, belonging to curculios. The remedy for these consists in digging up the plants as soon as they wilt and burning them root and all.

The Grape-Cane Borer, Amphicerus bicaudatus. - If a young shoot on a grapevine suddenly wilts and dies, you will probably find it hollowed out near its junction with the vine, and, within this hollow, a cylindrical brown beetle about one-half inch long. Sometimes all the new growth on a vine is killed in this way, and twigs of pear, apple, plum, peach, forest, shade, and ornamental trees may be found to contain the same pest. The beetle is single brooded, the eggs being laid from March to May, or June, according to latitude. The larvæ develop in dying or diseased 
wood, such as prunings of fruit and shade trees, never in thoroughly dry nor in vigorously growing wood, and the adult beetles, after passing the winter in such material, attack the growing shoots in the early spring. Thus the remedy consists in burning all prunings during the fall or winter.

The Rose Chafer, "Rose Bug," or " Rose Beetle," Macrodactylus subspinosus. - The adult insect is too commonly known to need description. But whence come the countless hordes that suddenly appear in June on rose bushes, fruit trees, ornamental shrubbery, especially spiræas and grapes of every variety, is not so well understood. They often come in such numbers that spraying with poisons is ineffectual in preventing the plants from being stripped of their leaves. The mystery of their sudden appearance is explained when we learn their life story. The eggs are laid in the ground in June and July, in grass land, generally sandy meadows, and the grubs, resembling the larva of the June beetle, only smaller, feed upon the roots of grasses, attaining their growth by autumn of the same year. The following spring they transform into pupæ in the ground and in two to four weeks, according to weather, emerge as adults. From this life story it is thus seen that, for a neighborhood seriously afflicted by this pest, the most effectual remedy consists in plowing up their breeding grounds and raising some other crop than grass. Little is known about the birds that feed upon this beetle, and the children should be encouraged to keep watch of all birds about their homes, for observations in this field may prove of value. A large percentage of the food of the bluebird, brown thrasher, catbird, house 
wren, downy and hairy woodpecker is known to consist of beetles, and it is possible that a sufficient number of these birds might be reared to deal effectually with this pest. The toad may devour enormous numbers of them, and, as we shall see when we study its life, they can often be gathered in such numbers as to afford instructive feeding tests. Spiræas planted about the garden serve to protect other plants and form convenient collectors, and if it is desired simply to destroy the beetles, they may easily be shaken into a pan containing a little kerosene oil.

The Tent Caterpillars. - These are of two kinds, somewhat similar in appearance, but differing widely in habit of life. The apple-tree tent caterpillar, Clisiocampa Americana, is a pest so common and destructive and so easily dealt with that Saunders says of it : "Governments might well enforce under penalties the destruction of these caterpillars, as their nests are so conspicuous that there can be no excuse for neglecting to destroy them, and it is unfair that a careful and vigilant fruit grower should be compelled to suffer from year to year from the neglect of a careless and indolent neighbor." The moths lay their eggs in easily recognized "belts" on the slender twigs of trees, chiefly apple and wild cherry, in July. The minute black caterpillars complete their development during the summer and fall and may be seen curled up within the eggshell any time during the winter. Early in the spring, generally before the buds burst open, they eat their way out and feed first on the cement with which the egg cluster is protected. As soon as they appear they begin feeding on the tender leaves and commence building their tent in a convenient crotch. There are about three hundred eggs 
in a belt, and so voraciously do the young caterpillars feed that it has been estimated the occupants of a single tent may cost a tree from 10,000 to 12,000 of its leaves, each caterpillar eating two a day as it approaches maturity. Early in June the caterpillars scatter from the trees in all directions, seek out protected crannies about fences and buildings, and spin their cocoons. Within these they change to pupæ, and after two to three weeks emerge as moths, to repeat the life story.

No insect is better adapted for rearing in the schoolroom. Simply place the branch with its belt of eggs in a bottle of water, feed as required with fresh leaves, and thus let the children read the story in nature. ${ }^{1}$

The forest tent caterpillar, $C$. disstria, differs from the above in having, instead of a white line, a row of light dots down the middle of the back. The egg belt is cut off squarely at the ends, the moths are light brown with dark lines on the fore wings, and they do not build a conspicuous tent.

Cankerworms. - There are also two species: the fall cankerworm, Anisopteryx pometaria, and the spring cankerworm, Paleacrita, or $A$. vernata. The larvæ are the commonly known "measuring" or "inch" worms of shade trees and orchards, but the moths and other characters in the life story are not so generally understood. After

1 A school in which this has been done for the past three years reports that tent caterpillars have been practically exterminated from the district. The eggs are collected and burned, each child being given credit for the number he brings in, and any tents found in the spring are destroyed. The caterpillars troop out of the tent to feed twice a day, mid-morning and afternoon; hence, in order to find them all at home the tents should be destroyed in the early morning or evening. 
spinning down from the trees in summer the larvæ burrow into the ground three or four inches and there transform into pupæ. With great show of wisdom the fall species wait until after the first hard frosts, when our summer birds have flown, and then, during the first warm spell, emerge to lay their eggs. They may also come forth during any warm days in winter. The spring form, a few of which may come out in the fall, wait until the first warm weather in spring, also before many of the birds are back. The male is a frail silken-winged moth, while the female is wingless and must, therefore, crawl up the trunk where she lays her eggs, often a hundred in a plate, on the bark or on the twigs of the food tree. The eggs hatch with the bursting of the buds, and the year story is again begun. Our winter birds, especially the chickadee, eat great quantities of the eggs and female moths. Professor Forbush has demonstrated that an orchard can be practically rid of them by protecting these birds and attracting them with winter food. The wingless condition of the females makes this one of the easiest insects to deal with. Bands of coal tar, mixed with oil or printer's ink, are for this purpose fastened around the trees. They often fail because those who do the work are ignorant of the insect's life story and do not put on the bands until large numbers have ascended the trees and laid their eggs, or they allow the bands to get dry during warm spells in the winter or early spring. While the English sparrow was imported largely to destroy cankerworms, they have greatly increased where the sparrow has become most numerous and where our native birds have, in consequence, been driven away. 
The White-Marked Tussock Moth, Orgyia leucostigma.-The larvæ are among our most beautiful caterpillars, but they may become so numerous as to strip a city's shade and fruit trees of their foliage. They feed upon almost all of our deciduous trees and even on fir and larch and spruce as well. As in case of the cankerworm, the females are wingless, but unlike it there are two broods a year, and instead of going into the ground, they make their cocoons in the trees, pupate there, and the females crawl out of the cocoons and lay the eggs in a white frothy mass upon them. The white egg masses are conspicuous objects on the trees in winter, and since the insect is two brooded and may at any time become too numerous to control, they should be gathered and destroyed. This is another instructive insect to rear in the school vivarium.

The Fall Webworm, Hyphantria textor. - In July, after the tent caterpillars have run their course, the trees are again disfigured by large irregular masses of webs, sc conspicuous that their destruction ought to be a simple matter of common sense. This insect is single brooded; both male and female moths are provided with wings and hence spread more rapidly and are not so easily controlled as the two moths just described. The caterpillars burrow in the ground to pupate and do not emerge until the following July.

Cutworms. - These are caterpillars of the various species of the owlet moths, genus Agrostis. Their plan of work is to cut off every tender plant in the garden even with the earth. Both caterpillar and moth are nocturnal, the moth laying her eggs on plants near the ground during the latter part of summer. At first the larva feed upon 
the tender roots of grasses and other plants, but by spring have attained to nearly or quite an inch in length and are ready to begin their most wasteful and destructive careers.

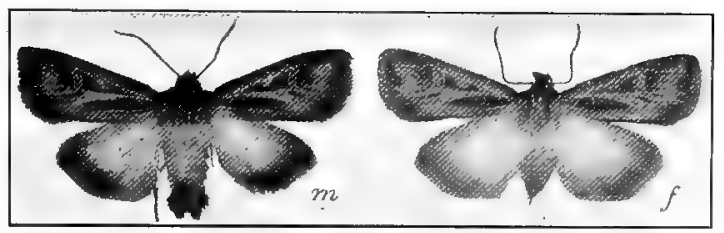

Fig. 81. Dingy Cutworm

Male and female. (After Slingerland)

Whenever we see a plant in the morning wilted and prostrate, the only thing to do is carefully to scrape the loose earth away from around its roots, find the culprit, and either keep him in a vivarium to develop into the moth or put him in the school collection; for both cutworms and

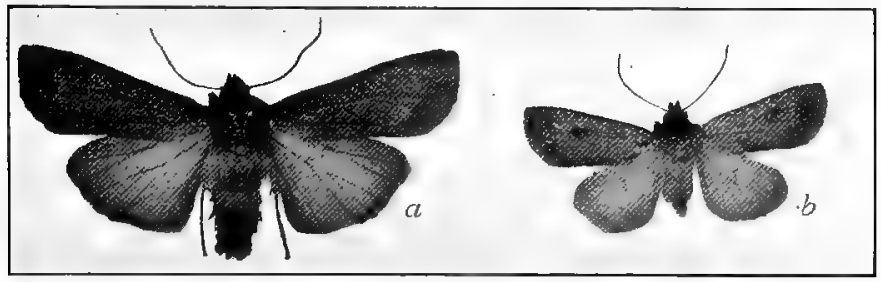

Fig. 8z. Cutworms

$a$, variegated; $b$, white. (After Slingerland)

their moths, especially, should be known much better than they are.

If other vegetation be lacking, almost any of the numerous species of cutworms assumes the climbing habit, 
ascending trees, grapevines, rose and berry bushes and eating out the fruit and leaf buds. Newly set orchards have thus been killed, and for a long time no one could find out what did the damage, supposing that it must be some winged insect. A man, happening to go through his vineyard at night, heard the gnawing of innumerable jaws and by striking a match solved the mystery. ${ }^{1}$

Plants may be generally protected from cutworms by folding a piece of stiff paper around the stem so that it goes into the earth an inch and reaches two or three inches above the surface. Young trees may be treated in a similar way, or tin cans, from which the solder has been melted, may be placed around them; but if cutworms are numerous and their food is scarce, they will climb over paper or tin. Their climbing may be prevented by tying a band of cotton batting so as to form an inverted funnel around the trunk of the tree; but when this is done the worms often girdle the tree below the band.

The Indians used to practice hand picking of cutworms in their primitive cornfields, and this has been the most satisfactory method of dealing with the pest ever since. But toads and robins should have delegated to them all the "picking." I shall refer to their work more at length in succeeding chapters. Poison baits and sprays have proved only partially effective.

Grasshoppers, or Locusts, of any species are well adapted for elementary lessons on account of their large eggs. These are laid during late summer or early fall and may readily be found in flask-shaped packets, an inch or more

1 M. V. Slingerland. "Climbing Cutworms," Bulletin 104, Cornell University Agricultural Experiment Station, Ithaca, N.Y., 1895. 
in length, just beneath the surface of the ground. If grasshoppers are numerous, the children may find them laying in September. Experiment by feeding a few, in order to determine how much grass they destroy. Grasshoppers are, further, of special interest in relation to bird foods. It will be noticed in the food chart, Chapter XIX, that all our common birds feed upon grasshoppers, the only insect, in fact, of which this is true. ${ }^{1}$

Crickets are similar to grasshoppers in life story, eggs, and feeding habits, and are even more interesting from the way they "chirp." This may readily be observed if a few are kept for a time in a vivarium, and the phenomenon never fails to fascinate a child. Crickets may be fed on grass, apple cores, or bits of raw carrot.

\section{Good Books on Garden Insects}

William Saunders. Insects Injurious to Fruits, $436 \mathrm{pp}$; 440 illustrations. J. B. Lippincott Co., Philadelphia, 1892.

MaRY TREAT. Injurious Insects of the Farm and Garden, 296 pp.; I 7 I illustrations. Orange Judd Co., New York, I 892.

1 Food for soft-billed birds, robins, orioles, mocking birds, etc., is expensive, "ants' eggs " costing about one dollar per pound. Some states are paying bounties of one dollar per bushel for grasshoppers destroyed, and it is quite certain that a very inexpensive and perfect bird food might be made by a suitable preparation of these insects. Possibly they could be scalded or steamed and thoroughly dried, then moistened again, as we treat "ants' eggs" for feeding. If the grasshoppers are caught, as they always should be, before egg laying has begun, no bird food could be more nutritious. 


\section{CHAPTER XIII}

\section{GARDEN INSECTS (Continued)}

The Apple Maggot, Trypeta pomonella. - This, commonly known as the "railroad worm," has become an enemy to apples and apple culture, ranking almost as destructive as the codling moth. Thousands of barrels of fruit are stored or marketed, apparently sound, only to be opened and thrown away.

Beginning this study with the opening of school in September, ask the pupils each to examine Ioo apples, preferably all of the same variety, and report the result at a subsequent lesson. If the pest be abundant, the teacher will find little difficulty in securing a few " railroaded apples" with which to show the class what to look for.

The injury to the fruit is done by the larva, or maggot, boring channels back and forth through the pulp as it -feeds. One such larva is sufficient to spoil an apple, and since the fly has been found to contain from 300 to 400 eggs, there is almost no limit to the damage that this one insect may cause.

By keeping a number of infested apples in a box the pupæ may be secured for the school collection, and a few of these should be put away in a cool place until June or July, in order to get the adult flies. These should also be sought for in the fall about apple trees. Fig. 83 sufficiently 
indicates their appearance. They are a trifle smaller than an ordinary house fly and may be recognized by a dark figure on the wing, shaped somewhat like a turkey, and also by the white lines across the back of the abdomen, three in the male and four in the female. No insect is better adapted to demonstrate to the children the work that so insignificant a creature is able to accomplish. The fly has been seen to puncture the skin of the growing apple, generally on the shaded side, and deposit a single
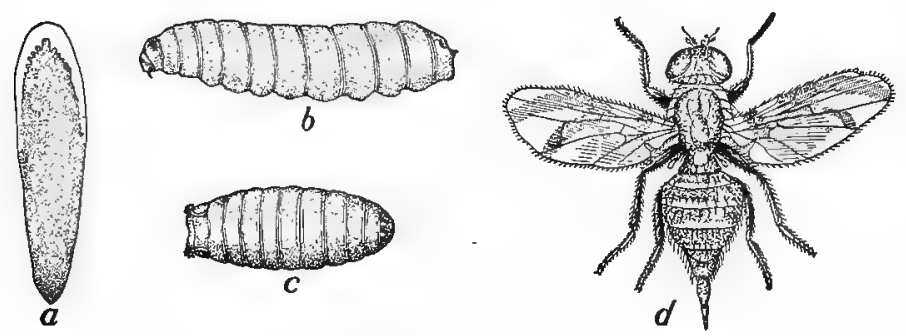

Fig. 83. Apri.e Maggot

$a$, egg; $b$, larva ; $c$, pupa ; $d$, adult female. (All enlarged.)

(After Harvey and Comstock)

egg directly in the pulp. Thus a single female may ruin one or two bushels of fruit. They may be found in the apple trees from June or July, according to latitude, until hard frosts occur in the fall, and they attack practically all varieties of apple. Nothing is known regarding the natural enemies of the apple maggot, and its life story renders it one of the most difficult of all insects to control. Possibly a pair of phœbes, or other flycatchers, or a few tree frogs in an orchard might save hundreds of 
bushels of fruit in a season. What boy will watch some of these, so as to be able to tell us what they do ? 1

The Curculios, or Snout Beetles.-The apple curculio, Anthonomus quadrigibbus, does considerable damage to cultivated apples in some of the Southern States, but is not generally numerous. There are also quince and grape curculios, Conotrachelus cratagi and Craponizes incequalis, which may be studied in neighborhoods where they are clestructive. Other members of this family infest nuts and

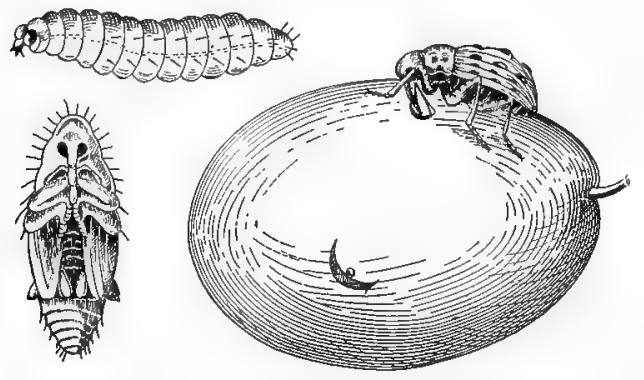

Fig. 84. Plum Curculio

Larva, adult, and mark on the fruit. (Enlarged) acorns and some other garden fruits. $\mathrm{Th}$ e insect for special study in this group is the plum curculio, Conotrachelus nenuphar. If neglected, this pest may take a large part, or the whole, of the peach, apricot, plum, and cherry crop.

The statistical method may be adopted again by asking each member of the class to examine 100 plums, peaches, or cherries, to discover what proportion of the fruit is affected. Ask the pupils to observe the laying of eggs, which may readily be seen shortly after the fruit has begun to grow in the spring, when peaches are about the

1 For full account of Trypeta, by F. L. Harvey, see Annual Report of the Maine State College Agricultural Experiment Station, 1889, pp. 190-237, Plates I-III. 
size of hazelnuts. The whole operation takes about five minutes. The beetle first digs an oblique hole in the fruit with her snout, enlarging it at the bottom. She then lays an egg in the mouth of the hole, pushing it to the bottom with her snout. Finally she cuts a crescentshaped flap around the egg. Her purpose in doing this seems to be to make a dead spot, so that the growing of the fruit at this point will not crush the egg. This crescent is the mark by which to distinguish the curculio's work, and it is rendered even more conspicuous by a copious exudation of clear gummy substance from the growing fruit. The larva feeds in the pulp, generally about the stone, and the fruit, except in case of the cherry, falls prematurely. When the larval growth is attained, in thref to five weeks, it burrows out of the fallen fruit and into the ground

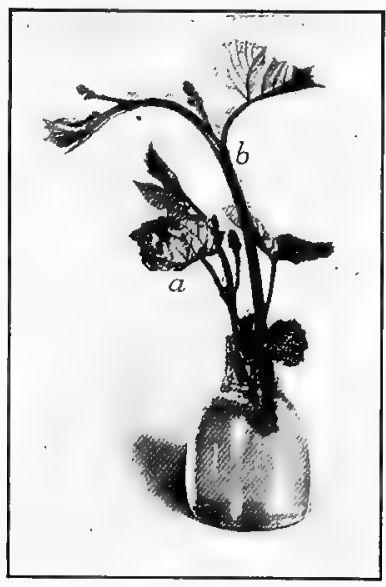

Fig. 85. YOUNG ShOOTS OF Grape to a depth of four to six inches. Here it pupates and emerges the $a$, attacked by plume moth; $b$, for comparison. same season as the little, rough, brownish beetle shown in Fig. 84. It may be recognized by the elongated hump of what appears to be black sealing wax on each wing cover. The winter is passed in cracks about buildings and in the bark of trees, whence the beetles come forth with the peach and plum blossoms, ready to begin their work of destruction. There is a single brood a year. 
The Apple-Leaf Crumpler, Pliysis indigenella. - Among a number of moths whose larvæ attack the leaves of fruit trees this one is chosen because of the ease with which it may be found. Any time during the winter little masses of crumpled and withered leaves may be seen attached by silken threads to the twigs. Within the mass will be discovered a little twistecl, horn-shaped case containing the half-grown larva of the leaf crumpler. In the spring
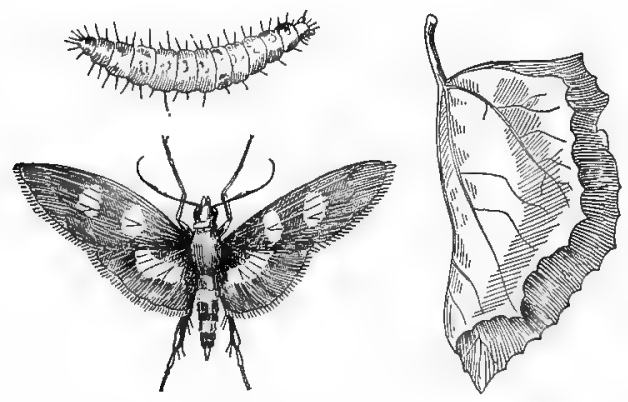

Fig. 86. Grape-Leaf Folder

Larva, adult female moth, and folded leaf (After Marlatt) it fastens the young leaves into little bunches by means of silken threads and continues feeding upon them until its growth is attained, about the middle of June. It then changes into a dark-brown chrysalis within its case and in July emerges to lay its eggs and thus begin its life story anew.

The Gartered Plume Moth of the Grape, Oxyptilus periselidactylus. - This is one of our prettiest little moths, but its work should be known to every child who has a grapevine. After the leaves have fairly started in the spring they will often be drawn together into round balls, and within may be found an active, wriggling, bristling larva of a greenish-yellow color, nearly half an inch in length when fully grown. These are the larvæ of the plume 
moth and, if neglected, they may destroy the entire crop of a vine while the blossom buds are opening. The vines should be daily examined at this season and, after securing specimens for the school collection, every larva should be destroyed. The insect being single brooded, thorough attention at the proper time will do away with the pest.

The Grape-Leaf Folder, Desmia maculalis. - This is another common enemy of the grape and should be treated, like the plume moth, by hand picking while in the early larval stages; the conspicuously folded leaves make this easy and effectual.

The Grape-Berry Moth, Eudemis botrana. - This insect often destroys nearly the whole crop of grapes in a garden. The larvæ pass the winter in cocoons attached to the leaves, and if these are burned in the fall, the pest may be greatly abated.

The Sphinxes, or Hawk Moths, might be treated among our most beauti-
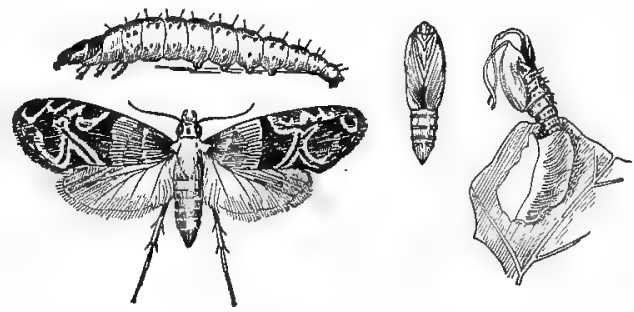

FIG. 87. GRAPE-BERRY MOTH Larva, pupa, aduit, and portion of grape leaf, showing method of making its cocoon for winter

(Enlarged. After Marlatt) ful and interesting insects were it not for the fact that the larvæ of at least ten species feed upon the leaves of the grape, and their enormous size makes it possible for a single larva to strip and kill a young grapevine in two or three days. The sphinxes are the large, narrow-winged moths, often 
mistaken for humming birds, that visit the flower beds at dusk. The Pandorus sphinx, Plitampelus pandonts, is one of the largest and most beautiful of the group and from tip to tip of expanded wings often measures more than four inches. It is single brooded. The moths appear in July and lay their eggs underneath the leaves of the grape and Virginia creeper.

One of the most common of our garden species is the green grapevine sphinx, Darapsa myron. It is two brooded, the moths of the first brood appearing during the latter half of May, those of the second during the latter part of July. The egg is laid on the under surface of grape leaves and hatches into a yellowish-green larva

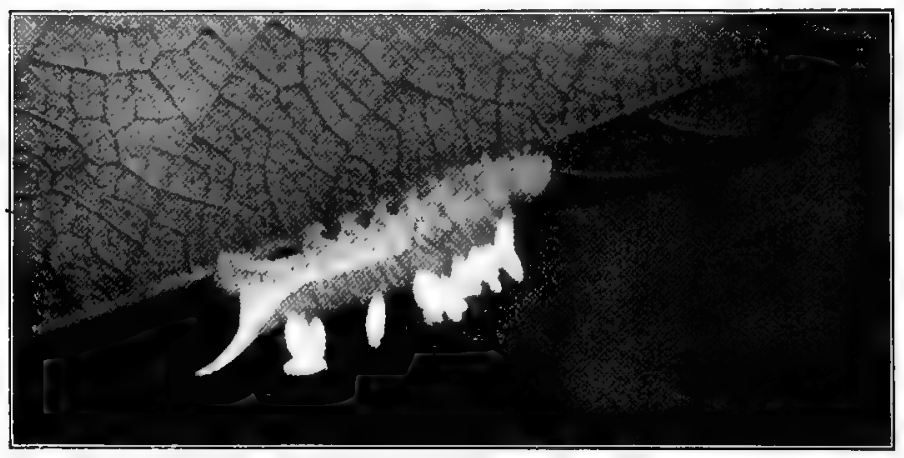

Fig. 88. Green Grapevine Sphinx, From which Parasites have EMERGED

with a long black horn near the posterior end. After successive moults, with attendant changes in color markings, it appears as in Fig. 88. It is then about two inches Jong, green, with yellow dots, white lateral stripes from the 
head back to the horn, and a row of yellow spots, with pink to lilac centers, along the back.

The Achemon Sphinx, Philampelos achemon. - Another of our most common species is found on the grape and

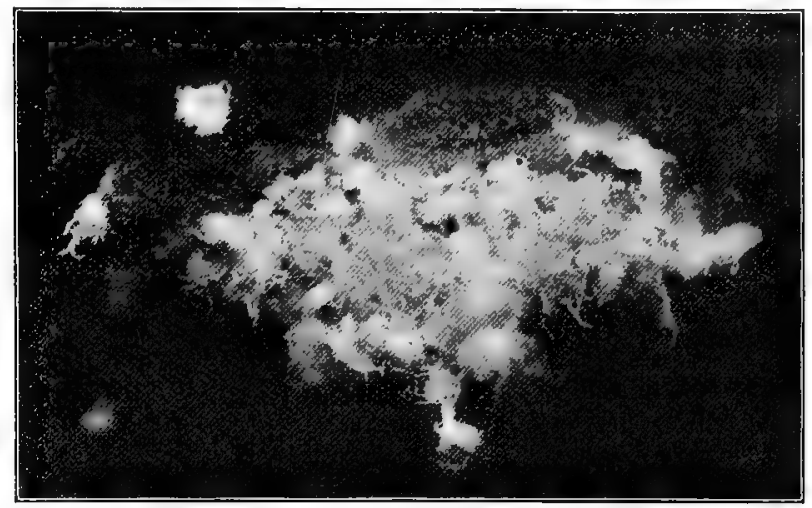

Fig. 89. Alder Aphids, with Harvester Caterpillar feeding UPON THEM

(Natural size. Photograph by Miss Katherine Dolbear)

Virginia creeper. The eggs are laid in July, under the leaves, and the larva matures about the first of September. It then burrows into the ground, transforms into a pupa, and passes the winter in this state. Just before going into the earth it assumes a pink or crimson color.

The Five-Spotted Sphinx, Phlegethontius celeus. - This is the moth of the common tomato worm. Its larva also transforms in the ground.

However terrible any of the sphinx larvæ may appear, they are all harmless and may be handled with impunity. They are easily reared by feeding with the leaves upon which they are found. It is always safe to provide them 
with moist earth, into which they may burrow when they wish to transform, since they either burrow or make their cocoons on the surface of the ground. The larvæ are especially interesting from the number of ichneumon flies parasitic upon them, and by keeping some in the vivarium, a school is almost certain to be afforded the spectacle of a swarm of minute larvæ suddenly boring their way out and spinning their little cocoons all over the back of their host. Do not say much about it beforehand, but when the first signs appear, gather the class around and let them wonder about it. They will learn a lesson never to be forgotten.

Plant Lice, or Aphids. - These are among the commonest and most annoying insects we have. They infest almost every plant of the conservatory, garden, field, and forest and often become extremely destructive. Their mode of life consists in puncturing the plant and sucking its sap. They may attack the roots, as does the corn plant louse, Aphis maidis, or they may live on both the roots and leaves, as does the grape phylloxera, Phylloxera vastatrix, or they may occur on roots and bark, as does the woolly apple louse, Schizoneura lanigera. The greater number of species confine their injuries to the tender, growing parts, - leaves, buds, and young fruit, — as, for example, the green apple-tree aphid, $A$. mali, the peach-tree anhid, Mysus persica, and the common aphids of the rose, elm, carnation, and many other trees, shrubs, and plants.

Many kinds of plant lice have a pair of minute tubes on the back, through which a sweet fluid, honeydew, is excreted. This often covers the leaves and even the pavement under the trees. Injury to the trees is increased by 
the various mildews which the honeydew invites, and the beauty of the foliage is destroyed as well. Ants attend the aphids for this excretion, and some species of ants also preserve the eggs in their nests over winter and carry the newly hatched plant lice to their food plants in the spring. Bees sometimes make honey from honeydew, generally of a rank, inferior quality, but pay no attention to the aphids themselves.

From the bodies of many species of aphids are also produced white, powdery, downy, or flocculent growths that may serve to conceal the insect or render it unpalatable to birds. The woolly aphids of the alder, beech, and apple are good examples of this.

A number of aphids have the strange instinct of migrating from one kind of plant to another. The green appletree aphid thus migrates to the grasses to spend the summer and in the fall comes back to the apple to feed for a time and deposit its eggs. In a similar way the hop aphid, Phorodon humuli, feeds upon the plum in the spring, migrates to the hop to spend the summer, and returns to the plum in the fall.

With such small insects we cannot hope to do much by way of description or classification beyond naming them roughly from the plants upon which they are found, but their powers of multiplication and their relations to lady beetles and other natural enemies are valuable lines of study. We may take them up in connection with the life story of one common and important species, the cherry aphid, Mysus cerasi.

In October ask the children to hunt over cherry trees in the neighborhood and bring twigs infested with the 
black-cherry aphid. If these are kept fresh, the plant lice will desert the leaves and gather about the buds on the twigs. If they are carefully watched, preferably with a hand lens, they may be seen to lay their eggs, generally, in the angle between the bud and twig. The eggs are visible to the unaided eye and appear at first as oval,

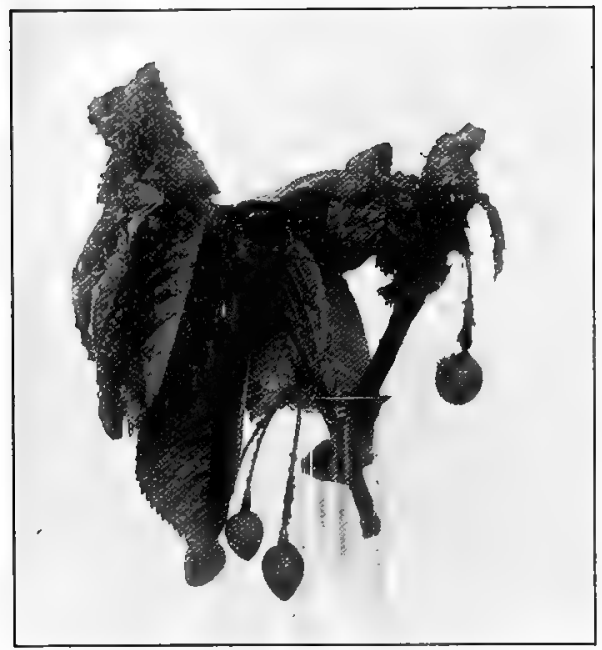

Fig. go. Cherry Twigs covered with Aphids yellowish-green bodies, which turn in a short time to shining black. The egg laying is an interesting process, a sight of which will repay much patient observation. The mystery to me always is how so infinitesimal a brain can know how to lay eggs at all, much less learn where to put them so that the young may find their natural food on hatching in the spring.

If this is not possible, the children will certainly be able any time during the winter to bring in cherry twigs that will have the eggs behind the buds. If these be taken into the schoolroom about the time the buds burst in the spring, the eggs will soon hatch into tiny black aphids. These have no wings and are all females, and 
after growing for about two weeks they will begin to give birth to living young - very small, but perfectly formed aphids - at the rate of possibly two or three a day. These also are females and, attaining their growth in a few days, in turn produce living young at this astonishing rate. Meanwhile, if we keep watch of the cherry trees, we may observe the increase of the aphids from a single one here and there to millions, covering the leaves, growing shoots, and even fruit, with disgusting black masses of the insects. When we think that the trees are about to be killed, a winged generation appears which leaves the cherry trees for some other plant. It is possible that this migration has been developed to save both trees and insects. It occurs generally about the time the cherries ripen, but to what plant they go has not been determined. In the fall winged females find their way back to the cherry trees, the eggs are laid behind the buds, and the year's cycle is completed.

Most of our common species of aphids present a similar life story. So far as is known, some do not migrate from one plant to another. A few, like the woolly aphid of the alder, have not been discovered to lay eggs, but pass the winter in the adult form in protected crevices about the bark and roots of their food trees, covered by their woolly coats.

Living the easy life of a parasite, sucking the nutritious juices of plants, aphids multiply at a most astonishing rate. Possibly for a month or so in the spring the class may arrange to have a single aphid on some convenient food plant and may be able to count from week to week the numbers produced. This will furnish the data for an 
interesting calculation as to the number that might arise from a single parent for a season or a year, and it will open the eyes of the pupils to the necessity of prompt action if they hope to prevent injury to their plants. The mathematician Réaumur estimated that in five generations, which might not require more than ten weeks, a single aphid could become the mother of 6,000,000,000,000. For the corn-root aphid Professor Forbes has calculated that a "stem mother," as the fertile females are called, might produce in a season $9,500,000,000,000$ young. Placed end to end these would form a procession $7,850,000$ miles in length, a distance equal to 3 I 4 times the earth's circumference; or, standing shoulder to shoulder, they would make an army ro feet wide and 230 miles long. Nothing in nature shows more clearly what an infinite power for harm a little thing may be.

Local conditions and interests should largely determine the species of aphids to be studied.

The grape phylloxera, $P$. vastatrix, is the insect which has devastated the vineyards of Europe, but it is not so destructive among the native grapes of this country. It exists in two forms, one infesting the leaves, the other the roots. In both locations the aphids cause knotty, wartlike galls, often conspicuous on the underside of grape leaves and also found on the finer rootlets. By cutting these galls open we may find the insects themselves. Plucking and burning the leaves as soon as the galls appear is the simplest remedy suggested, and any young vine with lumpy nodules on its roots had better be burned than planted. A little "sharp-eye" study of the grapevines about their homes will soon determine whether 
the children shall spend the time on the phylloxera or on some other form.

The apple-root plant louse, or woolly aphid, of the apple, Schizoneura lanigera, is another important species. Like the phylloxera it occurs in two forms. The one infesting the bark may be found in pits and crannies about the trunks and branches of apple trees; it is a blue-black aphid, the larger specimens covered with a bluish-white woolly growth. The underground form causes warty swellings on the roots. If an apple tree becomes sickly from no visible cause, borers or the like, its roots should be carefully examined, and if the root galls are found, it is generally best to dig it up and plant some other kind of tree,

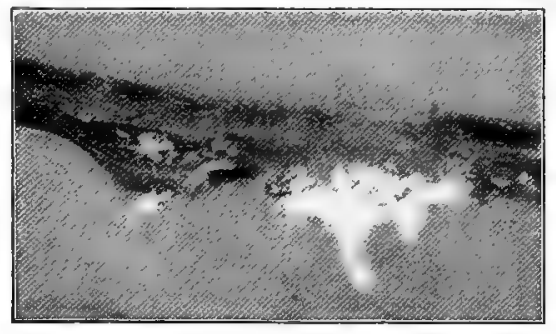

Fig. 9i. Woolly ApHids of Alple Showing characteristic swellings and cracks in the bark which they cause. (Natural size)

never an apple, in its place. Nursery stock that shows these root galls should be rejected, or if this is not practicable, the roots should be soaked for half an hour in water heated not above I $50^{\circ}$ Fahrenheit.

Other species, too numerous to name, may be found on the rose, apple, plum, peach, elm, maple, chestnut, oak, and on many herbaceous plants.

The Scale Insects, - Mealy Bugs, Scale Bugs, Bark Lice, resemble plant lice somewhat in their manner of life. As their common names imply, they appear as scales on the bark, leaves, and fruit of plants and, like the plant lice, 
subsist on the juices of their host by means of piercing and sucking mouth parts.

In the Lecaniums, or naked scale insects, the scale is the insect itself. In the majority of species, however, the scale is an armor composed of powdery, waxy, or even cal. careous substance, together with moulted skins, excreted by the insect and beneath which it lives. Several species

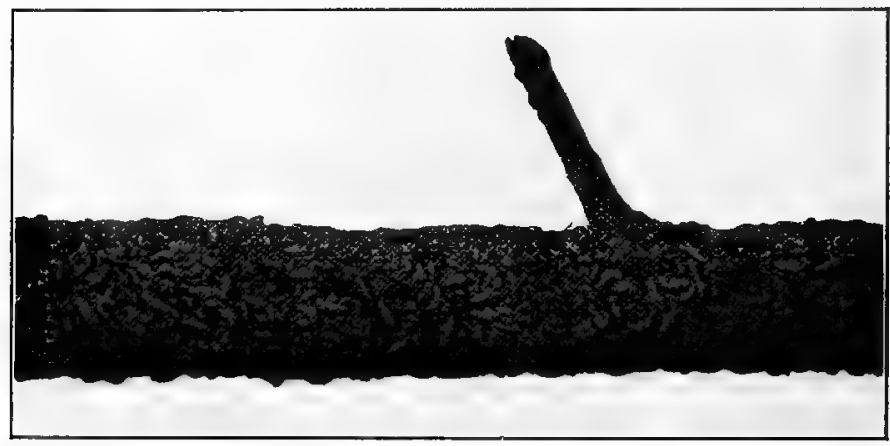

Fig. 92. Branch of WILlow Tree killed BY Oyster-SHell SCALE INSECTS

(About natural size)

furnish valuable commercial products, notably the cochineal insect, Coccus cacti, from which cochineal and carmine are derived, and Carteria lacca, living on the branches of several tropical trees, from which we get shellac; but our common species are among the most troublesome and destructive of insect pests. Like the plant lice they multiply with great rapidity, and their scaly coverings tend to protect them from the oily or soapy washes and sprays commonly used to kill insects by contact. 
Have the class hunt over the trees, shrubs, and vines in their gardens and bring in specimens of the scale insects that they find.

The oyster-shell bark louse, Mytilaspis pononm, is a common and easily distinguished scale, found often on the apple, pear, currant, and sometimes on the plum. The scale covering the female insect is about one-sixth of an inch in length, of characteristic oyster-shell form, sometimes completely incrusting the bark (Fig. 92). The males, which are not often seen, are smaller than the females and occur generally upon the leaves. The adult male is a minute two-winged fly whose relationship to its mate or parent could scarcely be suspected. By turning over one of the female scales any time during the fall, winter, or early spring, the eggs may be seen with the aid of a magnifying glass, sometimes as many as a hundred under a single scale. If an infested twig be placed in a bottle of water in the schoolroom, preferably one on each pupil's desk, in late May or early June, the eggs will soon hatch, and the young scales, appearing to the unaided eye as minute, crawling specks, may be seen swarming over the twig. In this stage they are without scaly covering, but after distributing themselves and finding suitable places, they settle down, insert their piercing beaks, begin to secrete a scale, and the females never again change their locations. Later in the season they are fertilized by the winged males, and by August the body of the female insect is little more than a bag of eggs. In the early autumn the eggs are extrucled underneath the scale, and the body of the female shrivels to a scarcely recognizable speck at the small end of the scale. Thus, 
for nearly nine months in the year, the oyster-shell bark louse exists in the egg state, and there is but one generation in a season. Hence the scales will never be found on the later growths of the preceding year; and while trees are frequently killed by this insect and young trees should not be planted until completely cleansed of them, it is a very slow process, and many trees are weakened rather than killed outright.

Many other scales will doubtless be found: Kermes on the oaks, interesting from their resemblance to gall-like knots on the twigs; Lecaniums, of a variety of shapes, on all kinds of plants. One of the Lecaniums, a large oval scale nearly a quarter of an inch in length, has become quite destructive to plum orchards in recent years. An instructive story attaches to the cottony cushion scale, Icerya purchasi, which some years ago threatened to destroy the orange groves of southern California. It had been introduced from Australia and before the danger was realized, as is too often the case, had become widely scattered. It was finally discovered that in its native home this scale is not particularly destructive, and a reason for this was sought and found in the fact that its numbers are there held in check by several predaceous lady beetles. One of these, Vedalia, a small red and black species, was successfully imported and soon relieved the orange groves of their unnatural burden and returned to them their loads of fruit.

In general, the smaller an insect enemy, the more dangerous it is, and its powers of destruction naturally increase with the number of plant species upon which it is able to feed. We might pass the scale insects by were 
it not for one pernicious kind, also a foreign importation, that now menaces the best horticultural interests of almost the whole country. Every child who has a garden should learn to know the San José, or pernicious, scale, Aspidiotus perniciosus.

The San José scale takes its name from the place of its introduction into this country, the San José valley, which took place through the medium of trees imported from Chili. Its original home may be Australia, but in spite of diligent search this has not been fully settled. It may have come from China or Japan. Three years after its introduction this scale was recognized as a dangerous insect enemy, but it had been widely distributed on cuttings, scions, nursery stock, and fruits shipped to all parts of the country.
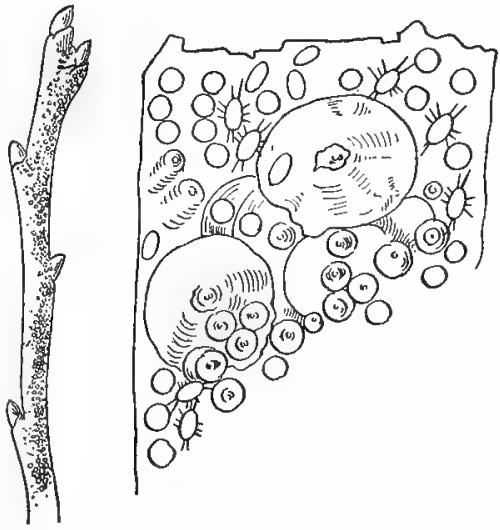

Fig. 93. The San Jose Scale

(Natural size and magnified)

The insect is minute and covers itself with a circular scale from one to two millimeters in diameter, of an ashy gray color, and with a minute prominence near the center. If unchecked, its power for evil is almost beyond estimate. The young are brought forth alive, and there are four or five generations a year, so that it has been calculated that a single female scale may be the progenitor of $3,216,080$,400 during a season. This gives the plant no chance for 
growth and little for life. As with the oyster-shell bark louse, the young crawl actively about for a short time after birth, and, since there are many generations, they flow up over the new growth, leaves, and fruit of the infested plant. The tree assumes the appearance of being dusted over with ashes, and each speck represents a tiny pump sucking its life sap.

The clanger from the San José scale is further enhanced by the great number of its food plants. It seems to thrive about equally well on the apple, apricot, cherry, currant, gooseberry, cotoneaster, hawthorn, peach, plum, pear, quince, rose, raspberry, spiræa, flowering quince, almond, euonymus, linden, flowering currant, acacia, persimmon, elm, osage orange, English walnut, pecan, alder, weeping willow, and laurel-leaved willow, and even this list is probably far from complete. Infested trees, if left to themselves, commonly die within a few years. Young peach trees may survive two or three years; older and hardier varieties, somewhat longer. Aside from injury by loss of sap the San José scale appears to poison the plant, and while there are two small, comparatively harmless, circular scales, which cannot be distinguished from it by the unaided eye, the sickly condition of the affected plant is generally a sign that we have to do with the pernicious scale.

If the San José scale is found, be careful to mount some permanently for the school collection and send a few twigs bearing specimens to the Agricultural Experiment Station of your state, with an exact statement of where they were found. Be sure that none of the specimens are alive. They should be held in boiling water for five minutes or left in a cyanide bottle over night before 
sending. If no pernicious scales can be found in the neighborhood, it might be well to send to your Agricultural Station for prepared specimens to be permanently kept in the school collection. From this source you can obtain any needed information about methods of dealing with the pest. ${ }^{1}$

Enemies of the pernicious scale are chiefly minute parasitic flies and several species of lady beetle. There is some evidence that it is attacked by a fungus, but by which one has not been discovered, if, in fact, it prove to be a fungus. These are topics somewhat minute to be studied by other than specialists.

A matter of great importance concerns the manner in which the insect is disseminated. The females have no wings, and, therefore, during the free-moving stage distribution by crawling is slow and can generally take place from tree to tree only when they stand close together or have interlacing branches. It has been discovered, however, that the young often crawl upon other insects, ants, and lady beetles, and probably also upon the feet of birds, and may be carried long distances. Any infested tree may thus be a menace to an entire neighborhood. The first method of its wide dissemination, before the danger was recognized, was on infested nursery stock, young trees, scions, cuttings, fruit, etc., but this is now controlled by

1 " There is perhaps no insect capable of causing greater damage to fruit in the United States, or perhaps the world, than the San José, or pernicious, scale." "The San José Scale: First Occurrences in the United States, with a Full Account of its Life History and the Remedies to be used against it," Bulletin NC. 3, New Series, United States Department of Agriculture, Washington, 1896 . See also "How to control the San José Scale," Circular No. 42, Second Series, Oct. 22, I goo. Same address. 
the nurserymen. The young trees and all other stock, if there is the least suspicion that the scale may be present, are put in a tight box and treated with the fumes of hydrocyanic acid, somewhat as we learned to kill insects in the cyanide bottle; so that, if such stock is accompanied by a certificate that it has been so treated, we need have no fear in planting trees, even if there are a few dead scales on them.

The following insects are so well known and found so easily that I shall do little more than mention their names. On account of their importance they should be included in a nature-study course.

The Colorado Potato Beetle should be studied in the spring. It is a good form to use in lower grades, in connection with their garden work, to show feeding, eggs, and larvæ. Professor Fernald has made a careful estimate that this insect collects a tax from the people of Massachusetts of not less than $\$ 75,000$ a year. If every one in a neighborhood would sprinkle his potato vines with a mixture of one part of Paris green to twenty of flour or plaster, as required, for the first week or two after they come up, there would be no more potato beetles that season. They pass the winter as adults in the ground, and since a female may lay from 500 to I000 eggs, and since there are from two to four broods a season, this is the time to do thorough work.

The Asparagus Beetle, Crioceris asparagi, has a life story similar to that of the potato beetle.

The Striped Cucumber Beetle, Diabrotica vittata. - The eggs are laid about the roots of cucumber, squash, melon, and other plants of the same family, and the larva feed upon the roots. 
The Grapevine Flea-Beetle, or Haltica chalybea.

The Imported Elm-Leaf Beetle. - Where numerous, this is a good insect with which to study bird foods. This may be done by making feeding tests, and by observing the birds that feed upon it, as the children go to and from school. They have increased especially in cities and towns where the native birds have been driven away by English sparrows.

The Imported Currant Worm, Nematus ventricosus. - This and the native currant worm, Pristiphora grossularia, are both sawflies about the size of the house fly, but more slender and with black areas on the front border of the forewings. The males and females may be found about the time currant leaves open in the spring, and a few days after, the white eggs are placed end to end along the veins on the underside of the leaves. I have been informed that a pair of black and white creeping warblers

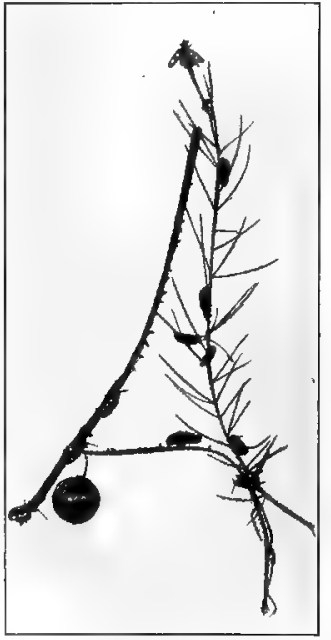

Fig. 94. Asparagus Beetles Eggs, larvæ, and adults

(Photograph by the author) kept one row of currant bushes so clean that the box of white hellebore, provided against them, remained unopened.

The Rose Slug, Monostegia rose. - This, familiar pest feeds upon the upper surface of the rose leaf, chiefly at night, remaining hidden beneath the leaf during the day. The rose bushes appear as if scorched and are greatly 
damaged. The parent is a small black sawfly with smoky wings. Numbers may be caught about the rose bushes on sunny mornings in May or early June. When full-grown the larvæ burrow into the ground and there pass the winter. Several authorities - Harris, Comstock, Cragin - state that there are two broods of rose slugs a year. Miss Murtfeldt's experiments, with which the writer's observations agree, prove that there is but a single brood.

The Pear-Tree Slug, Eriocampa cerasi, is the larva of a sawfly about the size of the above, shining black with

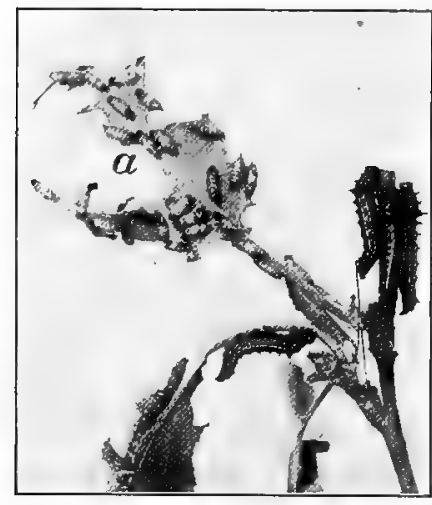

Fig. 95. Red-Humped Apple-Tree Caterpiliars

$a$, larvæ parasitized by ichneumons iridescent wings, the front pair smoky in the center. It feeds, like the rose slug, on pear or cherry leaves and winters in the ground.

The Red-Humped Apple-Tree Caterpillar, Edemasia concinna. - This species and the yellow-necked apple-tree caterpillar, Datana ministra, are apt to attract attention in the late summer or early fall. Their caterpillars are striped yellow and white on a dark ground, the one with the head and fourth segment coral red, the other with the head shining black and first segment orange. They feed and rest in close ranks and strip the branches perfectly clean as they descend. When disturbed they secrete an acrid-smelling fluid, which evidently protects them from birds. They are the larvæ of moths which spend the 
winter in the ground as pupæ and emerge in July to lay their eggs on the leaves.

The Cabbage Butterfly, Pieris rapa, is our commonest white butterfly. The females have two black spots on the fore wing, while the males have but one. This is one of the best forms for the pupils to rear. The writer has counted 465 ovules in a single specimen, which shows what a power for damage one little butterfly may be. But this is possibly the only one of our common butterflies that should be destroyed wherever seen.

The Cabbage Plusia, Plusia brassice. - The larva is a green, striped, measuring or looping caterpillar. The moth is dark smoky gray and flies and lays its eggs at night.

The Corn Worm, or Bollworm, Heliothis armigera. - This insect attacks the two great staples, corn and cotton, and is also a common pest on tomatoes, peas, and beans. When numerous enough to demand study, the larvæ, varying from grass green to dark brown, with a yellow stripe along each side, may be found in the tips of the ears of corn. When fully grown - they are about one and onehalf inches long - they bury themselves in the ground. Here they transform into brown chrysalids and emerge, after three or four weeks, as clay-yellow moths.

The Army Worm, Leucania unipuncta.

The Squash Bug, Anasa tristis. - This is a good example of a true bug, but a serious garden pest for all plants of the cucumber family. The eggs are yellowish brown or bronze in color, large and conspicuous, and neatly spaced in groups of twenty to forty on the leaves or stems of the food plant. 
The Chinch Bug, Blissus leucopterus, should be studied in sections where it is important. It will be particularly interesting to experiment with the white fungous clisease (see Chapter XXVII) which has been used in recent years to combat the pest.

The average annual loss which this insect causes to the United States cannot be less than $\$ 20,000,000$. HoWARD.

The Hessian Fly, Cecidomyia destructor. - The adult insect is a minute two-winged fly, the larvæ of which live between the sheathing bases of the leaves and in the stalks of wheat near the root. It derives its name from having been introduced, probably, with the bedding straw of the Hessian soldiers during the Revolutionary War, and has become, according to Comstock, "perhaps the most serious pest infesting wheat in this country." The larvæ and pupae, "flaxseed stage," may be found by opening the leaf sheaths.

Methods of controlling Insects. - In connection with the different insects already described I have laid all the emphasis on nature's methods. This, it has seemed to me, is the field for nature study. As an intelligent people we can no longer put off the agreeable task of learning the resources of life and nature to the end that we may make the most of the good forces of nature to suppress the evil. The chapters on birds and other insectivorous animals are written, in part, from this point of view. The swallows and swifts, night hawks and flycatchers, with the bats for night police, might sweep the air of insects. The warblers, vireos, cuckoos, wrens, orioles, chickadees, woodpeckers, cedar birds, and others protect 
the trees from their tops to their trunks. The robins and bluebirds, meadow larks and blackbircls, many of the sparrows, toads, frogs, and salamanders, and several of our harmless snakes (probably) feed largely on the insects of the ground. We need to know and cherish them all; and when we attain to this larger response to nature the insect problem will be for the most part a thing of the past. What insects now destroy we may have for education, art, and science. But until that time arrives we shall need to know some other methods of dealing with insects, and many of them are much in vogue at present.

Insects that chew - potato beetle, currant worm, rose slug, cankerworm, tent caterpillar, cabbage worm, codling moth, as it gnaws its way into the fruit, and a host of others - may be combated by means of poisons dusted or sprayed upon their food plant. A SprayCalendar, which any one can obtain from the Agricultural Experiment Station of his state, will give the formulas for all the different sprays and the times when each should be applièd.

Insects that suck - plant lice, scale insects, squash bugs, and bugs generally - require substances that will kill by contact, or soapy or oily mixtures that will get into their breathing pores and smother them. Your Spray-Calendar will give all of these preparations with directions for their use.

Insects that bore can be detected by the sawdust-like chips or the exudations of sap or gum from burrows. Those that work in or just under the bark may be cut out with a knife. Such as work deeper can often be destroyed with a piece of piano wire. Another way to reach the villains is to inject a little carbon bisulphide into the burrow and quickly plug it up tight. 


\section{CHAPTER XIV}

\section{BENEFICIAL INSECTS}

\section{The Honeybee}

WE may begin by asking the class some bright morning in May: What did you see the bees doing, on your way to school? What flowers were they on? Did you see their hip pockets full of pollen? What do you suppose they do with that? Where do they find the honey? These with a hundred others are just the questions with which to begin the study of the honeybee's life and work.

Have in different vials a house fly, bluebottle, wasp, hornet, ant, bumblebee, a honeybee, if possible with pollen on its thighs, and any other insects that may look somewhat like a honeybee. Pass them around and find out how many can tell a honeybee from every other insect. Do not let anybody tell until all have had a good chance to see. Ask each child to borrow somebody's watch between this lesson and the next and to follow a bee for five minutes, and be prepared to tell exactly what it did. How many blossoms did it visit? What kind were they? Were they all the same kind, or did it go from one kind to another? From their observations, what can they say as to the flowers the bees like best? Could they see how a bee fills its pollen baskets? For lower grades and the kindergarten, a pound section of honey may furnish 
material for an instructive demonstration. In higher grades, something of the same kind may be done by way of testing different specimens, to see if the pupils can distinguish the aroma of the flower from which the honey is made, comparing pure honey with a sample of some adulterated honey that may have found its way into the neighboring stores.

The next series of lessons may well be directed to discovering the influence of bees on the pollination of flowers and fruits. Select, or raise in the school garden, two similar clumps of white or alsike clover. To study the work of bumblebees red clover may be used. Cover one clump with netting before any of the blossoms open, leaving the other uncovered. Have some one appointed to save and count all the heads that mature in each clump; carefully thresh out the seeds

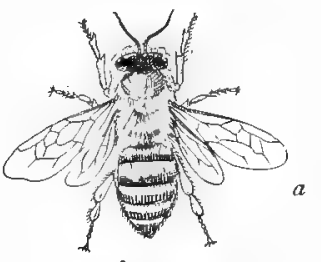

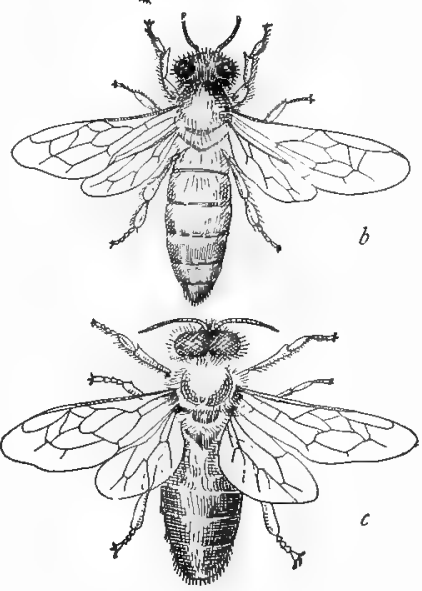

Fig. 96. Honeybees

$a$, worker; $b$, queen; $c$, drone. and put up in two vials, properly labeled. ${ }^{1}$

Any other flowers that are of interest in the locality may be treated in the same way; at least, a number of

1 If crimson clover is used, the whole experiment may be completed in the spring term. 
our common garden fruits should be experimented with. Cover a clump of strawberries before the buds open, and count the blossoms; leave a similar clump uncovered, and compare the fruit. In the same way cover a small branch of plum, peach, quince, pear, cherry, and apple. This has been done for some of our fruits, with the result that not only are more fruits generally found to "set" on the exposed branches, but the fruit is often larger, plumper, and richer in quality, and the seeds are large and well developed, while those in self-pollinated fruits on the same tree are small and often abortive, i.e., without kernels. When these experiments are made, the fruits may be saved, preserved in formalin, or may be carefully drawn to exact size for the school collection. The seeds may also be preserved to show that, in times past, a honeybee possibly assisted in the production of those seeds that have given origin to many of our improved varieties of fruit. ${ }^{1}$

The study will naturally irradiate into the more general subject of the value of insects in cross-pollination. What other insects are seen about the fruit blossoms? Are other insects numerous at this season? With all of our native bees - bumblebees, hornets, wasps - the queens alone survive the winter. Comparatively few of the other blossom-seeking insects live through the winter, and many of these do not come out of their winter quarters in time for fruit bloom. Here we have the one efficient insect which carries over the winter an army of workers, ready to

1 "The Pollination of Pear Flowers," Merton B. White, United States Department of Agriculture, I894. See also "Pollination in Orchards," Bulletin I8I, Cornell University Agricultural Experiment Station, I900. 
pour forth into the orchards and do the work that the trees require at this season. How many fruit blossoms does a bee visit in a minute? I have counted a number of times, and the average is about twenty per minute. How many men or boys would it take to do as much of this work as a single bee? as a hive of twenty thousand? Attempts have been made to raise fruit on a large scale with no bees in the locality, but year after year no fruit has been produced. Bees were introduced, and abundant crops followed. Seasons in which the weather is too cold or stormy for bees to fly during fruit bloom are well known to be poor fruit years.

Is the neighborhood well stocked with bees? This is the next question. Mr. Benton has estimated that there are about one-tenth as many bees as the flowers of the land will support, at the average profit per hive. Some approximation to an answer to our question may be attained by asking the pupils to collect statistics as to the yield of honey per colony in the neighborhood. An average yield of honey for large apiaries is from about 50 to roo pounds per colony. Of course the management of the bees makes a great difference in the yield, as does also the season. ${ }^{1}$ A single swarm has been known to make I 000 pounds in a season. Bees are supposed to fly and do most of their collecting within a radius of about two miles, and within this circle, four miles in diameter, it is commonly estimated that 200 swarms may be maintained. ${ }^{2}$

$1 \mathrm{~A}$ hive has been known to gain thirty-two pounds in weight in a single day during an abundant flow of linden nectar. Of course this is nectar, which must be evaporated down by the bees before it is honey.

2 Bees have been kept on an island and have been proved to fly as far as seven miles to find the flowers. How well they thrived under these conditions, however, is not stated. 
The next topic is the management of a hive of bees. How many of the class know anything about it? How many have bees of their own? Do any of their parents keep bees? If none of the chilclren or their parents have bees, the study may have to be concluded at this point. If, however, the locality be favorable, there is one more question to be asked. Who will volunteer to get some bees and begin to study them?

A swarm of bees in a glass hive in an upper story or attic window of the school building may prove a most instructive part of the nature-study equipment, where conditions in the school and district permit. Under these conditions, I include a number of things. The spirit of the school comes first. If bees are common and everybody knows and sees enough of them, it may not be valuable. If nobody knows anything about the management of them, wait until somebody learns before attempting it. Bees are sometimes kept with profit on the roofs of houses in large cities, but, in general, where there are no flowers within two or three miles, a school hive is out of the question.

One thing is clear at the outset. If it is deemed advisable to have a school hive, none of the care of it should be allowed to devolve upon the teacher. True, if one thoroughly understands the subject, there need be but little work about managing a single swarm of bees; still this little must be done at the proper times, and a teacher already has too many things to look after. If some one, or better, if a group of the older children, wish to volunteer to put the hive in the school or in one of their homes, where it will be available for study, then the experiment 
may be tried and will probably prove successful. Its success will be doubly assured if some parent who understands bee keeping and is interested in the school will direct and assist the children in their work. The following suggestions are offered to help such a group of children. They embody the results of four years of experimenting as to the simplest methods of demonstrating the life of the hive. ${ }^{1}$

First a "nucleus hive," i.e., a little hive, may be made with an ordinary one-pound section and a glass case to fit over it. To arrange this select a partially filled section of honey and drive small brads into the corners, letting the heads stick out one-half of an inch below for it to stand on and a quarter of an inch at the sides to insure room for the bees to

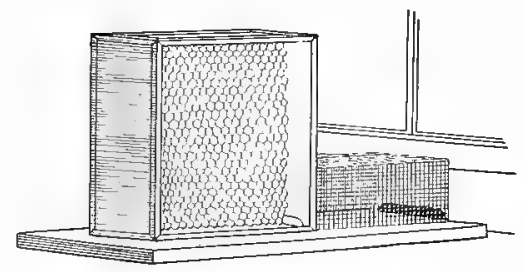

Fig. 97. Nucleus Hive pass between the section and the glass case that is to cover it. Next cut pieces of glass the right size to make a glass case to slip over the section. The front glass must be cut one-quarter of an inch short to allow a space for the bees to go in and out at the bottom in front. Fasten this together with half-inch strips of black cotton cloth and glue, laying the strips over the corners. After

1 If local libraries or the neighborhood are not supplied with books on bees, the class should get Bulletin No. $I$, United States Department of Agriculture, "The Honey Bee," by Frank Benton. It may be obtained from the Superintendent of Documents, Union Building, Washington, D.C., for 25 cents. 
the glue is dry flow a little melted beeswax, with a hot case knife, all around the corners on the inside. This is to prevent moisture of the bees from softening the glue. The bottom should be made of a board, about six inches

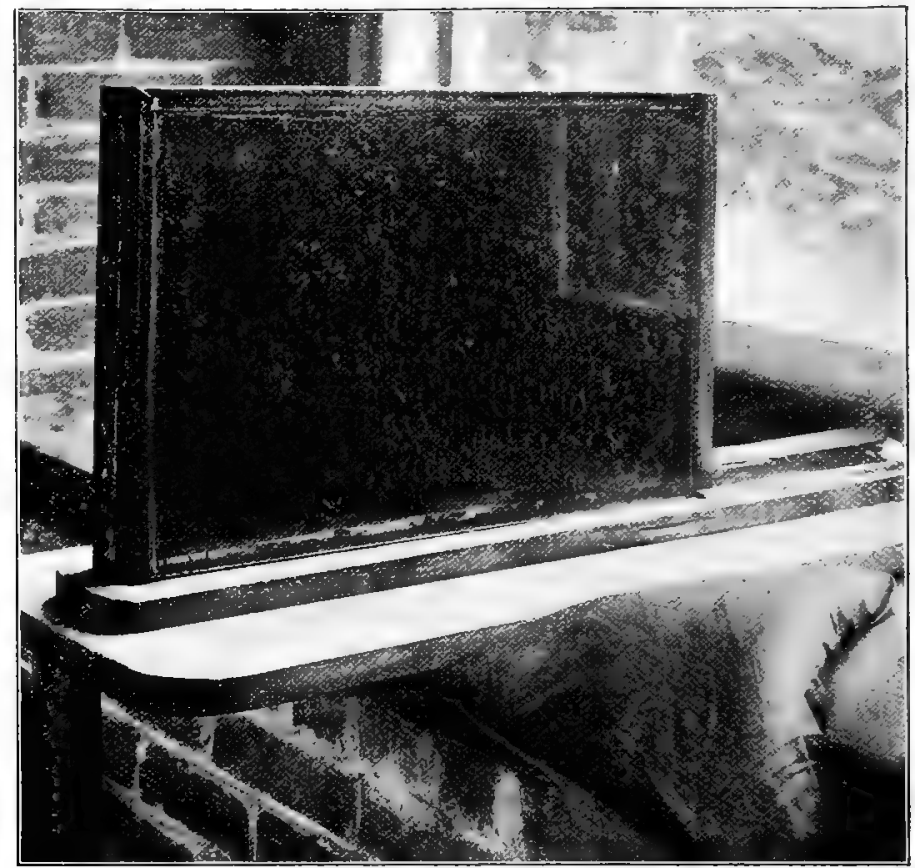

Fig. 98. Single-Frame Observation Hive in Position (Photograph by the author)

wide and long enough to extend ten inches in front of the hive. Bees need to be kept warm, and they commonly insist upon having their hive totally dark. To secure both of these conditions, make a rather thick quilt that can be pinned snugly over the glass case. 
It remains to mount the hive in some upstairs window, preferably in the attic, or in some room that is not used.

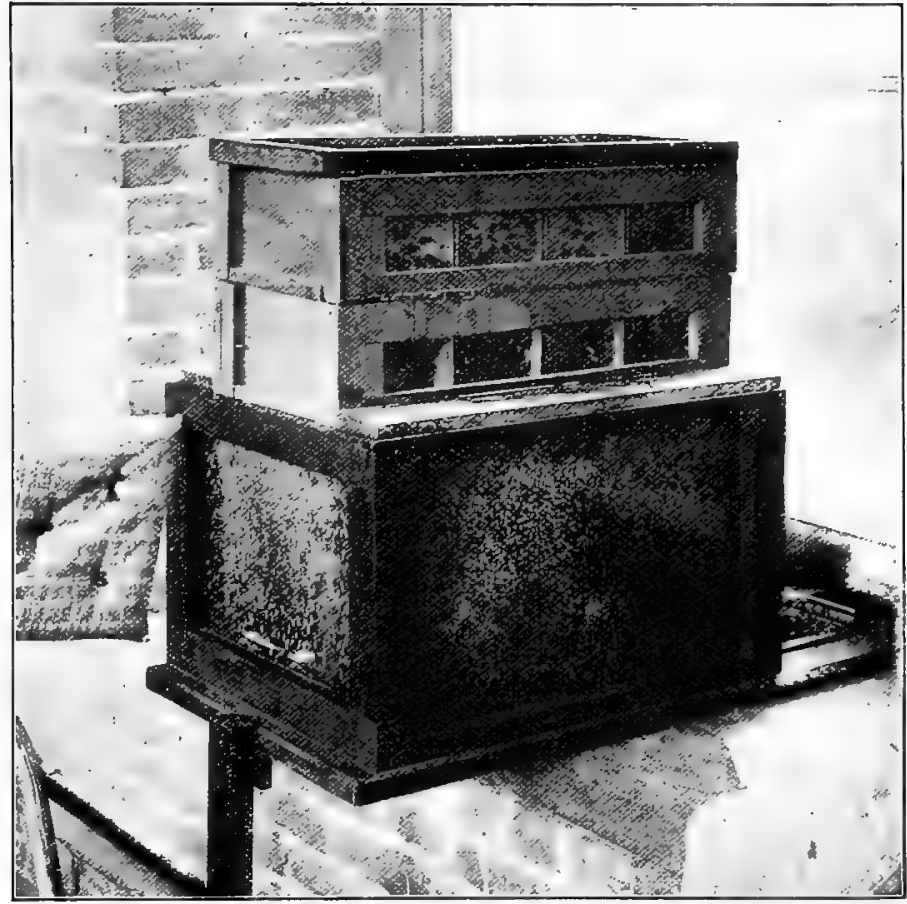

Fig. 99. Observation Hive in Position

The large box is known as the "brood chamber," or "hive body." In it the queen lives and lays eggs, and the bees nurse the young, or "brood." The two cases above are the "supers," in which the bees store their surplus honey. Toward the window is seen the wire screen passageway, through which the workers go and come

Fasten a narrow board under the sash, and, setting the hive in place, mark where the bottom board comes and cut a hole one inch wide by one-half of an inch deep, through 
which the bees may go out. Finally, make a screen-wire tunnel, an inch high and as wide as the hive, to fit perfectly between the hive and the board under the window sash. This is to prevent the bees from escaping into the room.

The best time to fill the hive is in the spring, when some local bee keeper is "cutting out" his first queen cells. Take the little hive to him and get him to insert a capped queen cell with about a teacupful of bees from the same hive, closing it up so that no bees can escape. It may then be screwed to the window sill where it is to stand. The bees should be confined for three or four days, if possible, until the young queen emerges, and it is well to feed them a little syrup or honey daily to make them feel at home, otherwise they may all decamp to their hive. ${ }^{1}$ Fig. 97 shows this hive in position.

An observation hive that is more certain to give satisfaction is shown in Fig. 98. The glass case for this may be made like the other except that the front glass is replaced by a strong wooden post, with entrance hole below, very securely screwed to the bottom board. The size must be governed by the size of the frames in the hive from which the bees are to come. Take this to a bee keeper and have him set in one of his frames, well filled with brood and covered with bees. $\mathrm{He}$ will be sure

1 I have had two of these little hives made from one-pound sections, and nothing more interesting could be desired. In one of them that stood in my window an entire season I was able to study every activity of bees, even better than in a larger hive. The third one I tried in exactly the same way worked well for a few weeks, when the queen concluded that it was too small for her ambitions, and she forthwith decamped, taking all the bees with her. They next went into one of my bird houses in a tree, but soon left that. It would probably be difficult to keep so small a hive alive over winter. 
that there are eggs in it from which the bees may rear a queen, and this interesting process may then be observed by the school from day to day, and it will be a red-letter day when her royal highness comes out.

A third form of school hive is a full-sized swarm in a glass box. This can be made of one-inch pine for the frame, with glass set in for ends and sides. The top should be made of a similar, glazed frame just large enough to cover a honey super. If this be narrower than the top of the hive, it may be supplemented by narrow strips of board. The whole stands, without fastening, on a solid bottom board, which may be screwed to the window sill in front and supported by a post at the back. Otherwise its mounting, covering, and manipulation is in every way like that of the smaller hives described above. ${ }^{1}$

Each form of hive has some special feature to its advantage. The small one requires little room and still demonstrates the whole life of the hive. The single large frame does this more perfectly, but may cost something. The single-frame hives both possess the advantage that the queen can always be found, and in the larger one young bees may generally be seen gnawing their way out of their cells, - two most interesting things to watch. Marked bees may also be followed when they come in, and may be seen distributing their load of nectar to the other bees or kicking off their pollen balls into the cells. On the other

1 Bees are greatly disturbed by any jarring of their hive, about as much as human communities are by earthquakes. This is obviated by the qui't coverings. For the large hive it is well to make these in square sections, each large enough to cover a side or end, and with one longer strip which can cover one side, and the top with three supers in place. 
hand, these little swarms can make no surplus honey, the chief reason for which bees are kept, and they will not be likely to "swarm," which is an interesting thing, an advantage or disadvantage according to taste. In the large hive the queen will be busy laying eggs in the inner frames and may not be seen from one year to another, honey being stored usually in the combs next to the glass. This is a disadvantage; still it is only in such a

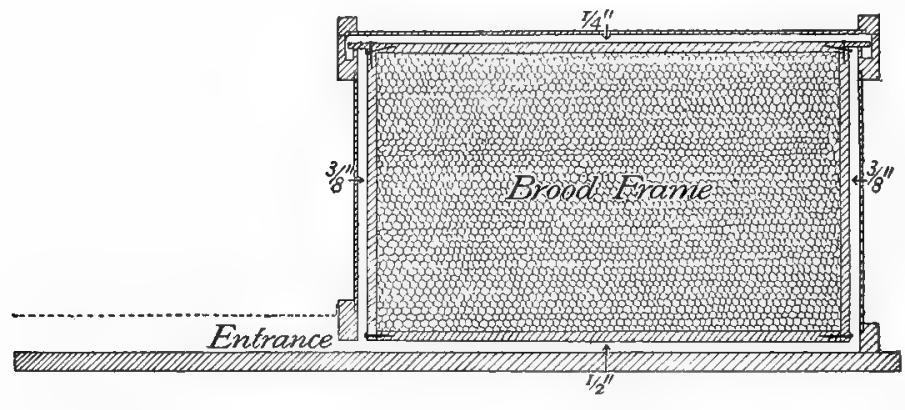

Fig. ioo. Sectional Plan of Observation Hive

The size depends on size of brood frame. The bee space should be $\frac{1}{2}$ in. below, $\frac{3}{3}$ in. at ends, and $\frac{1}{4}$ in, above

large hive that we can see the life of a bee-city in its fullness, - the thousands of workers, the continuous streams of out-going and in-coming bees, - and thus gain some conception of the great work they perform.

The honeybee is not native to this continent. It was imported from Europe, when or by whom is not known, and has since spread from the Atlantic to the Pacific. Since about 1860 the United States Department of Agriculture has been engaged in searching over the greater part of the globe to find and introduce the best races of bees 
that could be discovered, so that we now have four varieties, each excelling in certain points.

The common black or brown or German bees have become better acclimated than any of the others, and during their 200 years of residence have become the common wild bees of the whole country. Their faults are: bad temper, which makes them hard to handle; their tendency to desert their combs and to "ball up" so that it is difficult to find the queen; and their failure to resist the attacks of the bee moth. This is a most serious defect. A colony of black bees left a season without being looked over and the moths removed from time to time is likely to be found empty of bees and a mass of ugly caterpillars, moths, webs, and cocoons. The bees themselves are fair honey gatherers, make white comb honey, and winter well. They are medium-sized and dark brown, sometimes almost black, in color.

The Italian bees, imported to this country in I860, have found greater favor with bee keepers than any other race. They are large, beautiful bees, with the first three bands of the abdomen yellow or leather colored. They are gentle, can be handled easily, stick to their combs so well that the frames may be lifted from the hive and stood up about the yard, while the bees go on with their work as if nothing had happened. On this account, the queen may easily be found at any time. I have sometimes seen an I talian queen continue laying eggs while the frame she was on was taken from the hive. Italian bees are better honey gatherers than the blacks, cap their honey fairly white, and resist attacks of the bee moth, so that for this reason alone, where this pest is present, it would pay to keep only Italian bees; but they do not winter quite so well in the colder sections of this country.

Carniolans are large ashy gray bees with silvery white hairs, the gentlest and most beautiful of all races. They were imported from the Alpine province of Carniola, Austria, in 1884. They are fair honey gatherers and cap their honey exceedingly white. How they cope with the bee moth is not stated in the books. The Carniolans winter better than any other strain and are prolific, but they have the reputation of swarming excessively. This is their greatest disadvantage, and Frank Benton is inclined to think that it is due to the 
warmth of our summers, and that consequently the hives should be well protected by shade.

Cyprians, Holy Lands, or Syrians have scored the highest honey record of any bees ever tested in this country, I000 pounds from a hive in a single season. They were brought from Cyprus. They are a small bee, slender and active, with the first three bands of the abdomen orange above and all the segments underneath yellow; often to the tip. The white appearance of honey is chiefly due to a little harmless deception on the part of the bees that make it. Instead of filling the cells full they leave a little bubble of air under the cap, and this looks white by reflected light. The Cyprian bees are too honest for this and fill the cells full of honey. Their pains, however, gives the honey a dead, "watery" look, which injures its selling quality. It is said that they never molest one that may pass their hives or be working among them, unless a hive itself be directly interfered with. Then they are the fiercest and most persistent of fighters. They thus protect their hives better than any other race from robber bees, bee moths, and all other intruders, but this character has rendered the handling of them so disagreeable that their culture has not made much progress in this country.

As may be inferred from the above, the effort is to obtain the best variety of bee in the world. When this is discovered, the stock may be still further improved by selection and breeding, as in the case of other domestic animals and plants. Just now the attempt is being made to find a bee whose tongue is long enough to reach the nectar in the red clover. If any child can find a honeybee that is working on red-clover blossoms and can discover the hive to which it belongs, he may help along this work and possibly make a name and a fortune for himself. Both the farmer and the bee keeper would be benefited. It would doubtless make possible the more complete cross-fertilization of the clover and give the farmer more and better seed than he now gets by the help of bumblebees. The bee keeper could then save the barrels of nectar that now go to waste in the red-clover blossoms.

"Lining" bees is a topic that may well be studied during an excursion, or even in the school yard, if bees can be found. Take a little honey, and after allowing a bee to fill her honey sac take the 
direction of her flight. She will make a bee line toward the hive, or bee tree, from which she came. A little flour dusted over the bee will make it easier to follow her flight. In this way bee hunters locate bee trees in the woods. A bee line is obtained at one position; the hunter then moves to a new position some distance to the right or left of his first stand and gets another bee line. The bee tree will be found where the two lines intersect. In tracing bees from red clover, if they can find any such there, let some of the class dust flour on the bees in the field and others watch at the apiary toward which they fly and find the hive to which the floured bees belong. Follow the matter up by finding out how much honey this hive makes (it may be one or two hundred pounds more than any other colony in the neighborhood), and then see if any one can be found who has a microscope and can measure the tongues of the redclover bees, comparing them with the tongues of bees that do not work on red clover. Finally, have a member, or committee, of the class write up the story and get it printed in the local paper and in some bee journal. Possibly, if all the boys and girls in the United States keep a sharp lookout all next summer, not more than a dozen will find honeybees working on red clover. But even if these few were discovered, by modern methods of queen rearing we might have within ten or fifteen years, the long-tongued bees as common as ordinary bees are now.

\section{Comparative Value of Differen's Races of Bees}

(Marked on a scale of ten. Estimates of FrANK BENTON)

\begin{tabular}{|c|c|c|c|c|c|c|c|}
\hline RACE & $\begin{array}{c}\text { GENTLE- } \\
\text { NESS }\end{array}$ & $\begin{array}{c}\text { Honey } \\
\text { Gather- } \\
\text { ING }\end{array}$ & $\begin{array}{l}\text { RESIST- } \\
\text { ANCE TO } \\
\text { MOTH }\end{array}$ & $\begin{array}{l}\text { WINTER- } \\
\text { ING }\end{array}$ & $\begin{array}{c}\text { ProLIFIC- } \\
\text { NESS }\end{array}$ & $\begin{array}{c}\text { SWARM- } \\
\text { ING }\end{array}$ & $\begin{array}{c}\text { LENGTH } \\
\text { OF } \\
\text { Tonguh }\end{array}$ \\
\hline Black . . & 5 & 5 & 4 & 8 & .5 & 6 & 6 \\
\hline Italian. . & 8 & 7 & 8 & 6 & 7 & 8 & 8 \\
\hline Carniolan & Io & 8 & 7 & Io & 9 & 10 & 8 \\
\hline Cyprian. & 7 & Io & Io & 7 & 10 & 8 & 10 \\
\hline Dorsata. & 7 & & & & 8 & & IO \\
\hline
\end{tabular}


Besides the honeybee there are about five thousand different kinds of bees, bumblebees of many different kinds, carpenter bees, digger or burrowing bees, potter bees, and cuckoo bees, all having most interesting habits and instincts, and many exceedingly beautiful. With all our native bees the life story of the individuals is similar to that of the honeybee, except in regard to the food of the larvæ, which may be leaves or insects; but the story of the colony is altogether different. Most of them are "solitary," and those that have social habits have not developed the stability and perfection of organization found in the hive bee and among the ants.

In the spring, for example, there are no colonies of bumblebees, and the few we see about early spring flowers are solitary queens that have hibernated in some protected shelter during the winter. They collect honey and pollen and select suitable places for their homes (commonly deserted mice nests), build cells and lay eggs in them, feed the young, and thus continue until the larvæ begin to emerge. The first bees are small workers, and they soon relieve their mother of the labors of both field and nest. Subsequent broods during the summer are large workers, and these rapidly increase the stores of the nest. In August a generation of queens and drones emerge, and these soon scatter over the fields and leave the nest deserted. The workers and drones die, and the queens alone survive the winter.

Coville succeeded in moving bumblebee nests to glass-covered boxes in his window arranged essentially like the beehives above described. He did this by chloroforming the bees lightly in the evening, when they were all at home. After being confined for a day 
they learned their new location and accepted it without difficulty. One other observer has told me of catching a queen bumblebee early in the spring, taming her by feeding with honey, and inducing her to accept a nest he had provided in a large bottle. He was thus able to watch the colony from beginning to end.

Bumblebees are valuable insects, aside from the interest attaching to the study of them, from the work they per- . form in the fertilization of flowers, especially red clover. Greenhouse men, who raise melons, cucumbers, and tomatoes under glass, are obliged to keep swarms of honeybees to carry the pollen from flower to flower. But honeybees do not live long under such confinement and hence must be replaced by fresh hives perhaps once or twice a year. It has been suggested that bumblebees might do this work fully as well at little or no expense. To try the experiment it would only be necessary to catch a few queens as late in the fall as possible and confine them in the greenhouse, supplying them with field-mice nests. What boy will try this plan and report results?

Other near relatives of the honeybees are the wasps and hornets, and here again we have hundreds of different species, some social, like the bumblebees, and many solitary. Most of these make burrows in the ground, like the digger bees, but they provide as food for their young, instead of pollen and honey, insects, spiders, etc., stung with such care and precision that they are paralyzed but not killed. The common mud wasp, or mud dauber, is very easily studied and will serve, if time permits, to initiate the children into the mysteries of this fascinating group. ${ }^{1}$

1 George W. and Elizabeth G. Peckham, "On the Instincts and Habits of the Solitary Wasps," Bulletin No. 2, Wisconsin Geological and Natural 
Among the social wasps the white-faced hornet is the one to study. It may seem strange to classify this archenemy of our boyhood, whose huge paper nests have been the legitimate targets for stones and later for rifle and shotgun, among the beneficial insects. But Mrs. Treat says of them:

Are orchardists and gardeners aware of the untold numbers of noxious insects that a colony of White-faced hornets will destroy in a season?... I would rather have a colony in my orchard when infested with the slug, Selandria cerasi, than ever so many barrels of London-purple. In the summer of I886 I found these hornets were busy from morning until night in the orchard, taking slugs from the leaves, and carrying them to their young, where their nest was suspended in one of the trees. Injurious Insects of the Farm and Garden, p. 288. (On the other side it should be stated that where grapes or peaches are raised the hornets are known to gnaw holes in the fruit, and this opens the way for honeybees and may lead to great injury to the crop. It thus sometimes becomes necessary to destroy all the hornets in the neighborhood before the fruit begins to ripen, and this is a simple matter, since the nests are so easily found.)

The life story of the white-faced hornet resembles that of the bumblebee. The queen alone lives over winter and in the spring makes her own paper and begins to build the nest alone. As cells are made she lays the eggs in them and feeds the larvæ on finely chewed insects. To see the tiny maggot-like larvæ stretch themselves almost out of their cells when the queen mother comes with food puts one in mind of nestling birds, only it seems more

History Survey. Of this Howard says (Insect Book, p. 18) : "No more readable book on a natural history topic was ever prepared, not even excepting the famous Natural History of Selbourne or the general volume of Kirby and Spence's Introduction." 
wonderful. The first brood consists of small-sized workers, and, as these take up the labors of nest-building and food-bringing, larger workers are produced. Finally, in the early autumn a generation of males and females is produced, and the queens hibernate, to repeat the story the following year. The queens often crawl into attics to spend the winter, and a few are sometimes found in the old nests. A queen might be taken in the fall or early in the spring, and if provided with paper pulp, honey, and abundance of insect food, she would quite probably build a nest and afford a most instructive demonstration of insect life. The white-faced hornet is especially interesting from the fact that the suggestion for making paper from wood pulp, which is now such an extensive industry, was probably obtained directly from its wonderful nest.

The specimen figured below, from which one side has been cut to show internal arrangement, was built by the queen before any of her brood had come to her aid.

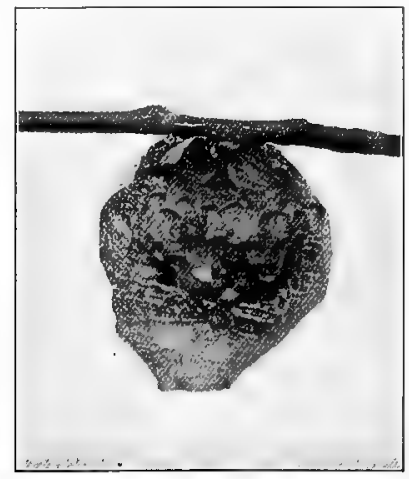




\section{CHAPTER XV}

\section{INSECTS BENEFICIAL AND BEAUTIFUL}

Ichneumon Flies. - The insect photographed in Fig. 101 is drilling into hard maple wood for the purpose of laying

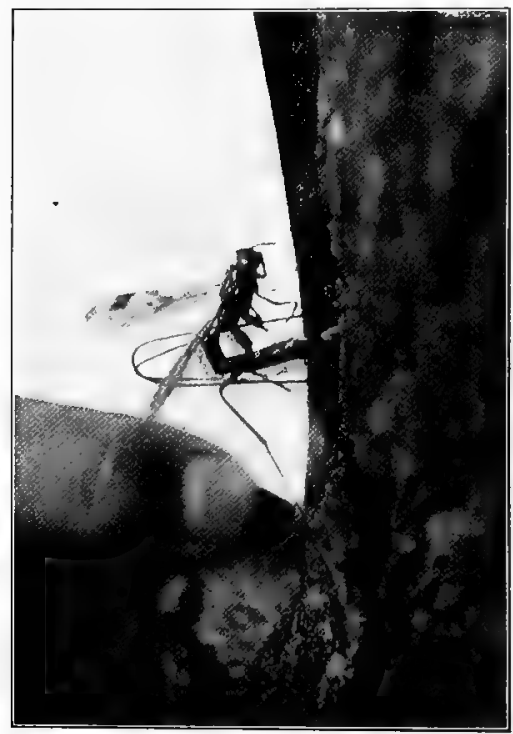

FIG, IOI. ICHNEUMON FLY BORING INTO A TREE

(About g natural size) an egg in the burrow of a wood-boring larva. How long she had been there before I found her it is impossible to state, but for more than two hours she worked, inserting and partially withdrawing her drill repeatedly, until it had penetrated nearly two inches into the hard wood. At last she withdrew the drill, apparently satisfied, and flew away, to save more maple trees from borers, I hope, for, after seeing her good works I had
cyanide bottle. It was not the heart to put her in the cyanide bottle. It was wonderful to see another, that came to the same tree while 246 
I was watching, hunt over the surface inch by inch for a likely place to drill; but, after about an hour's search, she flew away. Certainly nothing I have ever observed has so impressed upon my mind the marvelous perfection of Nature's mechanisms and the completeness with which every darkest nook and corner of her domain is guarded. A horntail, Tremex, bores deep into the tree and deposits her egg. Who would think that any harm could reach it there? But the ichneumon fly is armed and equipped for

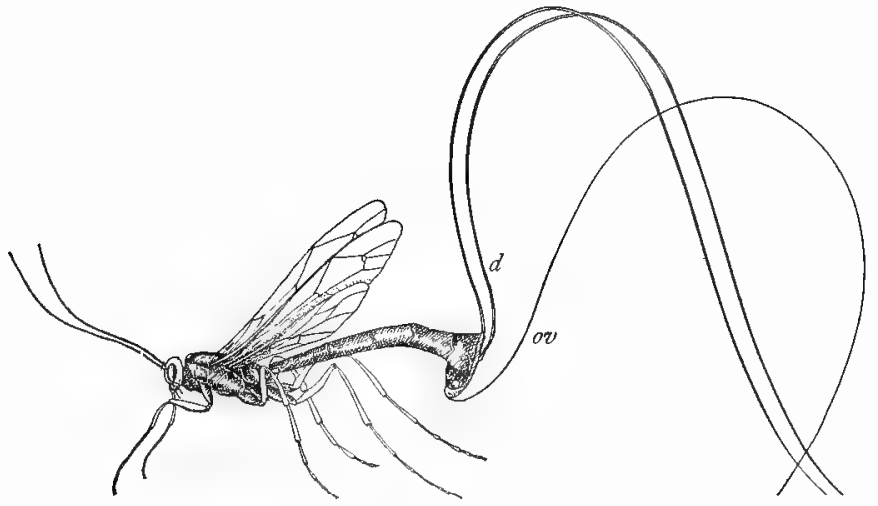

FIg. to2. Black Thalessa

$d$, drill; ov, ovipositor. (Th natural size)

her task. Her egg hatches in the burrow of the Tremex, the young ichneumon finds the wood-boring larva, lives as a parasite upon it, and, finally, after completing its transformations, emerges as the ichneumon fly in the picture.

There are more than a thousand genera of ichneumon flies, with, of course, a great many more species, and if the Tremex larva is not safe in the heart of a maple tree, what must be the fate of the thousands of larvæ that feed 
unprotected on the leaves of plants? The truth is that nearly all of them have one or more species of ichneumon fly ever seeking a victim in which to deposit her eggs. So we shall find with nearly every species of larva we attempt to rear that one of these parasitic flies has come before us, and instead of the moth or butterfly we expected, we get the brood of parasites. If we are intent on securing butterflies and moths, this is sometimes annoying; but if we are studying insect life in the large, we are thus often rewarded with a glimpse of one of its most interesting and important phases.

Simply ichneumons or, if that is not sufficient, ichneumon wasps would be a better term by which to designate this group, since they resemble wasps much more than they do flies; but they are described in all the books as "ichneumon flies," and to change the name will take a long time. Ichneumons are generally large or good-sized parasitic insects, but some are minute. They have four wings, like the bees and wasps, long, incessantly vibrating antennæe, and their prevailing color is dull yellow, though many are black, marked with yellow. Our largest species is the beautiful Thalessa atrata, which from the tip of the antennæ to the end of the ovipositor measures nearly ten inches. It is parasitic on the larva of the pigeon horntail, Tremex columba, a common borer in elms, oaks, buttonwoods, and maples. Pimpla inquisitor, one of the commonest and most widely distributed, ranging from Massachusetts to California, is parasitic on a number of caterpillars. The body is about half an inch long, shining black. The pupils are pretty certain to find it in connection with their studies on the tent caterpillars and 
the white-marked tussock moth. A favorite time for the Pimpla to sting her victim is while the caterpillar is spinning its cocoon; and if a number in this stage are placed in an open window in the schoolroom, it is quite possible that a Pimpla may come and show how she does her work. The eggs of the Pimpla hatch into whitish larvæ, which feed actively and attain their growth in about four days.

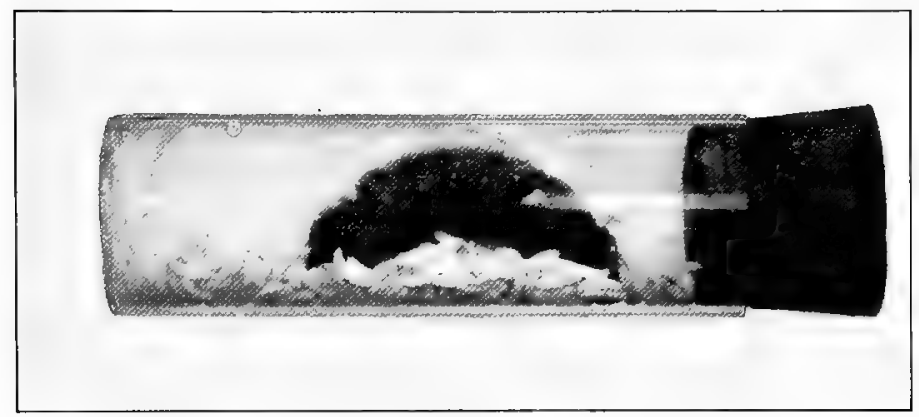

Fig. io3. Tomato Sphinx Larva

With parasites emerging; 268 are out or in sight. (Natural size)

They then spin slender yellowish-brown cocoons, transform into pupæ, and emerge in about ten days as adult ichneumons; so that the whole life story from egg around to egg may not require more than fifteen days to be completed.

Until recently all the four-winged parasitic insects were called ichneumon flies. Now the group has been much subdivided; but since the distinctions upon which these divisions have been made are mostly minute and technical, we may leave them to specialists. It will be sufficient, for elementary work, if we gain some clear ideas of the rôle that parasitic insects play in nature. 
The smaller ichneumons (of course there are distinctions other than size) are now called "braconids," and the smallest, many of them not more than one one-hundredth of an inch in length, have been set apart by themselves as the Chalcis flies.

The Braconids. - One of the commonest braconids is parasitic on the tomato sphinx. Others are found on the grape sphinx and the cabbage worms. Little bunches of white or yellow cocoons, often found attached to grasses and weeds, if preserved in a bottle covered with gauze, will be found to contain insects of this family.

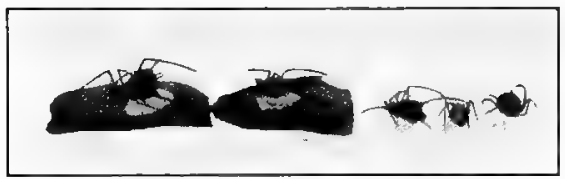

Fig. 104. Parasitized Plant Lice

(Photograph by the author)

One of the most interesting of these little parasites for the children to study belongs to the genus Aphidius, so named from its work with the plant lice. If colonies of aphids are examined late in the season, from July to October, many will be found lighter colored than the rest and much swollen. Often an artichoke leaf or a spray of yellow dock will have a dozen or more such specimens. Keep a number in a glass covered with gauze, and within a few days you will find neat little trapdoors cut in the backs of the aphids and the minute parasites flying about in the glass. Let them have golden-rod or asters and a fresh supply of plant lice in a window or large gauze cage and see who can observe them laying their eggs. Another similar parasite of the aphids emerges from the plant louse when it reaches maturity and spins a flat cocoon, using the shell of its 
late victim as a roof. Some of these will probably be found during the search for plant lice.

The Chalcis Flies. - These are the smallest of the parasitic Hymenoptera. They are generally black with metallic luster, but a few are yellow. Slingerland writes of one of them:

It would seem that the codling-moth's egg, not quite so large as a common pin's head, would escape the eye of the enemy, but many of them do not. In June, I 896 , we were surprised to find that quite a number of the eggs we saw had a peculiar black appearance. These were placed in cages, and a few days later the mystery was explained. For instead of little apple.worms hatching from them, there appeared fully developed adult insects, the surprising number of four coming from a single tiny egg in some cases. It is wonderful to think of four perfect animais having been born in, and having obtained sufficient sustenance to develop into perfect insects from the contents of such a tiny thing as the egg of a codling-moth. In figure 138 is shown a greatly enlarged picture of this pretty little parasite, which is of course an exceeding small creature, yet it is easily visible to the naked eye. ${ }^{1}$

Many of the Chalcis flies are parasitic on the scales and on the eggs of other insects. To keep watch for them will add interest to many of our lessons.

The Syrphus and Tachina Flies. - Though related to the ichneumons only by their parasitic habits, these may be considered in this connection. Both belong to the fly family proper, since they have but a single pair of wings.

The syrphus flies are the ones we all have wonclered about from our infancy. They are par excellence the flies of bright sunshine and flowers, where they disport

1 M. V. Slingerland. "The Codling-Moth," Bulletin I42, Cornell University Agricultural Experiment Station, 1898, p. 37. 
their gorgeous colors. Some appear to be always on the wing, while others may be seen resting lightly on flowers, especially of Helianthus, golden-rod, and asters in the early autumn. The fact that renders

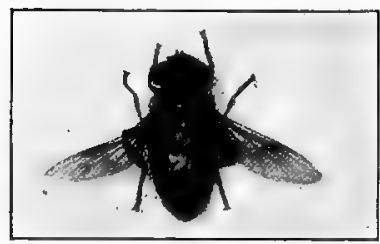

Fig. I05. A Syrphus Fly

(Enlarged about one-half) a study of this family important is that the maggots, or larva, of many of them feed upon plant lice and other small, soft-bodied insects. In collecting plant lice, especially such as cause great deformity of the leaves, as in case of the currant, elm, and snowball, keep a sharp lookout for slender maggots within the gall-like cavities, and do not mistake them for the insects that do the harm. Preserve them in the vivarium, supply with aphids, and watch them as they transform, first into hardened pupa cases, and finally into adult syrphus flies.

The syrphus flies whose larvae are not predaceous feed on wet, decaying wood, manure, and mud, or live in filthy water. Their larva are the curious "rat-tailed maggots" that the children are sure to bring in with the question: What is that? Keep the larva with appropriate food and surroundings, and they will soon answer the question them-

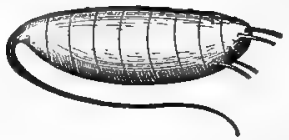

FIG. 106. RAT-TAILED Maggot of AQuatic SYRPHUS FLY (After Riley) selves. More than three hundred different species of syrphus flies have been described in the books. Many of them mimic other insects, especially bees, wasps, and bumblebees. 
The tachina flies are another numerous family of extremely beneficial insects. They are large to mediumsized flies and resemble the house fly in form and general appearance. They are the stout, bristly flies that we see so often on sunny days about rank vegetation. Their larvæ are all parasitic on other insects, chiefly on the injurious leaf-eating caterpillars. While an ichneumon commonly attacks only a single species or its near relations, the tachina flies present the advantage of working upon almost any insect that may be numerous. Thus a tachina fly will lay her eggs on a caterpillar, if she can find one. If not, she may lay them on grasshoppers, bugs, beetles, sawflies, or
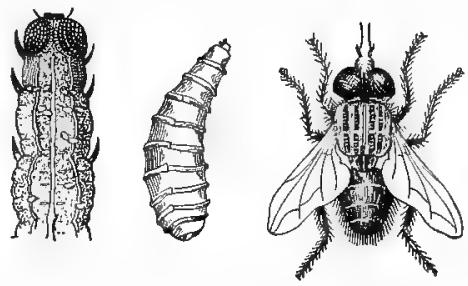

FIG. IO\%. TACHINA FLY

Eggs on a caterpillar, larva, adult, and pupa; size a little larger than a house fly even bumblebees.

The white, oval eggs are glued to the body of an insect as though they were a part of its own skin. The little maggots on hatching burrow into their victim and feed upon its tissues and juices. Growth is rapid and after its attainment the little plunderers are said to murder their host by destroying a vital organ, after which they work their way out. Unlike the ichneumons the tachina larvæ spin no cocoons, but instead the outer skin hardens into an oval case, the pupa case, or puparium ; within this the larvæ change into pupæ, and in about ten days we may expect to see them emerge as adult flies. There may be several generations a year. 
By far the favorite hosts of these flies are the leaf-eating caterpillars and the numbers destroyed in a single season by these parasites is quite beyond computation. I have seen vast armies of the army-worm, comprising unquestionably millions of individuals, and have been unable to find a single specimen which did not bear the characteristic eggs of a tachina fly. These flies were present in such numbers that their buzzing, as they flew over the army of caterpillars, could be heard at some distance and the farmers were unnecessarily alarmed since they conceived the idea that the fies were the parents of the caterpillars and were flying everywhere and laying their eggs in the grass and wheat. As a matter of fact, one great outbreak of the army-worm in northern Alabama, in the early summer of I88I, was completely frustrated by the tachina flies, aided by a few other parasites and predatory insects. L. O. HowARD, The Insect Book, p. I 58 .

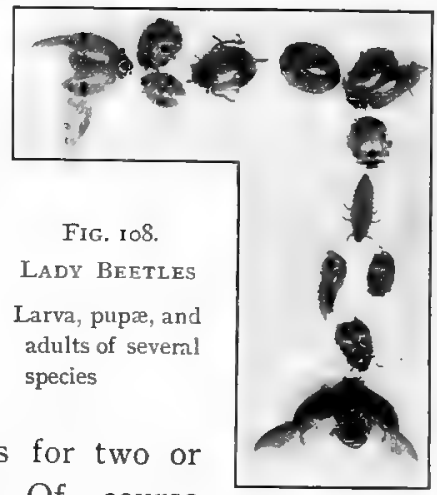

Valuable shade trees are sometimes cut because they are infested with caterpillars for two or three years in succession. Of course trees may be killed by being stripped of their leaves repeatedly; but frequently the year after the pests seem to have become unendurable there may be scarcely one in the whole neighborhood, all but a few having been killed by increase of their natural enemies.

Lady Beetles, Ladybirds, or Ladybugs. - These insects are too familiar to require description. We may bring one to class in a vial and let the children learn their next day's nature-study lesson by observing what the lady beetles are doing. A branch of apple or cherry covered with 
aphids in June will be likely to show lady beetles in all stages; the yellow eggs in clusters, often in the midst of a swarm of aphids; the alligator-shaped larvæ, black with red or yellow spots and covered with warts or spines; the angular pupæ suspended from the leaves or twigs by their tails; and the adult beetles. Both larvæ and adults spend a large part of the time devouring plant lice, scales, and the eggs and young larvæ of other insects.

Lady beetles often come into houses to pass the winter, and their presence may well be encouraged, as it would seem that they might be the best protectors of the window garden against plant lice and scale insects. I have not been able to find any account, however, in which it is stated that they have been successfully kept alive and feeding during the entire winter, but this might prove a valuable line of experiment. ${ }^{1}$

Lion Beetles. - Among the beetles there are a number of other carnivorous species that are of great service in our gardens. If any of these or their larvæ can be found, instructive feeding tests may be made.

The lion beetle, Calosoma scrutator, is our most beautiful species. It is somewhat over one inch in length, the wing covers are bright golden green, and the body is marked with blue, gold, green, and copper. This beetle

1 Professor Weed has described finding "balls" of hibernating lady beetles containing as much as a quart. He stated that they occurred about the borders of woods under piles of leaves and brush. One other observer has reported to me a similar find in a hollow stump. We ought to learn more of this, and if such a ball could be captured and the beetles be distributed among the cherry, peach, and plum trees of a neighborhood, they might nip many a serious outbreak of plant lice in the bud. 
hunts over trees in search of caterpillars. It has also been described as climbing cornstalks, stopping apparently to listen at the tip of the ear, and if a corn worm is within, it speedily drags it out and devours it.

Calosoma calidum is another lion beetle, a little smaller than the above, shining black, with three rows of coppercolored pits down each wing cover. This is chiefly nocturnal and is said to feed largely on cutworms. The larvæ of both the Calosomas are flat, fish-shaped creatures, sometimes two inches long, with somewhat the appearance of having pincers at both ends. They are fierce hunters after caterpillars, climbing trees and often burrowing in the ground after cutworms. They may be found in the daytime generally under boards, stones, or heaps of leaves and rubbish.

The Tiger Beetles, Cicindelida. - These are described both in appearance and in character by their common name. They are the lively beetles that we have all seen in dusty roads, which fly up as we approach and always alight with head toward us. Their color is usually green or bronze, spotted and banded with yellow, but some are sand colored. Their larvæ are ugly but very interesting creatures. They live in vertical burrows, often a foot deep. The flattened dirt-colored head with its jaws wide open fills and conceals the opening, and unsuspecting insects, as they walk over, are seized, dragged down to the bottom, and there devoured.

The Bombardier Beetles. - There is certainly nothing more startling and comical than one of these insects "a regular sharp-shooter, blue uniform and all." 1 They

1 Gibson, Sharp Eyes, p. 73, gives an amusing account of a bombardier beetle. 
are ground beetles and may be found by turning up flat stones in pastures. The head and legs are reddish yellow, and the wing covers are commonly blue, sometimes black. If any of the children succeed in finding one, it should be made at home under a stone in a vivarium, well fed with insects, and experimented with as occasion offers. It would be interesting to know how a toad might fare with a bombardier.

There are many other common carabids, or ground beetles, whose strong jaws mark them as carnivorous species. It will be well not to try to keep any such beetle with other insects that we may wish to rear or preserve.

Dragon Flies. - These may be classed among beneficial insects as long as there are mosquitoes, gnats, and flies to be destroyed. They are the swallows among insects, capturing and eating a great variety, especially of the smaller insects, on the wing. But long after flies and mosquitoes cease from troubling we shall need dragon flies, that we may enjoy their beauty and that each year we may watch a few crawl out of the water and change to fairies. The eggs are laid in or on the water, often on the stems of water plants. Sometimes the female crawls down a stem and under the surface to lay her eggs. The larvæ are active, predaceous creatures, feeding on aquatic insects, young fishes, and tadpoles, from the time of hatching until they leave the water to transform. In the last stage, before emerging from the water, they are known as "nymphs"; and this takes the place of the quiescent pupa, or chrysalis stage, of other insects.

Damsel Flies. - In habits and appearance damsel flies resemble dragon flies, but they are smaller, and the wings, 
instead of remaining spread out, are folded over the back while at rest. They are the delicate, shimmering, scintillating insects that we so often see flitting and darting about the borders of ponds and streams. The larvæ are aquatic, and the life story in general is like that of the dragon flies. The French call them demoiselles.

Caddis Flies. - "Will you please tell us what these things are? Teacher does n't know nor any one else in our school. .They are alive." The speaker was one of a halfdozen boys; he had a tin can in one hand and held out some small objects in the other. "Those are caddis fly worms," I answered. "What do they eat?" was his next question. I told him that they fed upon water plants, and said that if they would keep them in an aquarium with plenty of plants, they might see one pop out of the water and change like a flash into a four-winged fly. ${ }^{1}$

More than 150 different kinds of caddis flies have been described for North America. Most of them are vegetable feeders and build cases of tough silk, with all sorts of materials, - grains of sand, small stones, bits of wood, pine needles, snail shells, etc., - woven into their . walls; so that their occupants are pretty well protected from predaceous insects and even from fishes. Generally - the case is free, and the larva drags it about as it seeks its food. In swiftly flowing streams, however, the cases are often fastened to the rocks. In one family of caddis flies the larvæ are carnivorous, and these construct funnelshaped silken nets attached to stones, the small end of the

1 I learned that the boys had "fixed up" one of the chicken coops in the neighborhood into what they called their "laboratory" and were spending their summer vacation "studying insects and all kinds of things." 
funnel tapering down to the opening of the case. Howard speaks of finding 166 of these nets on a rock about eighteen inches in diameter.

The larva of dragon flies, damsel, and caddis flies may best be collected in May or June by raking out the

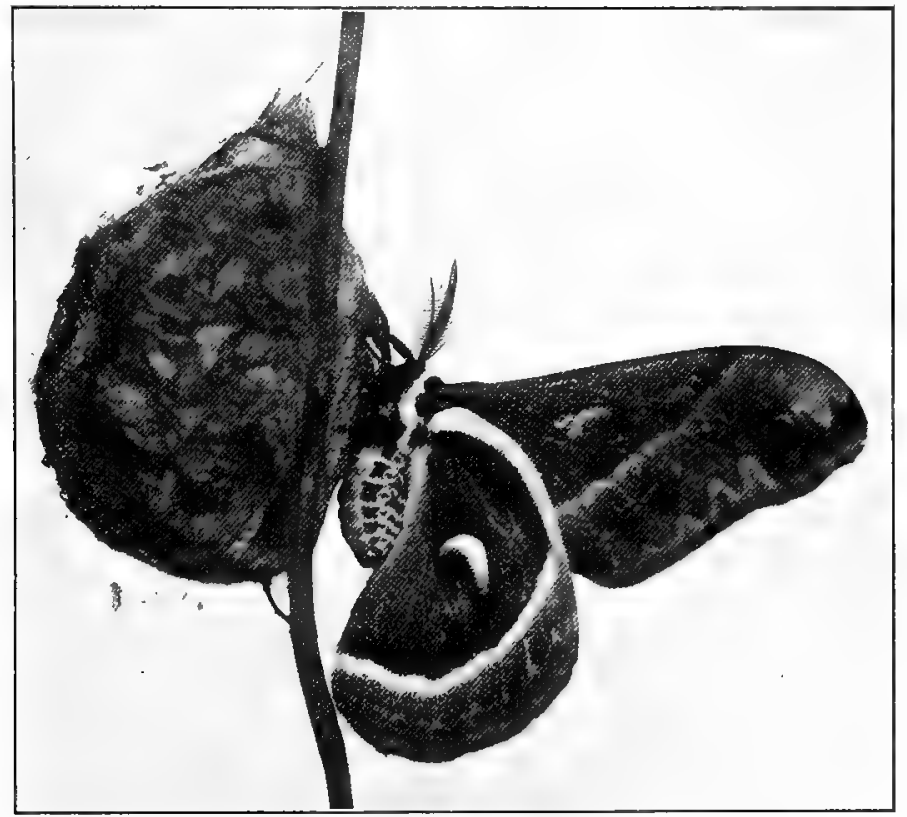

Fig. iog. Male Cecropia and Cocoon. Lowland Form (8) natural size. From photograph by the author)

leaves and bunches of grass from the bottom of pools and streams. They may then be kept in the school aquaria, and the feeding and final transformations be easily observed. An excursion to some pond in June, when the dragon and 
damsel flies are emerging, - when we can let the nymphs crawl up on our hands and see them transfigured in the bright sunshine, - will give us glimpses of nature that cannot be forgotten, and will make nature lovers of us all.

Butterflies and Moths. - In advocating the possession of insect nets by the children I have had in mind chiefly the collection of injurious insects, not the extermination of our butterflies. As with roadside flowers, our nature-study les-

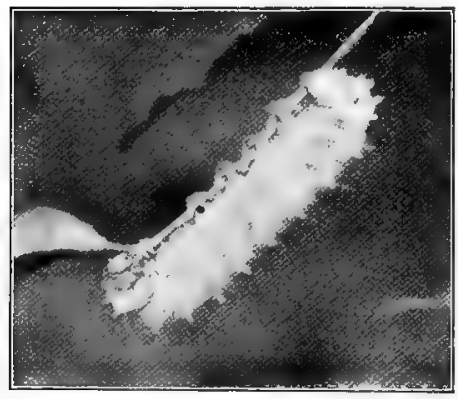

Fig. ito. Ceeropia latava Asleep (Length 3 inches. Photograph from life) sons with butterflies may well be protective rather than destructive. Even in connection with the collection of cocoons and chrysalids, I prefer to store them in a cold outbuilding and bring them into the schoolroom only after furnace fires are extinguished in the spring, so that they may emerge in their normal season; and then, after we have seen them emerge and, perhaps, fed them a few times with honey, let them go, to keep the world as full of butterflies as possible. Mrs. Brightwen ${ }^{1}$ in this way tamed the butterflies about her home so that they would follow her about and alight upon her hands to be fed. Is not this a better ideal, especially for young children, than the collection of dead specimens? And, furthermore, if we follow it, we shall be able to study 
their lives, habits, and instincts in a way that the older methods cannot approach. I shall never forget with what a growing sense of wonder I first watched a parsnip butterfly as she laid her eggs. It was before I had read Gibson's description of butterflies as botanists. There were long, straight rows of vegetables the length of the garden, - one of carrots and, several rows removed, one of parsnips. The plants had just put forth the third leaf, and it was about all I could do to distinguish them from the numerous weeds; but that little creature, for nearly an hour, unerringly laid her eggs either on the carrots or the parsnips. I have often thought that I never learned so much from all the collections of insects, including my own, as I did from that living butterfly. It was a revelation to me.

Still there is much to be said on the other side. Collections of butterflies are different from collections of birds. A mounted butterfly may retain its natural beauty to a greater degree. Butterflies are not intrinsically so valuable as birds for the work they do in nature. Most of them at best are but creatures of a few days, and we may thus prolong their beauty by preserving them. On the whole, if it is done with care, and if the specimens are used as a means by which to stimulate study of the life and work of the species rather than as an end in themselves, I should encourage butterfly collections both in the school cabinet and on the part of the children who wish to make them. In cloing the collecting, however, it is a good rule to examine all specimens before killing them and to let all the imperfcct ones go. There are so few perfect specimens that the species will suffer but 
little, and the children will have the more exercise in the fresh air.

Few species of butterflies do enough harm to require attention on that account. The mourning cloak, Euvanessa antiopa, occasionally does some damage to shade trees, elms, willows, and poplars; and this is about the only species that lays its eggs in clusters and the caterpillars of which feed close together so that their depredations are conspicuous. Of the entire group the cabbage butterflies, - Pieris napi, protodice and, especially, rapa, - are the only serious pests. These are our commonest species, unfortunately. The larvæ are the slender green caterpillars so numerous on cabbage, cauliflower, other Cruciferæ, and also on nasturtiums. Where any of these plants occur we are sure to find, on any warm day between May and October, one or more of these white butterflies laying her eggs. ${ }^{1}$

Space does not permit more than the mention of the names of some of our commonest and more conspicuous

1 The story of the accidental introduction and spread of what is now the common cabbage butterfly $(P . r a p a)$ is of interest as showing the importance of such apparently trifling things. It was brought from England to Quebec about 1860, probably in ship's supplies or in imported cabbages. In three years it had spread over an area about sixty miles in diameter; by 187 I it covered eastern Canada and the New England states; ten years later it was common over the eastern half of the continent from Hudson Bay to Texas; and for some years now it has had possession of every cabbage patch from the Atlantic to the Pacific. In this rapid conquest of the continent our native species of the same genus, which feed on the same plants, have been almost exterminated in many regions where they were once numerous. The writer has counted over five hundred ovules in the ovaries of a newly emerged cabbage butterfly. There are three broods a year in the North and more in the South; hence a new insect without natural enemies practically owns the earth. 
INSECTS BENEFICIAL AND BEAUTIFUL 263

species; and, while tables have certain disadvantages, it is hoped that the following table will answer more of the questions that arise as butterfies and their caterpillars are brought into the schoolroom, than could be disposed of in any other way. These tables are the more interesting because they represent the work, ingenuity, and observation of a schoolboy aged fifteen, Master W. T. M. Forbes. The species given have been collected, and in many cases their larvæ reared, by this enthusiastic young naturalist.

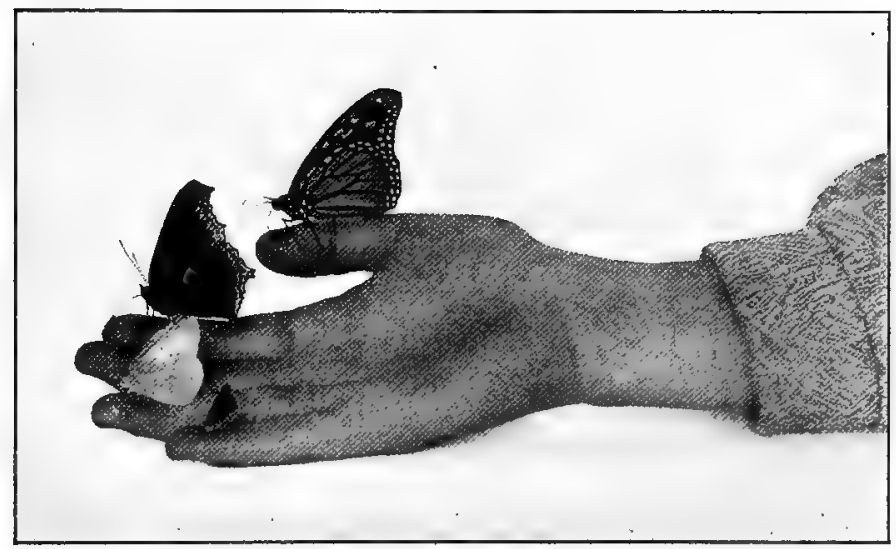




\section{BUTTERFLIES}

Name
Giant Fritillary, Argynnis
cybele
Aphrodite, Argynnis aphro-
dite
Little Silverspot, Brenthis
myrina
Marsh Fritillary, Brenthis bel-
lona
Baltimore, Melitaa phaëton

Harris' Checkerspot, Melitad harrisi

Pearl Crescent, Phyciodes tharos

Silver Crescent, Phyciodes nycteis

Harvester, Feniseca tarquinius

Ismeria, Phyciodes ismeria

Semicolon, Grapta interrogationis

Green Comma, Grapta comma

Gray Comma, Grapta progne

Brown Comma, Grapia faunus

Large Tortoise-Shell Butterfly, Vanessa j-album

Small Tortoise-Shell Butterfly, Vanessa milberti

Milkweed Butterfly, Anosia plexippus

False Milkweed Butterfiy, Basilarchia disippus

Common Copper, Chrysophanus hypophlaas

Large Copper, Chrysophanus thoe

Prominent Colors and Markings

Wing

Orange brown, black checkered, silver below

Orange brown, black checkered, silver below

Orange brown, black checkered, silver below

Orange brown, no silver

Orange, black, and yellow, no silver

Orange brown, black mottled

Orange brown, black mottled

Orange brown, black mottled

Orange brown, black border and spots

Orange brown, black mottled

Orange brown, black dotted, wings angled

Orange brown, black dotted, wings angled

Orange brown, black dotted, wings angled

Orange brown, black dotted, wings angled

Orange brown, black dotted, wings angled

Black, orange band, wings angled

Orange brown, black veined

Orange brown, black veined

Orange, hind wing black

Orange brown, hind wing black (m. washed out)
Expanse

in Inches

Fre-

quenty

\begin{tabular}{c|c}
\hline $3-4$ & C. \\
$2 \frac{1}{2}-3 \frac{1}{2}$ & R. $C$. \\
$m . I_{2}^{1}, f . I_{4}^{3}$ & C.
\end{tabular}

$1_{4}^{8}$

C

$\mathrm{R}$.

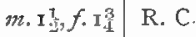

m. 14,f. I5

It-2

C.

I 1

R. R.

m. I $1 \frac{1}{4}, f .1 \frac{3}{4}$ V.R.

$2 \frac{1}{2}$ R. C.

2

R. C.

2

R. C.

2

$\mathrm{R}$.

$2 \frac{3}{1}$

R.

I $\frac{3}{4}$

R.

$4-4{ }^{2}$

V. C.

2.

C.

I

v. C.

I $\frac{3}{3}$ V. R. 


\section{BUTTERFLIES}

\begin{tabular}{|c|c|c|c|}
\hline \multirow{2}{*}{ Food of Caterpillar } & \multicolumn{2}{|c|}{ Broods per Season } & \multirow{2}{*}{ Haunts } \\
\hline & Number & Month & \\
\hline Violets, pansy & I & July, Aug. & Meadows, on fireweed \\
\hline Violets, pansy & I (or 2$)$ & July (and Sept.) & Meadows, on fireweed \\
\hline Violets, pansy & 3 & June, Aug., Sept. & Meadows and hillsides \\
\hline Violets, pansy & 3 & June, Aug., Sept. & Meadows and hillsides \\
\hline $\begin{array}{l}\text { Turtlehead (while young) } \\
\text { Aster (when older) }\end{array}$ & $\mathbf{I}$ & June, July & Swampy places \\
\hline $\begin{array}{l}\text { Aster (only Diplopafpus } \\
\text { wmbellatus) }\end{array}$ & I & June & Roadsides, on clover \\
\hline Aster and daisy & 2 & July, Sept. & Roadsides \\
\hline Aster & $\mathbf{I}$ & July & Roadsides \\
\hline Plant lice, mealy bugs 1 & 3 & June, July, Sept. & Edge of water \\
\hline Elm, hop, nettle & 2 & July, Aug., May & Roads near trees \\
\hline Elm, hop, nettle & 2 & May, June, Aug. & $\begin{array}{l}\text { Roads near trees and } \\
\text { waste land }\end{array}$ \\
\hline Elm, currants & 2 & July, Sept., May & $\begin{array}{l}\text { Roads near trees and } \\
\text { gardens }\end{array}$ \\
\hline Willow & $\mathbf{I}$ & All summer & $\begin{array}{l}\text { Roads near trees and } \\
\text { gardens }\end{array}$ \\
\hline Willow & 2 & Feb.-Oct. & Edge of water \\
\hline Nettle & 3 & May, June, Aug., Sept. & Roadsides \\
\hline Milkweed, dogbane & 2 or more & May-Oct. & Everywhere \\
\hline Willow, poplar & 2 & June, Aug. & Roadsides \\
\hline Sorrel, dock, oxalis & 3 & May, June, Sept. & Everywhere \\
\hline Sorrel & 2 & July, Aug. & Moist land \\
\hline
\end{tabular}




\begin{tabular}{|c|c|c|c|}
\hline Name & Prominent Colors and Markings & $\begin{array}{l}\text { Wing } \\
\text { Expanse } \\
\text { in Inches }\end{array}$ & $\begin{array}{c}\text { Fre- } \\
\text { quency }\end{array}$ \\
\hline $\begin{array}{l}\text { Dark Fritillary, Argynnis } \\
\text { idalia }\end{array}$ & $\begin{array}{l}\text { Orange brown, hind wing black, } \\
\text { silver spots }\end{array}$ & $23-4$ & c. \\
\hline $\begin{array}{l}\text { Thistle Butterfly, Pyrameis } \\
\text { cardui }\end{array}$ & $\begin{array}{l}\text { Pink or red, black and white } \\
\text { mottled }\end{array}$ & $2-2 \frac{1}{4}$ & C. \\
\hline $\begin{array}{l}\text { Painted Beauty, Pyrameis } \\
\text { huntera }\end{array}$ & $\begin{array}{l}\text { Pink or red, black and white } \\
\text { mottled }\end{array}$ & 2 & C. \\
\hline $\begin{array}{l}\text { Snout Butterfly, Libythea } \\
\text { bachmanni }\end{array}$ & $\begin{array}{l}\text { Black, orange and white banded } \\
\text { and dotted }\end{array}$ & & V. R. \\
\hline $\begin{array}{l}\text { Variegated Fritillary, Eup- } \\
\text { toieta claudia }\end{array}$ & $\begin{array}{l}\text { Orange brown, black checkered, } \\
\text { no silver }\end{array}$ & $13-23$ & V. R. \\
\hline $\begin{array}{l}\text { Orange Sujphur, Colias eury- } \\
\text { theme }\end{array}$ & $\begin{array}{l}\text { Yellow orange, or white, black } \\
\text { border }\end{array}$ & 2 & V.R. \\
\hline $\begin{array}{l}\text { Little Orange Sulphur, Terias } \\
\text { nicippe }\end{array}$ & $\begin{array}{l}\text { Yellow, orange, or white, black } \\
\text { border }\end{array}$ & $I_{2}^{1}-2$ & V. R. \\
\hline $\begin{array}{l}\text { Common Sulphur, Colias phi- } \\
\text { lodice }\end{array}$ & Yellow or white, black border & $I \frac{1}{4}-2 \frac{1}{4}$ & V. C. \\
\hline Little Sulphur, Terias lisa & Yellow or white, black border & I住-I & $\mathbf{R}$ \\
\hline $\begin{array}{l}\text { Cloudless Sulphur, Catopsizia } \\
\text { eubule }\end{array}$ & Yellow or white, no black border & $2 \frac{1}{2}$ & $\mathrm{R}$. \\
\hline $\begin{array}{l}\text { Tiger Swallowtail, Papilio } \\
\text { turnus }\end{array}$ & Yellow, black bands & $3-5$ & R. C. \\
\hline Mustard White, Picris napi & White, or white with black dots & 2 & R. R. \\
\hline Cabbage Butterfy, Picris rape & White with black dots & $\mathbf{2}$ & V. C. \\
\hline $\begin{array}{l}\text { Checkered Cabbage Butterfly, } \\
\text { Pieris protodice }\end{array}$ & $\begin{array}{l}\text { White with black dots ( } f \text {. gray } \\
\text { brown checkered) }\end{array}$ & 2 & R. \\
\hline Orange Tip, Euchlö̈ genutia & $\begin{array}{l}\text { White with black dots ( } m \text {. or- } \\
\text { ange tipped) }\end{array}$ & $\mathbf{I}_{2}^{\frac{1}{2}}$ & V.R. \\
\hline $\begin{array}{l}\text { Light Blue, Lycana pseudar } \\
\text { giolus }\end{array}$ & Light violet ( $f$. dark bordered) & I & C. \\
\hline $\begin{array}{l}\text { Tailed Blue, Lycana comyn- } \\
\text { tas }\end{array}$ & Purple ( $f$. often brown) & $\mathbf{I}$ & C. \\
\hline $\begin{array}{l}\text { Brown Emperor, Chloripte } \\
\text { clyton }\end{array}$ & Dark brown ( $f$. with eye-spots) & $m \cdot 2, f \cdot 2 \frac{1}{2}$ & V.R. \\
\hline Pearly Eye, Debis portlandia & Dark brown, 20 eye-spots & $I_{-1}^{8}-2$ & R. R. \\
\hline $\begin{array}{l}\text { Many-eyed Satyr, Satyrodes } \\
\text { canthus }\end{array}$ & $\begin{array}{l}\text { Dark brown, } 20 \text { eye-spots (semi- } \\
\text { transparent) }\end{array}$ & $I_{1}^{13}$ & R. C. \\
\hline $\begin{array}{l}\text { Common Wood-nymph, Neo- } \\
\text { nympha eurytus }\end{array}$ & Dark brown, 6 eye-spots & I菜 & R. C. \\
\hline $\begin{array}{l}\text { Blue-Eyed Satyr, Satyrus } \\
\text { alope }\end{array}$ & $\begin{array}{l}\text { Dark brown, some eye-spots in } \\
\text { a yellow-spot }\end{array}$ & 2 & C. \\
\hline Dull-Eyed Satyr, $s$ a. nephele & Dark brown, 6 eye-spots & 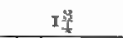 & R. \\
\hline
\end{tabular}




\begin{tabular}{|c|c|c|c|}
\hline \multirow{2}{*}{ Food of Caterpillar } & \multicolumn{2}{|c|}{ Broods per Season } & \multirow{2}{*}{ Haunts } \\
\hline & Number & Month & \\
\hline Violets, pansy, and aster & $\mathbf{I}$ & July, Aug. & Low land \\
\hline Thistle, other Compositæ & 2 & Aug., Sept., May & High pastures \\
\hline $\begin{array}{l}\text { Thistle, burdock, everlast- } \\
\text { ing }\end{array}$ & 2 & July, Sept., May & $\begin{array}{l}\text { High pastures, on } \\
\text { thistles }\end{array}$ \\
\hline Hackberry & & & \\
\hline (Not native) Passion flower & 3 & August & Low fields \\
\hline Clover & 3 & $\begin{array}{l}\text { May, July, Sept., } \\
\text { April } 2 \mathrm{~d}\end{array}$ & Open fields \\
\hline Pea family & $2(?)$ & June, Aug., March & Open fields \\
\hline Clover and pea family & 3 & May, June, Sept. & $\begin{array}{l}\text { About cultivated fields, } \\
\text { every where }\end{array}$ \\
\hline Clover, cassia & 2 & July, Aug., April & \\
\hline Pea family, cassia & 2 & August & \\
\hline Tulip tree, wild cherry, etc. & 2 & June, Aug. & Open woods \\
\hline $\begin{array}{l}\text { Mustard, etc. (rarely cab- } \\
\text { bage) }\end{array}$ & 3 & May, July, Aug. & Waste land \\
\hline Cabbage, mustard, etc. & 3 & May, July, Aug. & Gardens \\
\hline Mustard family & 3 & May, July, Sept. & Gardens \\
\hline $\begin{array}{l}\text { Mustard family (eats flow- } \\
\text { ers and seed pods) }\end{array}$ & I & May & Open woods \\
\hline $\begin{array}{l}\text { Pea family, and almost } \\
\text { everything }\end{array}$ & 2 & May, July & Roadsides \\
\hline Pea family & 3 & May, Aug., Sept. & Roadsides \\
\hline Hackberry, elm, etc. & I & June, July & \\
\hline Grasses & $\mathbf{I}$ & July & Open woods \\
\hline Grasses & $\mathbf{I}$ & July & $\begin{array}{l}\text { Meadows, in grass, or } \\
\text { open woods }\end{array}$ \\
\hline Grasses & I & June & Hillsides \\
\hline Grasses & $\mathbf{I}$ & July & Hillsides \\
\hline Grasses & I & August & Hillsides \\
\hline
\end{tabular}




\begin{tabular}{|c|c|c|c|}
\hline Name & Prominent Colors and Markings & $\begin{array}{l}\text { Wing } \\
\text { Expanse } \\
\text { in Inches }\end{array}$ & $\begin{array}{l}\text { Fre- } \\
\text { quency }\end{array}$ \\
\hline $\begin{array}{l}\text { Red Admirai, Pyranteis ata- } \\
\text { lanta }\end{array}$ & Dark brown, oval orange band & 2 & C. \\
\hline $\begin{array}{l}\text { Mourning Cloak or Yellow- } \\
\text { Edge, Vanessa antiopa }\end{array}$ & Dark brown, yellow edge & 3 & C. \\
\hline $\begin{array}{l}\text { Blue Eniperor, Basilarchia } \\
\text { asty'anax }\end{array}$ & Blackish, blue shadings & 3 & R. C. \\
\hline $\begin{array}{l}\text { White Admiral, Basilarchia } \\
\text { arthenis }\end{array}$ & Blackish, a white band & $2 \frac{1}{3}$ & V.R. \\
\hline $\begin{array}{l}\text { Black Swallowtail, Papilio } \\
\text { asterias }\end{array}$ & $\begin{array}{l}\text { Blackish, blue shading and yel- } \\
\text { low dots }\end{array}$ & $m \cdot 3, f \cdot 4$ & C. \\
\hline $\begin{array}{l}\text { Blue Swallowtail, Papilio } \\
\text { troilus }\end{array}$ & $\begin{array}{l}\text { Blackish, blue sliading and } \\
\text { greenish dots ( } m \text {. blue green) }\end{array}$ & $34^{3}-4 \frac{3}{4}$ & R. C. \\
\hline $\begin{array}{l}\text { Green Swallowtail, Papilio } \\
\text { philenor }\end{array}$ & $\begin{array}{l}\text { Blackish and iridescent blue } \\
\text { green }\end{array}$ & $3 \frac{3}{4}-4$ & V.R. \\
\hline $\begin{array}{l}\text { Giant Swallowtail, Papilio } \\
\text { cresphontes }\end{array}$ & Blackish, yellow dots & $4-5 \frac{1}{3}$ & V.R. \\
\hline Peacock, Junonia conia & $\begin{array}{l}\text { Blackish, three large peacock } \\
\text { eyes }\end{array}$ & $2-21$ & V. R. \\
\hline $\begin{array}{l}\text { Hop Hairstreak, Thecla meli- } \\
\text { nus }\end{array}$ & Blackish, gray below & $\mathbf{I} \frac{1}{8}$ & R. C. \\
\hline $\begin{array}{l}\text { Banded Hairstreak, Thecla } \\
\text { calanus }\end{array}$ & Blackish, light brown below & $\mathbf{I}_{\text {要 }}$ & R. R. \\
\hline $\begin{array}{l}\text { Acadian Hairstreak, Thecla } \\
\text { acadica }\end{array}$ & Blackish, light brown below & $1 \frac{7}{4}$ & R. R. \\
\hline $\begin{array}{l}\text { Edward's Hairstreak, Thecla } \\
\text { edtwardsi }\end{array}$ & Blackish, light brown below & $\mathrm{x} \frac{1}{4}$ & R. C. \\
\hline $\begin{array}{l}\text { Striped Hairstreak, Thecla } \\
\text { liparops }\end{array}$ & Blackish, light brown below & $I \frac{1}{3}$ & R. R. \\
\hline $\begin{array}{l}\text { Olive Hairstreak, Thecla } \\
\text { damon }\end{array}$ & $\begin{array}{l}\text { Blackish, orange brown, green- } \\
\text { ish below }\end{array}$ & $7-x$ & R. R. \\
\hline Brown Elfin, Thecla augustus & Blackish, brown below & $\frac{7}{8}$ & R. \\
\hline Hoary Elfin, Thecla irus & Blackish, brown below & $I \frac{1}{8}$ & R. \\
\hline $\begin{array}{l}\text { Henry's Hairstreak, Thecla } \\
\text { hcnrici }\end{array}$ & $\begin{array}{l}\text { Blackish and red brown, brown } \\
\text { below }\end{array}$ & I & V. R. \\
\hline Banded Elfin, Thecla niphon & $\begin{array}{l}\text { Dark reddish brown, brown } \\
\text { mottled below }\end{array}$ & $\mathbf{I}_{\mathrm{B}}^{\frac{1}{3}}$ & R. R. \\
\hline Early Hairstreak, Thecla lat $a$ & Blackish, light gray below & 茈 & V.R. \\
\hline Coral Hairstreak, Theclatitus & $\begin{array}{l}\text { Blackish, blackish and red band } \\
\text { below }\end{array}$ & $I_{1}$ & R. R. \\
\hline $\begin{array}{l}\text { Least Copper, Chrysophanus } \\
\text { spixanthe }\end{array}$ & $\begin{array}{l}\text { Blackish, darker dots ( } m \text {. pur- } \\
\text { plish) }\end{array}$ & $\frac{7}{8}-I$ & R. R. \\
\hline
\end{tabular}




\begin{tabular}{|c|c|c|c|}
\hline \multirow{2}{*}{ Food of Caterpillar } & \multicolumn{2}{|c|}{ Broods per Season } & \multirow{2}{*}{ Haunts } \\
\hline & Number & Month & \\
\hline Nettle, elm & 2 & July, Sept., May & Waste land \\
\hline Willow, poplar, elm & 2 & July, Scpt., April & Edge of water \\
\hline Wild cherry, etc. & 1 or 2 & July (Sept.) & Roads near trees \\
\hline Wild cherry, hawthorn, etc. & I (or 2) & July (Sept.) & Open woods \\
\hline Parsley family & 2 & June, Aug. & Fields and gardens \\
\hline Sassafras, spicebush & 2 & June, Sept. & Open woods and brush \\
\hline Dutchman's pipe & 2 & July, Sept., May & Near houses \\
\hline (Orange tree) rue family & 2 & June, Aug. & Meadows \\
\hline Plantain & 2 & & Open fields \\
\hline Hop vine, bean pods, etc. & 2 & May, July & About shrubbery \\
\hline Oak & I & July, Aug. & About shrubbery \\
\hline Willow & I & July, Aug. & Edge of water \\
\hline Oak & $I$ & July, Aug. & About shrubbery \\
\hline $\begin{array}{l}\text { Oak, willow, apple family, } \\
\text { etc. }\end{array}$ & $\mathbf{I}$ & July & About shrubbery \\
\hline Ledar & 1 or 2 & May, June, Aug & Near cedars \\
\hline $\begin{array}{l}\text { Unknown (perhaps like } \\
\text { next) }\end{array}$ & I & May & Rough land \\
\hline $\begin{array}{l}\text { Bores in young plums } \\
\text { Bores in young plums }\end{array}$ & I & May & Roadsides and bushes \\
\hline Pine & I & May & Roads near pine trees \\
\hline Unknown & & & \\
\hline Wild cherry, etc. & $\mathbf{I}$ & Last of July & $\begin{array}{l}\text { Open places near } \\
\text { brush }\end{array}$ \\
\hline Unknown (probably sorrel) & $\mathbf{I}$ & July & Meadows \\
\hline
\end{tabular}




\begin{tabular}{|c|c|c|c|}
\hline Name & Prominent Colors and Markings & $\begin{array}{l}\text { Wing } \\
\text { Expanse } \\
\text { in Inches }\end{array}$ & $\begin{array}{c}\text { Fre- } \\
\text { quency }\end{array}$ \\
\hline $\begin{array}{l}\text { Silver-spotted Skipper, Epar- } \\
\text { gyreus tityrus }\end{array}$ & Brown, silver spot below & 13-2 & C. \\
\hline $\begin{array}{l}\text { Northern Dusky-Wing, Thory- } \\
\text { bes pylades }\end{array}$ & Blackish, few faint light spots & I $\frac{5}{8}$ & c. \\
\hline $\begin{array}{l}\text { Hoary-Edge, Achalarus lyci- } \\
\text { dus }\end{array}$ & Blackish, orange spot & $\mathbf{r} \frac{9}{4}$ & $\mathrm{R}$. \\
\hline $\begin{array}{l}\text { Checkered Skipper, Hesperia } \\
\text { centauree }\end{array}$ & Blackish, white dots & $\mathrm{I} \frac{1}{6}$ & V.R. \\
\hline $\begin{array}{l}\text { Sooty-Wing, Pholisora catul- } \\
\text { lus }\end{array}$ & Black & $\mathbf{I}$ & R. R. \\
\hline $\begin{array}{l}\text { Sleepy Dusky-Wing, Thanaos } \\
\text { brizo }\end{array}$ & Gray, mottled & $I_{2}^{\frac{1}{2}}$ & R. C. \\
\hline $\begin{array}{l}\text { Dreamy Dusky-Wing, Tha- } \\
\text { naos icelus }\end{array}$ & Gray, mottled & $I-1 \frac{1}{4}$ & R. C. \\
\hline $\begin{array}{l}\text { Lucilius' Dusky-Wing, Tha- } \\
\text { naos tucilizes }\end{array}$ & Gray, mottled, white dots & $1 \frac{1}{4}$ & R. R. \\
\hline $\begin{array}{l}\text { Persius' Dusky-Wing, Tha- } \\
\text { naos persizıs }\end{array}$ & Gray, mottled, white dots & $x_{1}^{\frac{1}{4}}$ & R. C. \\
\hline $\begin{array}{l}\text { Martial's Dusky-Wing, Tha- } \\
\text { naos martialis }\end{array}$ & Gray, mottled, white dots & $1 \frac{7}{4}$ & R. R. \\
\hline $\begin{array}{l}\text { Juvenal's Dusky-Wing, Tha- } \\
\text { naos juveralis }\end{array}$ & Gray, mottled, white dots & I $\frac{9}{8}, \mathrm{I} \frac{5}{8}$ & R. \\
\hline $\begin{array}{l}\text { Horace's Dusky-Wing, Tha- } \\
\text { naos horatius }\end{array}$ & Gray, mottled, white dots & I5 & $\mathbf{R}$. \\
\hline $\begin{array}{l}\text { Roadside Skipper, Amblys- } \\
\text { crites vialis }\end{array}$ & Blackish, white dots & I & R. C. \\
\hline $\begin{array}{l}\text { Pepper and Salt Skipper, } \\
\text { Amblyscrites samoset }\end{array}$ & Blackish, white dots & $\mathbf{I}$ & R. \\
\hline $\begin{array}{l}\text { Bordered Skipper, Ancyloxy- } \\
\text { pha numitor }\end{array}$ & Orange brown, black border & $\frac{3}{4}-1$ & C. \\
\hline $\begin{array}{l}\text { Indian Skipper, Erynnis sas- } \\
\text { sacus }\end{array}$ & $\begin{array}{l}\text { Light orange brown, black } \\
\text { border and marks }\end{array}$ & $1 \frac{1}{2}$ & R. C. \\
\hline CobwebSkipper,Erynnismetea & Gray brown, white bands & I & R. \\
\hline $\begin{array}{l}\text { Leonard's Skipper, Erynnis } \\
\text { leonardus }\end{array}$ & $\begin{array}{l}\text { m. Black and orange, } f \text {. black, } \\
\text { yellow band }\end{array}$ & $m \cdot \frac{1}{1}, f \cdot I_{\frac{1}{2}}$ & R. R. \\
\hline $\begin{array}{l}\text { Attalus' Skipper, Erynnis } \\
\text { attalus }\end{array}$ & Gray brown, yellow dots & $m \cdot \mathbf{I}_{4}^{1}, f \cdot \mathrm{I}_{\mathrm{s}}^{3}$ & V.R. \\
\hline $\begin{array}{l}\text { Whirlabout, Thymelicus bret- } \\
\text { tus }\end{array}$ & $\begin{array}{l}\text { m. orange, black dots, } f \text {. black- } \\
\text { ish, yellow dots }\end{array}$ & $m . I \frac{1}{d}, f \cdot I \frac{1}{1}$ & V.R \\
\hline $\begin{array}{l}\text { Volcanic Skipper, Thymelicus } \\
\text { atna }\end{array}$ & Blackish, white dots & $m . \mathrm{I}, f . \mathrm{I}_{4}$ & $\mathbf{R}$. \\
\hline Long-Dash, Thymelicusmystic & Blackish, yellowish blotches & m. I $\frac{1}{8}, f .1 \frac{1}{4}$ & $\mathbf{R}$. \\
\hline
\end{tabular}




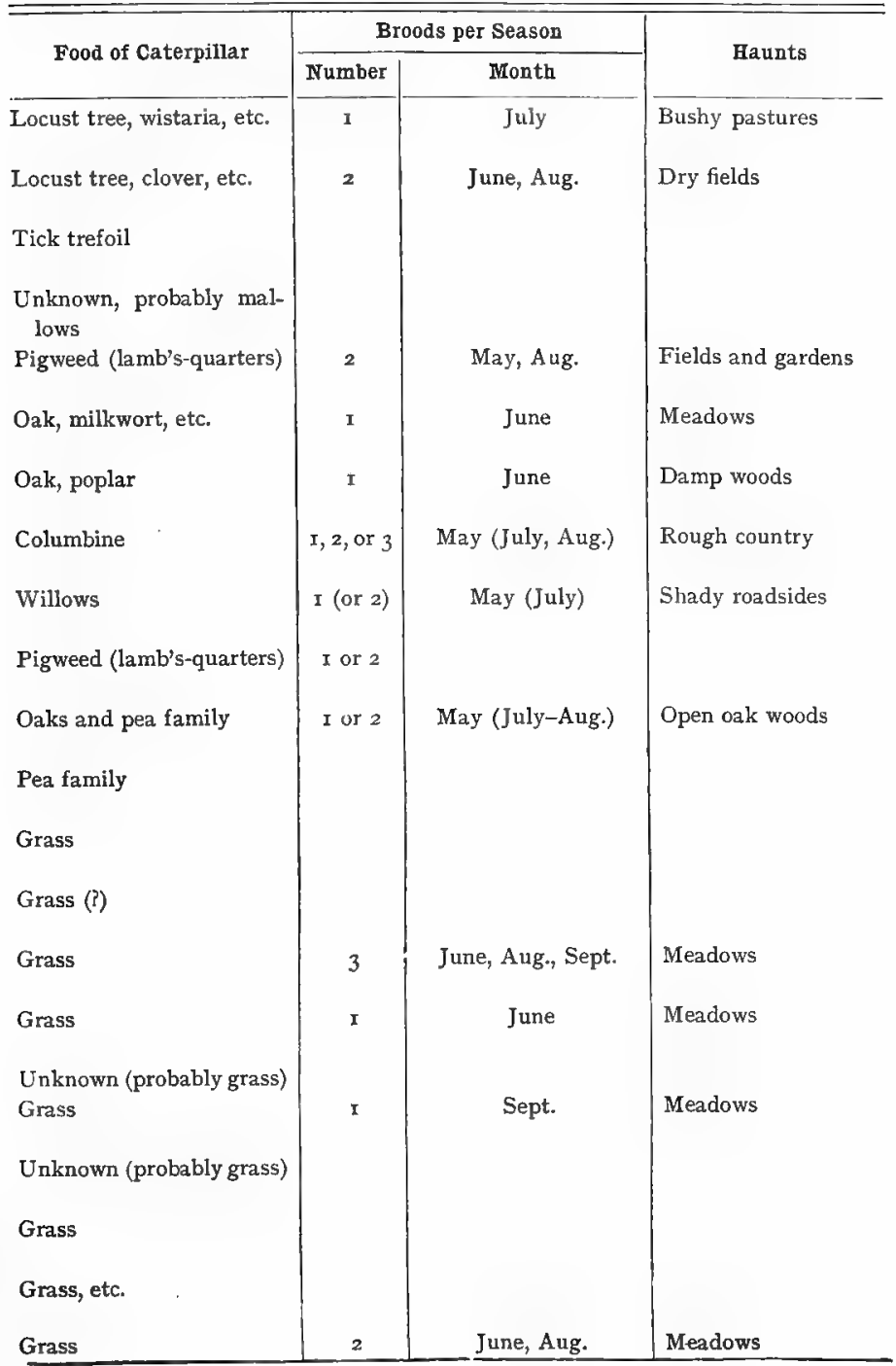




\begin{tabular}{|c|c|c|c|}
\hline Name & Prominent Colors and Markings & $\begin{array}{l}\text { Wing } \\
\text { Expanse } \\
\text { in Inches }\end{array}$ & $\begin{array}{c}\text { Fre- } \\
\text { quency }\end{array}$ \\
\hline Peck's Skıpper, Polites peckizts & Blackish, rows of orange dots & $m .1, f .1 \frac{1}{4}$ & C. \\
\hline $\begin{array}{l}\text { Tawny-Eyed Skipper, Limo- } \\
\text { chores taumas }\end{array}$ & $\begin{array}{l}\text { Blackish, orange dots (m. orange } \\
\text { blotch) }\end{array}$ & $m .1, f .1 \frac{1}{4}$ & C. \\
\hline $\begin{array}{l}\text { Cross-Line Skipper, Limo- } \\
\text { chores manataaqua }\end{array}$ & Blackish, white dots & I & R. R. \\
\hline $\begin{array}{l}\text { Pontiac Skipper, Limochores } \\
\text { pontiac }\end{array}$ & $\begin{array}{l}\text { Blackish, light brownish orange } \\
\text { mottlings }\end{array}$ & $m .1 \frac{1}{3}, f .1 \frac{1}{1}$ & R. \\
\hline $\begin{array}{l}\text { Little Glass-Wing, Eupliyes } \\
\text { verna }\end{array}$ & Blackish, white bars & $m . \mathrm{I} \frac{1}{8}, f . \mathrm{I} \frac{3}{8}$ & R.R. \\
\hline $\begin{array}{l}\text { Dun Skipper, Euphyes meta- } \\
\text { comet }\end{array}$ & Blackish & $m .1 \frac{1}{4}, f .1 \frac{1}{3}$ & R. \\
\hline $\begin{array}{l}\text { Mulberry-Wing, Poanes mas- } \\
\text { sasoit }\end{array}$ & Blackish (orange dots in $f$ ) & $\mathrm{r} \frac{1}{8}$ & $\mathbf{R}$. \\
\hline $\begin{array}{l}\text { Hobomok Skipper, Atrytone } \\
\text { zabulon }\end{array}$ & $\begin{array}{l}\text { Light brownish orange, black } \\
\text { border and marks }\end{array}$ & $m \cdot I_{4}^{1}, f \cdot I_{\frac{1}{2}}$ & C. \\
\hline $\begin{array}{l}\text { Delaware Skipper, Atrytone } \\
\text { delaware }\end{array}$ & $\begin{array}{l}\text { Light brownish orange, black } \\
\text { border and marks }\end{array}$ & $I \frac{1}{4}-1 \frac{1}{2}$ & R. R. \\
\hline $\begin{array}{l}\text { Accius' Skipper, Lerema ac- } \\
\text { cius }\end{array}$ & Deep brown & $I_{3}^{1}$ & V. R. \\
\hline $\begin{array}{l}\text { Dusted Skipper, Lerema hi- } \\
\text { anna }\end{array}$ & Olive brown & $m . \pm \frac{1}{8}, f .1 \frac{7}{4}$ & R. \\
\hline
\end{tabular}

\section{MOTHS}

Regal Moth, Citheroniaregalis
Imperial Moth, Eacles im-
perialis
Io Moth, Hyperclivia io

Promethea, Callosamia promethea

Polyphemus, American Silkworm, Telea polybhemus

Cecropia, Emperor Moth, Platysamia cecropia

Luna Moth, Actias luna
Olive, spotted with yellow veins red

Yellow, spotted and banded with purplish brown $m$. yellow, $f$. purplish red

$f$. reddish brown, light wavy bands; $m$. darker, markings indistinct

Yellowish brown, dusky band, four transparent eye-spots with pink outer margin

Red brown, wavy dull red bands

Light green, tailed, front border purple brown

\begin{tabular}{c|c}
$4-7$ & I. R. \\
$4-5 \frac{1}{2}$ & R. R. \\
m. $2 \frac{1}{2}, f \cdot 3 \frac{1}{2}$ & R. C. \\
$3 \frac{1}{2}-4 \frac{1}{2}$ & C. \\
$5-6$ & R. C. \\
$5-7$ & R. C. \\
$4-5 \frac{1}{2}$ & R. \\
\hline
\end{tabular}
KEY : $\quad$ R., Rare $\underset{m ., \text { male }}{\mathrm{C} ., \text { Common }} \underset{f, \text { female }}{\mathrm{R} .}$ C., Rather Common 


\begin{tabular}{|c|c|c|c|}
\hline \multirow{2}{*}{ Food of Caterpillar } & \multicolumn{2}{|c|}{ Broods per Season } & \multirow{2}{*}{ Haunts } \\
\hline & Number & Month & \\
\hline Grass & 2 & June, Aug. & Meadows \\
\hline Grass & 2 & June, Aug. & Meadows \\
\hline \multicolumn{4}{|l|}{ Grass } \\
\hline \multicolumn{4}{|l|}{ Unknown (probably grass) } \\
\hline \multicolumn{4}{|l|}{ Grass } \\
\hline Unknown (probably grass) & I (?) & July & Meadows \\
\hline \multicolumn{4}{|l|}{ Unknown (probably grass) } \\
\hline Grass & $\mathbf{I}$ & May, June & Meadows \\
\hline Grass & I (?) & July & Meadows \\
\hline \multicolumn{4}{|l|}{ Grass } \\
\hline Unknown (probably grass) & & & \\
\hline
\end{tabular}

\section{MOTHS}

\begin{tabular}{l|l|l|l}
\hline Hickory, walnut, pine & I & June & Borders of woods \\
$\begin{array}{c}\text { Maple, buttonwood, pine } \\
\begin{array}{r}\text { Clover, corn, hops, cotton, } \\
\text { elm, cherry, and other } \\
\text { trees, spines venomous }\end{array}\end{array}$ & I & June & June \\
$\begin{array}{c}\text { Wild cherry, tulip, ash, } \\
\text { and other trees }\end{array}$ & I & June, July & Open woods \\
$\begin{array}{c}\text { Oak, elm, hickory, bass- } \\
\text { wood, maple, and other } \\
\text { trees }\end{array}$ & I & June, July & Open woods \\
$\begin{array}{c}\text { Apple, cherry, plum, and } \\
\text { many other trees } \\
\text { Walnut, hickory, birch }\end{array}$ & I & June, July & Open woods \\
\hline
\end{tabular}

R. R., Rather Rare V. R., Very Rare V. C., Very Common

I The only native carnivorous butterfly-caterpillar. 


\title{
CHAPTER XVI \\ INSECTIVOROUS ANIMALS
}

\section{The Common Toad: its Life Story and Work; the Biological Type}

\begin{abstract}
Life runs its rounds of living, climbing up
From moat, and gnat, and worm, reptile, and fish,

Bird and shagged beast, man, demon, deva, God,

To clod and moat again; so are we kin

To all that is; and thus, if one might save

Man from his curse, the whole wide world should share

The lightened horror of this ignorance

Whose shadow is chill fear, and cruelty

Its bitter pastime.
\end{abstract}

Sir Edwin Arnold, Light of Asia.

If the children are interested in their gardens, vines, and fruit trees, and if they have begun to study intelligently the insects about their homes, they will be ready to commence with zest the work with our insectivorous animals.

Possibly some child in the class has a pet toad. If so, have it brought to school and make it at home in an aquarium or glass box of some sort with about two inches of moist earth in the bottom. It will probably bury itself with only its back and eyes above the surface. Then ask the children to bring in all sorts of insects - flies, caterpillars, hornets, wasps, rose beetles, spiders, ants, moths, roaches, squash bugs, anything they can find- 
especially such as may be destructive and annoying in the neighborhood. During the nature-study hour turn these in with the toad and let the class gather around and count the number it requires for a clinner. They will be able to observe the manner in which the toad catches an insect, - a flash of pink, almost too quick for the eye to follow, and the insect is gone. From the numbers

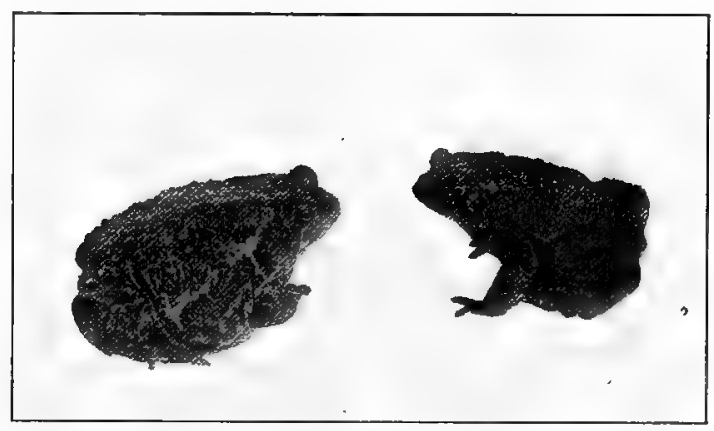

Fig. III, A PAIR OF TOADS

Female and male. (Photograph by the author)

obtained, they may be led to reason what a power for good one such little animal may exert in their gardens. They will also notice that a toad never snaps at anything until it moves, so that all its food must consist of moving living things. ${ }^{1}$

For the next lesson the children may be asked to study the toads about their own homes. First, how many have

${ }^{1}$ For suitable vivaria or aquaria, see Chapter XXIII. If insects are not obtainable, bits of fresh meat may be dangled on the end of a thread, dragged slowly in front of the toad, etc., thus demonstrating its manner of feeding almost equally well. 
they? This question may be answered by searching over the lot about sundown or after a shower. Do they have enough to keep the ground free from insects? How

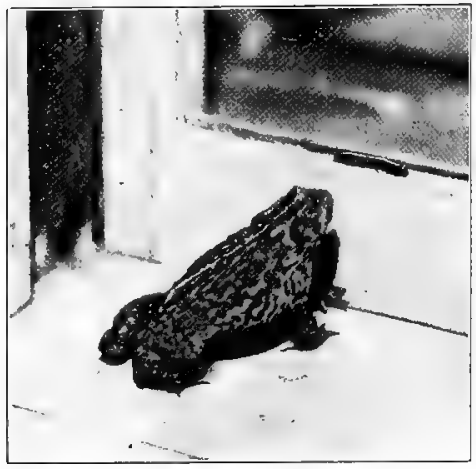

FIG. II2, JUST BEFORE large are their toads? Let us see who can bring in the biggest toad, and the smallest. What kinds of places do toads select to spend the day in? This is an important point. It will be found that they choose moist, shady places, under stones, leaves, or, more often, under boards. Are there enough such shel-

ters well distributed about their gardens?

Before I knew what to do to save my garden from the slugs, I have stood at evening rejoicing over rows of fresh emerald leaves just springing in rich lines along the beds, and woke in the morning to find the whole space stripped of any sign of green, as blank as a board over which a carpenter's plane has passed.

In the thickest of my fight with the slugs some one said to me, "Every living thing has its enemy; the enemy of the slug is the toad. Why don't you import toads?"

I snatched at the hope held out to me, and immediately wrote

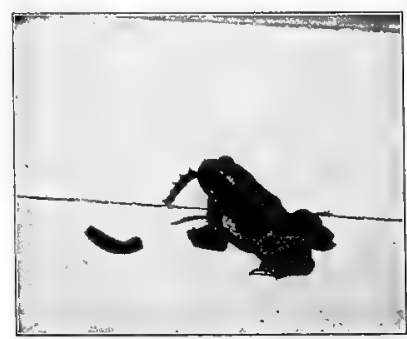

FIG. II3. JUST AFTER to a friend on the continent, "In the name of the Prophet, Toads!" At once a force of only too willing boys was set about the work 
of catching every toad within reach, and one day in June a boat brought a box to me from the far-off express office. A piece of wire netting was nailed across the top, and upon the earth with which it was half filled, reposing upon some dry and dusty green leaves, sat three dry and dusty toads, wearily gazing at nothing. Is this all, I thought, only three! Hardly worth sending so far. Poor creatures! they looked so arid and wilted, I took up the hose and turned upon them a gentle shower of fresh cool water, flooding the box. I was not prepared for the result! The dry, baked earth heaved tumultuously: up came dusky heads and shoulders and bright eyes by the dozen. A sudden concert of liquid sweet notes was poured out on the air from the whole rejoicing company. It was really beautiful to hear that musical ripple of delight. I surveyed them with eager interest as they sat singing and blinking together. "You are not handsome," I said, as I took a hammer and wrenched off the wire cover that shut them in, "but you will be lovely in my sight if you wiil help me to destroy mine enemy"; and with that I turned the box on its side and out they skipped into a perfect paradise of food and shade. All summer I came upon them in different parts of the garden, waxing fatter and fatter till they were as round as apples. In the autumn baby toads no larger than my thumb nail were found hopping merrily over the whole island. There vere sixty in that first importation; next summer I received ninety more. Celia Thaxter, An Island Garden, pp. 9, ro. (See also Letters of Celia Thaxter, p. I79.)

We may next take up the life story. Who can bring in the first eggs? Where shall we look for toads' eggs? At what season are they laid ? Who ever heard of toads' eggs, anyway? What do they look like? What child in the class can tell us?

This part of the subject should be taken up in the spring, about the time the frost comes out of the ground. On some of the first warm evenings after this, a rustling of dry leaves and grass may be heard in every direction, 
where toads are plenty. It will often be mingled with low musical trills of the male toad. This is the signal by which you may know that all the adult toads are migrat. ing to the nearest pond to lay their eggs. That same night, or as you awake in the morning, you will hear the country ringing with the music Gibson has so well described as the "sweetest sound in nature." As spring draws slowly on, my ears grow impatient to hear it, and as the years go by I enjoy it more and more. True,

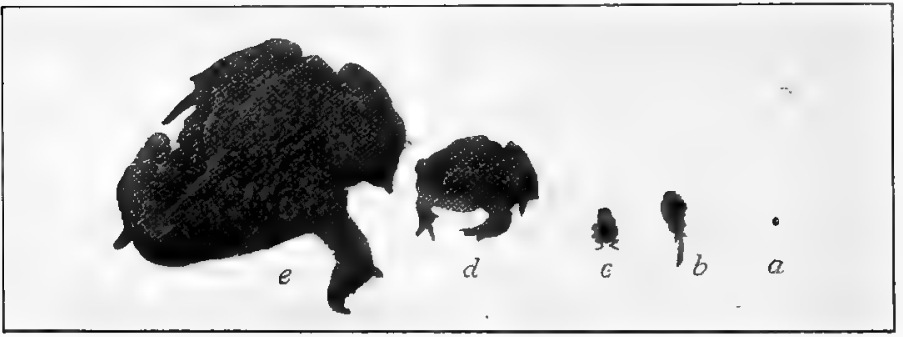

Fig. I14. LIFE STORY

Showing egg, tadpole, young toad just emerged from water, one year old, and adult. ( $b, c, d, e$, photographs by the author)

some may think it monotonous. It may come but once a year, and then only for a few days, and to me it is one of the cheeriest wedding bells of the season.

But the early musicians are now forgotten. A new singer has come upon the scene, and his mellow nocturne in the twilight marshes brings a message unknown to his predecessors. This is no shrill peep that stirs your blood and sets your ears a-tingle, no bubbling rattle or vibrant croak that cries "qui vive" to your eager senses, but a drowsy drool that brings your feet to loitering in the deepening dusk, and whose distant music from the swampy lowlands lulls you 
on your pillow. It is to me the sweetest sound in nature, the faithful chosen voice of the twilight, one of the most characteristic attributes of late spring, and yet, like the sprightly welcome of the hylodes which ushers in the vernal season, it still remains unsung by our poets, or if occasionally acknowledged the true singer never gets the credit.

Who will immortalize in verse the pensive witchery, "most musical, most melancholy," of this tremorous song of the toad, for it is in truth the uncouth and ill-favored toad that now swells his bagpipe in the marshes and fills the night with music? It is one of the beneficences of nature that the twilight glamour throws a veil of obscurity over the performer while it emphasizes and consecrates its music. Hamilton Gibson, Sharp Eyes, p. 54.

If we go down to the pond next morning, we may see them by scores, hundreds, possibly thousands, paddling about in the water, the males, many of them, trilling at the top of their voices. Many, possibly, are still arriving, hopping along, all toward the pond. The males do all the piping, and it will be noticed that the throat is swelled into a bagpipe while the sound is emitted. Males and females are otherwise distinguished by the larger size of the female, the body being also greatly distended with eggs. ${ }^{1}$

The mass of eggs laid by a toad is remarkable. It may be demonstrated by placing a pair, before they begin to lay, in an aquarium or bucket half full of water. If the water and receptacle are clean, i.e., if there is no sand or plants to become mixed with the eggs, a clear, bright mass of eggs may be obtained. A stone should be placed

1 Children, when they begin studying toads in the spring, often think that the male is "eating" or "sucking the blood" of the female. They should be told that he is helping the female lay her eggs. 
in the water, rising to the surface, for the toads to rest on. Some boy or girl may volunteer to secure the entire laying of a pair of toads to show the school, and it might be interesting to count or estimate the number. Toad spawn is distinguished from that of frogs and salamanders by the fact that it is laid in strings or "ropes," the eggs lying in single rows inclosed in a transparent jelly. They are about the size of a small pin head at first, black

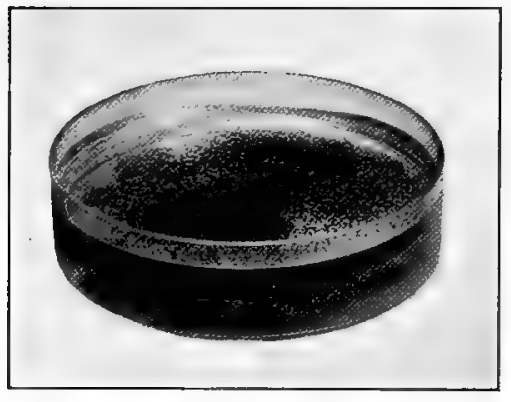

Fig. II5. EgGS LAID by A TOAD The glass dish is nine inches in diameter. Number of eggs, 9500 (estimated) above and light below; as they float they look like strings of black beads. It may stagger the class to believe that a toad can lay a mass of eggs eight or ten times as large as its whole body, - as though a hen were to lay an egg the size of a bushel basket. $T h$ is mystery is explained by the swelling of the jelly on contact with the water. But the number of eggs is almost incredible. Layings of four toads contained, respectively, 7587 and I I, 545 (counted), and 8000 and 9500 (estimated). This number is laid in a few hours, generally at night; and then, quitting the water, the parents probably return to the same gardens whence they came. Beginning with the egg, the most interesting part of the toad's life story may be read in its reality by occasional observations in the ponds and by taking a few eggs home or to the schoolroom to watch their development from 
day to day. No aquatic egg is better adapted for such use. It is large enough to be seen with the unaided eye,

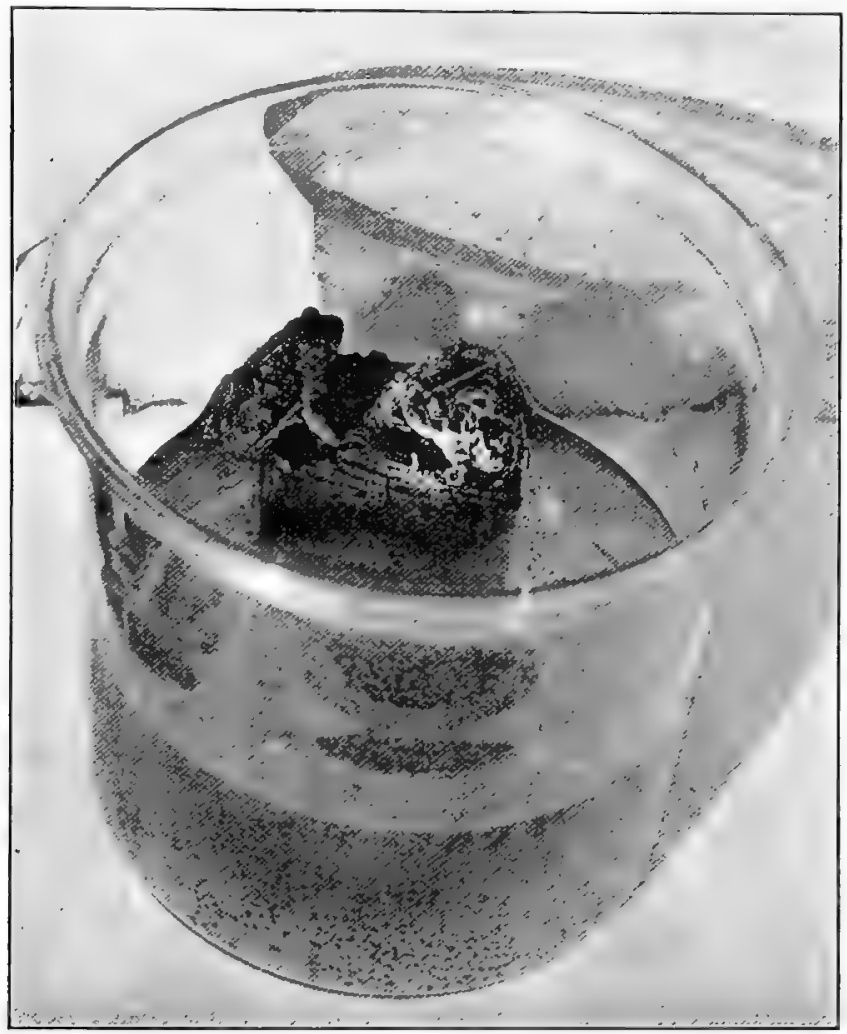

Fig. in6. AQUariUm

Arranged to collect eggs of a toad

develops under all sorts of conditions, and the progress is so rapid that interest is sustained to the end. First the egg elongates, then the tiny flat tadpoles hatch and, 
-feeding first on the gelatinous matter of their envelope, they soon begin to eat the slimes in the aquarium and grow with great rapidity; hind legs appear, fore legs come, the tail is absorbed, and the little toads emerge from the water, - all within little more than a month from the time the eggs are laid.

To do this in the schoolroom, have some of the children arrange two or three aquaria (glass, earthenware, wood, or iron may be used, but tin, lead, zinc, galvanized iron, copper, and other metals should be avoided, since they may poison the water and kill the tadpoles) as nearly as possible like the pond from which the eggs are taken. Have the water not more than two to four inches deep in the deepest part, and let the bottom slope up gradually to the surface at one end. This will enable the tadpoles to find any depth of water they wish and afford a place for them to come out gradually into the air at the proper time. In fact, the bottom of the aquarium may be made of sand, gravel, and moss-covered stones from a fairly clean pond. It is necessary also to have plenty of green algæ and water plants, duck's-meat, stonewort, bladderwort, milfoil, water cress, or the like, to oxygenate the water properly, furnish food, and take up the excretions of the growing tadpoles. If the aquarium is large enough, a water hyacinth is an excellent plant to have growing in it for this latter purpose. If the tadpoles do not keep the water perfectly clear, a fresh-water mussel or two will accomplish this. Give them a window with sunlight a good part of the day; as they grow, let the children carry any surplus back to the pond, and avoid overcrowding by allowing about an inch of water surface to 
a tadpole. If they tend to eat the aquarium bare, add fresh supplies of slime and plants from the pond and, in a word, keep them healthy, vigorous, and growing.

Encourage as many children as possible to provide little pools in their gardens, stock them well with water lilies, pickerel weed, cat-tails, iris, and other of our interesting aquatic plants, and put in as many toads' eggs or tadpoles as the pool will support. For this purpose a water-tight box or tub may be set in the ground, or a more natural pool may be made by arranging large flat stones around a hole in the ground and plastering up the cracks between them with water-lime cement. The top of any such receptacle should be two or three inches below the surface, and the earth well packed around the edges to prevent rains from splashing out its occupants. If natural food be not abundant, its place may be supplied by bits of dog biscuit, fresh meat, fish, or even bread, but care should be taken to put in no more than is eaten clean or to remove uneaten pieces before they foul the water. In this way, without appreciable expense, any child can raise toads by thousands, until many of our most injurious insect pests become curiosities. The danger of ever getting too many toads we will discuss in a moment.

Emphasize throughout these lessons the work the tadpoles are doing in the water. They are known as the "best scavengers" of aquaria, and it is difficult to keep an aquarium clean without them. Their little horny jaws are continually scraping the slimy growths from everything in the water. Their food at this time is commonly stated to be vegetable, but if one examines these slimes with a microscope, he will always find a considerable 
proportion of animal life as well. Toad tadpoles are especially good for this work and will generally keep the water in the aquarium as clear as crystal. An instructive experiment may be arranged by setting up two small aquaria just alike. Put in plants and everything else, but leave all the tadpoles out of one and observe differences in cleanliness of the water. Unite with this study observations as to feeding habits of tadpoles in the ponds. They may be seen swarming around dead fishes, frogs, or other matter that would otherwise pollute the water. Apply the knowledge gained to the problem of keeping the ponds and park waters in the neighborhood clear and sweet. ${ }^{1}$

Natural enemies of the toad form the next series of topics for study. Why is it that, laying from five to ten thousand eggs a year, toads do not become more numerous? No one knows the natural length of a toad's life. It is claimed that one lived for thirty-six years in a garden in England and was then killed by a tame raven. They probably mature and begin to lay eggs when about four years old. Suppose the females continue laying for ten years, the fact that the species does not increase in numbers means that of the possible I00,000 eggs only two survive to take the place of their parents. How are all the rest killed off ?

Practically every egg in a laying hatches, and I have not discovered that any fishes, newts, tadpoles, or aquatic insects eat the eggs. But the tadpoles from the time

1 As filth is washed into the ponds by the freshets of early spring, no small service may be rendered in cleaning surface waters at this season. I have seen pools even among city dumpage perfectly clean while the tadpoles were in them during the spring. 
they hatch until they leave the water are preyed upon by water beetles, dragon-fly larva, newts, and possibly fishes. The entire hatching of a pond may be thus destroyed. Probably ducks feed upon both eggs and tadpoles in great numbers. On leaving the water the little toads are at the mercy of ducks, hens, and many insectivorous birds. Crows and snakes, and many species of hawks and owls feed upon the adults. In addition to those destroyed by natural enemies many are killed by wheels of vehicles and lawn mowers, and many more are trodden under foot and burned in rubbish. ${ }^{1}$

The toad is known to possess something of a "homing instinct"; so that if they are collected and put into a garden, they immediately leave it, unless confined, in their attempt to find their familiar haunts. It is also said that the adults generally return to the pond in which they were hatched, to lay their eggs. Both of these considerations, coupled with the fact that it is difficult or impossible to protect them from natural enemies in the ponds at large, emphasize the advisability of each garden or farm raising its supply in the easy manner suggested above. It is work that any child can do and be the better and wiser for doing, aside from any more material benefits that may accrue, and these are likely to be by no means small.

The criticism naturally arises that such artificial culture might result in a plague of toads. This is scarcely

${ }^{1}$ In looking over burned brush lands and weedy vacant lots, where the leaves and rubbish have been burned in the spring, the writer has so often found the charred bodies of toads that general attention should be called to this matter. If this be done, common sense as well as humanity will dictate that such burning should be done, when possible, either after the ground freezes in the fall or before the frost comes out in the spring. 
possible, for a number of reasons. First, the retiring and wholly inoffensive nature of the animal could not constitute it any such plague as we already have in many species of insects that it destroys. As it is nocturnal, even its proverbial ugliness is not conspicuous. Its powers of locomotion are so limited that it could be easily caught and destroyed, if that should ever become necessary. Finally, its natural food supply, consisting wholly of insects, worms, slugs, and the like, would inevitably set a natural limit to its increase. ${ }^{1}$

We have before us an example of the plasticity of one of nature's mechanisms. A toad can live a year, or even two, in apparent comfort, without any food whatever, but no eggs will be produced. If food be abundant, it will eat voraciously and produce eggs in great numbers, possibly twice a year. ${ }^{2}$ Every such plastic living mechanism is a bow bent back, and wherever its force is beneficent we should be careful to keep it bent so that its spring will be able to do the greatest good possible at any opportune moment.

"However useful they may be," one teacher remarked, "a toad is such an ugly, lisgusting creature we never can use it in school." This is tradition, against which it is

1 Destruction of honeybees is about the only damage toads could do, should they become too numerous. But as bees are not nocturnal and are not much on the ground, this danger is imaginary.

- 2 In some seasons toads are found in considerable numbers laying eggs in July. These may be belated individuals, but I am inclined to think that they are laying a second time. Celia Thaxter's experience supports this view, for her toads, brought to the Shoals in June, filled the island with little toads the same summer. They must have laid once before their importation. 
well worth while to contend. ${ }^{1}$ Children are rarely, if ever, troubled by such notions, unless they have been implanted by their elders; and while no compulsion is called for, their objections are often easily overcome. The toad is not a handsome animal, yet its eye, the fabled "jewel" in its head, is one of the most beautiful in nature.

Ask the children why they think the toad was made so ugly, all but the eye. There are important lessons in the answer to this question. Keen-eyed birds of prey and snakes are continually seeking it for food. With no means of defense or escape from these swift pursuers, its only hope of life lies in being as inconspicuous as possible. This story is thousands of years old, and all this time the more brightly colored toads have been snapped up first and those that most resembled clods of earth have escaped. On the other hand, insects must come close enough for the toad to capture. They must practically walk into its mouth, and thus it depends for its food upon looking like the harmless earth over which they crawl. These are lessons applicable to every living thing we study, and when their significance is appreciated, they may do much toward reconciling the fastidious to the homeliness of the toad. Its life and its work in the world depend upon it.

1 Farewell, farewell! but this I tell

To thee, thou Wedding-Guest, -

He prayeth well, who loveth well

Both man and bird and beast.

He prayeth best, who loveth best

All things both great and small;

For the dear God who loveth us,

He made and loveth all. 
If roughly handled, a whitish liquid, which is somewhat poisonous, is secreted from the skin of a toad, especially from the large glands near the head. It will cause some swelling of a dog's mouth, and

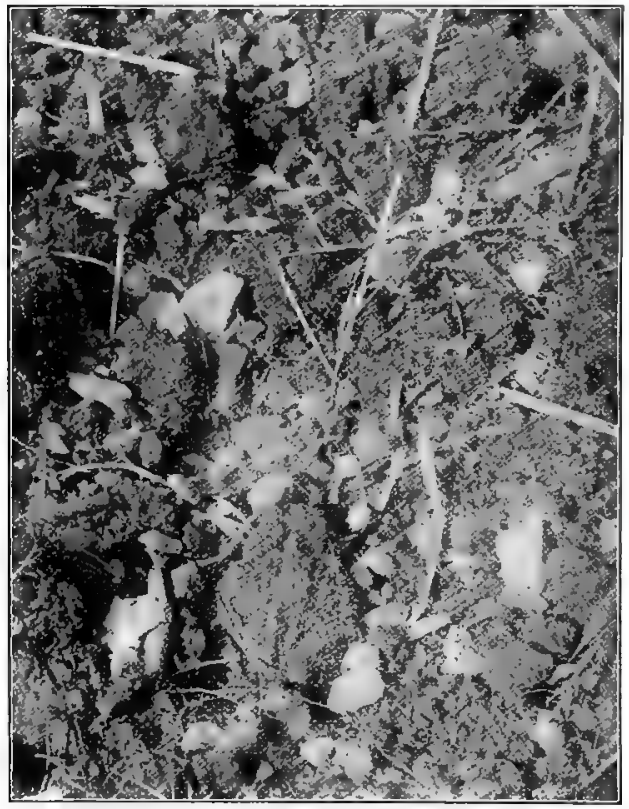

Fig. II7. Protective Coloration

care should be taken not to allow it to get into the eyes when handling toads. The natural precautions, gentle handling and washing the hands afterwards, are all-sufficient safeguards against any venomous properties, and these also apply to the handling of many other animals ${ }^{1}$; but everything advocated in this chapter can be done without so much as touching a toad. We may catch it in a large leaf, a piece of paper or cloth or in a tumbler or jelly glass. The neatest way to demonstrate a toad to a class is to have it in a clean tumbler with a piece of gauze securely tied over the top. It may then be

1 A. H. Kirkland, "The Habits, Food, and Economic Value of the American Toad" (Bullitin 46 , Hatch Experiment Station, Amberst, Mass.), gives the fullest account extant of the toad from this standpoint. By his method, killing the animals and opening the stomach, he identified eighty-three different species of insects, most of them injurious, as entering into its dietary. By the method advocated above, however, i.e., by making feeding tests in a vivarium with insects collected for the purpose, any school could add 
passed around and examined without danger of offending the most fastidious. The idea that warts are caused by handling toads is ancient myth without foundation in fact.

The Biological Type. - Types of animal forms and structures have long been used in college courses in biology and belong properly to this grade of advanced instruction. The many attempts to introduce these same "types" into more and more elementary work have seemed to me premature and ill advised. Before such studies are undertaken the children need a foundation of living interests in the animal life about them, and I have advanced this study as a new kind of type, adapted to elementary education. I have called it the biological type. In less technical words it may be called the life type, or life-story type, for the study of an animal species. We have come of late to appreciate the necessity of studying animals and plants with children "as wholes," but this too often has been interpreted to include little more than their forms and structures, which to children are dead and without interest. By this life type I mean the activities, the work of a species in its wholeness, - the active relations of the animal to the life about it and especially to man. This is the side of fundamental, large, and universal interests in the life about us.

hundreds of species to this list, if they knew the species. Still this, of course, would not show what might be termed the natural feeding habits of the toad. But the toad's stomach is a straight sac extending from the mouth, where it is very wide, back almost to the end of the body. It is easily everted, and by gently inserting a wire loop (a hairpin does very well) the whole stomach contents may be drawn out without the least injury to the animal. I do not, however, give this as a method to be used, but merely as a suggestion, by which the animal's life may be saved when it is desired to make such examinations. 
There can be no reasonable doubt that this aspect of movement and activity is the natural side of approach for the child. It is akin to that animism of childhood which projects life and action even into inanimate things. It is this side of living nature which, from intrinsic fascinations and varied affinities with the passion for activity of child life itself, is best adapted to create enduring interests and love of nature. It is, moreover, with this side of nature that a child's activities come into frequent clash, which results in all sorts of apparently brutal harms to nature. With but a minimum of proper instruction which may bring the child into sympathy with the life around it, and especially show its values and relations to human life and interests, all such activity may be easily guided into beneficent channels. Instead of being repressed, as is now so much the case, this activity may be greatly developed and encouraged; and then child life will flow happily along with the life of nature.

But why choose such an animal to illustrate the biological type? There are many reasons, which I may briefly state, in relation to the fundamental values of nature study discussed in a former chapter.

First, on the asthetic side, to find any beauty in a form proverbially the ugliest in nature carries the whole battle,sweeps the field of ancient prejudice and unfaith in nature. To discover here the brightest jewel and the "sweetest sound in nature" awakens a child's faith and impels him to seek and find beauty in everything about him.

I pick up a toad a hundred times a season just to enjoy looking at its eye, - a living, sparkling, ever-changing jewel, — and his nusic in the springtime brings a pleasure that nothing else affords. 
On the side of public economy, the toad is one of the most important animals we have. Toads are practically at every child's door; it need cost nothing for specimens, and their commonness makes it possible for children to observe and study them at odd times about their homes. Further than this, the school children might save in the course of their outdoor laboratory work and play from $\$ 100,000,000$ to $\$ 200,000,000$, - nearly half the expense of their entire public school education, - by learning and utilizing this one species as a beneficent force in nature ${ }^{1}$; and the effect will first be felt in their own gardens.

As an introduction to zoölogy no animal has a development better adapted for study. The eggs are abundant, come at a convenient season, and pass so rapidly through the different transformations that even young children do not lose interest. Nothing could be better calculated to open the door of interest into comparative embryology and zoölogy. Then there is the sleight-of-hand magic of catching insects. Nothing in all the varied performances of animals brings so quickly: How did he do it? What did he do it with? Such questions open the way to comparative anatomy. Next we have a question that will prove a puzzle. Ask the children if any of them ever saw a toad drink. How did it drink? Here we have comparative physiology. A toad drinks by absorbing water through the skin.

Deprive a toad of water for a day and weigh the specimen carefully. Next let it sit on a wet blotting paper, or pour a little water into its vivarium, and, after an hour, weigh the toad again. The gain will represent water absorbed.

${ }^{1}$ Riley's estimate is that insects cause from $\$ 300,000,000$ to $\$ 400,000,000$ damage annually. 
Again, where do we find a better example of protective coloration, harmony with environment, and life work? This is a point of view that, when once appreciated, makes interesting a thousand other things we shall see in nature. Finally, the food of the toad shows the necessity of learning about insects and their work. Entomology as a science is far too little studied in this country.

On the ethical side, no animal is more apt to be grievously abused by the children. Experience has shown that a little instruction of the right kind wholly does away with this and makes them its most sturdy protectors. What child could ever again harm a toad after watching it catch insects for an hour, or after raising a few from the egg ? ${ }^{1}$ The study may thus yield the best kind of moral culture.

Early in April, as I was vigorously hoeing in a corner, I unearthed a huge toad, to my perfect delight and satisfaction; he

1 My attention to this subject, and, in fact, to nature study in general, was aroused by the wholesale killing of toads when they came to the ponds to lay their eggs. While walking once around a small pond I counted 200 dead or mangled and struggling in the water, and learned next day that two boys had killed 300 more, carrying them off in an old milk can to empty on a man's doorstep. This 500 does not represent probably one-tenth of the number killed by the children that spring (1897) around this one pond. A "civilization" in which such abuses of nature are possible ought to be eaten alive by insects, and something must be fundamentally wrong with a system of public education that does not render such a thing impossible. My first impulse was to get a law passed and appeal to the police, but the wiser counsel of a friend prevailed, and I was induced to try education of the children instead. Accordingly, a prize of \$10 was offered to the Worcester school child who would make the best practical study of the "Value of the Common Toad." This was offered March 3r, I898, and there was no evidence that a single toad was harmed at the pond the following April and May. I would have been well satisfied had such a result been attained in five years. The fact that it came within thirty days reveals the possibility of nature study when united to human interest. 
had lived all winter, he had doubtless fed on slugs all the autumn. I could have kissed him on the spot! Very carefully I placed him in the middle of a large green clump of tender columbine. He really was n't more than half awake, after his long winter nap, but he was alive and well, and when later I went to look for him, lo! he had crept off, perhaps to snuggle into the earth once more for another nap, till the sun should have a little more power.

To our great joy the frogs that we imported last year are also alive. We heard the soft rippling of their voices with the utmost pleasure; it is a lovely liquid-sweet sound. They have not lived over winter here before. We feared that the vicinity of so much salt water might be injurious to them, but this year they have survived, and perhaps they may be established for good. CELIA Thaxter, An Island Garden, p. 56.

For four hundred years we have not added a single animal to our list of domesticated species. The turkey was taken to Europe and domesticated soon after the discovery of America, and while ostrich farming is in its experimental stages, Professor Shaler seems inclined to consider this our last assured conquest over wild nature.

From this point of view our domesticated creatures should be presented to our people, with the purpose in mind of bringing them to see that the process of domestication has a far-reaching aspect, a dignity, we may fairly say a grandeur, that few human actions possess. Shaler, Domesticated Animals, p. 8.

In a large way the work of domestication represents one of the modes of action of that sympathetic motive which more than any other has been the basis of the highest development of mankind. Ibid., p. $22 \mathrm{r}$.

Thus we see that to domesticate an animal species is no mean work with which to begin a century.

The toad has come more than halfway, to man's doorstep in fact, to escape its natural enemies and 
demonstrate its usefulness. To complete the process of domestication it is only necessary to develop the intelligence and sympathy that shall afford it universal protection. In addition, before considering a species a full member of the human household, it is generally necessary to discover means of breeding it in confinement or under human control. With this condition met, in the manner already described, there will remain no doubt that we have added a new and important species to the domesticated animals of this country.

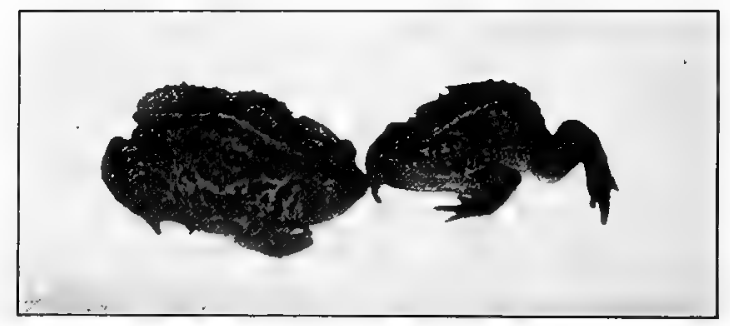




\section{CHAPTER XVII \\ COMMON FROGS AND SALAMANDERS}

How many different kinds of toads and frogs do we know? Encourage the children to bring in as many kinds as they can find, and study and compare them a little as to size, color and markings, habits and habitats. Learn their different notes, make feeding tests with each, stucly the season of spawning and the characteristic appearance of the eggs and, in a word, since they are all good friends, begin to make their acquaintance.

And first, I wonder how many know the difference between a frog and a toad. Aside from mere outward appearances, form, warty skin, colors, etc., which are not very constant, one of the prime differences is that toads have no teeth on their upper jaws, while the frogs always do. Here is a little matter of the common use of the English language that might as well be set right in the beginning. It is as easy to say "tree frog" as it is to say "tree toad," and since they are all frogs we may as well call them so. In case of doubt, gently open the mouth and pass a finger along the upper jaw, and if teeth are present, we will call it a frog, if not, a toad.

Our froglike animals are further divided into two great classes : those in which the adults have tails, and those that have none. Here is another little matter of good English that we may learn rightly to begin with. Our long-tailed Batrachia (frogs and salamanders) are 
commonly called lizards. But lizards are always covered with horny scales, somewhat like the skin of a snake. We have no common lizards in the northern states, although they are numerous farther south. The little chameleon and the " horned toad," often brought north as curiosities, are lizards. Possibly one of the children has a specimen and can bring, it to school to make this difference clear. Lizards and salamanders are shaped much alike, but if the skin is smooth, like that of a frog, we will call the animal a salamander or newt, not a lizard.

Taking our study of the toad as the life type, we may apply similar methods to investigating any frogs and salamanders; and we will choose such as are most worthy of our study. This is a great field, almost wholly unknown. Any feeding test with one of these animals, by using a variety of insects, is likely to yield knowledge to the class that is valuable and that no one else in the world knows. It is safe to say that all these animals are harmless, i.e., not venomous or likely to injure by biting; that, with one or two exceptions to be noted below, they are all valuable insect destroyers, each for its peculiar haunts; and that they should be generally protected and utilized as beneficent forces in nature. It is with this point in view that the general study of them is advocated; that as each fact - their harmlessness, their usefulness, their varied beauties, their interesting ways and lives - comes to be generally known and appreciated they may be treated from motives of conscience and humanity rather than from those of ignorance and prejudice.

In order to start the children intelligently on these interesting researches, I shall give, in scarcely more than 
tabulated form, descriptions and suggestions of a few of our commonest species. Naturally a species may be common in one locality and not in others, but it is intended that the pupils should spend their time learning the life stories of what they have rather than in hunting for what they have not. The table thus aims to aid in naming forms that may be brought in rather than to suggest what to hunt for, and the scientific names are inserted in order to facilitate reference to special books, not to be learned by the children or teacher.

\section{Toads, Frogs, and Salamanders}

\section{Batrachia}

TOADS, Bufo. Jaws toothless, skin generally warty. Genera three, species thirty; found in all parts of the world except Australia.

Common Toad, B. lentiginosus. Variety of northern form, americanus. Very variable; adults warty; young almost smooth. Note a prolonged trill, uttered by the males during the breeding season, April and May, sometimes also in July. Food: insects, spiders, millipeds, slugs, and worms. Feeding habit chiefly nocturnal. Does not eat young of its own species. ${ }^{1}$

FROGS, Rana. Skin smooth; toes and fingers fully webbed; maxillary and generally vomerine teeth; chiefly aquatic. Genera fourteen, species about fifty. Eggs are laid in masses of gelatinous matter.

Common Frog, Leopard Frog, R. virescens. Greenish, sometimes brassy, above, with light-edged dark spots arranged in two irregular rows along the back; beneath, pearly white or yellowish.

1 This is an interesting point to test. I have found that a toad will snap a little toad, as it will any moving thing; but my experience has been that they always immediately open the mouth and set the little one free uninjured. T have never seen an insect or any other living thing treated in this way. 
About three inches long. Our commonest and most beautiful frog. Note, a cluck much like that of a hen but more musical; one of the first species heard in the spring. Eggs laid about as soon as the snow melts in the spring. Food: insects (?).

Brown Frog, Pickerel Frog, R. palustris. Brown, spots squarish in four rows; beneath, yellowish white. Length, three inches. Note, a low, hoarse croak, like the sound made by tearing coarse cloth. Spawning season is early spring. Habitat, cold springs and streams. This frog has a somewhat disagreeable odor and is remarkable for the length of its leaps, being next to the most agile frog we have. Food: insects (?).

Northern Frog, $R$. septentrionalis. Color above, olive with large nearly circular blotches of brown; whitish beneath. Most variable of all our frogs. Body stout, about two inches in length. Possesses a strong odor of mink. Inhabits marshy waters, northern United States and Canada; quite aquatic. Feeds on insects and small fishes. Note and spawning season not given in the books.

Green Frog, $R$. clamata. Color above, bright green, rarely brownish, with blackish spots ; white below. Note, a musical "Chung" as it leaps into the water. Food: insects; otherwise practically unknown. Spawning season not given in the books.

Bullfrog, $R$. catesbiana. Our largest North American species. Color, greenish olive above, variously marked with dusky blotches; below, white, often bright yellow under the throat. The note is a deep bass " $\mathrm{Br}$ 'wum," "more rum " or " jug o' rum," heard so often in the early summer evenings. The spawning season, so far as I have been able to observe, is late June and July. The young remain in the water as tadpoles at least two years and attain a length of five to eight inches. This is our most valuable frog, but its work in nature is probably worth more than its market price. The services of the large tadpoles, too, in cleansing shallow ponds must be of considerable value. The number of eggs laid by a large frog is not known, but is probably not less than 20,000 . Whatever the number, the frogs should be carefully protected - along with trout and other fishes - until after 
spawning is well over. The open season should not be longer than August and September. The food of the bullfrog seems to be any living thing that it can even partially swallow. I have seen one swallow the head end of a live mud puppy fully twice the length of the frog's body. Another observer has recorded a similar instance of the fate of a young alligator. Mice, birds, feathers and all, fishes, crayfishes, insects, worms, tadpoles, and frogs of its own and other species are acceptable, and in this struggle size may not count for so much as first hold. In confinement they may be fed on earthworms, grasshoppers, and other insects, and it is not beneath the dignity of the biggest of them to sit all day long beside a bone and snap the fies as they come.

Wood Frog, R. sylvatica. Color, greenish to reddish brown, changing somewhat according to surroundings; a dark band on each side of head extending over the eye and ear to insertion of arm; legs obscurely barred, and sides speckled with black. A small frog found commonly in the woods, scarcely aquatic, can leap farther than any other of our frogs. Its note is a hoarse croak, heard in April, when it comes down to the ponds to spawn. Aside from the common notion that it feeds on insects nothing definite is known as to its food.

SPADEFOOTS, Scaphiopus. Terrestrial frogs, heel provided with a spur for digging. Form toad-like. Genera two, species four.

Spadefoot Frog, S. holbrookii. Length, three inches; skin rough ; color, earthy or ashy brown. From all accounts these frogs bury themselves in the earth during the day, coming out to feed at night, and, while widely distributed, are neither seen nor heard except during the spawning season, when they are said to be "noisy whistlers."

TREE FROGS, Hyla. Small; arboreal; fingers and toes with tips expanded into clasping disks. Genera ten, species sixty.

Common Tree Frog, H. versicolor. Color above, green, gray, or brown, with irregular dark spots; white or yellow below. A common inhabitant of orchards and waysides, but a good test 
of any child's sharp eyes to find. Its note is the musical "Tur-r-r-r-t" so often heard on a summer evening. The eggs are laid in May or June in small masses attached to stems of weeds and grass in shallow pools. This is to me the most interesting of frogs. It is easily domesticated, so that it may be carried about on the finger from fly to fly. If kept in a vivarium and well fed, it is said to make an interesting barometer, climbing to the top of its ladder in fair weather and descending into the water before a storm. The distribution of these frogs is one of the greatest puzzles I have encountered. I have repeatedly brought them to the trees about the house, where attractive pools are provided, but they never stay more than a day or two. Why they are not more numerous is another question for which I have found no satisfactory answer.

Pickering's Tree Frog, H. pickeringii. Color above, yellowish brown, with a dark $X$ on its back, by which it may always be recognized. These little "spring peepers" announce the very first day of spring with their shrill, clear whistles, "Uh-e-e-t, wh-e-e-t, wh-e-e-t," from the pools of ice water in the glades and meadows. One may hear them all the years of his life but never know whence the sound comes, unless he puts on his rubber boots, takes a lantern to the pool, and picks them up in the very act.

Little Tree Frog, Chorophilus triseriatus. Color, ashy gray, brown, or fawn color, with three brown stripes down the back. Habitat, small pools in the densest thickets. Note resembles the low jingling of sleigh bells in the distance. Range is given as eastern United States, south of central New Jersey, and westward.

CRICKET FROGS, Acris. Small; not arboreal. Genus one, species one; with regional variations.

Cricket Frog, A.gryllus. Color above, brown or gray, readily changing, a dark triangle between the eyes, the apex pointing backward and continued down the middle line as a light stripe; three large oblique blotches on the sides; a dark (or white) line from eye across the eardrum. Its note may be imitated by striking 
two marbles together twenty or thirty times, at first slowly, then rapidly. It inhabits the weeds, the tall grass, and bushes of muddy shores. No good account is given of its foods, breeding season, or habits.

Both the time and place of spawning for most of our species of frogs and toads is best indicated by their music.

SALAMANDERS, Urodela. Smooth, elongated bodies; four limbs; long tails; no external gills when adult. Sixteen genera and fifty-three American species.

Newts, Diemyctylus viridescens. Color above, olive green, variable; a row of black-bordered vermilion spots on each side; below,-yellowish dotted with black. The tail is flattened and has finlike expansions of skin above and below. This description applies to the adult form of our common newt during the breeding season or while it is in the water. Found under stones and under logs out of the water, this newt (formerly classed as a distinct species, D. miniatus) is vermilion red above, paler or yellowish below; spots arranged as in the breeding form; tail fins absent. As these newts have been kept in confinement by a number of different people and have been observed to change from one form to the other under varied conditions, there can be no further doubt that they are one and the same species, the different forms and colors depending possibly on condition of maturity or on seasonal changes. The red form should be kept in a damp, mossy vivarium with a pool or dish of water sunk level with the ground at one end. The green form may be kept in an ordinary aquarium, covered to prevent its escape, and provided with floats of bark or cork, upon which it may rest. Both forms may be fed on worms or insects or small bits of raw meat. Valuable feeding tests may thus be made, since we know very little of the newt's feeding habits. It is especially instructive to see them eat mosquitoes and mosquito wrigglers in the water. The egg-laying season extends from April to July, and the eggs are laid singly, securely glued to and hidden within little tufts of aquatic leaves which the female carefully draws together 
around the egg as it is deposited. The egg is brown, about the size of a toad's egg.

Red-Backed Salamander, Plethodon erythronotus. Body slender, about three inches long; lead colored, with a broad reddish dorsal band, which varies greatly in color or may be absent. This is our most common salamander; it is found under stones and logs or beneath the bark of decaying stumps, and, unlike the forms thus far noted, its eggs are laid in these places and not in the water, and are watched over by the parent. Who can tell us at what season the eggs are laid? The food is insects and their larvæ.

Red Triton, Spelerpes ruber. Length, five to six inches; color, vermilion to dark salmon red, spotted with brown. No account is given of its eggs or breeding season. This is the triton that John Burroughs describes (Pepacton, Chapter V) as making "more music in the woods in autumn than any bird." The note is said to resemble that of Pickering's Hyla, only not so loud. No other naturalist, so far as I can learn, has succeeded in hearing it. Its haunts are springs and rocky streams, where it may be found by turning over the stones. In rainy weather it makes excursions on land.

Spotted Salamander, Amblystoma punctatum. Length, six to seven inches; color, black above, with a series of yellow spots on each side of back. Eggs of the spotted salamander will often be brought in by the children. They are found in the icy pools and ditches of early spring (March to April, according to season and latitude), large, oblong, cylindrical masses of rather tough jelly. They are transparent, and within the mass may be seen the clear, spherical oval, about one-quarter of an inch in diameter, each one containing a dark-brown yolk. This will prove a most instructive object to watch for the next three or four weeks.

PRoteans, Mud Puppies, Proteida. Medium- to large-sized animals, shaped like salamanders but thoroughly aquatic and provided with external gills. One American genus with two species. 
Mud Puppy, or Water Dog, Necturus maculatus. Length, ten inches to two feet; color, dusky brown, more or less mottled. Breeding season, early spring (?). Neçturus has the reputation of following fishes to their spawning grounds in order to eat the eggs and young.

We have noted but five of the fifty salamanders, but this will be sufficient for a beginning. In trying to keep them in confinement we must remember that some are aquatic, some terrestrial, and some both; and we must be careful to note the haunts of any common species we wish to study and render our vivarium as much like its normal environment as possible. I must repeat that the above forms are not described in order that they should be " learned," but solely to help toward an acquaintance with these and similar forms, to the end that intelligent sympathy may take the place of ignorant fear.

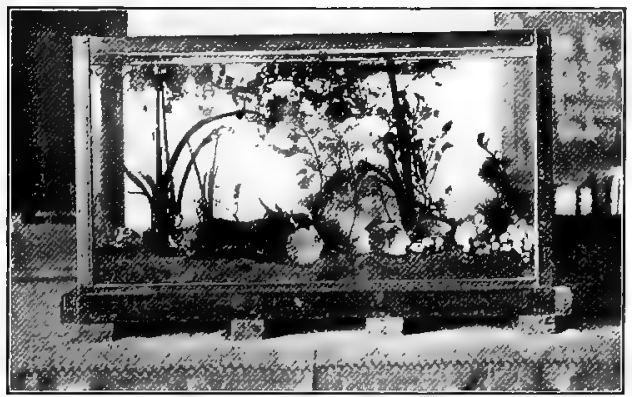




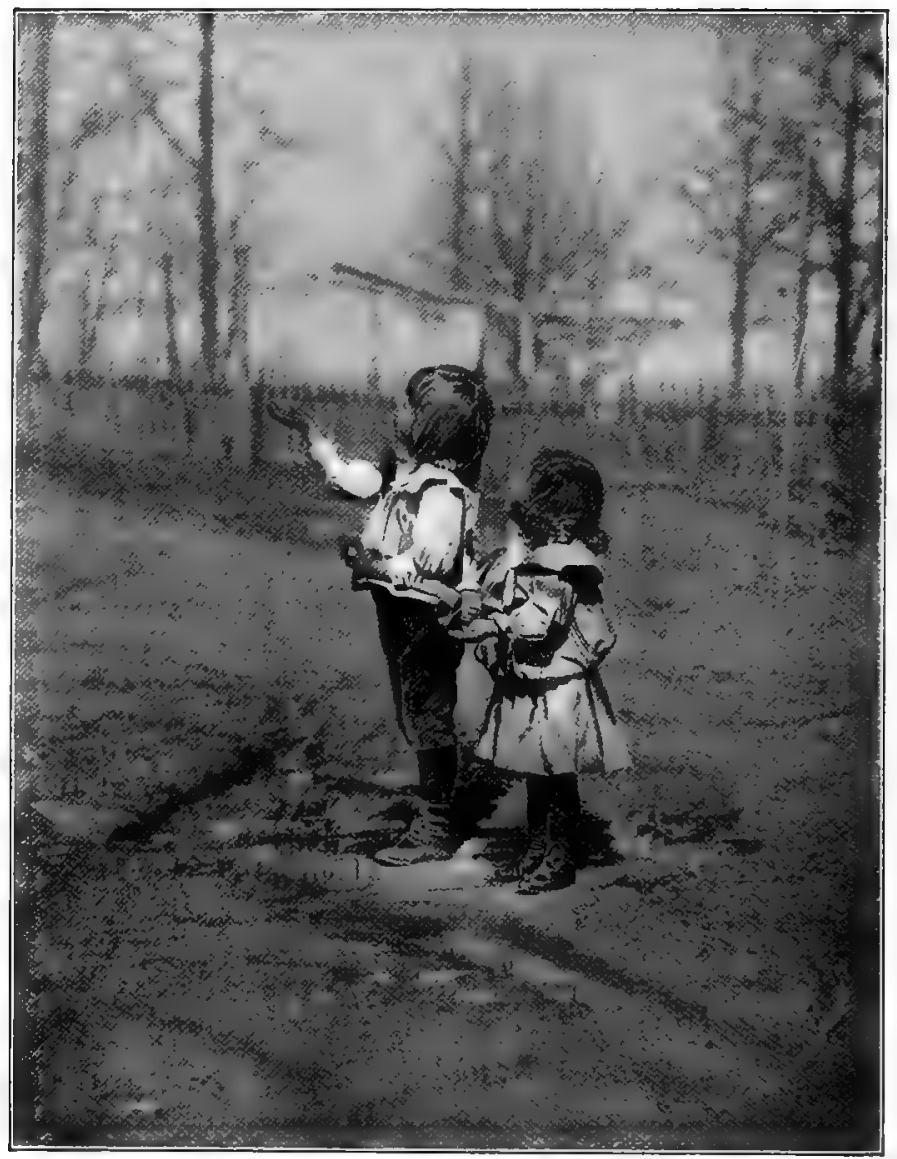

Fig. Ii8. An Invitation to the Birds 


\section{CHAPTER XVIII}

\section{OUR COMMION BIRDS}

Their Life, Work, and Natural Enemies

Beloved of children, bards and Spring,

$O$ birds, your perfect virtues bring,

Your song, your forms, your rhythmic tlight,

Your manners for the heart's delight,

Nestle in hedge, or barn, or roof,

Here weave your chamber weather-proof,

Forgive our harms, and condescend

To man, as to a lubber friend,

And, generous, teach his awkward race

Courage and probity and grace!

EMErson, May-Day.

BIRD study is no trifling fad. Our bird life represents a public property, protected by laws that are beginning to be respected and enforced. We may begin again with a few oral or written language lessons to find out how many birds the children know and what they have already learned about them.

There are so many books devoted to describing and identifying birds, and all the species which we wish to study are so common, that we may omit the descriptive side. In fact, I should relegate the whole subject of bird nature'study to some one of the excellent books we already have were it not for the fact that, with all our books and all our birds, year by year boys and girls are passing through our schools who are not able to recognize 
even our commonest species, and what is worse, do not care to learn or know anything about them. This means that, excellent as our bird books are, there is something lacking; and it is in the hope of supplying two vital relations between child life and bird life that the following pages are written. We must teach the children the human value and importance of birds. We must suggest things for them to do which shall help and increase the bird life about their homes.

Up to within a few years the usual methods of studying birds consisted in mounting, preparing skins, and making collections of nests and eggs. More recently we have come to know that birds are too valuable to be used in this way, and the opera glass and camera have to some extent happily displaced the gun. But, in general, we are in the negative phase expressed by a sentence from one of the best outlines of the course of study for a city school: Insist that no boy or girl destroy a bird or its nest. Negative effort is uninteresting and, at best, little more than a suggestion to do the thing prohibited. In the same time we can much more easily teach, on the positive side, work that the children will enjoy doing and that will make abuse of bird life impossible.

The important question is: What do birds do in the world? About this point center all our laws for bird protection. We must first gain, by observation and personal acquaintance with the living birds of each species, a knowledge of their ways, their foods, their beauties, and their songs. Then give the imagination full play to picture what the whole species is doing in every farm and garden and about every home in the land. Think 
of the millions of beautiful wings and building nests and eating bills and singing throats. Aside from their intellectual and esthetic values the paramount service of the birds lies in their power to destroy insects. For this work we have a vast mechanism in nature, an army plastic almost as air, on wings, powerful and beautiful, able to carry their flying squadrons hundreds and even thousands of miles whither food abounds and insects threaten destruction to vegetation.

In studying living things we should bear in mind the truth, stated often in these

Think, every morning when the sun peeps through

The dim, leaf-latticed windows of the grove, How jubilant the happy burds renew

Their old, melodious madrigals of love!

And when you think of this, remember too

'T is always morning somewhere, and above

The awakening continents, from shore to shore,

Somewhere the birds are singing evermore.

The summer came, and all the birds were dead;

The days were like hot coals; the very ground

Was burned to ashes; in the orchards fed

Myriads of caterpillars, and around

The cultivated fields and garden beds

Hosts of devouring insects crawled, and found

No foe to check their march, till they had made

The land a desert without leaf or shade. LONGPELLOW, Birds of Killingworth. words: As long as there is life there is hope. In everything that lives there are infinite possibilities. No seed or egg is so tiny but that it may hide the possibility of covering the world with forms of its kind in an incredibly short time. A pair of bird's eggs, with proper care by the children, could produce in ten years a pair of birds for every child in

A bird came down the walk:

He did n't know I saw ;

$\mathrm{He}$ bit an angleworm in halves

And ate the fellow, raw.

And then he drank a dew

From a convenient grass,

And then hopped sideways to the wall To let a beetle pass.

Emily Dickinson, Poems, p. 140. the land. Let us consider for a moment the possibilities that lie hidden within the blue shells of a pair of robin's eggs. Allowing that ten young may be produced 
by a pair each year, and that the life of a robin is ten years, we shall have:

$$
\begin{aligned}
& \text { Ist year }(2+10) \text {. . . . . . . . I2 robins. }
\end{aligned}
$$

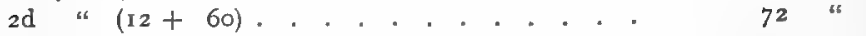

$$
\begin{aligned}
& 3^{\mathrm{d}} \text { " }(72+360) \text {. } \\
& 4^{\text {th }} \text { ". . . . . . . . . . . 2, } 2,592 \\
& 5_{\text {th }} \text { ". . . . . . . . . . . . } 15,552 \text { " } \\
& 6 \text { th ". . . . . . . . . . . . . 93,3I2 " } \\
& 7_{\text {th }} \text { ". . . . . . . . . . . . . . . } 559,872 \\
& \text { 8th ". . . . . . . . . . . 3,359,232 } \\
& \text { 9th ". . . . . . . . . . . . 20, } 555,392 \\
& \text { Ioth ". . . . . . . . . . . . . . . . 120,932,352 } \\
& \text { 5oth " } 1,616,400,000,000,000,000,000,000,000,000,000,000,000 \text { " } \\
& \text { Iooth "I I, 320,000,000,000,000,000,000,000,000,000,000,000,000,000,000,- }
\end{aligned}
$$

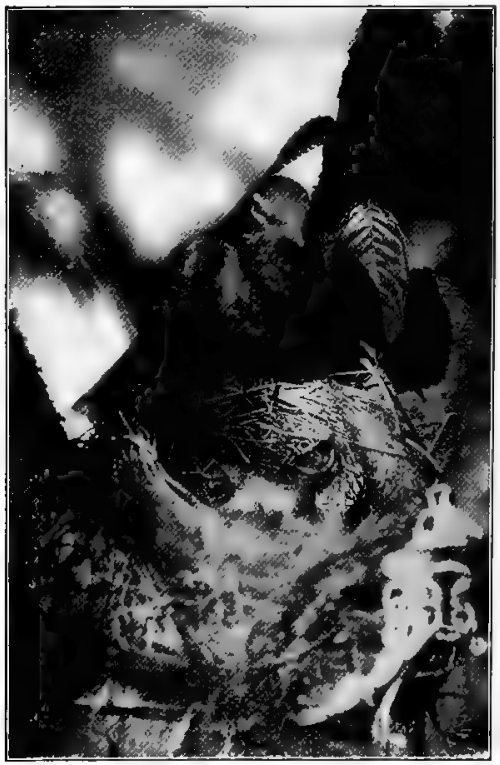

Fig. IIg. Young Robins Two Days Otd
If we do not have all the robins we want (and this applies to any living thing) it is because we do not know enough about rearing them or are not willing to act in accordance with our knowledge.

In addition to this infinite power of multiplication we must never lose sight of another law of biology, viz., that every living thing possesses possibilities of development and improvement. No one has 
yet produced the best and most beautiful rose or peach or bird or man or anything else that the world is capable of yielding. By proper care we can have a world full not only of such birds as we have now, but of birds with sweeter and sweeter song The winds blow east, the winds blow west, The blue eggs in the robin's nest Will soon have wings and beak and breast, And flutter and fly away. Longrellow.

and more and more beautiful plumage. And in presence of these infinite possibilities for good or for ill we must above all things remember that every human action tends to make the world a garden or a desert, a paradise of joy and beauty or a vale of tears.

To produce and multiply endlessiy, without ever reaching the last possibility of excellence, and without committing herself to any end, is the law of Nature.

Burroughs, Birds and Poets, p. $5_{56} 6$.

If our birds felt a sense of security in our presence, they might sing even more sweetly and more abundantly than they do now. Indeed, Burroughs remarks of English birds : "They sing with more confidence and copiousness, and as if they, too, had been

Wood birds here are house and garden birds there [Eng.].

$$
\text { BURRoughs, Fresh Fields, p. } 136 .
$$

touched by civilization." They sing more hours in the day and more days in the year. Furthermore, if our birds were uniformly safe in man's presence and undisturbed, they would come much closer to us, as they did to Thoreau, and to Celia Thaxter in her garden. With proper care many of our best songsters and most

Many haps fall in the field Seldom seen by wishful eyes;

But all her shows did Nature yield, To please and win this pilgrim wise. He saw the partridge drum in the woods; He heard the woodcock's evening hymn; He found the tawny thrushes' broods; And the shy hawk did wait for him; What others did at distance hear, And guessed within the thicket's gloom, Was shown to this philosopher, And at his bidding seemed to come.

$$
\text { EMERSon, Woodnotes, I, } 2 .
$$
useful birds that are now rare might become more common, filling our parks and the thickly planted portions of our 
towns, and even cities; and with more caution than preceded the introduction of the English sparrow, we might bring about our homes the most beautiful songsters of other lands. But the safer and wiser course will be to begin by making the most of our native birds. These are a heritage infinitely rich, developed through geological epochs to fit exactly all the conditions of life on this continent. It is no light matter to disturb this living harmony, as our experience with the English sparrow bears testimony.

With this wonderful power of increase the questions naturally arise: Why do we not have many more birds than we find about us? Why have we not hundreds where we have but one? Has the natural limit been already reached, so that attempts to increase the numbers would be useless? All such questions open important fields for observation and study. Food supply for all seasons of the year is the main factor in this series of problems. This will be considered in a section by itself. The next factors are natural enemies of bird life. In connection with each element in nature which tends to decrease our valuable bird life, we should endeavor to discover the means of preventing its operation. That this matter is now a national exigency, in the careful study of which every patriotic citizen and every school child should participate, may be duly appreciated by referring to William T. Hornaday's recent paper ${ }^{1}$ on the destruction of our birds and mammals. We learn from this that during the

1 William T. Hornaday, Director of the New York Zoölogical Park. "The Destruction of our Birds and Mammals," Second Annual Report, New York Zoölogical Society. New York, 18g8. Office of the Society, 69 Wall Street. 
past fifteen years our birds have decreased 46 per cent in thirty states and territories. For each of the states named this decrease has been as stated in the margin. Three states - North Carolina, Oregon, and California - show neither increase nor decrease; and only four states Kansas, Wyoming, Washington, and Utah - have had an increase of bird life. It would be a worthy ambition to infuse into our school system, reaching, as it does, the life and heart of every child, the purpose to change this destructive process to one of increase in every county, farm, and city lot of the land.

Climatic influences are severe in this country. Great numbers of birds are killed in heavy rain and hailstorms. Whole species are decimated in sleet and snowstorms within the

Maine
New Hamrshire.
Vermont

range of their southern migrations. Thus our bluebirds were killed off in 1895 , and fearful havoc was wrought in a number of our most valuable species in the Southern States during the winter of I898-I899. With these elements it is difficult to contend. To what extent man is responsible by reason of clearing out natural shelter and destroying natural food supplies it is impossible to say. 
Again, in times of great drought in regions where our common species breed, both food and water may become so scarce that numbers of nestlings famish or starve. The birds then are loath to desert their nests to go to regions of plenty. If birds were tamed sufficiently to come to man as their friend in times of great need, as they do in rare cases now, and as they learned to come to Mrs. Brightwen, a little food and shelter might tide them over the hard time, and their service afterwards would repay the outlay a thousandfold. About the house and barn and shade trees safe places of shelter might save great numbers of birds every year, due care being exercised to keep them clear of English sparrows and place them out of the reach of cats.

Cats are generally recognized as the worst enemies of our native bircls. ${ }^{1}$ Professor Forbush has estimated that a cat is responsible on the average for the death of about fifty song birds a year; and one cat, to his knowledge, destroyed six bird's-nests in a single day. In connection with their bird work the children should be encouraged to gather all the evidence they can for their district; they will then be more willing to choose other pets. All the wild, stray, or worthless cats of a neighborhood should be destroyed, as a mercy not only to the birds but to the cats themselves. People who have cats that they value, ought, for love of nature, to see to it that they are provided with other food than young robins, orioles, thrushes, and song sparrows. Much may be done by way of training cats to let birds alone, and lastly, they should be kept in

1 "The foremost place among all song bird destroyers, as we have already said, must be assigned to the house cat." LANGE. 
as much as possible at times when young birds in the neighborhood are learning to fly. ${ }^{1}$

Next to the cat the English sparrow is responsible for great decrease among certain of our native birds, especially of some of our most useful and desirable species about the cities and towns. This is the obstacle that blocks the way of younger children in doing effective work for our native bircls. They put out food in winter and we ask: "What birds came for it?" "English sparrows." They arrange drinking fountains. "Do the birds come?" "Yes, English sparrows." They build nest boxes. "What birds do they have in them ?" "English sparrows." If other birds come, the sparrows will mob them. They will break up the nests and devour the eggs of our robins, bluebirds, wrens, tree swallows and martins, song sparrows and vireos, and the children's work results in increasing this "ruffian in feathers," "a bird too pestiferous to mention." The sparrows begin nesting in February or March, thus preëmpting available bird houses before the native birds arrive, and rearing, as they do, five or six broods a season, they increase with incredible rapidity. It has been estimated that a pair in ten years might produce 275,7 16,983,698 sparrows. $^{2}$ What

1 On a farm from which the cats were banished increase of birds was so great the following year as to cause general remark among the neighbors. Rats and mice, for destruction of which cats are sometimes kept, can certainly be more effectively dealt with by intelligent use of poisons and traps. Since not one of these vermin should be allowed on the premises, this argument for the cat does not hold.

2 " The English Sparrow in North America," Bulletin No. $I$, United States Department of Agriculture, ought to be accessible for reference to every class in nature study. The summing up of all the evidence is in part as follows: "The English sparrow is a curse of such virulence that it ought to be 
are we to do with this enemy of our valuable native birds? So many differences of opinion and so many delicate points of sentiment, morals, and pedagogy are involved in answering this question that all a teacher can do is to lead the children to observe and study the facts as they occur about their homes, and then leave the solution of

attacked and destroyed before it becomes necessary to deplete the public treasury for the purpose, as has been done in other countries. By concerted action, and by taking advantage of its gregarious habits, much good may be accomplished with little or no expenditure of money" (p. 164). Among the "Recommendations for Legislation" I may also quote the following : "(I) The immediate repeal of all existing laws which afford protection to the English sparrow. (2) The enactment of laws legalizing the killing of the English sparrow at all seasons of the year, and the degtruction of its nests, eggs and young. (3) The enactment of laws making it a misdemeanor, punishable by fine or imprisonment, or both $-(a)$ to intentionally give food or shelter to the English sparrow, except with a view to its ulti. mate destruction; $(b)$ to introduce or aid in introducing it into new localities; (c) to interfere with persons, means, or appliances engaged in, or designed for, its destruction or the destruction of its nests, eggs or young " (p. I 50). Methods of destroying sparrows that involve suffering, wounding, etc., should be avoided so far as possible. The same is true of methods which advocate destruction of "nests, eggs or young," which I regret to find are favored by the Department of Agriculture. Among the many arguments against this method we may say that a nest is a sacred thing, except to collectors, and the deliberate destruction of it violates our finest sentiments of home and confidence. I have known people to advocate the merciful extermination of sparrows out of nesting time, but they will not allow a nest to be disturbed under their own roof. Recent opposition to attempts to rid Boston of the English sparrow by destruction of “eggs, nest and young" is history in point. I am also obliged, on biological grounds, to differ from the Bulletin on the point of protecting carnivorous birds, like the sparrow hawk, shrike, and screech owl, because, since English sparrows are so shy and cunning, these birds will be feeding largely on the more easily caught native birds which we wish to protect. And, further, if they did kill English sparrows in great numbers, in proportion as these become scarce they would take more and more of our valuable song birds, until we should be obliged to make war on the hawks and 
the problem to the parents. The one preliminary to having our valuable native birds numerous in our cities and towns, and in many parts of the country as well, is practical extermination of the English sparrow. If at the time the pest was imported general attention had been aroused to the necessity of protecting our native birds

shrikes. Directions for poisoning sparrows, given on page I74 of the Bulletin, are evidently not derived from adequate experimental data. For example, arsenic is recommended. I have given this a thorough trial during three winters, and while a few may be killed at first, their numbers cannot be effectively diminished by its use. Strychnine sulphate is, according to practical experience, the poison to use; and with regard to its preparation, the Bulletin is singularly inaccurate. It says: "Dissolve two grams of strychnine in a liter of tot water." This is not possible, since this amount of the pure alkaloid is not soluble in less than five liters of boiling water. The directions further state: "Soak the grain in the poison solution at least forty-eight hours," but they nowhere say how much grain to take. Strychnine sulphate is evidently meant, and two grams of this are readily soluble in 100 cubic centimeters of water. Lange (Our Native Birds, p. 76) falls into the same inaccuracy. I am also obliged, on experimental grounds, to dissent from the directions given by Lange, viz., "two small bottles of strychnine" to "nearly if not quite a peck of wheat." This is not strong enough, as I have repeatedly caught sparrows poisoned by grain prepared in this way, and they often recovered completely.

My own formula is as follows: Dissolve one-eighth of an ounce of powdered strychnine sulphate in one-half pint of boiling water. Pour this, while hot, over two quarts of wheat (or cracked corn), stir well, and continue stirring from time to time, until all the liquid is absorbed. Dry thoroughly, without scorching, and put away in some safe receptacle, labeled

\section{Poisoned Grain. Strychnine.}

It requires but one kernel to kill a sparrow. A quart of wheat contains about 23,000 kernels, and as a sparrow seldom takes more than two or three, you have enough to rid the neighborhood of about 20,000 sparrows. Expose the grain where poultry and tame pigeons cannot get it, and by operating only during the winter there will be no danger of poisoning seed-eating wild birds, at least for all northern towns and cities. By taking advantage of 


\section{6

and of giving them a chance to do the work of insect destruction for which our natural conditions had developed them, there would have been no serious insect outbreaks, such as are now so frequent. It is coming to be a wellrecognized observation that insect scourges occur where the sparrows are most numerous. The gypsy moth in

the sparrows' gregarious habits, and the fact that they drive off other birds from localities where they are numerous, much might be done even in the South.

Sparrows are such suspicious and cunning birds that, if the strychnized grain be exposed at first, they will probably roll each kernel in their bills, taste it, reject it, and possibly refuse to touch it again that winter. The best way is to select a safe place, where the wind is not likely to scatter it, a walk, driveway, or porch roof with a smooth surface, so that the grain may be swept up after each trial. Accustom them to feeding there daily with grain exactly like that which is medicated ( $I$ often do this for a week or even a month, until all the sparrows in the neighborhood are wont to come regularly), study the times when they come for their meals, and then on a cold, dry morning after a heavy snowstorm, having swept up all the good grain the night before, wait until they have gathered, and then put down enough strychnized grain to feed the entire flock. You have about ten minutes before any begin to drop, and those that have not partaken of the grain by this time will probably be frightened off; but, by timing it properly, I have repeatedly caught every sparrow in the flock. I have found morning the best time, as they all come then; and it is essential to success to select a dry day, since in wet weather they taste the strychnine too quickly; I have seen them actually throw it out of the crop.

With this simple method at command, by concerted action a few friends of our native birds can rid any northern city of the sparrow pest in a single winter. This is no more than parents ought to be willing to do, if not for the sake of the native birds, at least to clear the way for the children to do effective work in their behalf. And if any continue to think English sparrows worthy of protection, despite all the evidence in hand, they should protect them in cages on their own premises, and be placed under heavy bonds never to let them out.

It is not intended that the children should do this work, but the necessary information has been given for the use of parents or teachers. 
Massachusetts would probably never have come to our notice had it not found free course in localities where the sparrows had driven off the native birds. The same is true of many other destructive caterpillars and of the elm beetle. Even with the few birds that we now have in rural districts, these pests do comparatively little damage and never become so numerous as in the cities that are swarming with sparrows. The sparrow has thus had many opportunities to distinguish himself and has failed in every case. Besides refusing to assist materially in the extermination of insects, the sparrow has attacked the gardens, orchards, vineyards, and grain fields in a most destructive manner. 


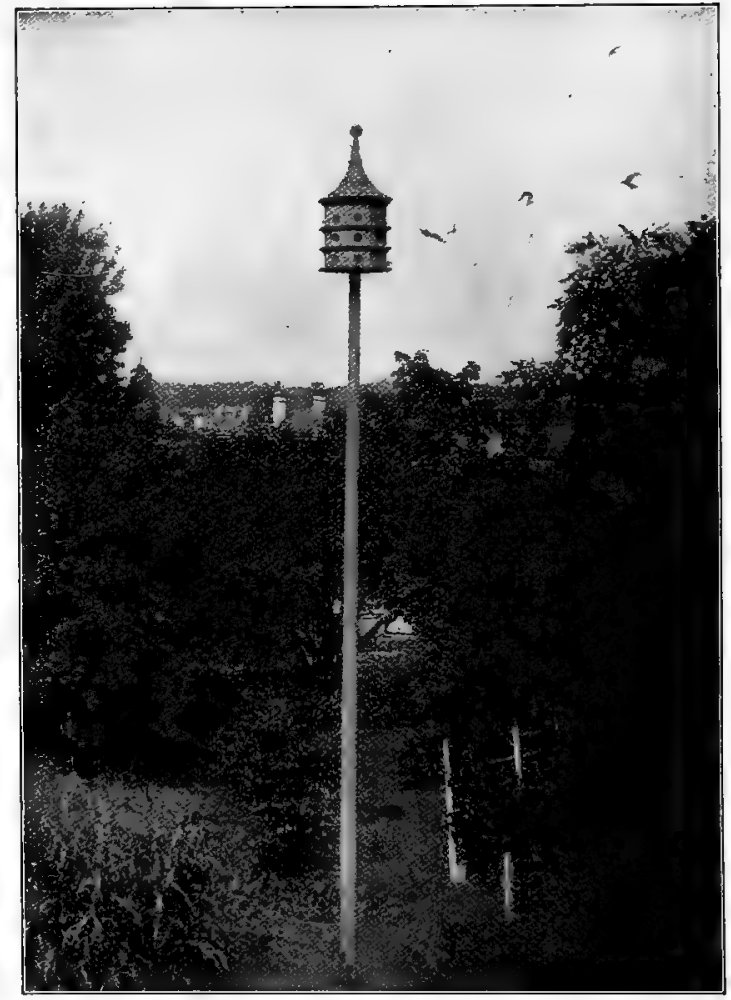

Fig. I2o, Ineal Martin House, Worcester, Mass. 


\section{CHAPTER XIX}

\section{THE BIRD CENSUS AND FOOD CHART}

SCARCEIY any one line of nature study possesses so many interesting features as that connected with keeping track of the number of birds in a neighborhood, with a view to increasing the more desirable species. The best method of making a bird census is to count the nests in a certain district as soon as the leaves fall in autumn. ${ }^{1}$ People generally

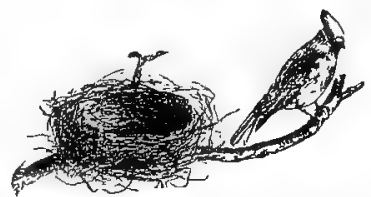

Fig. I2I. CEDAR BIRD AND Nest would find it interesting to do this for their city lots or dooryards; and if they would send the results from year to year to their local bird club, to some bird magazine, or to the writer, valuable data might be gathered as to the hoped-for increase of our native birds in different parts of the country. It is helpful for schools, besides being good geography work, to make a chart or map of the district, with each house, tree, hedge, vine, bush, and thicket in its proper place. The separate counting of each kind of tree gives the children a good reason for learning the different species, and, if any bird shows preferences for particular trees, this fact will be brought out. Essays and language lessons may be devoted to

${ }^{1}$ I take pleasure in acknowledging for this valuable suggestion my indebtedness to Frank M. Chapman. 
discussions and descriptions as to the kind of places the different birds chonse to nest in. Drawing should be combined with this, and each schoolroom might contain,

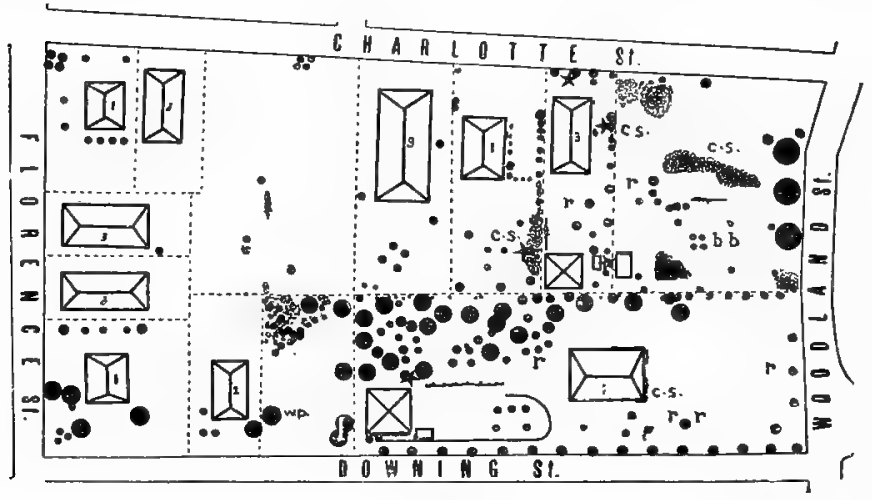

FIG, 122.

Chart and census of a city block, Worcester, Mass., for 1898 and 19or. Stars siguify nests in 1898 , viz., two robins, one oriole, one chipping sparow, and one downy woodpecker. Initial letters stand for nests in 1903 . Note the gain, 300 per cent, in three years. Houses, trees, and shrubbery are appropriately indicated; $r$., robin; 0. , oriole; 6.6. . bluebird: $w . p .$, wood pewee; c.s., chipping sparrow. The trees are:

Apple . . . . . . . . . 5

Ash, Mountain . . . . . . 2

Birch . . . . . . . . . . . 13

Cherry - (one redstart, Igoo). . . 9

Chestnut - one woodpecker (one ori-

Elm . . . . . . . . 5

Hawthorn-one chipping sparrow . I

Hickory . . . . . . . . . 4
Maple-one robin (two robins, rgoo) . 45

Oak - (one robin, 1900) ... 55

Peach ......... 5

Pear - one robin, one oriole . . . 38

Pine, etc. . . . . . . . 95

Plum . . . . . . . . . 7

Others .......... 6

Total number of trees . . . . . . $\overline{319}$

Bignonia vines - (three chipping sparrows, Igoo)

either in a case or hung about the walls and windows, a collection of a few deserted nests. These the pupils could use for special drawing work and for the study of 
form, structure, methods, and materials used by the birds in building. Knowledge on all the above points wili find application in a succeeding section, when we consider methods of attracting the birds and of providing for their needs. Nothing in all ornithology is better fitted to inspire in a child the love of bird life than

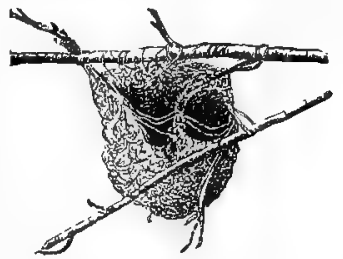
the study of their wonderful nests. Fig. 123. Nest of BaLtiIf the children were given a course MORE ORIOLE in such study during February or March, they could hardly be induced to molest a bird's nest the following season.

A great deal of information, giving at a glance the essence of years of study and hundreds of pages of bird

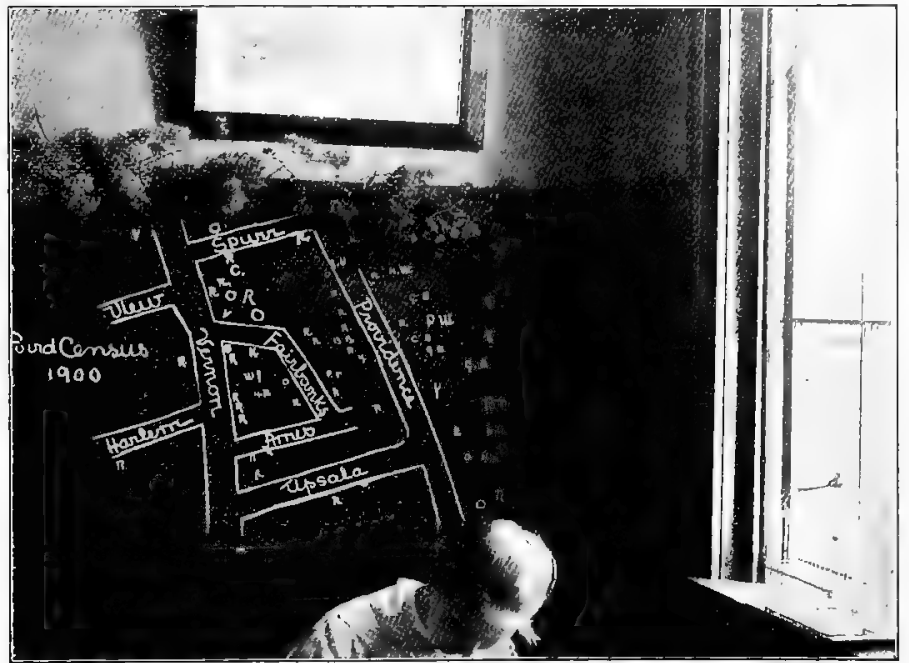

Fig. 124. Bird Census as kept on Blackboard, Upsala Street School, GRADE VII 
books, has been collected by Miss Ball into the chart opposite. We can see, for the various birds, so far as is known, what the species does for man and what, in

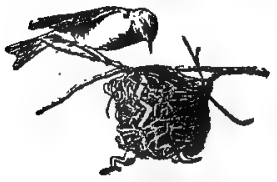

Fig.I25. VIREOAND NEST turn, we may do for the birds by way of insuring for them an abundant and inexpensive supply of their preferred foods. Birds have been persecuted and slaughtered for generations because they have been compelled to levy toll in cultivated fruits for their invaluable services. I say compelled, because we have hitherto paid no attention to the natural sources of food supply for our birds and, in clearing the land, have destroyed, often unnecessarily, the native trees and shrubs upon which they depended. It is now well known that birds prefer wild to cultivated fruit, and that to protect our fruit the most effective and humane way is to leave or plant such wild or valueless fruits as ripen at the same time. In coming to realize how recklessly the country has been stripped, the writer considers it bad biology even to put scarecrows in the cherry trees to frighten the birds from our gardens until we have planted wild cherries, mulberries, and Juneberries for the birds to feed on. We can find plenty of other things to eat, while the birds cannot. All farms and many gardens

The little bird sits at his door in the sun, Atilt like a blossom among the leaves, And lets his illumined being o'errun With the deluge of summer it receives; His mate feels the eggs beneath her wings, And the heart in her dumb breast flutters and sings;

He sings to the wide world, and she to her nest, -

In the nice ear of Nature which song is the best?"

\section{LowelL, The Vision of Sir Launfal, p. 106.} and city lots have room for some tree or trees which would furnish food for birds. Our city streets, school yards, and public parks might be planted most profitably 


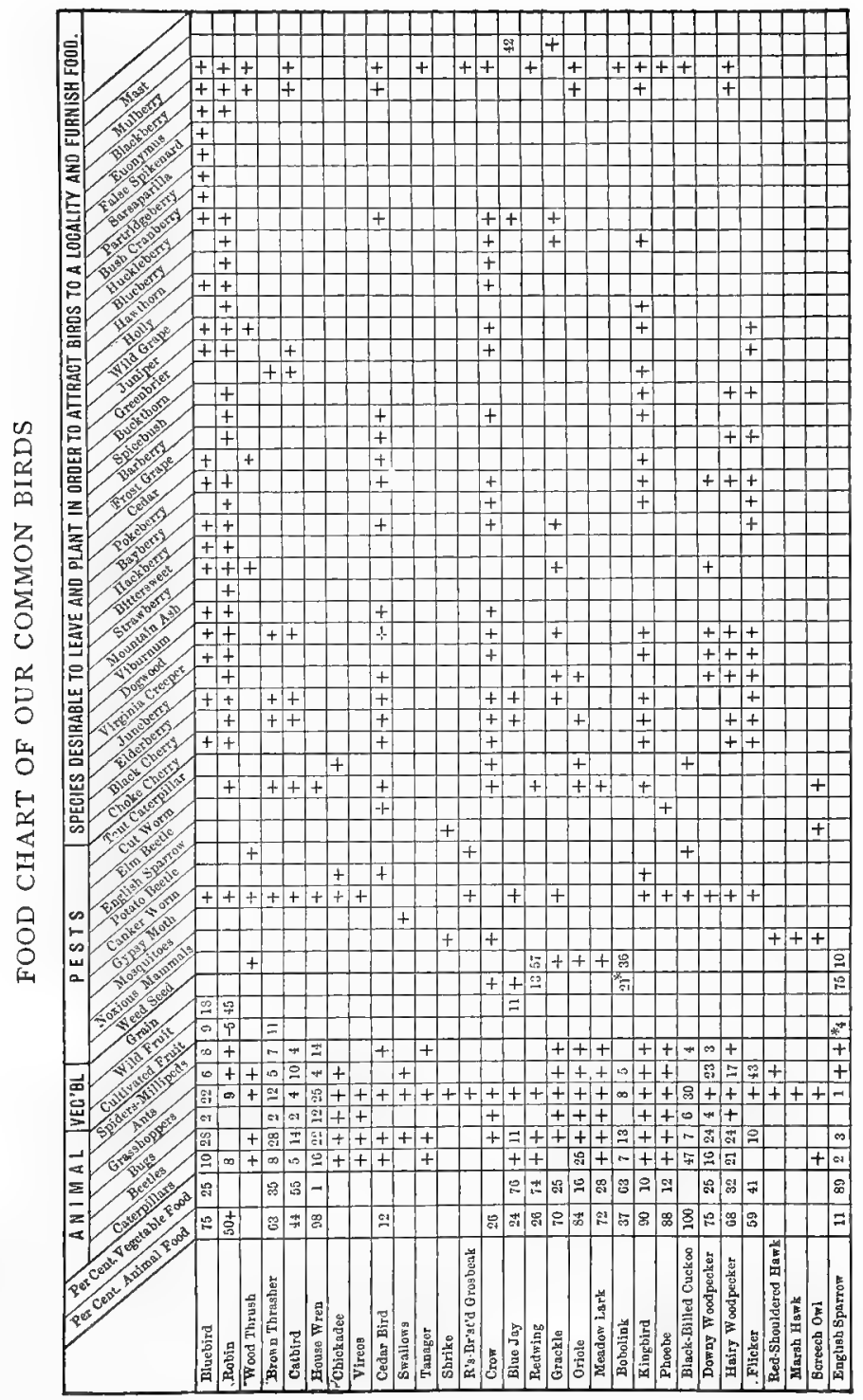


with some regard to this matter, since, besides adding pleasing variety, it would tend to fill the towns and even cities with our native birds. No less an observer than John Burroughs says: "Indeed, the food question seems to be the only serious one with the birds. Give them plenty to eat and no doubt the majority of them would face our winters." He goes on to describe how a pair of bluebirds and even a mocking bird were induced, by the shelter of his porch and the fruit of a hackberry tree that stood close by, to spend the winter with him eighty miles north of New York. With available room properly planted we might have ten wild birds to one that we have now in our towns and many of our cities; and those who favor the English sparrow, because he is the "only bird we have in winter," might soon be consoled for his absence.

It would be ideal nature study if all the children in our schools would learn the list of bird-food trees and plants. By learning them I do not mean being able to say over their namcs merely; but they should be able to recognize each at any season of the year; they should know its possibilities of growth for purposes of decoration and ornament; and, most of all, they should study how to propagate each species, so that they can actually plant and have a tree anywhere they wish.

Glancing down the first column of the chart, we see that certain birds subsist on animal food, insects, worms, etc. These birds are the house wren and cuckoo; and, when it is determined, we may add to this list the chickadee, vireos, swallows, swifts, martins, and flycatchers. We could not have too many of these in this country. Another larger class of birds takes 50 per cent or over of animal 
food but, even with the others, as well stated by Wood (Theodore Wood, Our Bird Allics, p. 7), birds that take but a small per cent of insect food may still destroy insects which would have damaged fruits and crops much more than the birds themselves. Birds that come early, like the bluebird, robin, redwing, and grackle, may be of especial service by destroying insects before they have laid their eggs for the season.

For four years now the food chart has occupied a place on the wall of my study. I have had occasion to refer to it many hundred times, and never without learning something that I was glad to know. Still its best service, after all, lies in showing us how little we know about the foods of our birds. Each blank square is really a question, a suggestion to try this or that, and an infinite number of other things not mentioned in the chart, to see whether any particular bird will eat it. And when a child finds that any bird will eat something which it is not shown to eat in the chart, he may have discovered a fact which no one else in the world knows. If it be some destructive insect, his observation may be very valuable, and if he tells everybody about it, he may lead people to protect the bird more carefully and so help to make the world better.

As years go by and great numbers of our bircls become so tame that they will come to us and eat from our hands and allow us to observe them as they hunt their natural foods and feed their young, we may be able to cliscover more in this important field, in possibly the next ten years, than man has learned in as many centuries. Methods suggested for taming birds may assist in this work. 


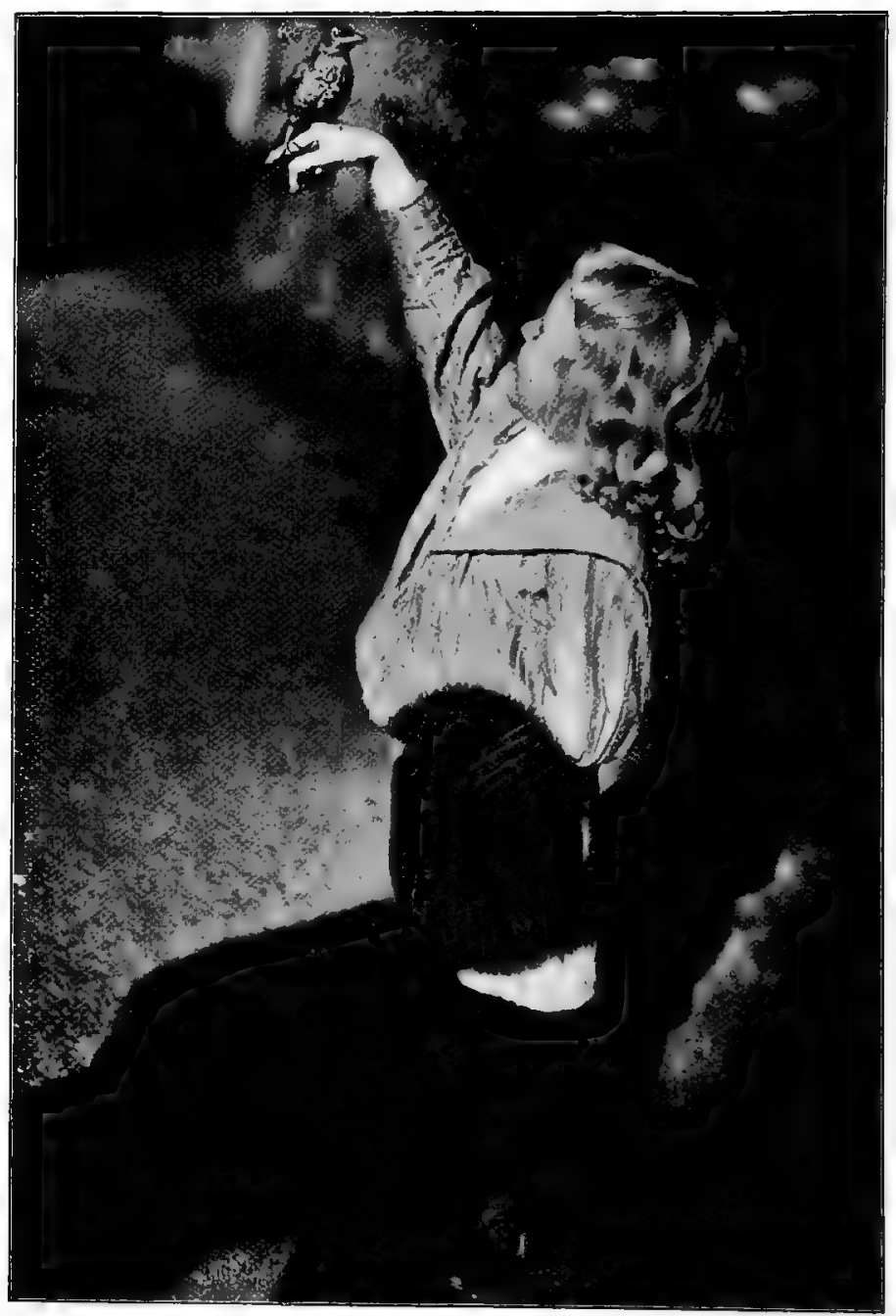

Fig. 126. SHELley's Prophecy fulfilled 


\section{CHAPTER XX}

\section{PRACTICAL DOMESTICATION OF OUR WILD BIRDS}

No longer now the wing'd habitants, That in the woods their sweet lives sing away, Flee from the form of man; but gather round, And prune their sunny feathers on the hands Which little children stretch in friendly sport Towards these dreadless partners of their play. happiness And science dawn though late upon the earth.

SHELIEY, Damon of the World.

THE process of domestication consists in three things : first, in development of intelligence sufficient to discern between friends and foes; second, in development of a sympathetic appreciation of the animal's physical needs sufficient to enable it to live with man in mutually helpful relations; and third, in so universalizing these attainments and relations that all may work in unison, to the end that what one builds up others will not tear down. The evidence is already obtained to prove the value of a number of the common species. On the æesthetic side alone the sentiment is growing rapidly that our birds are worth their board and lodging, which they pay for many times over with their beauty and their song. In addition 'to this, recent discoveries as to their work in insect destruction should win for them an assured place in nature-study courses; and, it would seem, that in no other way could 
we bring about that universal regard for bird life that the country needs.

Before giving them any of these data below, ask the pupils, as a part of a writing lesson, to make a list of the birds they like best, stating after each how much they would be willing to give to have a pair nest by their home.

People buy birds and go to the expense and care of keeping them in cages. How much more is it worth to have a pair of free birds come and nest by your window, to have them sing to you the season through and show you the secrets of their wonderful housekeeping! Four of my friends have kindly given me estimates as to how much they would be willing to give thus to have a pair of the following birds. (We may compare the figures with Holden's prices for choice songsters of the same species. ${ }^{1}$ )

\begin{tabular}{|c|c|c|c|c|c|c|c|c|c|}
\hline & & & \multicolumn{4}{|c|}{ Estimated Value } & \multicolumn{3}{|c|}{ Holden's Prick } \\
\hline \multicolumn{3}{|c|}{ FOR A PAIR OF } & IST & $2 \mathrm{D}$ & $3 \mathrm{D}$ & 4 TH & \multicolumn{3}{|c|}{ FOR A MALB BIRD } \\
\hline Brown Thra & shers & s. & $\$ 5$ & $\$ 3$ & $\$ 3$ & $\$ 8$ & $\$ 5$ & to & $\$ 8$ \\
\hline Catbirds . & . . & & $\mathbf{I}$ & I & .75 & $\mathbf{I}$ & 5 & $"$ & 10 \\
\hline Tanagers . & . . & - & I & 10 & 3 & 4 & 3 & " & 5 \\
\hline Grosbeaks & . . & . & $I$ & 8 & 7 & 8 & 5 & " & 8 \\
\hline Robins . & .. & & 5 & 5 & I & I & 3 & $“$ & 5 \\
\hline Bobolinks & . . & & 2 & Io & 6 & 8 & 2 & " & 3 \\
\hline Orioles & . & - & 6 & 4 & 3.50 & 3 & & & 5 \\
\hline Chickadees & . & & 2 & $I$ & 2 & 2 & & & - \\
\hline Bluebirds . & $\therefore$ & - & I & 5 & 4 & 3 & & & 一 \\
\hline \multicolumn{7}{|c|}{ Mocking birds (not thought of as a possibility) } & 3.50 & “ & 50 \\
\hline
\end{tabular}

Anything that a man can avoid doing under the notion that it is bad, he may also avoid under the notion that something else is good.

1 I had hoped to place alongside of the xsthetic value the economic value of the different birds; but our highest authorities in ornithology tell us that this is not known for a single bird. If a toad may be worth $\$ 9.88$ each season for cutworms alone which it destroys (Kirkland's estimate, "The Common Toad," Bulletin No. 46 , Hatch Experiment Station, Amherst, Mass.), many of our birds, like the chickadee, swallow, wren, robin, and others, must be worth much more. 
.. Wean them [school children] from their native cruelty by imparting to them some of your own positive sympathy with an animal's inner springs of joy. JAMEs, Talks to Teachers, p. 195.

What positive work can the children do for birds that will tend to their increase and draw them closer and closer about our homes year by year? Let us apply ourselves thoughtfully to this question; for I am sure we shall find increasing pleasure in following its varied suggestions as long as we live. We have been chasing the birds farther and farther back into the woods long enough. Let us reverse all this and induce them to come to us.

Food, Water, and Home, Essentials of Bird Life.- Since their homes are such frail affairs, we should expect birds to build where food and water are abundant. Still we should remember that the idea of home, with bircls as with men, is intimately associated with a sense of security, and that the predominant characteristics of birds are wings, timidity, ability to flee. The sight of a cat, the careless throwing of a stone, when a pair are seeking a nesting place, may often influence them to go elsewhere. On the other hand, no animals have eyes so quick to discern acts of friendliness, and, if all appearance of hostility is avoided, I doubt if we need to modify the daily course of our lives essentially to have the birds come to us. Their nests often stand close to railroads and overhang busy streets, and if not directly molested, many of our most valuable species seem quite content to take the world as they find it. This is the result of my observations and experience for the past ten years. 
Few people realize the importance of water to bird life. How many times a day a bird drinks I have never

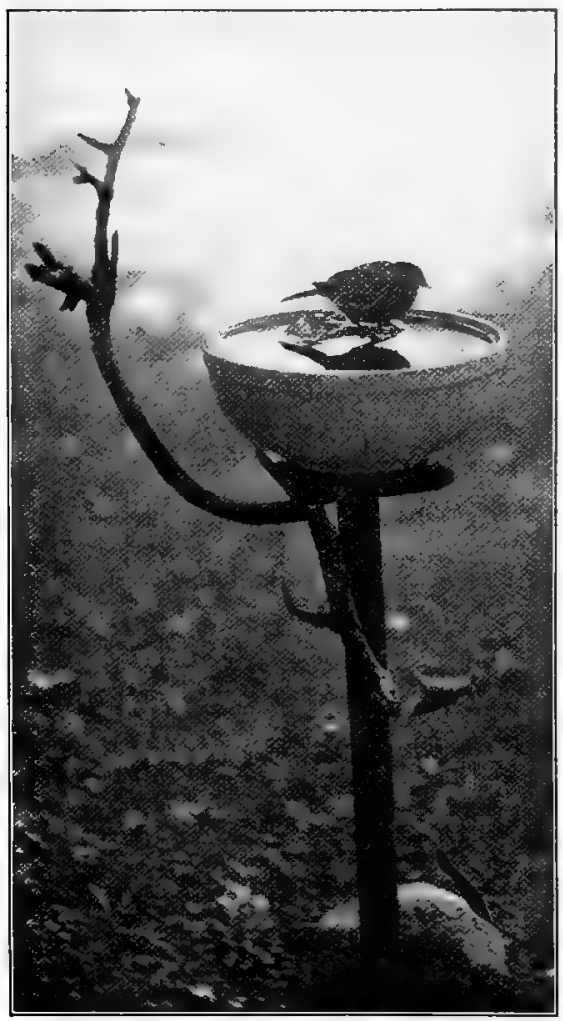

Fig. 127. A BIRD BATH

(Photograph by Timothy F. Myers) seen stated or even mentioned in any of the books. ${ }^{1}$ But we

1 Water may be provided by placing a shallow dish on a short post, high enough to be out of the reach of cats. The water should be from one-half inch deep on the shallow side to two or three inches in the deepest part, which may be accomplished by either tilting the dish or by partially filling it with washed sand or fine gravel. A large flowerpot saucer makes a good dish, as it is a little rough, and it is said that birds do not like a slippery floor to stand on when they bathe. Few people who have not tried it can have any idea of the satisfaction there is in seeing the thirsty birds come down to bathe and drink. For five years past I have had one by my study window, and at the present moment a robin is making the water fly in every direction. The next comer is an English sparrow, and the next and the next and the next two, English sparrows, - while they are with us we should not wish them to be thirsty, - and the next is a female robin, the next a red-eyed vireo, the next an English sparrow, all within 
know they drink often, and they must have their baths once a day and probably twice in hot weather.

Another kind of bath the birds know how to take, and people should indulge in more, is the sun bath. The bird leans over, broadside to the sun, the wings fall, the bill opens, and every feather is raised to let the light strike the skin. When we see it for the first time, we think the bird is dying; but as the solid comfort of it is appreciated,

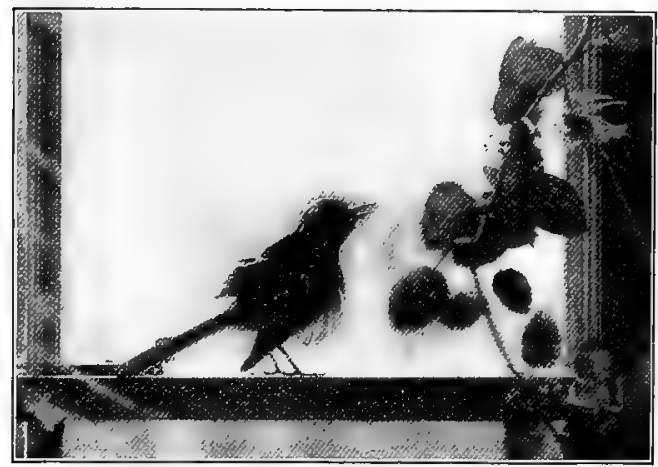

Fig. i28. Mocking Bird taking a Sun Bath

we can hardly resist the temptation to go and do likewise, - bask in the sun.

The lack of pure water and suitable places to bathe may go farther than anything else toward explaining the disappearance of birds from our cities during the hot, dry summer months. We see them drinking and bathing in the gutters and mud puddles, and is it not natural that they take their nestlings to the country as soon as they can fly?

fifteen minutes, and so it goes in the noon hour whenever I have time to watch. Nothing adds more to the comfort of birds in hot weather. 
As an outdoor lesson ask the class to hunt the district over thoroughly and report on the number of suitable places for birds to drink and bathe. Previously discuss with them what constitutes a suitable place. Our park waters are commonly too deep and, with their rock-bound borders, seldom afford a bathing place. Birds recognize their helplessness when their feathers are wet, so that

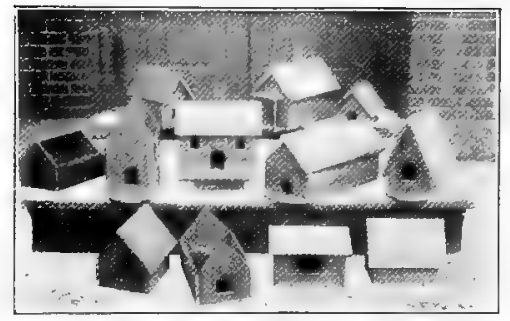

FIG. I29. BIRD Houses

Designed and made, at suggestion of Principal J. Chauncey Lyford, by ninth grade manual training pupils, Winslow Street School, Worcester, Mass. The bird house is now adopted as one of the regular models in the ninth grade manual training course throughout the city

Leaving the matter of food, as most important, to the last we may next inquire what the children can do to supply bird homes. The idea of building a bird house and of having birds live in it has a great fascination for children. The bare suggestion is sufficient, and off they go, perhaps carrying the house and running after every bird they see, calling "Come, birdie," and great will be the disappointment at first that every imaginable bird does not come forthwith and take up its abode. 
We should guard against such disappointments in connection with the autumn bird census and during the study of nests and nesting materials. For each bird included in their grade plan they should have clear ideas as to its preferences and be led to accommodate themselves to the bird's life, rather than expect the bird to do impossible things.

To supply homes, nesting places, and materials for nests is a fascinating study. Trees may be pruned to make inviting crotches, and a dark tangle of bushes overgrown with vines and sunflowers, dense lilac bushes, or a "syringa thicket" will be sure to attract catbirds, brown thrashers, and some others. Bird houses furnish homes for wrens, bluebirds, chickadees, nuthatches, tree swallows, and purple martins, but here, again, Eng-

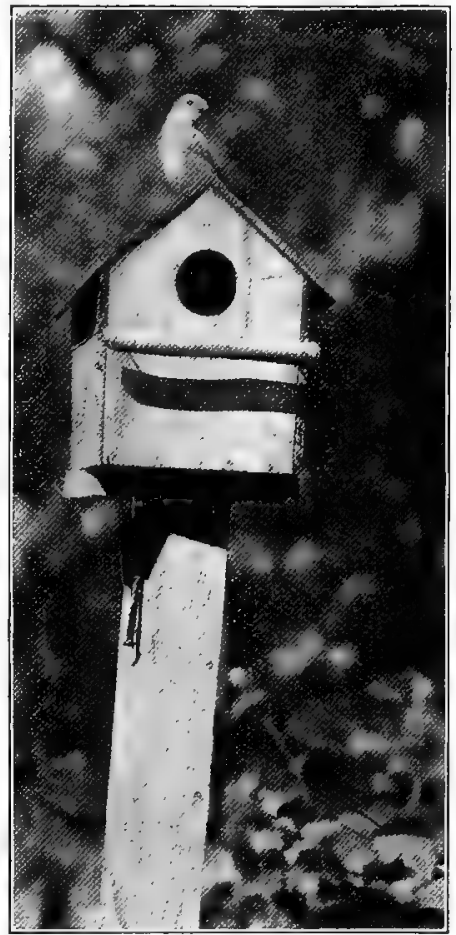

FIg. I30. Bluebird

One of the author's tenement houses. There are five young ones inside, and the pair reared three broods in Igor lish sparrows are the omnipresent nuisance and must be served frequent notice to quit the premises. The proper size for a bird house is six inches square floor space and 
eight inches high, and houses of more than one compartment may be made by cutting the boards in multiples of these numbers. Old weathered boards should be used, or, if painted, they should be made the color of an old tree trunk. A single opening near the top should be made, two inches in diameter for most birds ; although, for wrens and chickadees, onc

Alas, dear friend, that, all my days, Hast poured from that syringa thicket The quaintly discontinuous lays To which I hold a season-ticket,

A season-ticket cheaply bought With a dessert of pilfered berries, And who so oft my soul hast caught With morn and evening voluntaries.

Lowel, Nightingale in the Study. inch is sufficient and will serve to keepout English sparrows, and for wrens the house should be set in a shady place.

Besicles bsing a cheery songster and a most sprightly and fascinating fellow, the wren depends for practically his whole food supply upon the insects of our grounds and gardens. While wrens have become scarce of late

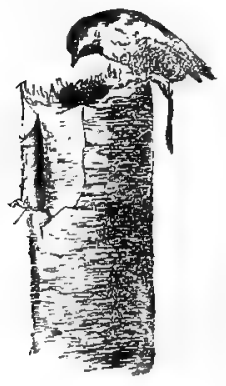

Fig. rj.

ChickAdeE years about our towns and cities, driven out probably by English sparrows, a few of the children in Worcester have reported them as occupying their bird houses. No doubt, we may soon have them common again if we supply sparrow-proof homes and get rid of the English sparrows.

Probably no bird possesses a higher economic value than the chickadee. All summer he feeds on insects and all winter on the eggs which they lay on the twigs and bark and around the buds of trees. Professor Forbush reports finding $5500 \mathrm{eggs}$ of plant lice in the crop of a chickadee, this number representing what the bird had gathered for a single breakfast. When heavy snow and 
especially sleet covers the trees, be sure to see that your chickadees are provided with food. A fresh bone with

marrow and meat on it or

a piece of suet fastened to the limb of a tree and kept free from ice from time to time may save dozens of these precious little lives during a winter. Chickadees are also among our cheeriest and tamest birds, and we could not have too many of them about our homes.

For swallows every barn, and I am tempted to say house attic as well, should be provided with a hole high up in the gables, which can be left open the whole year, or at least all the time the swallows are with us. This is a custom of our fathers which should not be permitted to lapse. It is sometimes objected that the birds bring undesirable insects into the house. The idea is probably based on faulty observations, but, in any case, the parasites may be easily destroyed, and we should do this rather than not have the
A mong the dwellings framed by birds

In field or forest with nice care,

Is none that with the little Wren's

In snugness may compare.

And when for their abodes they seek

An opportune recess,

The hermit las no finer eye

For shadowy quietness.

Wordsworth, The Wren's Nest.

This poet, though he live apart,

Moved by his hospitable heart,

Sped, when I passed his sylvan fort,

To do the honors of his court,

As fits a feathered lord of land,

Flew near, with soft wing grazed my hand.

EMERSon, The Titmouse.

Further on we found what we were chiefly looking for - a flock of lively little chickadees. ... They would light on our hands, inspect the pieces of crushed nut there, knock off the ones that did not suit them, and finally fly off with one - usually the largest.

Floyd C. Noble, aged 14, Bird-Lore, Vol. I, p. $5^{8}$.

On two occasions, Chickadees have flown down and perched upon my hand. During the few seconds they remained there I became rigid with the emotion of this novel experience. It was a mark of confidence which seemed to initiate me into the ranks of woodland dwellers.

CHA PMAN, Handbook, p. 390.

Note also Chapman's "The Legend of the Salt," Bird-Lore, Vol. I, p. 55.

Gentle swallow, thou we know

Every year dost come and go ;

In the spring thy nest thou mak'st;

In the winter it forsak'st,

And divert'st thyself awhile

Near the Memphian towers, or Nile. Anacreon, XXXV, p. 89, Stanley's Translation ( 562 B. C.). 


\section{swallows. Old barns are sometimes seen with this wise} provision, but it is seldom, if ever, found in the new ones that are fast taking their places. ${ }^{1}$

As the old barns fell to ruin,

New ones, raised to take their places, Lacked the broad and generous shelter Which the eaves had once afforded To the owners of the mud huts, To the swallows of the Saco.

Weary-winged, from distant Southlands, In the spring bave come the swallows, Seeking hopefully their nestings, Seeking eaves and sun-warmed barn sides; Come and found the crackless clapboards, Come and found ill-odored pigments, Come and found new barns for old ones, Come and found no eaves for shelter, Come with joy and met with sorrow, Seeking vainly for old barn sides Changeless as the cliffs of Paugus.

Weary-winged, the homeless swallows Flutter on into the darkuess Whither going? That they know not. But 't is certain that the Saco, That the lonely cliffs of Paugus, That the steeps below Chocorua, Do not bear their cosy dwellings. Years ago, on man depending, Mother swallows taught their nestlings Barns alone were made to build on Barns have failed them, man betrayed them.

\section{Bolles, Chocoria's Tenants.}

As well suppose the trees without leaves as the summer air without swallows. Ever since of old time the Greeks went round from house to house in spring singing the swallow song, these birds have been looked upon as the friends of man, and almost as the very givers of the sunshine. ... The beautiful swallows, be tender with them, for they symbol all that is best in nature and all that is best in our hearts.

JEFFries, Field and Hedgerow, p. noo.

Then out of the high heaven above, at once one hears the happy chorus of the barn swallows; they come rejoicing, their swift wings cleave the blue, they fill the air with woven melody of grace and music. Till late August they remain. Like the martins', their note is pure joy; there is no coloring of sadness in any sound they make. The sandpiper's note is pensive with all its sweetness; there is a quality of thoughtfulness, as it were, in the voice of the song sparrow; the robin has many sad cadences; in the fairy bugling of the oriole there is a triumphant richness, but not such pure delight; the blackbird's call is keen and sweet, but not so glad; and the bobolink, when he shakes those brilliant jewels of sound from his bright throat, is always the prince of jokers, full of fun, but not so happy as comical. 'The swallow's twittering seems an expression of unalloyed rapture, - - I should select it from the songs of all the birds 1 know as the voice of unsliadowed gladness.

Celia Thaxter, AnIsland Garden, p. 22.

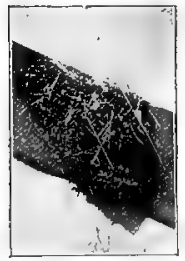

FIG. 132. BARN SWALLOW'S NEST

1 The nest in the margin was taken from such an old barn, with swallow holes in the peak, belonging to Elliott Moore of Worcester, and the swallows have nested in it regularly for many years. Paint and planed lumber are fast making our buildings impossible for swallows. A case has recently come to my knowledge, and they are doubtless numerous, where the nests of a large colony of eave swallows were scraped down in order to paint a barn. They deserted the place and have never returned. Itwould certainly pay to tack a rough board along under the eaves of barns, to attract colonies of this most valuable bird. 
Even the Indians used to hang gourds to their wigwam poles for the martins. The Greeks celebrated the swallows in poetry and song as early as the dawn of authentic history. We cannot afford to let these deep lines of sentiment and human good fail from our lives. I have heard complaints that our barn swallows are becoming scarce, as though it were due to some inevitable change in natural conditions. Look at our barns, and the whole matter is explained. Provide homes, wherever this has been neglected, and swallows will soon be numerous again. It was indeed a pathetic thing to see, as I did recently, a fine colony of barn swallows flying round and round a large barn, examining every knot, clinging about the too well glazed windows, unable to find an entrance. Farmers should realize the hot days of suffering and annoyance from flies, gnats, and mosquitoes which a beautiful colony of swallows would save.

The purple martin has been practically driven from our towns and cities by the English sparrows. It should be considered no mean public service to keep a suitable house clear of sparrows for these beautiful

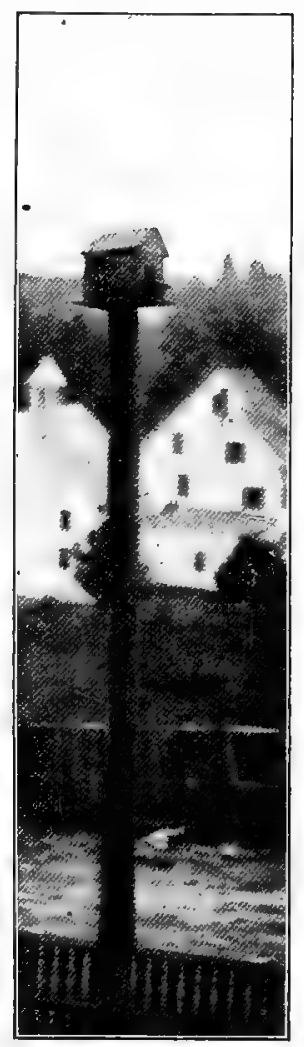

FIG. 133. BIRU House Erected in the school yard (Upsala Street). It was taken by a pair of tree swallows before it had been up an hour 
birds. ${ }^{1}$ The bird house for purple martins should be placed on a pole some distance from trees and buildings,

This guest of Summer,

The temple-haunting martlet, does approve, By his lov'd masonry, that heaven's breath Smells wooingly here. ....

Where they most breed and haunt, I have observ'd,

The air is delicate.

ShaKespeare, Macbeth.

All the summer long the swallow is a most instructive pattern of unwearied industry and affection.... The swallow is a delicate songster.

Gilbert White, Selborne, 1767 , Vol. II, p. 5 .

most carefully protected. The night hawks nest on the flat roofs of buildings, and the swifts in unused chimneys.

If every bird has his vocation, as a poetical French writer suggests, that of the American robin must be to inspire cheerfuliness and contentment in men. His joyous "Cleer up! Cheer up! Checry! Be cheery! Be cheery!" poured out in the early moming from the top branch of the highest tree in the neighborhood, is one of the most stimulating sounds of spring.

Besides admonishing others to cheerfulness, the robin sets the example. Not only is his cheering voice the first in the morning and the last at night, - of the day birds, but no rain is wet enough to dampen his spirits.

Olive Thorne Miller, In Nesting Time, p. 2. and the openings may be three inches in diameter.

The little chimney swift and the night hawk are and usefulness in sweeping the air clear of insect pests. Both have applied for homes in our cities and should be The swifts nest in colonies in the same chimneys and are often killed in great numbers by fires that are built during cold weather in early summer. Great care should be exercised to avoid this whenever possible.

To one awakened at morning and cheered at evening birds of wonderful power

${ }^{1}$ It is often stated that purple martins are becoming rare, English sparrows being generally given as the cause. This is probably true in the main, since the sparrows nest before the martins come north, and especially because the sparrow nuisance has discouraged people from providing martin houses. That the lack of suitable houses for martins may be at the bottom of the difficulty is indicated by the fact that a martin house, erected in Worcester, May $\mathrm{I}$, became within three weeks the home of nine pairs of these "rare" birds. Within limits of food supply, we can doubtless have as many purple martins as we furnish with sparrow-free houses. 
by their songs through years of childhood, robins are necessaries of life. No summer is complete without a pair of these rollicking birds nesting about the house.

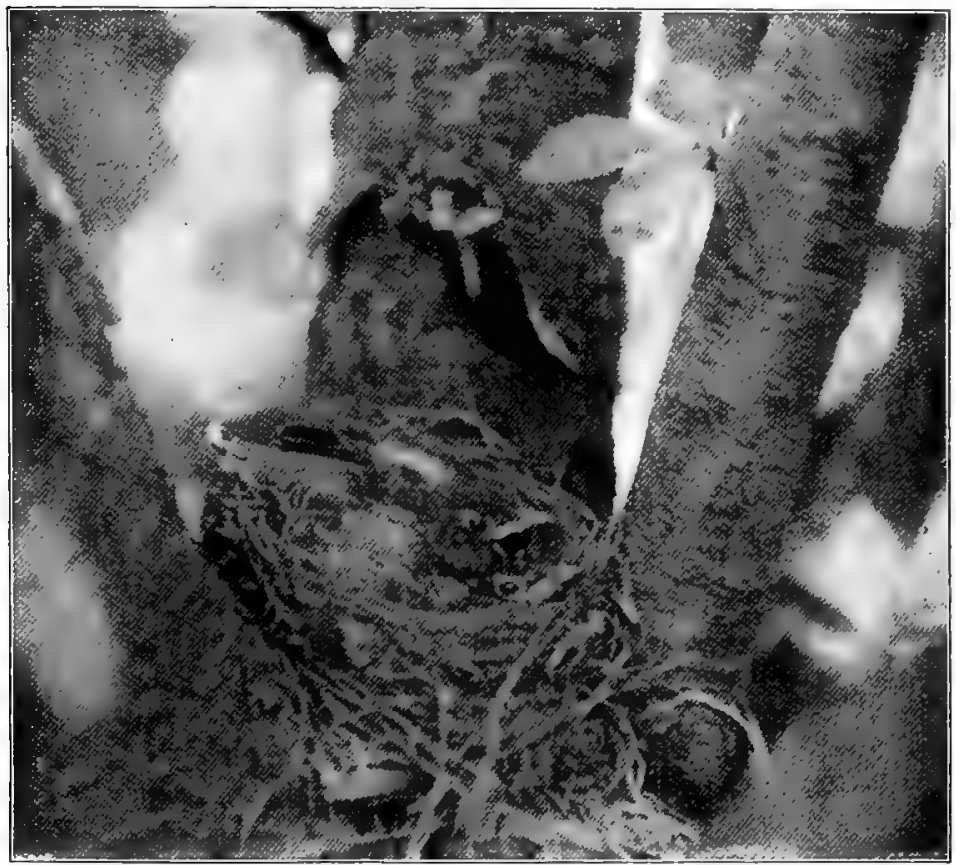

Fig. 134. Robin's Nest in the CherRy TREe

(Photograph by the author, 1901)

But how to induce a pair of wild robins to do this is a problem fascinating but as yet almost wholly unsolved.

In very dry weather, or where mud is not easily obtained, it is a good plan to keep a pan of mud on the post with the birds' watering dish. Mrs. Treat has 
described how robins take mud for their nests from her flowerpots, and Olive Thorne Miller relates that a female robin has been known to dip herself in water, fly directly

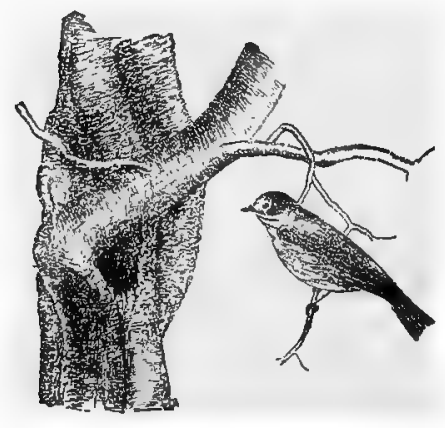

FIG. I35. BLUEBIRD into the dust of the street, and then pick off the mud from her feet and feathers. When it comes to this, we may be sure that a little help will be appreciated. Several children in the Worcester Ten to One Clubs have put out pans of mud and have been greatly delighted in a number of cases by seeing robins come and carry the mud away. But I hope the one who first discovers how to make a nook so inviting that a pair of robins cannot resist the temptation to build their nest in it will tell me, and every one else, all about it.

It is almost as hard to do without bluebirds, orioles, and vireos, and a host of others, and if plenty of nesting material be provided at the proper time, it is perhaps easier to attract orioles and vireos than any others.

A rout of evanescence With a revolving wheel;

A resonance of emerald, A 1 ush of cochineal;

And every blossom on the bush Adjusts her tumbled head, The mail from Tunis, probably, An easy morning's ride.

Eniluy Dichinson, Second Series, p. 130.

A 1ash of harmless lightning, A mist of rainbow dyes,

The burnished sumbeams brightening,

From flower to flower he flies;

While wakes the nodding blossom,

But just too late to see

What lip hath touched her bosom And drained her nectary.

JUHN B. TABB, p. 59.

They can build in almost any tree and find food in cvery garden and orchard. Hence abundance of nesting material, linen and cotton thread and strings, store twine, yarn, 
or tow, may decide a pair to build on the spot. A little hair for a chipping sparrow is another thing not to be forgotten, and plenty of honeysuckles and other nectarbearing flowers will be sure to attract humming birds.

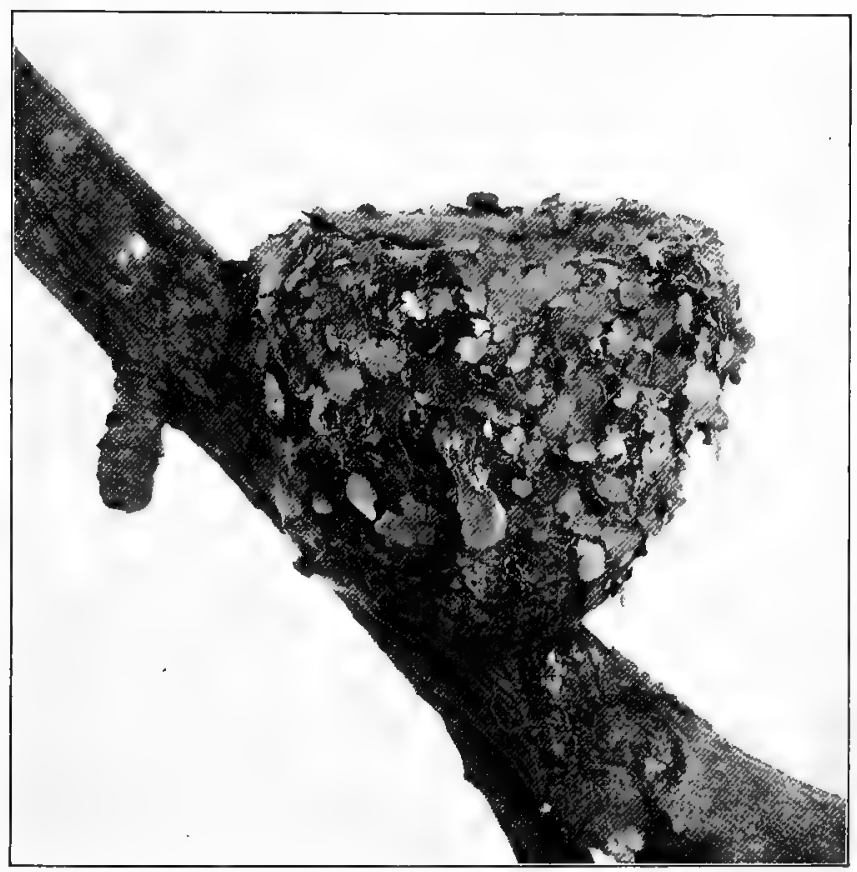

Fig. 136. Humming Bird's Nest on an Apple Limb (About natural size)

Whatever we do to attract a pair of birds to nest on the premises must be done, of course, at the proper time, and to this end we should know when each species begins to nest, and our preparations should be made a week or 


\section{LIFE CHART OF OUR COMMON}

\begin{tabular}{|c|c|c|c|c|c|}
\hline$\cdot$ & Arrive & Depart & $\begin{array}{c}\text { Number } \\
\text { of } \\
\text { Broods }\end{array}$ & $\begin{array}{l}\text { Begins } \\
\text { to nest }\end{array}$ & $\begin{array}{l}\text { Incu- } \\
\text { bation } \\
\text { Days }\end{array}$ \\
\hline Bluebird & A few resident, March & Nov. & $2-3$ & May, early & 12 \\
\hline Robin & A few resident, March & Oct., Nov. & $2-3$ & May & 12 \\
\hline Wood Thrush & May & Oct. & $2-?$ & May, late & 12 \\
\hline Brown Thrasher & April, late & Oct., late & I or 2 & May, early & \\
\hline Catbird & April, late & Oct., late & $2-?$ & May, early & \\
\hline House Wren & April, late & Oct., mid. & 3 & May, early & \\
\hline Chickadee & Resident & & 2 & May, early & \\
\hline Vireos & May & Oct., late & $\mathbf{I}$ & May, early & \\
\hline Cedar Bird & Resident & & $\mathbf{I}$ & June-Oct. & \\
\hline Swallows $\left\{\begin{array}{l}\text { Barn } \\
\text { Eave } \\
\text { Tree }\end{array}\right.$ & $\begin{array}{l}\text { April, mid. } \\
\text { April } \\
\text { April }\end{array}$ & $\begin{array}{l}\text { Sept., mid. } \\
\text { Oct. }\end{array}$ & 2 & & \\
\hline Purple Martin & April & Sept., mid. & & & \\
\hline Tanager & May & Oct., early & I & May, late & \\
\hline Grosbeak & May, early & Oct., early & I & & \\
\hline Orioles & May I & Sept. I & $\mathbf{I}$ & $\left\{\begin{array}{l}\text { May, mid. } \\
\text { Worc, } 1899\end{array}\right.$ & 14 \\
\hline Bobolink & May & Oct., early & $\mathbf{I}$ & - June I & \\
\hline Kingbird & April, late & Sept., early & I $(2 ?)$ & May, early & $12-13$ \\
\hline Phobe & March, mid. & Oct., last & 2 & May, early & 12 \\
\hline Cuckoo & May, early & Oct., late & 2 & May, mid. & \\
\hline Chipping Sparrow & April 9 & Nov. 7 & & May, mid. & \\
\hline Song Sparrow & Resident & & & May I & \\
\hline
\end{tabular}


DOMESTICATION OF OUR WILD BIRDS

BIRDS. (LAtitude of NEW YoRK.)

\begin{tabular}{|c|c|c|c|c|c|}
\hline \multirow{2}{*}{$\begin{array}{c}\text { Foung } \\
\text { remain } \\
\text { in Nest } \\
\text { Days } \\
\end{array}$} & \multicolumn{3}{|c|}{ Nest. } & \multicolumn{2}{|r|}{ Eggs } \\
\hline & Location & \multirow{2}{*}{$\frac{\begin{array}{c}\text { Height } \\
\text { Feet }\end{array}}{4^{- \text {Io }}}$} & Material & Num- & Color, etc. \\
\hline & $\begin{array}{l}\text { Hollow in tree } \\
\text { or box }\end{array}$ & & Grass & $4-6$ & Pale blue \\
\hline & Crotch of tree & $5-15$ & Rootlets, grass, mud & $3-5$ & Greenish blue \\
\hline & In sapling & 8 & $\begin{array}{l}\text { Rootlets, mud, fine } \\
\text { grass }\end{array}$ & $3-5$ & Greenish blue \\
\hline & $\begin{array}{l}\text { Low, thick } \\
\text { bushes or on } \\
\text { ground }\end{array}$ & $0-5$ & Twigs, rootlets & $3-6$ & $\begin{array}{l}\text { Grayish white, finely } \\
\text { speckled with cin- } \\
\text { namon }\end{array}$ \\
\hline & $\begin{array}{l}\text { Thicket or dense } \\
\text { tree }\end{array}$ & $3-30$ & $\begin{array}{l}\text { Twigs, leaves, grass, } \\
\text { rootlets }\end{array}$ & $3-5$ & Dark greenish blue \\
\hline & $\begin{array}{l}\text { Hollow tree, box, } \\
\text { or cranny }\end{array}$ & $\mathrm{I}-$ ? & Twigs, grass & $6-8$ & $\begin{array}{l}\text { Wine or flesh colored, } \\
\text { finely speckled }\end{array}$ \\
\hline & $\begin{array}{c}\text { Hollow trees, } \\
\text { birch, stubs }\end{array}$ & $4^{-20}$ & $\begin{array}{l}\text { Moss, grass, feathers, } \\
\text { plant down }\end{array}$ & $6-8$ & $\begin{array}{l}\text { White, spotted, and } \\
\text { speckled with brown }\end{array}$ \\
\hline & $\begin{array}{l}\text { Pensile in fork } \\
\text { of branch }\end{array}$ & $15-70$ & $\begin{array}{l}\text { Bark fibers, paper, } \\
\text { plant down }\end{array}$ & $3^{-4}$ & $\begin{array}{l}\text { White, black spots on } \\
\text { larger end }\end{array}$ \\
\hline & $\begin{array}{l}\text { Fruit and shade } \\
\text { trees }\end{array}$ & $3^{-25}$ & $\begin{array}{l}\text { Twigs, bark, grasses, } \\
\text { leaves, moss, rootlets }\end{array}$ & $3-5$ & $\begin{array}{l}\text { Pale bluish green, } \\
\text { spotted with dark }\end{array}$ \\
\hline & $\begin{array}{l}\text { On rafters, etc., } \\
\text { ledges, eaves, }\end{array}$ & & $\begin{array}{l}\text { Mud, twigs, grass, } \\
\text { feathers }\end{array}$ & $4-6$ & $\begin{array}{l}\text { White, spotted with } \\
\text { brownish }\end{array}$ \\
\hline & holes in trees, & & Same as above & $4-7$ & White \\
\hline & bird houses & . & Twigs, grass, feathers & & White \\
\hline & $\begin{array}{l}\text { Bird houses } \\
\text { clear of trees }\end{array}$ & & Straws, twigs & $4-5$ & White \\
\hline & Trees & $3^{-20}$ & $\begin{array}{l}\text { Twigs, weed stems, } \\
\text { tendrils }\end{array}$ & $3-4$ & $\begin{array}{l}\text { Pale bluish or green- } \\
\text { ish white, brownish } \\
\text { markings }\end{array}$ \\
\hline & Bushes or trees & $5-20$ & Fine twigs, rootlets & $4-5$ & $\begin{array}{l}\text { Pale blue, with brown } \\
\text { markings }\end{array}$ \\
\hline 14 & $\begin{array}{l}\text { Pendent from } \\
\text { branches }\end{array}$ & $8-50$ & $\begin{array}{l}\text { String, hair, plant } \\
\text { fibers }\end{array}$ & $4-6$ & $\begin{array}{l}\text { White, with dark } \\
\text { scrawls and blotches }\end{array}$ \\
\hline & $\begin{array}{l}\text { On ground, in } \\
\text { grass }\end{array}$ & & Grasses & $4-7$ & $\begin{array}{l}\text { Grayish white, with } \\
\text { brownish spots and } \\
\text { blotches }\end{array}$ \\
\hline 14 & Trees & $4-40$ & $\begin{array}{r}\text { Weeds, grass, moss, } \\
\text { plant down, rootlets }\end{array}$ & $3-5$ & $\begin{array}{l}\text { White, spotted with } \\
\text { umber }\end{array}$ \\
\hline 14 & $\begin{array}{l}\text { On beams or } \\
\text { ledges }\end{array}$ & $6-20$ & Moss, mud, hairs & $4^{-6}$ & $\begin{array}{l}\text { White, rarely spotted } \\
\text { with brown }\end{array}$ \\
\hline & $\begin{array}{l}\text { Low trees or vine- } \\
\text { covered bushes }\end{array}$ & $4^{-10}$ & Sticks, grass & $3-5$ & Pale bluish green \\
\hline & Bushes and trees & $5-20$ & $\begin{array}{l}\text { Twigs, grasses, root- } \\
\text { lets, hairs }\end{array}$ & $4-6$ & $\begin{array}{l}\text { Bluish, brownish } \\
\text { markings }\end{array}$ \\
\hline & $\begin{array}{l}\text { On ground, rare- } \\
\text { ly on bushes }\end{array}$ & & $\begin{array}{l}\text { Grasses, dead leaves, } \\
\text { bark }\end{array}$ & $4-6$ & $\begin{array}{l}\text { White, or bluish white, } \\
\text { covered with brown- } \\
\text { ish markings }\end{array}$ \\
\hline
\end{tabular}


two before this occurs. The preceding table, which we may call a Life Chart of a few of our commoner species, may serve to bring a number of points of interest together in convenient form for reference. It would be well if, each spring, classes in nature study could make a table of this kind for their own localities. This would bring out variations in season from year to year, define these periods more exactly, and furnish incentive and guidance to active work in supplying homes and nesting materials.

Organized Bird Protection; the Audubon Societies. - "As for the birds that are the special object of preservation of your Society, we should kecp them just as we keep trees. They add immeasurably to the wholesome beauty of life." 1

These words of President Roosevelt express the matter in a nutshell. We should have birds about our homes just as we have trees and flowers. In planning for farms or gardens, for public parks or for homes, we should always provide for birds. Bird life, in fact, is the natural complement of plant life, both useful and beautiful.

To impart to our work for the birds the universality that shall render it effective for the whole country we need organization. Happily, this is provided for in the Audubon Societies, now established in twenty-two states. Both teachers and pupils may join the societies of their respective states, and it would be none too many if every nature-study class should form a branch Audubon Society. The teachers receive suggestion and help, and the children feel the inspiration there is in all working together for a cause of truly national importance, - the universal protection, domestication, and increase of our native birds.

1 From a letter of Theodore Roosevelt, Bird-Lore, vol. ii, p. 98. 
Objections have been raised to the usual Audubon Society pledges, due to the negative elements that enter largely into all those I have seen. The objections do not hold with regard to a clear, positive statement of purpose, which is always of value in active organizations, and as such a pledge I would submit the following:

$I$ promise to do all I can for our native birds by treating them with kindness and by providing them with food, water, and homes.

The official organ of the Audubon Societies is Bird-Lore (The Macmillan Company, Harrisburg, Penn.), each number of which contains an Audubon Society directory. From this any who wish information about organizing branch societies may obtain the address of their State Secretary.

Mrs. Brightwen. Wild Nature zern by Kinduess. London, I898.

Charles A. Babcock. Bird Day. Silver, Burdett \& Co., 1901.

F. E. L. BEAL. "Some Common Birds in their Relation to Agriculture," Farmer's Bulletin No. 54, United States Department of Agriculture, Washington, I898.

D. LANGe. Our Native Birds. The Macmillan Company, I899.

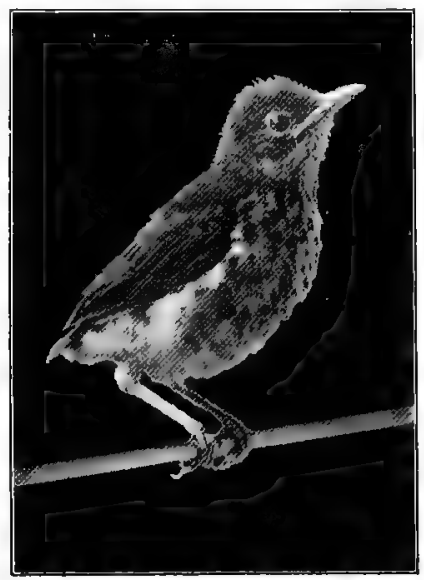




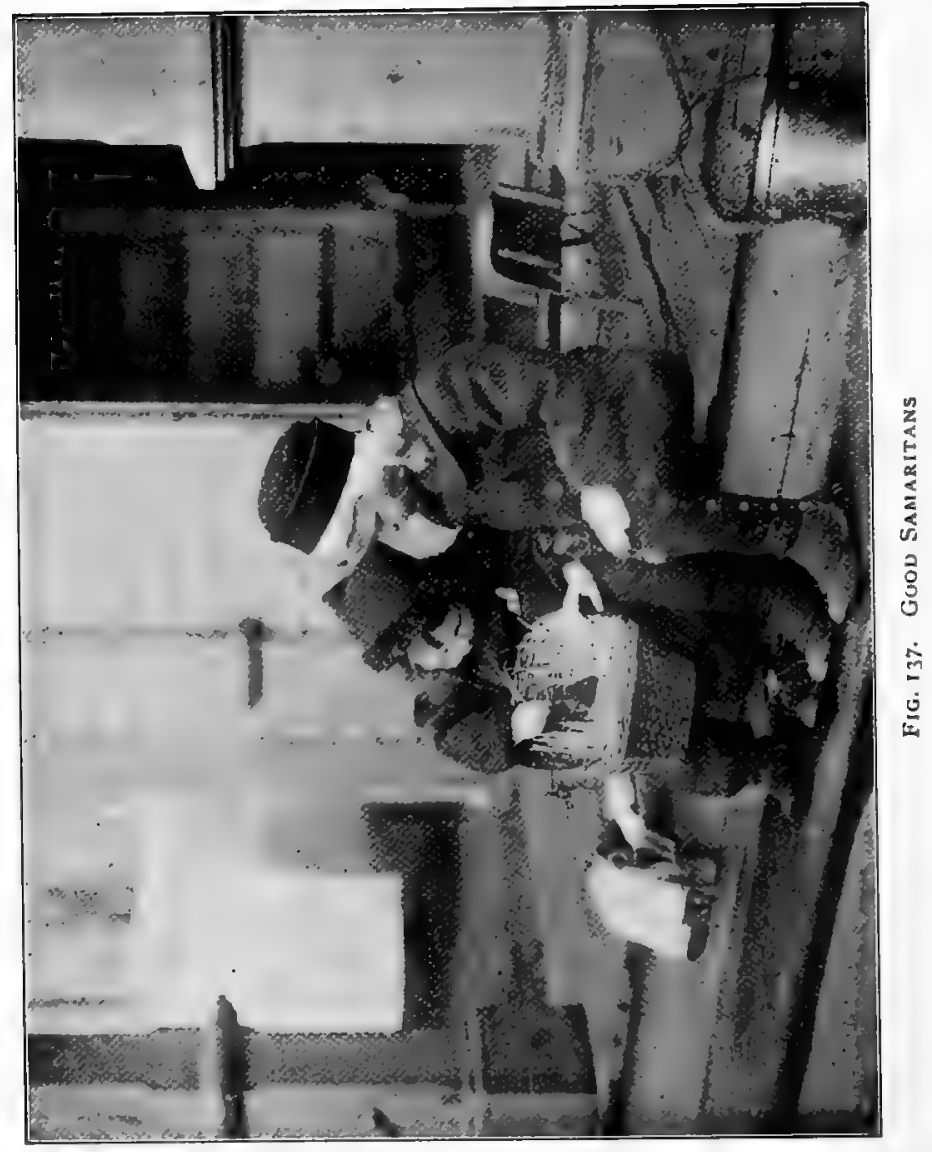

346 


\section{CHAPTER XXI}

\section{TAMING AND FEEDING BIRDS}

Like one in danger; cautious,

I offered him a crumb,

And he unrolled his feathers

And rowed him softer home

Than oars divide the ocean,

Too silver for a seam,

Or butterflies, off banks of noon,

Leap, plashless, as they swim.

Emily Dickinson, In the Garden.

FeEding and taming go together, for the only way to a bird's heart is through his crop. If we have a tempting morsel in the palm, they will fly to our hands. Had Emily Dickinson offered a meal worm instead of the "crumb," the result might have been different (see Fig. I 38). We must learn enough about a bird's food to know what to offer, and we need to come into sympathy with a bird's life to know how to offer it so that the proffer may be accepted.

As indicated on the chart, bird foods may be divided into vegetable and animal, and among the latter different kinds of insects form the most important part. Artificial foods will also require a little attention for reasons to be developed later. It is a fortunate coincidence that many of the most useful birds are also the most beautiful and our best songsters. We may divide them into three classes. 
The first class includes those that are wholly or almost wholly insectivorous: the swallows and martins, wrens, vireos, flycatchers, warblers, cuckoos, night hawks, whippoor-wills, swifts, and humming birds. We cannot have too many of these birds. All they need is safe homes and water, and they should be encouraged and protected up to the very limit of insect food. We should not attempt

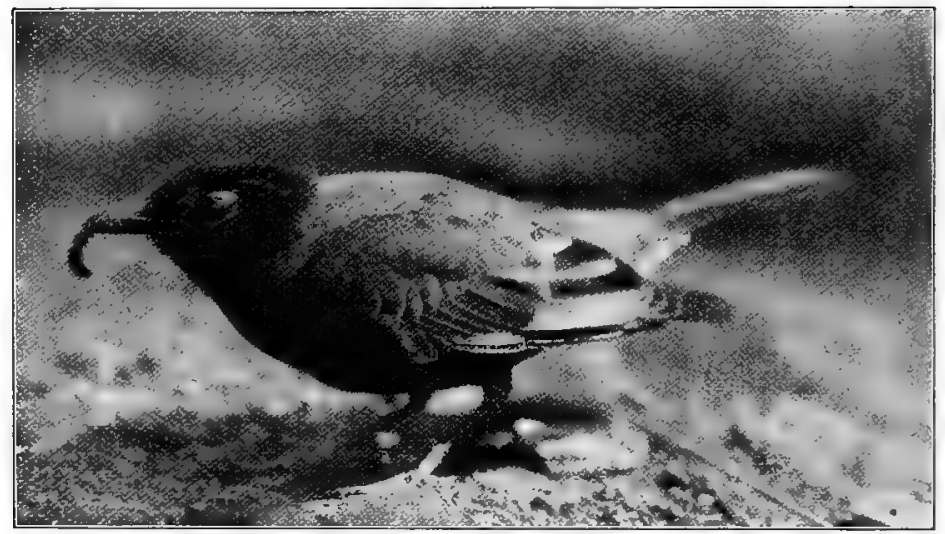

FIG. 138. Q. E. D.

A wild robin tamed to come at call by means of a few meal worms.

(Photograph by the author, Igor)

to keep one in confinement for any length of time unless we have an enormous supply of suitable insects, and even then, with some of them, their manner of snapping insects on the wing is so different from that of picking them up from the ground that we could hardly expect to feed them adequately or give them sufficient freedom for health. Those birds, however, that do not catch their food on the wing, such as the wrens, vireos, warblers, 
cuckoos, and the humming bird, are easily tamed and may be fed successfully and kept in comfort, if accidentally disabled for flight.

The second class includes birds that by preference feed on insects but are able to vary their diet to fruits, nuts, or grains when insects fail. The bluebird, robin, wood thrush, mocking bird, brown thrasher, catbird and all other thrushes, chickadee, ceclar bird, grosbeak, meadow lark, grackle, oriole, and woodpecker belong in this class. For these the best work must consist in planting and preserving such trees, shrubs, and vines as will insure them an abundant supply of their favorite fruits. If desirable, any of this class may be fed in confinement on fruits, meats, bread, eggs, potatoes, and meal worms, as will be described presently. The birds in this class that spend the winter with us - chickadees, nuthatches, brown creepers, and

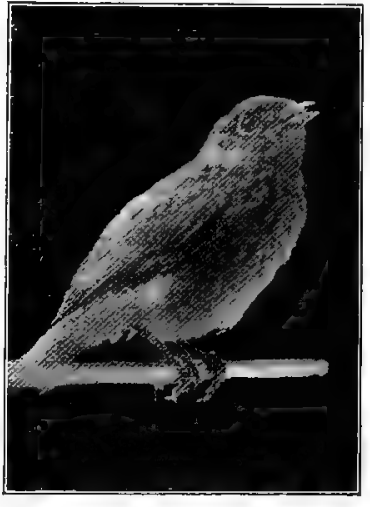

Frg. I39. Purtrait uf a Younci BLUEBIRD

(By Myron W. Stickney) woodpeckers - may be attracted to our window sills and made very tame by supplying them with cracked nuts, suet, meat, bones, doughnuts, etc., during severe weather.

The two classes already described are commonly known to bird fanciers as "soft-billed" birds. To the third class belong the seed-eatins, "hard-billed" birds, the canary, goldfinch, song and chipping sparrows; in short, all the finches and sparrows. These birds are most easily 
and hence most commonly kept in confinement, because they can be fed almost entirely on seeds. Outside, it is only necessary to keep a pile of hay-loft sweepings, with its grass and weed seeds, or to scatter millet, sunflower seeds, or grain in some sunny, sheltered spot to have such as remain with us all winter long or arrive early in the spring feeding under our windows.

To effect the practical taming of the wild birds about our homes we should do everything calculated to attract them and to give them a feeling of security in our presence; and food is the great loadstone. When we begin this positive work little attention need be given to the negative side, i.e, refraining from such things as disturb and frighten them away.

It is comparatively useless to attempt to tame an old bird. A bird is a quick-lived, extremely sensitive creature, keenly intelligent within narrow limits. The ability to help itself within this narrow range, that a child takes years to learn, the little bird masters in so many weeks or even days; hence a bird's brain is so organized that one decisive lesson commonly lasts its lifetime. This fact we must bear in mind when we seek to tame a bird, and one other fact also, which is that a bird is a timid, defenseless creature whose life for ages has depended chiefly on ability to fly. With so many enemies on every side, a bird must interpret any quick movement as a hostile act. Its eyes are probably keener than ours. So in approaching a bird we can come quite near if we are careful not to look at it and if we zigzag toward it or pretend to be looking for something else. For a bird to stop singing is a signal that we have come as close as we 
dare until we reassure it of our good intentions, possibly by withdrawing a little or by sitting down and pretending to look the other way. We must always remember that one careless or hostile act may make a bird "wild" for life.

I mention these points in order that we may unite intelligently in taming the birds about our homes by doing only those things that assure them and make them feel that we are their friends. Among the little acts by which we are able to give this assurance the proffer of food is the most effective. Our little friend in the picture proves that we may have them coming to our hands, and this is now such a familiar experience that there is no longer any doubt that

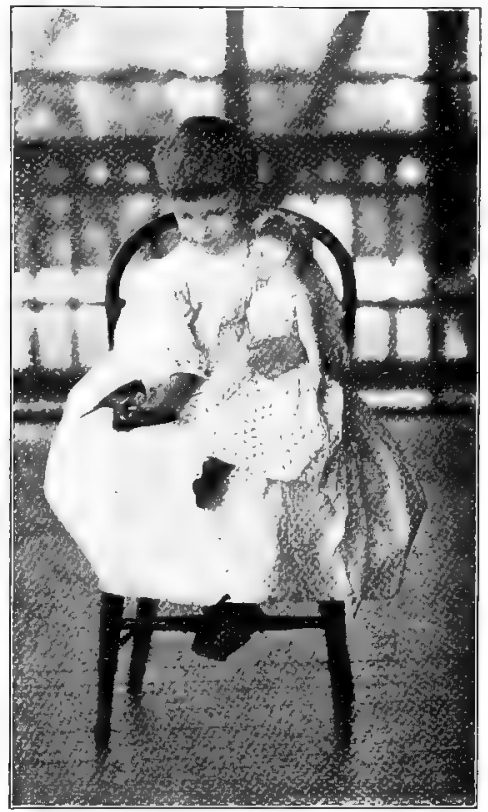

Fig. I40. Chippy tamed to FEed from A CHILD'S HAND

From Bird-Lore, Vol. I. By permission. (Photograph by Mr. George B. Wood)

a general movement to domesticate our common wild birds would be successful. John Burroughs had the robins in his garden so tame that they would perch on his knee, waiting for him to turn up a worm. The song sparrows and humming birds perched upon Celia Thaxter's 
arms as she busied herself with her flowers, and Mrs. Treat has long had the birds as tame around her home. These are leaders who have shown how readily the birds respond to domestication.

People not infrequently say that wild birds should be wild. It is not "natural" for them to be tame. Why man's best friends, so beautiful, so graceful in every act, so harmless and so important, should not be sufficiently domesticated to look upon man as a friend rather than as an enemy is a mystery indeed. That it is "natural" for birds not to fear man is abundantly attested by their behavior on islands to which unnatural human abuses have not extended and in wildernesses where man is seldom seen. Furthermore, I have never known young birds in the nest to show "instinctive" fear of man. If a nestling be taken without the least fright and without hearing the cries of the parents, it is practically a tame bird from the first. It will take food eagerly from the hand, follow one about, beg, and from the first day act toward a person as toward its own parent. The same is true of nestlings not quite able to fly that are picked up on the ground. If this can be done without frightening them, they will often immediately perch on the finger and feed from the hand. I have tested this with young vireos, chipping sparrows, orioles, grackles, and repeatedly with young robins, which some even put clown in their books as untamable. To demonstrate this let any one use ordinary care not to startle or try to grab the little stranger. Think what a monster the open hand must seem to a bird. The grabbing of a bird must be, from its point of view, nothing short of 
being swallowed alive. It is a rare lesson in gentleness to capture a young bird without frightening it, but if successfully done, your bird is practically tame. If even a young bird is caught after a severe chase, it is likely to be days, weeks, and even months, before the effects of its fright can be obliterated, and I have known one case of a young robin that had not recovered from the effect of such treatment in connection with its capture after more than a year.

I have one reason for mentioning these facts. It is not that $I$ wish children to catch and tame bircls to keep in cages. One tame bird at liberty about a home is worth a hundred in captivity. The reason is, in a word, that thousands of fledgelings yearly leave the nest a day or two before

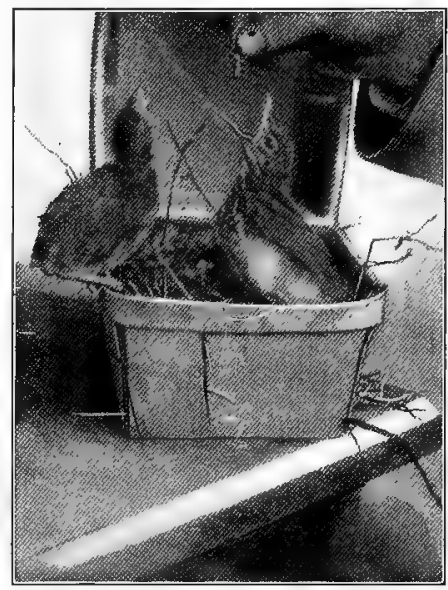

FIg. I4I. A GOOD ORPHAN'S HOME FOR A DAY OR TWO UNTIL THE WINGS GROW STRONG

(Photograph by Myron W. Stickney) their wings are quite strong enough to fly, and fall a prey to cats. No work in the entire nature course is more valuable either in humanizing influences for the children or in practical service in fostering and increasing our valuable bird life than this tiding of the little orphans over these first hard days out of the nest. With our rapidly decreasing bird life, the children owe this wcrk to the birds, to the community, and to 
themselves. But in order that it may effect the desired saving of birds, the children should be carefully instructed in the work.

A nest of robins is in the cherry tree. We have been careful to disturb them as little as possible. We have kept the water fresh, dug worms for them in the garden, and with every look and movement have tried to assure them that they are welcome. Stray cats that have worried them we have driven off. Finally the most ambitious of the overflowing nest tries his wings too soon and falls to the ground. Both birds are in a panic of alarm, and the little wide-eyed adventurer, with spotted breast, nest-down sticking to his feathers, and stubby tail just starting to grow, sits in the grass and calls loudly for help. Now is the time to cultivate patience and tact. In a few minutes the old birds will probably quiet down and go off in search of food. Then if we approach slowly, the youngster will quite likely open his bill to swallow us, when we can let a bit of earthworm or a crushed raspberry fall into the yawning chasm. $\mathrm{He}$ is ravenous. The chasm yawns again, this time with a new purpose, and in less than five minutes the nestling is -sitting contentedly on our hand and gulping down berries and worms. Then the little head grows heavy, the eyelids droop, and Bob is asleep in our hand.

What we do now depends upon how much time we have and on whether or not we wish to make a study of the food of a young robin. Certain it is that returning it to the nest will avail nothing. If our time is limited, we may place it in a cage with some green oilcloth for a roof and hang in the tree near the nest. We may put 
worms and berries around the base of the cage, outside the wires, to show good intentions, and we shall have the pleasure of seeing the parent birds coming regularly to feed its occupant. In two or three days the wings will be strong enough to try again, and if the bird can fly and has sense enough to take refuge in the trees, it may be given its liberty.

Any one who has once reared a young bird by hand, even from the time it leaves the nest until it is able to shift for itself, will appreciate the fact that we should leave this work to the parent birds whenever possible. Still an experience of this sort is a revelation of the mysteries of bird life.

The first thing we learn is that a nestling does not know how to feed itself. We may pile all sorts of berries and worms around it, but it simply sits and clamors for food. Innumerable young birds have died of starvation at this juncture in the hands of well-meaning children, much to their discouragement, simply because they did not think how young and ignorant their pensioners really were. The bird is probably not more than twelve or fourteen days out of the eggshell; and for those few days it has sat in the nest, with nothing to do but to open its mouth and swallow what its parents put into it. Suddenly it sees the wide world around it. Its mouth has always been so wicle open that it could not see what was being put into it. How is it to know berries or worms or to know how to get them into its bill? I am convinced from careful study of a number of young birds of different species that the day they leave the nest they do not know either of these things, and how could we 
expect them to, - twelve days out of the egg and part of one out of the nest?

It is a fascinating study to discover how the parent birds tide their nestlings over this most difficult period of their lives. Ask the pupils to watch a family of birds as the young leave the nest and to describe what they see. Olive Thorne Miller writes of seeing one parent bird call her young one into a berry bush, and while the youngster clamored for food and beld its mouth wide open, she quietly helped herself, as much as to say: "This is the way we do it. See?" But the young one could not "see"; for the only thing it had ever done or knew how to do was to hold its mouth open and flutter its wings and beg; and it must have thought the mother cruel when she slipped away, leaving it alone to study the lesson. One of the most interesting lessons I ever saw was given by my big cock robin to his class of four young ones. The task for that morning was evidently to learn how to catch and eat earthworms. It was a drizzling morning in June. All the youngsters were fully fledged, and each appeared about as large as the daddy. They all hopped along in a group, the parent a little in the lead. Soon he pounced upon a large worm, and while he tugged it out of its burrow, what did the young ones do but sit back, hold their mouths open, flutter their wings, and beg? He threw the worm, squirming, among them. Not one attempted to touch it. He picked it up again and, whacking it on the ground, broke it into bits. Not one of his class offered to help. They, every one, simply held their mouths open and begged. He tossed the squirming bits on the ground before them. Not one caught the idea, 
and finally he fed a piece of the worm to each one. The same lesson was repeated with the next worm, and the next, and so on for nearly an hour; but never a youngster offered to do anything but sit up and beg. That teacher will remain a model of patience as long as I live. It was the most amusing and most instructive bit of bird life I ever observed, and I saw in a flash just why it is that a young bird may starve with food piled high around it.

How long this period of helplessness lasts for different birds I have never found stated in the books. I have found it to be from two to five days with young robins. During this time every morsel must be placed in the young bird's mouth, and it should be fed at least once an hour from sunrise to sunset.

What is a nestling's menu for a day? No one has answered this question. ${ }^{1}$ There are about sixteen meals to be accounted for. Are they varied course dinners, with insects and fruit for dessert? Are they rather monotonous affairs? Does a parent bird bring worms to its young for one meal, grasshoppers for the next, and berries for the third or do they get the same thing all day long? Do they make no intelligent choice, but feed whatever they find first? These questions may seem farfetched, but to one who has been trying his hand at feeding young birds they become intensely practical. None of them have been answered, so far as I know; but the fact seems to

1 I was once watching five young cedar birds just out of the nest, when the mother bird flew down to them. They were all in a row on a twig, and I saw her drop a red currant into each of the open mouths in turn. I should like to have known what their next meal was. 
be, that while different species doubtless have quite different habits of feeding, all birds seek and enjoy great variety in foods.

As to the choice we make, the only rule to follow is to provide as nearly as possible the natural foods of the species. The food chart tells us nearly all that is known on this subject. With any species we have only to follow out the line from the name and read at a glance what the bird is known to eat. If the exact species is not on the chart, we may study the foods of closely related birds and not go far astray. We should also bear in mind that even the finches and sparrows feed their young as long as they are in the nest, chiefly, or wholly, on insects. Spiders are often called, among bird fanciers, the best medicine a bird can have, and I have found this true. If your bird seems to be inclined to droop, a meal of these will almost invariably act like magic. It will be noticed that every bird in the chart eats grasshoppers. These can generally be caught in abundance toward the end of summer. At this season they are filled with eggs and form a most nutritious diet. Grasshoppers would make a most valuable insect bird food for winter use if caught at this time and dried. They should be scalded and dried thoroughly, and then if scalded again a short time before feeding, they are nearly as good as fresh. "Ants' eggs," which are the pupæ of ants, are also a valuable bird food. They may be had of bird dealers for about a dollar a pound, but for a dry food I think grasshoppers may well take their place. For the sake of variety the children may be encouraged to try gathering a few from underneath stones and logs or from ant-hills. 
The best insect food for all soft-billed bircls is meal worms, and every child that wishes to help young birds in the way suggested or care for any wounded bircl that may fall in his way should learn how to rear them and keep a supply on hand. They are also excellent food for winter birds and for robins and bluebirds and many others that come early in the spring. We do not always have the time to collect insects in sufficient quantity, but we can always have a supply of meal worms if we once learn how to rear them.

The meal worm is the larva of a black beetle which can be found from May to October about granaries, mills, where feed is kept in stables, in the dust of haylofts, in pigeon lofts, and meal chests. The eggs are laid in these places and when hatched and fully grown the larve are smooth yellow, Tenebrio molitor, or blackish, T. obscurzts, "worms," about an inch in length. While commonly looked upon as pests, for feeding birds they are well-nigh indispensable. The writer has paid twenty-five cents a dozen for them to feed mocking birds, and the market price by the wholesale is $\$ 1.50$ per thousand. If we know how to use them, the worms in a meal chest may thus be worth many times the value of the meal, chest and all.

Directions in the bird books for raising meal worms are quite misleading, and in order to go to work intelligently we must learn the life story from egg to egg. The first fact to learn is that the insect is single brooded, i.e., it requires an entire season to complete its growth. The beetles may be found laying eggs from May until freezing weather in the fall. The early eggs will produce larvæ that are fullgrown by September or October of the same season, and 
larvæ from the late eggs do not attain their growth until about midsummer of the next season. A female beetle lays from twenty to fifty eggs. While practically any farinaceous material — corn meal, ground feed, cracker crumbs, bread crusts - is suitable, feeding experiments have proved that wheat, in some form or other, is preferred and yields the best specimens.

The easiest way to rear a supply is to imitate nature, i.e., make a heap of bran and shorts in some out-of-theway corner in the barn. Ground feed, corn meal, oatmeal, flour, bread crusts - any of these, discarded for fresher supplies - may be used. The beetles will find it and do all the rest. It is well to tuck into different parts of the pile raw potatoes or apples to supply water from time to time as they are eaten, and the whole should be covered with sacks or pieces of carpet. Woolen rags are called for in the usual directions, but the number of clothes moths that they may breed makes their use unadvisable, and cotton cloths or burlap seem to answer about as well. The only difficulties with this method are that other insects are apt to find the material and become a nuisance and that rats and mice, if they are allowed on the premises, may clevour practically the whole crop.

Perhaps a better way is to fill a tight box or earthen jar half full of the food material, put in scraps of old leather, cover with woolen cloths, and have a lid of wire screen. Put in a few hundred larvæ or beetles and leave undisturbed, except to insert a raw potato from time to time. If this be done about April, a good supply of larva will be obtained for use the following fall, winter, or spring. 
Where natural insect food is not obtainable a number of artificial bird foods are availablc, the chief of which is the so-called "mocking-bird food" of the bird stores. But if we bear in mind what has been said of variety, the use of this somewhat troublesome mixture is not a necessity. The people in Ireland, it is said, feed their pet birds chiefly on mashed potato; in Scotland, on oatmeal; in China, on rice. Bread and milk form a good staple food for young soft-billed birds. Vary this dict with berries, a few insects, the yolk of hard-boiled eggs, scrapings from raw beefsteak or finely chewed or minced cooked meat, and almost any bird of this class will thrive. Finely chewed nuts are also eaten with great relish and may be given with advantage once or twice a week.

These directions are given with the primary purpose of teaching chilclren enough to enable them to save fledgelings and wounded birds, tame them, and let them go when they are able to take care of themselves. If they remain tame, so that they will come at call, build their nests near by, and allow us to study their foods and habits at close range, they will be the most interesting pets in the neighborhood; and in this way practical domestication may be extended to many of our valuable wild birds.

A secondary purpose has to do with practical lessons upon bircl foocls. Numbers of birds have been shot in different parts of the country, and the contents of their stomachs have been analyzed to discover what the species feeds upon. This has resulted in acquisition of much valuable knowledge, which has stimulated interest in better laws and in the more efficient protection of bird life. But this method is quite imperfect and cannot be 
recommended for school use; while feeding tests with nestlings, conducted in the manner suggested for the toad, would open the eyes of children to the work birds perform in nature as no amount of book work could do. Toward the end of the spring term the fledgelings that the children are rescuing should be utilized for such study, and not infrequently a crippled bird that could not be

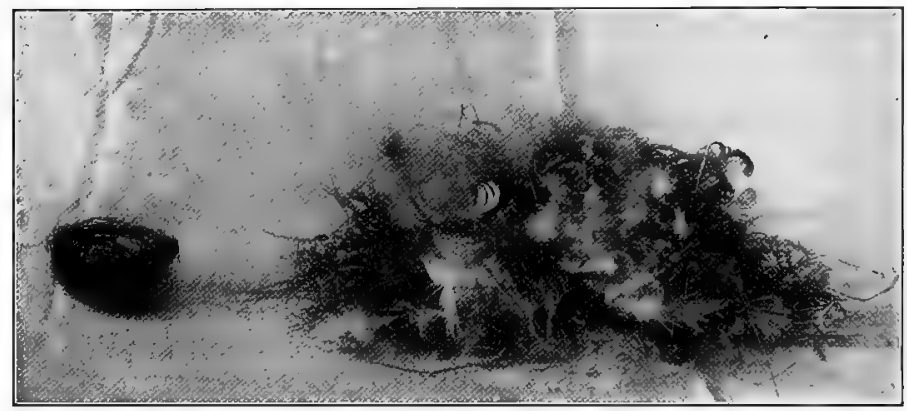

Fig. I42. A Contrast in HousekeEping

Nests of chipping sparrow and English sparrow

safely liberated may come into the possession of the school and may be kept for such tests. The usual objections to caged birds would not apply to such cases.

But, after all, the taming of a bird is the great lesson, - great chiefly for its influence upon the child. It is a lesson in gentleness, tact, and patience that cannot be excelled in the whole realm of nature study. If a child has once accomplished this feat, its civilizing influence may go with him as long as he lives.

Books about birds are now so numerous and so accessible to all that I hesitate to name any, since space forbids 
giving a complete list. A few hours spent in the public library with the different authors may spare the purse and save the shelves from a burden of books that will be opened but once. We may leave to specialists the treatises which deal chiefly with classification and museum methods of bird study. Happily, we have a goodly number of books that enter into the spirit of bird life. We will follow these and still bear in mind that the great book lies daily open before us in the bird life about our homes.

Natural history is taught in infant schools by pictures stuck up against walls, and such like mummery. A moment's notice of a redbreast pecking at a winter's hearth is worth it all. WiLliam WORDSWORTH.

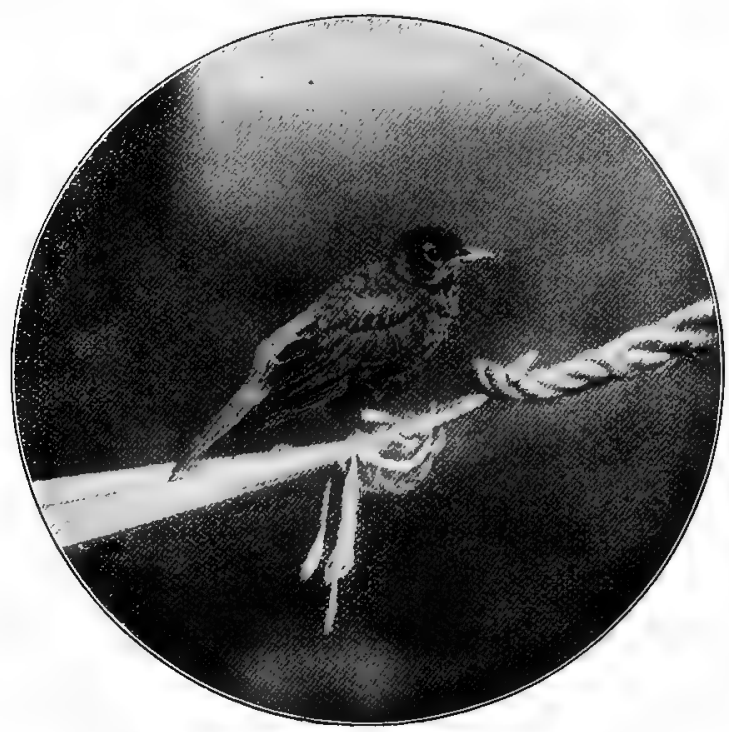




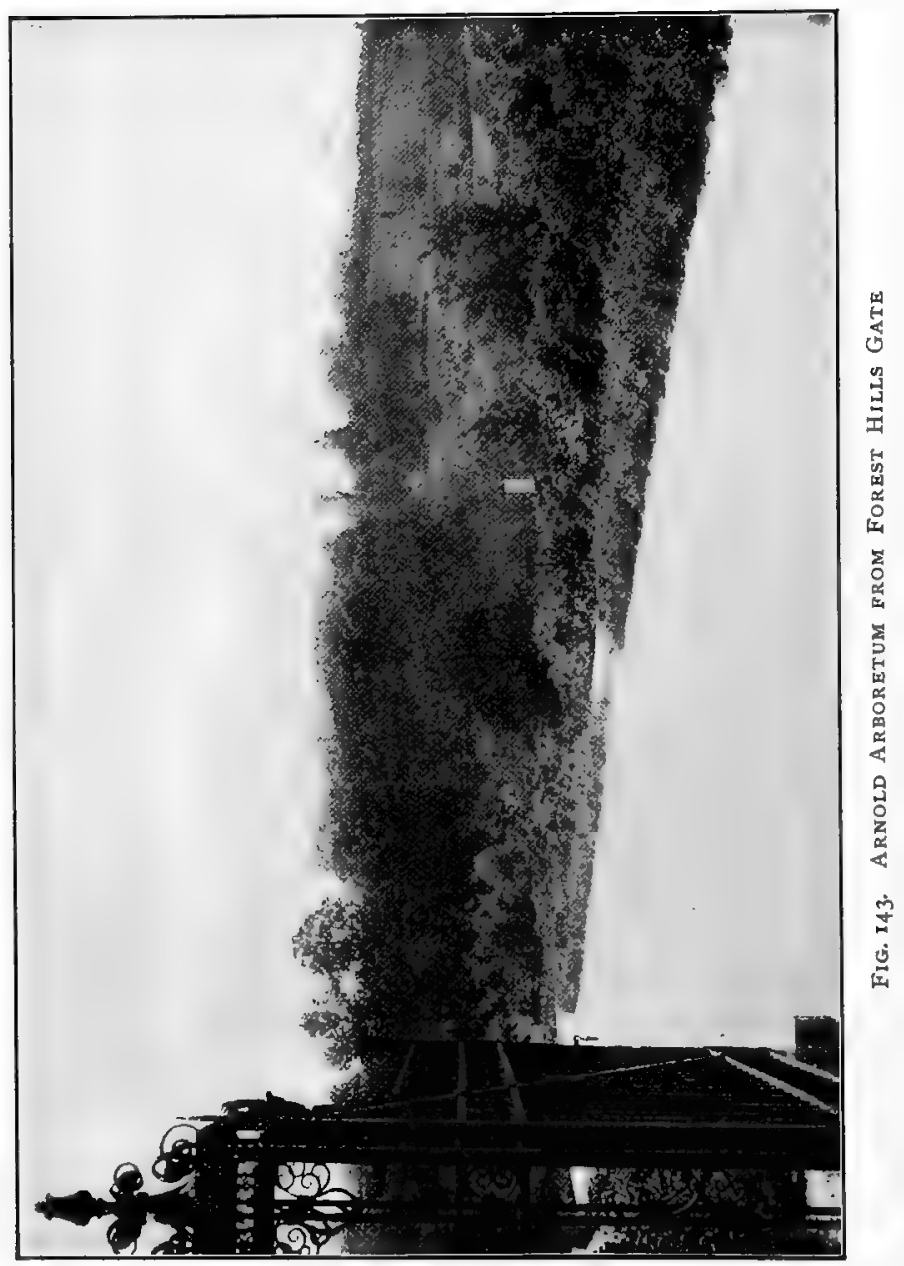




\title{
CHAPTER XXII
}

\section{ELEMENTARY FORESTRY}

\section{The Culture and Appreciation of Trees}

\author{
Who does his duty is a question \\ Too complex to be solved by me, \\ But he, I venture the suggestion, \\ Does part of his that plants a tree.
}

LOWELL.

To surround the home and schoolhouse and to shade the roadsides with trees is a worthy purpose about which to group our studies, and without some such aim what is learned about bark, leaves, and forms of tree tops one day may be forgotten the next. As with flowers the inner purpose is to develop an enduring interest, love, and appreciation of trees that shall make impossible their so common injury and abuse. To this end we must again have recourse to the fundamental principle of "doing."

Ask the pupils to write a description from memory of the trees about their homes, telling the clifferent kinds they know, giving the story of their planting, the rapidity of their growth, their present size, and other points of interest. For another writing lesson the pupils may sketch a plan giving the kinds of trees they would like to rear and plant about the schoolhouse. These exercises will serve to bring out what the children know about trees, and by giving some attention to the subject each year, according 
to the grade plan, we may teach a working knowledge of from twenty to forty important forest trees during the school course.

It has seemed to me that the key to the situation lies in a knowledge of the seeds of trees and methods of saving and germinating them. A tree seed in the act of sprouting is one of the inspiring things in nature. The possibilities contained in it, the size to which it may grow, the beauty it may develop, the long years it may live, the infinite numbers of seeds it may produce, all

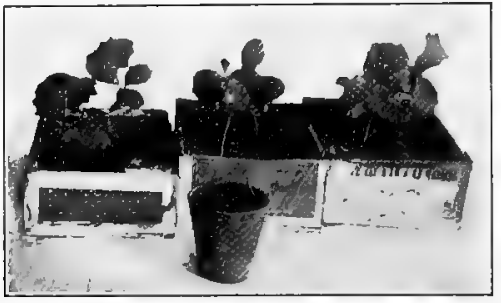

Fig. I44. Seedling Trees

Reared in a schoolroom stretch out into a vista before us. It is here, too, that we grasp the lever with which to do something worth while. Too much of our tree study is passive and selfish and lacking in the ideality and altruism of our grandfathers who planted the trees we now enjoy. A bright young man recently said to me: "I would have as soon thought of planting a gold mine as of planting a chestnut tree." And so we have "four boys to one chestnut." But why should this be so? What a tremendous force in nature we lay hold of if we have the faith to place a seed in the earth and give it a chance to grow! Centuries of sunshine and rain will do the rest.

Beginning, then, with the seeds let the children bring such as they can find to make a school collection of the kinds most desirable to plant in the neighborhood. 
Encourage them to notice when each species blossoms and ripens its seed. A calendar, like that suggested for the flowers, may be put on the blackboard as a stimulus and reward for diligent observation. Many trees have such inconspicuous flowers that the children may need some help, especially in the lower grades; and often the stamens and pistils are borne on separate flowers and sometimes on different trees. ${ }^{1}$

The next topic is methods of germinating tree seeds. When we relegate the discussions of "cotyledons," "plumules," and "radicals" to high-school or college botany we may utilize some of the wealth of tree seeds that fall on our streets and forests every year for truly elementary studies in germination, instead of confining the work to beans, peas, squashes, and corn. The first suggestions as to methods of planting may well be taken from the trees themselves. Encourage each child to observe and reason for himself and then write, or tell in the lower grades, how the tree plants its own seeds. This is a fine study. Each kind has a method of its own, but they all may be grouped for convenience as follows.

I. Trees that ripen their seeds in the spring. - Among these are the elms, soft maples, poplars, cottonwoods, and willows. They all scatter their seeds to the winds. The seeds are light, and when they reach the ground they are floated by the rains to low, moist places, - the banks of

1 My attention has been called to the fact that single nut trees, especially the chestnut, where they are not indigenous, fail to mature nuts. This is probably due to the necessity of cross-pollination. Thus, instead of planting a single tree, or single trees far apart, better results might be obtained by planting in groups. 
streams, the shores of ponds, the gutters of city streets, where they quickly germinate (except the red elm, which will not sprout until the following spring) and, if conditions remain favorable, produce vigorous seedlings the same season.

2. Nut seeds that ripen in the fall. - Oak acorns, chestnuts, black walnuts, butternuts, hickories, hazels, and lindens fall under their parent trees, and their rounded forms enable them to roll into holes or down the hillsides. The trees cover them with their leaves, and the winter snows bury them. The spring freshets carry many of them down the gullies and ravines and leave them buried in masses of dead leaves, leaf mould, and rubbish along their courses. This class of trees also, by their nutritious nuts, seeks the aid of animals in the dissemination of the seeds; the rows of nut trees along our stone walls show how well the squirrels, especially, have done their work. To this class may be added also the seeds of our cone-bearing trees, the pines, spruces, and larches, but they are largely disseminated by the winds.

3. Seeds in fleshy fruits, - Among these are the wild cherries, hawthorns, hackberries, plums, mulberries, dogwoods, and crab apples. The fruits of most of these roll into holes or down the streams with the nuts, but they also hire the birds to plant and scatter, and most of the trees of this class that we have were probably cared for in this way.

4. Dry seeds that ripen in the autumn. - The ashes, birches, hard maples, box elders, and ironwoods, like the soft maple and elm, trust their seeds to the winds and waters to disseminate and plant. 
5. Seeds borne in pods. - The locusts and coffee tree, the catalpa, the Juclas tree, and acacias have hard, dry seeds, difficult and slow to germinate, which they scatter to the winds.

Taking our primary suggestions from the trces themselves, we may next ask the children to observe, in case of certain trees in the neighborhood, about how many of their seeds produce trees. Is the small proportion due to failure in securing favorable conditions to germinate, or are the seedlings dried up or overgrown with weeds before they become strong enough to take care of themselves? We may answer this question in a general way by saying that the trees have done their best to secure the germination of the seeds, but that they are forced to depend largely on accidents of wind and water. These may take them to unsuitable places, may bury them too deep, or leave them exposed to dry up. What, then, may we do to assist the trees in their work? We may help them save their seeds, we may plant them under the most favorable conditions, and protect the seedlings until they are strong enough to take care of themselves.

Methods of saving tree seeds is a large subject, and I shall give only a few hints, in the hope that they may be helpful in making a beginning. ${ }^{1}$

The first fact to bear in mind is that most tree seeds lose their vitality rapidly and hence should be planted as soon as possible after ripening. Drying is the thing chiefly to be guarded against, especially with nuts, acorns, and similar seeds; these and fall-ripening seeds may best

1 For further instructions, see Forestry in Minnesota, Samuel B. Green, Delano, Minn., isg8. 
be planted as soon as ripe. If it be desired to keep them until the following spring, they should be mixed with moist sand and left out of doors through the winter. Small quantities may be covered with a flat stone or an overturned sod in a place where water is not likely to stand.

Seeds of fleshy fruits should be washed clean of pulp and planted in the fall, or they may be kept uncler stones or sods and planted in the spring. Many of these - the pits of cherries, plums, and peaches - germinate better if allowed to freeze while moist.

A number of the tree seeds are said to be "refractory" from the fact that they insist upon lying dormant one or two years before germinating. The locusts, redbud, thorn apples, red cedar, and lindens belong in this class. If seedlings do not appear the first year, keep the rows in the seed bed well marked and watch for them the following spring. Germination may be hastened with the leguminous seeds and the lindens by pouring boiling water over them just before planting. To germinate the red cedar soak the berries in strong lye for twenty-four hours, rub off the pulp, and then mix with moist sand and let them freeze during the winter. Even after this, they will probably not germinate until the sccond spring. Unless magnolia seeds be thoroughly cleansed of their gummy coverings, they will not germinate at all.

Seeds of coniferous trees should be gathered in the early fall, before the cones open. As soon as the cones dry they open and release the seeds. They should be mixed with $d r y$ sand and kept in a cold place until the following spring. 
After clirections for saving the seed, the next topics are naturally the seed bed and methods of planting.

For the school bed select a strip of ground about three feet wide, sheltered on the north and west by a hedge or fence. Make the soil mellow to a depth of from twelve to fifteen inches and enrich it with leaf mould or rotted sods. Sow the seeds in drills eight inches apart across the bed, quite thickly since many tree seeds are imperfect. When

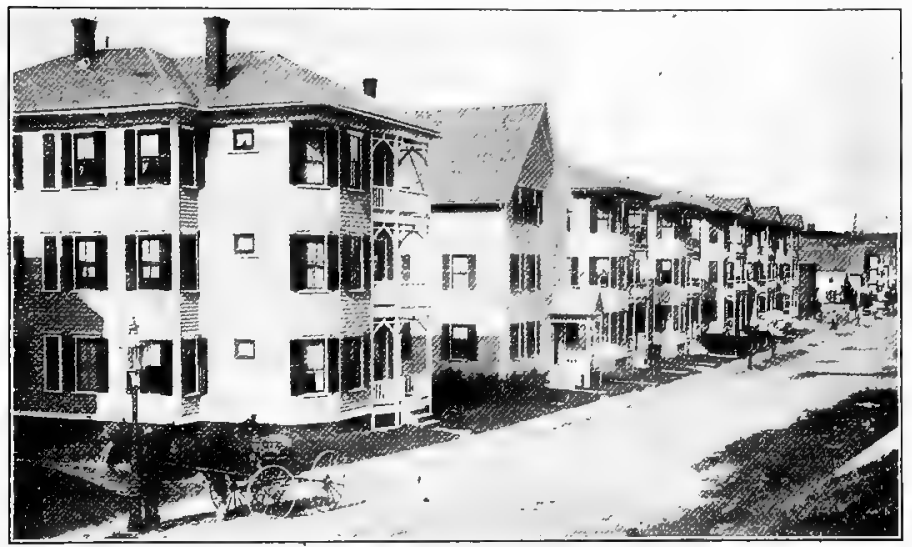

Fig. I45. A Treeless Street

they come up, thin to about an inch apart by removing the weaker seedlings after danger of damping off is past.

The depth to which the seeds are covered is a matter of great importance, more tree seeds being killed by too deep covering than in any other way. Elm seeds, for example, are unable to germinate if planted half an inch deep. A good general rule, as with many other seeds, is to cover them about their own diameter. The ground 


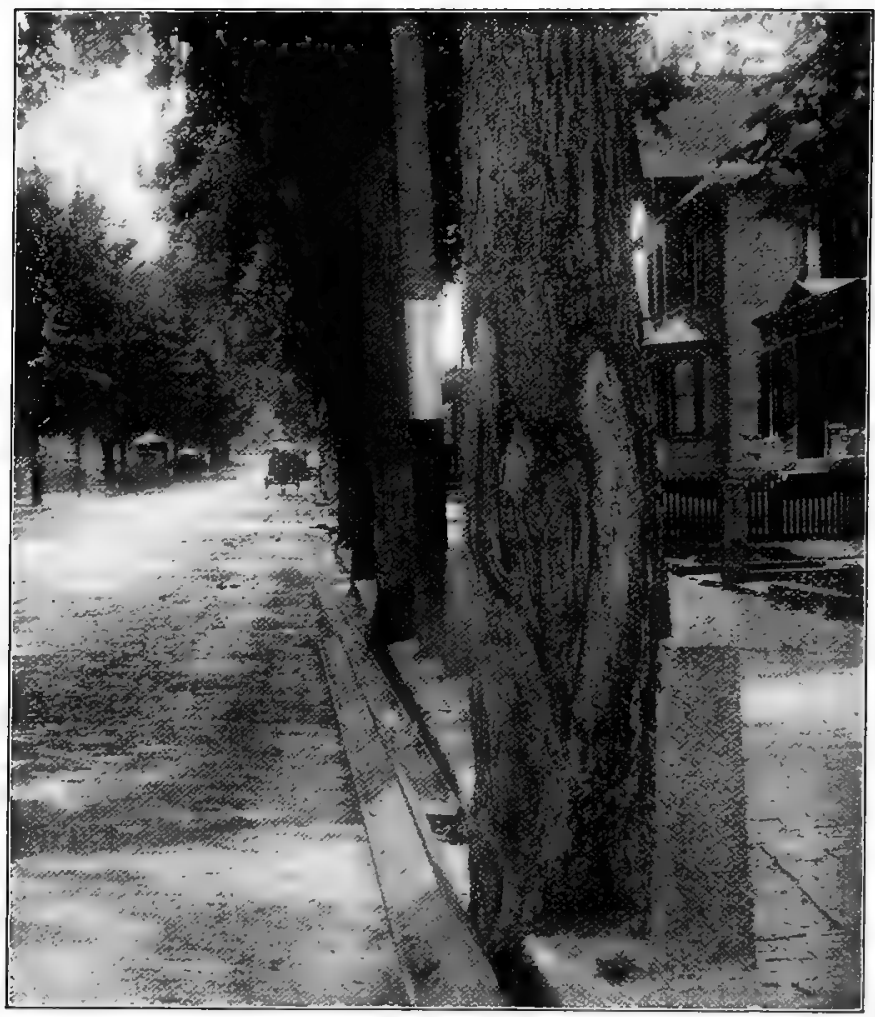

Fig. 146. Abused Street Trees

should be neither wet nor dry, but mellow, and after the seeds are planted it should be lightly rolled or packed and then well wet down. If the bed is likely to dry out quickly, it is well to sprinkle over it a thin layer of pine needles or sphagnum moss, but this should be drawn aside when the plants appear, to avoid mould and damping off. 
Most tree seedlings start in spots partially shaded by other trees, and, if possible, the bed should be located where it will be shaded in the afternoon. The two dangers to which the little trees are subject are drying and burning up in the sun, and damping off in the shade and wet. If natural shade be not at hand, a convenient screen may be made by nailing laths on a frame the width of a lath apart. Supported on little posts one or two feet above the bed, this will give half-shade.

Where land is not available the children may rear their trees in flowerpots or in winclow boxes, and the main iclea be attained, - that of planting and rearing trees from the seed.

The next topic is the treatment and care of trees. Are there trees enough on the streets? Ask the children to investigate the conditions prevailing in the locality, and let them write or tell how street and roadside trees, especially, may be protected from injury. Have them learn the city or town ordinance with reference to injury of shacle trees and the rules of the tree warden of their neighborhool. The chief object of these inquiries should be, not to threaten or suggest punishment in case they injure the trees, but to develop their ideas of the public values of trees for shade and beauty and make them active protectors of the trees in their own town or city. Let each member of the class examine one hundred roadside trees and state how many are horse-gnawed or barked by wagons, how many have tree guards around them, and what kinds are used. Do the tree guards add beauty to the street? These studies may be used to interest the public in the proper care of shade trees. 
Instead of inclosing the trees in guards, it has always seemed more fitting the crime if those who injure them were put into the guards for a while. Still, accidents are likely to happen, and cheaper and less conspicuous guards may be made with strong wire netting fastened around the trunk, as shown in Fig. 148. However, in my vari-

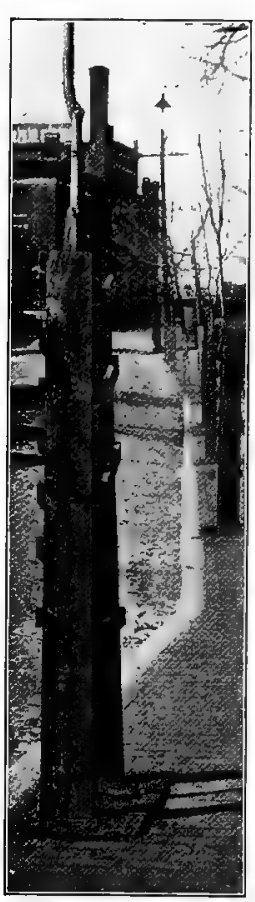

FIG. I47.

Tree Guards ous travels I have found at least one city where public sentiment adequately protects the shade trees of its beautiful streets. This city is Richmond, Indiana, and it may well stand as the ideal for less favored cities in this respect. Its wide streets, with their four rows of beautiful trees, without guards of any sort, and none of them injured, make its residential sections practically forest parks, shady and cool by day and a fairyland under the electric lights at night.

Nut trees and their planting and treatment should form a study well calculated to appeal to the children. Nuts are a

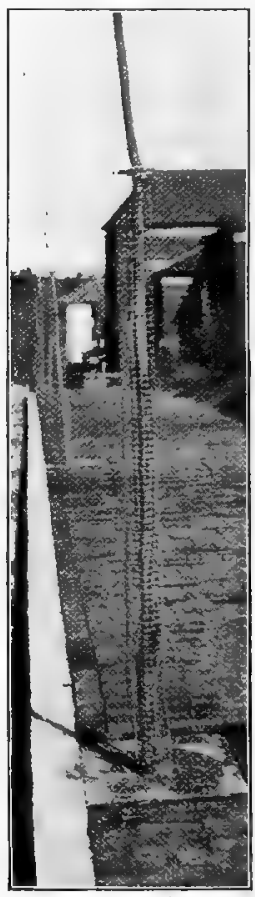

FIG. I48.

WIRE GUARDS

delicious and wholesome food for the fall and winter months, and nutting parties are outings with exercise and purpose in them. Are there nuts enough, and a good variety, for all the children to have a supply from 
October to May? If not, ask the class to explain why not. Let them ask their parents about the history of nut trees in the neighborhood to find out whether they haveincreased or decreased in number during their recollection. Let them ascertain, so far as possible, the causes for decrease in nut trees, if such has occurred, and encourage them to reason out the best ways by which these causes may be counteracted and nut trees increased.

In the writer's experience abuse of nut trees, and of those who own them, is the chief reason why we do not have as many as we could wish. Is that true in the neighborhood? The

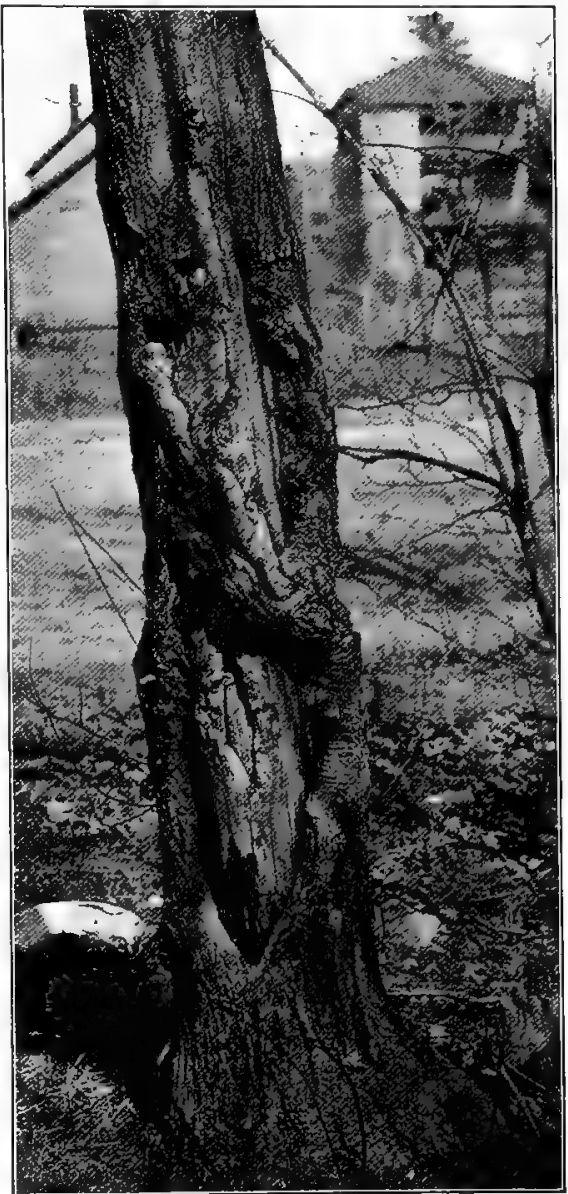

Fig. I49. Thanks for bearing Chestnuts (Photograph by the author) 
accompanying photographs tell the story. It is certainly a brutal recompense when a tree has borne its load of nuts to stone it or pound it with iron sledge hammers, to throw ropes over it and tear off its branches. So it has come to pass that farmers in the neighborhood of towns, at least, cannot raise chestnut timber, because the trees are bruised, glowth is stunted, and at the wounded places decay develops, which soon renders the whole tree worthless. Thus nut trees must be ruled

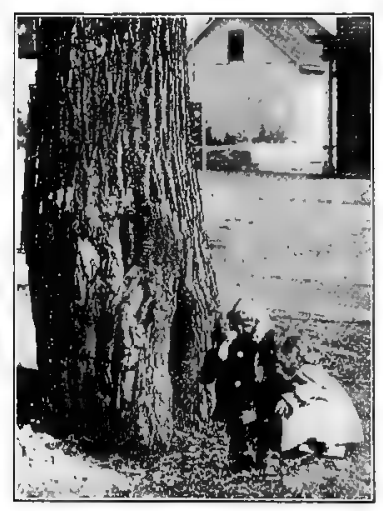

Fig. 15o. Marks of Ancient ABuse

This chestnut tree will soon have to be cut to avoid danger to near-by houses out from roadside planting, simply on account of thoughtless abuse, and year by year fine bearing trees are cut down on account of the clubbing and stoning and nuisance that rages around them while the nuts are ripening. If this senseless process goes on, many districts will be wholly reduced to deserts as far as their nut trees are concerned, as some already have been. Our only hope is again on the positive side. Set the chilclren to planting nuts. Cannot they do what the squirrels have done so well? It is a

little thing to plant a nut in a sheltered place by the edge of a flat stone along a roaclside wall, but there is altruism and ideality in the act, and the child who has done it will begin to love and appreciate the trees as never before. 
A generous portion of the propagation bed may be devoted to nut raising, and the seedlings may be used in lessons on grafting with the best varieties and, later, be transplanted into favorable locations. We must, then, study what the best varieties are. Nut culture is a subject that has been neglected in this country, and, as a consequence, we annually import about $\$ 4,000,000$ worth of nuts and then do not have enough to go around. Little is known as to best varieties of any kind of native nut. No two trees of any given kind produce nuts exactly alike, in size, shape, flavor, and other qualities. Which is the best chestnut, hickory nut, black walnut, butternut tree in the neighborhood? A nut show in the school, similar to the fruit and flower exhibitions spoken of in previous chapters, will prove an instructive bit of nature study and may serve to awaken interest in the possibilities of their rational culture. ${ }^{1}$

1 Nut Culture in the United States, Department of Agriculture, Washington, 1896 , should be referred to in this connection. See also "The Forest Nursery: Collection of Tree Seeds and Propagation of Seedlings," by George B. Sudworth, Bulletin No. 29, United States Department of Agriculture, Washington, 1900. 


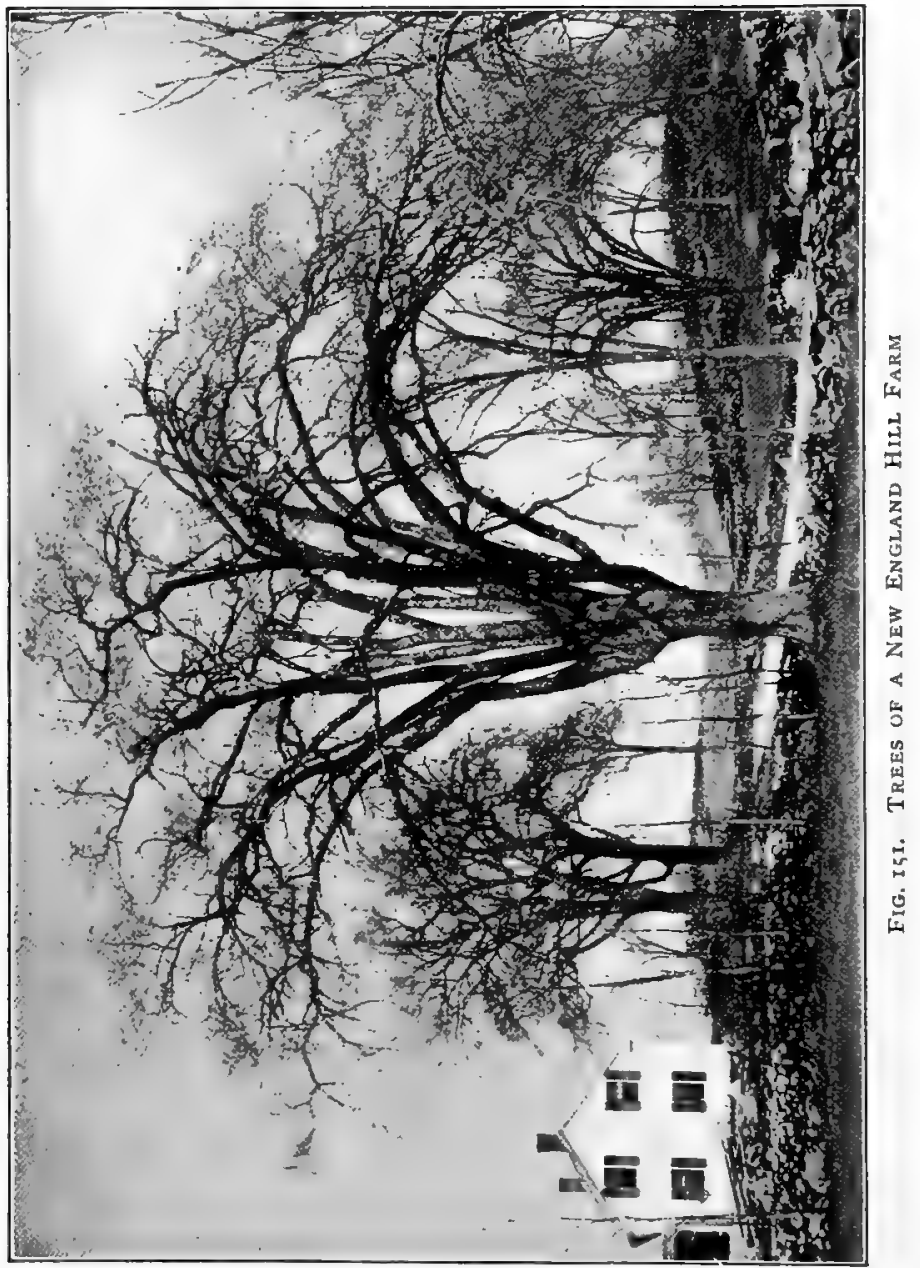




\section{CHAPTER XXIII}

\section{ELEMENTARY FORESTRY (Continued)}

Influences of Forests on Soll Formation, Surface Waters, and on Climate; Forest Fires

Ask the class to observe freshly cut banks, railroad cuts, quarries, excavations, washouts, etc., in forest land to learn two things, not sufficiently appreciated in this country: (I) formation of humus or leaf mould; (2) distribution of roots below the surface. With a sharp tool, when the ground is wet, cut out a square foot of the "forest floor," - leaves, dead sticks, leaf mould, - down to solid earth; mount in a box with at least one side glass for study and for experiments to be described below. Beneath this covering the soil is black for some distance, - "surface soil" or "loam." Take a pound or so of this also for study and experiment, and, to compare with it, secure a similar specimen of loam from a field long under cultivation. Compare the two as to color, appearance, and consistency. Which seems to be "richest"? Which would be best to plant seeds in?

What makes the loam black and rich? Suppose we take an equal amount, say roo grams (one of the children can get it weighed at the nearest drug store, if there are no scales in the school), of leaf mould, of loam from the forest and of soil from the field. 'We know that 
wood, leaves, and all kinds of vegetable matters burn up readily; and we know that coal is vegetable matter that has been buried in the earth. We must be sure

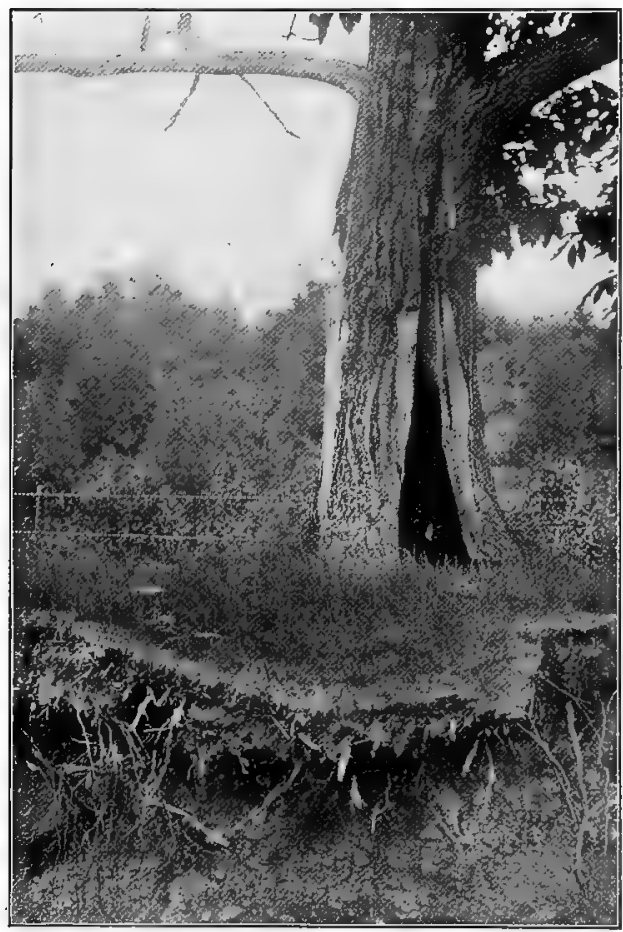

Fig. I52. How a Chestnut Tree holds Soll TOGETHER that the samples are dry before we weigh them; then we will see how much of them we can burn away. To do this we will place the sample on a clean piece of tin or sheet iron and heat it red hot over a gas stove or over a bed of coals in the furnace, and, after we are sure no more can be burned away, we will weigh again. We saw that the leaf mould burned brightly and left a light mass of ashes on the tin. These weighed 22 grams, which means that leaf mould is 78 per cent vegetable matter. The black loam from the woods left more earth and ashes behind. This remainder weighed 89 grams, 
which proves that forest loam is I I per cent vegetable matter. The soil from the barren field did not burn and, on weighing, we found 99 grams, giving only I per cent organic matter. Put the burned samples away in dry bottles, of clear glass and similar size and shape, for the school collection. These arevaluable specimens that tell a Iong story. Compare again as to color and composition, so far as this can be

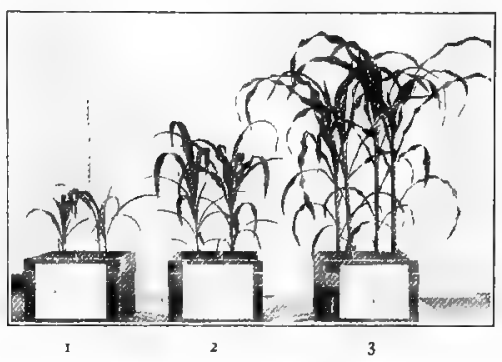

Fig. 153. Relation of Humus to GROWTH OF CORN I, clay subsoil ; 2, same with fertilizer; 3, same, wich humus.

(Photograph by C. L. Goodrich) done by the unaided eye and by feeling with the fingers. Are the samples not more alike than before they were burned?

Have a few of the class fill a series of flowerpots or boxes with different kinds of soil, as shown in Fig. I 53, and in them plant corn or other seeds. This work may be varied in regard to soils and seeds planted. The plants should stand together in one of the schoolroom windows, where they may receive equal light and care. Observe and possibly measure the growth from time to time.

We have thus found that vegetable matter is the chief constituent that makes the soil black and rich; and we know that this comes from falling leaves and twigs and from decaying roots of the forest. How long does it take the trees to make rich loam? In the main, this is a question that the children will not find time to answer. They 
may find freshly cut stumps near some of the sections of the soil that they have been studying, and, by counting the annual rings, they may arrive at some idea as to how long the forest has been at its work. Their fathers may also tell them something about the woods in the neighborhood. The following answer (from Green, p. 36) is the most

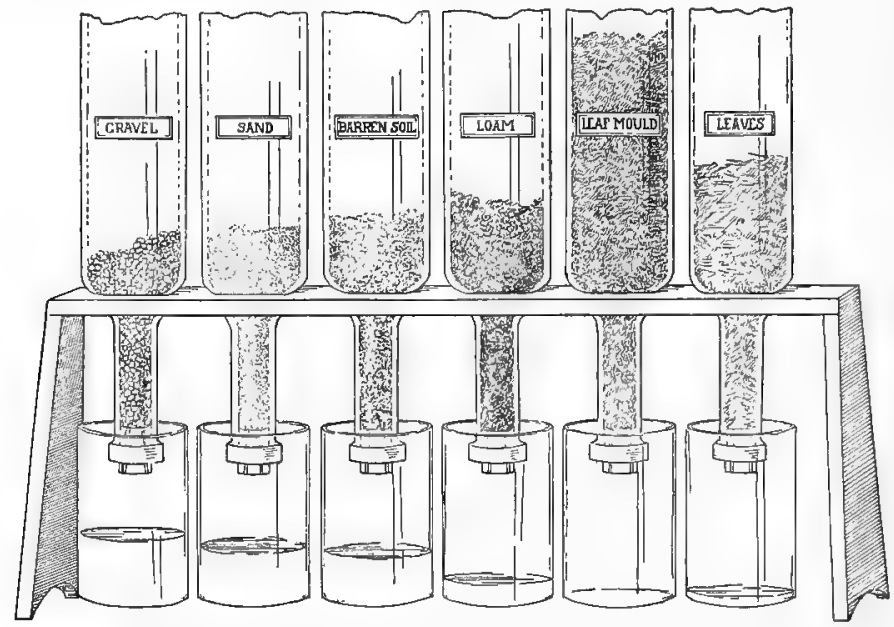

Fig. I54. Apparatus for testing Retention of Water by DIFFERENT SOILS

The figure represents roo grams each of gravel, sand, barren soil, loam, and leaf mould, and 25 grums of leaves

definite that I have been able to find. He says: "It has been estimated that after a sandy soil in New England is so exhausted that it will produce nothing but red mosses it may be renewed to its pristine vigor and productiveness by the growth of trees on it for thirty years."

Let us next see what relations soils of different kinds bear to the water that falls upon them. These questions 
are of interest in connection with all the foregoing work in gardening and the cultivation of plants, for water, in connection with rich soil, is the great essential to plant growth.

Let us take again Ioo grams of gravel, sand, soil from the barren field, rich loam from the woods, leaf mould, and 25 grams of dry pulverized leaves. Knock the bottoms out of six tall, slender bottles (the common olive-oil bottles are well adapted for this experiment, or large glass tubes may be used). Dry before weighing and put the samples each into its bottle, inverted, with the neck stoppered with a notched cork. Shake the different materials so that they lie evenly and compactly, and then from a measuring glass pour in water slowly, so that the whole mass is wet, and see how much water each will absorb before the water begins to run out at the bottom. Or we may pour into each a known amount, say 100 cubic centimeters, and then measure all that runs through. The quantity absorbed is known as capillary water or film moisture. It is this that constitutes the water supply for the roots of plants in the soil. Fertility, the power of the soil to support plants, thus depends largely upon its power to retain water.

In the experiment represented in Fig. I 54 the results were as follows :

\begin{tabular}{|c|c|c|c|}
\hline \multirow{3}{*}{$\begin{array}{l}\text { Gravel } \\
\text { Sand }\end{array}$} & \multirow{3}{*}{$\begin{array}{c}\text { Grams } \\
\text { I00 }\end{array}$} & \multirow{2}{*}{\multicolumn{2}{|c|}{$\begin{array}{l}\text { ABsorbed } \\
8.5 \text { grams }\end{array}$}} \\
\hline & & & \\
\hline & & 36 & "6 \\
\hline Barren Soil & 100 & 40 & " \\
\hline Rich Loam & 100 & 69 & “ \\
\hline Leaf Mould & 100 & 210 & “ \\
\hline Leaves & 25 & I 20 & “ \\
\hline
\end{tabular}

To make the result still clearer we may take a piece of punk, or partially decayed wood, dry thoroughly and 
cut down until it weighs Ioo grams; soak in water and weigh again. We thus find that the vegetable matter in the soil is one of the chief elements that enables it to soak up water.

From the data gained in the above experiments encourage the children to estimate the influence of the forest floor on soaking up and retaining the water that falls in the form of rain or snow upon it.

Next, ask the class to describe the springs and streams in the neighborhood. This will form a valuable coördination with their geography lessons, and they should draw maps showing the woods, springs, and streams. Ask them especially to note whother the springs are muddy. Are the streams of the neighborhood muddy? Are they muddy all the time or only after heavy rains?

With a series of tumblers of water, into which a little gravel, sancl, loam, and leaf mould have been stirred, study the way different materials settle to the bottom. How does this illustrate the way we find such materials deposited in sand banks along a stream? Some part of the district may afford a good example. Let the children, from time to time, bring in bottles of water skimmed from the surface of the stream and have them study what the stream is doing, - what it is carrying away. Wood and leaves, stubble and cornstalks, with now and then an acorn or a nut - everything that floats - is going down stream. Examine the banks of the stream, where often tons of this rich material have been lołged during a freshet. Lead the class to reason from these observations and experiments that the best part of the soil is being washed away. 
In connection with geography lessons trace the journcy of the soil that is being carried from the district, until it reaches the ocean. Ilas the teacher or have members of the class visitcrl any of the cities along the route and

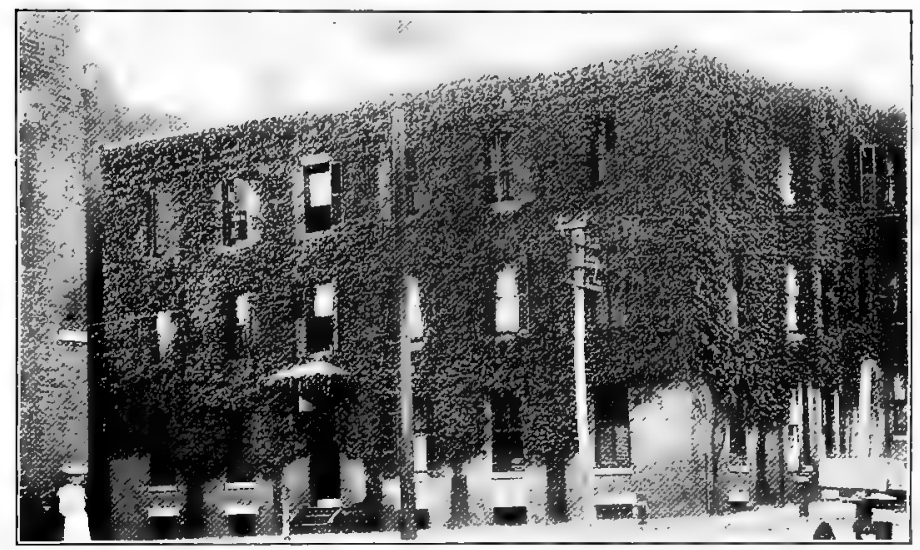

Fig. I55. Tenement Houses made Beautieul

(Photograph by Louis P. Nash, Holyoke, Mass.)

observed the working of dredges in decpening the channels and cleaning the mud out of the harbors? Many millions of dollars are expended annually in river and harbor improvements, much of which might be saved by keeping the soil at home.

Now follow this material back into the fields and hills, where the forest has been recently cleared away, and where the ground is bare and has been washing badly. Show how, after the lighter constituents of the soil have been washed away, the sand and gravel are taken up and carried over the fertile ground below. Compare the way 
the soil washes in the woods, in grass land, and where the ground is bare.

Next let us study how we can keep the soil at home and make the water clear as crystal. Pour a tumbler of muddy water into a filter and catch the water in a clean glass as it comes through. In one of the bottles with the bottom out make a filter of leaf mould, pack it well and wash the dust out of it, if necessary, and then see how clear muddy water may be made by passing through it. Can we make it as clear as the water from the spring or well? Why not? How deep is the filter through which the spring water passes? Do we need a very thick filter, if it is fine enough?

Find a pond in the neighborhood with an inlet and outlet; a temporary one will serve the purpose if no permanent ponds are available. Study the water that flows in and compare it with that which flows out. Refer back to the experiments of settling muddy water in the tumblers, and call attention to the fact that the lighter particles remain floating a long time and may even leave the pond by the outlet. There are other ways of keeping the water pure, which will be taken up when we study aquaria, but these two, filtering and settling, are the chief methods with which every plan for purification of surface waters must begin.

The water supply to a district is another topic closely related to the foregoing. Does the water run off in torrents after a rain and when the snows melt in the spring? Do the springs and wells go dry and the streams fail in a long period of drought? Are the springs and streams generally lower than they used to be? If this 
is so, why is it? What do the children know about the way the snow melts in the spring? Where does it melt first? Where can they find the last snow bank in the spring? Bring out the fact that the snow melts slowly in the woods, allowing the water to soak into the ground.

We have already seen that the leaf mould, with its mass of tangled roots, and the loam of the forest floor absorb water like a huge sponge and give it up slowly to the springs below and to the leaves of the trees above. It has been found that only from one-half to one-quarter as much water evaporates from forest land as from land under cultivation, and to gain a hint as to one of the factors that cause this we may make some further experiments upon soil of different kinds in the tumblers.

Let the class arrange and label eight tumblers of the same size and shape and, having the materials dry, fill to within one-half inch of top with the following materials : gravel, No. I ; sand, No. 2 ; barren soil, No. 3 ; rich loam, Nos. 4 and 5 ; about one inch each of gravel, sand, and loam in order, the loam on top, No. 6 ; two inches of rich loam with one inch of finely pulverized leaf mould on top, No. 7 ; water, No. 8. Weigh each and, unless it is desired to study fractions, bring them all up to even grams to start with by adding a little of the appropriate dry material. Then pour into each, except the last, an equal amount of water, say roo cubic centimeters. Place the tumblers somewhere in the schoolroom where the sun will not shine on them and every day at the same time weigh them all carefully to see how much water has evaporated from each. Set down the weighings on the 
blackboard in the following form. If desired, the children may copy them into their notebooks.

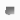

WEIGHT

\begin{tabular}{|c|c|c|c|c|c|c|c|}
\hline No. & $\begin{array}{l}\text { First } \\
\text { Day }\end{array}$ & $\begin{array}{c}\text { SECOND } \\
\text { DAY }\end{array}$ & $\begin{array}{c}\text { THIRD } \\
\text { DAY }\end{array}$ & $\begin{array}{c}\text { Fourth } \\
\text { DAY }\end{array}$ & $\begin{array}{c}\text { Fifth } \\
\text { Day }\end{array}$ & $\begin{array}{c}\text { TENTH } \\
\text { DAY }\end{array}$ & $\begin{array}{c}\text { TWENTI- } \\
\text { ETH DAY, } \\
\text { ETC. }\end{array}$ \\
\hline $\begin{array}{l}\text { I, Gravel } \\
\text { 2, Sand } \\
\text { 3, Soil } \\
\text { 4, Loam } \\
\text { 5, Loam } \\
\text { 6, G.S.L. } \\
\text { 7, L.Lf.-m. } \\
\text { 8, Nater }\end{array}$ & & & & & & & \\
\hline
\end{tabular}

With No. 5, keep the top, to a depth of about half an inch, loose and fine by stirring. ${ }^{1}$

The infuences of trees on weather and climate are topics

1 These observations may be repeated in various ways that will readily suggest themselves to the teacher. The two main facts that the children should get, are, first, that loam and leaf mould protect the water in the soil from drying up; and, second, that a covering of fine dry dust serves this purpose most effectually. They should thus learn, as Professor Bailey puts it, how to water their gardens with a rake instead of with a watering pot. It would also be well, in clayey districts, to have a third tumbler of loam and stir it thoroughly, after adding the water, to show the effect of working the soil while zet; it will then dry in hard lumps.

In this connection, too, it is well to repeat the common experiment of wetting two spots on the blackboard and fanning one to show how much more rapidly it dries. The trees thus prevent the winds from drying out the water in the soil.

Shade is another important infuence that trees exert. If possible, to the above eight add three tumblers filled respectively with gravel, sand, and loam and set in the sunniest window of the schoolroom. This will demonstrate, aside from the influence of forests, the value of planting gardens so that the ground may be well shaded in districts where drought is common. 
of great interest, but the problems are so large that the children cannot do much practical work with them. Cooi shade, however, is appreciated by all in hot weather, and two thermometers, one hung in theshade of a tree, the other in the open sunshine, will tell an interesting story. Protect two thermometers with a bit of paper and bury the bulbs an inch in the ground, one in the sun, the other in the shade. If we do this about three o'clock on a warm day in June, it will show how hot the unprotected soil becomes. Let as many of the children as have thermometers in their homes take a careful reading at exactly 12.30 P.M., on some hot sunny day, compare

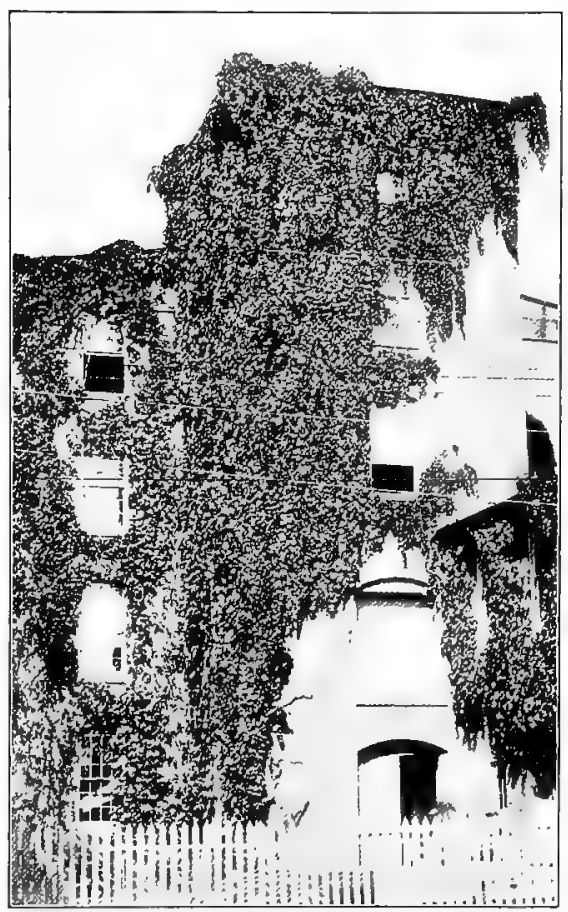

FIG. I56. A FACTORX COVERED WITH WOODBINE

(Photograph by Louis P. Nash)

the temperatures, and try to explain any differences that may have been observed. This should be done on a clear, hot day. 
If the school possesses a hygrometer, an instrument for measuring moisture in the air, it will be interesting to test the relative humidity in woods or well-planted districts and in the hottest and driest place available, the business portion of a city, for example. Without instruments this cifference is often appreciated in the moist, "soft" air of the forest.

It has been estimated that forest fires cause a loss of not less than $\$ 30,000,000$ annually in this country. Ask the class to collect all the data possible as to such fires in the neighborhood. We have seen that not only may the trees be destroyed, but the leaf mould and even the loam, representing the work of the trees in enriching the soil for many years, may be burned away. If practicable, make an excursion to some tract that has been recently burned over and study on the ground the damage to timber and soil that has resulted. Inquire particularly into the causes of such fires in the neighborhood and consider the means of prevention; and, finally, obtain a copy of the law against setting forest fires in your state and discuss its provisions with the class.

Forest Resources. - As a national industry, forestry stands second only to agriculture in number of people and amount of capital employed and in value of product. In connection with language lessons develop all that the children know about the uses of wood and the adaptation of different kinds to various purposes. A part of the work in manual training may well be devoted to making a collection of native woods to show cross, slab, and quartercut sections, in natural state and finished in various ways. Study in this connection the market price of different 
woods. What determines price? According to the price of lumber, what is the value of different trees in the neighborhood? How long has it taken for them to grow? What is the difference in price between clear lumber and knotty lumber? How may we grow clear lumber?

It has been estimated that we have 500,000,000 acres in growing forest, and that 35 cubic feet of wood are annually produced per acre. Annual consumption of wood, according to Professor Fernow, is probably double the amount produced. Inferences from these facts are obvious.

Interesting geography lessons may be made by asking the children to draw in their maps the ranges, as given in - Sudworth's Check List, of the trees included in their grade plan.

For additional information on the topics of this chapter, consult :

George B. SuDworth. "Check List of the Forest Trees of the United States," Bulletin No. 17 . This contains the scientific and common names of 495 species and gives the geographical range of each. Washington, I 898 .

E. B. Fernow. "Suggestions to Lumbermen of the United States in Behalf of a more Rational Forest Management," Circular No. ro.

E. B. Fernow. "Facts and Figures regarding our Forest Resources briefly stated," Circular No. $I X$.

E. B. FERNOW. "Forest-Fire Legislation in the United States," Circular No. 13.

E. B. FER Now. "Forestry for Farmers." Washington, 1805. (Reprint from Yearbook, I894.)

N. H. Egleston. "Arbor Day: Its History and Observance." Washington, 1896 .

For all the above, address United States Department of Agriculture, Washington, D.C. 


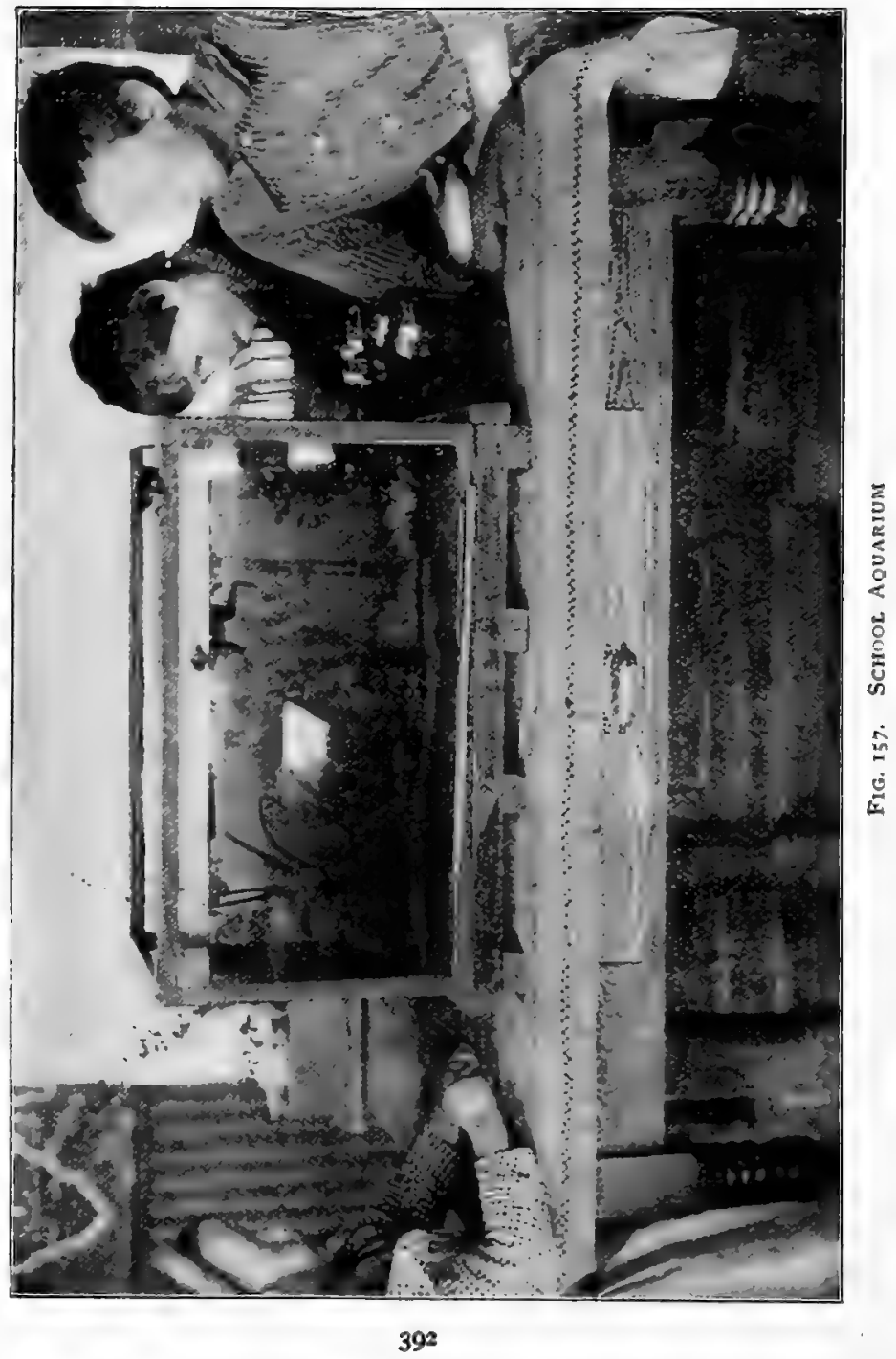




\section{CHAPTER XXIV}

\section{AQUARIA \\ Their Construction and Management}

No one piece of nature-study apparatus is capable of serving so many and so various uses as an aquarium. It may be used wet or dry; filled with water it becomes the means of practical acquaintance with all kinds of aquatic life, both plant and animal; managed as a vivarium, or terrarium, it makes a fine insect-breeding case, a fernery, a place for a collection of living mosses, the home of frogs, tree frogs, turtles, salamanders, snakes, slugs, and land snails. With one end arranged for water and the other for land, and filled with mosses and ferns, pitcher plants, and sundews, it may be at once a paradise for all kinds of things, both aquatic and terrestrial. Filled with earth, it may be used to germinate seeds in. By planting them against the glass and darkening with a black cloth we may study "root and all" in its natural environment, observe the root systems of various plants, and make all sorts of interesting experiments. If we wish, we may plant a hill of potatoes ; and we must certainly plant against the glass all sorts of seeds of our forest, fruit, and nut trees.

Every schoolroom should have at least two good-sized aquaria for general purposes, and then if each child could have a little one, on his desk or in a window, for his own use, there would be none too many. We now furnish books in abundance, but here is a book of fascinating continued 
stories which a child could read, one after the other, in the reality of nature itself for the entire eight or nine years of his primary and grammar-school life.

Aquaria are ordinarily too expensive (or so considered) to be used in the way suggested. The usual directions for making them, with wooden frames, result in aquaria that are always cracking and leaking and hence are unsatisfactory. and generally discouraging. Our first topic is, thus, the best way to make an aquarium.

Instead of wood for the frame, which will never stop warping, swelling, and shrinking, and is wholly discarded by all makers of aquaria, we will use angle tin, and the only other materials needed are glass, of the desired size, aquarium cement, and solder with soldering fluid or resin. A few tools will be required, most or all of which may be borrowed for the occasion, - a wheel glass cutter, a pair of timner's snips, a pair of pinchers, a soldering iron, and, last and most important of all, a carpenter's square. A small anvil or block of iron with square corners and a light hammer are convenient to square up the corners nicely, but this may be done with the pinchers. The angle tin, solder, and soldering fluid ${ }^{1}$ we will get at the tinner's. For the glass, we will ask the children to bring all the broken window panes and spoiled photographic negatives that they can find.

The temptation of beginners is to make the aquarium too large. It is then hard to fill, hard to keep clean, hard to move, and is apt to be an elephant in the way. A good size for general purposes is I 3 inches deep, 15 inches long,

1 Soldering fluid is made by dissolving pieces of zinc in hydrochloric acid to saturation. 
and 8 inches wide. Where a larger aquarium is desired, which may be partitioned off with panes of glass to keep a variety of specimens, a good size is 12 (or 15 ) inches deep, 24 inches long, and 8 (or 9) inches wide. As it is often desirable to use this as a terrarium for turtles, frogs,

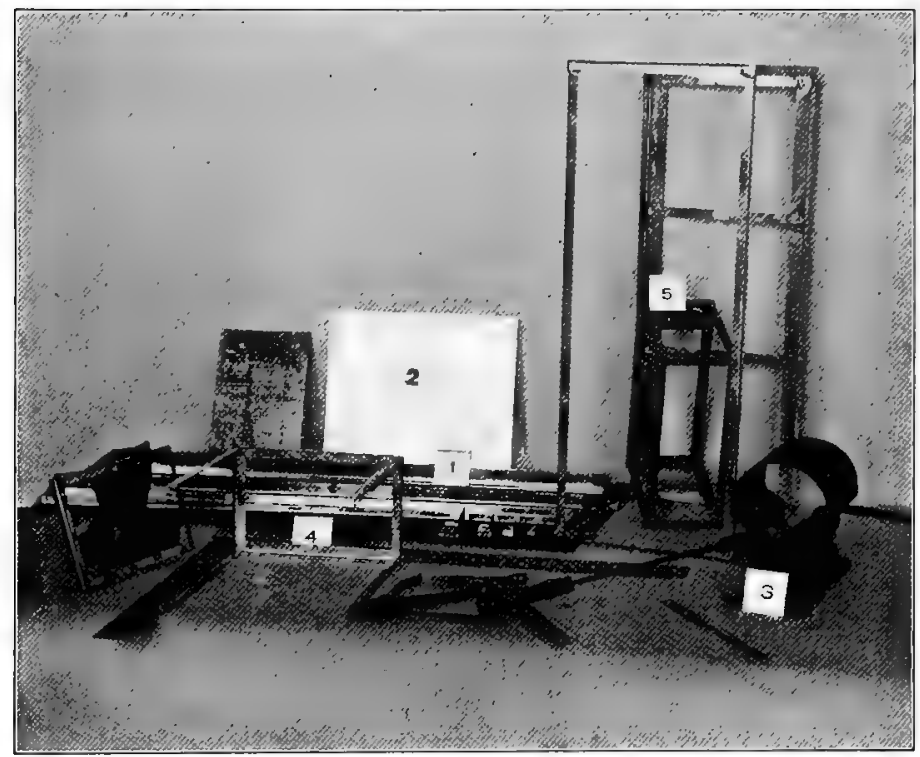

Fig. 158. Making an Aquarium I, angle tin ; 2, glass; 3 , soldering outfit ; 4, frame in process of construction; 5 , completed frames.

toads, or plants, when floor space is a desideratum, it may be well to make at least one 12 inches wide. For individual pupils, or even for school use, it is surprising how many interesting studies may be carried on with smaller aquaria, made from waste negatives $8 \times 10,7 \times 9$, or even $5 \times 7$, having them 4 or 5 inches wide. In fact, 
these little aquaria are so convenient that they will be used much oftener than the larger ones for definite experiments, like germination of seeds, rearing insects, feeding tests with toads, frogs, and salamanders, purification of water by tadpoles, fresh-water clams, mosquito

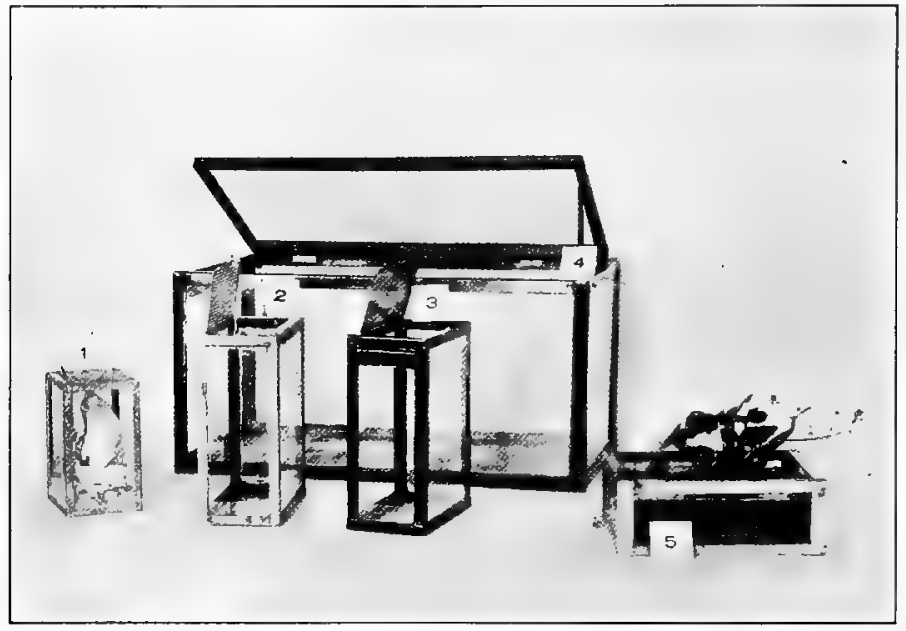

Fig. 159. Forms AND SIzES OF AQUARIA

$\boldsymbol{I}, 5 \times 7 \times 4$, in which meal worms are being reared; $2,8 \times 10 \times 4 ; 3$, same, with flytrap attachment; $4,12 \times 24 \times 12 ; 5,8 \times 10 \times 4$, made flat and set up for toads' eggs.

larvæ, etc. They are useful at every season and easily changed from one kind of work to another.

Suppose we have decided on $10 \times 8 \times 5$, the size shown in course of construction in Fig. 158 , and have our glass cut square to these dimensions. We go to a tinner's and ask him for two strips of $\frac{3}{8}$-inch, "three-cross" angle tin the length of the sheet, which is 28 inches, and four pieces $10 \frac{1}{4}$ inches long. These should be made 
of "three-cross" tin by cutting strips $\frac{6}{8}$ inch wide and folding to a right angle along the center. We must allow $\frac{3}{8}$ inch for thickness of cement and interference of the glass at the upright corners; so that we will now cut the long pieces halfway in two with the snips, i.e., in as far as the angle, at exactly $8 \frac{3}{8}, 13 \frac{6}{8}, 22 \frac{1}{8}$, and $27 \frac{4}{8}$ inches, cutting off the end at the last mark. We thus have the top and bottom of our frame each in one piece. We next bend them to a rectangular figure, squaring the corners neatly, and, holding the open corner inside the square, solder this joint. We now have the top and bottom of our frame. Taking the four vertical corner pieces, we solder them over the corners, holding each carefully in the square while we solcler, and the frame is done. With tools and materials at hand, it should take about ten minutes to make the small frame. If we do not wish to have the children learn to solder, ${ }^{1}$ or cannot get the tools, the tinner will do this in a few minutes.

If we wish a cover to keep insects, frogs, toads, and even fishes from jumping out, we solder two small brass hinges to the frame. We may use for the cover perforated zinc or tin, folded over one-quarter of an inch all around to strengthen the edges, or wire screen in a wooden frame. The perforated metal makes a neat cover, with hinges soldered to one edge and a handle ring to the other. To hold it shut it is well to solder a little ring to

1 Soldering is a good exercise in patience; the secret of getting a smooth joint is to heat the iron properly and to hold it still long enough and to move it slowly enough to melt the solder thoroughly. The iron will then leave the surface perfectiy smooth, without wrinkles or points that will be likely to break the glass. 
snap over the edge of the frame, as shown in Fig. I60. If a handle is desired, solder wire eyes into the middle of each end of the frame. The bale should be made of stiff galvanized wire, bent at right angles, with the drop just

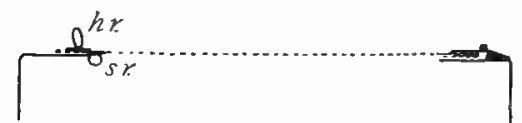

Fig. 160. Cover of AQUarium s.r., snap ring; h.r., handle ring. long enough to let it fall neatly along one corner of the frame.

To set the glass lay aquarium cement evenly in the bottom of the frame and press the bottom glass into place; lay the sides in the same manner, and finally the ends. Then, very carefully, for this is the point where some glass is likely to break, spring in some limber green twigs to press the glass gently against the frame and hold it in place while the cement hardens. Cut off all superfluous cement and then smooth neatly along the angles and seams, inside and out, and set away to dry. After a week it is ready to fill with water.

Larger sizes may be made, and at least the bottom of the largest size should be made, of double-thick glass. As in any case the glass is likely to be warped and bent, we should select plane pieces if possible, but if curved a little, the convex surface should be placed inside. For the larger sizes we naturally use wider angle tin. The table below represents my own experience in this matter. Length, depth, and width are given in order.

For aquaria $5 \times 7 \times 4$ to $8 \times$ Io $\times 5$ use $\frac{3}{3}$-inch angle tin for frame.

$$
\begin{aligned}
& \text { " " } 10 \times 12 \times 6 \text { " } \frac{1}{2} \text { " " " " " } \\
& \text { " "I } 5 \times 12 \times 8 \text { to } 18 \times 13 \times 9 \text { " } \frac{3}{4} \text { " " " " " } \\
& \text { "* } 20 \times 12 \times 9 \text { to } 24 \times 13 \times 12\left\{\begin{array}{l}
\text { use either I-inch angle tin for } \\
\text { frame or } 1 \text { inch around bot- } \\
\text { tom and } \frac{8}{4} \text {-inch for the rest. }
\end{array}\right.
\end{aligned}
$$


For larger sizes it is safe to say that angle iron or aluminium bronze, either cast in a single piece or riveted at the corners, would be preferable.

The corners of all sizes larger than $8 \times 10^{\circ} \times 5$, around the bottom and up the vertical angles, should be laid as represented in cross-section in Fig. I6I, with a prism of cement in the angle, covered by a narrow strip of glass. This greatly strengthens the joint and protects the water from the cement. ${ }^{1}$

A good aquarium cement, for either fresh or salt water, is made by mixing dry ten parts each, by measure, of fine, dry, white sand, plaster of Paris, and litharge, and one part powdered resin. Mix as required, to a stiff putty with boiled linseed oil. (This must be warranted free from any trace of adulteration with fish oil, and it is commonly necessary to buy raw oil of a practical painter, who should know that it is pure, and boil it for a few minutes, to drive off the water in the raw oil.) The simplest and best aquarium cement, the formula of which has been given me recently by the United States Fish Commission, is made as follows: Stir together dry, by weight, eight parts putty (dry whiting), one part red lead, and one part litharge. Mix, as wanted for usc,

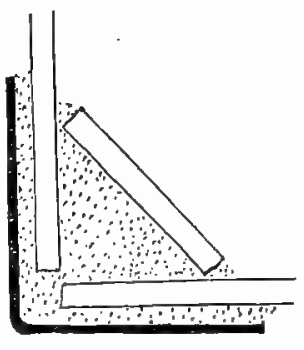

Fig. 16r. SECTION OF CORNER OF AQUARIUM with pure raw linseed oil, to consistency of stiff putty.

1 Although not necessary, I generally put one or two coats of copal, or spar varnish, around the angles on the insicle. No aquarium has leaked when this has been done; and if a leak occurs, it is necessary only to dry very thoroughly and varnish on the inside around the angles. 
How to set up or fill the aquarium for general purposes is the next topic. First put in about two inches of sand, washed until a stream of water runs off clear; then, with the sand only moist, set the plants about the corners, making furrows in the sand in different directions and laying the roots in them; finally, arrange pebbles, shells, and larger stones about the bottom where they will keep the plants in place. Next pour in the water up to

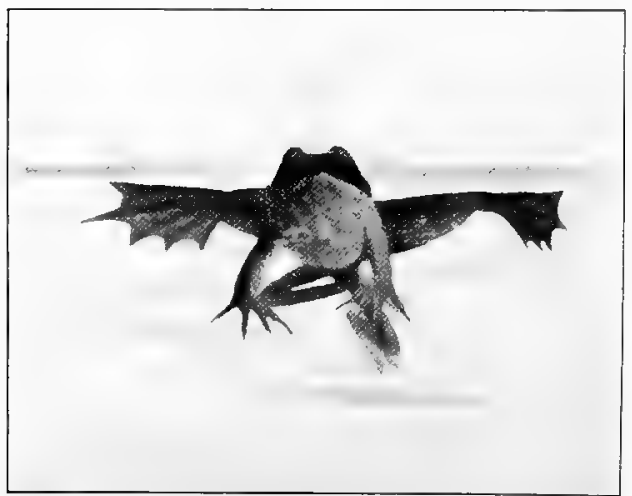

Fig. I62. A Frog withi Six Legs

A curiosity for the aquarium within an inch of the top, holding the hand or a piece of thin board so as to break the force of the stream, and avoid washing the plants loose. Finally, put in a freshwater clam or two, some snails, a few taclpoles (if the fishes will allow of it), to keep the water clean, and, after a day or two, such fishes - not more than two or three - as it is desired to study. Overcrowding is the common temptation to be resisted. Allow one gallon of water to each fish three inches long, and where enough water plants are present to oxygenate the aquarium, the fishes will show by their actions, quiet movements, and breathing that they are comfortable. If they come to the surface and gasp for air, 
we may know that the water is not properly oxygenated, and we must take out some of the animal life or put in more plants, or do both. Children will be much more interested in the plants and animals that they have collected for their aquaria themselves; and for other reasons we should use chiefly the native life of our ponds and streams.

A large aquarium should be permanently located before it is filled. The best place is near a light window where the sun shines but a few hours during the clay, and then it must be placed so that most of the time it may be shaded from direct sunlight. It is generally stated that an aquarium should stand where the sun will not shine directly on it, but the plants are then apt to grow weak; hence it is desirable, and should be possible, to admit sunlight without moving the aquarium. However, a more serious difficulty in properly locating the aquarium is that of too much light. A pond receives light only from above, and even there the water is generally the clearest and the plants freest from overgrowths of slimes in shady nooks along the shore. We must study nature closely and try to imitate the conditions that produce the best results in the ponds of the neighborhood. The growth on the glass and plants of green or brown algæ, often in slimy masses that fill the water, indicates too much light. Shade well for a time and put in tadpoles and snails to feed upon the algæ. While difficult enough to make it interesting, it is a valuable study, - that of balancing the life and managing the light in an aquarium so that the water will remain clear and sweet; and the knowledge thus gained will be found applicable to the conditions of park waters and ponds in general. 
How often does the water require changing? This is the question often asked by those who wish to start an aquarium. The answer is: "Not once a year, if the animals and plants and light are properly balanced and regulated." In doing this it is best to use the plants and animals that live in still water, in ponds and quiet pools, rather than those characteristic of the running streams. Aquaria with running water are more difficult to manage and are expensive in use of water. They are, moreover, a constant menace as to flooding the building, and cannot be recommended for school use.

What causes the water to become cloudy or milky? This is the next troublesome question, and with fifty chilclren all anxious to feed the'fishes something, it would seem that every school aquarium must be in this condition all the time. But onc of the chief uses of an aquarium is to make the children careful and thoughtful, and as experience has shown, they readily learn that giving more food than the fishes and other animals will eat clean, generally before it sinks to the bottom, is the quickest way to make the water foul and, possibly, to kill their pets. We shall learn more of this when we study about bacteria in the water. Fishes, and aquatic animals in gencral, should not be fed oftener than once a day, and then only so much as will be eaten clean. If mistakes are made in their eagerness to feed bountifully, the children who do it should be asked to remove all surplus food with a siphon or dipping tube before it has had time to decay.

What animals can be safely kept together in the aquarium is another frequent question. The general rule of keeping predaceous species by themselves, except while 
we are making definite feeding tests, is the best one to follow. The vegetable feeders, or those that eat only animals not larger than worms and insects, may be kept together. If we are not certain what a new specimen may do, it is best to partition off one end of the aquarium for it while we study its foods and habits. This may be done by forcing a pane of glass into the sand below and wedging it at the top with bits of cork. Goldfishes and other varieties of carp, shiners, dace and all kinds of suckers, darts, orfs, frog and toad tadpoles, young newts, and salamanders may be kept together. Bass, perch, sunfish, trout, pickerel and pike, pouts and eels, sticklebacks and paradise fishes, turtles, water snakes, large salamanders and frogs, leeches, water beetles and dragonfly larvæ must generally be kept by themselves. Clams, snails, and tadpoles form the scavenger brigade for every well-ordered aquarium.

A few simple pieces of apparatus will aid greatly in management of the aquaria. A shallow dip net is indispensable in catching specimens. It may be made according to directions for the insect net, except that it should not be deeper than about the diameter of the ring. A small rubber scraper will probably be needed to keep the slimes off the glass until animal scavengers and light can be properly regulated. A clipping tube, i.e., a piece of glass tubing, about fifteen inches long and a little less than one-half inch in diameter, with nicely fused ends, will be used daily. A piece of half-inch rubber tubing about two and one-half feet long may serve as a siphon to draw off the sediment from the bottom from time to time. 


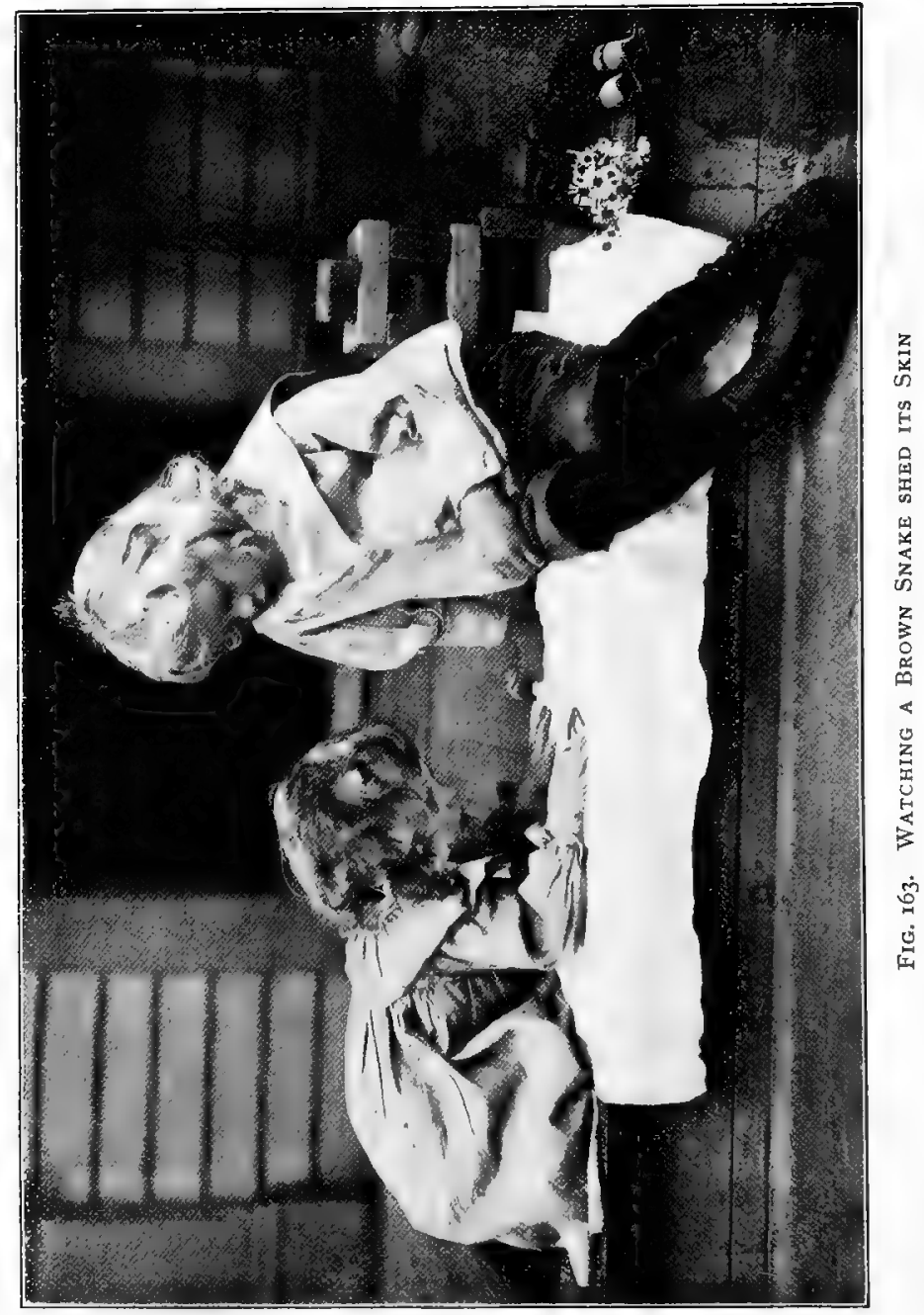




\section{CHAPTER XXV}

\section{MISCELLANEOUS ANIMALS}

A NUMBer of animals, too important to omit from nature-study courses but not fitting in with those already treated, may be grouped together in this chapter. Each may be taken up as occasion presents itself during the year and season indicated in the grade plan.

The Bat. - This is an interesting but misunderstood animal. Not infrequently one drops out of a ventilator into a schoolroom or is brought in as a curiosity, too often dead, by one of the pupils. Suppose we have a live bat, let us see what it will eat. It may open its mouth and chatter in a most threatening manner, but while we should not put our fingers in the way of its sharp teeth, it can be handled in a towel or handkerchief. It may be tamed, generally in a few minutes, by gentle treatment and feeding, so that it will take insects and lick drops of water from the fingers. It is only necessary, when it opens its mouth to defend itself, to drop in a fly, meal worm, spider, or even a bit of raw meat, possibly at first on the end of a toothpick or hat pin. It will soon understand, and then feeding tests may be made with whatever bugs or insects the children can find. ${ }^{1}$

1 The writer has not been able to find any insects that a hungry bat refuses to eat; but we must be a little careful not to overfeed; on one occasion he fed a bat 243 flies, but, while it apparently ate the last one with relish, it died a few minutes afterwards. 
Whether or not we are able to do any of this practical work, we should strive to gain definite knowledge of the rôle these animals play in nature. So few of our birds are truly nocturnal, and so many of our worst insect pests - the codling moth, tent-caterpillar moths, the whitemarked tussock moth, owlet moths, parents of the cutworms, June beetles, mosquitoes, and a host of others -

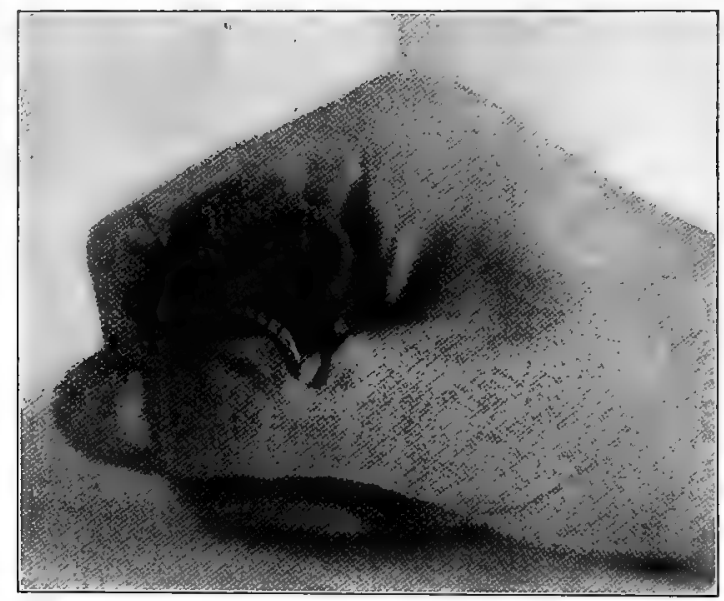

FIG. I64. FEEDING A BAT

have taken refuge in the darkness, that we need the bat as the night police of our gardens. They should be accorded much the same protection as our most valuable insectivorous birds. Koebele describes bats flitting about an infested apple tree catching codling moths on the wing and even snapping them from the leaves, and the writer has repeatedly fed these moths and their larvæ to bats in confinement. 
An instructive problem may be made as follows: If a bat catch one female codling moth every night from May 20 to July I, how many bushels of apples may be saved, allowing that each moth lay fifty eggs on as many apples and that there are two hundred apples to the bushel? Ans. 273 bushels.

An unwarranted fear and dislike of bats seems to be general in this country. They are said to fly into people's hair, necessitating cutting it off, if long, in order to get them out. The writer has had bats for months at a time given full liberty of the house, but has never known of such an accident. Even if one should get into the hair, it would do no harm and could be easily removed if the person were not frightened. It is also said that they carry vermin, especially bedbugs, but I have examined dozens and never found a single specimen; and, further, I have found that they actually eat bedbugs with apparent relish. Bats are known to live in caves, hollow trees, and the crevices about barns and houses, often in colonies of scores or even hundreds. The fact that such numbers are able to find subsistence is sufficient proof that a family of bats is a valuable acquisition to a farm or garden.

Squirrels. - These are graceful pets and, next to the birds, form the most animated life of parks and woodlands. It is one of our crimes against nature that they have been so nearly exterminated in many sections. What the children can do to bring them back is the question for nature study. Their food consists chiefly of nuts and acorns, which fall in such abundance that we should not begrudge them the few they need, and they undoubtedly plant enough to repay the trees for those they eat.

Perhaps one of the pupils has a tame squirrel that he can bring to school for a few days. If so, we shall be able to study its foods and habits in such wise as to enable the children to form a genuine acquaintance with it. If there 
are squirrels or chipmunks about the schoolhouse, it is generally an easy matter to tame them by leaving nuts or bits of bread in some convenient crotch, and. soon they will be coming regularly to share the children's lunch.

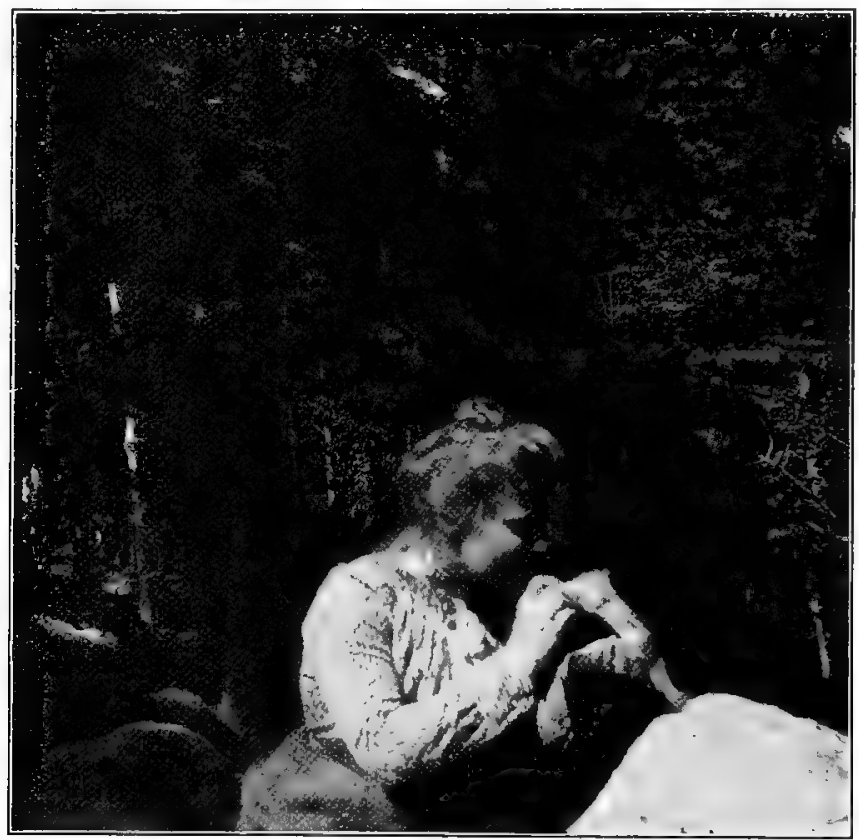

Fig. I65. TAMing a ChipMUnk

(Photograph by Miss Jessie Gelston Whiting)

As to the different species, a few facts should be developed in connection with rearing them, especially in towns and city parks.

The common red squirrel, or chickaree, is the living impersonation of mischief. $\mathrm{He}$ will cut every pear from 
a tree, - to eat the seeds of a few perhaps, - apparently for the mere fun of seeing them drop. This alone makes it inadvisable to have him around. But a more serious crime of which this little rogue has been convicted consists in robbing nests and eating birds' eggs and young bircls; so, in general, the fewer red squirrels we have the better for our birds. Have any of the children observed this for themselves?

Our gray squirrel is commonly accredited with neither of these injurious traits and, together with the large fox squirrel, may be freely encouraged to come and live with us. In a single instance, among many that the writer could cite, in which gray squirrels became too numerous, some damage was done to fruit; but this may have been due to lack of food or, more probably, to lack of water. It would be advisable, at least, to bear these points in mind before passing final judgment. That both food and water in plenty have no influence in reducing the mischievous propensities of at least one red squirrel the writer has had abundant proof.

The flying squirrel, though it is nocturnal in its habits, is one of the most interesting of the group and is easily domesticated.

Rats and mice are too common intruders to be omitted from a course in nature study. We sometimes find them recommended for pets, and they both have some interesting traits; but they have long been recognized as hostes humani generis, enemies of the human race, and the plain truth may as well be taught. By the skillful and persistent use of traps and poisons these pests may easily be exterminated. No less than this should be aimed at, as they 
multiply with such rapidity, and when this is accomplished there will be one less argument for keeping cats.

Several other common animals may be studied as occasion offers, among them, woodchucks, muskrats, minks, otters, skunks, moles, shrews, and weasels. For the character of the latter the description of Kagax given by Long in Wilderness Ways is admirable. To his graphic account

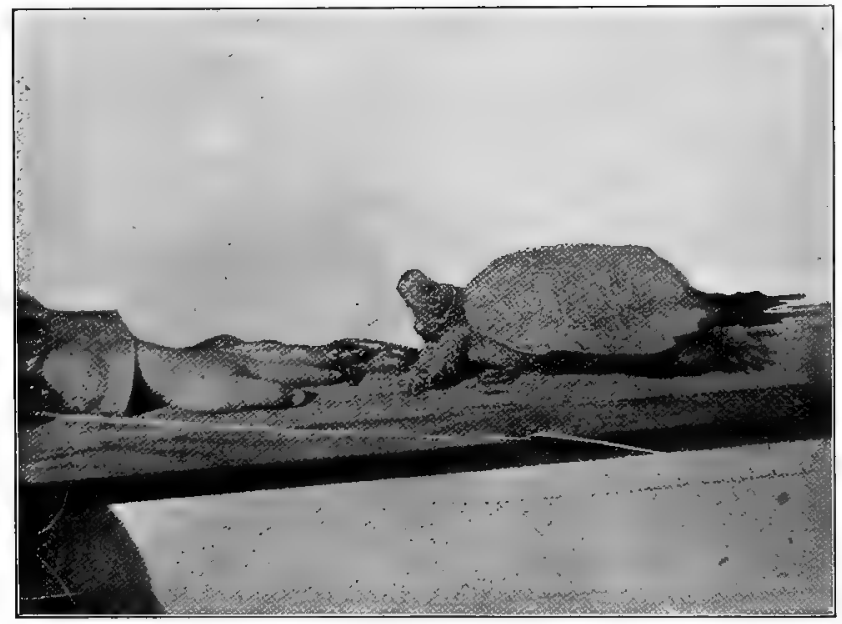

Fig. i66. TAming A Wood Turthe

the writer may add that one morning, when a boy, he found six sheep dead near an old straw stack in a field. The only marks of violence in each case were four little cuts behind the ear, where an artery had been severed. The straw stack was burned during the day, and two old weasels, with a litter of half-grown young, were found and killed.

Turtles. - These may be brought in by the pupils and acquaintance made with a few of the commoner species. 
Most of them are aquatic or semi-aquatic and may be kept in the aquarium. Their habit of crawling out on rocks and logs to sun themselves should be borne in mind in setting up the aquarium for them. As some are terrestrial, a good rule to follow is the one already given for other animals: Study the environment in which they may be found and make that of the aquarium, or vivarium, as nearly like it as possible. Little seems to be known about the food of even the commonest turtles. The aquatic forms - snapping turtles, painted and spotted turtles, and the soft-shelled turtles - are carnivorous and feed mainly on fishes, although they often take young ducks and goslings. The fact, as every fisher boy knows to his chagrin, that they are often caught with the baited hook demonstrates their fondness for earthworms, and this is the food upon which they may be most easily kept in confinement. The box and wood turtles subsist chiefly on worms, slugs, and insects, but also eat succulent leaves. They should be given lettuce or cabbage, together with earthworms, and if some child has a tame turtle, interesting feecling tests may be made. Young turtles will be found to eat mosquito wrigglers with great avidity.

Not the least interesting things about these queer animals are their nests and eggs. What boy or girl will volunteer to find some turtles' eggs and bring them to school? They may be found, often in great numbers, buried in the sandy banks of ponds or streams. It is said that young turtles as soon as hatched crawl toward the nearest water. Test whether this is true.

Lizards. - These are different from salamanders, which they resemble in form, in having the skin covered with 
overlapping scales. Very few are found farther north than Pennsylvania, being chiefly tropical or subtropical in distribution. They are insectivorous, and in the Southern States, where they abound, valuable feeding tests may be made as suggested for toads, frogs, and bircls. The manner of catching insects with their long tongues is interesting, as are also the rapid changes of color of several species.

Snakes. - Many of the common species are among our most beautiful animals. A strange fascination seems to attach to them, which is almost certain to result in their intrusion into the nature-study course whether the teacher wishes it or not. The fear of anything is a heavy burden to carry through life. The lurking fear of something that we are jikely to mect in our daily walks in the fields or woods may spoil much of our enjoyment in nature or, at least, hem us in on every side. If for no other reason than to cast out this fear, we may introduce a reasonable study of these animals.

While some may be inclined to consider the fear of snakes hereditary, it may quite as well be explained as a matter of suggestion. The fact, to which my own experience attests in many instances, that it can be thrown off by a moment's exercise of the will, and also the fact that children who have never been frightened by the fears of others may show no traces of it, render this explanation the more reasonable. My own children, for example, have always handled and played with our harmless little snakes as freely as with kittens. A single concrete instance will make my meaning clear. I was demonstrating our common green snake, when one of the members of the class asked if I would hold it while she touched it. After touching it she asked if she could take it in her hands. A year or two afterwards she referred to the circumstance and said that she had never since felt the least aversion for snakes but had thoroughly enjoyed studying them. She expressed her thanks for being 
helped over her "last nature fear." Was not the momentary effort well worth the while?

This study is the more to be recommencled because so little is known about the food and habits of even our commonest species. Any child who tames a snake and finds out what it eats is quite likely to discover facts that may extend the range of knowledge. This in itself is a keen incentive. Are they valuable or harmful animals? We cannot tell until we learn their foods, and this, according to the Washington authorities, "is not known for a single species of North American snake."

We know, in general, that all snakes feed upon living animals, which they swallow whole, and very often alive. Garter snakes feed largely on toads and frogs; water snakes are known to destroy great numbers of fishes; and the black snake has the well-earned reputation of killing birds and robbing their nests. Whether they do enough good to offset this harm, or whether they do any good at all, remains to be discovered by patient observation and study. As far as the evidence goes at present, however, it seems that the fewer we have the better.

No such harmful traits can be attributed to our green, or grass, snake or to the little brown snakes, since they probably feed exclusively upon worms and insects. As they are gentle and harmless, never attempting to bite or to defend themselves, they are the best forms with which to begin acquaintance. They may be readily found under flat stones. In June or July they deposit their eggs under the stones where they live. The eggs are white, irregularly oblong, few in number, and about the siza of sparrows' eggs; the shells are thin and papery, and a little later, when we hold them up to the light, we may see the young snakes coiled up inside.

Fishes. - The original plan of this book included a chapter on the common fresh-water food and game fishes. As it is, a few of the more important are distributed 
through the grade plan, with the understanding that the pupils shall study them alive in their aquaria, and in the ponds and streams by the general methods suggested for frogs and salamanders. Feeding tests will be found especially interesting. Ask the pupils particularly to observe the spawning seasons and habits of the different species. These matters should be as thoroughly learned as the nesting seasons of the birds, in order that we may give fishes the universal protection which may result in restocking our barren waters.

Botflies. - A family of flies which do not belong properly with household or garden insects, may be introduced here. The botflies are large brownish hairy flies, found buzzing about horses and cattle. There are a number of species. The ox bot, or heel fly, lays its eggs on the hair about the fetlocks. The eggs are licked off and soon hatch in the animal's mouth or stomach. The larva bore their way through the tissues and finally reach the skin, which they perforate, probably to obtain air. After attaining their growth they crawl out, drop to the ground, burrow under the surface, and transform into pupæ. The following spring they emerge to repeat the story. The elk in Fig. 167 is seen to be afflicted with bots.

Other botflies lay their eggs in the nostrils of animals, and the larva develop in the cavities of the head. They attack sheep especially and cause not only much loss to the farmers, but great suffering to the animals as well. Several kinds attack our native wild herbivora. The elk in Fig. I 68 was thus killed by "grubs in the head." A kingbird on every mullein stalk in the pasture would possibly be the best remedy for these pests. 
Ants. - No insects, excepting the honeybees, have proved more interesting to study than the ants. Turn over a flat stone any time after the middle of May and you are almost certain to find a colony of ants. As the stone is lifted, if the day be warm, you will see little piles of whitish oblong bodies, - the pupa, — commonly caller

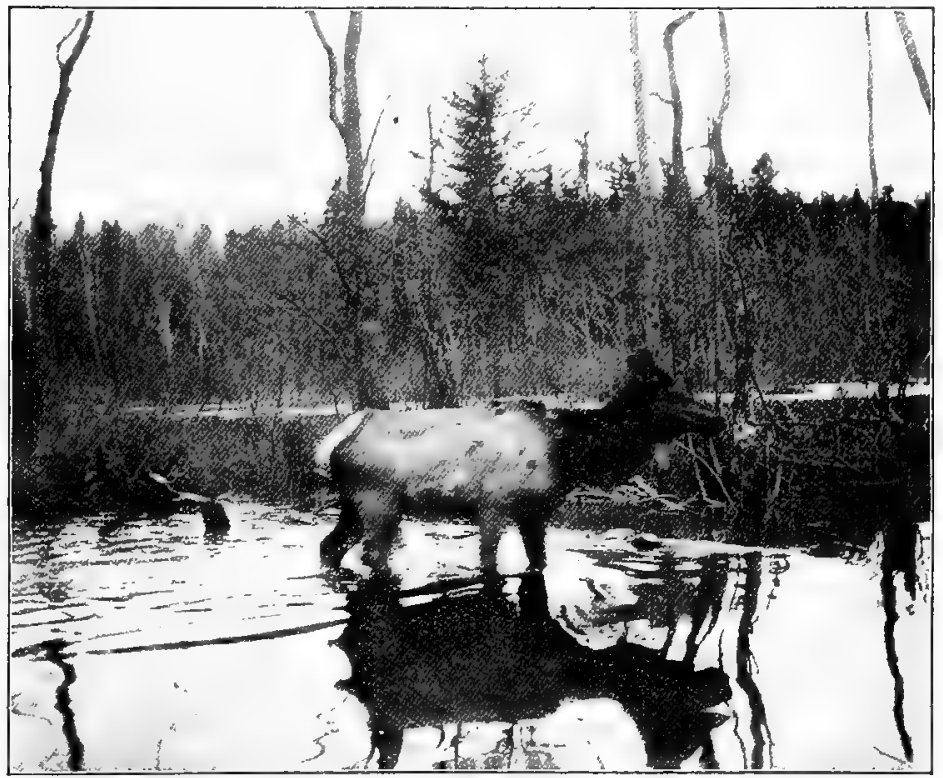

FIG. 167. Cow ELK

The lumps in the skin are caused by botflies. (Copyright by Charles Irving Rice)

eggs; and immediately the workers seize them and hasten to carry them down into the nest. Besides these you may often find smaller masses of shining black eggs. These, probably eggs of plant lice, the workers also carry into 
their holes. At this season you will commonly find at the surface only workers, pupæ, and eggs. If now a spade be deeply thrust into the earth and the whole nest turned out, you may be able to discover the queens, much larger than the workers, and the white naggot-like larvæ. At this season you are not likely to find any winged ants in the nest, but later, in August or September, the air may be filled with them, flying in every direction. If we now visit an ants' nest or some ant-hill in the neighborhood, we may see swarms of winged males and females issuing from the ground and taking flight. This is their wedding journey, and after it the males soon die. The females either join a colony of the same species as one of its queens or found a new colony. They tear off their wings as of no further use, or the workers do this for them.

Any species that is common in the neighborhood may serve as the basis for these lessons, but perhaps the best ones to work with, aside from the ants that infest the house, described in Chapter V, are the following:

The carpenter ant, Camponotus pennsylvanicus, one of our largest black ants. Its nests are built in timbers of buildings, logs, and even trees, by excavating a complicated series of passages and chambers. A nest of this species may be arranged for study, if one is not convenient outside, by bringing the wood in which they are working into the schoolroom and mounting it on two bricks which stand in shallow pans of water. This latter is to prevent them from escaping into the room.

The mound-building ant, Formica exsectoides, is perhaps our most conspicuous species on account of its large hills, often from one to two feet in height and five or six feet 
in diameter. The head and thorax are dull red, and the abdomen and legs black.

The slave-maker ant, Formica difficilis, resembles the above in size and appearance, but builds its nests almost wholly underground, often beneath large flat stones.

The slave ant, Formica subsericea, is found in colonies of its own under stones and commonly, also, as slaves in the nests of the last-named species.

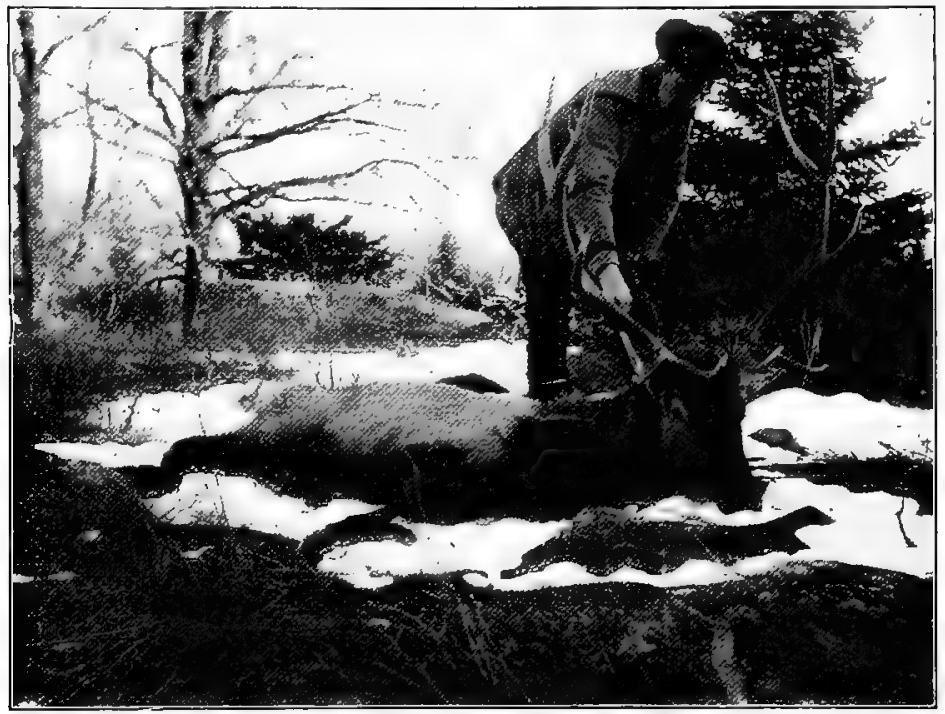

Fig. I68. Elk killed by Grubs in the Head (Photograph by Charles Irving Rice)

The corn-louse ant, Lasius bmuneus, is the brown ant, about one-eighth of an inch in length, so common about roads and pastures. Many, if not all, ants attend aphids, in order to obtain the sweet sccretion, commonly known 
as honeydew, which some species discharge. For this reason aphids are sometimes called "ant cows." The milking of their cows is readily observed. Practically all the ants seen about trees are tending their herds of cows, and if we follow one we may soon see her come up to an aphid and stroke it gently with her feelers. In response the aphid emits a little droplet of honeydew from two minute tubes on its back, and this the ant eagerly licks up. A destructive species of aphid, the corn louse, feeds upon the roots of corn, and it has been found that the brown ant collects the eggs of this aphid in the fall, takes care of them in its nest during the winter, and carries the newly hatched plant lice back to the corn roots in the spring. It is possible that this or other species of ants may distribute plant lice in a similar manner to the leaves of trees or shrubs, but this has not as yet been discovered.

An ants' nest may be made with a slate and a pane of glass large enough to rest upon the frame all the way around. Cut one or more little passageways in the frame, have a board just as large as the glass to keep the nest dark when not under observation, and stand the slate on two bricks in a shallow pan of water. To fill the nest select a hot, sunny afternoon, turn over a flat stone quickly, and with a spoon first scrape up as many ants, pupæ, and eggs as possible into a wide-mouthed bottle; then dig open the nest and be sure to catch one or more queens, with as many more ants, eggs, and larvæ as possible. Cork the bottle and, without more delay than necessary, turn the contents upon the slate, spreading it out so that the glass will rest on the frame, and cover up. By the next morning you will find a well-ordered 
ants' nest, with its chambers and passageways, the queens, eggr, larvæ, and pupæ all nicely arranged in the center. By feeding with sugar, crumbs of cake, insects, or bits of meat placed on the board cover or around the edges of the frame, they may be kept as long as is desired. In this way the whole life and work of the colony may be observed and studied in the most convenient manner.

An ordinary roofing slate, about twelve inches square, with strips of one-quarter inch wood glued to it so as to include a rectangular area a little smaller than the slate, say ten inches square, and arranged as above described, makes a most satisfactory ants' nest.

Spiders. - These interesting creatures play too important a rôle in nature to omit from the course. To gain an idea of how many spiders there are, look out on some grassy meadow on a dewy morning. The grass is carpeted with webs. On the one side, spiclers destroy winged insects - flies, mosquitoes, gnats, and

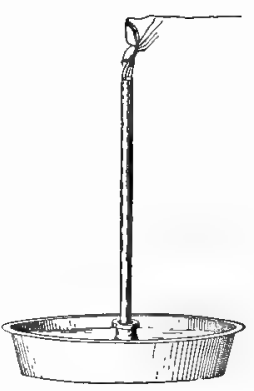

Fig. 169.

AN INTERESTING

EXPERIMENT moths. Let each one of the children examine some con. veniently placed spider web from time to time for two or three days and report, as nearly as possible, how many and what insects are caught in it. On the other hand, spiders are most valuable food for birds. Bird fanciers, in fact, consider them the best medicine for birds, acting like magic to make them well.

While the class is studying spiders, which should be in September, have them collect all the different kinds of 
spiders' eggs they can find. They are laid in little bags of spider web, hung up in the web, as with the common house spider, or placed in cracks, under boards, scales of bark, or under stones. If the eggs are kept in a cold place, the hatching in the spring will furnish interesting lessons.

A spider may be encouraged to spin in one of the schoolroom windows, or one may be confined for this purpose in a dry aquarium, and then, with the aid of their insect nets, the children can bring in flies and mosquitoes to feed it. Besides the common house spicler for these observations, be sure to have an orb weaver, as its web is the most interesting and beautiful of all. By studying a jumping spider, a running spicler, a cobweb or funnel weaver, an orb weaver, and a gossamer or flying spider a fair idea of the life and habits of this group may be obtained. The jumping spiders are found on plants, logs, sides of buildings, etc. They are usually hairy, are very agile, and catch their prey by springing upon it. They spin webs only as egg sacs or as shelters in which to moult or hibernate. For the South the trapdoor spider should be added to the list.

An interesting lesson with the spider. Have a pan or basin filled with water on a table in the largest open space in the schoolroom. By using an ink bottle or even a potato to hold it upright, erect in the pan a stick twelve or fifteen inches high. Have the children bring in various kinds of spiders, - almost any kind will do for this experiment. Select one and place it on the top of the stick and let the class watch the spider's movements. It will first run down the stick, but will find that it cannot escape, because this is surrounded by water; it will then mount to the top again. After several more trials to escape, the children will notice that the spider is spinning a 
fine silken thread. This grows longer and longer and floats out into the schoolroom. It floats to and fro and at last is caught on some piece of furniture, perhaps a desk. The thread, which extends from the top of the stick to the desk, is very slack, and now the little weaver is seen to tighten and fasten it. This done, he quickly runs across and makes his escape.

The story of the first suspension bridge is thus told, "an engineering feat of which the spider was the earliest discoverer."1

How many of the class think that spiders are insects? What is an insect? What is a bug? What is a worm? These are questions relating rather to the right use of language than to comparative zoölogy, and

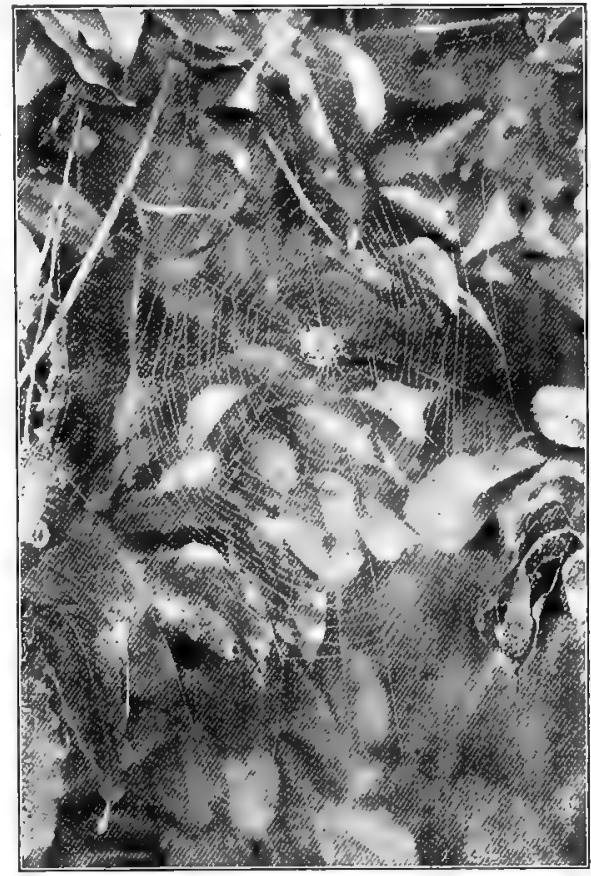

Fig. I7o. AN ORB Weaver we may as well clear them up. Ask each child, after putting these questions and letting him try to answer them, to bring to school a worm, a bug, another kind of insect, and a spider. It is convenient to have them brought in dry, clean bottles for ready observation and 1 Read Gibson's “The Spider's Span” in Sharp Eyes. (Mary C. Henry.) 
comparison. Has every one a worm? They should all have an earthworm or a leech. What is the main difference between the worm and all the reșt? While it is made up of segments, somewhat like many caterpillars and grubs, it has no legs. What difference can the children discover between the mouth of a worm and that of a grub or caterpillar? The children have had occasion to observe various caterpillars as they eat the leaves by gnawing off particles with their sharp jaws. What does an earthworm eat, and how does it manage without either jaws or teeth? What child will volunteer to find out and tell the class? What does a leech eat? Boys who have been in swimming or who have caught fishes with leeches attached to their gills can tell. Hereafter we shall try to distinguish between worms and the larvæ of insects, and we can tell most of them apart at a glance. Several marine worms are provided with sharp hooks or teeth, but they have no legs.

Next, what chief differences do they see between a spider and an insect? The insect is divided into three parts, viz., a head, chest, or thorax, and abdomen; the spider into two,-- head and chest united and abdomen. Further, all insects have six legs, no more nor less, and most of them have one or two pairs of wings. Do any spiders have wings? How many legs do spiders have? Eight. Hereafter, then, we will try to call spiders, spiders, and not insects. We have found, too, that insects go through wonderful transformations, the egg hatching into a larva, the larva changing into a pupa, the pupa finally transforming into the perfect insect like that which laid the egg. What hatches from a spider's 
egg? It is never a wormlike larva but always a little spider.

Nearly every small creeping thing is called a bug. All bugs are insects, but not all insects are bugs. The distinction is more difficult than those we have just made. Are any of the class sure that they have a bug in their bottles? Good examples are the giant water bug, Belostoma americanum, water boatman, Corisa undulata, squash
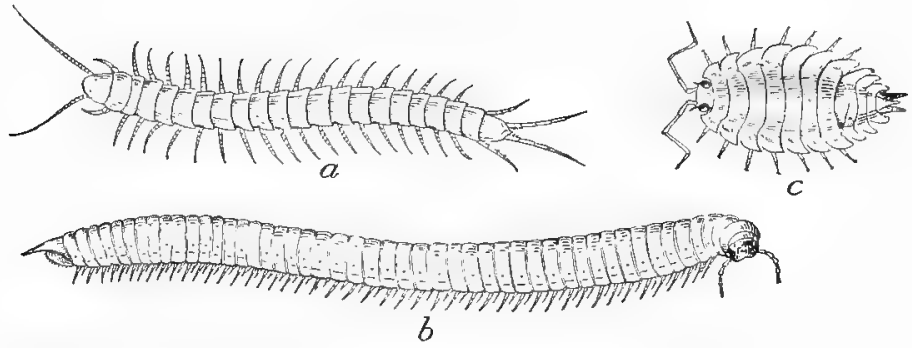

FIG. I7I.

$a$, centipede; $b$, millipede; $c$, sow bug.

bugs, soldier bugs, lice, bedbugs, plant lice, leaf hoppers, and scale insects. Bugs may or may not have wings, but all agree in having mouth parts for piercing and sucking. If some child will volunteer to bring in eggs of the squash bug, we will watch them hatch and thereby gain one of the distinguishing characters of the group. If a good magnifying glass is at hand, the eggs of plant lice will do. The eggs of bugs hatch into forms more nearly like their parents than is the case with most other insects. They have no wings at first, but otherwise resemble their parents. We will thus understand by bugs certain kinds of insects that do not undergo a complete change in 
passing from the egg to the adult and that live by sucking the juices of plants or animals. They stand low in the scale of insect life.

The children will doubtless have brought in, for worms or insects, a number of forms that do not fit in any of the above groups. They are probably wormlike but have far too many legs to be classed with the insects or spiders. If not garden slugs, which will be described under the head of mollusks, they are probably either centipedes (hundred legs), millipedes (thousand legs), or "sow bugs." Thcse are figured above, and when we speak of them hereafter we shall call them by their right names and not call them insects, worms, or bugs.

The centipedes live in clamp places, uncler logs and stones, and feed on insects. The millipedes live in similar places and eat decaying vegetable matter principally, but sometimes living plants. They may become a serious pest in a strawberry bed by eating holes in the ripest berries. The sow bugs are often found in great numbers under rotting boards and logs. They undoubtedly find plenty to eat, but to discover just what it is we shall have to make feeding tests. Sow bugs belong to the great group of Crustacca along with the crayfishes and crabs.

Earthworms. - Every boy has made the acquaintance of these animals as bait for a fishhook, but how many know or realize the rôle they play in nature? Says Darwin ${ }^{1}$ :

When we behold a wide, turf-covered expanse, we should remember that its smoothness, on which so much of its beauty depends, is mainly due to all the inequalities having been slowly levelled by worms. It is a marvellous reflection that the whole of the superficial

1 Vegetable Mould and Earth-Worms, p. 313. 
mould over any such expanse has passed, and will again pass, every few years through the bodies of worms. The plough is one of the most ancient and most valuable of man's inventions; but long before he existed the land was in fact regularly ploughed, and still continues to be thus ploughed by earth-worms. It may be doubted whether there are many other animals which have played so important a part in the history of the world, as have these lowly organized creatures.

Earthworms burrow into the soil to a depth of from three to eight feet, making channels for water, air, and the roots of plants to penetrate. In order to study this subject have each child count the worm burrows in a square foot of ground. They may be found by the little piles of castings at the mouth of each burrow and also by the leaves and grass that the worms have pulled into the opening to feed upon and to close the cloor. If a box be turned over the area a day or two before the count is made, so that the surface will not be disturbed or the castings washed away by rains, the burrows will be more easily found.

Next fill a small aquarium with fine sand or garden earth and place three or four large worms on the surface. Study the way they burrow. After they have established themselves in their burrows scatter a little grass or a few dead leaves on the surface and observe from day to day what the worms do with them. If sand and leaves be used, and the aquarium be left for a number of weeks, the formation of vegetable mould may be observed in a striking manner.

Von Hensen placed two worms in a vessel eighteen inches in diameter, which was filled with sand, on which fallen leaves were strewed; these were soon dragged into their burrows to a depth of three inches. After about six weeks an almost uniform layer of sand, 
a centimeter (.4 of an inch) in thickness, was converted into humus by having passed through the alimentary canals of these two worms. DARWIN, loc. cit., p. 3 IO.

To see the earthworms at work under natural conditions, since they are nocturnal, we must ask the pupils to take a lantern in the evening and study this lesson, for at least fifteen minutes, out on the ground. Just after a good rain in June is the time; for if it is dry, the worms will be feeding on the materials they have drawn into their holes and will not come to the surface. They may, however, be induced to come out by wetting down a flower bed with the garden hose. Let each child tell what he has observed.

Sometimes, especially after heavy rains, the worms are seen crawling all over the ground; but generally they will be found with the tail end clinging to the burrow, the body stretched out over the ground, and with the mouth sucking and pulling at bits of leaves or grass. When a hold is obtained on a leaf the body contracts and the leaf is drawn toward the burrow. If the children have learned their lesson properly and have observed this, ask them why the worm clings to its burrow. Can they find eyes, nose, or ears anywhere in the bocly of an earthworm? Can a worm see? Can it hear? Can it smell? Let them try to answer these questions for themselves by appropriate experiments and observations. If they turn the light of a lantern on the head encl of a worm, after a few seconds it will generally draw back into its burrow. This proves that it can slowly distinguish light from darkness. This is further shown by the fact that earthworms are nocturnal. As to hearing, one 
may whistle, shout, or even fire a toy pistol, but the worms give no response. They cannot hear at all. To test for smell, place a bit of onion a little to one side and near the head of the worm. It soon reaches about and finds it. It can smell a little. This experiment may be made with the worms in the aquarium, as Darwin has shown, by burying the onion, when it will always be found and dug up by the worms. Lacking all the special senses that higher animals use so much, if a worm lets go the burrow, it cannot find it again, but is obliged to make a new one. It may be lost within an inch of its home, and most of those we see about the pavements die by drying up before they can find a place to burrow. Lacking the other sense organs, earthworms have a most delicate sense of touch. Jar. the earth a little, stroke with a feather, blow lightly; in response to all these stimuli the

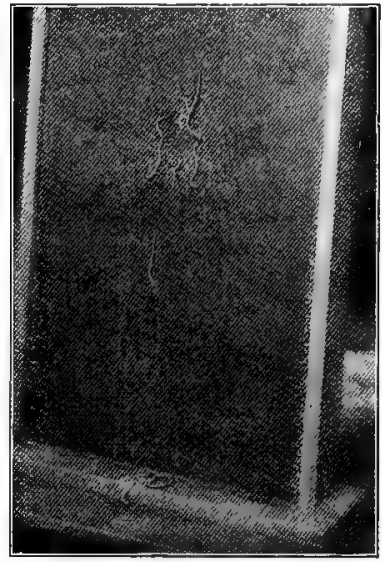

FIG. I72, EARTHWORMS"RAINING UP" ON A VERTICAL PANE OF GLASS worm dashes like a rabbit into its burrow.

Earthworms lay eggs almost too small to see with the unaided eye, but they are done up in capsules about the size of mustard seeds, which may be found by sharp eyes near the openings of the burrows along in June. They may be hatched in a watch glass, and a little fine, moist earth may be added as soon as they come out. 
It is a common belief that earthworms "rain down." What do the children think about it? The evidence that is popularly assumed to prove this consists in finding worms in rain-water barrels or gutters. Let the class observe how easily a worm can ascend a vertical surface, even a pane of glass, and then decide whether the worms

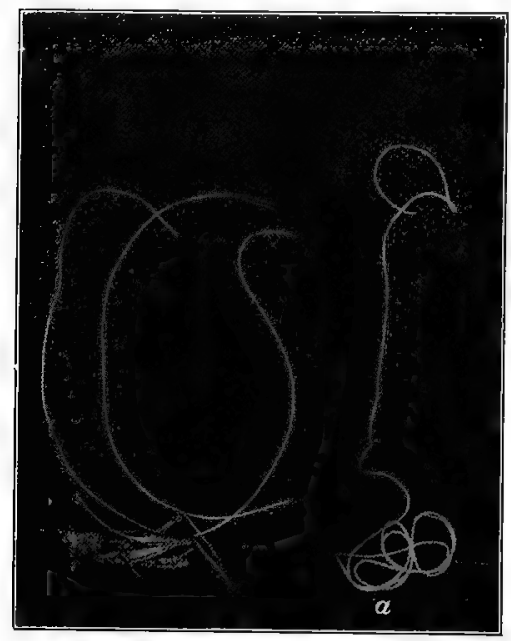

Fig. 173. Three Hair Worms Removed FROM A GRASSHOPPER

$a$, a specimen $22 \frac{1}{2}$ in. long, from a katydid. "rain down" or "rain up."

Hair Worms. - These strange creatures resemble animated hairs so closely that it is not strange that the myth should arise as to their origin from hairs left in the water. If the children insist upon this belief as strongly as some grown people do, it might be well to let them put some hairs in water and see if they turn into hair worms. But the true life story of hair worms is more wonderful than the fiction. They are usually found in one of two places, - in roadside or meadow pools after a rain, in the spring and summer; in the bodies of insects, late in the summer and fall. In the insect's body they are long white threads. I have found one in a katydid, more than twenty-two inches long. In the pools they are 
dark in color and continually writhing and twisting about, tying themselves into knots. This peculiarity has given them the generic name "Gordius," from the Gordian knot.

In a word, the life story of one of our common forms is simply this: The mature worm lives in the ground and comes out into the pools to lay its eggs. The egg is very minute, and the tiny worm that hatches from it bores its way into some insect, usually a grasshopper, and lives as a parasite within its body. The insect dies, and the worm enters the ground to pass the winter.

The nematodes, to which the hair worms belong, are a large class of lowly organized worms. Most of them live in water, soil, or decaying matter and are harmless. Many are almost or quite microscopic in size, the "vinegar eel" being one of our most common forms. A few are parasitic in animals, living either in the intestine or in the flesh. It is these latter, especially the trichina of pork, that make it unsafe to eat meat that has not been thoroughly cooked. Other nematodes are parasitic in plants, especially in the roots, where they produce swellings or galls. They are particularly destructive in the greenhouse and window garden in the North, where the eggs are killed by freezing during the winter, but they often seriously injure field and garden crops farther south. ${ }^{1}$

Mollusks. - These form one of the largest animal groups, there being 2I,320 living species and an almost equal number $(20,895)$ of extinct fossil species. How many kinds do the children know? They may be defined as

${ }^{1}$ George E. Stone and Ralph E. Smith. "Nematode Worms," Bulletin No. 55, Massachusetts Agricultural College, Amherst, 1898. 
soft-bodied animals without segments and without jointed limbs. Generally the body is protected by a shell, either single and coiled spirally, as with snails, periwinkles, and conchs, or composed of two pieces or valves, as in clams, oysters, and mussels. A few have no shell, as the garden slugs and the most highly developed of the whole group, the octopus and ink squid.

While the children may be encouraged to collect fossil
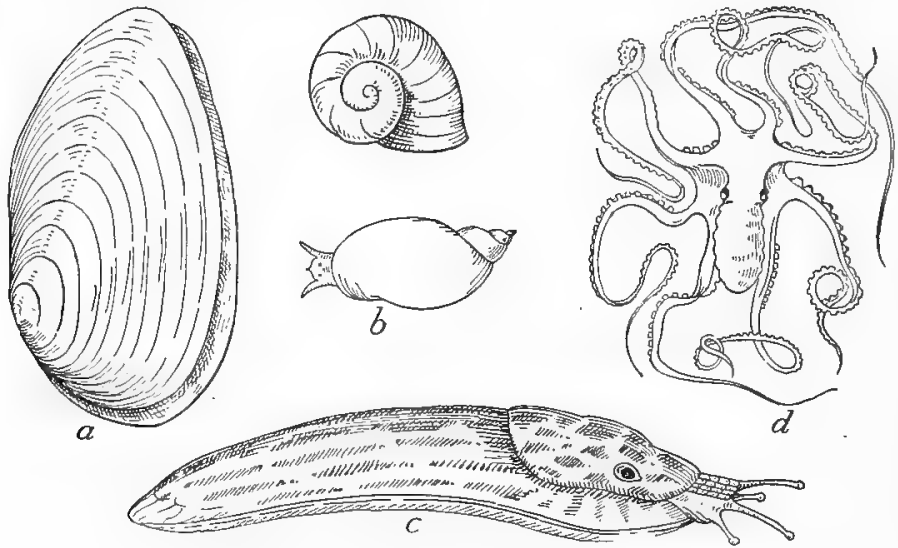

FIG. I74. TYPE FORMS OF MOLlusks

$a$, fresh-water clam; $b$, pond snails; $c$, garden slug; $d$, octopus.

shells and the many species that they may find during their summer vacations at the seashore, we will confine our attention to four of the commonest and most widely distributed kinds.

Can some boy or girl bring in two or three specimens of the common garden slug, with a nest of eggs, if they can be found? They may be kept in a small aquarium and fed on lettuce leaves or fresh young radishes to show what 
havoc they may make in a garden or greenhouse. It is interesting to watch their movements in gliding over the glass. How do they do it? Not like a leech or measuring worm, by looping the body and holding on with first one end, then with the other; not like an earthworm, by stretching the body and catching hold and drawing the rest of the body up. But they remain apparently motionless, neither longer nor shorter, and still glide smoothly and rapidly along. They are nocturnal, feeding by night and lying hidden in damp places during the day; but a telltale trail of slime is left wherever they go, and if they have been doing mischief in the garden, they may easily be followed home. The eggs are found under boards in damp places, but instead of describing them I wiil ask the children to find them, if they can, and keep them to make sure that they hatch out into little slugs. The pupils may observe how a slug eats, and they are sure to be interested in the way it breathes, - through a large hole, or spiracle, on the right side.

In order to keep the alga from overgrowing the sides of our aquaria we need some snails, which the children can find in any fresh-water pond or stream. The two kinds that are most useful are represented in Fig. I74. Their eggs are laid in glairy masses fastened to the water plants or often to the glass where their development may be easily watched.

Among the bivalve mollusks are the oyster, clam, quahog, scallop, and mussel, all valuable for food and connected with interesting methods of cultivation and with fishery industries. Where these can be studied alive, as along the coast, they may be brought into the course. But the 
bivalves of most importance for the school aquaria and for the work of purifying surface waters are the common fresh-water mussels, or clams. They may be found in any pond or stream. Ask the children to bring in a few and keep three or four large ones in each of the larger aquaria and one in each of the small aquaria. Now ask a group of

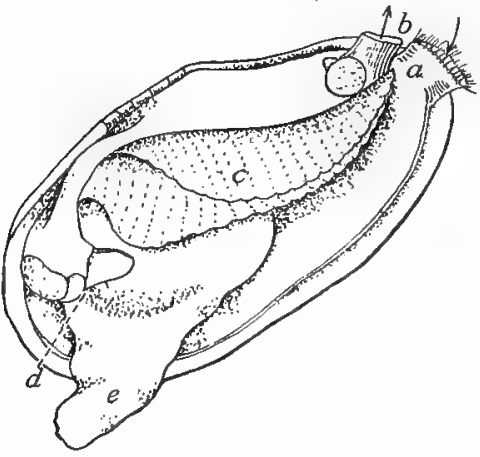

Fig, I75. FRESh-WAter Clam $a$, inhalant siphon; $b$, exhalant siphon; $c$, gills; $d$, mouth ; $e$, foot.

the class to test the purification of water by clams. They may do this by arranging two small aquaria, exactly alike, with sand and plants, filling them with water that is turbid from growth of algæ or bacteria. Put a clam in one but not in the other and watch the result. Generally the water with the clam in it will become perfectly clear in a few hours or days, according to the size of the aquarium, while the other grows more and more turbid.

Next we will try to discover how the clam works. If we look at the clam from above, we notice two openings between the posterior ends of the valves. These are surrounded with a fringe of dark papillæ which are sensitive to light. This may be demonstrated by suddenly cutting off the sunlight, when the valves will close. With a fine straw, or a glass tube drawn to a fine opening, let fall close to the upper siphon a little colored liquid, - carmine or dilute India ink. It is sent whirling away from the clam. Now, 
without touching the tentacles, let a little more fall near the lower opening. It is all drawn into the clam, and if a solution or a very fine suspension of inert matter, like carbon, chalk, clay, etc., it is soon seen streaming out of the upper siphon. If this prove irritating to the clam, it will shut up with a snap, throwing clouds of the liquid out of both siphons. We thus see that a stream of water is being drawn into one siphon and thrown out at the other. Next, take a suspension of yeast plants, small algæ, or bacteria, let it pass into the inhalant siphon, and watch the exhalant siphon. It goes in turbid and comes out perfectly clear. This shows what the clam feeds on, - minute floating particles in the water. The currents are set up by the gills of the clam, the water being passed through while the food material is strained out and carried up to the mouth. A culture of typhoid fever bacteria, for example, flowed through the gills of an oyster, which are quite similar to those of a clam, came away sterile, i.e., with all the bacteria filtered out. Clams are thus living filters, and in a pond well stocked with them they must exert considerable influence in keeping the water cleansed of floatir.g organic matter. ${ }^{1}$

1 The structure of the clam is explained somewhat in Fig. I75, and, if the school possesses a compound microscope, the action of the gills may be demonstrated, but this may as well be left to later courses in zoölogy. 


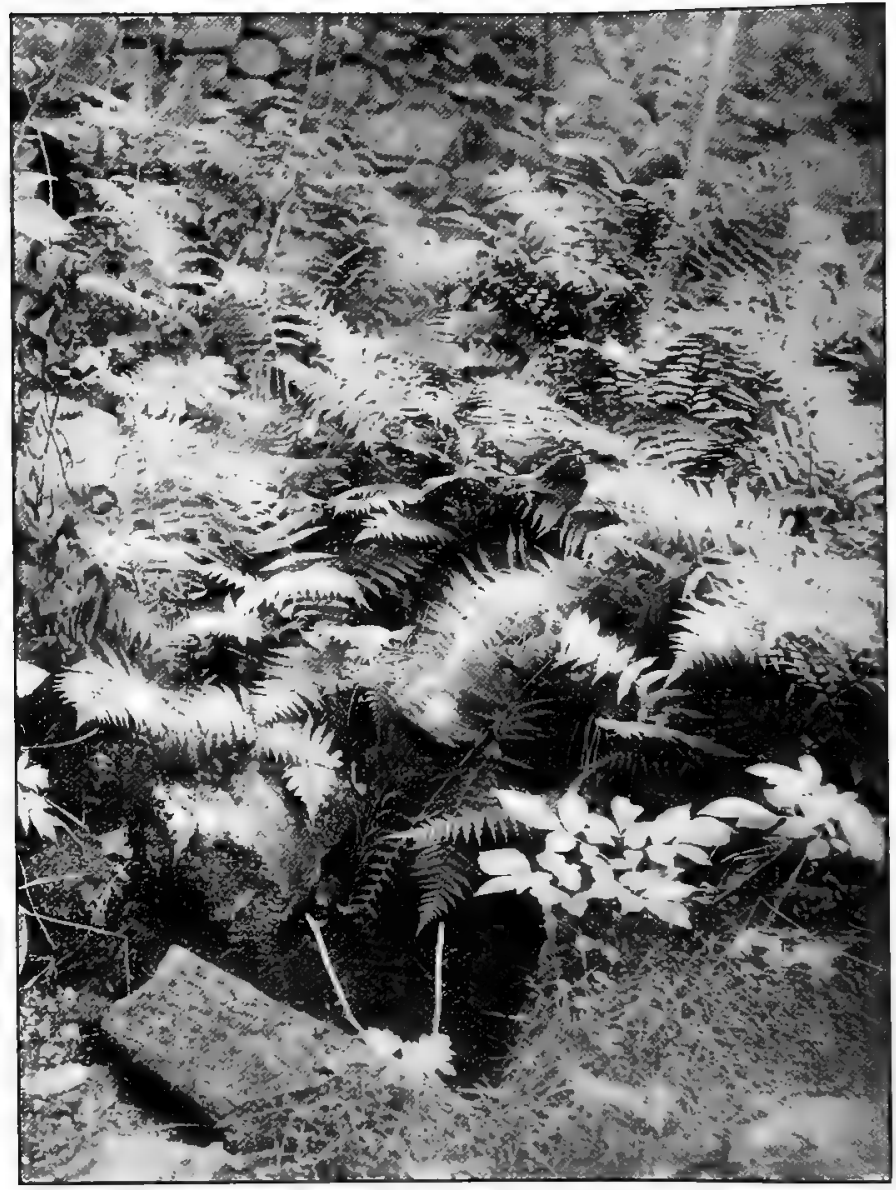

Fig. 176. A Woodland Spring 


\section{CHAPTER XXVI}

\section{FLOWERLESS PLANTS}

Ferns, Mosses, Liverworts and Lichens, Alge, Mushrooms

Elementary studies of plants commonly include only those that bear flowers and produce seeds. The importance attaching of late years to many of the lower forms, together with their educational values, renders it advisable to include their study in a course that pretends to give adequate elementary instruction in the natural environment of a community.

Ferns. - These form a natural introduction to this group of plants. Gray's Botany gives sixty-two species native to the United States. How many different kinds can the pupils find in their neighborhood? A bed or rockery of ferns will make a beautiful nook in the school garden. Have the children notice and describe the places where they grow best; then select the most favorable spot for the bed, generally a corner on the shady side of the school building. If the soil is not suitable, have a load of black leaf mould from the woods put on the bed and arrange naturally a few moss- and lichen-covered rocks to give the ferns their appropriate setting. Since the ferns are all hardy perennials, a bed once planted will continue with little care from year to year and yield good material for drawing and 
language lessons, and for study and genuine acquaintance. A small pool in one edge of the bed will acd to its beauty and may support a collection of interesting water ferns.

Aside from their grace and beauty the interesting fact connected with the study of ferns is their method of reproduction by spores. Watch the underside of the leaves, and when the fruit dots, or sori, as they are called, turn

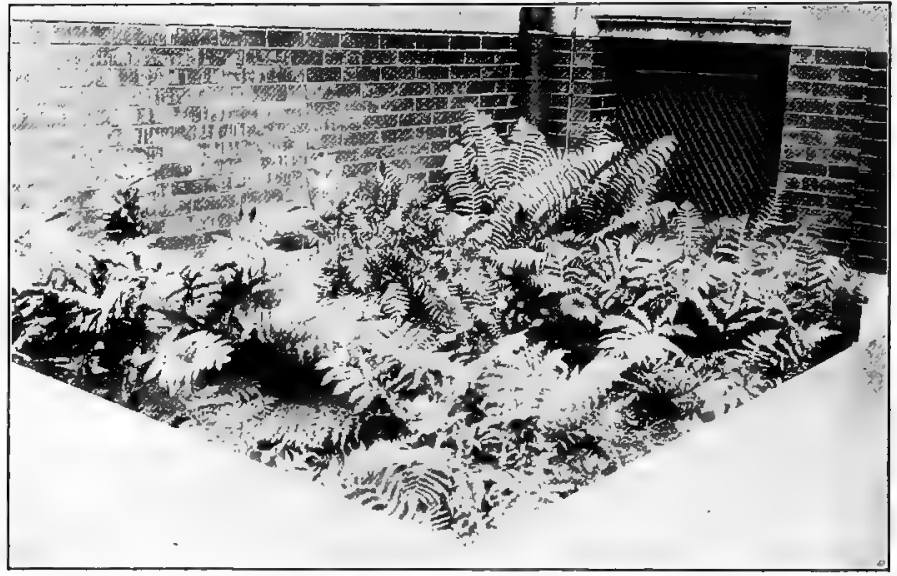

Fig. 177. Collection of Ferns

George Putnam School, Roxbury, Mass.

brown and appear to be ripe, distribute pieces of the leaf to the class and let them pick out some of the spores on a sheet of white paper to gain a definite idea of what is meant by the much-used term "spore." The finest dustlike particles that they find in the sori are the spores. If a few leaves are permitted to dry over a sheet of paper, spores may be obtained in quantity. It may be too difficult a task for the children to undertake, but if any wish to volunteer, 
let them try to rear some fern plants from the spores. To do this the spores must be kept uniformly damp. Have an inch of wet sand in a small aquarium and lay on this a fragment of mossy flowerpot, thickly dusted over with spores. Cover the aquarium with a piece of glass; keep the sand wet and watch carefully to see what grows on it. It might be well to set the aquarium in a greenhouse, if one is available, so that it may be kept at a constant temperature. If the experiment succeeds, the strangest thing of all will come to light, viz., that the spores do not produce ferns but, instead, tiny little plants, consisting each of a single heart-shaped leaf. This is called a "prothallium," and from the underside of this a little fern will finally grow.

Mosses. - The mosses are still smaller plants that do not bear flowers but reproduce by spores. These are often borne on slender stems in little capsules. A collection of as many of the common sorts as the children can find may well be transplanted to the fern bed. There are 6750 species known. How many different kinds can the children find in their school yard?

Liverworts. - These are little mosslike plants, but their stems are always flat, or, in other words, carry a leaf-like expansion on either side. Their fruiting capsule opens by two or four valves and never by a lid such as we find in the mosses. There are several beautiful little plants of this kind well adapted for the school aquaria. How many different kinds can the children find?

Lichens. - These are a step lower in the scale of plant life. They have no stems but are leaf-like growths, gray or yellowish green, on rocks, boards, the bark of trees, or the ground. Their spores are borne in little cups on the surface. 
An abundance of these plants will probably occur on the stones in the fernery or on the tree trunks in the school yard. It is not intended, for these elementary lessons, that any of the different species be learned, for we have no common English names with which to designate them. There are 5600 named species, but it will be sufficient if the class study and draw two or three of the commonest in the neighborhood and learn to associate the name "lichen" with them. It may be possible to explain to the class that a lichen consists of two different plants living together: a white fungus, consisting of a felt work of minute threads, such as we shall see in the moulds and mushrooms; and much smaller, generally greenish plants, algæ, entangled in the meshes of the fungus. The fungus furnishes support and moisture to the algæ, and, in return, the algæ by means of their green coloring matter and sunshine supply food to the fungus. The algæ can live without the fungus, for they can find support and moisture for themselves, but the fungus invariably dies if deprived of the help of the algæ, for it cannot get food enough from the stone to which it clings, and without chlorophyll it cannot draw food from the air by the aid of light. From this point of view the lichens serve as an introduction to the two next plant groups, - the algæ and the fungi.

Algæ. - We can always find algæ in the school aquaria, often as incrustations or velvety growths on the glass, or as green slimes attached to the plants or floating on the surface. Snails, tadpoles, and clams will be required to keep the aquarium clear. Algæ vary in size, from plants as small as a fern spore to the large brown rockweed, fucus, that clings to the rocks and piles all along the coast. As 
Dr. Brooks has shown, they supply, directly or indirectly, the food for all animal life of the ocean. Oysters feed upon little else, and their quality is influenced by the kinds of algæ that grow in the water over their beds. Algæe may be classified according to color: (I) the blue greens, found as slimy patches on damp wood or stones, or in shallow fresh water; (2) the green algæ, found in fresh water chiefly; (3) brown algæ, kelps, rockweeds, etc., found on the coast, chiefly marine; and (4) red algæ, the "seaweeds," or "sea mosses," also mostly marine. Ask the children who go to the seashore to bring back a few handfuls of such as they can find. They may be dried as they come from the salt water and at any time floated in fresh water upon cards or white paper. To come to know them as objects of beauty is deemed sufficient. There are at present described and named I 4,854 species of algæ. How many kinds have the class been able to discover?

Fungi. - In descending the scale of plant life, from trees, wild flowers, and garden plants, we left flowers and seeds behind when we came to the ferns. In passing now from the algæ to the fungi we leave the green coloring matter, the chlorophyll, by which these higher plants use the sunshine to help them build wood, leaves, and fruit from water, soil, and air. ${ }^{1}$

The fungi form an enormous group of most interesting and important plants. Numbering the 970 species of

1 To illustrate this important relation between green plants and the sunshine ask a few of the class to sprout a number of plants - potatoes, beans, corn, squash, and peas - and keep them for a week in the dark. Then let the class watch them from day to day to see them develop the green color and begin to grow as they are exposed to the light. A few may be kept in the dark by inclosing them in tubes of black paper for still further comparison. 
bacteria with them, 43,830 different kinds are now described, nearly one-quarter of all the plant species known to science. In size they range from large mushrooms and giant puffballs, of many pounds in weight, to moulds and bacteria, so small that it would require 10,000 placed side by side to measure an inch, - far too minute to see with the unaided eye, even as a speck of dust on a polished mirror. The prime characteristic of this large group is absence of the green coloring matter, chlorophyll, of the higher plants. Lacking this, the fungi are unable to build up living matter from the elements by the aid of sunlight; hence, they commonly grow in dark or shady places, and they must depend for their food upon other organisms, animals, or plants, either dead or alive. While we shall find many and beautiful colors, the prevailing tone throughout the whole group is white or gray. A few of the higher plants, notably Indian pipa, pine sap, dodder, have lost more or less of their chlorophyll and, at the same time, have become parasitic upon other plants. Those fungi that live upon dead matter are sapropliytes; those that live upon the tissues of plants or animals to their detriment are parasites. Si11 other species, especially bacteria, subsist upon or in living organisms with mutual benefit and are called symbiotes, i.e., "together-livers."

When we inquire what this group of plants does in the economy of nature, we must study them in connection with their foods, as above specified.

By far the greater number subsist upon dead matter the remains of animals and plants. Imagine all the trees. plants, and animals that have died since the world began, whose bodies did not happen to have been burned or eaten, 
still lying as they fell, and we have a picture of what nature would be without the beneficent work of fungi; that is, they cause decay. They return to Mother Earth the matter which has lived, that it may live again. Without them all available food in the world would soon be locked up in dead forms, and new life would be impossible.

This is a rather knotty point; but it may be attacked in a direct and simple manner by asking the children: "Where does our food come from? What is its last or ultimate source?" They will say: "It comes from plants, wheat, corn, fruits, vegetables; and animals, beef, mutton, pork, fish, fowl, etc." "But where do the animals that we eat obtain their food?" "It comes from the plants; so that, in the last analysis, the food of animals, man included, comes from plants, directly or indirectly." The next question is: "Where, then, do the plants get their food?" "With the help of sunshine green plants clerive the food with which they build up

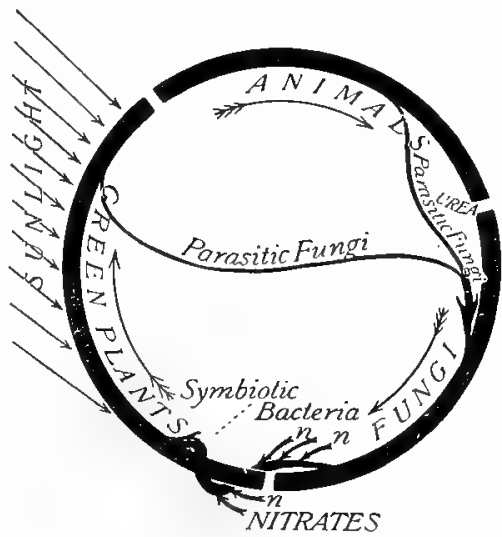

Fig. 178. The Circle of Proteid Food MATERIALS

$n, n$, represents free nitrogen drawn in from the air leaves and grains and fruits and woods from the soluble materials in the soil and from the invisible matters in the air." Now comes the crucial question: "Can a green plant grow in wood, or leaves, or fresh meat, i.e., in the undecayed body of an animal or plant? Have any of the class ever seen a green plant, not a parasite, growing in this way?"

The diagram, Fig. I 78, will make these relations plain. In their elementary physiology lessons the children may have had simple 
discussions of the three classes of foods: fats and oils, starches and sugars, and, most important of all, proteids, or nitrogen-containing foods, sucli as flesh, the white of egg, or the gluten or similar substances of wheat and other vegetable foods. This is the great essential food for all animal life. On no amount of fats or sugars can any animal sustain its life for more than a few days.

Without the help of the fungi we might, with a great deal of labor, burn everything that died and thus return the elements to the air and to the soil; but in burning nitrogenous compounds we should return their nitrogen to the air along with all the other gases, and the green plants are not able to take nitrogen directly from the air. They require nitrogen in some soluble form, as nitrates in the soil ; so that the burning of nitrogenous compounds is a most wasteful process. In fact, up to within a few years it used to be said that when a rifie is fired a man is killed, whether the bullet strikes one or not. This was thought to be true, because it was supposed that in burning the soluble nitrate in the powder, thus returning the nitrogen to the air, the nitrate could not be recovered and that eventually some one would starve for the lack of it. How certain bacteria are able to take free nitrogen from the air, and thus give food to plants and everything that lives, we shall discuss in the next chapter.

Another line along which this may be explained to the children in a practical way has reference to their plant lessons. When the children were given seeds and asked to see who could rear the best plant, many of them immediately asked: "What will make a plant grow best? What can I feed my plant to make it grow fast?" The answer is nitrates, chiefly of potassium and sodium. These are the main constituents of chemical fertilizers, now so commonly used. No knowledge of chemical formulas is necessary to make this plain. Simply get a little potassium nitrate, let the children see, handle, and taste it, burn a little of it, and, finally, dissolve a teaspoonful in a quart of water and treat a certain plant with it once a week. It would be well to have two similar plants growing in two pots of rather poor soil and give this solution to one and not to the other, to let the class see how it makes the plant grow. This is a simple elementary lesson in fertilization of the soil and will serve to show the rôle that nitrates play in plant growth. 
Thus we see in a general way that the fungi recluce dead nitrogenous matter to soluble plant food in the soil. Leaves, twigs, and wood decay to form vegetable mould and animal matters; manures and composts must be thoroughly rotted before they become available for plant foods.

A smaller group of fungi live as parasites upon or within plants and animals, and thus cause the majority of those diseases commonly known as contagious or infectious. We should know something about these and how they may be controlled, and to this end we may describe a few that commonly attack garden plants and trees, as well as some that are of great importance in relation to home and school sanitation.

Finally, a small group of bacteria are truly symbiotic and live within the roots of plants, especially of the clovers and peas, and possess the power of absorbing nitrogen from the air and of fixing it in soluble form as food for the plants. As with the lichen and the algæ, the root supplies moisture and support, while the microbe manufactures plant food in return. It has long been known that clover, for example, enriches the soil in which it grows, and this fact is now, in a measure, explained.

The above facts are given to aid the teacher in planning the lessons and in appreciating the value of the observations and experiments that follow.

Mushrooms. - The best time during the school year to study mushrooms is in the fall, after a spell of wet weather. We may begin by asking the class how many know mushrooms and have found them growing in the neighborhood. The children may know them better by the popular name "toadstools," which is commonly used to designate poisonous or worthless mushrooms; but, since this is not a helpful term, we had better make the clistinction by calling them "poisonous mushrooms" instead. Possibly one of the class knows some one who is raising mushrooms and can tell the rest how it is done. Ask the children each to dig 
up one or two mushrooms, being sure to get the "roots," and bring them to school for the next nature-study period. Look over the specimens and place the amanitas by themselves. Then have the class sort the others into piles according to their characteristic forms and structures, putting the puffballs, the gill-bearing kinds, all having tubes,

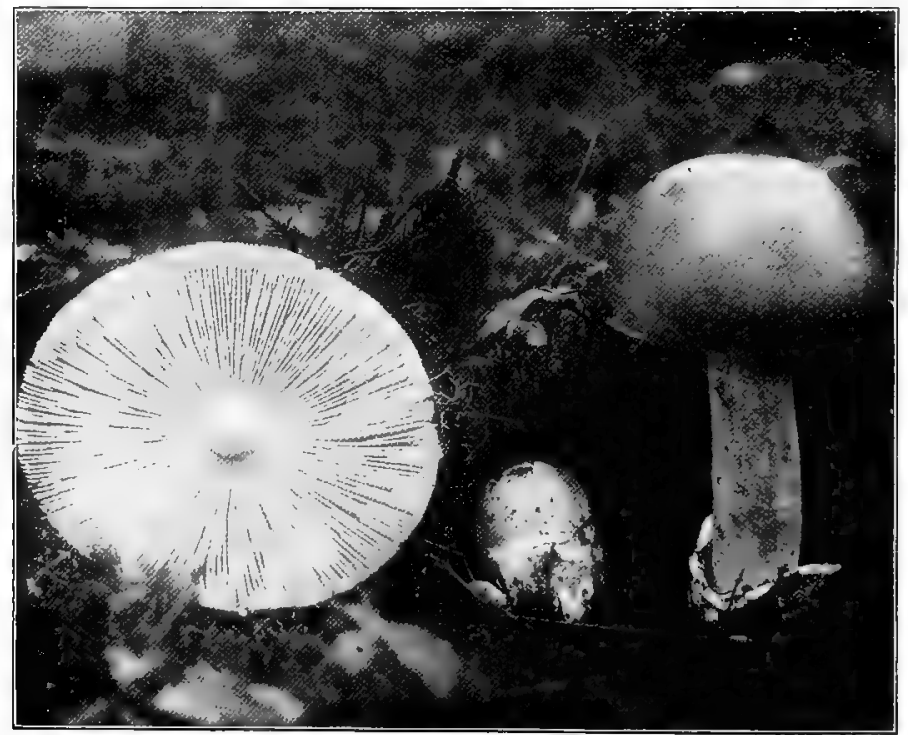

Fig. I79. The Deadly Amanita

The gills; a button just pushing out of the cup; a mushroom showing cap, or pileus, stem, and cup, or volva at base of stem

and those with fine pores underneath, and such as present branching forms, the Clavarias, each in a pile by itself. We thus see that there are marked and interesting differences in form and structure.

To understand the growth of these strange plants have some of the children carefully wash the earth away from 
the base of the stem, selecting specimens with a large ball of earth. They should find an irregular mass of whitc threads, some of them running into the bottom of the stem. They may also find among these threads "buttons" of various sizes. These are young mushrooms that will grow larger and finally push their way up into the air, - for what purpose we shall see in a moment. Have the class compare their specimens and try to find a series from tinc smallest "button" to a full-grown mushroom. Do any in the class know what relation the white threads bear to the mushrooms? While not conspicuous these are really the main part of the plant. They are called the "mycelium" of the mushroom. This mycelium may grow for months or even years, sending thread after thread in every clirection through the soil or through the wood of a tree, absorbing food and increasing in size. It is thus the vegetative or nutritive part of the plant. We shall find something similar when we study the moulds. When the proper conditions arrive, generally after heavy rains (for mushrooms are almost all water), the "buttons" enlarge and push up through the surface, often in a night. Fig. I 79 will serve to explain the conspicuous parts of a mushroom - stem, cap or pileus, gills or spore-bearing structures. Emphasize the fact that the mushrooms that we ordinarily see are only the spore-bearing, or reproductive, part of the plant. They are pushed up into the air by the mass of the mycelium, in order that the spores may be carried in every direction by the winds.

Let us next ask the children to study the sporing of their mushrooms. From any large specimen the spores are probably being shed, from between the gills or from 
within the tubes or pores, in a constant shower; but they are far too small to see. Cut off the stem close to the gills and lay the mushroom, gills down, on a piece of paper and cover it with a glass so tight that not the slightest current of air can enter. The spores will then fall straight down and draw a picture of the under surface of the mushroom. We make, in other words, a "spore print." A few

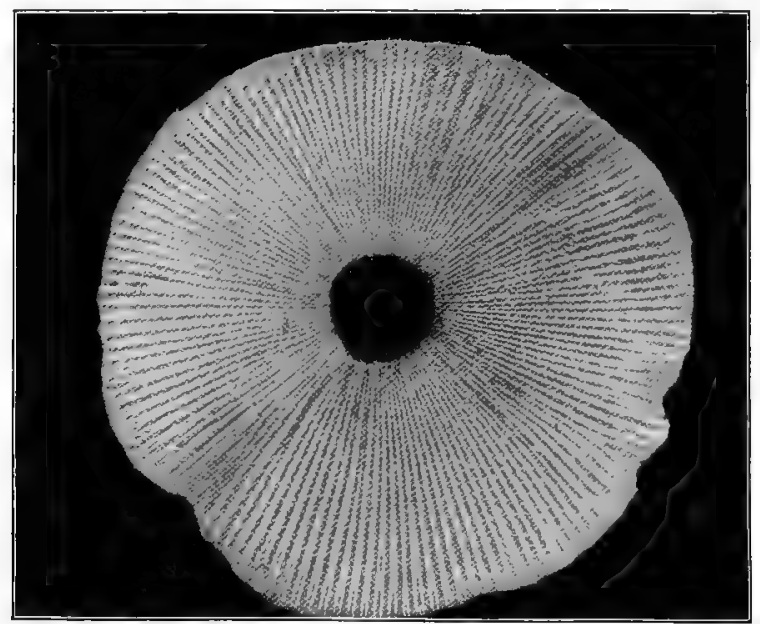

Fig. I 80. The Deadly Amanita

Spore print

of these will greatly aid the children in forming clear ideas about spores as we have found them in the ferns and mosses and are soon to study them in the moulds and bacteria. The spore dust of a ripe puffball should also be studied in this connection. The important fact to be brought out is that spores are so small that they become invisible as they disperse in the air and are so light that they are readily 
carried by air currents. Thus they form a constituent of dust. If the gills or tubes of a mushroom are dark colored, we will make the spore print on white paper, if white, on black paper, and if we care to keep the spore prints, we will use paper over which a thin coating of mucilage has been laid. This may be allowed to dry, as the moisture in the spores will cause them to stick to it.

The food value of mushrooms has been exaggerated by popular writers. Chemical analyses have shown that thcy are about as nutritious as cabbage. Rated at twenty-five cents a pound, which is from one-fourth to one-tenth the ustual price, they cost about ten times as much for actual nutrition obtained as beef at fifteen cents per pound and I 24 times as much as wheat flour at two and one-half cents a pound. However, they afford variety; a few species are said to be "delicious," and a very few are poisonous. As a people we are behind most European nations in knowledge of mushrooms and, hence, in ability to utilize them for food. The main reason for introducing their study into nature-study courses is to give definite instruc. tion, first, about the few poisonous species and, second, to point out a number of the more valuable kinds that now go to waste in large quantities in our woods and pastures and even city lawns and gardens. To do this adequately would require a book, but a few points of general importance may be given in connection with the following partial outline of their classification.

Since the conspicuous part of a mushroom is a mechanism for producing and disseminating the spores, they are naturally classified by the position and form of the spore-bearing surfaces or parts. 
Puffballs, Lycoperdacca. - Puifballs have a rincl or wall and produce their spores within a closed cavity. When the spores are ripe the wall ruptures, and off they go with every puff of wind in the well-known clouds of dust. No puffball, so far as known, is poisonous if taken while the flesh is perfectly white, but some caution must be observed not

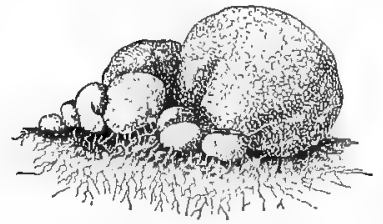

Fig. ISI PUliballs

to mistake for a puffball a "button" or " egg" of some other kind of fungus.

\section{Coral Mushrooms, or Cla-}

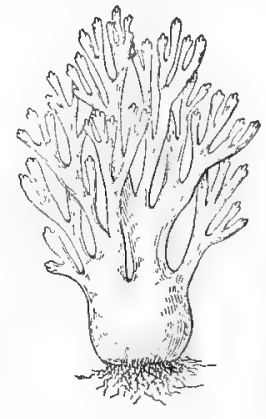

FIG. I82.

A Coral Mushroom

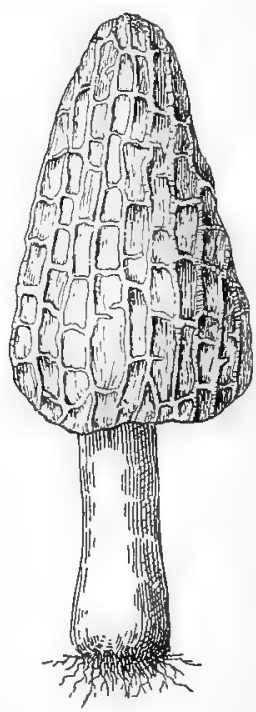

varias, Clavariacea. - These grow either in the form of single clubs or manybranched masses. The spores are shed from the entire surface of the branches. So far as is known, all the clavarias that are of any size are edible.

Fig. 183. A MOREL

Morels, Cup Fungi, Discomycetes. - These have a stem and cap, but unlike most mushrooms the spores are borne in pits distributed over the convex surface. They appear early in the season, May and June, are generally free from insects, and may be dried for future use; all the common species are edible. A morel may be recognized by its resemblance to Fig. I83, which is Morchella conica. MTorchella 
esculenta, the esculent morel, has an oblong or egg-shaped cap, and in $M$. deliciosa, the "delicious" morel, the cap is nearly cylindrical.

Stinkhorn Mushrooms, Phalloidece. - These might be omitted, did they not too often force themselves upon our attention. Their vile odors, suggestive of decaying animal matter or escaping sewer gas, strike consternation to the householder, and he is likely to begin a vain, because misdirected, search for the cause of offense. The odor probably serves the plant by attracting insects, which in return for their feast disseminate its spores. While there are several kinds, differing in color and somewhat in structure and form, the general appearance of the plant as shown in Fig. I84 will be sufficient to classify any specimen that may be brought in. The stinkhorns are not given in the books as poisonous; in fact, most of them have the reputation of being "edible" if taken in the egg stage. The most

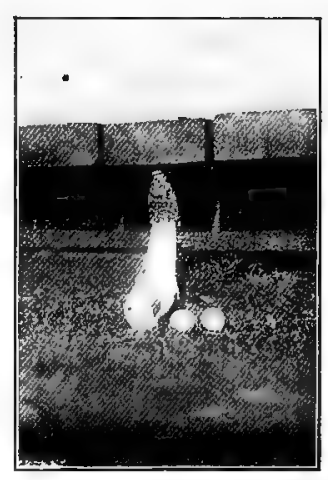

Fig. 184. STINKHORN MUSHROOM AND EGGS frequent question about them, however, relates not to their edibleness, but rather to methods by which they may be exterminated. They are apt to grow about rotting wood in damp places, and since we know that the main portion of the plant, the mycelium, consists of a mass of fine threads beneath the surface it will probably be necessary only to scrape up and clear away any decaying wood and possibly turn over the soil to a depth of a foot effectually to rid the place of the nuisance. 
Trembling Mushrooms, Tremellinca. - These strange fungi derive their name from their gelatinous consistency. The spores are borne over the entire surface. They occur generally on decaying twigs or wood, drying up so as to be scarcely distinguishable and swelling again when wet. Little or no food value attaches to the group, but none have been reported as poisonous.

Agarics, Agaricacee. - Any mushroom having the sporebearing surface arranged in folds or gills radiating from the stem, or from the point of attachment when no stem is present, is an agaric. Possibly the chief reason for introducing the study of mushrooms into elementary courses is to enable the pupils to distinguish certain extremely poisonous plants of this group, the amanitas. The distinguishing features of Amanita phalloides, our most deadly species, are sufficiently well indicated in Fig. I79; but the way to teach them is to have the specimens brought in wherever this is possible. Amanita verna, appropriately called the "destroying angel," so closely resembles $A$. phalloides that it may be considered, for elementary purposes, a white variety of it. A. muscaria, the fly agaric, is generally larger than $A$. phalloides and differs from it in having the cap bright yellow, varying to orange and even red. Crumbled into a saucer of sweetened water, it serves as an effective fly poison, whence its name. The gills are white, rarely yellowish, and the cap is typically dotted over with whitish flocks or scales formed from the part of the volva that clings to the cap as it expands. These may dry up and blow off and hence be absent from old specimens - a fact that should be borne in mind if we are to make the acquaintance of $A$. ccesaria. 
Two or three amanitas are edible, notably $A$. mbescens and $A$. casaria, but the variations in size, color, and other characteristics that occur, as they grow under different conditions of soil and weather, are so great, and their resemblance to the poisonous species so close, that we must pass them over to the specialists.

A. rubescens is dingy red, and the flesh quickly turns red when broken. The gills are white, and there is scarcely any trace of a cup at the base of the stem, since nearly the whole of the volva is carried up and remains as warts scattered over the cap. A. cessaria, the imperial agaric, cibus deorum, reddish or orange fading to yellow with age, is one of the most beautiful and "delicious" of mushrooms. While its cap resembles somewhat $A$. muscaria in color, it rarely has any flocks from the volva on it, and the gilis are bright yellow.

From Figs. 179 and 180 we see the general characteristics of this group of deadly plants. No one infallible rule or test can be given to distinguish an edible from a poisonous agaric; but the death

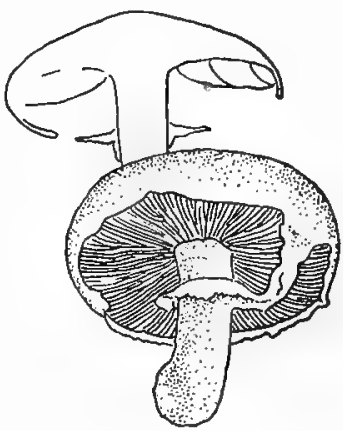

Fig. 185. CoMmon MeAdow Mushroom cup or a scaly bulbous stem, the veil or annulus, and the white spores, taken together, indicate that a specimen belongs to the amanita family and must be avoided. These poisonous mushrooms are common in the woods but occur on open meadows or lawns The common meadow mushroom, Agaricus campestris, the species raised for markets, has brown spores, flesh-colored to dark-brown gills, and, since it is not inclosed in a volva or sac in its early stages, it has no cup at base of stem or 
warts on the cap, but has a well-marked veil on the stem. It grows in open meadows and pastures, though species much like it are found in woods.

This is considered far enough for elementary pupils to go in the classification of the agarics. Still, many others are likely to be brought in, and it may be helpful, rather than otherwise, to distinguish a few of the more prominent groups.

The shaggy mane and ink cap, of the genus Coprinus, are common about rich lawns and barnyards after wet weather. The spores are black, and the gills turn black and liquefy as the plant reaches maturity. The black fluid thus formed, mixed with the spores, falls in inky drops from the cap. If taken before the gills turn black, they are edible.

The milky mushrooms, of the genus Lactarius, form an interesting group, easily distinguished by the milky, or colored, juice which exudes from any part of the plant when it is broken. The juice of these mushrooms may be tasted if care is taken not to swallow any of it, and those that are not bitter or peppery may be considered edible.

The Russulas (Lat. russus, " red ") are the brilliantly colored inushrooms - red, pink, purple, blue, green, and yellow - that enliven the woods of summer and early fall. In form and fragile structure they resemble the milky mushrooms, but none of them exude any milky juice when wounded. One of them, R. emetica, is rated as poisonous by most authors, but its acrid taste is sufficient to prevent a person from eating enough to do serious harm. In color it passes from rose, when young, to blood red and finally to tawny or yellow when old. Other species of russulas which have a mild and agreeable flavor are considered edible.

Pore- or Tube-Bearing Mushrooms, Polyporaceœ. - Numbers of mushrooms will probably be brought in which resemble the agarics in form but, instead of gills, have innumerable tubes or pores, from which the spores are dropped. Most of these, except the Boleti, grow upon wood, stumps, and 
trees, both dead and alive, and many are directly responsible for the death of trees upon which they are found.

Boleti. If the mushroom is soft, not woody, and has tubes easily separable from the rest of the cap, it belongs to the genus Boletus. Several Boleti are pronounced edible, but, as with the amanitas, taste is not a safeguard against the "poisonous kinds. Satan's Boletus, B. satanus, $B$. luridus, $B$. alveolatus, and other allied species are set down in most of the books as poisonous. Mcllvaine pronounces them "remarkably fine

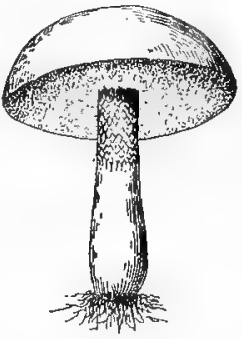
eating." B. satanus is a large mushroom, three Fig. 186. A Boletus to eight inches in diameter, brownish yellow to dull white in color. The tubes are yellow, except at their mouths, which are bright red. The stem is thick and swollen and is marked with red reticulations near the cap. The flesh is whitish but changes to reddish or violet when wounded. B. luridus is similar, but smaller, two to four inches broad, brownish olive above, and the flesh turns blue when broken.

Fistulina. If the tubes hang separate, i.e., are not cemented together in a mass, the mushroom is a Fistulina. The common species is $F$. hepatica, the beef tongue, or beefsteak fungus, which grows sometimes in huge masses on oak and chestnut stumps. Its color is red, variegated above and streaked in lines of growth.

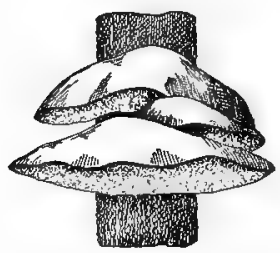
Below, the spore surface is pale, tinged with yellow or pink. The beefsteak mushroom is certainly not poisonous, and some consider it edible in spite of its marked acidity.

Polypori. If the tubes cling together, are inseparable from the cap, and the plant becomes woody or corky with age, it is probably a Frg. 187. A Polyporus, Polyporus. These are the "bracket fungi," OR BRACKET MUSH- "punks," and "conchs" often found growing upon trees. A few Polypori are "edible," after a fashion, when young and tender, but the chief reason for studying them relates to their injury of trees. Have the class examine the 
trees in the neighborhood and report the number attacked by these fungous growths. Can the children discover how the fungus gains access to the wood? They may find some broken limb or some place where the bark has been injured, to account for the infection. With shade and garden trees all wounds should be painted over as soon as made, to protect the trees from the spores of fungi. In general, decaying wood, stumps, branches, or trees upon which these fungi have begun to grow should be cut and burned, to prevent infection of healthy trees. Any piece of rotten wood will show how the fungous growth affects the tree. Seek for pieces that contain plainly visible mycelium, white threads, permeating the wood. These, as with mushrooms that grow on the ground, form the nutritive part of the plant, absorbing certain elements from the wood cells, thus causing them to soften and crumble.

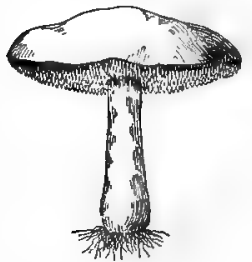

Fig. 188. A HedGe-

HOG MUSHROOM At certain seasons the spore-forming portion is pushed out into the air.

\section{Spine-Bearing or Hedgehog Mushrooms,} Hydnacea. - If a mushroom, instead of gills or tubes, has spines that point toward the earth, it may be called by either of the above names, or, botanically, it is a Hydnum. The class contains most variant forms. Some are umbrella shaped with central stems, others grow on wood and may form a mere flattened layer closely attached to it, while others may develop shelf or bracket forms, like many of the Polypori. Other species grow in branching forms, like the coral mushrooms, but are distinguished from them by the fact that the teeth or spines always point earthward instead of upward. Several common species are said to be edible, and no Hydnum described in the books is stated to be poisonous.

I have endeavored to give a few suggestions that may form an introduction for a child to a large, interesting, and 
important group of plants. It has been done with the purpose of preventing accidents from mushroom poisoning, and at the same time of opening the way toward a study of fungi that may lead to better utilization of the valuable kinds. In any favorable locality a continued search would probably be rewarded by finding at least five or six hundred different species of mushrooms. It is not strange that a few out of this number should be poisonous. If we are to use mushrooms, we should know them as we know apples and potatoes. They are fragile and plastic, vary under differing conditions, change color with age, etc., so that to know a species means ability to recognize it in all its different guises, and this is no slight task. Take one at a time is a good rule, and be sure you know it whenever and wherever met with. Soon you will have become acquainted with a group of interesting friends and acquaintances and fascinating enemies.

The way mushrooms have been tested to ascertain whether they are edible has been described somewhat as follows: Take a bit of the fresh mushroom the size of a pea, chew it and hold in the mouth for a minute or two, reject, wait twenty-four hours and note whether any bad effects supervene. If not, chew another bit of a perfectly fresh specimen the size of a pea and swallow. Wait a day and note effects.

Mushrooms often change their flavors on being cooked. If no bad effects have been produced thus far, cook and eat a small piece. Do not season, so that you may be able to describe the flavor accurately. If the tests indicate that the species may prove a valuable addition to the common dietary, gradually increase the amount eaten until thoroughly convinced that it is wholesome. The final step in the procedure is to try the mushroom on your friends.

I give these directions with the view not of encouraging people to begin testing mushrooms promiscuously, but rather of preventing accidents from careless or ignorant testing. 
When we come to know them as well as we do the common nuts and wild berries and fruits of the fields and woods, mushrooms will add spice, interest, and variety to every walk, excursion, hunt, or camping trip. But a few general precautions should be added, and those already given may be briefly summarized.

I. Never be tempted into eating a mushroom in the "button" stage, especially one found in the woods. At this time the marks by which the different species are distinguished are not developed. Many accidents have happened from disregard of this sensible precaution.

2. Reject all mushrooms that show signs of decay. Any food may become unwholesome or even poisonous if tainted. All specimens infested by insects should also be discarded.

3. Reject all mushrooms that have a cup or sac or scaly bulb at base of stem, a veil or annulus, and white spores. These three characters combined point infallibly to the deadly amanitas; but, at first, reject all that show any trace of a cup and use extreme caution in dealing with any members of this group.

The statement of Dr. George Francis with regard to all other mushrooms is: "Being certain that you have no amanitas, it is not unsafe to make cautious trial of any species whose raw taste is not objectionable." 


\section{CHAPTER XXVII}

\section{FLOWERLESS PLANTS (Continued)}

\section{Moulds, Mildews, Yeast, Bacteria}

IF we have studied the mushrooms and have seen the mycelium, it will be an easy step to understand the moulds, and from these, through the familiar yeast plant, we may pass to the study of the bacteria. We shall not have far to seek for specimens of moulds and mildews. We may find them too often on plants and trees that we are trying to rear. After a period of wet weather they may cover the books on our shelves, the clothes in our closets, - not to speak of the eternal vigilance necessary to prevent them from appropriating any food that is not sealed against their attacks. While many may be inclined to consider them too minute for elementary lessons, in the mass they are easily seen, and their relation to proper sanitation of the home and to fungous diseases of plants makes them an essential part of the plan for nature study. As a whole, too, the group plays a necessary and beneficent rôle in nature.

Moulds. - A jelly glass, or even a medicine vial, furnishes ample room for a garden of these instructive plants, and they may be cultivated on almost anything for soil. First we will take some kind of liquid culture medium in which we can see all the different parts of the mould plant as it 
grows. Fruit juice as it comes from preserves, - as clear and colorless as possible, - diluted one-half and filtered or strained through fine cheese cloth, makes an ideal medium. Fill the vial or glass half full and sprinkle a little dust from the schoolroom over the surface. Cover and set aside to observe from day to day. Three such cultures should be made, one of which should be kept in a dark place, one in a room where direct sunlight does

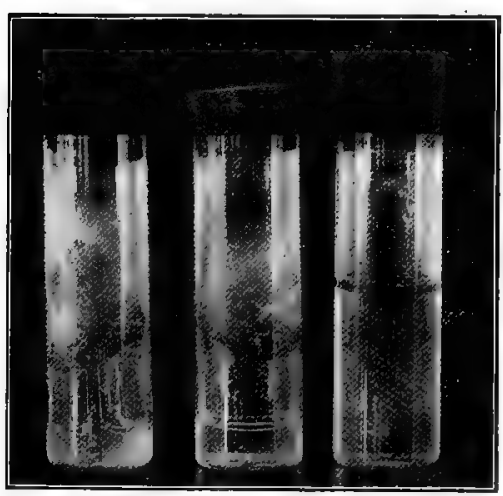

Fig. 189. Mould Gardens

The liquid culture is seen at the right. The others show arrangement for solid cultures. A little water is put in to keep the air moist, and the material is supported on a piece of glass not fall upon it, and the third should be kept in the sunshine as much of the time as possible. It would be better if each of the pupils had a vial and one-third kept theirs in the dark, another third, on their desks, in the shade, and the other third, in the sunshine. Then let them compare notes during the nature-study period and decide under what conditions moulds grow best. Let them vary the experiment to see if they can discover conditions under which moulds are unable to grow at all. Experiment by leaving the dust in the bright sunshine for one, two, or three days before planting it in the fruit juice. It should be kept in a dry vial stoppered with a plug of cotton batting. But before we can go further with this 
experiment we must be sure that we have killed all the germs that may be in the culture medium. Can any of the children suggest a way to do this? How is it done in their homes in the canning of fruit?

A convenient way is to plug the bottles with a wad of cotton batting and let them stand in a tightly covered steamer over boiling water for half an hour. This kills growing mould plants and bacteria, but not all the spores that may be present in the liquid. The heat will be likely to start any such spores into growth, so that if they are steamed again on the following day, or before the spores have had time to germinate and form spores again, we may be reasonably sure that no germ remains alive in our cultures. Two or three of these vials should be set aside to compare with others that are planted with dust or with the spores of different moulds; and, if all the germs have been killed and the cotton is not removed, the cultures will remain clear, and no growth of any kind will appear in them. This is known as "sterilizing." With a number of the cultures thus sterilized we may plant them with dust or the spores of any mould we wish to study. To do this, pick up a little of the dust or spores with the point of a clean needle and apply to the culture.

After a day or two, if there are any mould spores in the cultures, we should see a fine woolly growth spreading over the surface and sending its delicate threads down into the liquid. This is the mycelium, and the threads are known as hyphæ. The function of the mycelium, as in the mushrooms, is to absorb nutriment. Next we observe that a number of the hyphæ near the center of the mycelium are growing up into the air, and the forms they assume are characteristic of different species of mould. Four of these typical forms are shown in Fig. I90, but it is not intended to go farther into any details that require the use of the microscope. A number of the larger moulds, however, have fruiting hyphæ an inch or 
two in length, on the tips of which the beadlike spore cases are plainly visible to the naked eye.

We may next have the pupils substitute for the culture medium in their bottles various solid materials - bread, potatoes and other vegetables, meats, and a variety of different fruits. Each pupil may provide a different material, and in this way the class will gain a notion of how omnivorous the moulds are.

An experiment that must not be omitted consists in inoculating a number of different fruits with mould spores,
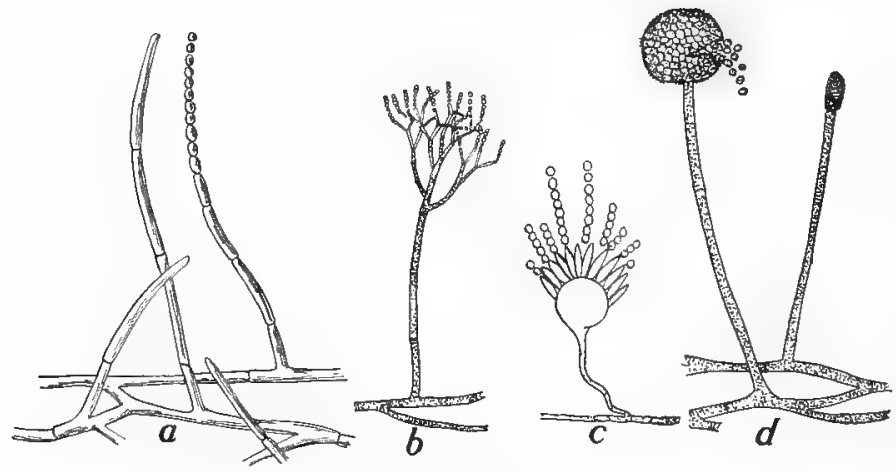

Fig. 190. Different Kinds of Movid $a$, milk mould; $b$, blue mould; $c$, black mould; $d$, white mould

to observe the process of decay. Here again the children may take different fruits for variety's sake - some apples, some pears, others plums, peaches, grapes, each child taking different varieties so far as practicable. We will suppose that the pupils have each three fruits of the desired variety. Having cautioned them to secure perfect specimens with stems attached and no breaks of the skin, let them each put one fruit aside, perfect; let them 
make a single puncture with a pin in the second and rub in some mould spores or a little dust; put this away with the first; and let them puncture the third, but, instead of inoculating it, let them leave it, puncture side up, exposed to the air on their desks. They may vary the experiment still further by having different pupils use for their inoculations a number of the moulds described below. This experiment coördinates itself with practical fruit culture and the need of "hand picking" of choice fruit. It also carries a larger lesson related to intelligent cleanliness in care of the skin and treatment of scratches, cuts, and bruises, since in this function of protection the skin of an apple and that of a child are much alike.

Our experiments and observations cannot go far before we see that there are many different kinds of moulds. We notice, first, that while the mycelia of all appear much alike to the naked eye (generally white, like cotton batting), the spores are of different colors; and these may serve as a basis for elementary classification.

Blue Mould, Penicillium glaucum. - This is the commonest mould we have, and its blue velvety growths over bread and all sorts of foods and on the leather of shoes and gloves have made it only too familiar to all. Its manner of spore formation is shown in Fig. Igo, $b$.

Black Mould, Aspergillus niger. - This is another common household form on bread, vegetables, and fruits.

White Mould, Mucor mucedo. - The white moulds are especially good for elementary lessons on account of their comparatively large size. They grow on all kinds of food, and after covering the mass with a white cottony mycelium they send up fruiting hyphæ, often one or two inches in height, which terminate in little black beads - miniature puffballs - in which the spores are produced. These are seen, enlarged in Fig. $190, d$, and natural size in the "mould gardens" in Fig. I89. 
Mildews, or Moulds of the Garden. - The moulds that attack plants are commonly known as mildews, rusts, blights, or smuts. The number of these minute parasitic fungi is legion, and as a group they rank with destructive insects in rendering the raising of flowers and fruits difficult and interesting. We can introduce into the course only a few of the more important, such as are most closely associated with the children's garden studies. They may be considered as types to indicate methods of study that can be applied to many other kinds. The methods of universal application, for preventing fungous diseases of plants, relate to intelligent cleanliness of garden and premises (the burning of rubbish and dead leaves that may harbor the spores) and to so planting and pruning as to admit sunlight and air to every part of the plant. For recent information about more special methods we should send to our State Experiment Station for the latest Spray-Calendar.

The Black Knot, Plowrightia morbosa. - Request the children to search their plum and cherry trees, bring in specimens, and report the distribution and prevalence of this fungus in the neighborhood. The summer crop of spores is produced in June. The knot at this time is greenish brown and velvety. The winter spores are produced in capsules in the black mass. From about December and for the rest of the winter these capsules are perforated and the spores are shaken out by every puff of wind, like pepper out of a pepper box. The spores that happen to lodge behind a bud or in a crotch or crevice send their mycelial threads into the living wood, where they multiply greatly and thus cause the swelling or knot. Finally, they send fruiting hyphæ to the surface, and the life story is repeated. A single knot is thus a menace to an orchard or neighborhood; one should never be permitted to develop spores, but should be cut off and burned as soon as any swelling appears. 
The Brown Rot, Monilia fructigena. - Plum, cherry, and peach trees are often stripped of their entire crop by this destructive fungus. It probably consumes more of these fruits than all the boys and girls in the country. The class should study its prevalence and distribution in the neighborhood along with that of the black knot. It is characteristic of this fungus that affected fruits cling to the branch over winter, often cemented together in clusters. In this condition they are said to be "mummied" (see Fig. 192). The life story of the brown rot is like that of all moulds: a spore lodges on a fruit, germinates and fills the fruit with its mycelium, and the fruiting hyphæ grow out to scatter the spores. If the pupils will inoculate a few plums, they will see how rapidly this fungus works, and by so doing appreciate the necessity of picking and burning

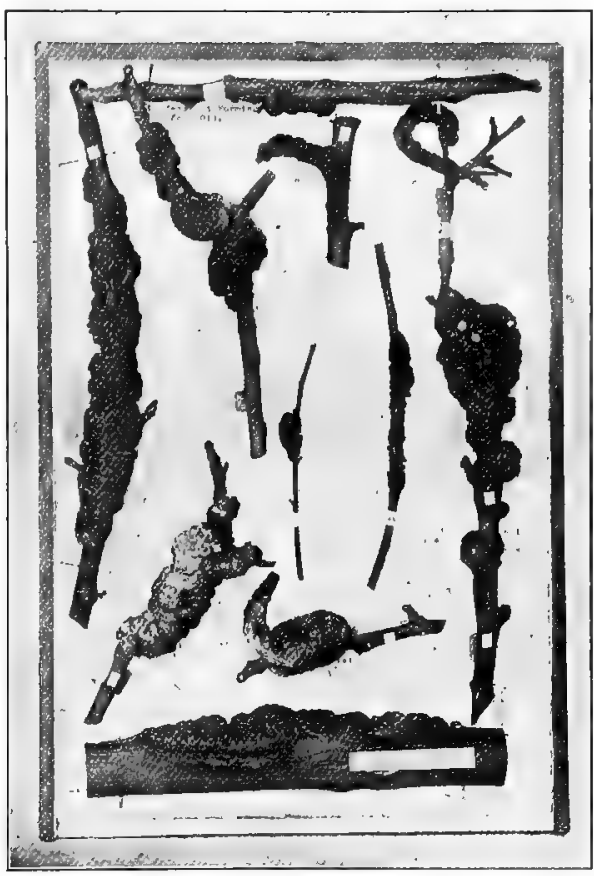

Fig. I9I. THE BLACK KNOT

(Photograph of collection prepared by Burton N. Gates, aged sixteen, for his class in the high school)

affected fruits before the spores are cast. Remedies for Monitia are pruning to let in light and air, thinning plums and peaches so that no two fruits touch, picking and burning all diseased fruits as soon as detected, and burning all mummified fruits in the fall, since they produce another crop of spores in the spring. 
Peach-Leaf Curl, Exoascus deformans. - By attacking the leaves, blossoms, and growing twigs of the peach this fungus sometimes causes the loss of the entire crop, and great damage to the trees. If present in the neighborhood, the pupils will have no difficulty in finding specimens for study. Peach-leaf curl is so easily prevented by spraying that there is no excuse for allowing an orchard to be affected by it.

Peach Yellows. - No fungus has been discovered in connection with this disease, although it has been sought for with great diligence. Expert testimony inclines to the view that it is not due to a germ of

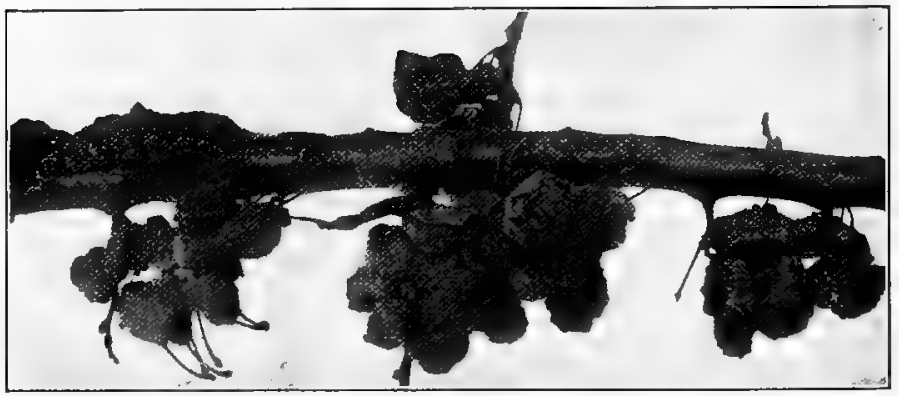

Fig. 192. Plums Destroyed by Brown Rot

any kind. Still it is clearly contagious, is transmitted by seeds or buds, and probably by the mere presence of a diseased tree in the orchard. How these facts can be explained on any other theory than that of the germ origin of the disease, it is difficult to imagine. Affected trees ripen their fruit prematurely, and many of the buds intended for the following spring burst into a spindling, sickly, yellow growth during the summer. No tree has been known to recover when once attacked, and since the fruit is worthless, the sooner it is uprooted and burned the better. Laws compel a man to do this in a number of states where peach raising is an important industry.

Other garden fungi that should be observed and studied are:

Downy Mildew, Peronospora viticola. - This fungus attacks grapes, especially vines allowed to grow without proper pruning. 
Orange Rust, Caoma nitens. - Raspberry and blackberry bushes are often attacked by this fungus, the leaves and young shoots coming out bright orange in the spring. The appearance is so striking as to need no description. Affected plants should be uprooted and burned before the spores ripen.

\section{Rose Mildew, Spharotheca pannosa.}

Apple Scab, Fusicladium dendriticum. - This fungus is commonly found as black scabby patches on the leaves and fruit and has been estimated to injure from one-sixth to one-half of the entire apple crop.

The Grain Smuts. - A conservative estimate of the damage caused by fungi attacking corn, wheat, oats, barley, and rye is said to be $\$ 200,000,000$ annually; and this amount is stolen so stealthily that few realize their loss. In grain-raising sections have each pupil gather one hundred heads of wheat and oats at random, and estimate the percentage destroyed by smut. ${ }^{1}$

Yeast. - Moulds and mildews are plants, many of which we can see without difficulty. We now descend a step lower to forms that we cannot see without a microscope, except in the mass. Greatly magnified, yeast plants have the appearance of tiny ovoidal bodies, of which it would take about 3000 placed side by side to Yeast Piants measure an inch. Still, small as they are, Showing manner we can study them in a practical way.

We may use our medicine vials again for this purpose. Suppose one-half of the class have their vials each partially filled with diluted fruit juice, such as we used in the study of moulds; and the other half, after thoroughly cleansing and scalding their bottles, have a large drop of freshly scalded flour or starch paste. It should be made as transparent as possible, be free from air bubbles, and be spread out evenly in one side of the vial. Let the pupils provide themselves with needles mounted in sticks and pieces of clean glass,

1 "The Grain Smuts: how they are caused and how to prevent them," by Walter T. Swingle, Washington, I 898, Farmer's Bulletin, No. 75 . 
and we will place upon each of the glasses a bit of compressed yeast the size of a pin head. Ask each to divide his yeast, first in halves, then one-half in halves again, and so on until he has a particle that he can just see. Let the pupils now plant these just visible particles in their vials. They may then cork them and observe the growth that takes place from day to day. If a piece of rubber dam is stretched over the top of one of the bottles containing fruit juice and tied tightly, the gases produced by the growth of the yeast will puff up the rubber and thus help to show that something is going on inside. The liquid will soon become turbid, full of bubbles, and at last a mass of white substance will settle to the bottom. This is composed of yeast plants, but may be many thousand times the amount witl which we started. The liquid will have lost its sweet taste and will smell and taste of alcohol, or possibly of vinegar. The particle on the starch paste will gradually overgrow the whole drop, changing it to a whitish mass of yeast plants.

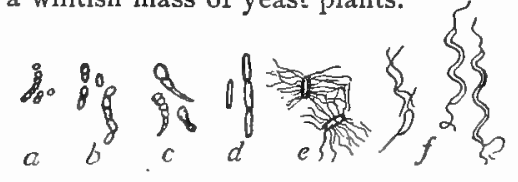

Frg. 194. Forms of Bacteria

$a$, grippe; $b$, bubonic plague; $c$, diphtheria ; $d$, tuberculosis; $e$, typhoid fever; $f$, spiral types.

Bacteria. - The smaller a living particle is, the more powerful may it become. This is because the smaller a cell is, the more surface it has in proportion to its bulk for the absorption of food. Bacteria are the smallest living things we know and, in many ways, the most powerful. Different forms of bacteria are shown in Fig. I94. Some are spherical and so minute that it would takc I 25,000 of them placed side by side to measure an inch. Others are rod shaped, but so. short that I 500 placed end to end would make a line only across the head of a pin. Many of the elongated forms are bent into commas or 
twisted into spirals or corkscrews. Minute as they are, many bacteria have threadlike appendages, with which they swim actively about.

It has been difficult to decide whether we should class bacteria as plants or animals. Their food and what little structure they possess are considered to show, however, that they are plants, related more closely to the fungi than to any other group.

Bacteria are practically everywhere in nature. They exist in the air as dust; they swarm in all surface waters; the top layers of fertile soil are literally alive with them, almost all of them harmless or beneficial. The udders of healthy cows, the healthy human mouth, the healthy stomach and intestines, all support varied floræ of these ubiquitous plants. Normally, however, they are not present in the blood or other tissues of a healthy animal.

Bacteria were discovered by Anton van Leeuwenhoek in 1683 , but were known merely as curiosities until about I880, when Robert Koch and Louis Pasteur demonstrated their power to cause disease. For a time people were greatly alarmed; they next bethought themselves that humanity had fared well before the bacteria were discovered and would doubtless continue to fare as well, or better, thereafter. As knowledge accumulated, they realized that there is no reason why bacteria should not be as good to eat as other vegetables; and finally arrived at the view as expressed by a leading scientist, that a healthy human body is, after all, the best microbe destroyer in the world. Fresh air and sunshine, exercise, good food, vigor, and a high health level give us these, and with a few reasonable precautions we have practically nothing to fear. 
Small as bacteria are, they possess powers of growth and multiplication not paralleled by any other living forms. It is estimated that if all the oceans were nutrient broth, with an average depth of one mile, the progeny of one microbe might fill them full in less than five days.

By precise methods it is possible to rear as pure a culture of a desired kind of bacteria as of any garden plant. While we shall not be able to do this, we may make a number of instructive observations if we are on the alert and know what to look for. The phosphorescence of decaying wood, fish, or meat is due to bacteria of decomposition. The red color, known in superstitious times as the "bleeding Host," that sometimes overspreads bread and other foods, is caused by other harmless bacteria.

It will be difficult or impossible, without expensive microscopes, to distinguish bacteria from yeasts and moulds. Still, a few simple experiments may be tried. We may use our vials again, - this time filled with hay infusion $^{1}$ or with a dilute, perfectly clear broth. We may sterilize, as before described, by boiling on two successive days, and then sow a minute quantity of dust from the schoolroom or the street, keeping other vials stoppered with cotton for comparison. The vials in which dust is sown will soon grow turbid, a scum will form on top, and an offensive odor of decomposition will probably make it necessary to wash the vials out before the experiment has continued too long. A boiled potato cut in two

1 Hay infusion is made by soaking a handful of hay in a quart of warm water for an hour and filtering. Bread water, potato water, or meat juice diluted - any clear solution containing a little organic matter - will serve the purpose. 
with a sterilized knife (a knife that has been held in a flame for an instant or in boiling water for a few seconds) makes a good field on which to sow dust and observe the growth of bacteria. The best culture medium, however, is gelatine, ${ }^{1}$ which may be used in the pupils' vials after the hay-infusion experiment. Dust sown on its transparent surface will leave little doubt in their minds as to the reality of microbes.

Some of the gelatine poured while warm upon a small pane of clean glass may be made to yield a most instructive demonstration. Touch the hand, soiled and dusty as it is, to the solidified gelatine for a few seconds; then wash the hands with soap and apply to a fresh surface of the gelatine; keep protected from dust for two or three days. The soiled hand will be outlined by colonies of bacteria, while possibly none or few will grow where the washed hand touched the gelatine. I know of no experiment which demonstrates so forcibly the reason for washing the hands before breaking bread.

Pear Blight. - The leaves and bark on branches of pear trees sometimes turn black. This is due to the work of bacteria which gain access to the tree through the blossoms or through some wound in the bark. It was thought that bees were largely to blame for carrying the germs of blight from blossom to klossom, and the experiment has been tried of removing them entirely from the neighborhood of pear orchards during the blossoming period. This

1 Gelatine for study of bacteria is prepared by dissolving in 200 cubic centimeters of water I gram each of Liebig's beef extract and common salt and $z$ grams of peptone, adding 20 grams of gelatine. Dissolve and neutralize, or make slightly alkaline with sodium carbonate. Stopper the bottle with cotton batting and boil for fifteen minutes on three successive days. 
resulted in greatly impaired fruit, from lack of cross-pollination, and apparently little difference in the distribution of the blight. Affected limbs should be cut off a foot below any traces of the blight and promptly burned.

Foul Brood. - Large numbers of young bees are sometimes found dead in the cells. This may be due to chilling, but if the larva have turned dark brown and softened to the consistency of ropy mucus, and if the hive smells like a glue pot, we have to do with the most fatal malady that can attack a colony of bees. The disease is caused by bacteria, and an affected hive may be the means of killing all the bees in the neighborhood. California, Colorado, Michigan, Nebraska, New York, Utah, Wisconsin, and Ontario, Canada, have passed laws relative to foul brood, which should be studied in connection with the lessons on the honeybee.

Symbiotic Bacteria. - Have members of the class prepare a demonstration of the nodules found on the roots of clover or peas. These are filled with bacteria, which we here find in the new rôle of helpers and food producers for the plant and for man. If time permits, we may try a most instructive experiment. Wash thoroughly and sterilize two flowerpots full of sand. Sow clover or peas in both alike, except that the seeds for one pot should be thoroughly washed with boiled water and soap, and those for the other moistened with water in which root nodules have been crushed. Let the plants stand side by side, sprinkle with boiled or distilled water, and wateh the difference in growth. Plants in the one pot can use only the food stored in the seed; those in the other will grow with the aid of their symbiotic bacteria by receiving nitrogen from the air. 
Intelligent Cleanliness. - Incidentally, and with a reasonable amount of tact, make plain the relation of certain bacteria to disease, laying all the emphasis on intelligent cleanliness as a means of prevention. Our lessons on moulds and mildews and other fungi will have done much to define the problem. I do not know of a better plan than to study with the class the board of health regulations of the city or town with regard to cleanliness of premises, isolation and control of contagious diseases, and practical methods of disinfection. Then, in order to test the efficiency of these health measures, take the published reports of the board of health. Are there cases of preventable contagious disease? Comparing recent reports with those of former years, has there been improvement? The story of epidemics in the neighborhood will be instructive.

Ways by which Bacteria enter the Body. - Ask the pupils to think of a way by which bacteria may gain access to the body. After our experiments with dust they should be able to do this intelligently. The various answers may be grouped as follows.

The Air Passages. - Since bacteria, as we have seen, form part of the dust, they may enter the body with the air we breathe. In elementary physiology lessons the children have learned that the nostrils are provided with curved and folded surfaces moistened with mucus, one of the functions of which is to catch all particles of clust and so prevent them from reaching the lungs. People who breathe through the mouth are continually taking dust into their lungs. Diphtheria, tuberculosis, pneumonia, and, especially, grippe are some of the diseases that may 
be transmitted by dust in the air. The bacteria get into the air chiefly, if not wholly, from sputum, which after drying may be taken up by the wind. For many localities the board of health reports will show that more than oneseventh of all the deaths are caused by the bacteria of tuberculosis. Regulations of the authorities with regard to spitting in public places should be heeded most carefully.

The Skin.-If cuts or scratches become inflamed, "sore," fester, and discharge pus, we may know that bacteria have forced an entrance. Thus, all breaks in the skin should be kept clean and carefully protected from dust.

The Mouth. - This is perhaps the most important portal of infection, especially with children. Typhoid fever, cholera, dysentery, and similar intestinal diseases commonly enter the system by this channel, and generally either with drinking water or with food. Ascertain from the board of health any local history there may be about typhoid fever outbreaks.

An instructive fragment of such local history happened in Worcester, Mass., in I896. Three cases of typhoid fever, all on the same milk route, were suddenly reported to the board of health. The clerk of the board hastened to the milk farm and found its proprietor sick with typhoid fever. By completely cleansing everything connected with the dairy and by insisting on its removal to a neighboring farm, the milk route was not interfered with, and no other cases developed. What might have proved a serious epidemic was nipped in the bud.

An epidemic with which the above should be contrasted happened in Stamford, Conn. In the spring of 1895,386 cases and 25 deaths occurred, practically all of them on the milk route of a man who distributed less than one-tenth of the milk supply of the town. The investigation indicated that all this suffering and loss of life was 
caused by rinsing the milk cans in water from a shallow well, practically a cesspool. The few bacteria clinging to the cans multiplied rapidly in the warm milk. ${ }^{1}$

The typical case in which typhoid fever was distributed through the water supply is that of 1885 in Plymouth, Pa., a mining town of about 8500 inhabitants on the Susquehanna River. A case of typhoid fever, contracted in Philadelphia, had been cared for during the winter in a house standing close to a stream that flowed into the town reservoir. The waste from the patient had been thrown out on the snow unsterilized. When the snow melted, this was carried down and mingled with the water supplied to the town. After about ten days cases of typhoid fever began to appear at the rate of from 50 to 200 a day until 1 I 04 had been taken ill, and as a result I I 4 died. This calamity befell the town because some one was negligent or did not know how to destroy a few germs of typhoid fever or prevent them from gaining access to a water supply.

The school is a natural mingling place for the germs of a community, and it is time that parents, teachers, and pupils should combine to make it the most ideally clean place in the neighborhood. Attention has often been called to the fact that diseases of children point to the school as the great center of infection. I dare say that the statistics of any town or city will show this; and until the feather duster is banished and intelligent cleanliness is secured, this will go on. Fig. I95 is plotted from the monthly reports of the Worcester Board of Health for the three children's diseases specified.

Why do we go to the expense of providing tools for manual training, household furniture, and materials for sewing, cooking, and domestic science, and leave the most important work of all — cleanliness of the schoolroom - to

1 Prof. Herbert E. Smith. Report on the Stamford Typhoid Fever Epidemic. Published by the State Board of Health, New Haven, Conn. 
the janitor? Why do we fail to give the lessons that will flow out in health and cleanliness into all the homes of the district and go with the children as long as they live?

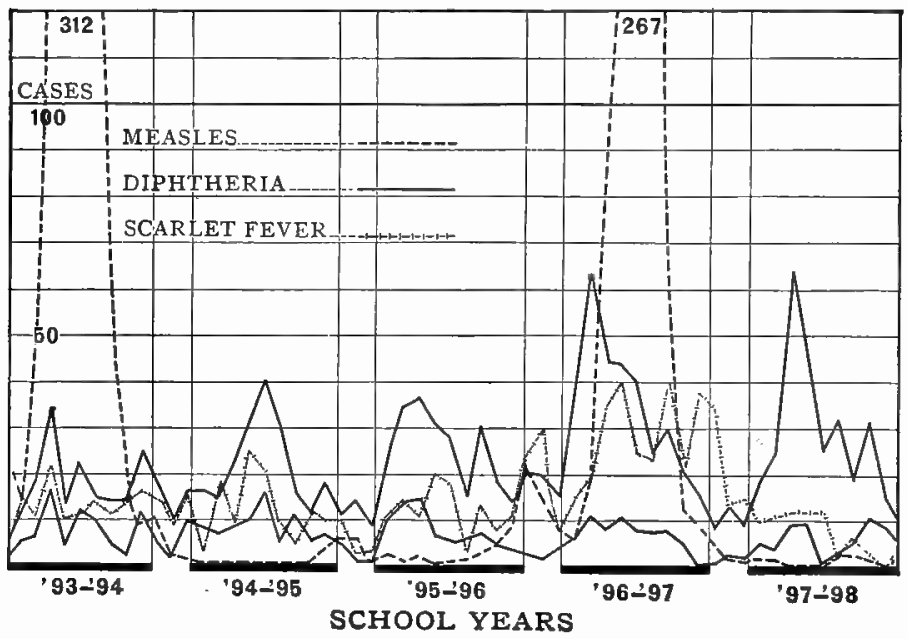

Fig. 195. The School and Contagious Diseases of Children The upper line for diphtheria gives the number of cases, the lower, the number of deaths. The summer vacations are indicated as breaks between the school years

The following, published by the Health Department of Providence, marks an advance in rational teaching of cleanliness and personal hygiene.

\section{HEALTH DEPARTMENT}

Suggestions for the Teaching of Cleanliness among SCHOOL Children

The poisons of some of the common and also of some of the most loathsome diseases are frequently contained in the mouth. In such cases anything which is moistened by the saliva of the infected person may, if it touches the lips of another, convey disease. The more direct the contact the greater the danger. 
It is the purpose of health officials to keep in isolation all persons having communicable disease during the time that they are infectious. But in many cases this is impossible. Little restraint is put on certain mild diseases, as measles, whooping cough, chicken pox, and mumps; and even such diseases as diphtheria, scarlet fever, and tuberculosis are frequently so mild as to be unnoticed, and children affected with them mingle freely with others. It is probable that in such cases one of the chief vehicles of contagion is the secretion of the mouth and nose. It is believed that much can be done to prevent contagion by teaching habits of cleanliness. But if such instruction is to be effectual it must be continuous. The teacher must notice and correct violations of those rules as habitually as the violation of the formal school rules are corrected.

Even if the question of disease and contagion did not enter into the matter at all the subject ought to be given more attention by teachers. Our schools should not only teach reading, writing, and arithmetic, but it is perhaps quite as important that they should inculcate cleanliness, decency, refinement, and manners. Cleanliness should be taught for its own sake, even if it had no relation whatever to health.

\section{TEACH THE CHILDREN}

Not to spit; it is rarely necessary. To spit on a slate, floor, or sidewalk is an abomination.

Not to put the fingers into the mouth.

Not to pick the nose.

Not to wet the finger with saliva in turning the leaves of books.

Not to put pencils into the mouth or moisten them with the lips.

Not to put money into the mouth.

Not to put anything into the mouth except food and drink.

Not to swap apple cores, candy, chewing gum, half-eaten food, whistles or bean blowers, or anything that is habitually put in the mouth.

Teach the children to wash the hands and face often. See that they keep them clean. If a child is coming down with a communicable disease it is reasonable to believe that there is less chance of infecting persons and things if the hands and face are washed clean and not daubed with the secretions of the nose and mouth.

Teach the children to turn the face aside when coughing and sneezing, if they are facing another person.

Children should be taught that their bodies are their own private possessions, that personal cleanliness is a duty, that the mouth is for eating and speaking and should not be used as a pocket, and the lips should not take the place of fingers.

Providence, May, IgoI. 
I may add to the above Miss Henry's solution of the schoolroom dust problem. At the beginning of the school year I900-IgOI all the feather dusters in the building were collected and burned. Dusting cloths were provided, and two girls in each room were honored by being appointed dusters for the month. They are given instruc-

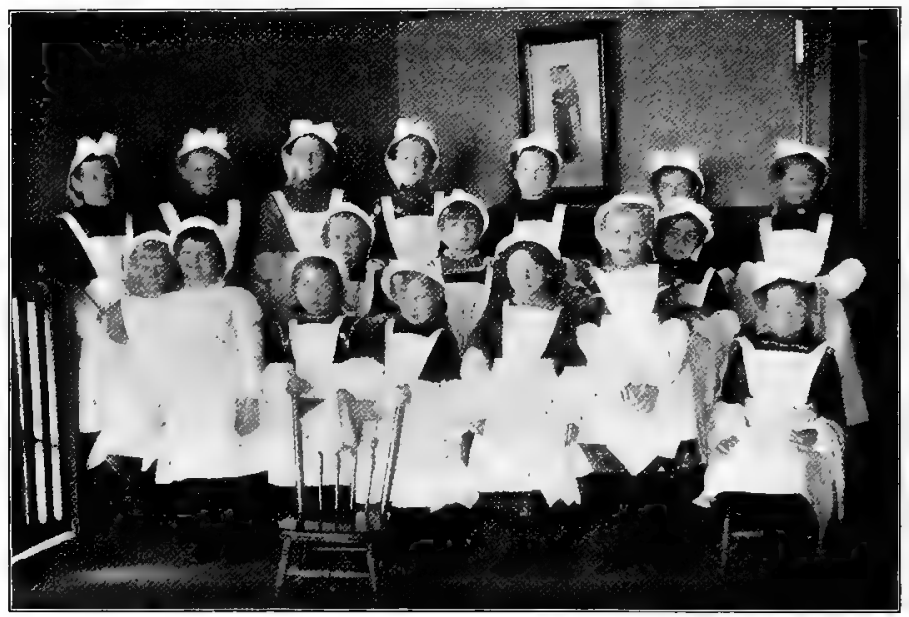

Fig. ig6. The Health Brigade

Upsala Street School, Worcester, Mass. (Photograph by Katherine E. Dolbear)

tion on dusting and on the care of the clust cloths and uniforms. The dusters come fifteen minutes early each morning, take their cloths to the sink, moisten them, wipe the desks and furniture of their schoolroom, rinse their cloths, and hang them up to dry. Once a week the cloths are laundered.

The result of the year's experiment was, not a case of contagion in a school of 425 pupils during the entive school 
year, - the first year in the history of the school of which this is true. The girls are eager to do the work and enjoy wearing the uniforms. In this way twenty girls, practically all in the class, are taught this element of domestic science and hygiene. Some slight objection has been made by a few parents on the ground of menial service or of soiling clothes. The little uniforms shown in the picture, it is hoped, may meet the one objection; and some appreciation of the value of the lessons and the dignity of the service, the other.

"I myself have washed a flight of stone stairs all down, with bucket and broom, in a Savoy inn, where they had n't washed their stairs since they first went up them, and I never made a better sketch than that afternoon." Ruskin.

"But so shall it not be among you : but whosoever will be great among you, shall be your minister : and whoso. ever of you will be the chiefest, shall be servant of all." 


\section{CHAPTER XXVIII}

\section{THE GRADE PLAN}

FOR a graded system of schools a few suggestions may be required as to the distribution of topics throughout the course. The following grade plan is offered, merely as a suggestion, by which progression and coördination of subjects may be secured, and confusion and repetition may be avoided. If $I$

\section{Grade I}

\section{LESSONS WITH ANIMIALS}

Domestic Animals: The dog; traits, uses, care, kinds

BIRDS: Robin

Bluebird
Chickadee.

Chipping sparrow
English sparrow Crow

Frogs and Salamanders:

Tree frog

Toad

Red and green newts, Feeding with insects; learn notes

Fishes: Goldfish

Shiners

Sunfish

INSECTS: Milkweed butterfly Cecropia moth Isabella tiger caterpillar Promethea moth Io moth Flea

Miscellaneous Animals: Turtles? Snakes $\}$ Living specimens, care and food 478 
thought that it would exert an undue influence toward rigidly fixing and mechanizing the course, I should leave it out.

Do not attempt too much at first. To begin with, select such topics under your grade as you are most familiar with, and such as are related to the interests of your pupils, and carry these through to a definite result. Gradually, as ease and familiarity are acquired, increase the number of subjects. For different parts of the country, as suggested throughout the book, free substitution of topics, different species of insects, birds, trees, flowers, etc., will be necessary. With the methods of study given for similar subjects, any such substitutions may be made without difficulty.

\section{GRADE I}

\section{LESSONS WITH PLANTS}

Competitive Flower Rearing: Dwarf nasturtium Study of Wild Flowers:

$\begin{array}{llll}\text { Arbutus } & \text { A golden-rod } & \text { Dandelion } & \text { An aster } \\ \text { Anemone } & \text { Oxeye daisy } & \text { Bluets } & \text { Burdock } \\ \text { A blue violet } & \text { Buttercup } & \text { Milkweed } & \text { Poison ivy }\end{array}$

Flower CaLENDAR

GARDEN WORK : Vegetable garden; radishes, onion sets, rhubarb

FRUIT: Peach (or plum); rear from seed

TrEes: $\left.\begin{array}{l}\text { Soft maple } \\ \text { Chestnut }\end{array}\right\}$ Save and plant the seeds

Flowerless Plants: Ferns; acquaintance with a few kinds

Myths, Legends, Stories, Poems, and Pictures of the Plants and Animals for this Grade 


\section{Grade II}

\section{LESSONS WITH ANIMALS}

Domestic Animals:

The cat

(Tame white mice?)

BIRDS :

Baltimore oriole

Song sparrow

Snow bunting

Downy woodpecker
Goldfinch

Blue jay

White-breasted swallow

Scarlet tanager

Frogs and Salamanders:

Bullfrog; feeding with insects; learn notes

FISHES :

Dace Acquaintance with living fishes in aquaria and in native Pout $\}$ baunts

INSECTS :

Grasshoppers

Crickets

June beetles

Flies

Lice
Black swallowtail

Polyphemus

Luna

Elm-leaf beetle

Potato beetle

\section{Miscellaneous Animals:}

Rats, mice; habits, destructiveness, methods of trapping 


\section{Grade II}

\section{LESSONS WITH PLANTS}

Competitive Flower Rearing:

Calliopsis

Study of Wild Flowers:

Cone flower

Iris

Trilliums

Mallow

Wild geranium Yarrow

Robin's plantain

Marsh marigold Healall

Bloodroot Poison sumac

Flower Calendar

GARDEN WORK :

Vegetable garden; lettuce, carrot, potato, onion (from seed)

FRUIT :

Grapes; layers and cuttings; save and plant the seeds

TREES :

$\left.\begin{array}{l}\text { Elms } \\ \text { Oaks }\end{array}\right\}$ Collect and plant seeds

Flowerless Plants:

$\left.\begin{array}{l}\text { Ferns } \\ \text { Mosses } \\ \text { Liverworts }\end{array}\right\}$ Acquaintance with a few kinds

Myths, Legends, Stories, Poems, And Pictures of the Plants and Animals for this Grade 


\section{Grade III}

\section{LESSONS WITH ANIMALS}

Domestic Animals:

Rabbit; foods, habits, care

BIRDS :
Barn swallow
Cedar bird
Night hawk
Phobe
Whip-poor-will
Chebec
Chimney swift
Junco
Humming bird
Meadow lark

Frogs and SALAMANDERS:

Leopard frog; live specimens, feeding tests with insects; learn notes

FISHES :

Pickerel Acquaintance with living fishes in aquaria and native Pike $\}$ haunts

INSECTS :

Mourning cloak

Imperial moth

Meal worm

Rose beetles

Clothes moth

Asparagus beetle
Caddis flies Water bugs Strawberry insects Dragon flies Damsel flies

\section{Miscellaneous Animals:}

$\left.\begin{array}{l}\text { Squirrels } \\ \text { Chipmunk }\end{array}\right\}$ Taming, habits, storing and planting of nuts 


\section{Grade III}

\section{LESSONS WITH PLANTS}

Competitive Flower Rearing:

Mimosa

StUdy OF Wild Flowers:

Solomon's seal

False Solomon's seal

Hepatica

Cinquefoil

Fringed polygala

Bur marigold

Flower Calendar

GARDEN WORK :

Vegetable garden; asparagus, beets

FRUIT :

Strawberry; varieties, propagation by runners, seeds

TREES :

Hard maples

Horse-chestnut Save and germinate seeds

Hickory

Flowerless Plants:

Lichens and algæ; recognize as classes of plants

Myths, Legends, Stories, Poems, and Pictures of the Plants and Animals for this Grade
Chickweed

Mountain laurel

Lambkill

Bellwort

Bittersweet

Wild carrot 


\section{Grade IV}

\section{LESSONS WITH ANIMALS}

Domesticated Animals:

Fowls ; kinds, habits, care, food, rearing

BiRdS :

Vesper sparrow

Catbird

Kingbird

Cowbird

Red-winged blackbird

Redstart

Flicker
Brown thrasher

White-breasted nuthatch

Red-breasted nuthatch

Quail

Partridge

Prairie chicken

Frogs and SALAMANDERS:

$\left.\begin{array}{l}\text { Green frog } \\ \text { Spotted salamander }\end{array}\right\} \begin{gathered}\text { Learn notes and make feeding tests with } \\ \text { insects }\end{gathered}$

Fishes:

Suckers; living fishes in aquaria and in native haunts

\section{INSECTS :}

Codling moth

Tent caterpillars

Cankerworm

Apple-tree borer

White-marked tussock moth
Fall webworm

Apple-leaf crumplet

Carpet beetles

Red admiral

Miscellaneous Animals:

Spiders and harvestmen 


\section{Grade $\cdot$ IV}

\section{LESSONS WITH PLANTS}

Competitive Flower Rearing:

Centaurea, Emperor William

Flower Calendar

Study of Wild Flowers:

Meadow rue

Purple avens

Indian pipe

Sundew

Shad bush

Saxifrage
Lady's slipper

Blue-eyed grass

Thoroughwort

Jack-in-the-pulpit

Corn cockle

\section{GARDEN WORK :}

Vegetable garden; parsnips, sage, horse radish

Wild-flower garden; lessons on transplanting

\section{FruIT:}

Apples; save and plant seeds, and learn varieties

\section{TreEs :}

Butternut; germinate nut Mulberry; propagate from cuttings

Flowerless Plants:

Mushrooms; collect specimens, learn to recognize poisonous Amanitas

Myths, Legends, Stories, Poems, and Pictures of the Plants AND ANImals FOR THIS GRade 


\section{Grade V}

\section{LESSONS WITH ANIMALS}

Domesticated Animals:

The horse; origin, domestication, traits, uses, care

Laws regarding cruelty to animals

BIRDS :

Bobolink

Kingfisher

Chewink

Ovenbird

Purple finch
Red-eyed vireo

Indigo bunting

Brown creeper

Purple martin

Sparrow hawk

Frogs AND SALAMANDERS:

$\left.\begin{array}{l}\text { Brown frog } \\ \text { Red triton }\end{array}\right\}$ Feeding tests with insects, notes, rear from eggs

\section{Fishes:}

Perch; feeding tests, spawning season, and habits

INSECTS :

Plant lice

Lady beetles

Mosquitoes

Regal moth

Curculios

Miscellaneous Animals:

Clams and snails Muskrat
Honeybee

Bumblebee

Mud wasp

Paper wasp

Slugs 


\section{Grade V}

\section{LESSONS WITH PLANTS}

Competitive Flower Rearing:

Balsam

StTudy of Wild Flowers:

Evening primrose

Meadow lily

Buttonbush

Jewelweed

Bishop's cap

Snake's-head
Sarsaparilla

Elecampane

Columbine

Blueberries

Checkerberry

Spurges

Flower Calendar

GARDEN WORK :

Vegetable garden; spinach, tomatoes, cucumbers

Wild-flower garden; ferns, spore formation

FRUIT:

$\left.\begin{array}{l}\begin{array}{l}\text { Plums } \\ \text { Apricots } \\ \text { Nectarines }\end{array}\end{array}\right\} \begin{gathered}\text { Learn varieties, and study buds, terminal, lateral, } \\ \text { fruit }\end{gathered}$

Trees :

Black walnut Cedars

Hackberry Juniper

Study and germinate seeds

Willows Larch

Flowerless Plants:

Moulds and yeast

Black knot

Foul brood

Monilia

Myths, Legends, Stories, Poems, and Pictures of the Plants and ANImals for this Grade 


\section{Grade VI}

\section{LESSONS WITH ANIMALS}

Domesticated Animals:

Pigeons; domestication, habits, feeding, and care

\section{Birds :}

Maryland yellowthroat

Rose-breasted grosbeak

Hairy woodpecker

Crossbills

Wood pewee
Veery

House wren

Warbling vireo

White-throated sparrow

Fox sparrow

State laws for protection of birds

Frogs and Salamanders:

Wood frog

Rear from eggs and make feeding

Red-backed salamander $\}$ tests with insects

\section{FISHES:}

Bass; rock, large and small mouth, black

INSECTS :

Borers; peach-tree and others

Cabbage worm and parasites

Tiger beetles

Squash bugs
Botfies

Apple maggot

House ants

Miscellaneous Animals:

Earthworms

Moles and shrews 


\section{Grade VI}

\section{LESSONS WITH PLANTS}

Competitive Flower Rearing:

Petunia

Study of Wild Flowers :

Foam flower

Early rue

Dogbane

Daisy fleabane

Speckled alder

Purple Gerardia
Celandine

Willow herb

Clematis

Sand spurry

Butter and eggs

Poison hemlocks

Flower Calendar

GARDEN WORK :

Vegetable garden; cabbage, turnip, mustard

Wild-flower garden; collect wild-flower seeds and plant

FrUIT :

$\left.\begin{array}{l}\text { Cherries } \\ \text { Peaches }\end{array}\right\}$ Study varieties, grafting, budding, pruning

TREES :

$\left.\begin{array}{ll}\text { Birches } & \text { Pines } \\ \text { Tulip } & \text { Sycamore }\end{array}\right\}$ Study and germinate seeds

City or town ordinances with reference to injury of shade trees

Flowerless Plants:

Apple scab Rose mildew Peach-leaf curl Peach yellows 


\section{Grade VII}

\section{LESSONS WITH ANIMALS}

\section{BIRDS :}

$\begin{array}{ll}\text { Tree sparrow } & \text { Yellow-billed cuckoo } \\ \text { Grackles } & \text { White-crowned sparrow } \\ \text { Wood thrush } & \text { Ruby-crowned kinglet } \\ \text { Yellow-throated vireo } & \text { Golden-crowned kinglet } \\ \text { Black-billed cuckoo } & \text { Myrtle warbler }\end{array}$

Frogs and SALAMANDERS:

Life story of common toad; rear from eggs, make feeding tests with insects

Newts

Fishes :

Trout

Salmon; spawning seasons, habits

State laws concerning fishes

INSECTS :

Cutworms

Lion beetles

Army worm

Corn worm

Sphinxes
Ichneumon flies

Gypsy moth (in eastern Mass.)

Brown-tailed moth (in eastern Mass.)

Household pests; bed bug, kissing bug, roaches

Miscellaneous ANimals:

Woodchuck

Mink and otter

Centipedes and millipedes 


\section{Grade VII}

\section{LESSONS WITH PLANTS}

Competitive Flower Rearing:

Ten-weeks stock

Flower Calendar

Study of Wild Flowers:

Ragwort

Milkwort

Chicory

Clethra

Baneberry

Star grass

Blue curls
St. John's-wort

Pitcher plant

Sweet vernal grass

June grass

Timothy grass

Fescue grass

Jimson weed

GARDEN WORK :

Vegetable garden

Common weeds

Wild-flower garden

FrUIT :

Grape, raspberry, blackberry

Grapevine culture; layers, runners, cuttings, seeds

TREES :

Chokecherry

Red cherry

Black cherry

Box elder

Ashes

Study and germinate seeds Poplars

Flowerless Plants:

Moulds

Orange rust

Grain smuts

Grape mildews

Review mushrooms

State laws concerning fungous diseases of plants 


\section{Grade VIII}

\section{LESSONS WITH ANIMALS}

BIRDS :

Chestnut-sided warbler

Blackburnian warbler

Magnolia warbler

Yellow-breasted chat

Solitary sandpiper

Little green heron

Red-headed woodpecker
Water thrush

Bank swallow

Hermit thrush

Marsh hawk

Wild ducks

Wild geese

Wild swans

Study game laws

Frogs and Salamanders:

Pickering's tree frog

Cricket frog

Mud puppy

Fishes :

Eels

INSECTS :

Aphids

Currant worms

Rose slug
Pear slug

Am. copper butterfly

Painted beauty

Miscellaneous ANimals:

Bat

Weasel

Porcupine 


\section{Grade VIII}

\section{LESSONS WITH PLANTS}

Competitive Flower Rearing:

Carnation

Flower Calendar

Study of Wild Flowers :

Spring beauty

Cassandra

Gentians

Cohosh

Pale Corydalis

Foxglove

Cardinal flower

Loosestrife

Groundnut

Herb Robert

Green brier

Gold thread

Viburnum

Nightshades

GARDEN WORK :

Vegetable garden

Wild-flower garden

FRUIT :

Currant, gooseberry

Methods of propagating fruit and forest trees

TREes :

$\left.\begin{array}{ll}\text { Spruces } & \text { Beeches } \\ \text { Tupelo } & \text { Lindens }\end{array}\right\}$ Study and germinate seeds State laws concerning forest fires

Flowerless Plants:

Bacteria

Foul brood

Pear blight 
494 NATURE STUDY AND LIFE

\author{
Grade IX
}

\title{
LESSONS WITH ANTMALS
}

BIRDS :

Northern shrike

Herons

Pine grosbeak

Eagles

Pine siskin

Hawks

Sapsucker

Owls

Loon

Gulls

Grebes

Terns

\section{Frogs and Salamanders:}

Spadefoot frog

Review and make feeding tests with frogs, toads, and salamanders

FISH :

Stickleback

INSECTS:

Scale insects

San José scale

Wood nymphs

Honeybee and cross-fertilization

Fritillaries

Swallowtails

Miscelianeous Animals:

Skunk

Fox 


\section{Grade IX}

\section{LESSONS WITH PLANTS}

Competitive Flower Rearixg:

Tea rose

Study of Wild Flowers:

Rhodora

Pipsissewa

Dodder

Pyrola

Pimpernel

Spicebush

Arethusa

Larkspur
Blazing star

Meadow beauty

Lobelia

Clover

Pokeweed

Sunflowers
Review and classify a number of the common plants under:

Rose family

Lily family

Mustard family

Pulse family

Parsley family

Aster family

Grass family

Flower Calendar

GARDEN WORK :

Vegetable garden

Wild-flower garden

F FRUIT :

Quince

Review fruits, varieties, culture and propagation

TREeS :

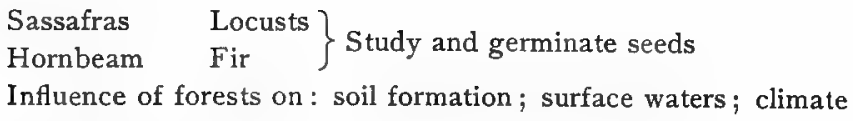

Flowerless Plants:

Bacteria, intelligent cleanliness

Symbiotic bacteria

Board of Health regulations and statistics 


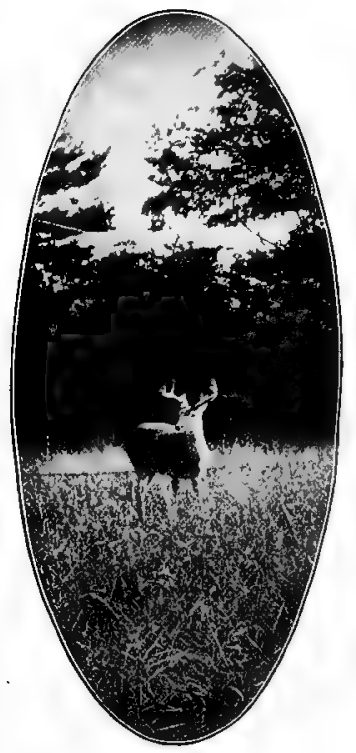




\section{N D E X}

[Numbers in black-face type indicate an illustration on the page cited.]

A, B, C of landscape gardening, I 36 . Abused street trees, 372 .

Acadian hairstreak, 268.

Achemon sphinx, 209.

Acris gryllus, 300 .

Active education, 132 .

Ægeria pyri, I9I.

polistiformis, I9I.

tipuliformis, I9I.

Esculus pavia, II 4.

Esthetic values of nature study, $20-22$.

Agarics, 450 .

Agrostemma githago, 113 .

Agrostis, 198.

Aims and purposes of a nature-study course, I.

Alder aphids, 209 .

Alexander the Great, 40.

Algæ, 103, 438, 483.

Amanita cæsaria, $45^{\circ}$.

muscaria, 450.

phalloides, $45^{\circ}$.

rubescens, $45 \mathrm{I}$.

verna, 450.

Amblystoma punctatum, 302 .

American copper butterfly, 264, 492.

false hellebore, II 7 .

laurel, II 4.

Pomological Society, I 50.
Amphicerus bicaudatus, 193.

Anacreon, 335 .

A narsia lineatelia, 193.

Anasa tristis, 225.

Anemone, 479 .

Angelus Silesius, IO2.

Animal species, 7.

Anisopteryx pometaria, 196.

Anopheles, 68-70, 70 .

Anthonomus quadrigibbus, 204.

Anthrenus scrophularixe, 59, 75-78,

76,78 .

Antiopa, 47, 262, 268.

Ants, 86-88, 86, 87, 41 5, 488 .

Ant's nest, how to make, 4 I 8,488 .

Aphids, 2 IO, 214, 486, 492.

Aphis maidis, 2 IO. mali, 2 ro.

Apple, 485 . curculio, 204. leaf crumpler, 206, 484 . maggot, 202-204, 203, 488 . of Peru, II 5 . root plant louse, 215 . scab, 465,489 .

Appleseed, Johnny, I 58, 59.

Apple-tree aphid, 2 Io.

borers, I9I, 192, 484 .

Apple tree, how to rear, 169.

tent caterpillar, 195. 
A pricot, I 52, I80, 487 .

Aquaria, feeding of the animals in, 403 .

construction of, 394-399, 395, $396,398,399$.

Aquarium, scavengers of, 403 .

cements, 399 .

how to stock, 400 .

Arbor day, $39 \mathrm{I}$.

Arbutus, 479.

Arethusa, 495 .

Army worm, 225, 490 .

Arnold Arboretum, 364 .

Amold, Edwin, 274.

Ashes, 49 .

Asiatic crab apple, 158.

Asparagus beetle, 222, 482 .

Aspidiotus perniciosus, 219.

Asters, 479, 495 .

Astragalus Lambertii, I I 7 .

mollissimus, II 7 .

Audubon Societies, 344.

Society,proposed pledge for, 345 .

Australian roach, 85 .

Babcock, Charles A., 345 .

Bacteria, I03, 440, 466, 466, 493, 495.

ways by which they enter the body, 471 .

Balsam, 96, 97, 487 .

Baltimore oriole, 480 .

nest of, 321 .

Banded hairstreak, 268.

Baneberry, 49I.

Bank swallow, 492.

Bark lice, 215.

Barn swallow, 342, 482 . swallow's nest, 336 .

Basilarchia arthemis, 268. astyanax, 268.
Bass : rock, large and small mouth, black, 488 .

Bat, as insect destroyer, 187,405 , 492.

feeding of, 406.

Beal, F. E. L., 345.

Bear corn, II 7 .

Beaver poison, III.

Bedbug, 82, 82, 490.

Beeches, 493.

Bee hunting, 240.

Bees, races of, $24 \mathrm{I}$.

Bellwort, 483 .

Big ivy, I 4 .

Biological type, 289 .

Birches, 489.

Bird bath, 330 .

census, 319, 320, 321 .

food chart, 323 .

homes, 332 .

house, 337 .

houses, 332.

Bird-Lore, 344, 345, 35r.

directory of State Auduvon Societies, 345 .

Birds, climatic influences upon, 3I I. decrease of, 3 I 1 .

eating codling moth, 187 . enemies of, 312-317.

food for the young, 361 .

foods of, 322,347 .

nesting materials, 340 .

rate of increase, 308 .

Bird taming, 347 .

Bishop's cap, 487 .

Bismarck apple, I 57, I58.

Bittersweet, I I 7, 483 .

Black ant, small, 86, 86.

bee, 239,241 .

Blackberry, 49 I. 
Black-billed cuckoo, 490.

Blackburnian warbler, 492.

Black cherry, I I 3,49 I.

knot, $462,463,487$.

mercury, 107.

mould, $46 \mathrm{I}$.

nightshade, II 7 .

roach, $85-86$.

swallowtail, $268,4^{80}$.

Thalessa, 247.

walnut, 487 .

Blanks for lessons with plants, 139 ,

$$
\text { I } 45, \mathbf{I} 48 \text {. }
$$

Blazing star, 495 .

Blissus leucopterus, 226.

Bloodroot, Io2, $48 \mathrm{I}$.

Blood-sucking cone nose, $8_{3}, 8_{3}$.

Blowpipe, 57 .

Blueberries, 487 .

Bluebird, 333, 340, 342, 349, 478 .

Bluebottle fly, 63,64 .

Blue curls, 49I.

emperor, 268.

jay, 323,480 .

mould, $46 \mathrm{I}$.

Mountain Forest, 9, 16.

swallowtail, 268 .

Blue-eyed grass, 485 .

Satyrus, 266.

Bluets, 479.

Board of health regulations, 474,495 .

Bobolink, 323, 342, 486.

Boleti, 453, 453 .

Bolles, Frank, 336.

Bollworm, 225.

Bombardier beetles, 256 .

Bordered skipper, 270.

Borers, 488 .

Borer signs around base of peach tree, rgo.
Botflies, 414, 488.

Box elder, 49I.

Brackett, G. B., I73.

Braconids, 250.

Branch ivy, II .

Brightwen, Mrs., 345 .

Brinton, Dr., on property, I27.

Broad-leaf laurel, i 44 . necked Prionus, I92.

Brown creeper, $349,486$.

elfin, 268.

emperor, 266.

frog, 298,486 .

rot, 463,464 .

tailed moth, 490 .

thrasher, $323,342,349,484$.

Browning, Mrs., 33.

Brunella, 48I.

Bucephalus, 40.

Budding a peach tree, I 75-I 79, I 75, 489.

Budding knife, I 75 .

Buds, lessons on, 161,487 .

Buffalo herd, 9 .

$$
\text { moth, } 75 \text {. }
$$

Bufo lentiginosus, 297.

Bug, correct use of word, 423 .

Bugbane, I 7 .

Bull, Ephraim, I 59 .

Bullfrog, 298, 480.

Bumblebees, 242, 486 .

Buprestis divaricata, 193.

Burbank, Luther, 159.

plum, I60.

Burdock, 479.

Bur marigold, 483 .

Burnham, Wm. H., 23.

Burroughs, John, 302, 309, 324

Butter and eggs, 489 .

Buttercup, 479. 
Butterfies and moths, 260.

Butterflies, table of, 264-273.

Butternut, 485 .

Buttonbush, 487 .

Cabbage butterfly, 225, 262, 266.

Plusia, 225.

worm and parasites, $6 \mathrm{I}, 488$.

Caddis flies, 258,482 .

Cæoma nitens, 465 .

Cajeput, oil of, 82 .

Calico bush, I 14.

California poison sumac, I ro.

Calliopsis, $48 \mathrm{I}$.

Calliphora crythrocephala, 63 .

Calosoma calidum, 256. scrutator, 255 .

Canary, 349.

Cankerworms, I96, 484 .

Caper spurge, II5, II6.

Carbon bisulphide, 74 .

Cardinal flower, 493.

Care of young birds, 354-357.

Carlyle, I44.

Carnation, 493.

Carniolan bee, 239, 24 I.

Carpenter ant, 416 .

Carpet beetle, 75-78, 76, 78, 484 .

beetle, black, 78 .

beetle, remedies, 77 .

Carpocapsa pomonella, I8I, I82.

Cashes, Iro.

Cassandra, 493.

Cat, the, $4 \mathrm{I}-43,342,349,480$. destruction of birds by, 312 .

Catalogue of fruits, I 50, 152.

Catbird, 323, 342, 349, 484 .

Caterpillars, 49, 265-273, 42I.

Catopsilia eubule, 266.

Cecidomyia destructor, 226 .
Cecropia, 47, 48, 49, 259, 260, 272, 478.

Cedar bird, 319, 342, 349, 482 .

Cedars, 487 .

Celandine, 489 .

Centaurea, Emperor William, 93, 485.

Centipede, 423 .

Chalcis fly, $25 \mathrm{r}$.

Chapman, Frank C., 335.

John, I 58, I 59 .

Chebec, 482 .

Checkerberry, 487 .

Checkered cabbage butterfly, 266 .

skipper, 270.

Cherries, I 57, I80, 489 .

Cherry aphid, 2II, 2 I2.

Cherry twigs, I60, I62.

Chesnut, V. K., 106.

Chestnut, 479 .

Chestnut-sided warbler, 492.

Chewink, 486.

Chickadee, 334, 334, 342, 349, 478 .

Chick weed, 483 .

Chicory, 49r.

Children's bane, I I I.

Chimney swift, $33^{8}, 482$.

Chinch bug, 226.

Chipmunk, 408, 482.

Chipping sparrow, 478 .

Chippy tamed to feed from a child's hand, $35 \mathrm{x}$.

Chlorippe clyton, 266.

Chloroform for killing insects, 52 .

Chokecherry, 49I.

Cholera, 472.

Chorophilus triseriatus, 300 .

Chrysalis, 48, 49.

Chrysobothris femorata, 192.

Chrysophanus epixanthe, 268. 
Cicindelidæ, 256 .

Cicuta maculata, II I, II2.

vagans, 117 .

Cimex lectularius, 82,82 .

Cinquefoil, 483 .

Clam, 432, 486.

Clapp, Henry Lincoln, school gardens, 132,133 .

Clavarias, 448 .

Cleanliness, $47 \mathrm{I}$.

Clematis, 489 .

Clethra, 49r.

Climbing cutworms, I 99.

Clisiocampa Americana, 195. disstria, 196.

Clothes moth, remedies, 73-75. moth, southern, 72,72 . moths, 7I-7 5, 7I, 482 .

Cloudless sulphur, 266.

Clover, 495.

Cobweb skipper, 270.

Coccus cacti, 216.

Cochineal insect, 216.

Cockroaches, 84,85 .

Codling moth, 18I-I87, I82, 484 .

Cohosh, 493.

Coleridge, 287 .

Colias eurytheme, 266 . philodice, 266.

Colorado potato beetle, 2 2 2 .

Columbine, 487 .

Common frog, 297.

Competitive rearing of flowers, 94IOr, 98.

Comstock, 6r, 71 .

Cone flower, $48 \mathrm{r}$.

Conium maculatum, I Iо, Iro.

Conorhinus sanguisuga, 83,83 .

Conotrachelus cratægi, 204. nenuphar, 204.
Contagious diseases, $47 \mathrm{r}, 474$.

Contrast in housekeeping, $\mathbf{3 6 2}$.

Coprinus, 452.

Coral hairstreak, 268. mushrooms, 448, 448.

Corbin preserve, 9, 16 .

Corn cockle, I I3, II3, 485 . louse ant, 4I 7 . root aphid, 2 I 4 . worm, 225, 490.

Cottony cushion scale, 218 .

Cowbane, III.

Cowbird, 484 .

Cow elk, 4I5.

Cragin, Belle S., 6r.

Craponius inæqualis, 204.

Creative effort for good, 30 .

Cricket frog, $300,492$.

Crickets, 20I, 480.

Crioceris asparagi, 222.

Crossbills, 488 .

Cross-pollination, 46, 229.

Crotalaria sagittalis, I 17 .

Croton bug, 85,85 .

Crow, 323,478 . poison, 117 .

Cuckoo, 323, 342, 348, 490 .

Culex, 70, 70 .

Cultivation of plants, Io.

Cultures of bacteria, 458 .

Cup fungi, 448.

Curculios, 204, 204, 486.

Currant, 493.

borer, 191.

worm, $223,492$.

Cutworms, I74, 198, 199, 490 climbing, 200, 490.

Cyanide bottle, 51, 52 .

Cyprian bee, 240, $24 \mathrm{I}$. 
Dace, 480.

Daisy fleabane, $4 \times 9$.

Damsel flies, 257, 482 .

Dandelion, 479.

Darapsa myron, 208.

Dark fritillary, 266 .

Darwin, on earthworms, 424, 426.

Datana ministra, 224.

Datura, II4.

stramonium, II 5 .

tatula, II 5.

Deadly amanita, $444,446,450$.

Death of man, III.

Death-cup mushrooms, II 7, 444,

$$
446,450 \text {. }
$$

Debis portlandia, 266.

Definition of nature study, $r$.

Delphinium menziesii, II7. tricorne, II6, II7.

Desmia maculalis, 207.

Devil's apple, i I 5 . bite, II 7 .

Dewey, Lyster H., II 9.

Diabrotica vittata, 222.

Dickinson, Emily, 307, 340, 347 .

Diemyctylus viridescens, $30 \mathrm{I}$.

Diphtheria, 47 I.

Discomycetes, 448 .

Divaricated buprestis, 193.

Dodder, 440, 495.

Dog, the, 37, 478 .

Dogbane, 489 .

Dogwood, rog.

Domestication of animals, 3, 293.

$$
\text { of birds, } 327 \text {. }
$$$$
\text { of toads, } 293 \text {. }
$$

Downy mildew, 464 . woodpecker, 323,480 .

Dragon flies, 257,482 .

Dreamy dusky-wing, 270 .
Duckretter, I $\mathbf{7}$.

Dull-eyed satyr, 266.

Dust in schoolroom, $476,476$.

Dwarf larkspur, II6, II7.

laurel, I 15.

Eagles, 494.

Early hairstreak, 268. rue, 489 .

Earthworms, 424, 427, 488 .

Eave swallow, 342 .

Economic values of nature study I7-20.

Ectobia Germanica, 85, 85 .

Educational values of nature study, 22-28.

Edward's hairstreak, 268.

Eels, 492.

Eggs of Antiopa butterfly, 47 . of codling moth, 182,184 . of malarial mosquito, 68 .

Egleston, N. H., 391 .

Elecampane, 487 .

Elementary botany, IO, IO2. zoölogy, 5 .

Elk, herd of, 5 .

Elk killed by grubs in the head, 417 .

Elm-leaf beetle, 223, 480 .

Elms, $48 \mathrm{r}$.

Emerson, 104, 305, 309, 335.

Enemies of San José scale, 221 .

English sparrow, 313-316, 323 .

Epargyreus tityrus, 270.

Epidemics, 47 I.

Eriocampa cerasi, 224.

Erynnis attalus, 270.

leonardus, 270.

meta, 270.

sassacus, 270.

Esopus apple tree, 160. 
Ethical and social values of nature study, 28-3o.

influence of school garden, 136 .

Euchloë gerutia, 266.

Eudemis botrana, 207.

Euphorbia bathyris, I I5, I 6 .

marginata, II 7 .

Euptoieta claudia, 266.

Evening primrose, 487 .

Example of tasteful planting, $\mathbf{1 3 8 .}$

Exoascus deformans, 464 .

Extermination of plants, 105. of mosquitoes, 67 .

of species, 8,9 .

Factory covered with woodbine, 389 .

Fall webworm, 198, 484 .

False Solomon's seal, 483 .

Feeding a bat, 406.

Fernald, Professor, 222.

Fernow, E. B., 39I.

Ferns, 103, 434, 435, 479, 48I, 487 . school collection of, 436 .

Fescue grass, 49r.

Fir, 495.

Fishes, 413.

Fiske, John, I4, I7.

Five-spotted sphinx, 209.

Flat-headed apple-tree borer, 192.

Flea, 78-8r, 8o, 478 .

$$
\text { trap, } 8 \mathrm{r} \text {. }
$$

Flicker, 323, 484 .

Flies, 62-64, 63, 48o.

Flower calendar, I04.

garden, I4I.

Flowers for competitive planting, 96-97.

Foam flower, 489 .

Food chart of common birds, 323 .

Forbes, Professor, 214.
Forest, influence on water supply, $3^{82}-388,495$.

fires, 390 .

resources, 390, 495 .

tent caterpillars, I96.

Fossil species, 8.

Foul brood, 470, 487, 493 .

Fowls, 484 .

Fox, 494 .

sparrow, 488.

Foxglove, 493.

France, C. J., I 27.

Francis, Dr. George, 456.

Fringed gentians, 106.

$$
\text { polygala, } 483 \text {. }
$$

Fritillaries, 464, 466, 494.

Froebel, 22, 25, 26, 1 29, 130, I 31, 143

Frog with six legs, 400.

Fruit culture, $148-153$.

exhibitions of, 149.

garden, trees for, 134 .

spurs of pear, 163 .

Fruits, best varieties of, 152 . improvement of varieties, 156 159.

Fungi, I03, 439.

Fusicladium dendriticum, 465.

Garden fruits, I $47-153$.

spurge, I 6.

Gartered plume moth of grape 205, 206.

Gentians, 493.

German bee, 239, 24 I. roach, 85,85 .

Giant swallowtail, 268.

Gibson, Hamilton, 278, 42 I.

Goethe, I 2 I.

Golden-crowned kinglet, 490.

Golden-rod, 479. 
Goldfinch, 349, 480 .

Goldfish, 478 .

Gold thread, 493.

Goodrich, C. L., $3^{8 \mathrm{I}}$.

Good Samaritans, 346 .

Gooseberry, 493.

Gopher plant, I 6 .

Grackles, 323, 349, 490.

Grafting an apple tree, $169-174$, I70, I7I, I72.

Grafting wax, 170 .

Grain smuts, 465, 49I.

Grape curculio, 204 .

mildew's, 49I.

phylloxera, 2 ro, 214.

shoots, 205.

Grape-berry moth, 207.

Grape-cane borer, 193.

Grape-leaf folder, 206, 207.

Grapes, 48I, 49I.

Grapevine cuttings, I64, I65.

flea beetle, 223 .

how to rear, 164 .

pruning of, 167 .

root borer, I9I.

sphinx, 208.

transplauting, $\mathrm{I} 66$.

Grass family, 495.

Grasshoppers, 200; 480.

as bird food, 20I, 323, 358, 480 .

Gray squirrel, 409.

Great laurel, II7.

Grebes, 494.

Green brier, 493 .

Greene, Samuel B., 369, 382 .

Green frog, 298, 484 . swallowtail, 268.

Grippe, 47 I .

Grosbeak, 323, 342, 349, 488.

Groundnut, 493.
Gulls, 494.

Gypsy moth, 490 .

Hackberry, 487.

Hair worms, 428, 428.

Hairy woodpecker, 323, 488.

Haltica chalybea, 223 .

Hard maples, 483 .

Harvester caterpillar, 209.

Harvey, F. L., 204.

Hawk moths, 209.

Hawks, 494 .

Hay infusion, 468.

Head louse, 8I-82, 480 .

Hedgehog mushrooms, 454, 454.

Helenium autumnale, II 7 .

Heleothis armigera, 225.

Hemiock, I 10.

Henry's hairstreak, 268.

Hepatica, 483 .

Herb bennet, I Io. robert, 493 .

Hermit thrush, 492.

Herons, 494 .

Hesperia centaureæ, 270.

Hessian $\mathrm{fly}, 226$.

Hickory, 483 .

High laurel, II4.

Hoary-edge, 270.

Home, a, Ir.

and school gardens, 121 .

Honeybee, 228, 229, 486, 494.

Honeydew, 2ro.

Hop aphid, 2 Io.

Hop hairstreak, 268.

Horace's dusky-wing, 270.

Hornaday, Wm. T., 310.

Hornbeam, 495.

Horse, the, 38-4I, 39, 486 .

Horse chestnut, II 4,483 . 
House ants, 89,488 .

wren, $223,342,348,488$.

Household insects, 89,490 .

Howard, L. O., 69, 89 .

Humming bird, 349, 352, 482 .

Humming bird's nest, 34I.

Humus, and growth of plants, $38 \mathrm{r}$.

Huxley, 2r, 28.

Hyla pickeringii, $300,492$.

Hyla versicolor, 299,478 .

Hypha, 459.

Hyphantria textor, 198 .

Icerya purchasi, 2 I 8 .

Ichneumon flies, $210,246,248,249,490$.

Imperial moth, 482 .

Indian pipe, 440,484 .

poke, II 7 .

skipper, 270.

uncus, II 7 .

Indigo bunting, 486 .

Ink cap, 452.

Insect, how to define, 422 .

collection, 60 .

net, 50, 51 .

Insects, destructiveness of, 46 .

method of spreading, 55 .

methods of controlling, 226 .

mounting of, 52-6I, 53 .

number of species, 7 .

Intelligent cleanliness, $47 \mathrm{I}$.

Invitation to the birds, 304 .

Io moth, 478 .

Iris, $48 \mathrm{I}$.

Isabella tiger caterpillar, 478 .

Italian bee, 239, 24I.

Itch weed, 1 I 7 .

Ivy, II 4 .

bush, II 4 .

wood, II4.
Jack-in-the-pulpit, 485 .

Jackman, 33 .

James, Wm., 329.

Jamestown lily, I I 6 .

weed, II 5 .

Jeffries, 336 .

Jewelweed, 487 .

Jimson weed, xI 4, I I 5, 491 .

Junco, 482 .

June beetles, 480 .

Juniper, 487 .

Junonia cœnia, 268.

Juvenal's dusky-wing, 270 .

Kalmia, I 4. angustifolia, I 5 . latifolia, I I4.

Kermes, 2 I8.

Kingbird, 323, 342, 483.

Kingfisher, 486.

Kirkland, A. H., 288.

Kissing bug, 84 .

Kline, Linus W., psychology of ownership, I 27.

Koebele, observations of bats, 187 .

Lactarius, $45^{2}$.

Lady beetles, 254, 254, 486 .

Lady's slippers, 485 .

Lambkill, I I 5, 483 .

Lamb laurel, 1 i 5.

Landscape gardening, 136 .

Lange, D., 31 2, 345.

Larch, 487 .

Larkspur, I16, I 7,495 .

Larva, 48.

Laurel, II 4.

Layers, propagation by, 165 .

Least copper, 268.

Lecaniums, 216,2 I 8 . 
Leonard's skipper, 270.

Leopard frog, 297, 482 .

Leucania unipuncta, 225.

Leucothoë catesbæi, I I7.

Libythea bachmanni, 266.

Lice, remedies, $8 \mathrm{I}-82$, 480 .

Lichens, 103, 437, 483 .

Light blue, 266.

Lily, 92, 495.

Linden, 493.

Lion beetles, 255, 490 .

List of animals, 6 .

Little green heron, 490.

silver spot, 264.

sulphur, 266.

tree frog, 300 .

Liverworts, I03, 437, 48I.

Living species of animals, 7 .

Lizards, 296, 4 II.

Lobelia, 495 .

Locusts, 200, 495.

Long, William J., 410.

Long-dash, 270.

Longfellow, 307, 309 .

Loosestrife, 493 .

Lowell, 91, 322, 334, 365 .

Low laurel, I 5.

Lucilius' dusky-wing, 270.

Luna moth, 480.

Lycæna comyntas, 266.

pseudargiolus, 266.

Lycoperdaceæ, $44^{8}$.

Macrodactylus subspinosus, I94.

Magnolia warbler, 492.

Making an aquarium, 395.

Mallow, 48I.

Many-eyed satyr, 266.

Marks of ancient abuse, 376 .

Markweed, 107.
Marlatt, C. L., 89 .

Marsh hawk, 323, 492. marigold, $48 \mathrm{I}$.

Martial's dusky-wing, 270.

Martin house, 3 I 8.

Martin, purple, 337, 342, 486.

Maryland yellow throat, 488 .

Masked bedbug hunter, 84 .

Meadow beauty, 495 .

lark, 323, 349, 482 .

lily, 487 .

mushroom, $45 \mathrm{r}$.

rue, 485 .

Meal worms as bird food, 359,360 , 482.

Mercury, I07.

Metamorphosis of insects, 49 .

Mice, 409, 480.

Mildews, 462.

Milkweed, 479.

butterfly, 264, 478 .

Milkwort, 49r.

Milky mushrooms, 452.

Miller, Olive Thorne, $33^{8}$.

Millipedes and centipedes, 423, 424, 490.

Mimosa, 483 .

Mink, 410, 490.

Miracle of blossoms, 154 .

Mocking bird, 328, 349 .

Mocking bird's sun bath, 33x.

Mole plant, i 6 .

Moles, 4 Io, 488.

Mollusks, type forms of, $7,429,430$.

Monilia fructigena, 463,487 .

Monomorium pharaonis, 86,87 minutum, 86, 86.

Monostegia rosæ, 223, 492.

Monthly list of publications, Department of Agriculture, 89. 
Morels, 448, 448.

Morgan, L. H., on property, 127.

Mosquito hawks, $7 \mathbf{I}$.

pupa, 66.

Mosquitoes, 64-7I, 65, 66, 69, 70, $89,486$.

and malaria, 68,68 .

Mosses, I03, 437, $48 \mathrm{I}$.

Mould gardens, 458 .

Moulds, I03, 457, 460, 487, 49I.

Mound-building ant, 4 I 6 .

Mountain laurel, I I 4, 483 .

Mourning cloak, 268, 48 z.

Mucor mucedo, 46I.

Mud puppy, 302.

wasp, 486.

Mulberry, $4^{8} 5$.

Mummied fruits, $46_{3}, 464$.

Musca domestica, 62, 63.

Museum pests, 59 .

Mushrooms, I03, 443, 485, 491 . spore prints of, 446,446 .

Muskrat, $4 \mathrm{I} O, 486$. weed, II I.

Musquash root, II I.

Mustard, 495.

Mycelium, 445, 459 .

Myrtle warbler, 490.

Mysus cerasi, 2 II, 212.

persicæ, 2 IO.

Mytilaspis pomorum, 216, 217.

Narrow-leaf laurel, I 15.

Nash, Lewis P., 385, $3^{89}$.

Nasturtium, 479.

Nasturtiums and mimosas, go.

Nature-study property of children, 139, 154 .

Nectarines, I $48,152,180,487$.

Necturus maculatus, 303 .
Nematodes, 428, 429 .

Nematus vcntricosus, 223 .

Neonympha eurytus, 266 .

Newman, S. M., 9r.

Newts, $301,478$.

Night hawk, $33^{8}, 48 z$.

Nightshade, 493 .

Nitrates, 442.

Northern dusky-wing, 270. frog, 298.

shrike, 494 .

Nucleus beehive, 233 .

Nut culture, 377.

Nuthatches, 349 .

Nuts, 368 .

Nymph, 49.

Oaks, $4^{81}$.

Observation beehive, sectional plav

$$
\text { of, } 238 .
$$

CEdemasia concenna, 224 .

Olive hairstreak, 268.

Orange rust, 465,491 .

sulphur, 266.

tip, 266 .

Orb weaver, 421 .

Oregon water hemlock, I I 7 .

Organized bird protection, 344 .

Orgyia leucostigma, 198.

Oriental roach, 85 .

Oriole, 323, 342, 349, 352, 480 .

Orphans' home for nestlings, 353.

Osborn, H., 89.

Otter, 4Io, 490.

Ovenbird, 490.

Owlet moths, I98.

Owls, 494.

Oxeye daisy, 479.

Oxyptilus periselidactylus, 206.

Oyster-shell scale insect, 216, 217. 
Painted beauty, 266, 492.

Paleacrita vernata, 196.

Pale Corydalis, 493.

Palmer, Alice Freeman, 23, 130.

Pandorus sphinx, 208.

Paper wasp, 244, 486.

Papilio asterias, 268.

cresphontes, 268.

philenor, 268.

troilus, 268.

turnus, 266, 494 .

Paradise for children, 146.

Parsley, 495.

Partridge, 484 .

Peach, 479, 489.

Peach-leaf curl, 464 .

Peach tree, how to raise, $174, \mathbf{1 7 4}$.

twigs, I64.

yellows, 464 .

Peach-tree aphid, 210.

borer, eggs, larva, pupa, and cocoons, I87-I9I, 186,188 , I89, 190 .

Pear blight, 469, 493 .

slug, 492.

twigs, 163 .

Pearly eye, 266.

Pear-tree borer, I9I. slug, 224.

Peckham, G. W. and Elizabeth G., 243.

Pediculus capitis, 8r.

Pepper and salt skipper, 270.

Perch, 486.

Periplaneta Americana, 85 .

Australasiæ, 85 .

orientalis, 85 .

Peronospora viticola, 464 .

Persius' dusky-wing, 270.

Pets, 33-37, 43-44.
Petunia, 489.

Philampelus achemon, 209. pandorus, 208.

Phlegethontius celeus, 209.

Phoebe, 342, 482 .

Pholisora catullus, 270.

Phorodon humuli, 21 I.

Phosphorescence, 468.

Phylloxera vastatrix, 210, 214, 492

Physis indigenella, 206.

Phytolacca decandra, III.

Pickerel, 482.

frog, 298.

Pickering's tree frog, 300, 492.

Pieris mariana, II 7 .

napi, 262, 266.

protodice, $262,266$.

rapæ, $225,262,266$.

Pigeons, 488.

taming the, 43.

Pike, 482 .

Pikry, ro7.

Pimpernel, 495.

Pimpla inquisitor, 248.

Pine grosbeak, 494 .

sap, 440 .

siskin, 494.

Pines, 489 .

Pipsissewa, 495.

Pitcher plant, 49I.

Plant breeding, 1 58-160.

lice, $210,486$.

parasitized, 250.

Planter and owner of peach trees, 126.

Plants, list of all known, I03.

Plowrightia morbosa, 462 .

Plum, 204, 487.

curculio, 204, 204 .

Plume moth, 205. 
Plums destroyed by brown rot, 464 . Plusia brassic 225.

Poison ash, rog.

$$
\text { elder, rog. }
$$

grain for English sparrows, 3 I 5 .

hemlock, I IO, I10, 489 .

ivy, 107-109, 108, I 10, I14, 479 .

laurel, I I 4.

oak, 107.

root, Iro.

snakeweed, I I o.

sumac, Iog, I09, 48r.

sumac, Californian, i ro.

Poisonous plants, 106-I 8 .

Pokeroot, II 7 .

Pokeweed, II I, 495.

Polyphemus, 480 .

Polypori, 453, 453.

Poplars, 49I.

Porcupine, 492.

Pore-bearing mushrooms, 452.

Portrait of a young bluebird, 349 .

Potassium cyanide, 5 r.

Potato beetle, 222, 480 .

Pout, 480 .

Primitive German home, 3.

Prionus imbricornis, 193.

laticollis, I 92.

tile-horned, 193.

Promethea, 272, 478 . just emerged, 46.

Propagation of fruits, methods of, I 80.

Property of children, 125.

Proteans, 302.

Protective coloration, 288.

Proteid foods, circle of, 44I, 442 .

Prothallium, 437.

Pruning a छrapevine, 167 .

Prunus serutina, I 3 .
Psychology of ownership, I27, I 28.

Puffballs, 444, 448, $44^{8}$.

Pulex irritans, 79-8I. serraticeps, 79-8 I, 80.

Pulse family, 495 .

Pupa, 48.

Purple avens, 485 .

finch, 486 .

Gerardia, 489.

larkspur, I I 7 .

martin, 486.

Pyrameis atalanta, 268.

cardui, 266.

huntera, 266.

Pyrethrum powder, 81, 83 .

Pyrola, 495.

Pyrus baccata, 158. malus, I 56, 158.

Quail, 490.

Quince, 495 .

curculios, 204, 486 .

Rabbit, 482 .

Ragwort, 49I.

Railroad worm, 202.

Rain crow (cuckoo), 323, 342, $34^{8}$.

Rana catesbiana, 298.

clamata, 298.

palustris, 298.

septentrionalis, 298 .

sylvatica, 299.

virescens, 297.

Raspberry, 49I.

rust, 49 r.

Rats and mice, 409, 480 .

Rat-tailed maggot, 252.

Rattlebox, II 7 .

Réaumur, 214. 
Rearing a peach tree, 174-179, 126, I 74, $175,176,1_{77}, 1_{78}$.

Red admiral, 268,484 .

ant, 86,87 .

backed salamander, $3 \circ 2,488$.

breasted nuthatch, 484 .

buckeye, II 4.

cherry, 49I.

eyed vireo, 486 .

headed woodpecker, 492.

humped caterpillar, 224, 224.

shouldered hawk, 323 .

squirrel, 408.

triton, 302,486 .

winged blackbird, 323,484 .

Redstart, 484 .

Reduvius personatus, 84 .

Regal moth, 486.

Religious values of nature study, 30 .

Research, spirit of, 14 .

Rhododendron maximum, I I 7 .

Rhodora, 495.

Rhus diversiloba, I Io.

radicans, 107.

vernix, rog, rog.

Riley, James Whitcomb, I39.

Professor, 46.

Roaches, 84, 84, 85, 85 .

Roadside flowers, 105 .

skipper, 270.

Robin, $342,348,478$.

Robin's nest in the cherry tree, 308 ,

339.

plantain, 48r.

rate of increase, 308 .

Roosevelt, Theodore, on bird pro-

Rose, 495.

tection, 344.

beetle, 194, 482 .

breasted grosbeak, 488 .
Rose chafer, I94.

mildew, 465, 489 .

slug, $223,492$.

Ruby-crowned kinglet, 490.

Ruskin, 17, 22, 477.

Russulas, 452.

St. John's-wort, 491.

Salamanders, 296, 301 .

Salmon, 490.

Sand spurry, $48 \mathrm{~g}$.

San José scale, 219-222, 219, 494.

Sanninoidea exitiosa, I87.

Saperda candida, I9I.

Sapsucker, 494.

Sarsaparilla, 487 .

Sassafras, 495 .

Satyrodes canthus, 266.

Satyrus alope, 266.

Saunders, William, I68, I73, 195.

Saxifrage, 485 .

Scale insects, 2I 5-222, 494.

Scaphiopus holbrookii, 299, 494.

Scarlet tanager, 480.

Scene on K Street, Dayton, Ohio, 120.

Schizoneura lanigera, 210,215 .

School and contagious diseases of children, 474.

aquarium, 392.

beehive, 234, 235 .

gardens, $132,133,135$.

Seedling trees, 366 .

Seeds of fruits, I 55-1 57 .

Selandria cerasi, 244, 399.

Shad bush, 485 .

Shaggy mane, 452.

Shakespeare, 338.

Shaler, 293.

Sheep laurel, I14, 1 I5. 
Sheep poison, II 5 .

Shelley, 327.

Shelley's prophecy fulfilled, 326 .

Shiners, 478 .

Shrews, 4 IO, 488.

Silver-spotted skipper, 270.

Skunk, 4IO, 494.

Slave ant, $4 \mathrm{I} 7$.

maker ant, $4 \mathrm{I} 7$.

Sleepy dusky-wing, 270.

Slingerland, M. V., I87, 188 , I89, I90, 19I, I99, 200.

Slugs, $276,429,486$.

Small laurel, I I 4, I 5.

Smith, Herbert E., 473.

Snakes, 4I 2, 478 .

Snake's-head, 487 .

Snakeweed, III.

Sneezeweed, II 7 .

Snout beetles, 204 .

butterfly, 266 .

Snow bunting, 480 .

on the mountain, II5, IIy.

Soft maple, 479 .

Soil, 436.

Soils, apparatus for testing retention of water by, 382 .

study of, $379-388$.

Solanum dulcamara, i I 7 . nigrum, II 7 .

Solitary sandpiper, 492. vireo, 492.

Solomon's seal, 483 .

Song sparrow, $342,349,480$.

Sooty wing, 270.

Sori, 436.

Sow bugs, 423, 424 .

Spadefoot frog, 299, 494 .

Sparrow hawk, 486.

Speckled alder, 489 .
Spelerpes ruber, 302 .

Sphærotheca pannosa, 465 .

Sphinxes, 207, 490.

Spicebush, 495 .

Spider, not an insect, 422.

Spiders, lessons with, 4I9, 420, 484

Spoonwood, 114.

Spore prints, 446, 446 .

Spores, I03, 436 .

Spotted cowbane, i I I.

parsley, i Io.

salamander, 302,484 .

Spray Calendar, 227.

Spreading of insects, 55-6r.

Spring beauty, 493 . cankerworm, 196.

Springwort, I I 6.

Spruces, 493.

Spurge, 487 .

Squash bug, 225, 488 .

Squirrels, 407, 482 .

Stable fly, 63.

Staggerbush, II 7 .

Stagger weed, I I 7 .

Star grass, 491 .

State Experiment Station, 156, I74, 204.

Stemless loco weed, I 7 .

Stickleback, 494.

Stinkhom mushroom, 449, 449.

Stinkweed, I I0, I I4, I 16.

Stinkwort, 116.

Stomoxys calcitrans, 63 .

Stone, George E., 103, 429.

Stramonium, 115.

Stratt, W. M., 32.

Strawberry, I 52, I 55, I 57,483 .

crown borer, 193 .

insects, 482 .

root borer, 193 . 
Striped cucumber beetle, 222 . hairstreak, 268.

Strychnine for use with English sparrows, 315.

Subjugation of animals, 2 .

Suckers, 484 .

Sudworth, George B., 377, 39r.

Sundew, 485 .

Sunfish, 478 .

Sivallows, $323,335,337,34^{2}$.

Swallowtail, 266, 494.

Swamp hellebore, II7. sumac, Iog.

Sweet vernal grass, $49 \mathrm{I}$.

Swingle, Walter T., 465 .

Sycamore, 489 .

Symbiotic bacteria, 470 .

Syrphus flies, $251,252$.

Tabb, John B., 340.

Table of best fruits, $15^{2}$.

for methods of propagating fruits, 180 .

Tachina flies, 253, 253.

Tailed blue, 266 .

Taming a chipmunk, 408 .

a wood turtle, 410.

Tanager, 323, 342, 480 .

Tansy, 48 .

Tasteful planting, 138 .

Tea rose, 495.

Tenebrio molitor, 359 .

Tenement house, a, I3.

houses marle beautiful, 385 .

Tent caterpillars, I95, 484.

Ten-weeks stock, 49I.

Terias lisa, 266.

Terns, 494.

Tetramorium cœspitum, 86.

Thalessa atrata, 247, 248.
Thanaos brizo, 270 .

horatius, 270.

icelus, 270 .

juvenalis, 270 .

lucilius, 270 .

martialis, 270.

persius, 270.

Thanks for bearing chestnuts, 375

Thaxter, Celia, 99, 276, 292, 336 .

Thecla acadica, 268 .

augustus, 268.

calanus, 268.

damon, 268.

edwardsi, 268 .

henrici, 268.

irus, 268.

læta, 268.

liparops, 268.

melinus, 268.

niphon, 268 .

titus, 268.

Thistle butterfly, 266.

Thoreau, Henry D., 309.

Thorn apple, II 5 .

Thoroughwort, 485 .

Thorybes pylades, 270.

Three-leaved ivy, 107.

Thrushes, 349 .

Thunderwood, rog.

Thymelicus ætna, 270.

brettus, 270 .

mystic, 270.

Tiger beetles, 256,488 .

swallowtail, 266, 494 .

Timothy grass, $49 \mathrm{I}$.

Tinea pellionella, 71, 72 .

Tineola biselliella, 72, 72 .

Toad, $274,478,490$.

enemies of, 284 .

feeding, 276 . 
Toad, life story of, $\mathbf{2 7 8 , 4 9 0 .}$ protective color of, 287,288 . song of, 278 .

Toads, a pair of, $\mathbf{2 7 5}$. aquaria for rearing, 282 .

Toad's eggs, $279,280,28 \AA$.

Toadstools, 443 .

Tomato worm, 209.

Treat, Mary, 201.

Tree frog, 295, 299, 478 .

guards, 374 .

roots, retention of soil by, $3 \mathrm{So}$. seeds, how to save and plant, $367-373$.

sparrow, 490 .

swallow, 342,480 .

Treeless street, $37 \mathrm{I}$.

Trees, care of, 373 .

dissemination of seeds, 367 , 368,369 .

for school gardens, 134 .

of a New England hill farm, 378.

Trembling mushrooms, 450 .

Tremex columba, 248 .

Trichophaga tapetzella, 72, 73 .

Trilliums, $48 \mathrm{r}$.

Trout, 490 .

Trypeta pomonella, 202 .

Tube-bearing mushrooms, $45^{2}$.

Tulip, 489 .

Tupelo, 493 .

'Turtles, 410,478 .

Tyloderma fragariæ, I 93 .

Typhoid fever, epiclemics of, 472 , 473.

Upsala Street School, bird census, $3=1$.

school garden, I35.

Urodela, 30 .
Van Dyke, Henry, I0I, 105.

Vanessa antiopa, 268.

Variegated fritillary, 266.

Vedalia, 218.

Veery, 488.

Vegetable garden, 145 .

Veratrum viride, I I 7 .

Vesper sparrow, 484 .

Viburnum, 493.

Vireo and nest, 322.

Vireos, 3:3, 342, 348, 352 .

Virginia deer, I 5.

Volcanic skipper, 270 .

Walking sticks, 53 .

Warblers, 348 .

Warbling vireo, 488 .

Watching a brown snake shed its skin, 404 .

Water bug, $85-86,85,482$.

dog, 303 .

hemlock, II I, II2.

thrush, 492 .

Weasels, 4 ro, 492.

Weed, C. M., 6r.

Weeds, it8, 49 I.

Whip-poor-will, 4 S2.

Whirlabout, 270.

White admiral, 268.

breasted nuthatch, 484 .

breasted swallow, 342,480 .

crowned sparrow, 490 .

faced hornet, 244 .

hellebore, II 7 .

man's plant, i 16 .

marked tussock moth, 198,484 .

throated sparrow, 488 .

White, Gilbert, $33^{8}$.

Wicky, II 4, II 5 .

Wild carrot, 483 . 
Wild cherry, I I 3 .

flower garden, 132.

geranium, $48 \mathrm{I}$.

sunflower, 495 .

Willow herb, 489 .

Willows, 487 .

Winchell grape, layer of, 166 .

Wode-whistle, „I IO.

Wolfsbane, I I 7 .

Wolf's milk, i 6 .

Woodchuck, 4IO, 490.

Wood frog, 299, 488 .

laurel, Ir 4 .

nymphs, 266, 494.

thrush, $323,342,345,349,490$.

Woodland spring, 434.
Woodpecker, $323 \cdot 349$.

Wood pewee, 488.

Woolly aphids of apple, 2 I5.

loco weed, II7.

Wordsworth, 335, 363.

Worms, defined, $4 \geq \mathrm{I}$.

Wrens, 348,488 .

Yarrow, 48I.

Yeara, I IO.

Yeast, $465,465,487$.

Yellow-billed cuckoo, 489 .

breasted chat, 492 .

necked apple-tree caterpillar, 224.

throated vireo, 490 . 



